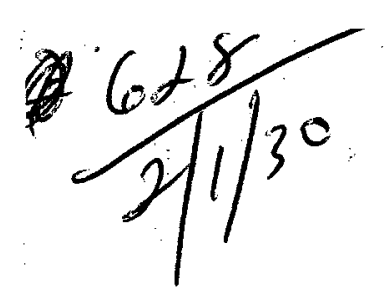

H. 627

LBL-7094

UC-66a

\title{
GEOTHERMAL RESOURCE AND RESERVOIR INVESTIGATIONS OF \\ U. S. BUREAU OF RECLAMATION LEASEHOLDS AT EAST MESA, IMPERIAL VALLEY, CALIFORNIA
}

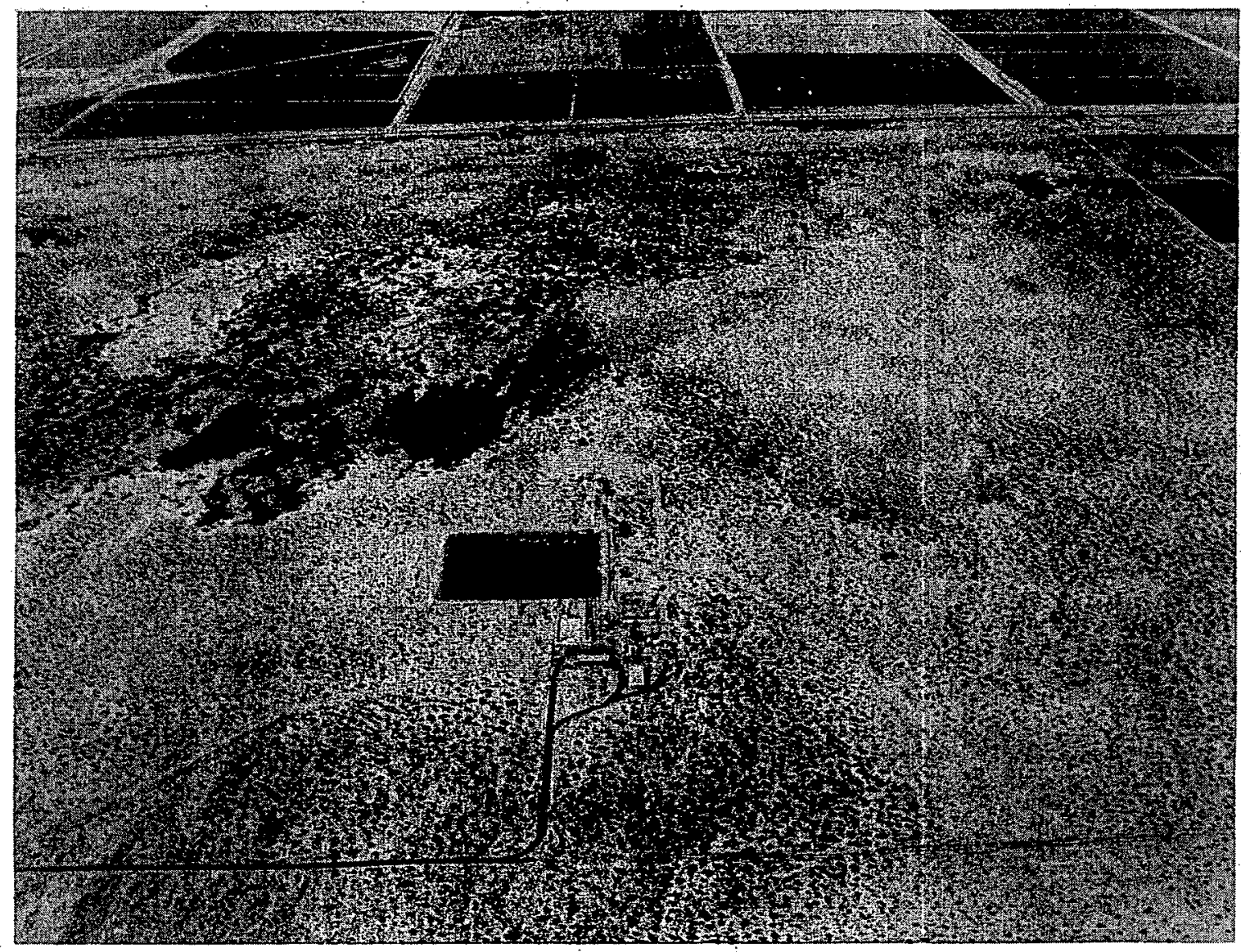

\section{October 1978}

\section{LAWRENCE BERKELEY LABORATORY UNIVERSITY OF CALIFORNIA}

BERKELEY, CALIFORNIA 94720 aistabution of this Document is unumiten. 


\section{DISCLAIMER}

This report was prepared as an account of work sponsored by an agency of the United States Government. Neither the United States Government nor any agency Thereof, nor any of their employees, makes any warranty, express or implied, or assumes any legal liability or responsibility for the accuracy, completeness, or usefulness of any information, apparatus, product, or process disclosed, or represents that its use would not infringe privately owned rights. Reference herein to any specific commercial product, process, or service by trade name, trademark, manufacturer, or otherwise does not necessarily constitute or imply its endorsement, recommendation, or favoring by the United States Government or any agency thereof. The views and opinions of authors expressed herein do not necessarily state or reflect those of the United States Government or any agency thereof. 


\section{DISCLAIMER}

Portions of this document may be illegible in electronic image products. Images are produced from the best available original document. 
LBL-7094

UC-66a

\section{GEOTHERMAL RESOURCE AND RESERVOIR INVESTIGATIONS \\ OF U.S. BUREAU OF RECLAMATION LEASEHOLDS AT \\ EAST MESA, IMPERIAL VALLEY, CALIFORNIA}

J. H. Howard, J. A. Apps, S. M. Benson, N. E. Goldstein, A. N. Graf,

J. P. Haney, D. D. Jackson, S. Juprasert, E. L. Majer, D. G. McEdwards,

T. V. McEvilly, T. N. Narasimhan, B. Schechter, R. C. Schroeder, R. W. Taylor, P. C. van de Kamp, and T. J. Wolery

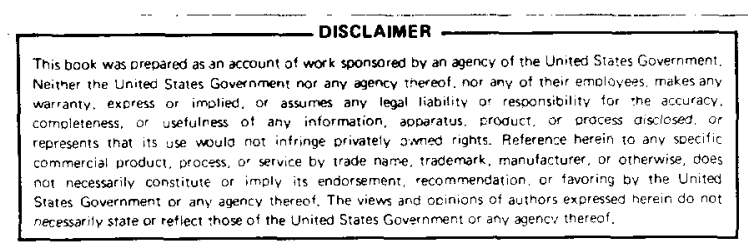

EARTH SCIENCES DIVISION

LAWRENCE BERKELEY LABORATORY

UNIVERSITY OF CALIFORNIA

BERKELEY, CALIFORNIA 94720 


\section{CONIENTS}

\section{PREFACE}

R. C. Schroeder

\section{SECTION 1: GEOLOGY}

P. C. van de Kamp. J. H. Howard, and A. N. Graf 1

Introduction $\quad 1$

Subsurface Geology

Structure $\quad 22$

Discussion $\quad 27$

Estimate of Fluid and Thermal Content of Leaseholds 1, 2, and $4 \quad 27$

References Cited $\quad 32$

SECTION 2: SEISMICITY

E. L. Majer, T. V. McEvilly, B. Schechter, and N. E. Goldstein 33

Introduction 33

Review of Seismic Studies at East Mesa 33

General Seismicity before 1973

USGS-CIT Imperial Valley Array $\quad 34$

Results of 1973 Microearthquake Study 35

Results of the 1974-1975 Microearthquake Study 35

The Brawley Swarm 36

Combs-Hadley Hypothesis Tested 41

Observation Procedures of LBL $\quad 42$

Results of the Present Study $\quad 50$

Network Performance $\quad 52$

Recommendations and Conclusions $\quad 54$

References Cited $\quad 55$

SECTION 3: WELL TESTS

D. G. McEdwards, J. P. Haney, S. M. Benson, and R. C. Schroeder

Introduction $\quad 57$

Well Tests at East Mesa

Contractual Well Tests for USBR $\quad 60$

USBR Production Tests $\quad 60$

Flow Rate Measurements $\quad 60$

Pressure Measurements $\quad 62$

Production Test Design $\quad 62$ 
Production Test Analysis Techniques $\quad 62$

Production Test Results 63

Discussion of Production Test Results 65

East Mesa Interference Tests $\quad 67$

Discusaion of Interference Test Results 69

Hydrologic Boundaries and Continuity between We11s 69

$\begin{array}{ll}\text { Conclusions } & 70\end{array}$

References vited $\quad 71$

SECTION 4: RESERVOIR SIMULATION

T. N. Narasimhari and S. Juprasert $\quad 75$

Introduction $\quad 75$

Factors Relevant to Economics 78

Assuraptions $\quad 79$

Limit of the Production Well Field 80

Limits of the Geothermal Reservoir 80

Reservoir Properties $\quad 82$

Fluid Properties $\quad 84$

Other Assumptions $\quad 84$

Methods of Analysis $\quad 84$

Prescure-transient Calculations $\quad 85$

Thenal-ibreakthrough Calculations $\quad 89$

Wellbore: Thermodyamics 91

Cases Studied $\quad 93$

Results of Simulation $\quad 93$

Pressure-Transieat Calculations 93

lio injection; Peripheral injection; Five-spot

patten; Effect of viscosity of pressure

distribution; Effect of wellbore damage

Wellbote Presure-Temperature Calculations 121

Hydrodynamic and Temperature Breakthrough Calculations 123

Hydrodynamic breakthrough; Thermal breakthrough

Ground Subsidence 
Indiced Seismicity

Discussion of Results

Pressure Transient Calculations

Hydrodynamic and Temperature Breakthroughs

Ground Subsidence

Interpolation of Results to USBR's Leasehold

Limitations of This Study

Summary and Conclusions

Nomenclature

References Cited

\section{SECTION 5: GEOCHEMISTRY}

R. W. Taylor, D. D. Jackson, T. J. Wolery, and J. A. Apps 165

Introduction

Chemical Composition of Fluids from East Mesa and the Salton Sea 169

Selection Criteria and Sampling Problems 159

$\begin{array}{ll}\text { Change in } \mathrm{pH} \text { with Sample Age } & 170\end{array}$

Analytical Errors vs. Sampling Problems 171

Compositionn Trends $\quad 172$

Conclusions $\quad 179$

Chemical Composition of the Salton Sea

Flashing and Fractionation of Volatiles 175

The Contribution of $\mathrm{CO}_{2}$ to Flashing 175

Fractionation of $\mathrm{CO}_{2}$ and $\mathrm{NH}_{3}$ During Fiashing 180

Observed Composition of Dry Gas from Well 6-1 183

Chemical Change in a Flashing Fluid 181

Scaling Potential of Geothermal Fluids $\quad 184$

$\begin{array}{ll}\text { Computational Methods } & 184\end{array}$

Scaling Potential of Individual Wells During

Production and Flashing 185

Potential for Scaling due to Mixing Geothermal Fluids 187

Potential for Scale Formation from the Use of

Salton Sea Water 195

Scale Formation by Heating Salton Sea Water 198

Mixing Salton Sea Water with Geothermal Fluids 200

Reactions of Injected Fluids with Reservoir Minerals 200 
Scale-Forming Experience

Downhole Scaling in We11 6-1

Scale Formation in the Multistage Flash-Evaporator Plant

Scaling in the Vertical-Tube Evaporator Plant

Scaling During Transport and Injection of Spent Fluids

Precipitation of Scale-Forming Minerals in Fluid-Mixing

Experiment

Scale Control

Conclusions and Recommendations

Acknowledgments

References Cited

\section{SECTION 6: SUMMARY}

R. C. Schroeder

We11 5-1 Injection Test

We11 8-1 Production Test

We11 6-2 Production Test

Wel1 6-1 Production Test

Introduction

Interference Tests in the USBR and Magma Power Properties

Test 1

We11 6-1

265

We11 44-7

265

We 11 31-1

266

Test 2

We11 6-1

Well 48-7

Interference Tests in the Republic Geothermal Property

Test 3 
APPENDIX C: PRODUCTION TESTS IN THE NORTHERN PORTION OF THE EAST MESA KGRA

We11 38-30 Production Test $\quad 281$

Well 18-28 Injection Test 281

We11 16-29 Production Test $\quad 281$

$\begin{array}{ll}\text { APPENDIX D: CONVERSION TABLES } & 285\end{array}$

APPENDIX E: CHEMICAL ANALYSES OF FLUIDS FROM EAST MESA WELLS 289

Table E.1. Chemical Analyses of Well 6-1 290

Table E.2. Chemical Analyses of Well 6-2 292

Table E.3. Chemical Analyses of Republic We1ls 294

Table E.4. Chemical Analyses of We11s 8-1, 31-1, and 44-7 296

Table E.5. Chemical Analyses of Well 5-1 298

APPENDIX F: RESULTS OF LABORATORY STUDIES OF SCALE SAMPLES TAKEN

FROM THE VTE 


\title{
PREFACE
}

\author{
R. C. Schroeder
}

Scientists from Lawrence Berkeley Laboratory (LBL) have been involved in resource-related activities at the East Mesa, California, Known Geothermal Resource Area (KGRA) since 1975. The earliest LBL activities were the geophysical and reservoir engineering work carried out in cooperation with the U. S. Bureau of Reclamation (USBR), the U. S. Department of Energy (DOE), Imperial Magma Co. (Magma) and Republic Geothermal, Inc. (RGI). In 1977, LBL personnel proposed a comprehensive reservoir and resource study program. The principal goal of the study was to present a qualitative and quantitative appraisal of the resource that would allow USBR to assess their geothermal desalination program.

The study program presented to the USBR included five parts: geology, geophysics, well testing, reservoir simulation, and geochemistry. The tasks and orientation of the LBL study were constrained by funding and by the principal goal referred to above. For example, the reservoir simulation was oriented toward answering the question of availability of fluid for desalination and the geochemistry study was 1 imited to certain questions of brine chemistry that were appropriate for the USBR desalination project. In both cases, if more time and money were available, the scope of the work would have been expanded to include more basic and comprehensive considerations. The topics agreed upon for study by USBR and LBL and the tasks to be performed are summarized below.

\section{Geology}

Review the regional geological setting of the East Mesa KGRA. Prepare a geological model of the East Mesa geothermal anomaly. Estimate the size of the resource at the USBR property.

\section{Geophysics}

Continue the seismic interpretation begun in 1977 .

Determine hypocenters of microearthquakes and higher-amplitude events.

Relate seismo-tectonic effects to the reservoir behavior, if possible. 
3. Reservoir Engineering (We11 Testing)

Conduct productivity tests of all USBR production wells.

Conduct injection test of we11 5-1.

Review and analyze all well tests.

Provide estimates for the reservoir material parameters, well conditions, and a preliminary appraisal of the hydrologic continuity of the East Mesa geothermal anomaly.

4. Reservoir Engineering (Reservoir Simulation)

Analyze and forecast reservoir behavior for production of specified amounts of water with and without injection.

Analyze and forecast reservoir behavior for different well patterns, and different numbers of wells.

Prepare estimates of reservoir lifetime for specified withdrawal and injection rates (for different patterns and wells).

Prepare estimates of surface subsidence for the cases chosen in the simulation.

\section{Geochemistry}

Evaluate the possibility of downhole production well scaling.

Evaluate the possibility of production pipeline scaling.

Evaluate the possibility of scaling and precipitation in injection wel1bores and adjacent formations.

Review problems associated with mixing of brines of different composition.

Whenever possible, we have drawn upon the work previously completed at East Mesa by people from the U. S. Bureau of Reclamation, TRW, Intercomp, University of California at Riverside, and others. Previous contributions are acknowledged in the report by referencing the appropriate publication. In addition to the principal contributors and authors shown here many more people have contributed substantially to this project.

Although the following 1 ist is incomplete, we can acknowledge a few of the people involved. They are: W. Fernelius, K. Fulcher, and K. Mathias of USBR; R. Sones, Westec; J. Angevine, R. Davis, C. Goranson, 
D. Lippert, M. Moebus, R. Phillips, R. Solbau and P. A. Witherspoon of LBL; T. Hinrichs and J. Featherstone, Magma; J. Barkman, D. Campbell and M. Walker, RGI; and A. Adduci, DOE/SAN.

The Geochemistry section was prepared primarily by $R$. W. Taylor, D. D. Jackson, and T. J. Wolery, all of the Lawrence Livermore Laboratory. Their contribution to this report is substantial, and the cooperation of the management of the Lawrence Livermore Laboratory in permitting their scientists to work on this project is gratefully acknowledged.

This work was partially supported by the U.S. Department of Energy, Division of Geothermal Energy, under contract W-7405-ENG-48. 


\title{
SECTION 1: GEOLOGY
}

\author{
P. C. van de Kamp. J. H. Howard, and A. N. Graf \\ Lawrence Berkeley Laboratory
}

\section{INTRODUCTION}

The fault-bounded Salton Trough is the nonmarine northerly extension of the Gulf of California physiographic province. The Salton Trough includes the Colorado River delta in Mexico and the Coachella and Imperial Valleys between the Peninsula Ranges of southern California and the south Mojave Desert mountains (Figures 1.1, 1.2, and 1.3).

Several major northwest-trending faults are present in the Imperial Valley. These include the San Andreas fault on the eastern margin of the Salton Trough, the San Jacinto fault on the western margin, and the Imperial fault in the center of the valley. These all are active faults with significant horizontal and vertical displacements. Other subparallel faults are present in the valley; some have surface expressions, others are seen only in wells or deduced from seismic data.

The Gulf of California and the Salton Trough developed in late Cenozoic time by a combination of strike-slip displacement and dipslip movement. This moved Mesozoic and older basement complex rocks as much as 15,000 to $20,000 \mathrm{ft}$ below sea level within the trough. Equivalent rocks are up to 5,000 ft or more above sea level in the mountains adjacent to the trough.

The present geographic limits of the trough correspond approximately to those of the late Cenozoic depositional basin. In the central Imperial Valley, up to $6 \mathrm{~km}$ of sediments have been deposited since the late Miocene. Figure 1.4 shows the stratigraphic column of the trough including marine and nonmarine facies derived from basin-margin sources and large volumes of sediment transported by the Colorado River and deposited in its delta. In the Pleistocene, the delta built up across the trough and closed off the northern portion from the Gulf of California (Downs and Woodard, 1961). The northern part of the trough has since been the site of nonmarine and lacustrine deposition (van de Kamp, 1973). The basement rocks are both Mesozoic to Precambrian metamorphic rocks and igneous rocks with local Mesozoic and Cenozoic volcanics. 


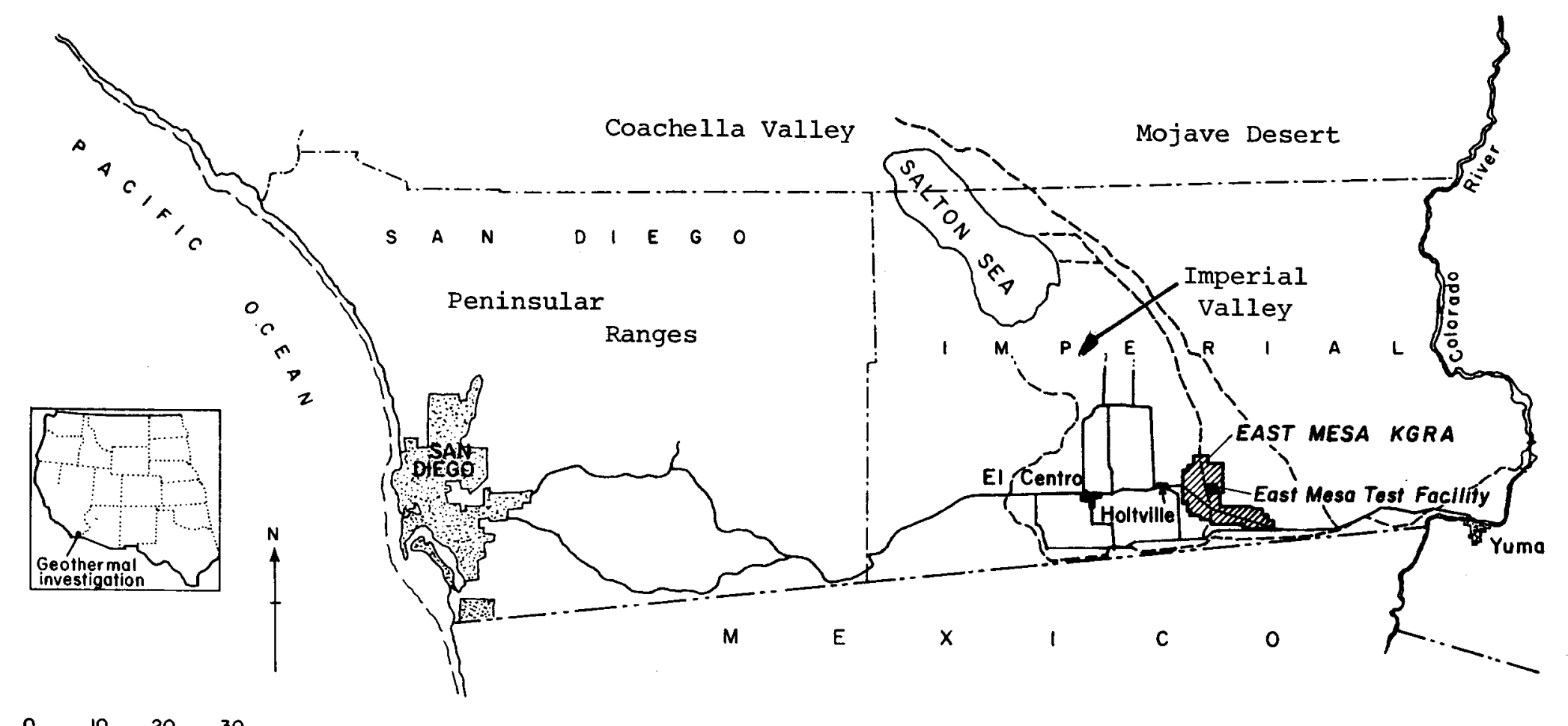

N

XBL 783-475

Figure 1.1. Location map, East Mesa geothermal resource. 


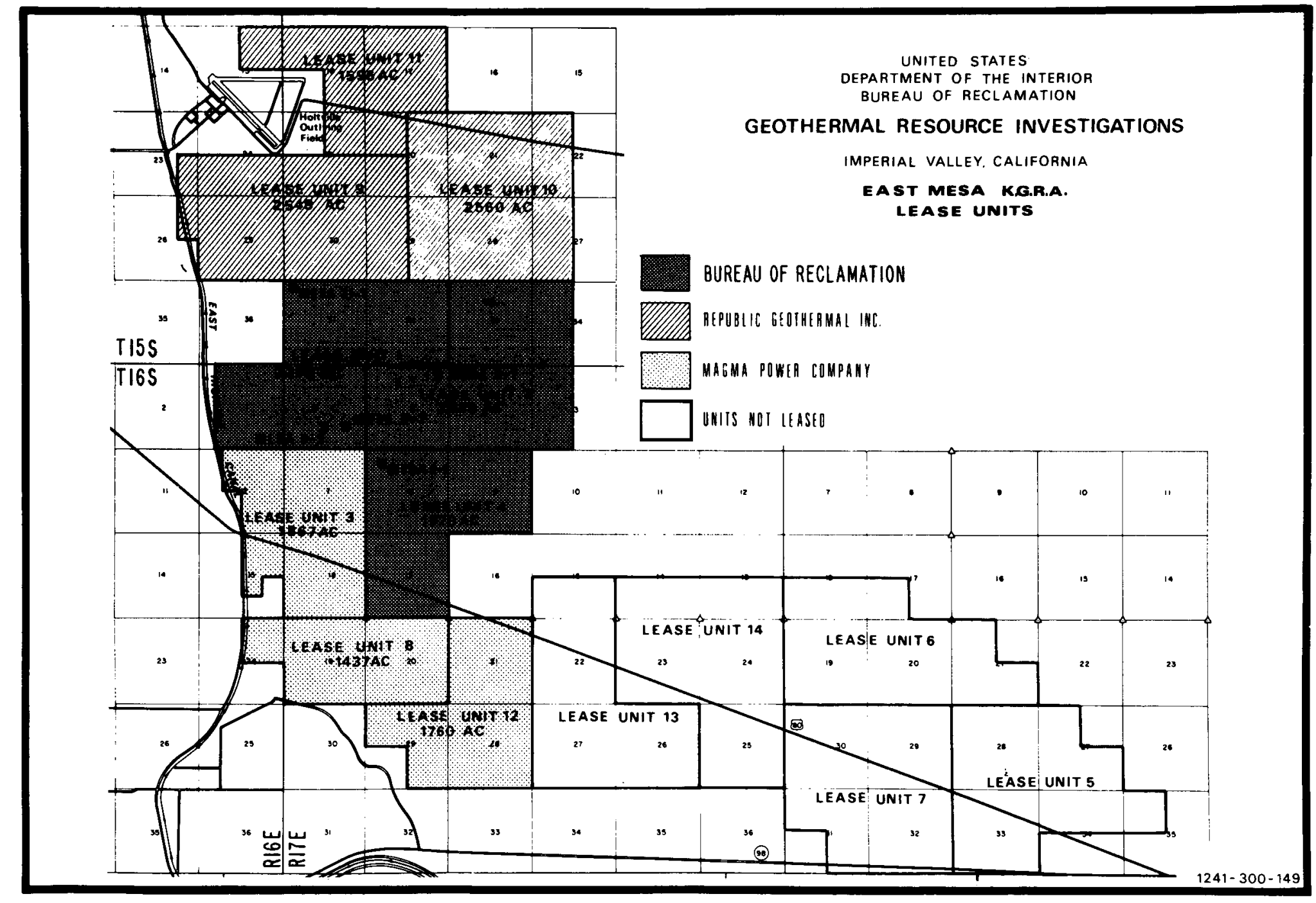

Figure 1.2. East Mesa KGRA lease units.

XBL 789-11161 


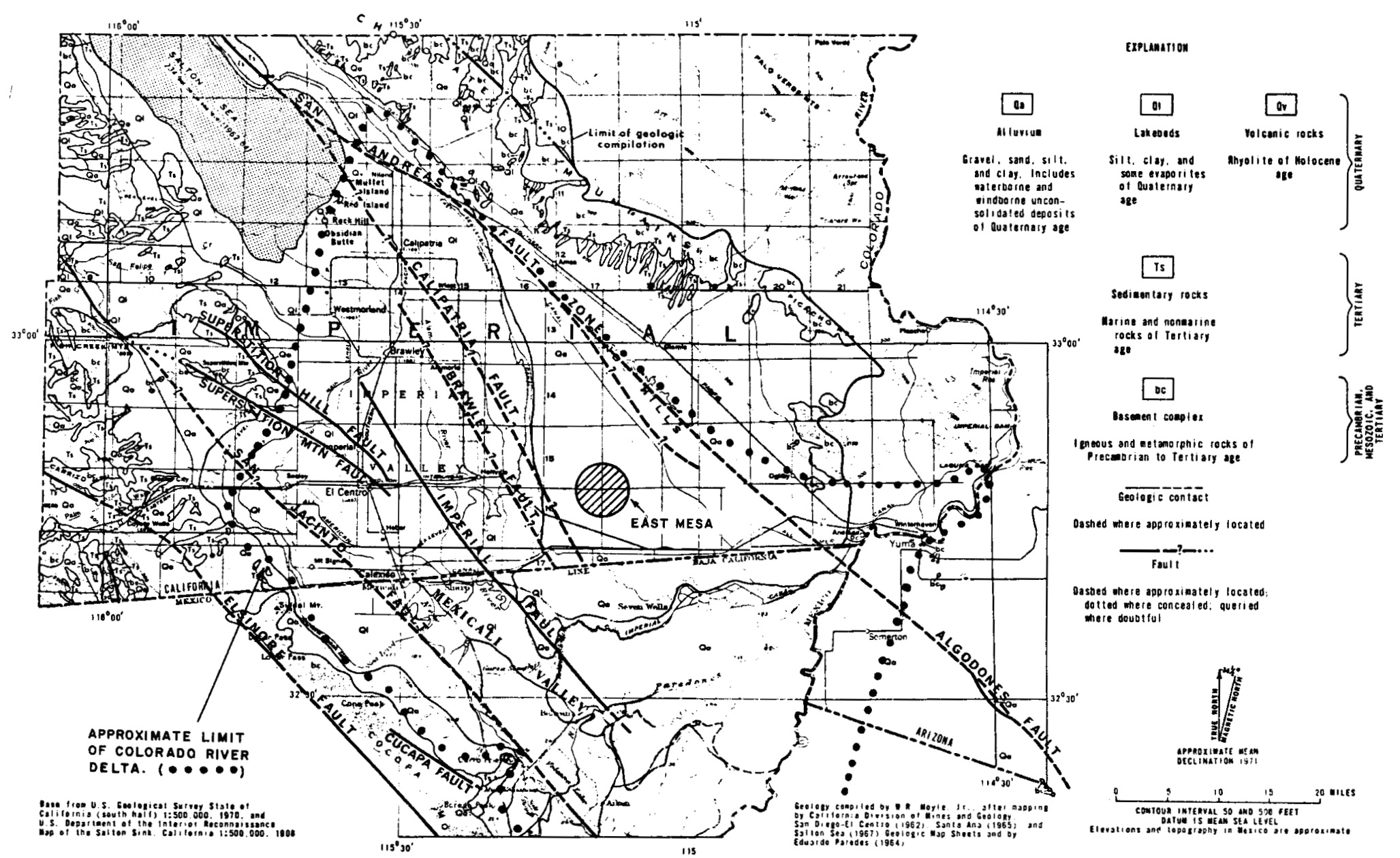

Figure 1.3. Geologic map of the Imperial and Mexicali Valleys.

XBL 788-10518 


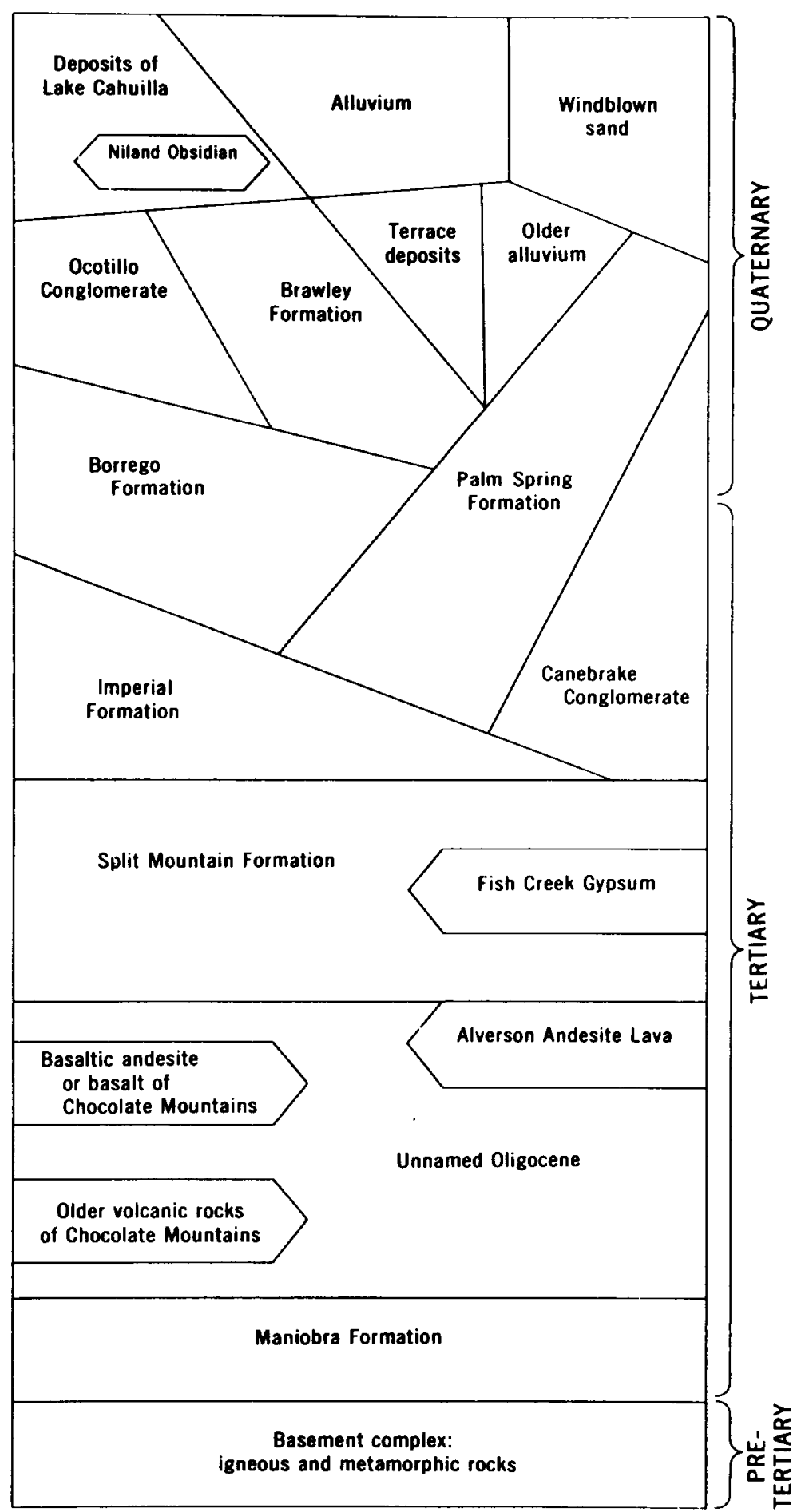

Figure 1.4. Composite stratigraphic section of the Salton Trough (after Loeltz et al., 1975).

XBL $789-11162$ 
East Mesa (Figure 1.3) is a triangular area southwest of the Algodones Dunes, east of the Eastside Canal and north of the Mexican border. Physiographically, the East Mesa is a plain sloping from the eastern basin margin into the central Imperial Valley. It was formed mostly by fluvial processes of the Colorado River delta deposition. Irregular deposits of aeolian sand up to $20 \mathrm{ft}$ thick mantle the fluvial deposits.

The purpose of the subsurface study was to determine the stratigraphy and structure of the area in order to facilitate mapping the structure and distribution of the sandstone reservoir. This information is used to determine the size, shape, and volume of the reservoir containing the geothermal energy resource and can be used along with other data in calculating the amount of energy in place.

\section{SUBSURFACE GEOLOGY}

In this study, we interpreted the subsurface geology of East Mesa from well data including electric, sonic, density and gamma-ray logs, and sample cuttings. The well data were generated mainly from the drilling programs of the U. S. Bureau of Reclamation, Republic Geothermal, Inc., and Magma 'Power, Inc., during the 1970s. Data collected from older petroleum wildcat wells in the area were also used. Reflection seismic data, obtained in 1966 by Geophysical Survey, Inc. (GSI), for American Petrofina and in 1977 by Western Geophysical for Systems, Science and Software (Goupilland and Cherry, 1977), were used to map structure on the stratigraphic markers.

We originally hoped to obtain a three-dimensional picture of the subsurface stratigraphy and structure by correlating electric logs. This method, however, soon proved unsuccessful since individual $10 \mathrm{~g}$ markers cannot be correlated with confidence from one well to another because of variations and discontinuities in the lithologic units between the wells. Nevertheless, the well logs have been essential for interpreting sandstone genetic units and porous zones, and for calibrating the seismic data (Figures 1.5 through 1.11) through the development of time-depth curves (Figure 1.7) from the sonic logs. These time-depth curves enabled us to convert the seismic reflection times to subsea depths. 


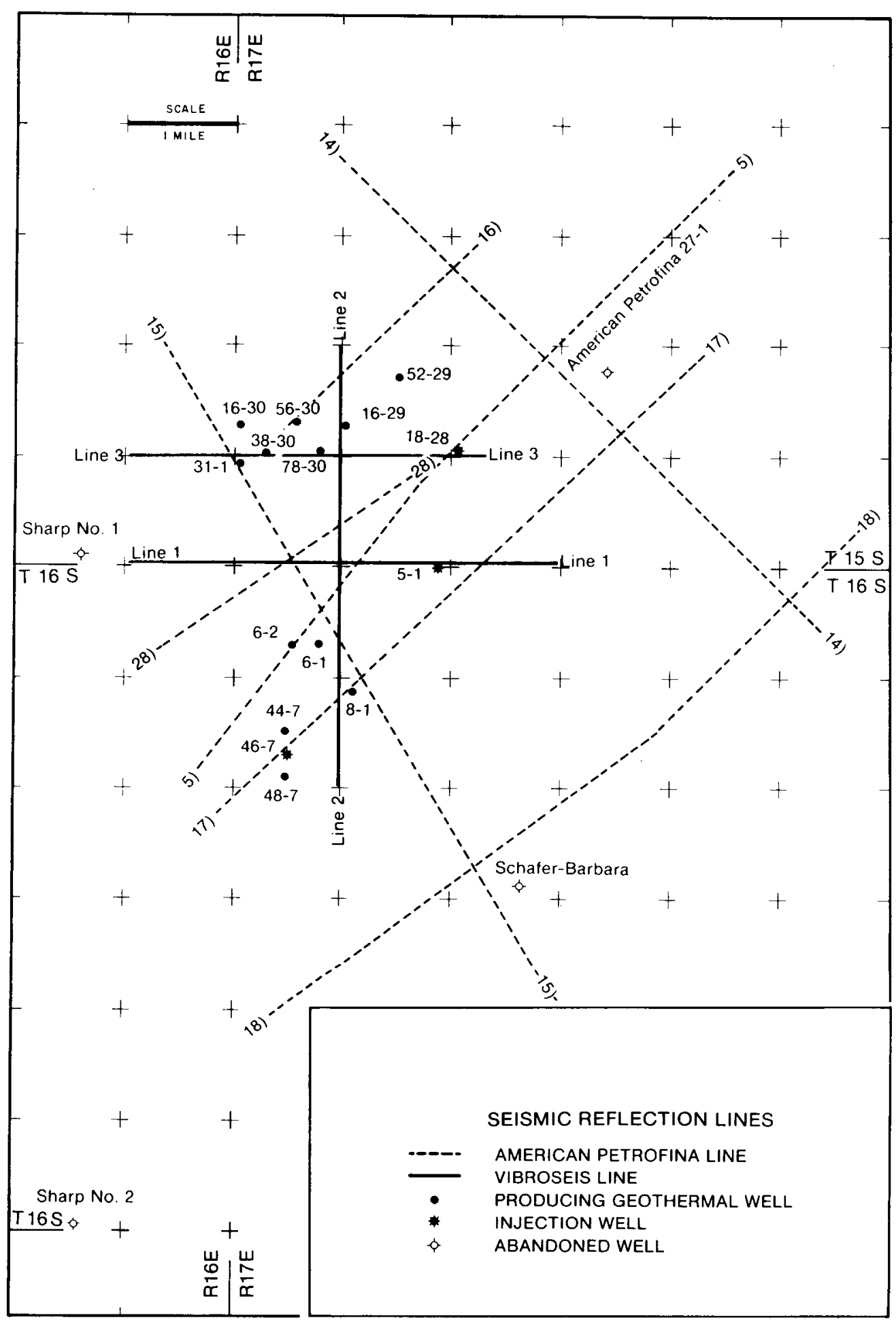

$\times 81786-1859$

Figure 1.5. Index map to the seismic data showing the grid of lines used to map the structure shown in Figures $1.7,1.8$, and 1.9. The quality of the data range from poor to good, but sufficient resolution exists for mapping presented in this report. 
The seismic reflection profile in Figure 1.6 is from 24-fold VIBROSEIS data acquired by Systems, Science and Software in 1977. The upper part of the profile exhibits good quality reflections; these deteriorate rather abruptly at 1.2 to 1.6 seconds, where the denser rocks of the poorly reflective zone ( $P R Z$ ) appear. In this zone, the velocity contrast between shales and sandstones is diminished so that the reflections are also diminished. Fracturing is believed to be another significant factor causing diminished reflections in this zone due to the dispersion of seismic energy. Figure 1.7 shows time-depth curves computed from sonic velocity logs. These illustrate the time required for seismic energy to reach a given depth and return to the surface (two-way time). This in turn facilitates the determination of depths from the seismic reflection data, which are recorded as a function of time. The time-depth curves are all very similar, which indicates that the response of seismic waves to rocks is homogeneous throughout the East Mesa field.

The seismic data proved very useful for mapping structure on throughgoing reflectors (Figures $1.5,1.6,1.9$, and 1.10). The wells could then be correlated by identifying these reflectors on the well logs at the depths indicated on seismic records. These data have been used to construct structure maps (Figures $1.8,1.9$, and 1.10) and crosssections (Figures 1.12 through 1.23).

Cross-sections 1 through 11 are vertical profiles derived from seismic reflection, thermal, and well-log data and show stratigraphic, structural, and temperature relationships in the East Mesa area. The blue, orange and yellow markers are mapped seismic reflectors (Figures 1.9 and 1.10). TPRZ is the top of the poorly reflecting zone (Figure 1.11). The lines for $300^{\circ} \mathrm{F}$ and $330^{\circ} \mathrm{F}$ represent isotherms that illustrate the form of the high-temperature zone. Horizontal and vertical scales are equal. The wells are represented with electric logs. The $S_{p}$ curve is to the left and the resistivity curve to the right.

Three prominent reflectors were mapped at shallow, intermediate and deep levels relative to productive zones in order to understand the structure and stratigraphy within and adjacent to the reservoir (Figures 1.8, 1.9, and 1.10). 


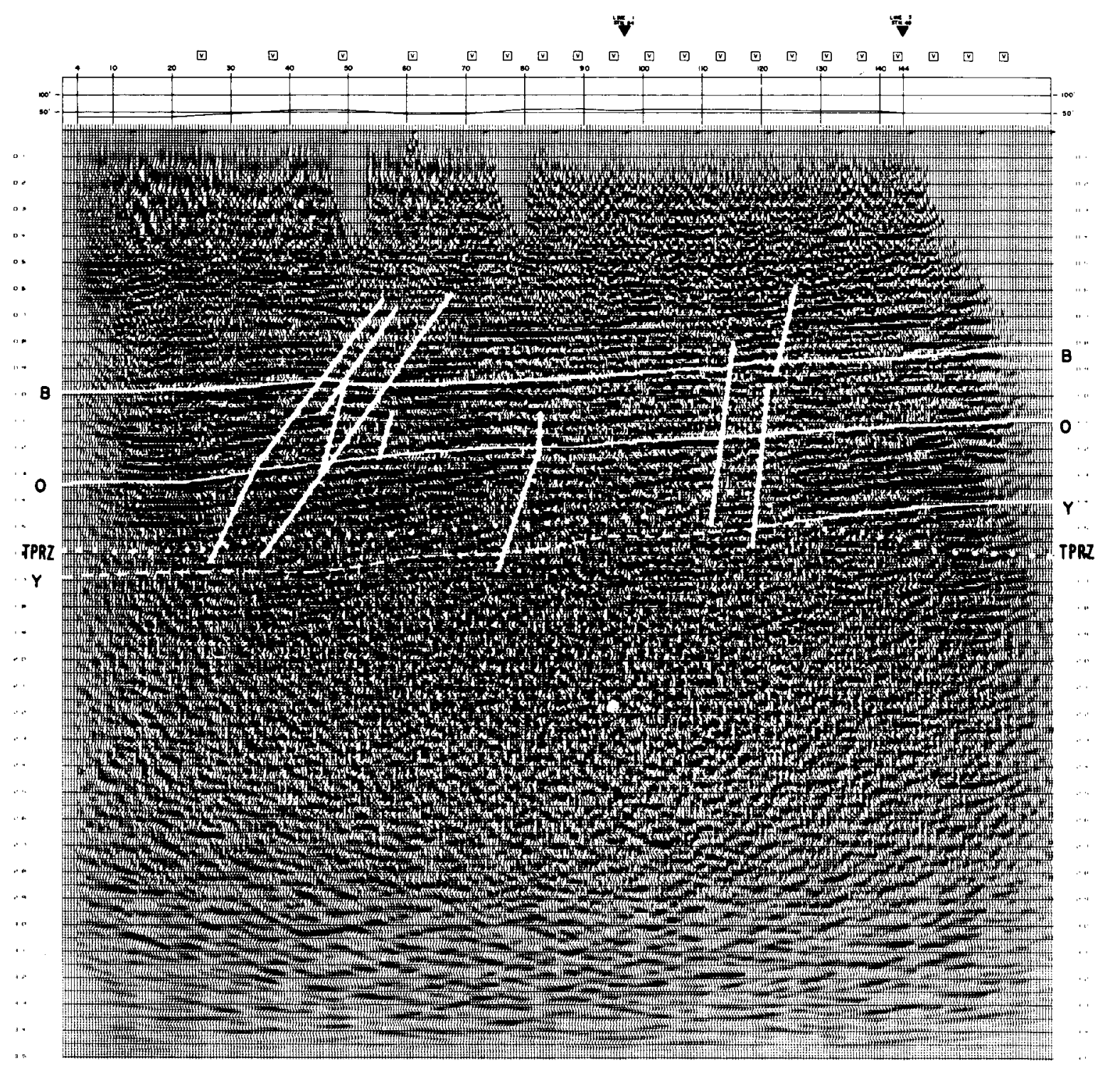

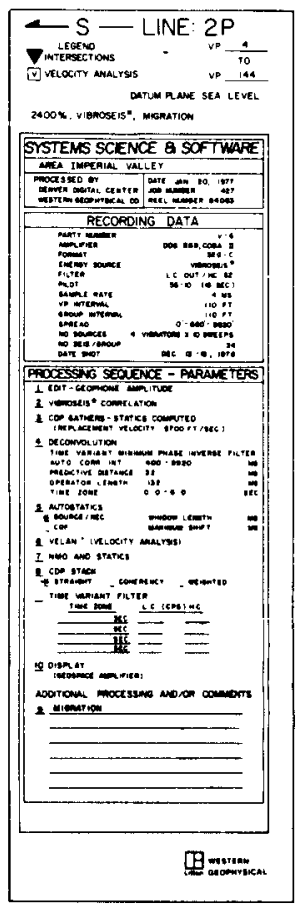

LEGEND

B BLUE MARKER

- oramge marker

Y YELLOW MARKER

- top poor Reflective zone

f FAults

XBL $791-7910$

Figure 1.6. Example of a seismic reflection profile in the East Mesa area. The stratigraphic markers used to map structure and the faults offsetting these markers are indicated (modified from Systems, Science, and Software, 1977). 

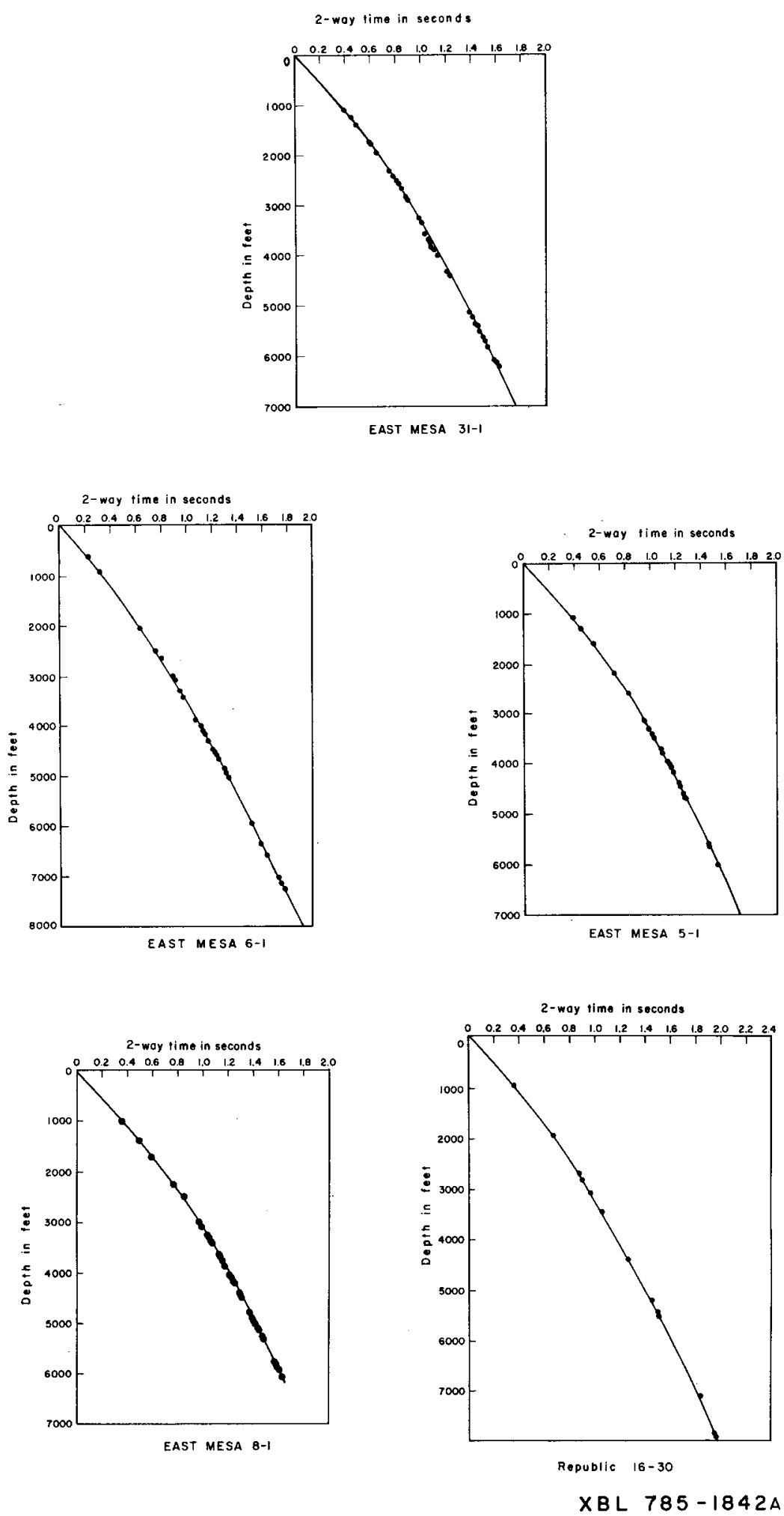

Figure 1.7. Time-depth curves computed from sonic velocity logs. 


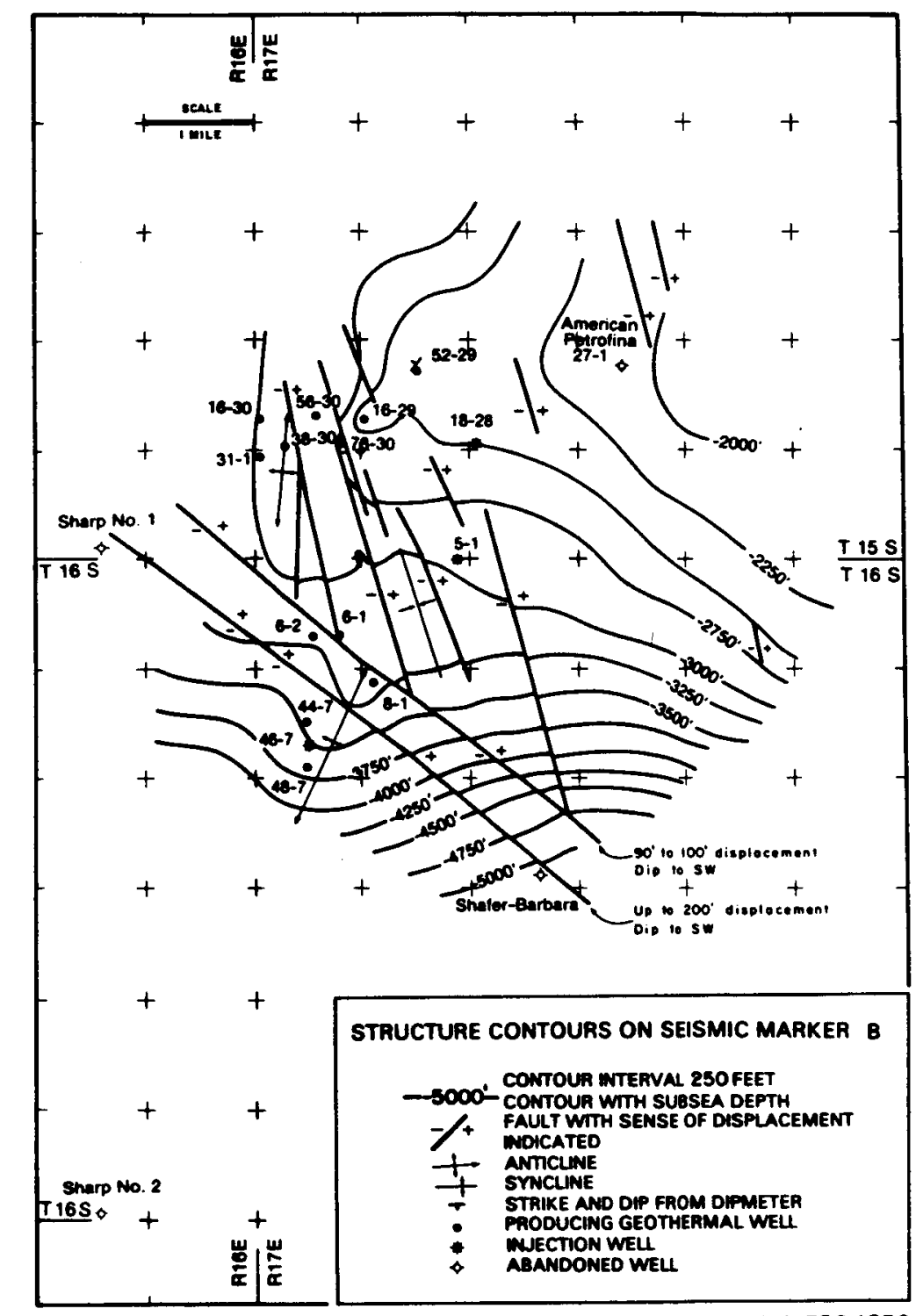

$X B L 786-1856$

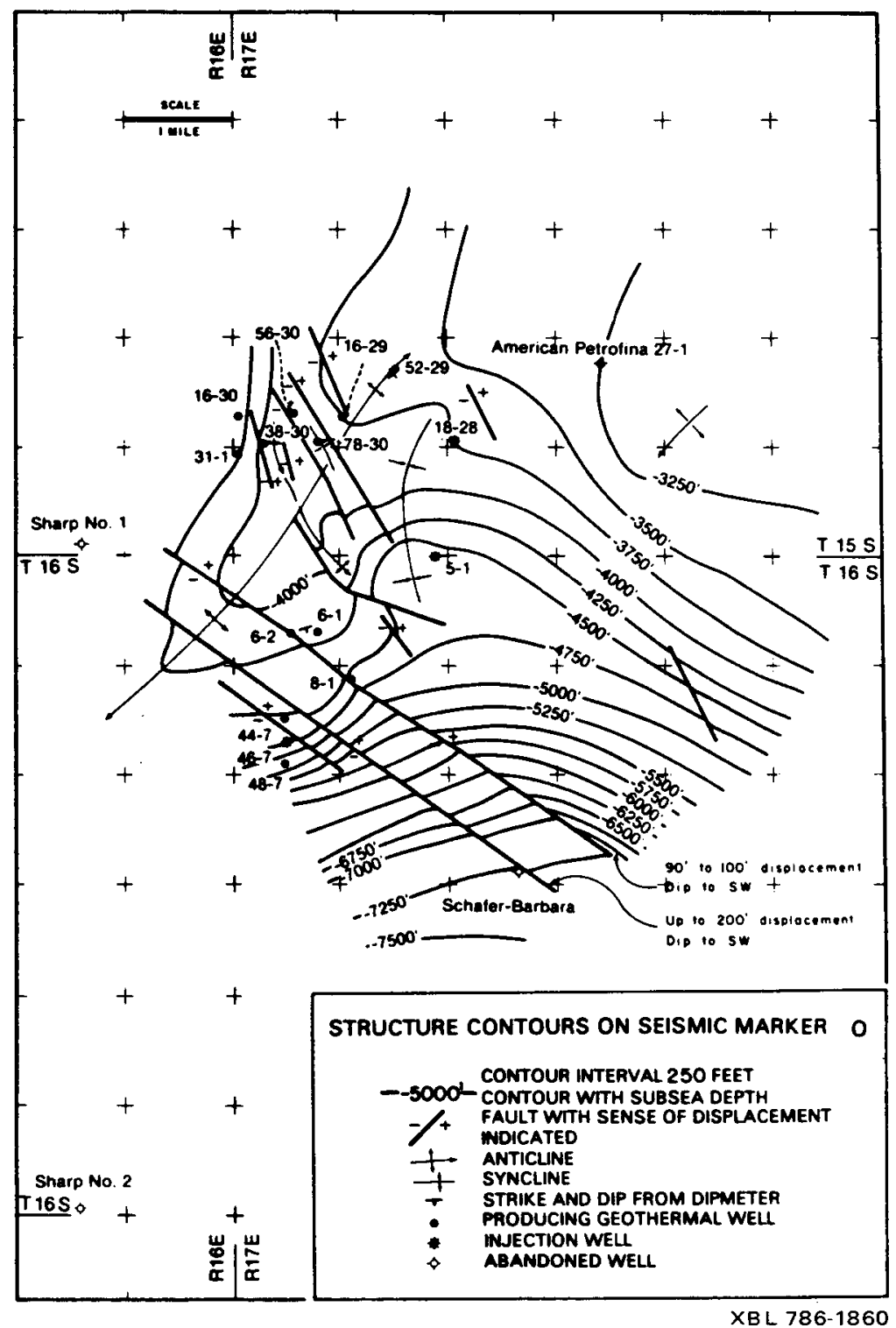

Figure 1.9. Structure contours on seismic marker 0 .

Figure 1.8. Structure contours on seismic marker $B$. 


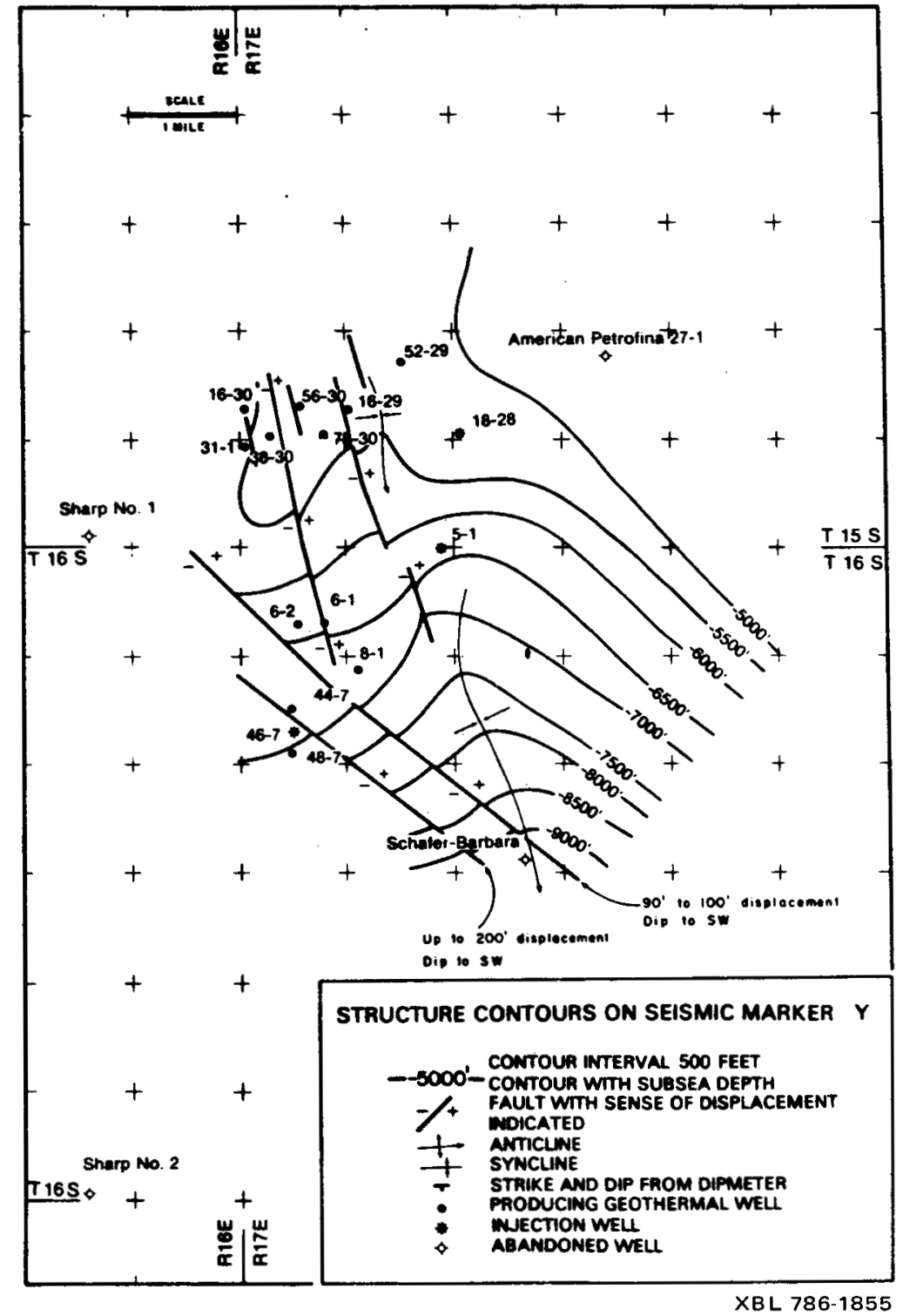

Figure 1.10. Structure contours on seismic marker $Y$.

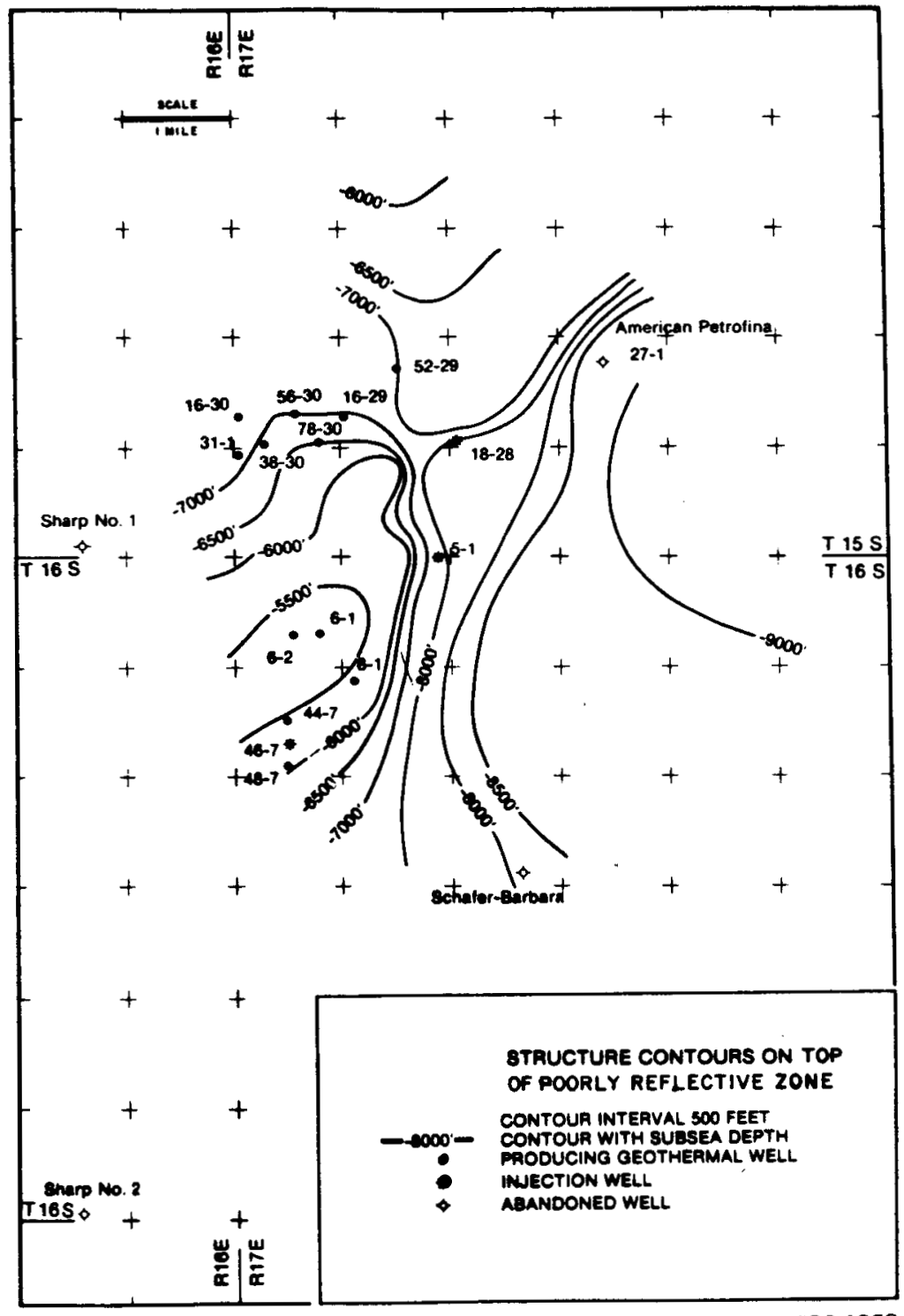

XBL 786-1858

Figure 1.11. Structure contours on top of poorly reflective zone (TPRZ). 


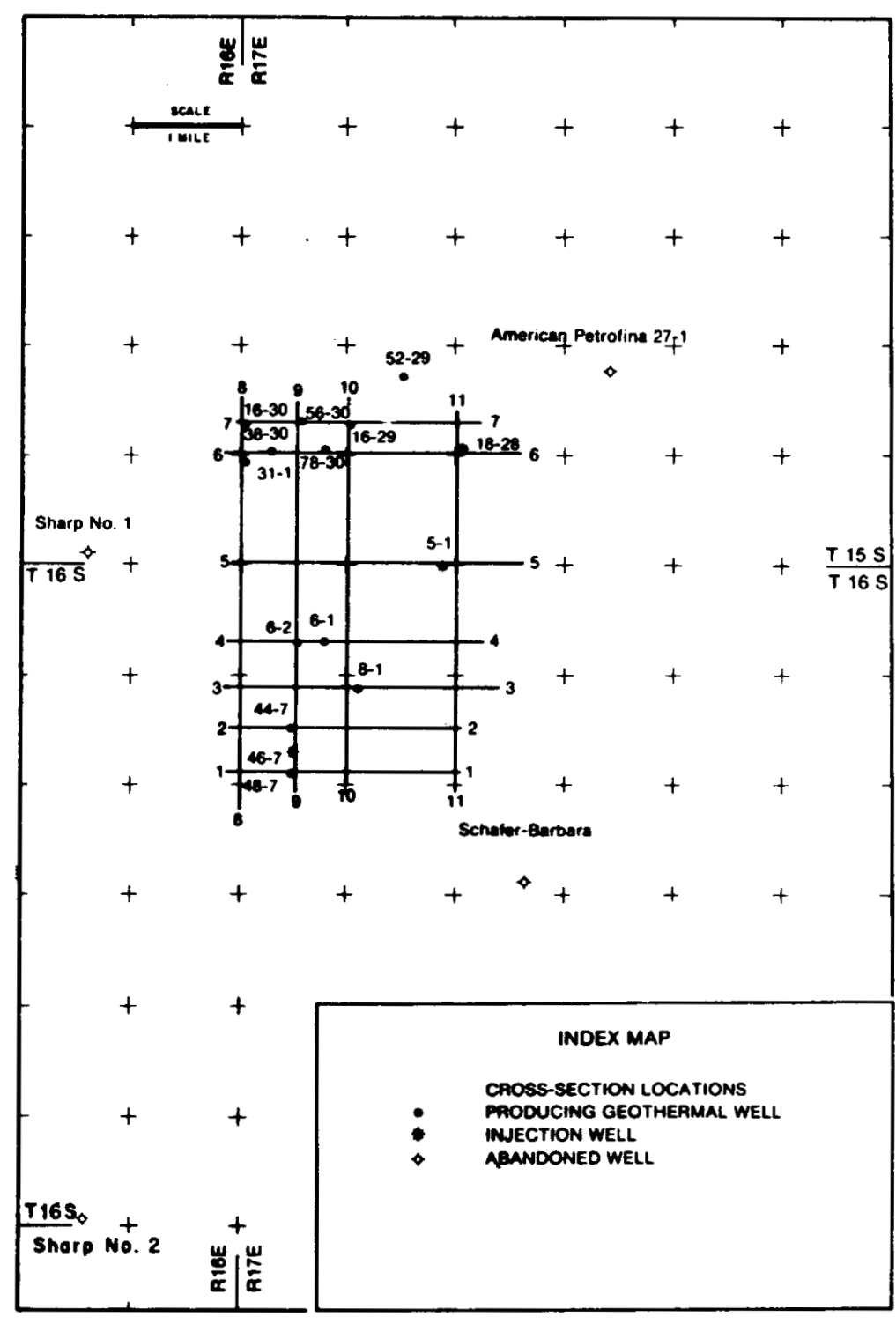

XBL 786-1857

Figure 1.12. Index map showing the locations of the 11 cross sections (Figures 1.13 through 1.23 ) that outline the stratigraphic, structural, and thermal geometry of the East Mesa subsurface. 


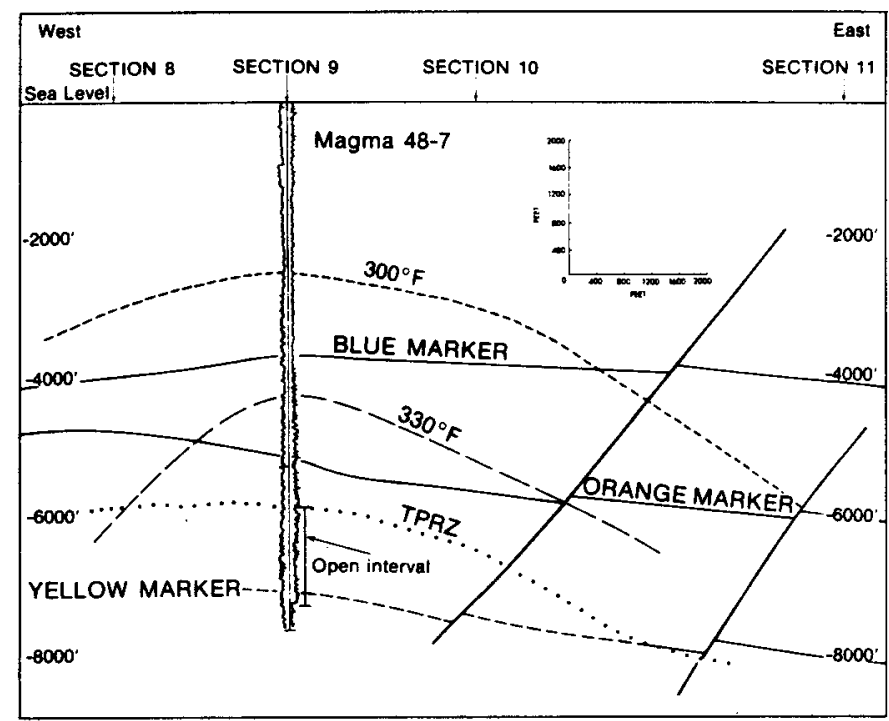

XEL 785-1844

Figure 1.13. Cross section 1. Isothermal surfaces at 300 and $330 \%$. Blue, orange, and yellow markers are seismic reflectors on which structure has been mapped.

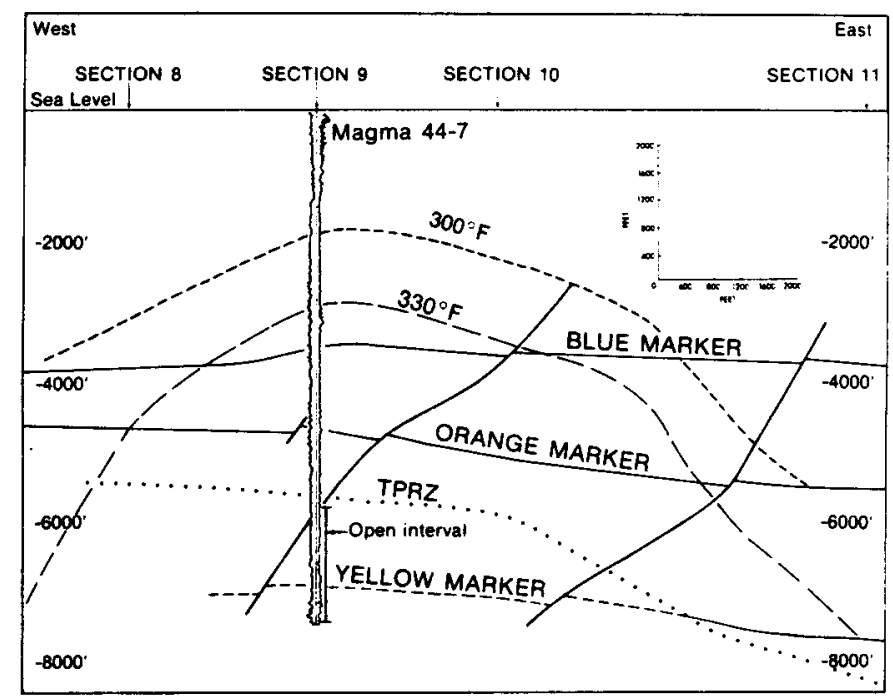

$\times 8 L 785-1845$

Figure 1.14. Cross section 2. Isothermal surfaces at 300 and $330 \%$ F. Blue, orange, and yellow markers are seismic reflectors on which structure has been mapped. 


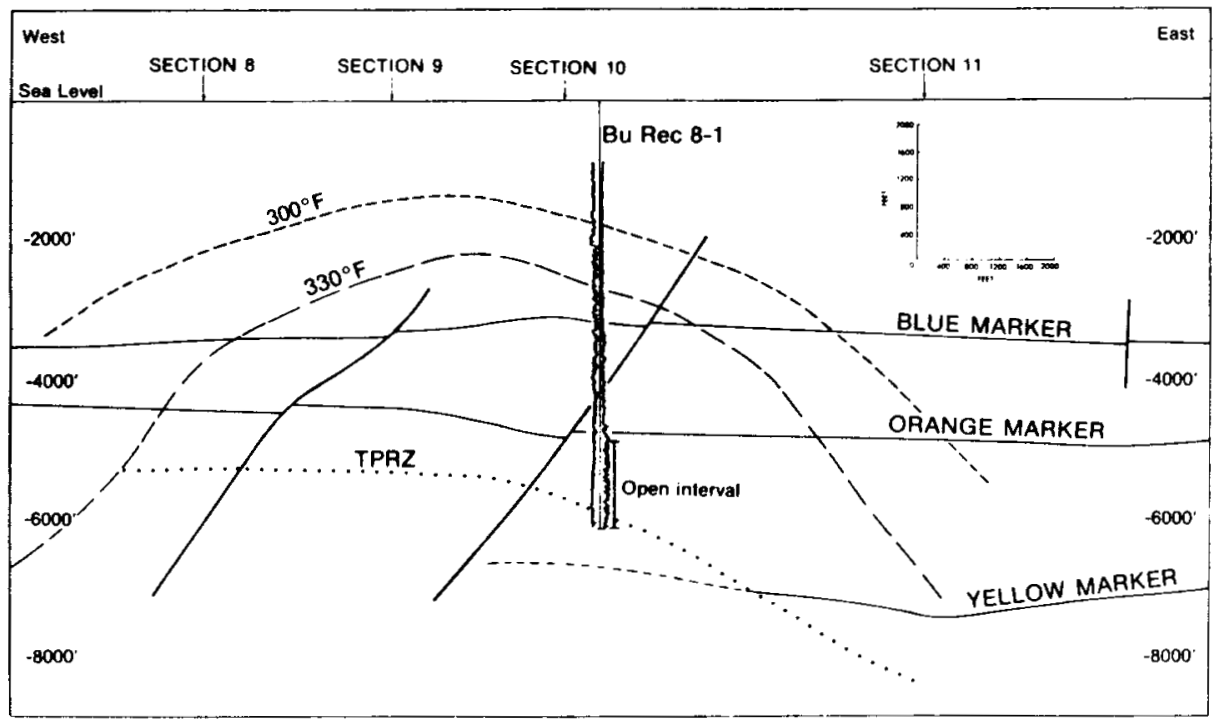

XEL $785-1846$

Figure 1.15. Cross section 3. Isothermal surfaces at 300 and $330^{\circ} \mathrm{F}$. Blue, orange, and yellow markers are seismic reflectors on which structure has been mapped.

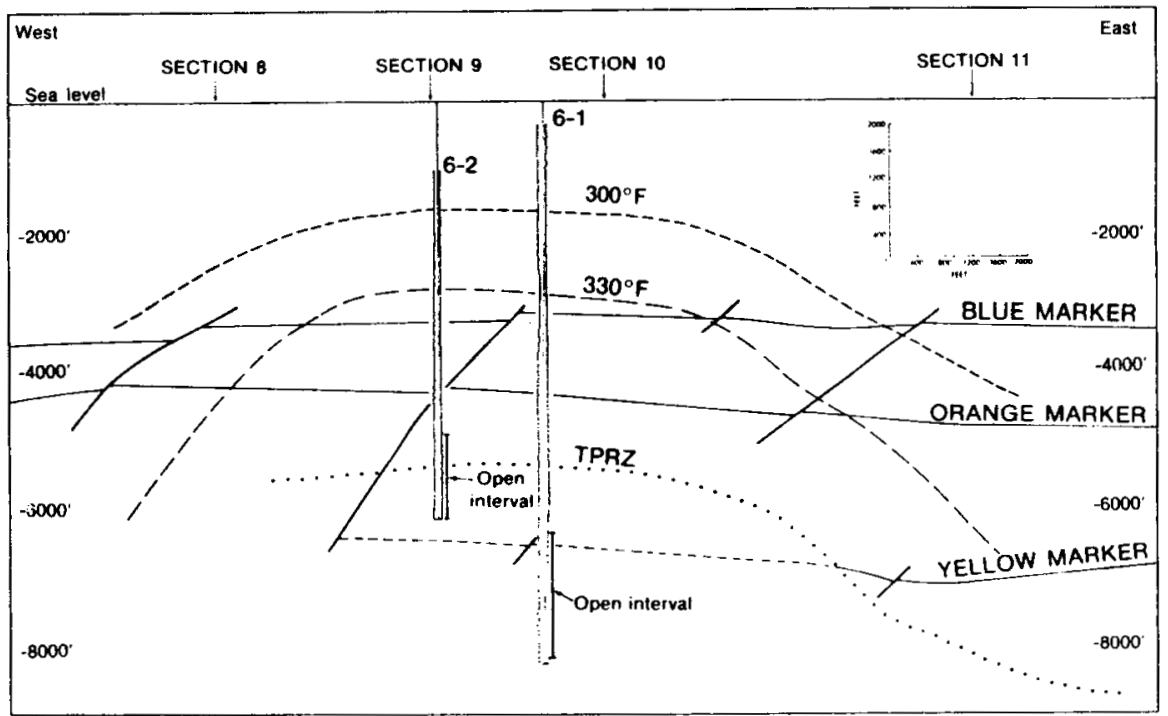

$\times B L 705-1847$

Figure 1.16. Cross section 4. Isothermal surfaces at 300 and $330 \%$. Blue, orange, and yellow markers are seismic reflectors on which structure has been mapped. 


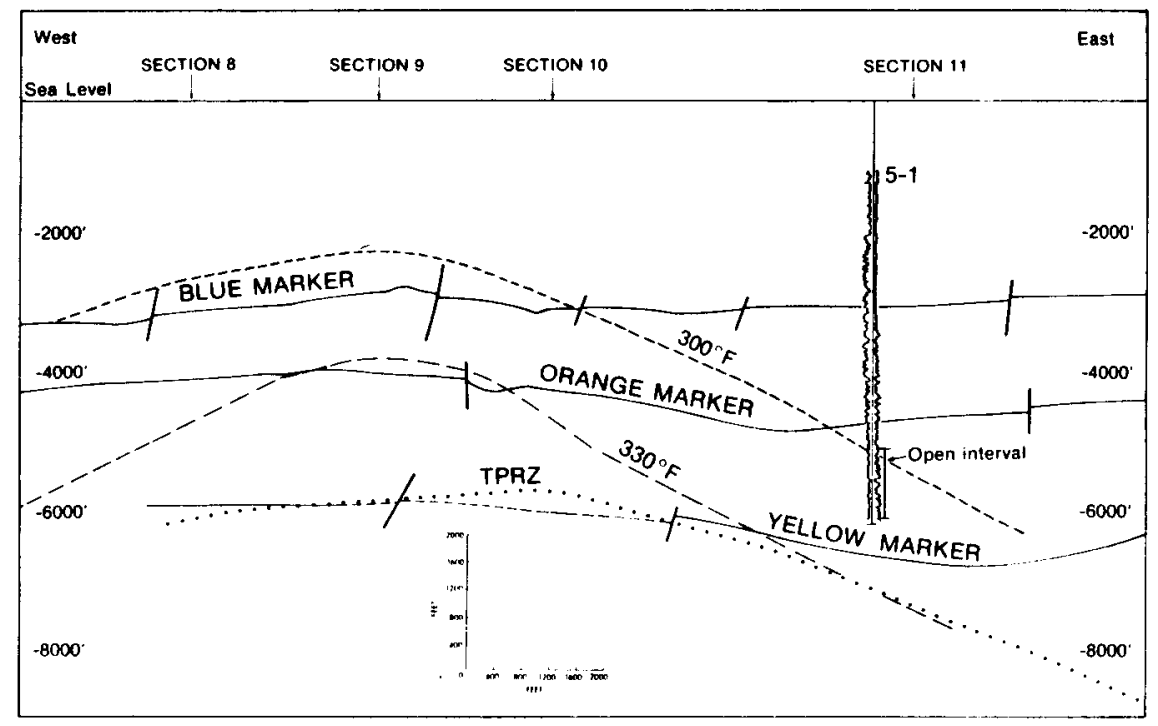

$X B L 785-1848$

Figure 1.17. Cross section 5. Isothermal surfaces at 300 and $330 \%$ F. Blue, orange, and yellow markers are seismic reflectors on which structure has been mapped.

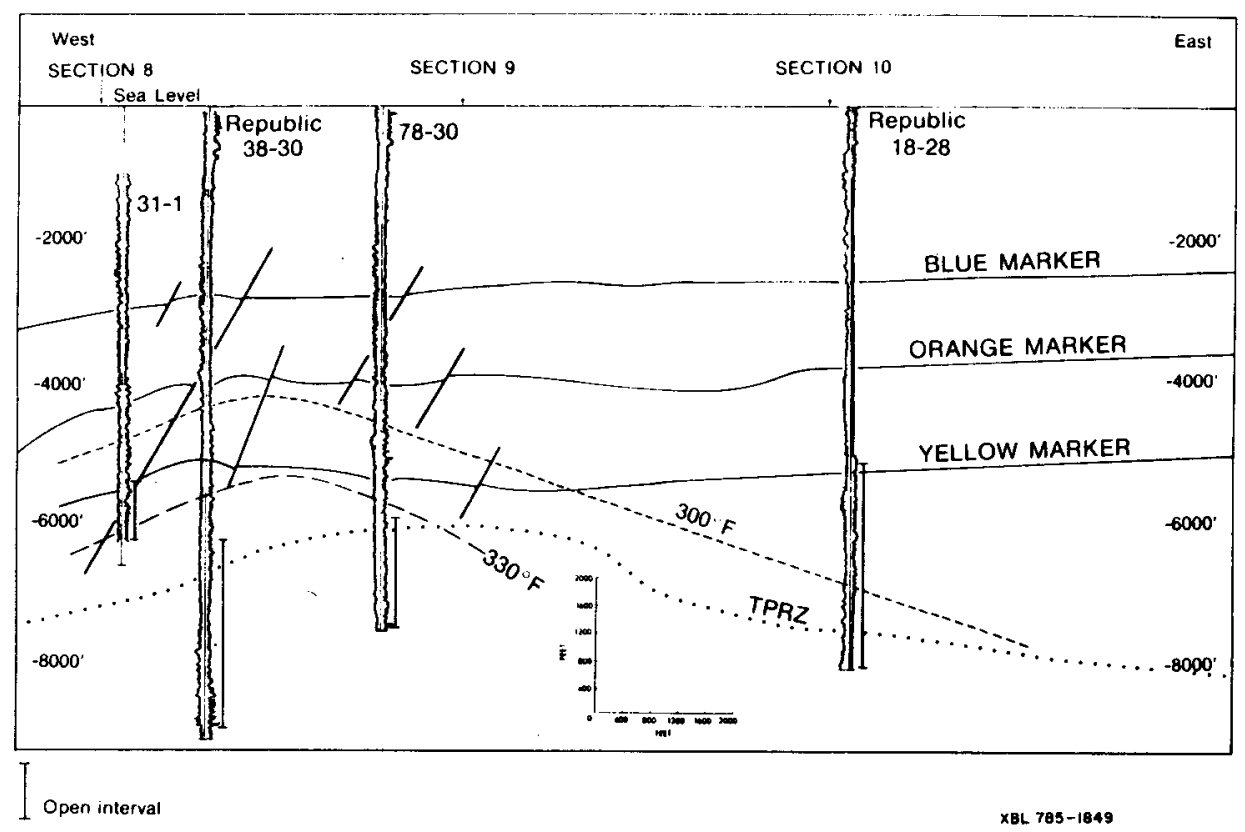

Figure 1.18. Cross section 6. Isothermal surfaces at 300 and $330 \% \mathrm{~F}$. Blue, orange, and yellow markers are seismic reflectors on which structure has been mapped. 

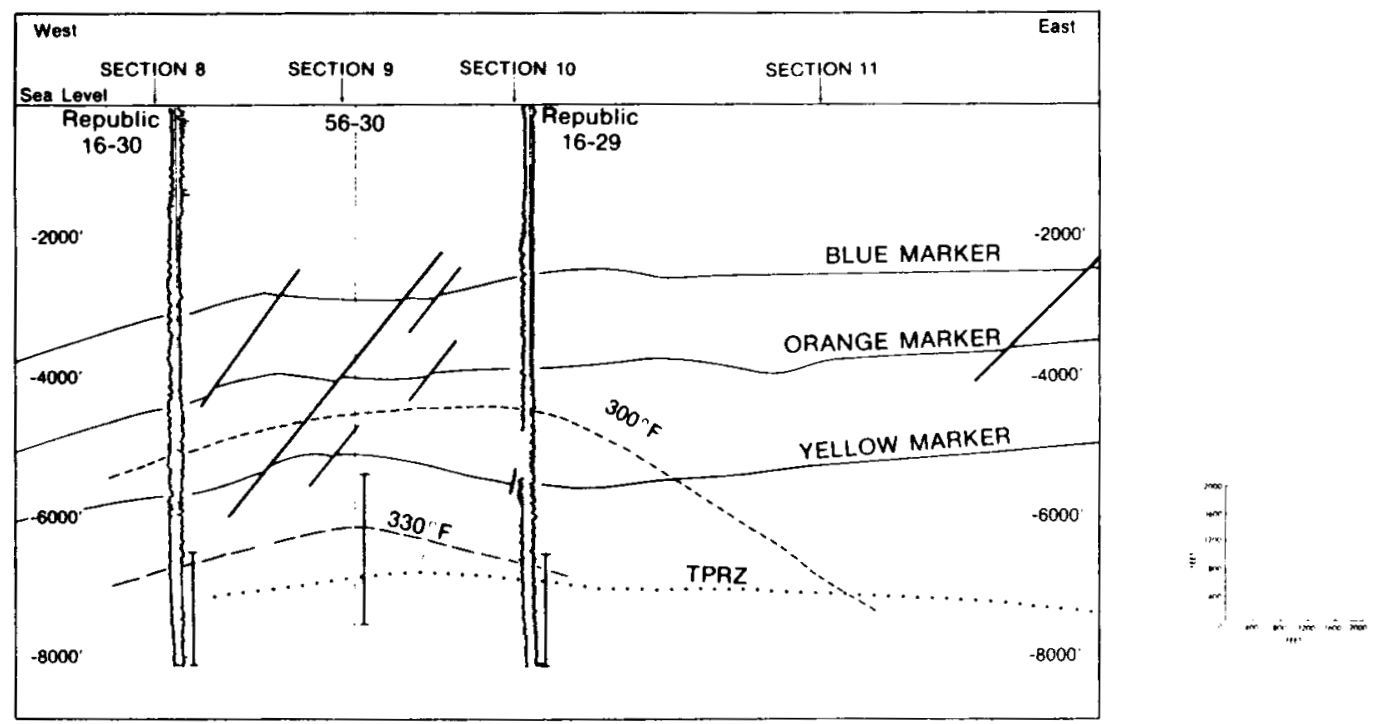

Topen interval

$x 8 \div 785-1850$

Figure 1.19. Cross section 7. Isothermal surfaces at 300 and $330^{\circ} \mathrm{F}$. Blue, orange, and yellow markers are seismic reflectors on which structure has been mapped.
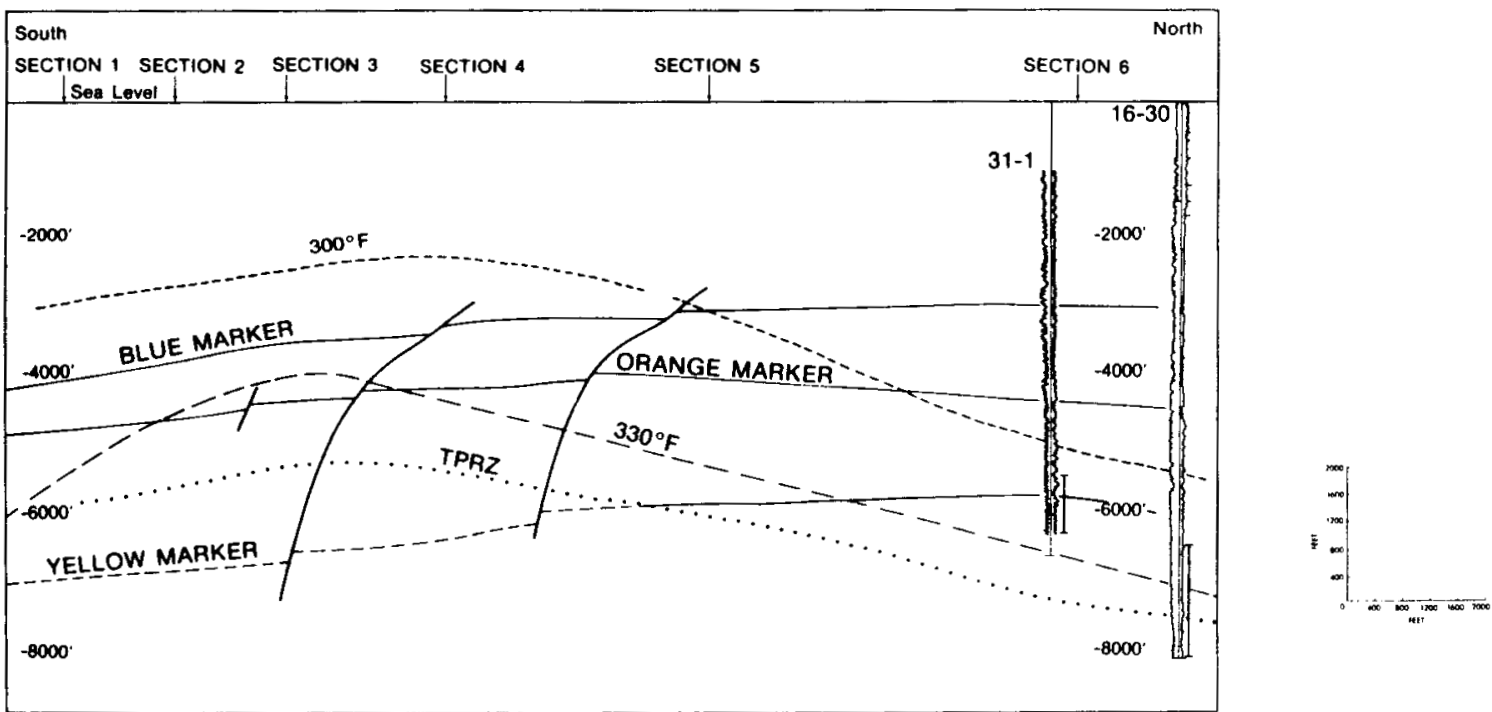

Open interval

$X B L 785-1851$

Figure 1.20. Cross section 8 . Isothermal surfaces at 300 and $330^{\circ} \mathrm{F}$. Blue, orange, and yellow markers are seismic reflectors on which structure has been mapped. 


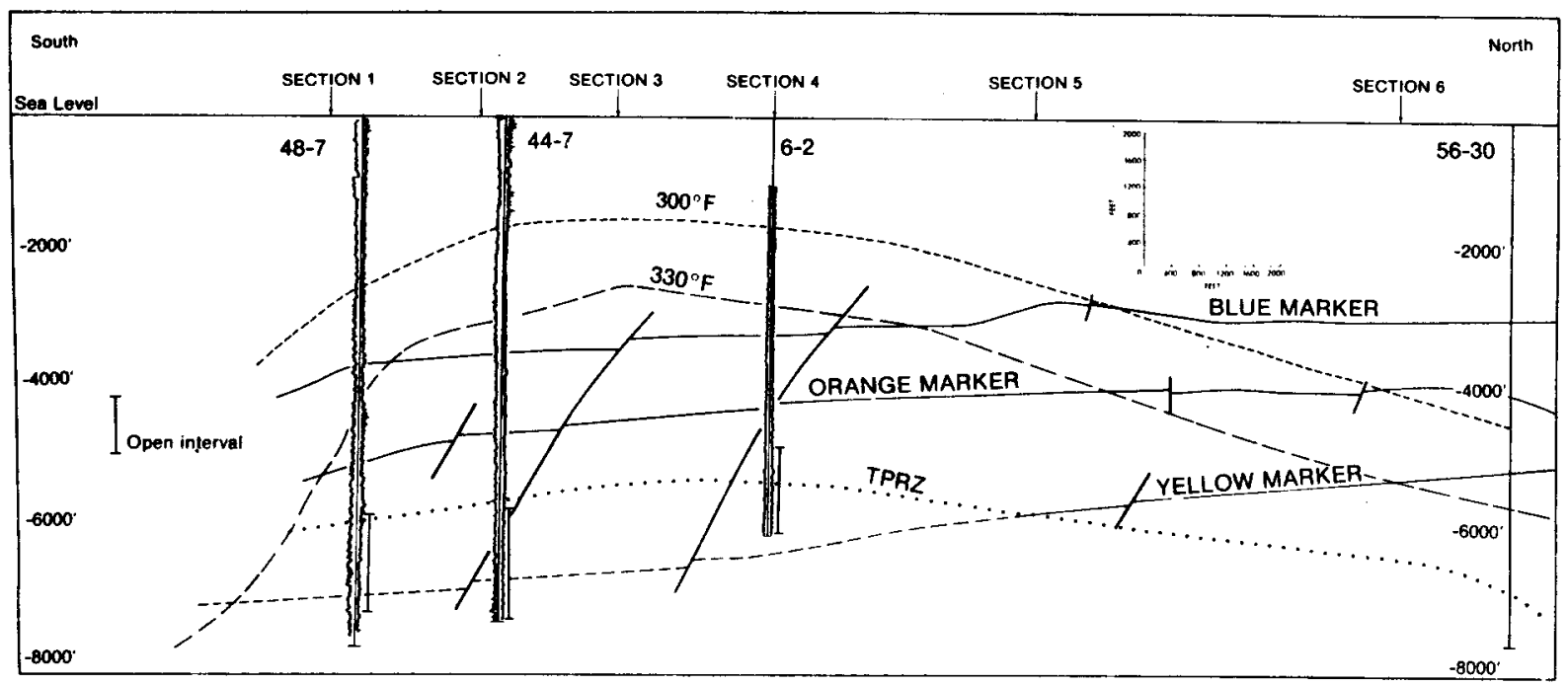

XOL $785-1852$

Figure 1.21. Cross section 9. Isothermal surfaces at 300 and $330^{\circ}$ F. Blue, orange, and yellow markers are seismic reflectors on which structure has been mapped.

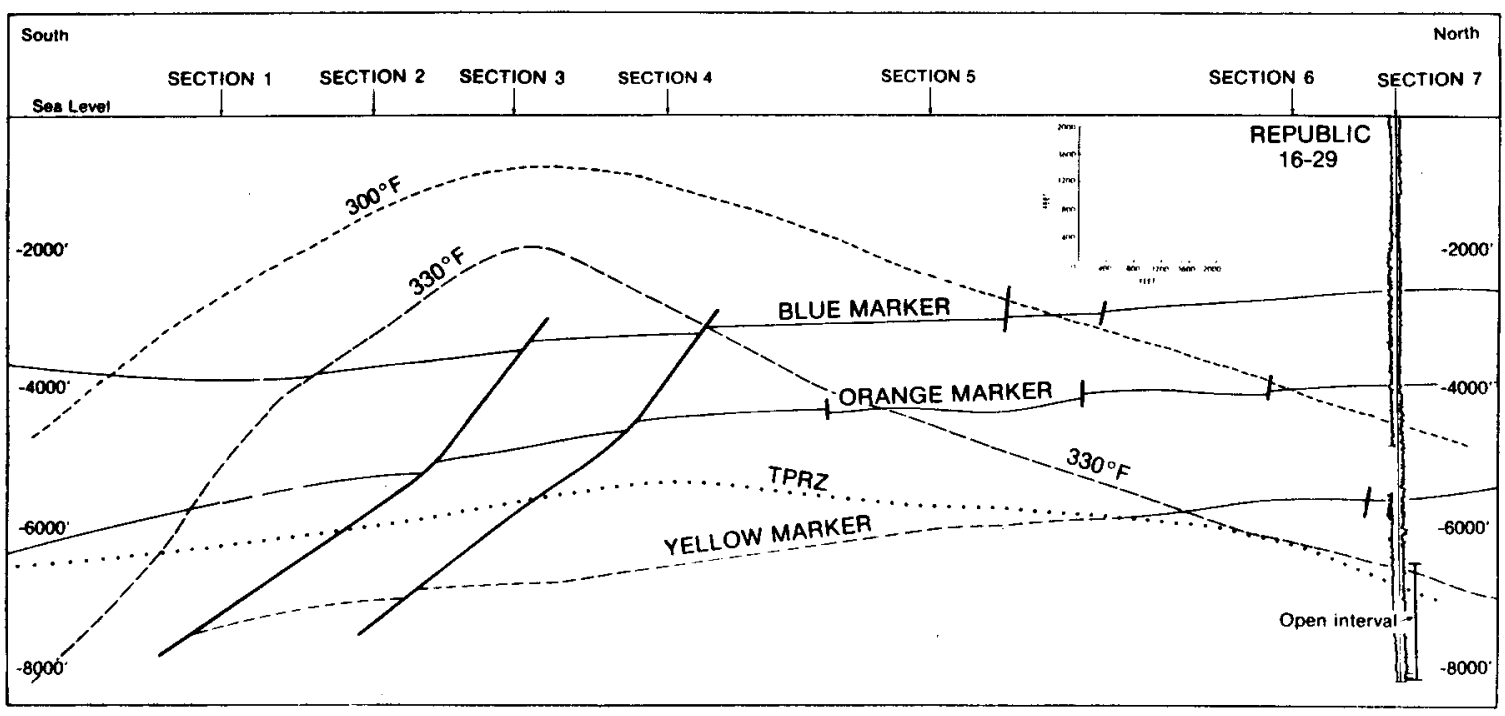

XEL TOS-1853

Figure 1.22. Cross section 10. Isothermal surfaces at 300 and $330 \%$ F. Blue, orange, and yellow markers are seismic reflectors on which structure has been mapped. 


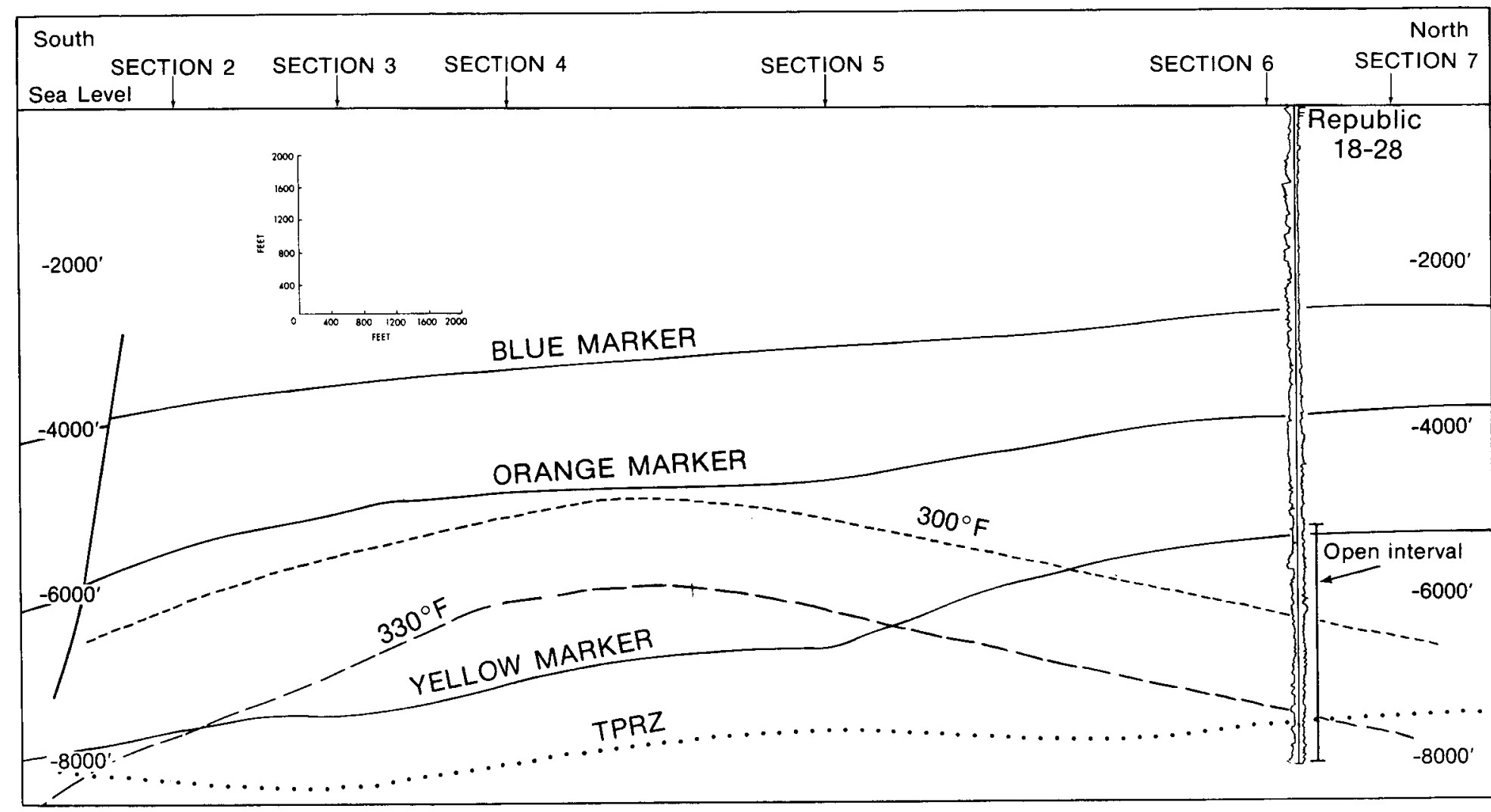

XBL 785- 1854

Figure 1.23. Cross section 11. Isothermal surfaces at 300 and $330^{\circ} \mathrm{F}$. Blue, orange, and yellow markers are seismic reflectors on which structure has been mapped. 
Reflections are represented in two-way time (the time for sound to reach the reflector plus return time to surface). This is then converted to depth using a time-to-depth conversion (in feet) from sonic velocity logs (Figure 1.7).

The blue, orange, and yellow markers represent structure at relatively shallow, intermediate, and deep levels with respect to the productive interva1s at East Mesa. These markers show a major anticline trending southwest through the field. Some cross-folds of a smaller scale are also present; these are particularly well displayed on the shallow blue marker where resolution is best. A pair of prominent faults trending northwest, with displacements of 100 to $200 \mathrm{ft}$ or more down to the west and dipping to the southwest, are evident. Smaller displacements (50 to $100 \mathrm{ft}$ ) high angle faults trending north-northwest, most of them with downward displacement to the west, are common in the field area.

Another seismic structure map, which is not confined to a single stratigraphic level but rather cuts across numerous reflectors above the basement, was made on top of a poorly reflective zone (PRZ, Figure 1.11).

The PRZ is visible on seismic reflection records as diffuse data below we11-ordered reflection data for porous and permeable rocks. The sedimentary rocks of the $P R Z$ have relatively low matrix porosity and permeability, but they are reservoirs for geothermal energy production. The poor matrix permeability is enhanced by fracturing to yield high production flow rates. Figure 1.11 maps the top of this zone. Compared with Figure 1.24, there is good correlation of high temperature at shallow depths with the top of the PRZ. This is caused by temperaturerelated alterations that reduce porosity and permeability in sandstones. These include quartz and carbonate cementation. A good correlation of the gravity maximum of Biehler (1971) with the PRZ high is also found. The top of the PRZ outlines the potentially productive zone as most well completions are in this zone and the $1000 \mathrm{ft}$ immediately above it. 
Velocity analyses suggest that the PRZ is a zone of relatively dense rocks in which seismic velocities are significantly higher (9500 to $11,000 \mathrm{fps} *$ or more) than in the overlying rocks (9000 fps or less). Wells that have penetrated this zone (Republic 38-30, 8000$8900 \mathrm{ft}$ ) show that the sandstones have considerably lower porosity $(10-20 \%)$ than shallower zones $(15-30 \%)$ and lower permeability (1-5 md). compared with shallower zones with tens to hundreds of millidarcies permeability. The gross transmissivity of these rocks is quite high and may be enhanced by fracturing in these relatively well-indurated rocks. Permeabilities computed from well test data (see Section 3) for the PRZ interval are much higher (30-84 md) than those measured on core and from SARABAND analyses for permeabilities (1-10 md) for the same interval. This contrast further suggests that PRZ rocks are fractured and that the fractures are providing the permeability necessary for the high flow rates in these wells.

If the PRZ is fractured extensively, then the fractures may cause considerable dispersion of seismic waves. This would explain the poor reflection data obtained in this zone. The relatively hard and brittle rocks of this zone are also more susceptible to fracturing.

A corollary to the above discussion is that the PRZ has been proved to have significant productive capability at East Mesa. The ability to identify and map this zone with seismic reflection data is important to exploration and development since the depth, distribution, and configuration of potential production zones are delineated (Figure 1.11).

If fractures exist to greater depths than those drilled to date (9000 ft), production might be extended deeper.

The form of the PRZ (Figure 1.11) is similar to the gravity high mapped by Biehler (1971) and is centered in the thermal high (Figures 1.24 through 1.30) of East Mesa. It suggests that the PRZ is composed of dense, highly altered and cemented sediments that have been subjected to temperature-dependent diagenetic alteration processes. Below the

${ }^{\star}$ Feet per second. 
top of the PRZ, exploration would seek fractured reservoir rocks in order to produce geothermal fluids.

The major sedimentary rock types present at East Mesa are sandstone, siltstone, shale and minor fine conglomerates (Fournier, 1973, 1976). Lithologic and geophysical $\log$ data suggest that many of the sandstones are channel fills and bars. The siltstones and shales represent lowerenergy environments such as interchannel and levee deposits. The sediment assemblages are characteristic deltaic deposits and are part of the Colorado River delta complex, which in the East Mesa is more than 10,000-ft thick (Biehler, et al., 1964). Seismic data suggest that the depth basement is at least 10,000 to $12,000 \mathrm{ft}$ in the East Mesa area.

Log data indicate a high proportion of sand (60-80\%) in the delta, which is to be expected in view of the relative proximity of East Mesa to the apex of the delta. Farther north and west in the Imperial Valley, a greater proportion of mud facies would be expected. The deposits are similar throughout the drilled section and show no great variations in the relative proportions of sand and shale.

\section{STRUCTURE}

Structure in the East Mesa was mapped (Figures 1.8, 1.9, and 1.10) using the reflection seismic data. The structure shows a west-southwesttrending anticline to the north with a flanking syncline to the south. Both folds plunge to the southwest, toward the center of the Salton Trough. The rocks involved in this folding are of Pliocene and Pleistocene age. Folding probably occurred in the Pleistocene since the Holocene strata appear relatively undisturbed.

Numerous faults are present in the East Mesa area as shown in Figures 1.8, 1.9, and 1.10. Two fault sets are present. One trends northwest through USBR we $11 \mathrm{~s} 6-1$ and $6-2$ with vertical displacements of 100 to $200 \mathrm{ft}$ down to the west. The magnitude of horizontal displacement is not known. These faults have roughly the same orientation as the Superstition Hills faults (Figure 1.3) located on the west side of the Imperial Valley. This set of faults appears to be a major, through-going displacement for the East Mesa area. Seismic data suggest 


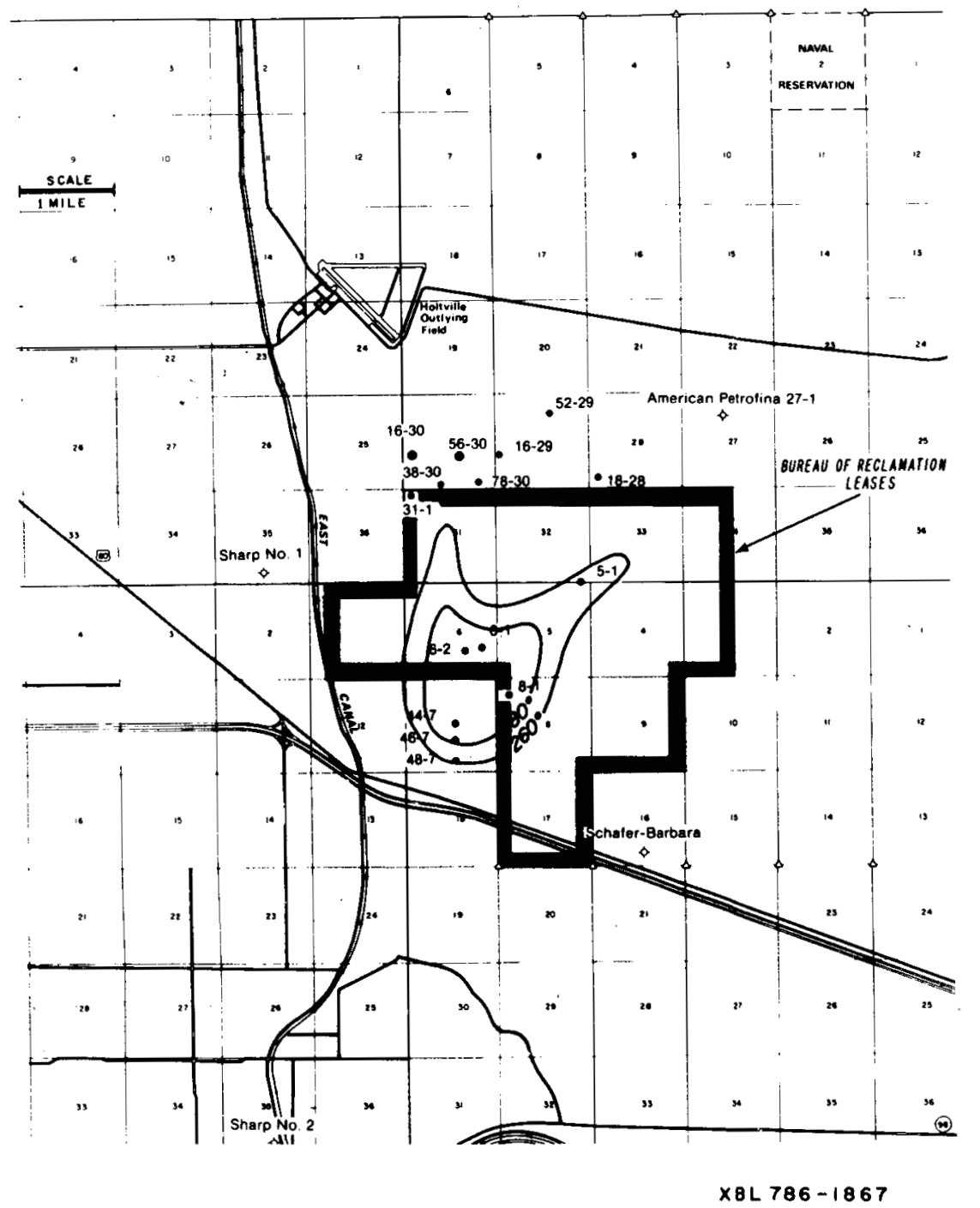

Figure 1.24. Temperature contours $\left({ }^{\circ} \mathrm{F}\right)$ at 2000-ft depth for East Mesa KGRA (nodified from TRW/Intercomp, 1976).

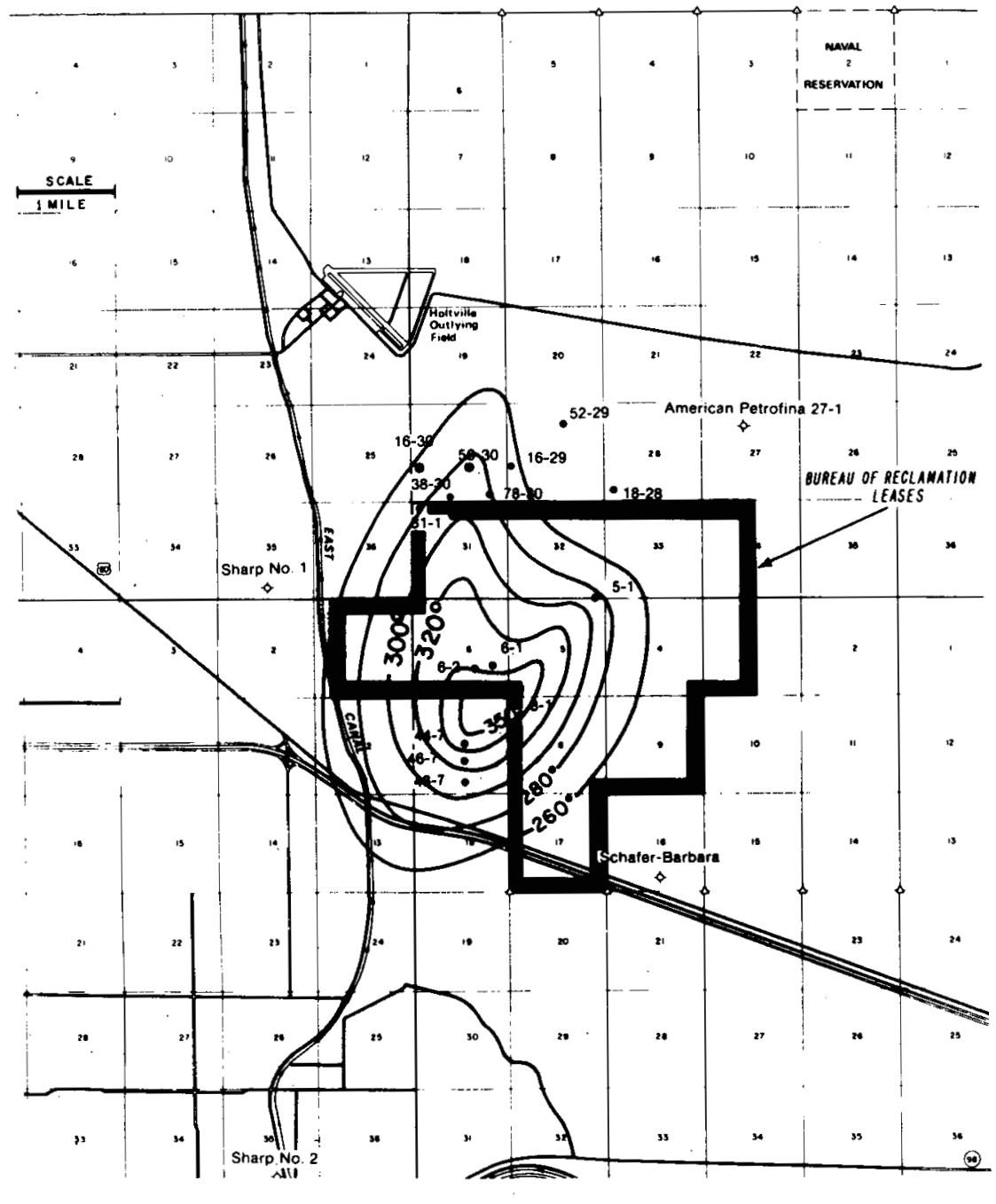

N

Figure 1.25. Temperature contours $\left({ }^{\circ} \mathrm{F}\right)$ at 3000-ft depth for East Mesa KGRA (modified from TRW/Intercomp, 1976). 


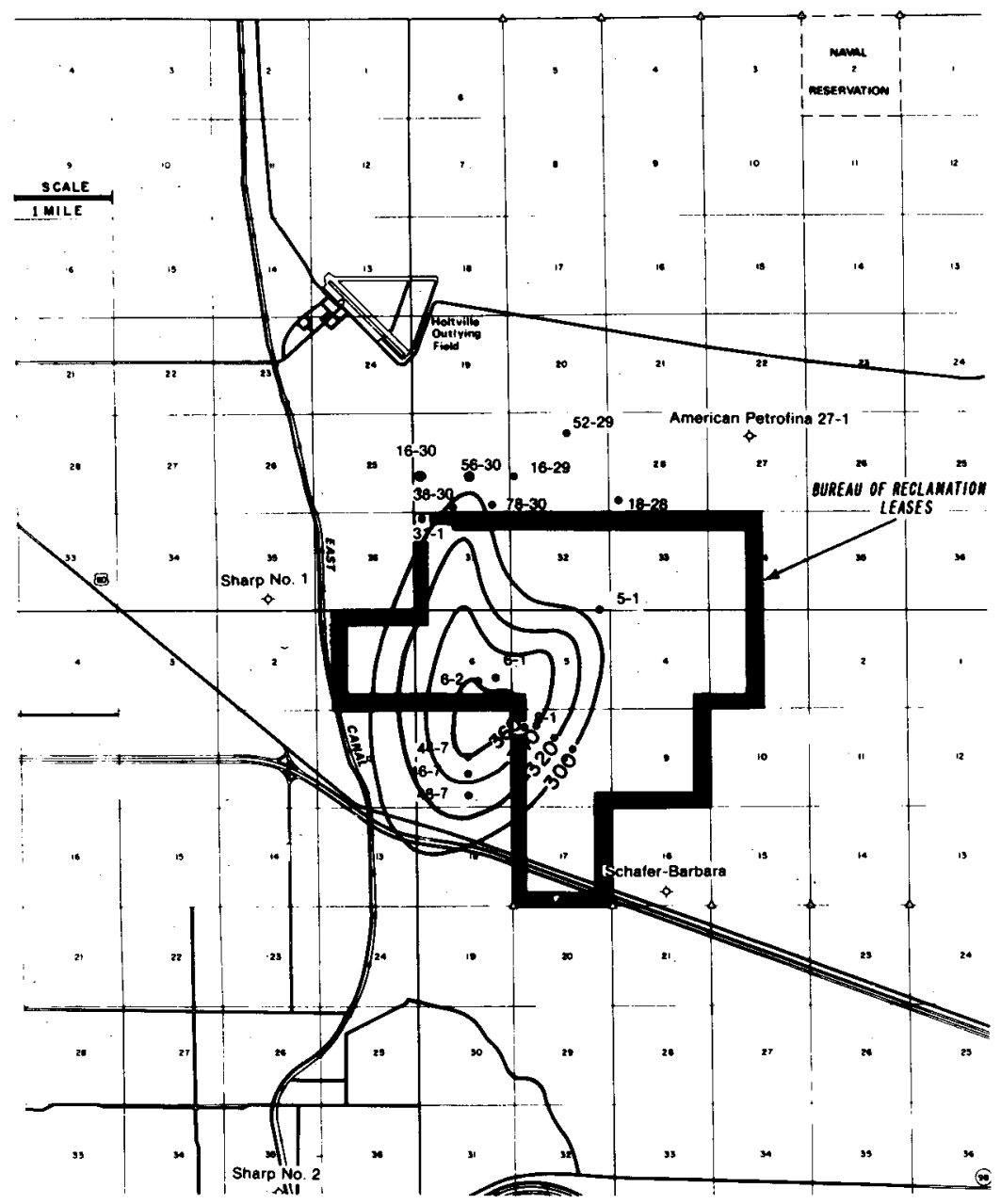

X BL $786-1863$

Figure 1.26. Temperature contours $\left({ }^{\circ} \mathrm{F}\right)$ at 4000-ft depth for East Mesa KGRA (modified from TRW/Intercomp, 1976).

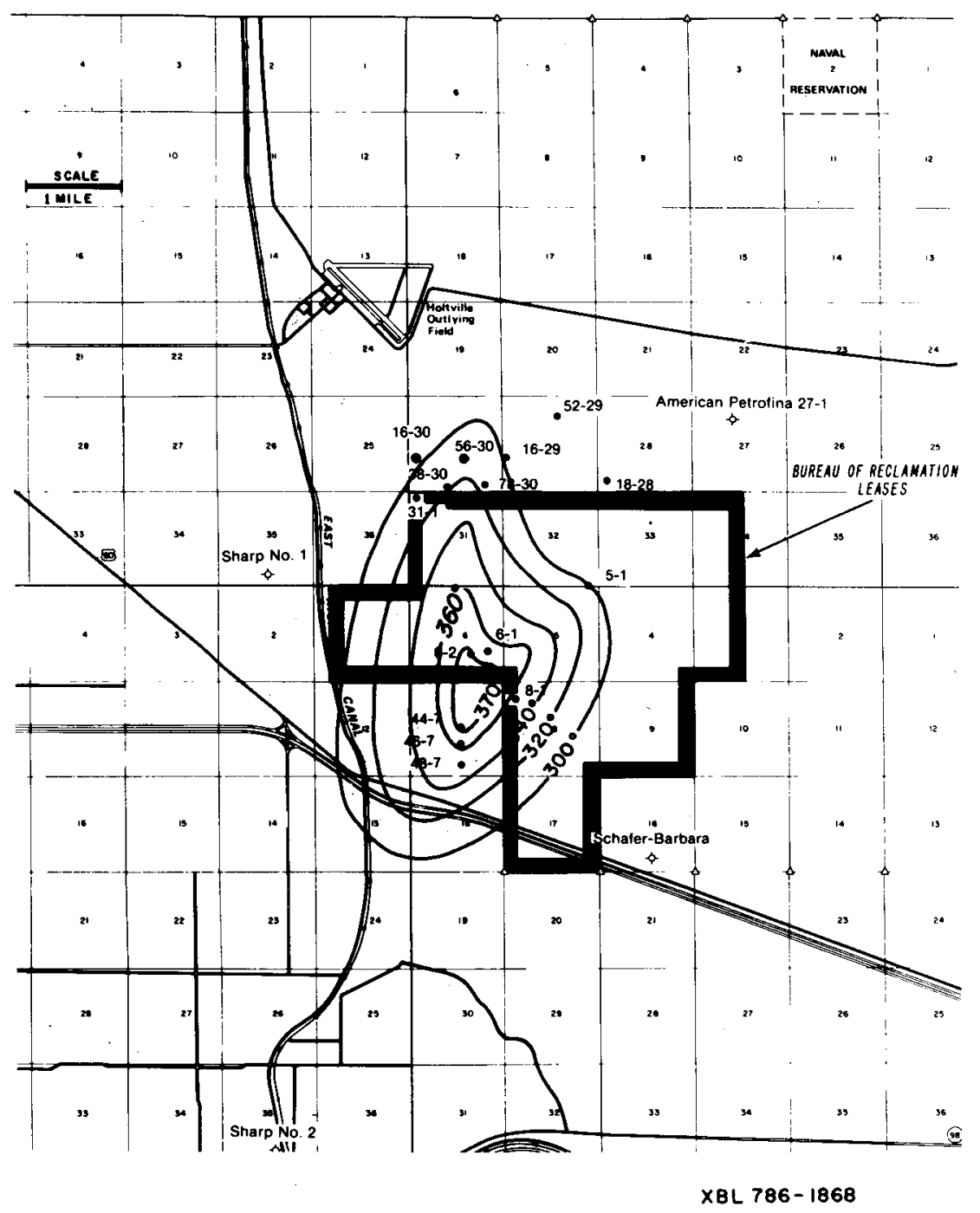

Figure 1.27. Temperature contours $\left({ }^{\circ} \mathrm{F}\right)$ at 5000-ft depth for East Mesa KGRA (modified from TRW/Intercomp, 1976). 


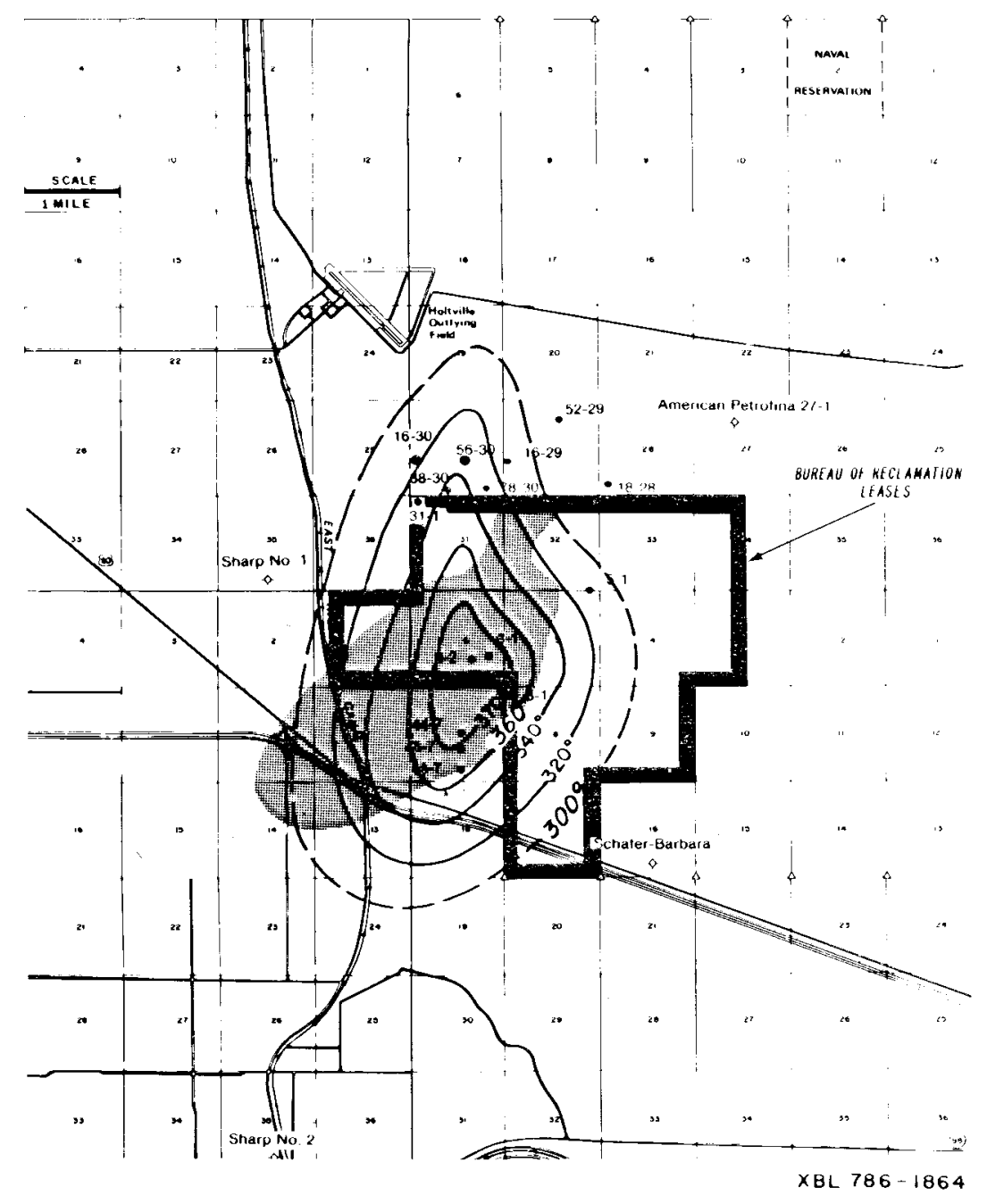

Figure 1.28. Temperature contours $\left({ }^{\mathrm{F}}\right.$ ) at $6000-\mathrm{ft}$ depth for East Mesa KGRA; shaded area is poorly reflective zone (modified from TRW/Intercomp, 1976).

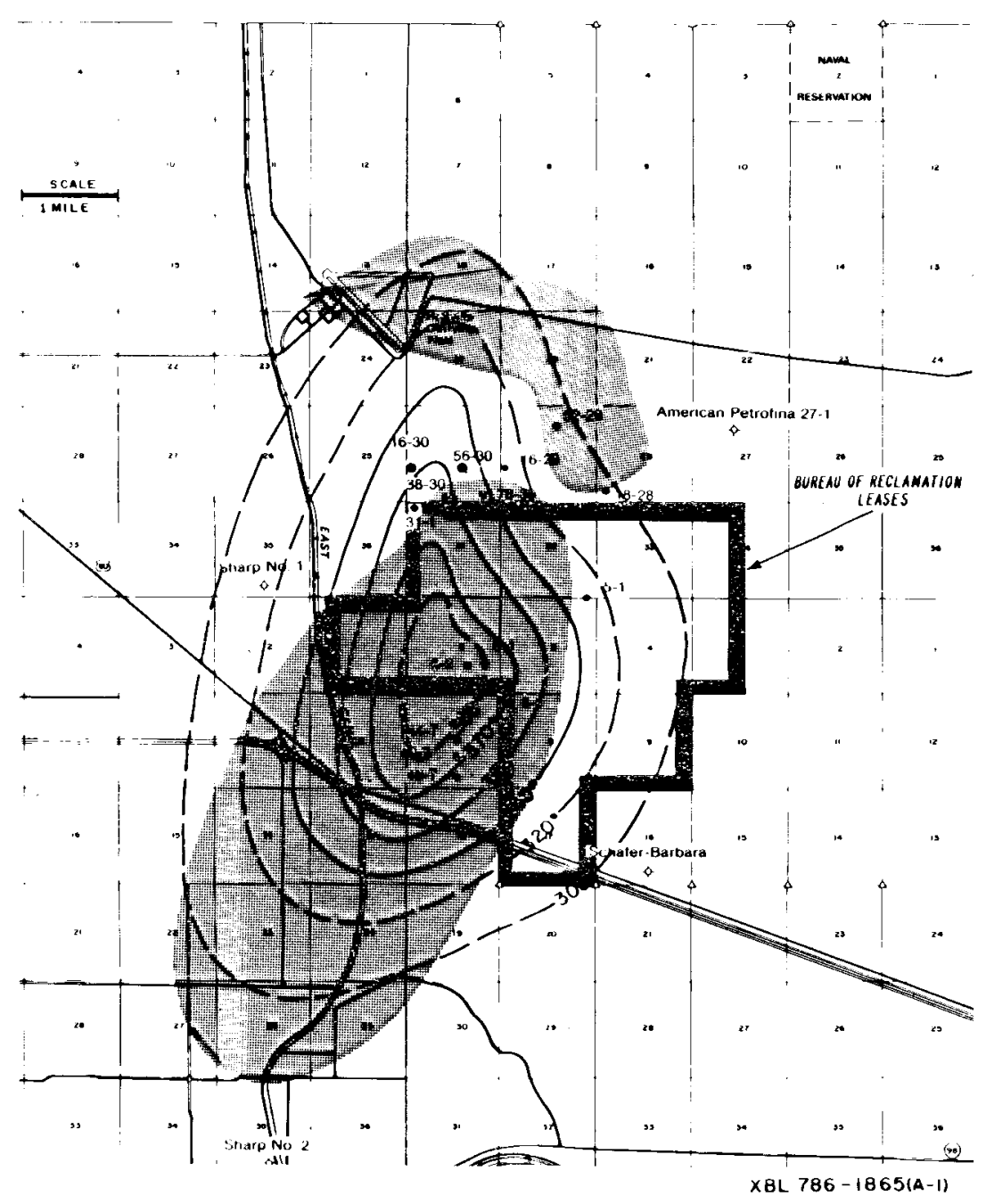

Figure 1.29. Temperature contours $\left({ }^{\circ} \mathrm{F}\right)$ at $7000-\mathrm{ft}$ depth for East Mesa KGRA; shaded area is poorly reflective zone. 


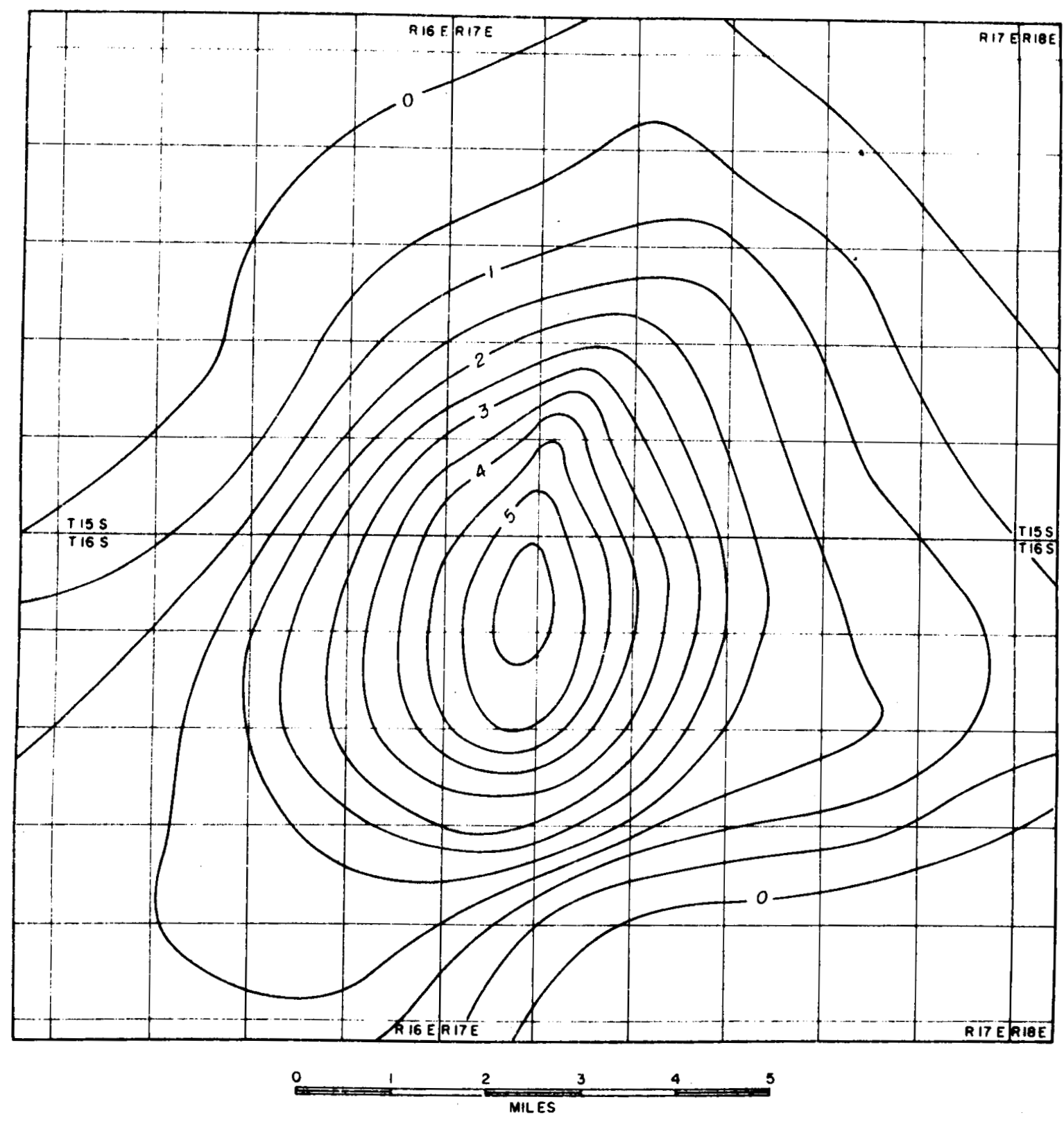

XBL $7810-11720$

Figure 1.30. Residual gravity anomalies of the Mesa area, contour interval 0.5 milligals (from Biehler, 1971). The southwesterly extension of contours suggests the extension of the geothermal anomaly in that direction. This correlates with the PRZ high. Future exploration might be focussed on this area. 
progressively greater vertical displacements with increasing depth (growth faulting) on these and another, north-trending fault set.

The numerous north-trending faults have displacements of about 50 to $100 \mathrm{ft}$, generally sloping down to the west. In a few cases, there are displacements down to the east.

We do not know whether or not any faults form barriers to the subsurface fluid flow. Our data do not indicate if any of the faults are active.

\section{Discussion}

The structure maps (Figures 1.8 through 1.11) and cross-sections (Figures 1.13 through 1.23 ) show the potentially producible zone. There appears to be a reasonable correlation of the gravity high and the high of the poorly reflecting zone with the thermal high. Where these parameters are well mapped, we obtained a good correlation of the physical parameters. If the high-temperature zone continues to track the gravity and PRZ high west and south of the mapped area, the potentially producible zone would extend farther to the southwest than is shown in Figures 1.13 to 1.16. Another apparent high in the PRZ is suggested north of the East Mesa in sections 7 and 18, T. 15 S., R. 17 E.

We suggest an investigation of these possibilities through seismic reflection surveys in order to map the areas (a) to the southwest and (b) to the north, contiguous with the area already mapped. By determining the form of the remainder of the PRZ high and a possible high to the north, potentially productive areas could be outlined for exploration drilling.

\section{ESTIMATE OF FLUID AND THERMAL CONTENT}

We have estimated the fluid and thermal content of that portion of the East Mesa reservoir underlying U. S. Bureau of Reclamation leasehold (see Figure 1.2) as a function of temperature and depth. The total reservoir volume has been defined as follows: the $300^{\circ} \mathrm{F}$ isothermal surface is the upper boundary; the $3000 \mathrm{~F}$ isothermal surface and USBR leaseholds are the lateral boundaries (see Figure 1.24); and a depth of $7500 \mathrm{ft}$ is the base of the reservoir for the purpose of this calculation. 
Extension of the reservoir to greater depths, based on the possible existence of fracture permeability, has not been considered. The net reservoir volume includes only sands with porosities greater than $10 \%$ within the boundary surface noted here.

A larger volume would result from including rock and fluid to a greater depth. However, from Table 1.1 and the geologic maps and crosssections, it can be seen that: (a) porosity decreases significantly below $7500 \mathrm{ft}$; and (b) there is little information available below this depth.

We compiled a table listing sand thickness and porosity (Table 1.1) from SARABAND logs of wells at East Mesa. Based on this compilation, we calculated average sand thickness and porosity for each depth interval of $1000 \mathrm{ft}$. TRW/Intercomp (1976) temperature contour maps (Figures 1.24 to 1.29) define the approximate location of selected temperature isotherms at $3000 \mathrm{~F}$ and above. Using the average sand thickness and porosity from Table 1.1 and the temperature contour maps, we estimated the contained volumes of fluid and sand bounded by selected isothermal surfaces over a depth interval of $1000 \mathrm{ft}$. An average temperature was assigned to each of these volumes based on the temperature of the bounding isothermal surfaces. Tables 1.2 and 1.3 exhibit the results of the above calculations, giving the volume and thermal content of the contained fluid and sand, respectively.

The reservoir, as defined above, contains approximately $5 \times 10^{11} \mathrm{cu} \mathrm{ft}$ of reservoir sand (gross sand volume minus porosity volume). Fluid volume (that is, porosity times gross sand volume), is approximately $1.1 \times 10^{11} \mathrm{cu}$ ft $\left(2.4 \times 10^{6}\right.$ acre-ft $)$.

We calculated the thermal content of the reservoir using a reference temperature of $60^{\circ} \mathrm{F}$. The thermal capacities were $1.005 \mathrm{Btu} / 1 \mathrm{~b} \circ \mathrm{F}$ for the fluid and $32 \mathrm{Btu} / \mathrm{cu} f t$ of for the sand. The thermal content of the reservoir fluid is $1.7 \times 10^{15} \mathrm{Btu}\left(0.4 \times 10^{18} \mathrm{cal}\right)$ and the thermal content of the reservoir sand is $4.4 \times 10^{15} \mathrm{Btu}\left(1.1 \times 10^{18} \mathrm{ca} 1\right)$. The total thermal content of U.S. Bureau of Reclamation leases 1, 2, and 4 as defined above is estimated to be $6 \times 10^{15} \mathrm{Btu}\left(1.5 \times 10^{18} \mathrm{ca}\right)$. 
Table 1.1. Sand thickness and porosity of East Mesa wells.

\begin{tabular}{|c|c|c|c|c|c|c|c|c|}
\hline & \multicolumn{8}{|c|}{ DEPTH INTERVALS (feet) } \\
\hline & $\begin{array}{l}1500- \\
2500 \\
\end{array}$ & $\begin{array}{l}2500- \\
3500 \\
\end{array}$ & $\begin{array}{l}3500- \\
4500 \\
\end{array}$ & $\begin{array}{l}4500- \\
5500 \\
\end{array}$ & $\begin{array}{l}5500- \\
6500 \\
\end{array}$ & $\begin{array}{l}6500- \\
7500 \\
\end{array}$ & $\begin{array}{l}7500- \\
8500 \\
\end{array}$ & $\begin{array}{l}8500- \\
9000 \\
\end{array}$ \\
\hline \multicolumn{9}{|l|}{ Well 5-1 } \\
\hline Sand (ft.) & 840 & 915 & 925 & 880 & $500^{1}$ & & & \\
\hline Porosity & 0.247 & 0.211 & 0.189 & 0.193 & 0.182 & & & \\
\hline \multicolumn{9}{|l|}{ Well 6-1 } \\
\hline Sand (ft.) & 640 & 845 & 820 & 1000 & 955 & 700 & $220^{2}$ & \\
\hline Porosity & 0.157 & 0.175 & 0.150 & 0.156 & 0.189 & 0.167 & 0.114 & \\
\hline \multicolumn{9}{|l|}{ Well 6-2 } \\
\hline Sand (ft.) & 815 & 820 & 840 & 965 & $425^{3}$ & & & \\
\hline Porosity & 0.186 & 0.234 & 0.170 & 0.150 & 0.140 & & & \\
\hline \multicolumn{9}{|l|}{ Well $8-1$} \\
\hline Sand (ft.) & 555 & 725 & 760 & 755 & $626^{4}$ & & & \\
\hline Porosity & 0.195 & 0.210 & 0.131 & 0.153 & 0.165 & & & \\
\hline \multicolumn{9}{|l|}{ Well 31-1 } \\
\hline Sand (ft.) & 715 & 855 & 705 & 774 & $582^{5}$ & & & \\
\hline Porosity & 0.221 & 0.203 & 0.170 & 0.176 & 0.157 & & & \\
\hline \multicolumn{9}{|l|}{ Well $16-29$} \\
\hline Sand (ft.) & --- & --- & --- & $780^{6}$ & 910 & 555 & $360^{7}$ & \\
\hline Porosity & --- & --- & --- & 0.166 & 0.175 & 0.170 & 0.133 & \\
\hline \multicolumn{9}{|l|}{ We11 $18-28$} \\
\hline Sand (ft.) & --- & --- & --- & $480^{8}$ & 880 & 654 & $328^{9}$ & \\
\hline Porosity & -- & -- & --- & 0.190 & 0.173 & 0.137 & 0.121 & \\
\hline \multicolumn{9}{|l|}{ We11 $38-30$} \\
\hline Sand (ft.) & 710 & 785 & 468 & 460 & 880 & 640 & 604 & $142^{10}$ \\
\hline Porosity & 0.159 & 0.198 & 0.195 & 0.215 & 0.207 & 0.225 & 0.146 & 0.107 \\
\hline Average Sand (ft.) ${ }^{11}$ & 713 & 824 & 753 & 845 & 924 & 637 & 627 & 330 \\
\hline Average Porosity ${ }^{12}$ & 0.194 & 0.205 & 0.167 & 0.175 & 0.173 & 0.175 & 0.130 & 0.107 \\
\hline
\end{tabular}

\footnotetext{
${ }^{1}$ Depth interval $5,500^{\prime}-6,000^{\prime}$.

${ }^{2}$ Depth interval 7,500' - 8,000'.

${ }^{3}$ Depth interval $5,500^{\prime}-5,924^{\prime}$.

${ }^{4}$ Depth interval 5,500' $-6,186^{\prime}$ '.

${ }^{5}$ Depth interval 5,500' $-6,180^{\prime}$.

${ }^{6}$ Depth interval 4,660' - 5,500'.

${ }^{7}$ 'Depth interval 7,500' $-7,960^{\prime}$.

${ }^{8}$ Depth interval 5,020' - 5,500'.

${ }^{9}$ Depth interval $7,500^{\prime}-7,980 '$ '

${ }^{10}$ Depth interval $8,500 '-8,930 '$.

${ }^{11}$ Sands measured in intervals less than 1,000 feet, have been adjusted to reflect 1,000 foot intervals.

${ }^{12}$ Porosity of sands measured in intervals less than 1,000 feet, have been adjusted to reflect 1,000 foot intervals.
} 
Table 1.2. Estimate of Btu's contained in fluid above $300^{\circ} \mathrm{F}$ (relative to $60^{\circ} \mathrm{F}$ ) to a depth of $7500 \mathrm{ft}$ for USBR leaseholds 1,2 , and 4 at East Mesa.

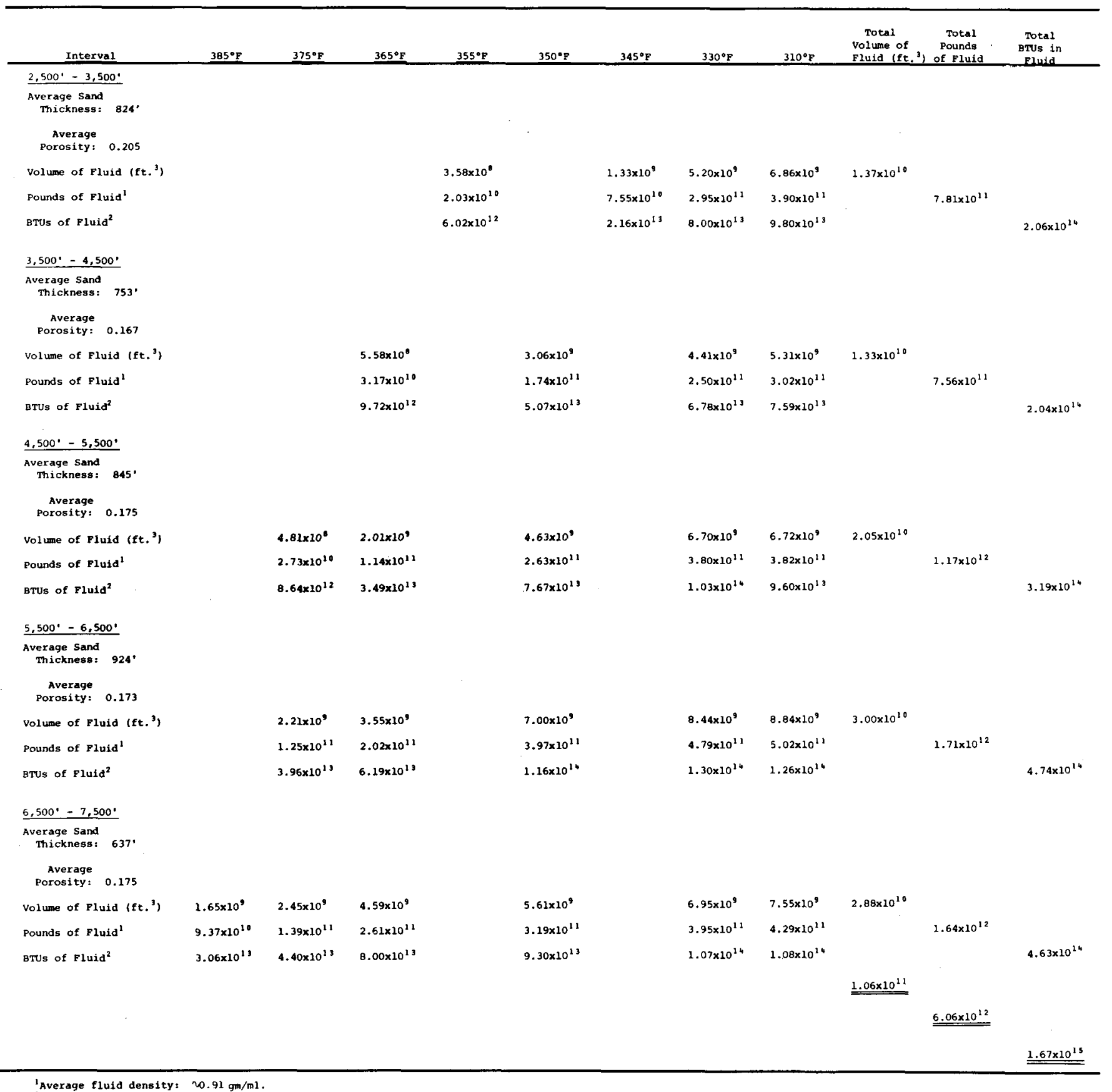


Table 1.3. Estimate of Btu's contained in sand above $300 \%$ (relative to $60 \circ \mathrm{F}$ ) to a depth of $7500 \mathrm{ft}$ for USBR leaseholds 1,2 , and 4 at East Mesa.

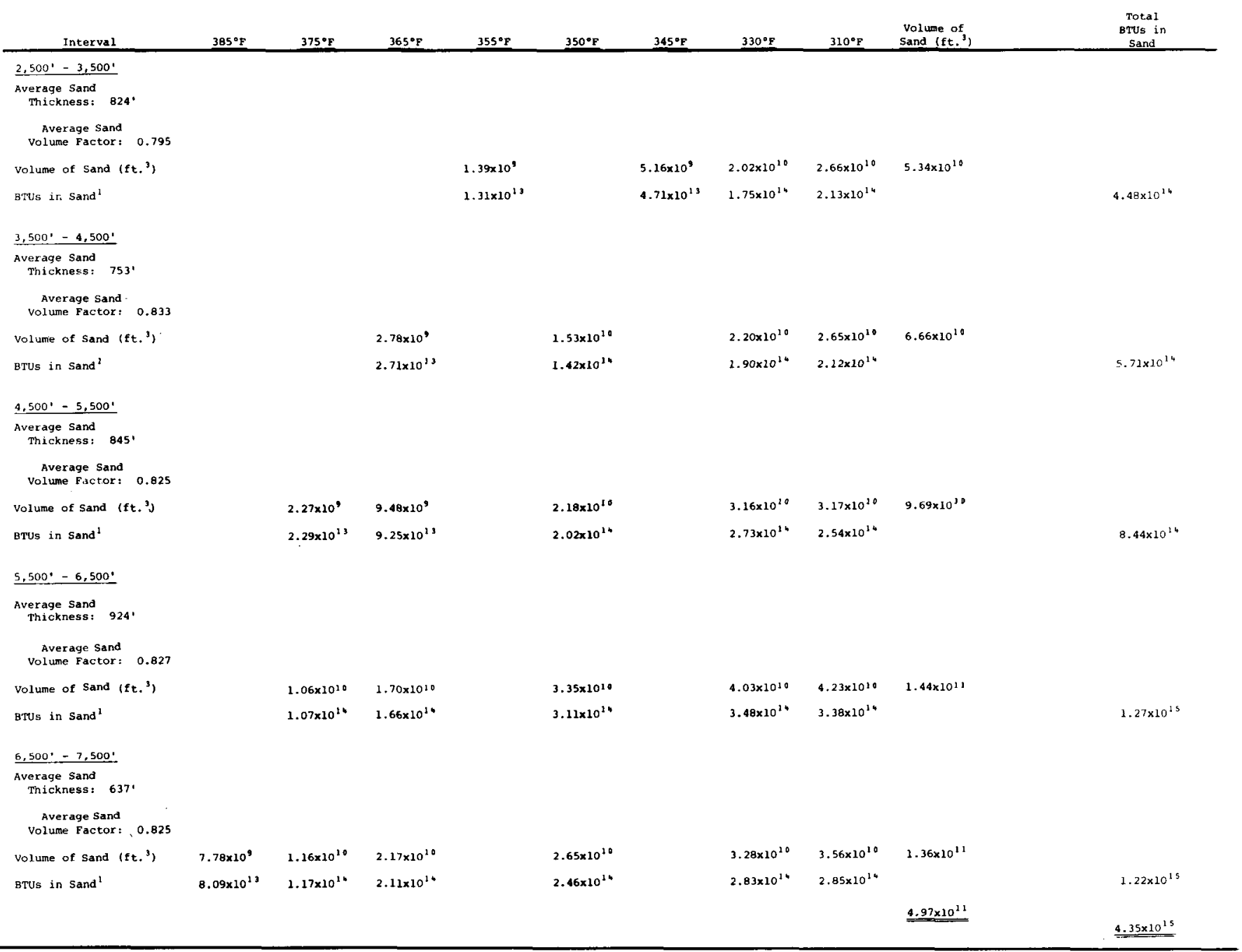


Note that these calculations pertain to fluid and heat in the reservoir. The question of recovery of fluid is discussed elsewhere in this report.

\section{REFERENCES CITED}

Biehler, S., 1971. Gravity studies in the Imperial Valley, in Rex, R. W., et al., eds., Cooperative geological-geophysical-geochemical investigations of geothermal resources in the Imperial Valley of California. Riverside, University of California, pp. 29-41. Biehler, S., Kovach, R. L., and Allen, C. R., 1964. Geophysical framework of northern end of Gulf of California structural province, in Van Ande1, T. H., and Shor, G. G., Jr., eds., Marine geology of the Gulf of California: a symposium. Am. Assoc. Petrol. Geol., Mem. 3, pp. 126-143.

Downs, T., and Woodard, G. D., 1961. Middle Pleistocene extension of the Gulf of California into the Imperial Valley, paper presented at Geol. Soc. Amer. Annual Meeting, Cordilleran Section, San Diego, CA. Fournier, R. 0., 1973. An $x$-ray and optical study of cuttings from the U. S. Bureau of Reclamation Mesa 6-1 drillhole, Imperial Valley, California. U. S. Geol. Survey open file report, 35 pp. , 1976. A study of the mineralogy and 1ithology of cuttings from the U. S. Bureau of Reclamation Mesa 6-2 drillhole, Imperial County, California, including comparisons with the Mesa 6-1 drillhole. U. S. Geol. Survey open-file Report 76-88. Goupilland, P. L., and Cherry, J. T., 1977. Utilization of seismic exploration technology for high resolution mapping of geothermal reservoir. Systems Science and Software, Report Number SS-R-77-3176. Loeltz, O. J., Irelan, B., Robinson, J. H., and Olmsted, F. H., 1975. Geohydrologic reconnaissance of the Imperial Valley, California. USGS Professional Paper 486-K, $54 \mathrm{p}$.

TRW/Intercomp, Inc., 1976. Study of the geothermal reservoir underlying the East Mesa area, Imperial Valley, California. TRW/Intercomp, Inc., Report no. 28859-6001-RU-00. van de Kamp, P. C., 1973. Holocene continental sedimentation in the Salton Basin, California, a reconnaissance. Geol. Soc. Amer. Bu11., v. 84, pp. 827-848. 


\title{
SECTION 2: SEISMICITY
}

\author{
E. L. Majer. ${ }^{1}$ T. V. McEvilly, ${ }^{2}$ B. Schechter, ${ }^{2}$ and N. E. Goldstein' \\ 'Lawrence Berkeley Laboratory \\ 2University of California, Berkeley
}

\section{INTRODUCTION}

The results obtained to date from the East Mesa seismic study are summarized below. The purpose of the present study of seismological data from the USBR East Mesa Network is threefold: (1) to obtain further details of the faulting and associated stress fields as defined by the occurrence of local microearthquakes; (2) to infer the properties of subsurface rocks from the characteristics of the $\mathrm{P}$ - and $\mathrm{S}$-waves generated, including wave velocities, Poisson's ratio, and at tenuation; and (3) to provide USBR personnel, and others, a set of procedural guidelines for subsequent analysis of network data. Three progress reports (McEvilly and Schechter, 1977a, 1977b and 1978) have also been completed.

Report No. 1 (McEvilly and Schechter, 1977a) details the techniques employed in the data analysis including hypocenter locations and magnitudes and summarizes the initial 35-day period of observations. Reports No. 2 and No. 3 (McEvilly and Schechter, 1977b and 1978) summarize observations made since that date. Included in Report No. 3 is a detailed review of present and past observed local seismicity.

The salient result obtained from the study has been the complete absence of detectable local microearthquakes within the geothermal field during the study period (1977-1978), which contradicts the findings of previous investigations .

\section{REVIEW OF SEISMIC STUDIES AT EAST MESA}

In this section we present a review of has been the previous seismic studies at East Mesa, emphasizing the conclusions that pertain to the local seismicity and comparing them with our results.

\section{General Seismicity Before 1973}

Before the installation of the U. S. Geological Survey-California Institute of Technology (USGS-CIT) Imperial Valley network in April 1973, minor earthquakes in the region could be located only approximately. Despite the low sensitivity of the systems before 1973, major swarm 
activity was detected in $1934,1949,1950$, and 1955. The Imperial Valley earthquake of 1940 , the largest event ever recorded in the region (located about $20 \mathrm{~km}$ west of East Mesa), broke the ground for over $60 \mathrm{~km}$ along what has become known as the Imperial fault. A maximum ground displacement of almost $6 \mathrm{~m}$ was reported (Richter, 1958).

of more immediate interest is a swarm of events in 1938, located approximately $10 \mathrm{~km}$ north of East Mesa, the largest of which had a magnitude of 5.0 on the Richter scale. Two other interesting events occurred in 1972 with magnitudes of 2.9 and 3.1 and were located about $15 \mathrm{~km}$ east and $20 \mathrm{~km}$ west of East Mesa, respectively.

Two microearthquake studies of the Imperial Valley conducted in 1967 and 1971, with two days and three weeks respective recording time in the East Mesa region, failed to detect any local seismic activity. The 1967 study, however, revealed intense swarm activity in the Obsidian Buttes region near the then-inferred Brawley fault. The East Mesa station was located about $25 \mathrm{~km}$ north of the present array in 1967 (Brune and Allen, 1967).

\section{The USGS-CIT Imperial Valley Array}

A network of 16 high-gain vertical seismic stations was installed throughout the Imperial Valley in April 1973, with good coverage in all directions around East Mesa. The results of the first year of operation have been summarized by Hill (1975).

The major events of the first year were four earthquake swarms in June and July 1973, which occurred along the Brawley/Imperial fault system. Combs (1974) and Combs and Hadley (1977) reported microearthquake activity at East Mesa coincident with the Brawley swarm. Hill noted that most of the events reported by Combs (1974) were too small to be located by the USGS-CIT network, which provided uniform coverage for events down to about $M_{L}=2.0$. A sma11 event $\left(M_{L}=1.5-2.5\right)$ was located at East Mesa, as indicated by Hill (1975).

Swarm activity along the Brawley/Imperial fault zone has been detected by the USGS-CIT network every year since 1973, but no significant seismic activity has been located at or associated with the East Mesa KGRA. It is interesting to note that although Hill reported 
earthquake activity at the Salton Sea and Brawley geothermal fields (associated with the Brawley fault), no evidence for seismic activity at the Dunes and Glamis KGRAs was apparent.

\section{Results of the 1973 Microearthquake Study}

The results of a five-week microearthquake study at East Mesa in 1973 have been reported by Combs (1974) and Combs and Hadley (1977). Their array consisted of 6 high-gain, portable, vertical seismometers deployed in roughly the same configuration as the present array, although the station separation was somewhat larger. The normal background seismicity was characterized by one or two locatable events per day (recorded on at least four stations) and 100 or more small events during days of swarm activity.

The pattern of seismicity suggested the existence of a fault (the Mesa fault) running west-northwest through the geothermal field across the zone of highest heat flow. Focal mechanism studies, coupled with the coincidence of swarm activity at both East Mesa and the Brawley/ Imperial fault zone, indicated that the Mesa fault was linked tectonically to the more extensive fault system (see Elders et al., 1972, for a discussion of the regional tectonics). Continuous "nanoearthquake" activity (defined as events too small to be located) persisting even during "quiet" times was recorded at a site close to the present MBR Station 9.

The magnitudes of microearthquakes at East Mesa during the JuneJuly activity, as determined by coda length, ranged up to an $M_{L}=2.9$ event with roughly half of the events having a magnitude $\geqslant 1.5$. It is not immediately clear why the bulk of this activity was not better recorded by the USGS-CIT array, with six stations in the vicinity of East Mesa.

\section{Results of the 1974-1975 Microearthquake Study}

An array of nine three-component seismographs was deployed at East Mesa from December 1974 to December 1975, recording microearthquake activity before, during and after the withdrawal and injection of geothermal fluids. Combs (1976) reported no significant change in seismicity 
throughout the entire period. The pattern of seismicity was found to be essentially the same as that found during the 1973 study--several locatable microearthquakes per day plus intermittent periods of swarm activity.

The seismicity is divided into discrete events and swarm activity. Discrete events are further subdivided, based on characteristic S-P times, as shown in Table 2.1 .

Combs noted several differences between events appearing to originate within the field and those from without:

1. Arrivals for local events appear more emergent and are of lower frequency than external "tectonic" events.

2. Local events appear to originate at shallower depths than tectonic events.

3. Brawley earthquakes show significant attenuation of highfrequency content as the wavefront travels across the array (through the zone of high heat flow).

\section{The Brawley Swarm}

The Brawley swarms of October-November 1977 were well recorded at East Mesa. In December 1977 at the American Geophysical Union Meeting in San Francisco, Dr. Carl Johnson of the Seismological Laboratory at CIT presented the preliminary results for the swarm activity, based on the data from the Imperial Valley USGS-CIT seismic array. We report here only on those aspects of interest in the present field-specific study. With one exception (discussed below), no earthquakes were detected during the swarm activity at East Mesa by either the USGS-CIT or East Mesa arrays.

As seen on the regional map (Figure 2.1), several stations of the USGS-CIT Imperial Valley array lie in close proximity to East Mesa. Two more stations are just off the map to the north. Considering the station deployment, it seems that any significant seismic activity at East Mesa would have been recorded at these stations, although it is not inconceivable that highly localized, low-magnitude activity might pass undetected. A search of the USGS files for the period of 
Table 2.1. Seismic events recorded at East Mesa during the 1974-1975 microearthquake study.

\begin{tabular}{lllll}
$\begin{array}{c}\text { S-P time } \\
(\mathrm{sec})\end{array}$ & Type of event & Location & $\begin{array}{c}\text { Depth } \\
(\mathrm{km})\end{array}$ & No. per day \\
\hline & & & & \\
$<1.5$ & nanoearthquake & not locatable & - & $10 \mathrm{~s}-100 \mathrm{~s}$ \\
$1.5-3.0$ & microearthquake & in field & $2-4$ & $\sim 5$ \\
$3-10$ & microearthquake & outside field & $4-10$ & $\sim 5$ \\
$>10$ & microearthquake & regional & - & a few \\
\hline
\end{tabular}

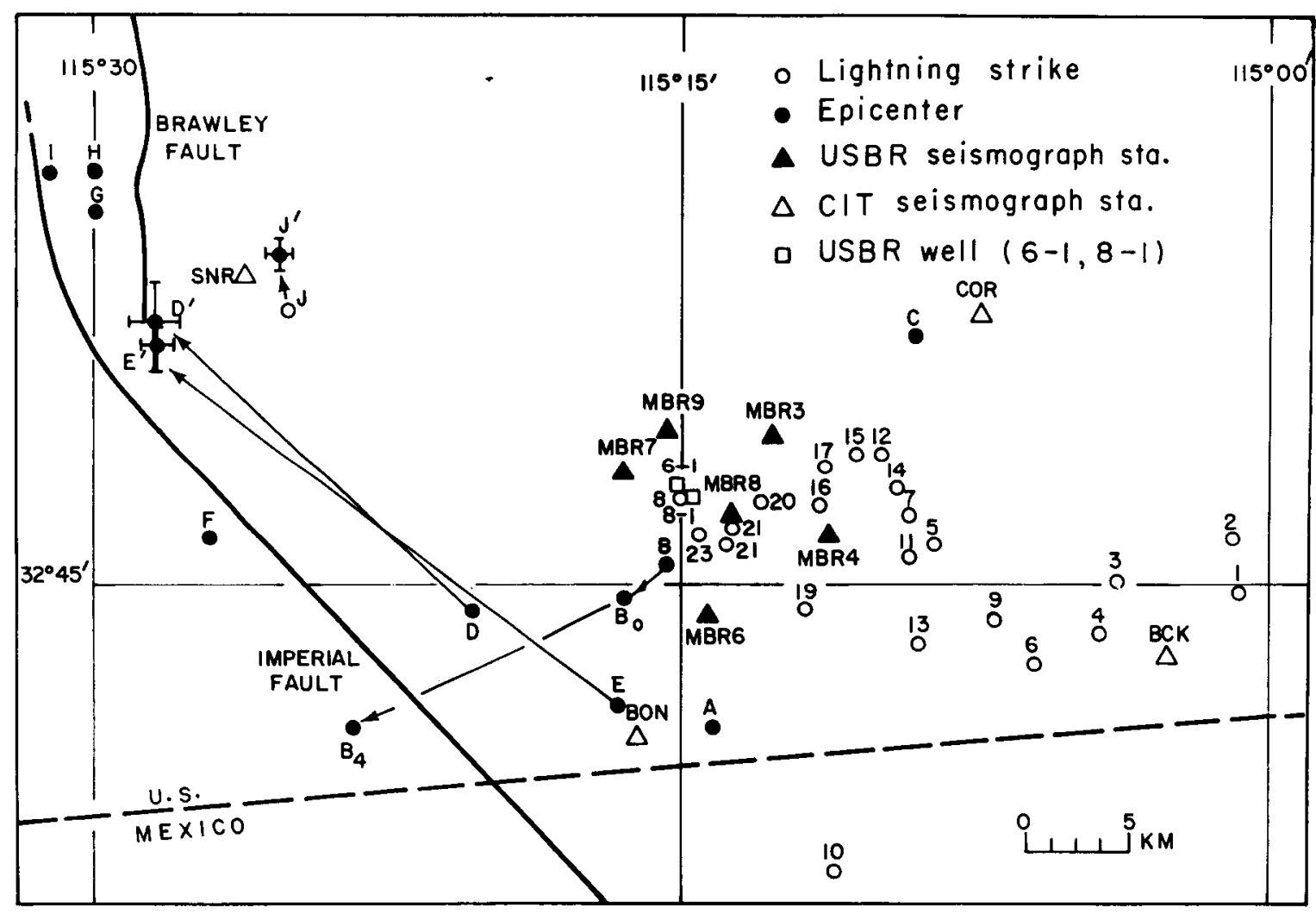

XBL785-795

Figure 2.1. Regional map showing East Mesa network stations, epicenters located, and USGS-CIT epicenters for larger events. 
days $178-364,1977$, within a range of lat. $320^{\circ} 0^{\prime}-32052^{\prime} \mathrm{N} .$, long. $115^{\circ} 05^{\prime}-115^{\circ} 21^{\prime}$ W., yielded events $A-E$, listed in Table 2.2.

Al1 these events, with the exception of $A$, have a quality factor of 4 , which indicates only a rough location (not known within $15 \mathrm{~km}$ ). (The quality of a location decreases with increasing quality factor from 1-6, a quality 4 is a poorly constrained solution). Events B-E were therefore examined in further detail.

Event B. As shown in Figure 2.2, the signal-to-noise ratio of this event is unusually low, especially for a local event that was we1lrecorded by the USGS-CIT array (although effects of attenuation and local ground noise should be considered). Using the S-P distance constraints of MBR stations 3 and 9, probable locations for this event at fixed focal depths of 0 and $4 \mathrm{~km}$ are shown on Figure 2.1 (labeled $\mathrm{B}_{0}$ and $\mathrm{B}_{4}$, respectively). Since a focal depth of $4 \mathrm{~km}$ seems more likely, based on USGS-CIT results, it appears that this event is actually associated with the Imperial fault.

Event C. Based on the East Mesa records, this event does not appear to be seismic in origin. Only slowly traveling surface waves propagating west to east are apparent.

Events $\mathrm{D}$ and $\mathrm{E}$. These were well recorded (both $\mathrm{P}$ - and $\mathrm{S}$-waves) and were relocated as shown on Figure 2.1 at $D^{\prime}$ and $E^{\prime}$ (with error bars for latitude and longitude). The new locations clearly associate these events with the Brawley/Imperial fault system. Thus, within the sensitivity of the USGS-CIT array, no events appear to have occurred in the immediate vicinity of the East Mesa geothermal field during the period. This supports the conclusion reached from a study of the East Mesa array data.

An event of magnitude 2.8 , which occurred on day 230,1977 (see Figure 2.3), is also plotted in Figure 2.1, with the USGS-CIT location at point $J$ and the East Mesa solution at $J^{\prime}$ (shown with standard error bars for latitude and longitude). This appears to be the largest event east of the Brawley/Imperial fault zone and close to East Mesa that has been detected by the Imperial Valley array since the beginning of the present study. The event had a minimum S-P time of 3.0 seconds (observed at MBR station 7 ). 


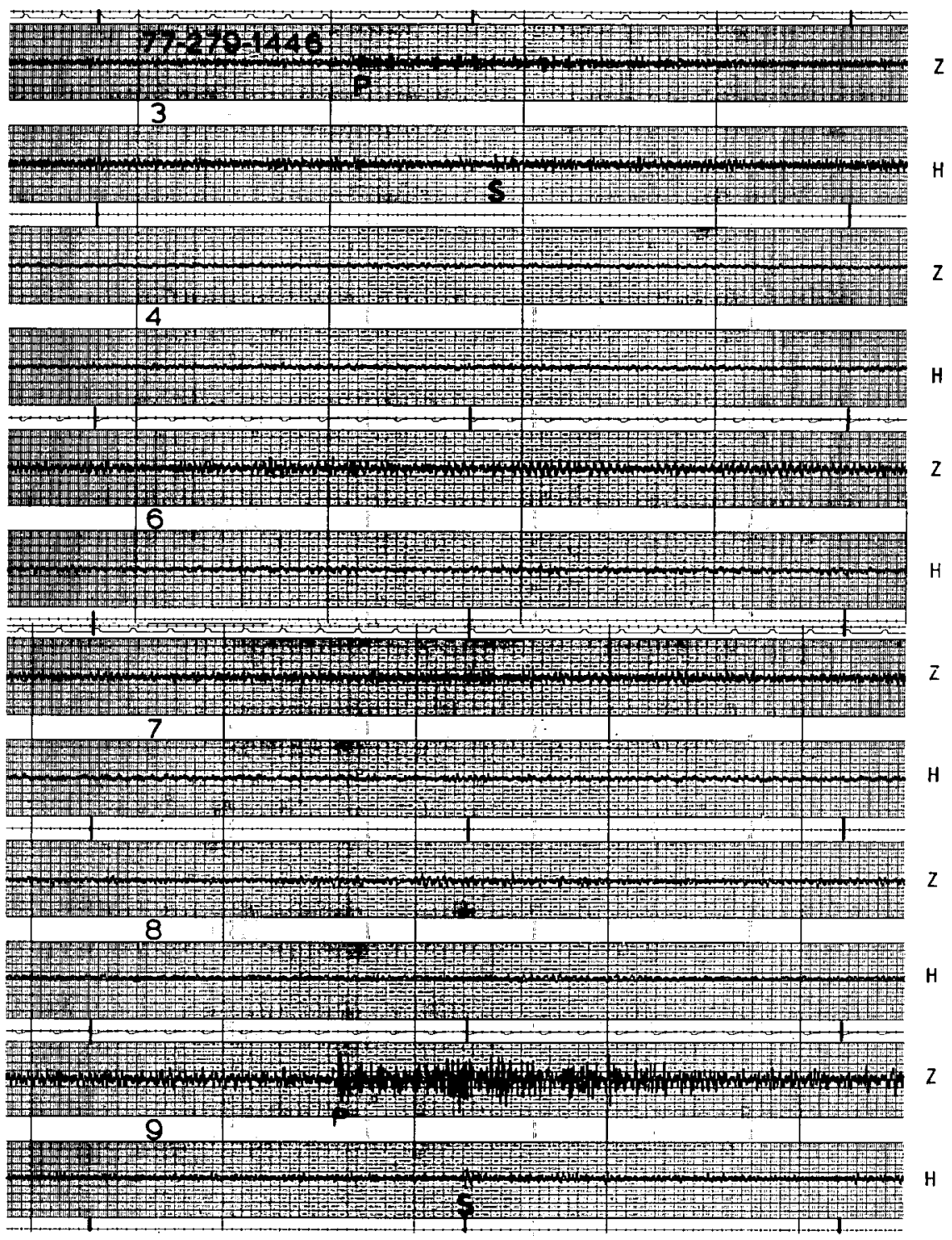

XBL $784-8083$

Figure 2.2. Seismograms for day 279 earthquake, located within East Mesa KGRA by USGS-CIT network. (See Figure 2.1, symbols $\left.\mathrm{B}, \mathrm{B}_{0}, \mathrm{~B}_{4}.\right)$ Stations $3 \mathrm{Z}, 3 \mathrm{H}, 6 \mathrm{Z}, 7 \mathrm{Z}, 9 \mathrm{Z}$ and $9 \mathrm{H}$ are highpass filtered at $4.5 \mathrm{~Hz}$ and displayed at $50 \mathrm{mv} / \mathrm{div}$; other stations are not filtered and are displayed at $100 \mathrm{mv} / \mathrm{div}$. Time lines are a $10-\mathrm{sec}$ intervals. 


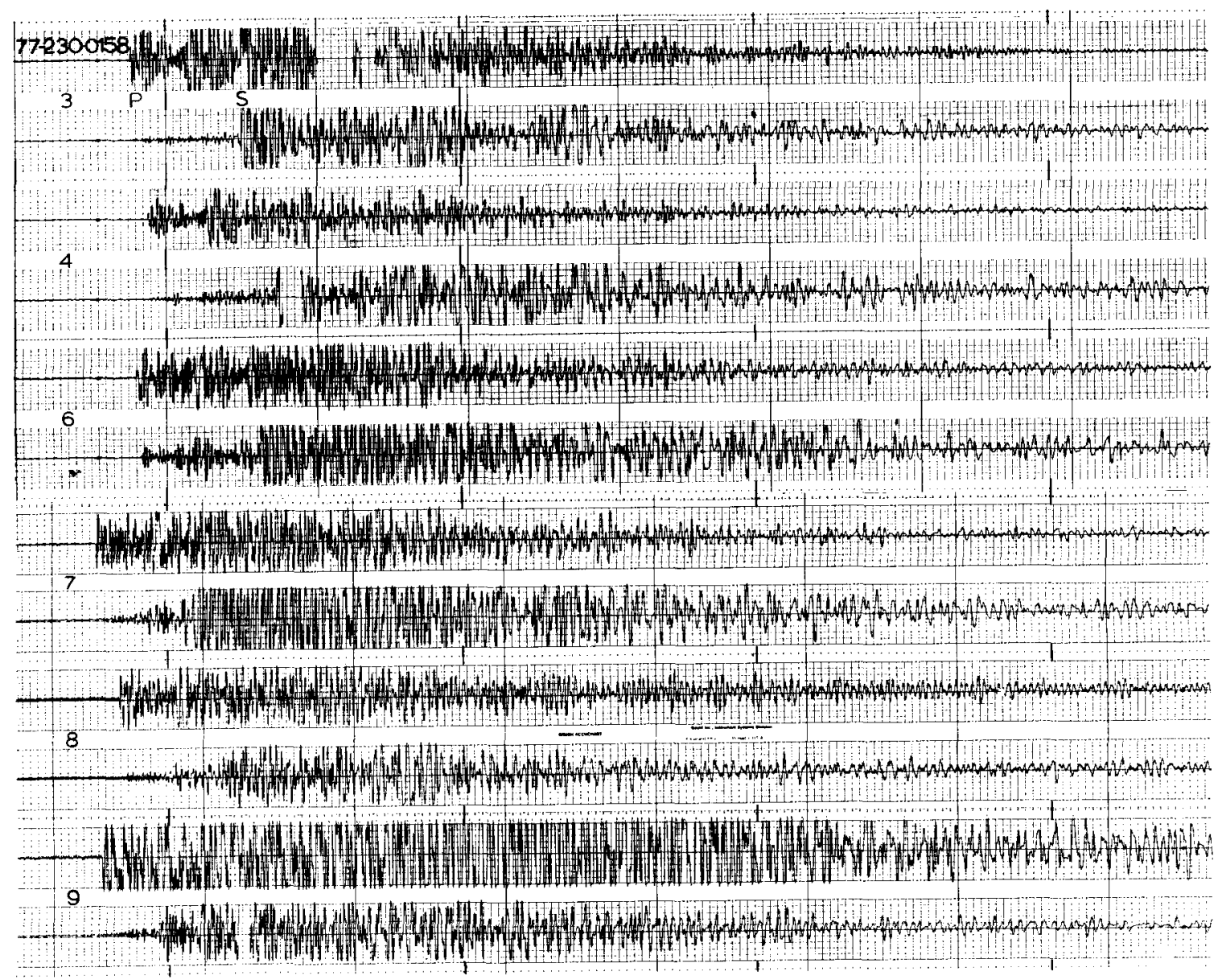

XBL 784-8059

Figure 2.3. Seismogram for $M=2.8$ event west of array for day 230,1977 .

Table 2.2. Events recorded by USGS for days 178-364, 1977.

\begin{tabular}{|c|c|c|c|c|c|c|c|}
\hline Event & & & igin & & & pth & \\
\hline (Map symbo1) & Day & time & (UTC) & Lat itude & Longitude & $(\mathrm{km})$ & Qual. \\
\hline A & 202 & 0517 & 04.4 & $32^{\circ} 41.8^{\prime}$ & $115^{\circ} 14.1^{\prime}$ & 5.0 & 3 \\
\hline B & 278 & 1446 & 25.7 & $32 \circ 45.3^{\prime}$ & $115^{\circ} 15.4^{\circ}$ & 4.9 & 4 \\
\hline C & 315 & 2155 & 02.1 & $32^{\circ} 50.5^{\prime}$ & $115^{\circ} 09.1^{\prime}$ & 5.0 & 4 \\
\hline D & 318 & 0311 & 24.4 & $32044.4^{\prime}$ & $115^{\circ} 20.3^{\prime}$ & 5.1 & 4 \\
\hline$E$ & 318 & 0416 & 17.6 & $32^{\circ} 42.3^{\prime}$ & $115^{\circ} 16.7^{\prime}$ & 5.0 & 4 \\
\hline
\end{tabular}


Combs-Hadley Hypothesis Tested

On the basis of their 1973 study, Combs and Hadley (1977) located microearthquakes within the East Mesa geothermal field for the period June-July 1973. They reported that the microearthquakes appeared to be tectonically associated with the more extensive and simultaneous swarm activity occurring along the Brawley/Imperial fault system. The larger events occurred on the Brawley fault, while the smaller events occurred at East Mesa and were associated with the Mesa fault.

During the same period, no earthquakes were detected at East Mesa by the USGS-CIT network, although as Hill (1975) points out, most of the events discussed by Combs were too small to be detected on at least four stations of the Imperial Valley array. In the East Mesa array used by Combs, station separation was greater than that of the present array and thus was even closer to the Imperial Valley array. Therefore, the question arises whether the microearthquakes actually occurred at East Mesa or farther to the west along the Brawley fault.

To test the Combs-Hadley hypothesis of Brawley-East Mesa interaction, seven hours of high activity, characterized by a large occurrence ratio of small to large events, were examined in detail. The period studied runs between 0720 and 1420 (Universal Time Code) on day 293. Forty-three events were identified on the visual records, which comprise a complete sample of the data since the signal-to-noise ratio observed on these records normally exceeds that of the data tape. The magnitudes of the events ranged from $M_{L}=4.0$ to $M_{L}=2.0$. AlI of the larger events with S-P times greater than $3 \mathrm{sec}$ (as determined by visual inspection) were discarded. A11 others were played out and analyzed. The events fell into three categories:

1. Large events clearly associated with the Brawley/Imperial fault.

2. Small events clearly associated with the Brawley/Imperial fault.

3. Small events, usually recorded only on stations 32 and $9 \mathrm{Z}$, which could not be located. 
Figures 2.4 through 2.7 illustrate each type of event. Every locatable event was found to originate along the Brawley/Imperial fault. The locations of the smallest events (see Figure 2.7), having magnitudes probably on the order of zero, are unresolved.

Attempts to increase the sensitivity of the records by means of filtering have been only partially successful. A comparison of the filtered versus unfiltered signals from station $7 \mathrm{H}$ in Figure 2.5 shows a considerable amount of ground noise in the 4-10 $\mathrm{Hz}$ bandwidth, a characteristic of $\mathrm{S}$-wave arrivals.

In summary, no local seismic events were detected at East Mesa by either the USGS-CIT Imperial Valley or the USBR East Mesa seismic arrays down to estimated thresholds of at least $\mathrm{M}_{\mathrm{L}}=2.0$ and $\mathrm{M}_{\mathrm{L}}=1.0$, respectively, during the recent Brawley swarm activity. This contradicts the observations of Combs and Hadley (1977) and may indicate that the East Mesa geothermal field is not tectonically linked with the Brawley/ Imperial fault system. The location of smaller events detected at East Mesa remains unresolved, but normal seismicity characteristics suggest extremely low activity. It is quite possible that previous investigators, confusing secondary $P$ arrivals on vertical components with S-waves, mislocated Brawley or Imperial fault events at erroneously short distances.

OBSERVATION PROCEDURES OF UC-LBL

Data from 1.0-Hz geophones (two horizontals in parallel and one vertical) are radio-telemetered to a control recording site. Data are recorded with time and tape speed compensation on a 14-channel FM tape recorder at $15 / 160$ ips with $0-$ to $34-\mathrm{Hz}$ bandwidth (Geotech No. 19429). The data-processing routine consists of four phases: event identification, playback, location, and analysis.

Local microearthquakes are routinely located using EPIC, an iterative linear regression hypocentral location program at the Seismographic Station, University of California, Berkeley. Input parameters include station locations, velocity model ( $\mathrm{P}$ - and $\mathrm{S}$-wave velocities in two layers over a half-space), $P$ and $S$ arrival times for each station, and an initial trial location based on relative arrivals. Initial, 


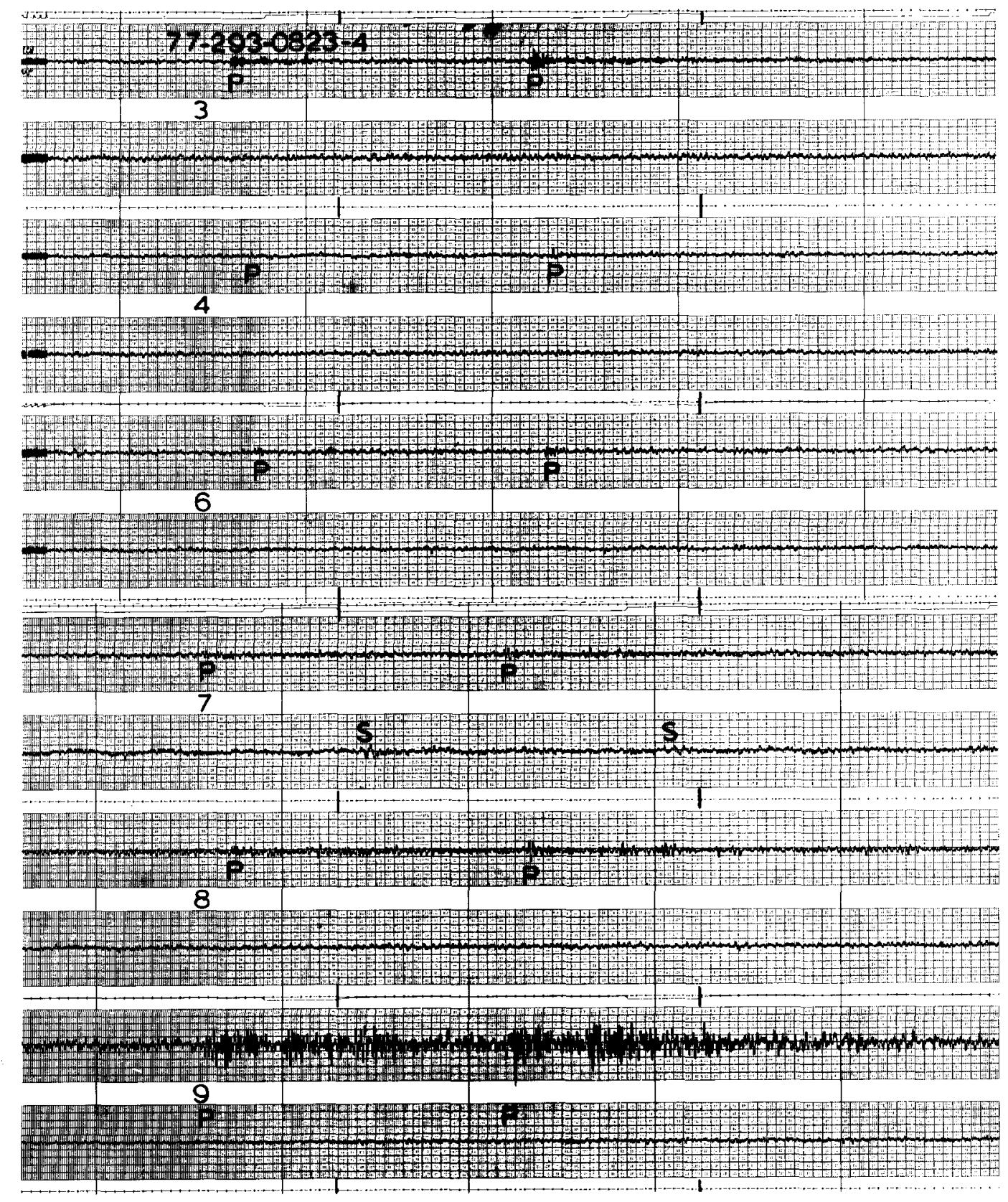

XBL 784-8084

Figure 2.4. Seismogram for two small earthquakes in the Brawley swarm ( $H$ in Figure 2.1), $100 \mathrm{mv} / \mathrm{div}$. These are the smallest locatable events. Time lines are at $10-\mathrm{sec}$ intervals. 


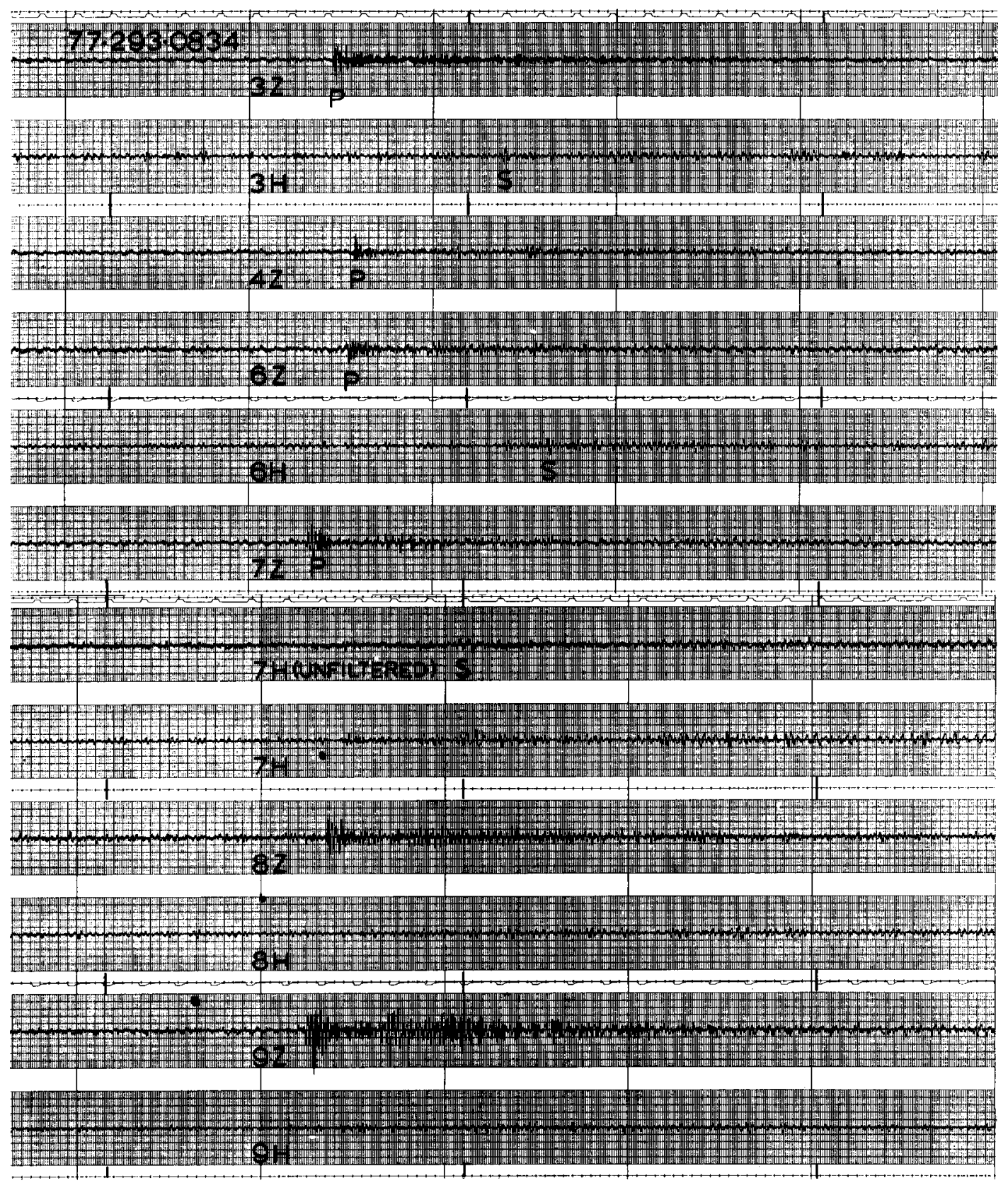

XBL $784-8079$

Figure 2.5. Seismogram for filter tests on small Brawley swarm event ( 1 in Figure 2.1). Verticals unfiltered at $100 \mathrm{mv} / \mathrm{div}$. except $9 \mathrm{Z}, 200 \mathrm{mv} / \mathrm{div}$. Horizontals at $50 \mathrm{mv} / \mathrm{div}$ are bandpass filtered at $4-10 \mathrm{~Hz}$. Time lines are at $10-\mathrm{sec}$ intervals. 


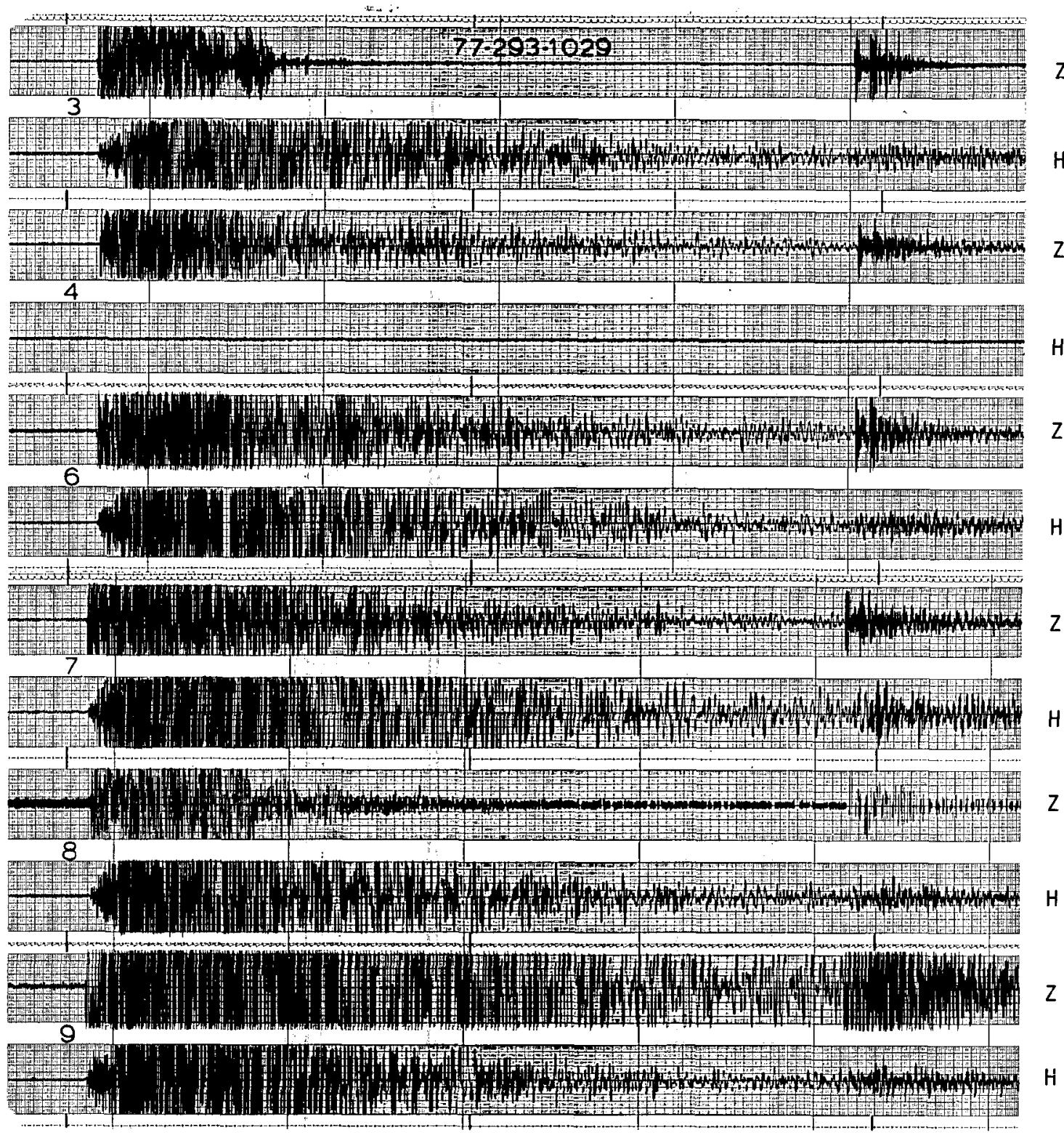

Figure 2.6. Seismogram for two Brawley swarm events (first one is magnitude 4.0) illustrating defective vertical seismometers at $3 \mathrm{Z}$ and $8 \mathrm{Z}$, reducing low-frequency response. Time lines are at 1-min intervals. (Symbol $G$ in Figure 2.1.) 


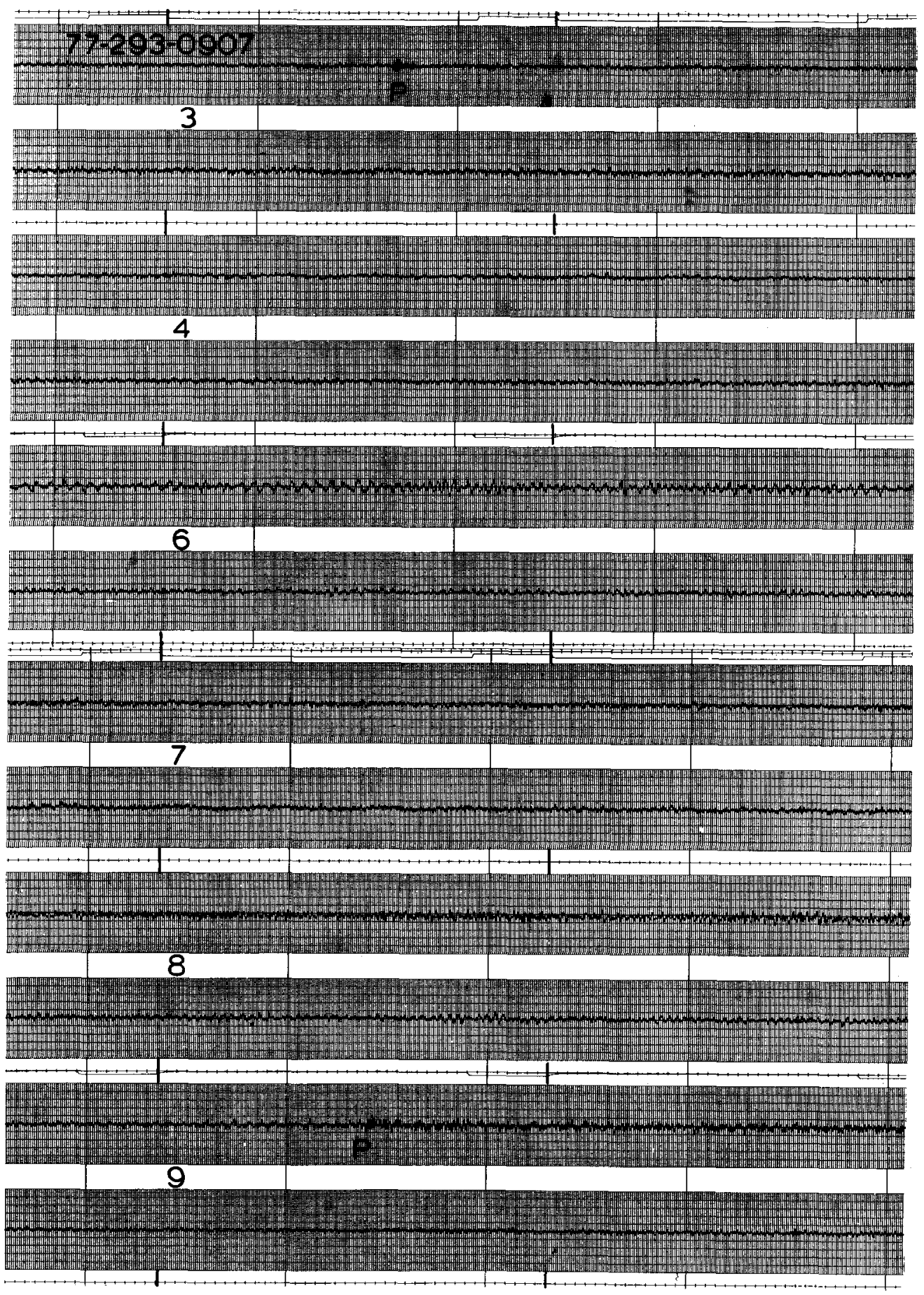

XBL $784-8080$

Figure 2.7. Seismogram for small event during the 7-hr test of Brawley swarm, the smallest presently detectable at East Mesa. Visible arrivals are only at stations $3 Z$ and 9Z. Horizontals are at $100 \mathrm{mv} / \mathrm{div}$ except $9 \mathrm{Z}$ at $200 \mathrm{mv} / \mathrm{div}$. time marks are at $10-\mathrm{sec}$ intervals. 
final, and incremental trial depths and the numbers of free (depth) versus fixed iterations, are selected by the user. The program then lists calculated hypocenters and residuals at each depth selected, with the final solution chosen to minimize the residuals. For a typical run, an initial depth of $2 \mathrm{~km}$, a final depth of $8 \mathrm{~km}$, and increments of $2 \mathrm{~km}$ were chosen, with seven fixed and three free iterations for each depth.

As determined from the USBR base map, with translation into angular coordinates, the present station locations are as given in Table 2.3.

The following model was used for hypocentral location estimation:

\begin{tabular}{|c|c|c|c|}
\hline Thickness $(\mathrm{km})$ & $\alpha(\mathrm{km} / \mathrm{sec})$ & $\beta(\mathrm{km} / \mathrm{sec})$ & $\sigma$ \\
\hline 1 & 2.0 & 0.8 & 0.40 \\
\hline 2.5 & 3.1 & 1.7 & 0.30 \\
\hline$\infty$ & 6.0 & 3.5 & 0.25 \\
\hline
\end{tabular}

A11 earthquakes detected were located outside the array, ranging in distance (as determined by S-P times) from about one to nearly six array diameters. At these distances, a linear regression location proprogram using $\mathrm{P}$-waves is poorly conditioned and generally will not converge to a valid solution. Other techniques are available for location in this case. The method used involves first measuring S-P times for each station, then, using a relationship between S-P times and distance, swinging arcs from each station to determine the epicenter. This scheme yields a well-defined distance from the epicenter to the array, but often leaves the azimuth poorly defined. In such cases, relative Parrival times are used to estimate the azimuth, assuming plane waves.

The normal to the apparent wavefront, centered at station MBR 8 , was chosen as the azimuth. The epicenters that have been located are listed in Table 2.4 and plotted in Figure 2.8. The locations determined as above were compared with those reported by the USGS-CIT Imperial Valley network, which was possible for six events. This verified that the computed values of distance are generally reliable, but the azimuths are not. In five of the six cases, when the epicenters as determined 
Table 2.3. Locations of USBR seismograph stations.

\begin{tabular}{ccc}
\hline Station & Latitude & Longitude \\
\hline MBR 3 & $322^{\circ} 48.24^{\prime} \mathrm{N}$ & $115^{\circ} 12.66^{\prime} \mathrm{W}$ \\
MBR 4 & $322^{\prime} 4.04^{\prime} \mathrm{N}$ & $115^{\circ} 11.14^{\prime} \mathrm{W}$ \\
MBR 6 & $32^{\circ} 44.28^{\prime} \mathrm{N}$ & $115^{\circ} 14.19^{\prime} \mathrm{W}$ \\
MBR 7 & $32^{\circ} 47.38^{\prime} \mathrm{N}$ & $115^{\circ} 16.42^{\prime} \mathrm{W}$ \\
MBR 8 & $32^{\circ} 46.50^{\prime} \mathrm{N}$ & $115^{\circ} 13.72^{\prime} \mathrm{W}$ \\
MBR 9 & $32^{\circ} 48.33^{\prime} \mathrm{N}$ & $115^{\circ} 15.26^{\prime} \mathrm{W}$ \\
\hline
\end{tabular}

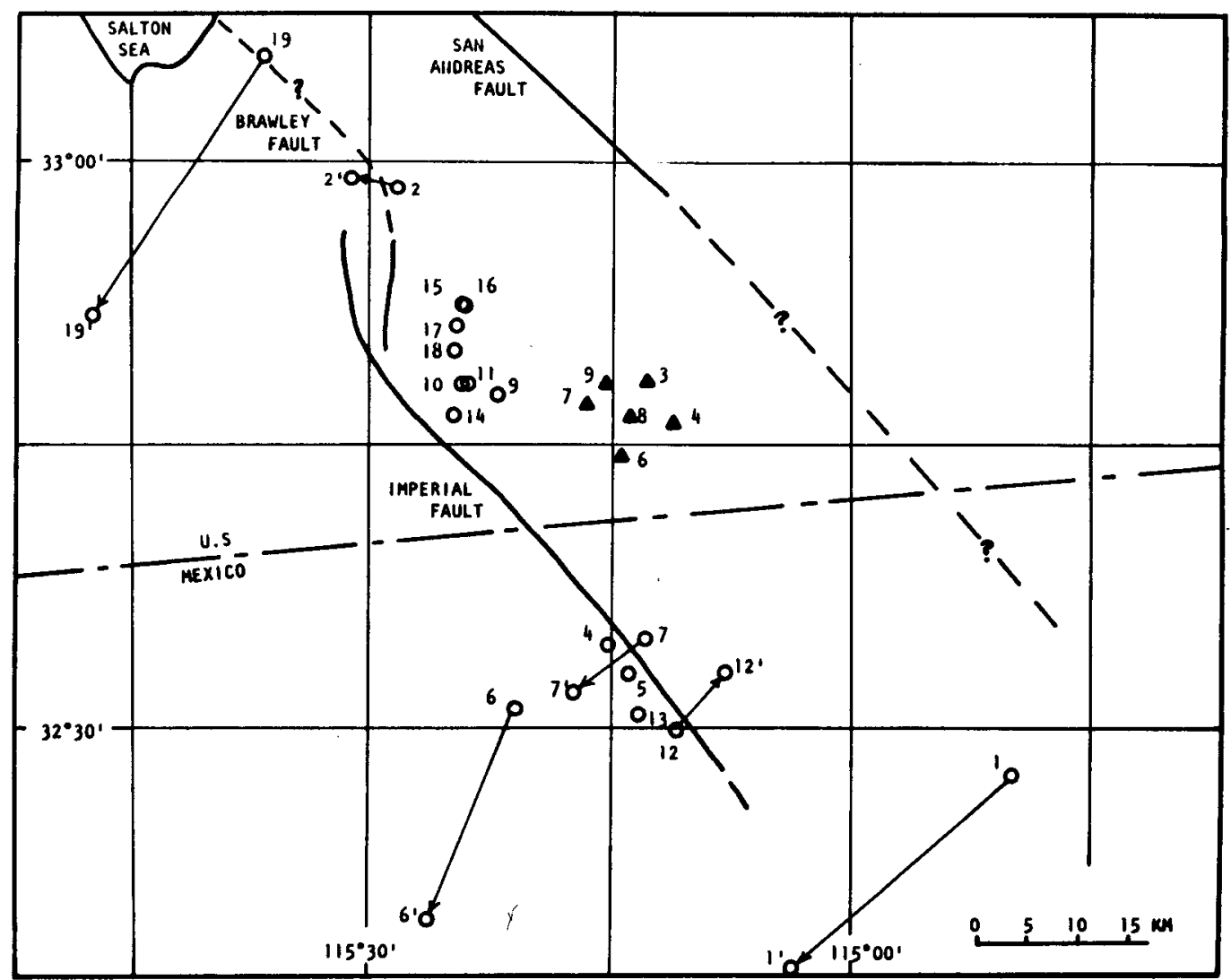

X8L $7710-6804$

Figure 2.8. Regional map showing East Mesa network stations (triangles), epicenters located (circles--numbers refer to Table 2.4), and USGS-CIT epicenters for larger events (primed numbers). 
Table 2.4. Microearthquake summary.

\begin{tabular}{|c|c|c|c|c|c|}
\hline & Day & Time & Latitude & Longitude & Magnitude \\
\hline 1. & 184 & 0558 & $32^{\circ} 28^{\prime}$ & $114^{\circ} 50^{\prime}$ & \\
\hline 2. & 184 & 1218 & $32^{\circ} 58^{\prime}$ & $115^{\circ} 28^{\prime}$ & \\
\hline 3 . & 184 & 1407 & & & \\
\hline 4. & 184 & 1841 & $32^{\circ} 34^{\prime}$ & $115^{\circ} 15^{\prime}$ & \\
\hline 5. & 184 & 1902 & $32^{\circ} 33^{\prime}$ & $115^{\circ} 14^{\prime}$ & \\
\hline 6. & 190 & 2200 & $32031^{\prime}$ & $115013^{\prime}$ & \\
\hline 7. & 191 & 2305 & $32^{\circ} 35^{\prime}$ & $115^{\circ} 13^{\prime}$ & \\
\hline 8. & 192 & 1200 & & & \\
\hline 9. & 196 & 1453 & $322^{\circ} 8^{\prime}$ & $115^{\circ} 22^{\prime}$ & \\
\hline 10. & 200 & 0833 & $32 \circ 47^{\prime}$ & $115025^{\prime}$ & \\
\hline 11. & 200 & 0839 & $32 \circ 47^{\prime}$ & $115^{\circ} 25^{\prime}$ & \\
\hline 12. & 207 & 0820 & $32030^{\prime}$ & $115011^{\prime}$ & \\
\hline 13. & 211 & 0236 & $32031^{\prime}$ & $115014^{\prime}$ & \\
\hline 14. & 211 & 0325 & $32 \circ 46^{\prime}$ & $115025^{\prime}$ & \\
\hline 15. & 211 & 0333 & $322^{\circ} 6^{\prime}$ & $115^{\circ} 24^{\prime}$ & \\
\hline 16. & 211 & 0347 & $32046^{\prime}$ & $115 \circ 24^{\prime}$ & \\
\hline 17 . & 211 & 0349 & $32 \circ 51^{\prime}$ & $115^{\circ} 25^{\prime}$ & \\
\hline 18. & 211 & 0355 & $32 \circ 50^{\prime}$ & $115025^{\prime}$ & \\
\hline 19. & 211 & 1024 & $32^{\circ} 06^{\prime}$ & $115^{\circ} 37^{\prime}$ & \\
\hline
\end{tabular}

\section{USGS-CIT Locations}

\begin{tabular}{rrrrrr} 
1. & 184 & 0558 & $32^{\circ} 17^{\prime}$ & $115^{\circ} 03^{\prime}$ & 2.8 \\
2. & 184 & 1218 & $32^{\circ} 59^{\prime}$ & $115^{\circ} 31^{\prime}$ & 2.2 \\
6. & 190 & 2200 & $32^{\circ} 20^{\prime}$ & $115^{\circ} 27^{\prime}$ & 2.5 \\
7. & 191 & 2305 & $32^{\circ} 32^{\prime}$ & $115^{\circ} 17^{\prime}$ & 2.7 \\
12. & 207 & 0820 & $32^{\circ} 3^{\prime}$ & $115^{\circ} 08^{\prime}$ & 2.7 \\
19. & 211 & 1024 & $32^{\circ} 2^{\prime}$ & $115^{\circ} 47^{\prime}$ & 3.3 \\
\hline
\end{tabular}


by USGS-CIT were shifted to the southwest relative to East Mesa by azimuths of $4^{\circ}-30^{\circ}$, the distance remained approximately unchanged, as seen in Figure 2.8.

Apparent distortion of the azimuth across the array was also observed in the case of surface waves from a known source. This azimuthal distortion may be explained by two assumptions. First, a change in the velocity structure occurs across the Brawley-Imperial fault system with lower velocity to the southwest. Five of the six earthquakes located by both East Mesa and the USGS-CIT arrays 1 ie close to the fault system. Such a lateral discontinuity refracts ray paths crossing the boundary obliquely, which results in a more southwesterly "virtual" azimuth being indicated as the rays sweep past East Mesa. The larger networks, with good coverage at all azimuths, would be less affected. Second, local variations in seismic velocities occur within or surrounding the East Mesa array. If, in general, velocities increased to the east, apparent azimuths would be shifted as observed.

Independent evidence for local variations in velocity comes from the large scatter observed in S-P versus $P$ times for individual events. More data are required, especially for earthquakes within the array, before station corrections can be determined and applied with any confidence.

\section{RESULTS OF THE PRESENT STUDY}

A major result of the present study has been the total absence of detected local microearthquakes originating within the East Mesa geothermal field. This is consistent with early microearthquakes in the Imperial Valley and with the findings of the USGS-CIT network, but inconsistent with two microearthquake studies at East Mesa in 1973 and $1974-75$.

Three possible explanations might account for the descrepancies.

First, the Mesa fault was active from 1973 to 1975 but has been inactive since July 1977. This does not seem likely, since local activity was assumed to be tectonically linked to the broader zone of seismicity associated with the Brawley-Imperial fault system, which has continued to be active throughout the period. According to this hypothesis, 
one would have expected to see local events during the recent Brawley swarms .

Second, the microearthquakes used to define the Mesa fault in 1973 were actually located along the Brawley fault. Only verticalcomponent instruments were then available to locate these events. In Report No. 2 (McEvilly and Schechter, 1977b) we demonstrated the problems of accurately locating events using only $P$ arrivals, especially for events located outside the array. A comparison of station deployment with epicenter distribution shows the station distribution heavily weighted to the east of the epicenters--a situation that could easily lead to mislocations. Relocation of these events farther to the west would also increase the computed focal depth to values more compatible with those reported by Johnson and Hadley (1976) for Brawley events. Only a reevaluation of the actual data can resolve this problem.

Finally, "geothermal events" may actually be nonseismic in origin. Figures of these events in Combs (1976) appear to be more consistent with air-coupled Rayleigh waves than with microearthquakes, featuring emergent low-frequency arrivals and similar waveforms that appear simultaneously on both vertical and horizontal records. The local velocity structure (very low velocities in the near-surface) constrains the ray paths even for local events to propagate almost vertically near the surface, clearly separating $P$ and $S$ waves as vertical and horizontal motions, respectively. The "geothermal event" waveforms (Combs, 1976, p. 34), if body waves, are not consistent with such characteristics. In addition, the manner in which the $S$-wave arrival was determined is often ambiguous. Improper determination of S-P times, more than any other error, would heavily influence the determination of local seismicity.

The observation that local seismicity remained unaffected by withdrawal and injection of geothermal fluids could be interpreted as evidence that the observed seismicity is not of local origin. A reexamination of the data appears necessary to resolve these questions. of specific interest are the determination of the apparent velocities associated with the "geothermal events" and the temporal correlation of these events with the records of the USGS-CIT Imperial Valley array. 
The small events detected at East Mesa during the present study (Figure 2.7) may be analogous to the nanoearthquakes discussed by Combs (1974 and 1976), since they were observed at roughly the same location now as then (MBR station 9 lies close to Combs' MGA 非). The S-P time of $1.5 \mathrm{sec}$ assigned by Combs to these events, indicating a local origin, has not been observed (no S-wave arrivals are, in fact, seen for these events). Because these events appear only in $M B R 9 Z$ and $3 Z$, we may speculate that they are actually the smallest members of the Brawley earthquake swarms with origins to the northwest of East Mesa. One would also expect the signals to show up on STA 7Z. However, a map of seismic ground noise (Combs 1974, p. 33) shows high noise levels in the vicinity of MBR 7 relative to levels around MBR 3 and 9 . Hopefully, records from the $4.5-\mathrm{Hz}$ buried geophones soon to be installed will enable an S-P time to be resolved and the sources of these events to be located without ambiguity.

\section{NETWORK PERFORMANCE}

The quality of data has slowly deteriorated over the past year, although the network can still detect local events up to an estimated threshold of $M_{L}=1.0$ and within the previously mentioned bandwidth $(0-35 \mathrm{~Hz})$.

One problem persisting throughout most of the period has been the loss of low-frequency response of station MBR $3 \mathrm{Z}$ and $8 \mathrm{Z}$. Station $9 \mathrm{Z}$ has recently succumbed to this problem, which is well illustrated by the response of these stations to the Nevada Test Site (NTS) explosion on day 231, 1977 (see Figure 2.9). In addition, MBR station 4H has been inoperative during much of the period, and recently, $4 \mathrm{Z}$ has become inoperative as we11.

The time code has generally been adequate, although spotty in places. In its present condition, the seismic array is operating far below its potential capability. Inoperative or poorly operating geophones should be replaced, and it would be best to plan geophones in 100- to 150-m-deep holes to reduce surface noise. 


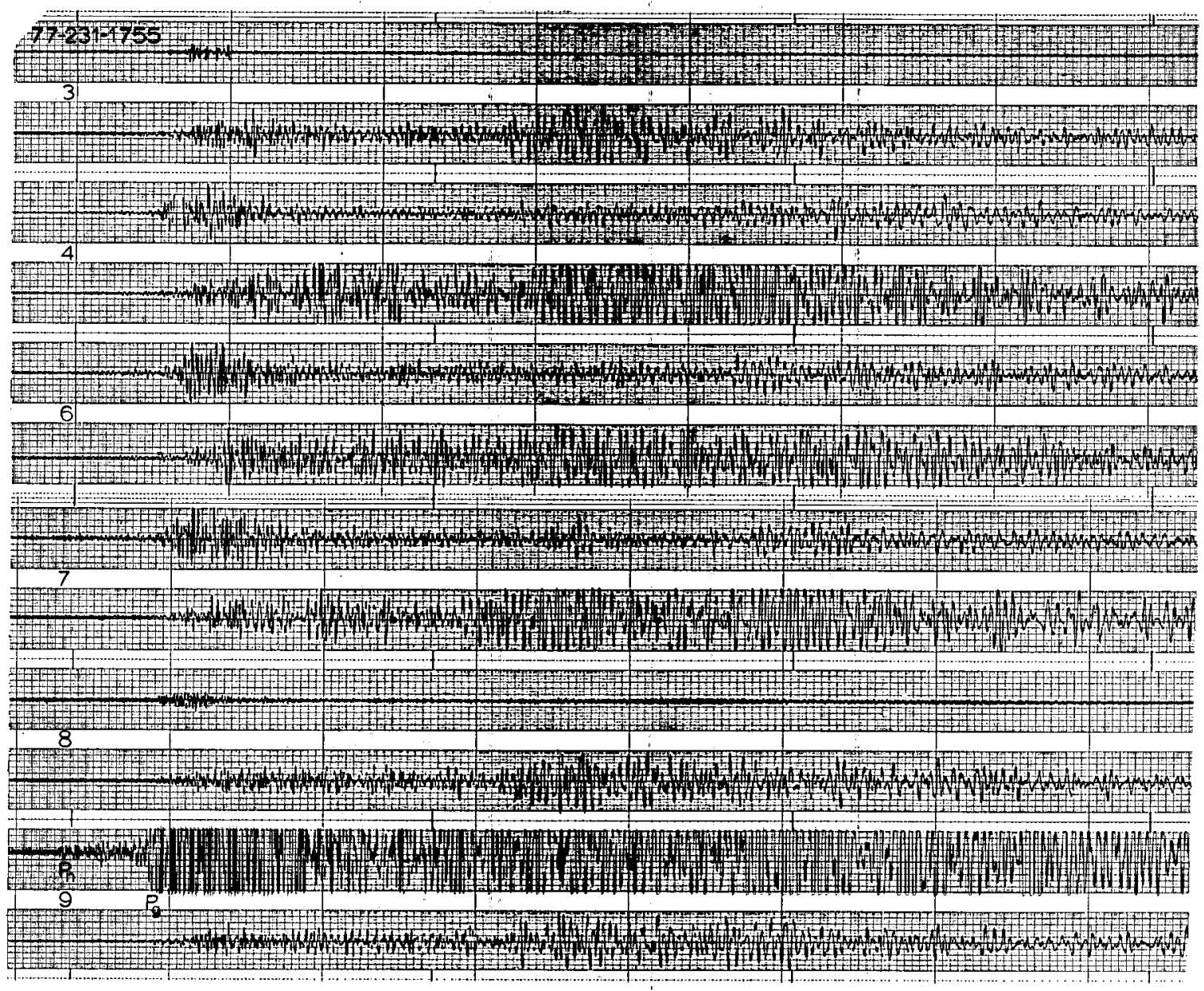

XBL $784-8060$

Figure 2.9. Seismogram of a nuclear explosion at nuclear test site; $\mathrm{M}_{\mathrm{L}}=5.5$. 
RECOMMENDATIONS AND CONCLUSIONS

The primary result obtained to date in the East Mesa seismic study has been the complete lack of detectable local microearthquakes to an estimated detection threshold of at least $\mathrm{M}_{\mathrm{L}}=1.0$. The detection of smaller shocks has been hampered by the high level of low-frequency surface noise in the field.

Regional seismic activity, events of magnitude 2.0 or less, is wel1-recorded at East Mesa and is distinguished from local events by S-P constraints (and less accurately by relative $P$-wave arrivals). The quality of the data makes possible the accurate location of larger $(M \geq 2.0)$ events, although local station corrections are not determined. Several phases, in addition to the initial $\mathrm{P}$ - and $\mathrm{S}$-wave arrivals, are routinely observed. Most of the events are associated with the active Brawley/Imperial fault system to the west and southwest. The closest events recorded, based on S-P time intervals, are located along this fault zone about $20 \mathrm{~km}$ west of the array. Other events have been recorded at distances exceeding $500 \mathrm{~km}$ (NTS for example) and at a11 azimuths in the two western quadrants. (A set of sources at varying distances and azimuths may provide data on subsurface properties within the network in the absence of local events.)

Other local disturbances not of earthquake origin have been detected and identified, including meteorological disturbances, drilling activity, and weapons testing. Although these may have been previously identified as local seismic events, they are distinguished by their waveform, frequency content, and most importantly, by their slow (subseismic) apparent velocities.

The major Brawley swarms of October-November 1977 were well recorded at East Mesa. Again, no local microearthquakes were recorded during this period--a result contrary to the findings of a previous investigation in which local seismicity was reported to have peaked during swarm activity. Our results lead to the conclusion that there is no evidence that the local stress regime is associated with the Brawley-Imperial fault system.

The origin of small events remains unresolved, but they are believed to represent the smallest members of the Brawley fault swarm activity 
observable at East Mesa. Installation of a $4.5-\mathrm{Hz}$ three-component geophone into a 300-ft borehole may help determine the source of these events and result in detection of small "geothermal events" not presently observable because of the high level of surface noise in the seismic bandwidth. We estimate that improvement of at least one order of magnitude in the threshold of detectability is required for serious study of the field seismicity.

\section{REFERENCES CITED}

Brune, J. N., and Allen C. R., 1967. A microearthquake survey of the San Andreas fault system in southern California. Bull. Seism. Soc. Am., v. 57, p. 277.

Combs, J., 1974. Microearthquake investigation of the Mesa geothermal anomaly, Imperial Valley, California. Final Report, U. S. Dept. Interior, Bureau of Reclamation. , 1976. Microearthquake studies before and during fluid withdrawal and reinjection test, East Mesa geothermal field, Imperial Valley, California. Final Report, U. S. Dept. Interior, Bureau of Reclamation. Combs, J., and Hadley, David, 1977. Microearthquake investigation of the Mesa geothermal anomaly, Imperial Valley, California. Geophysics, v. 42, p. 17 .

Elders, W. A., Rex, R. W., Meidav, T., Robinson, P. T., and Biehler, S., 1972. Crustal spreading in southern California. Science, v. 178, no. 4056, p. 15 .

Hi11, D. P., Mawincke1, P., and Peake, L. G., 1975. Earthquakes, active faults, and geothermal areas in the Imperial Valley, California. Science, v. 188 , p. 1306 .

Johnson, C. E., and Hadley, D. M., 1976. Tectonic implications of the Brawley earthquake swarm, Imperial Valley, California, January 1975. Bul1. Seism. Soc. Am., v. 66, p. 1133.

McEvilly, T. V., and Schechter, B., 1977a. East Mesa seismic study, report no. 1. Berkeley, Lawrence Berkeley Laboratory, UCID-3908. , 1977b. East Mesa seismic study, report no. 2. Berkeley, Lawrence Berkeley Laboratory, UCID-4029. , 1978. East Mesa seismic study, report no. 3. Berkeley, Lawrence Berkeley Laboratory, UCID-4030.

Richter, C. F., 1958. Elementary seismology. San Francisco, W. H. Freeman and Co. 


\section{SECTION 3: WELL TESTS}

\section{G. McEdwards, J. P. Haney, S. M. Benson, and R. C. Schroeder \\ Lawrence Berkeley Laboratory}

\section{INTRODUCTION}

Since 1976, LBL has conducted numerous well tests at the East Mesa KGRA. These include production, injection, and interference tests using all the available wells in the northern, central, and southern portions of the reservoir. From analyses of interference tests data, it has been possible to: locate hydraulic barriers; infer reservoir recharge; prove continuity between the northern and southern ends of the field; and provide global estimates of reservoir parameters, transmissivity $(\mathrm{kh} / \mu)$, and storativity $(\phi \mathrm{ch})$. Analysis of production tests data has also provided information about the condition of individual wells and local estimates of transmissivity.

\section{WELL TESTS AT EAST MESA}

We11-testing activities before 1976 consisted of measuring stabilized wellhead and downhole pressures for various flow rates of wells 6-1, 6-2, 5-1 and 8-1 (Mathias, 1975; Earlogher, 1977) and conducting transient pressure tests of relatively short duration $(\sim 10$ hours) on wells $6-1$, 5-1, 8-1, and 31-1. In addition, we11 6-1 was flowed for several months under compressed-1iquid conditions in a desalting test, during which the wellhead pressure was monitored. Injection and production tests, both using a downhole pressure gauge, were run on wel1 5-1 in which the injectivity and productivity indices were measured as functions of time (Mathias, 1975; Earlogher, 1977). Productive indices for wells 6-1, 6-2, 5-1, and 8-1, having a single flow rate (unrestricted flow) were calculated from the available data and are presented in Table 3.1 . The we11 6-1 desalting test data and the 5-1 injectivity index data provide additional estimates of transmissivity for these two wells. These estimates are included in a summary of the pre-1976 transient pressure test results, shown in Table 3.2. The test results shown in Tables 3.1 and 3.2 are compared with the latest production test results later in this section.

From 13 February 1976 to 29 September 1977, several interference and production tests were conducted by LBL in the USBR, Republic 
Table 3.1. Productivity indices for full flow (after Mathias, 1975).

\begin{tabular}{|c|c|c|c|c|c|c|c|}
\hline \multirow[b]{2}{*}{ WELL } & \multirow[b]{2}{*}{$\mathrm{P}_{\text {Shut In }}$} & \multirow[b]{2}{*}{$\begin{array}{c}\mathrm{P}_{\text {Flowing }} \\
\text { (Downhole) } \\
\text { bars }\end{array}$} & \multirow[b]{2}{*}{$\begin{array}{c}\Delta \mathrm{P} \\
\text { bars }\end{array}$} & \multirow[b]{2}{*}{$\begin{array}{c}Q \\
\mathrm{~kg} / \mathrm{min}\end{array}$} & \multicolumn{3}{|c|}{$\Omega / \Delta P$} \\
\hline & & & & & $\frac{\mathrm{kg} / \mathrm{min}}{\mathrm{bar}}$ & $\frac{g p m}{p s i}$ & $\mathrm{~m}^{3} / \mathrm{sec} / \mathrm{Pa}$ \\
\hline $6-1$ & 219 & 159 & 60 & 1600 & 26.7 & 0.590 & $5.40 \times 10^{-9}$ \\
\hline $6-2$ & 169 & 1.34 & 35 & 1134 & 32.4 & 0.715 & $6.54 \times 10^{-9}$ \\
\hline $5-1$ & 169 & 156 & 13 & 800 & 61.5 & 1.35 & $1.23 \times 10^{-8}$ \\
\hline $8-1$ & 168 & 157 & 11 & 1394 & 126. & 2.79 & $2.55 \times 10^{-8}$ \\
\hline
\end{tabular}


Table 3.2. Transmissivity values from pre-1976 pressure transient tests (after Mathias, 1975).

\begin{tabular}{|c|c|c|c|c|}
\hline WELL & DATE & TEST TYPE & $\begin{array}{c}\text { DURATION } \\
\text { (hours) }\end{array}$ & $\begin{array}{c}\text { TRANSMISS IVITY }-\mathrm{kh} / \mu \\
\mathrm{md}-\mathrm{ft} / \mathrm{cp} \\
\left(\mathrm{m}^{3} / \mathrm{sec} / \mathrm{Pa}\right) \\
\end{array}$ \\
\hline $31-1$ & $7 / 21 / 75$ & $\begin{array}{l}\text { Drawdown } \\
\text { Recovery }\end{array}$ & $\begin{array}{l}5.5 \\
4.7\end{array}$ & $\begin{array}{c}123,000 \\
\left(3.70 \times 10^{-8}\right)\end{array}$ \\
\hline $31-1$ & $7 / 30 / 75$ & Recovery & 10.0 & $\begin{array}{c}166,000 \\
\left(5.00 \times 10^{-8}\right)\end{array}$ \\
\hline $5-1$ & $1 / 8 / 75$ & Drawdown & 10.0 & $\begin{array}{c}32,000 \\
\left(9.6 \times 10^{-9}\right)\end{array}$ \\
\hline $5-1$ & $2 / 28 / 75$ & Injection & 10.0 & $\begin{array}{c}37,000 \\
\left(1.1 \times 10^{-8}\right)\end{array}$ \\
\hline $8-1$ & $4 / 21 / 75$ & $\begin{array}{l}\text { Drawdown } \\
\text { Recovery }\end{array}$ & $\begin{array}{l}5.7 \\
5.0\end{array}$ & $\begin{array}{c}75,000 \\
\left(2.3 \times 10^{-8}\right)\end{array}$ \\
\hline $6-1$ & $12 / 28 / 72$ & $\begin{array}{l}\text { Recovery } \\
\text { (before } \\
\text { perforation) }\end{array}$ & 16 days & $\left(4.8 \times 10^{-10}\right)$ \\
\hline $6-1$ & $1 / 24 / 73$ & $\begin{array}{l}\text { Recovery } \\
\text { (before } \\
\text { perforation) }\end{array}$ & 2.5 & $\begin{array}{l}1,600 \\
\left(4.8 \times 10^{-10}\right)\end{array}$ \\
\hline $6-1$ & $9 / 17 / 74$ & $\begin{array}{l}\text { Desalting run } \\
\text { drawdown } \\
\text { (after } \\
\text { perforation) }\end{array}$ & 3 mos. & $\begin{array}{c}70,000 \\
\left(2.1 \times 10^{-8}\right)\end{array}$ \\
\hline
\end{tabular}


Geothermal, Inc., and Magma Power Co. portions of the East Mesa field (Narasimhan et al., 1977a, 1977b; Witherspoon et al., 1978). Contractual we 11 tests for USBR were begun on 1 December 1977 and completed on 4 May 1978. Table 3.3 presents the chronology of these well tests.

CONTRACTUAL WELL TESTS FOR USBR

According to our contractual obligations with USBR, we agreed to perform well tests in order to: (a) determine productivity indices for wells $6-1,6-2,8-1$, and $31-1$ at various flow rates; (b) perform a long-term interference test by flowing wel1 8-1 and recording pressure changes at appropriate observation wells; and (c) determine the injectivity index of wel1 5-1 at various injection rates and evaluate its current condition.

Production tests were carried out on wells 6-1, 6-2, and 8-1 and an injection test was performed on well 5-1. Because no satisfactory method was found for disposing of the produced fluid, well 31-1 was not available for testing. An interference test using we11 8-1 as the flowing well and we 11 s $48-7$ and $6-1$ as observation wells was also completed.

\section{USBR PRODUCTION TESTS}

Flow Rate Measurements

Production rates of wells $6-1,6-2$, and 8-1 were measured using an atmospheric flash tank and a weir box equipped with a v-notch weir plate and a clock-driven water-level recorder. The liquid flow was measured and the total flow was calculated by assuming a stream quality of $11 \%$ for unflashed brine. This value was measured previously using temperature and pressure data of unflashed brine. The uncertainty of the flow measurements is about $10 \%$. Rate changes were accomplished using existing wellhead gate values. For the well 5-1 injection test, two positive displacement pumps of 150 and $220 \mathrm{gpm}\left(9.5 \times 10^{-3}\right.$ and $1.4 \times 10^{-2} \mathrm{~m}^{3} / \mathrm{sec}$ ) capacity were used singly and in combination to attain various injection rates. 
Table 3.3. Surmary of all tests by LBL at East Mesa KGRA.

\begin{tabular}{|c|c|c|c|c|c|c|c|c|c|c|c|c|c|c|}
\hline $7_{\text {Date of }}$ Well & $38-30$ & $56-30$ & $31-1$ & $16-29$ & $78-30$ & $18-28$ & $16-30$ & $6-1$ & 6-2 & $5-1$ & $8-1$ & $44-7$ & $46-7$ & $48-7$ \\
\hline $\begin{array}{l}2 / 13 / 76 \text { to } 2 / 24 / 76 \\
4 / 1 / 76 \text { to } 4 / 16 / 76 \\
1 / 28 / 77 \text { to } 2 / 20 / 77 \\
2 / 20 / 77 \text { to } 4 / 13 / 77 \\
7 / 14 / 77 \text { to } 7 / 28 / 77 \\
7 / 26 / 77 \text { to } 8 / 30 / 77 \\
8 / 26 / 77 \text { to } 10 / 05 / 77 \\
9 / 29 / 77 \\
12 / 1 / 77 \text { to } 12 / 6 / 77 \\
12 / 15 / 77 \text { to } 12 / 20 / 77 \\
1 / 6 / 77 \text { to } 1 / 27 / 77 \\
1 / 27 / 78 \text { to } 3 / 9 / 78 \\
4 / 17 / 78 \text { to } 4 / 21 / 78 \\
5 / 1 / 78 \text { to } 5 / 4 / 78\end{array}$ & $\begin{array}{l}\text { OBS } \\
\text { OBs } \\
\text { wro }\end{array}$ & $\begin{array}{l}\text { OBS } \\
\text { OBS } \\
\text { OBS }\end{array}$ & $\begin{array}{l}\text { WF } \\
\text { OBS } \\
\text { OBS } \\
\text { OBS } \\
\text { OBS } \\
\text { OBS }\end{array}$ & $\begin{array}{l}\text { OBS } \\
\text { WFO }\end{array}$ & OBS & $\begin{array}{l}\text { INJo } \\
\text { INJo } \\
\text { Inso }\end{array}$ & $\begin{array}{l}\text { OBS } \\
\text { OBS }\end{array}$ & $\begin{array}{c}\text { OBS } \\
\text { OBS } \\
\text { OBS } \\
\text { WF }\end{array}$ & $\begin{array}{l}\text { OBS } \\
\text { WFO } \\
\text { WF }\end{array}$ & InJo & $\begin{array}{l}\text { WFO } \\
\mathrm{WP} \\
\mathrm{WF}^{1}\end{array}$ & $\begin{array}{l}\text { OBS } \\
\text { OBS }\end{array}$ & OBS & $\begin{array}{l}\text { OBS } \\
\text { OBS }\end{array}$ \\
\hline
\end{tabular}

1) we11 8-1 was shut in $2 / 9 / 78$

SNMBOLS: WF - well flowing

Fo - well forng, pressure recorded (production test)

INJO - water infected, pressure recorded (infection test) INJ = water infected 


\section{Pressure Measurements}

Changes in downhole pressure were measured by using a sma11-diameter stee 1 capillary tube (0.054-in. I.D., 0.094-in. 0.D.) filled with silicon oil or nitrogen gas. The tube was placed in the well at an appropriate depth and a sensitive pressure transducer, accurate to 0.01 psi, was attached to it at the well head. The fluid in the tube reacted to changes in downhole pressure, which was sensed by the transducer. The transducer signal was then fed to a digital readout device and a paper printer. Pressures were continuously monitored. Readings could be taken at intervals of from one second to one hour.

\section{Production Test Design}

All production tests consisted of a series of step changes in the flow rate. Consideration of transient temperature effects on the downhole pressure-monitoring system strongly influenced production test design and data analysis. A11 production test wells were first flowed at a rate that would provide close to a steady-state temperature profile in the well. Subsequent small rate changes and pressure readings resulted in transient pressure data relatively free of temperature effects and therefore amenable to analysis. A flow-rate change was initiated when the downhole pressure had not changed appreciably with time. The average duration of the flow periods is about 18 hours, and the average rate change is about $60 \mathrm{gpm}$.

\section{Production Test Analysis Techniques}

Transient pressure data of selected test segments were analyzed for $k h / \mu$ and $\phi c_{c h r}^{2}$ using conventional isothermal oil-field techniques (Matthews and Russe11, 1967; Earlougher, 1977; and Lippmann et al., 1978). The quantity $\phi \mathrm{chr}_{\mathrm{e}}^{2}$ is the storativity ( $\phi \mathrm{ch}$ ) multiplied by the the square of the effective well radius $\left(r_{e}\right)$. The effective well radius is related to the skin-effect value by $r_{e}=r_{w} e^{-s}$ where $r_{w}$ is the nominal well radius, and $s$ is the skin effect value. Because production-test analyses directly yield the lumped parameter $\phi \mathrm{chr}_{\mathrm{e}}^{2}$, it is necessary to know $\phi \mathrm{chr}_{\mathrm{w}}^{2}$ to estimate skin values. Unfortunately, $\phi \mathrm{chr}_{\mathrm{w}}^{2}$ for each well is not known with sufficient accuracy to permit 
calculation and comparison of skin-effect values. However, productivity indices corresponding to equal periods of production can be calculated from the $\mathrm{kh} / \mu$ and $\phi \mathrm{chr}_{e}^{2}$ estimates and used for comparison of damage and reservoir permeability among wells.

Productivity indices corresponding to 18 hours of flow were calculated analytically rather than using measured stabilized pressures and flow rates. The latter calculation is redundant and provides less information than the former when transient-pressure data are available. Furthermore, for the instrument system used in these tests, stabilized pressure values do not reflect downhole conditions at late times. Although they are small, pressure changes at the top of the capillary tube (caused by transient temperature effects along its length) partially obscure the reservoir response. These temperature effects, however, do not appreciably affect the transient-pressure data.

Productivity index values increase with increasing permeability and/or the quality of well completion. The productivity index value therefore combines the influence of the skin effect and reservoir permeability.

\section{Production Test Results}

The final $\mathrm{kh} / \mu, \phi \mathrm{chr}_{\mathrm{e}}^{2}$, and productivity index values found for each well are given in Table 3.4. These results are average values obtained from several test segments of each well test. The accuracy of $\mathrm{kh} / \mu$ is governed by the accuracy of the flow-rate measurements and the quality of the pressure data. In general, the accuracy of the pressure data and its interpretation far exceeds that of the flow-rate measurements. Therefore, $\mathrm{kh} / \mathrm{h}$ values are believed to be correct to within the accuracy of the flow-rate values, which is on the order of $10 \%$. Because values of $\phi \mathrm{chr}_{\mathrm{e}}^{2}$ are predicated on $\mathrm{kh} / \mathrm{\mu}$ values, their accuracy is also within $10 \%$. Figure 3.1 shows, schematically for the USBR wells, the casing size, completion intervals (slotted and perforated), percentage net sand, and seismic marker horizons $O$ and $Y$ (see Figures 1.8 and 1.9 in the Geology section above). Also shown are permeability values in millidarcies for the net sand percentage of the completion interval and the average permeability value of the full 
Table 3.4. Summary of production test results.

\begin{tabular}{|c|c|c|c|}
\hline WELL & $\begin{array}{c}\mathrm{kh} / \mu \\
\mathrm{md}-\mathrm{ft} / \mathrm{cp} \\
\left(\mathrm{m}^{3} / \mathrm{sec} / \mathrm{Pa}\right)\end{array}$ & $\begin{array}{l}\phi \operatorname{chr}_{\mathrm{e}}^{2} \\
\mathrm{ft} t^{3} / \mathrm{psi} \\
\left(\mathrm{m}^{3} / \mathrm{Pa}\right)\end{array}$ & $\begin{array}{c}\text { P.I. } \\
\text { (@ } 18 \mathrm{hrs}) \\
\mathrm{gpm} / \mathrm{psi} \\
\left(\mathrm{m}^{3} / \mathrm{sec} / \mathrm{Pa}\right)\end{array}$ \\
\hline $5-1$ & $\begin{array}{c}43,000 \\
\left(1.3 \times 10^{-8}\right)\end{array}$ & $\begin{array}{c}7.14 \times 10^{-8} \\
\left(2.93 \times 10^{-13}\right)\end{array}$ & $\begin{array}{c}.79(\mathrm{I} . \mathrm{I} .) \\
\left(7.23 \times 10^{-9}\right)\end{array}$ \\
\hline $8-1$ & $\begin{array}{c}60,000 \\
\left(1.8 \times 10^{-8}\right)\end{array}$ & $\left(1.15 \times 10^{-7}\right)$ & $\begin{array}{c}2.47 \\
\left(2.26 \times 10^{-8}\right)\end{array}$ \\
\hline $6-2$ & $\begin{array}{c}73,000 \\
\left(2.2 \times 10^{-8}\right)\end{array}$ & $\left(4.31 \times 10^{-7}\right)$ & $\begin{array}{c}3.39 \\
\left(3.10 \times 10^{-8}\right)\end{array}$ \\
\hline $6-1$ & $\begin{array}{c}14,000 \\
\left(4.2 \times 10^{-9}\right)\end{array}$ & $\left(4.15 \times 10^{-7}\right)$ & $\left(7.59 \times 10^{-9}\right)$ \\
\hline
\end{tabular}

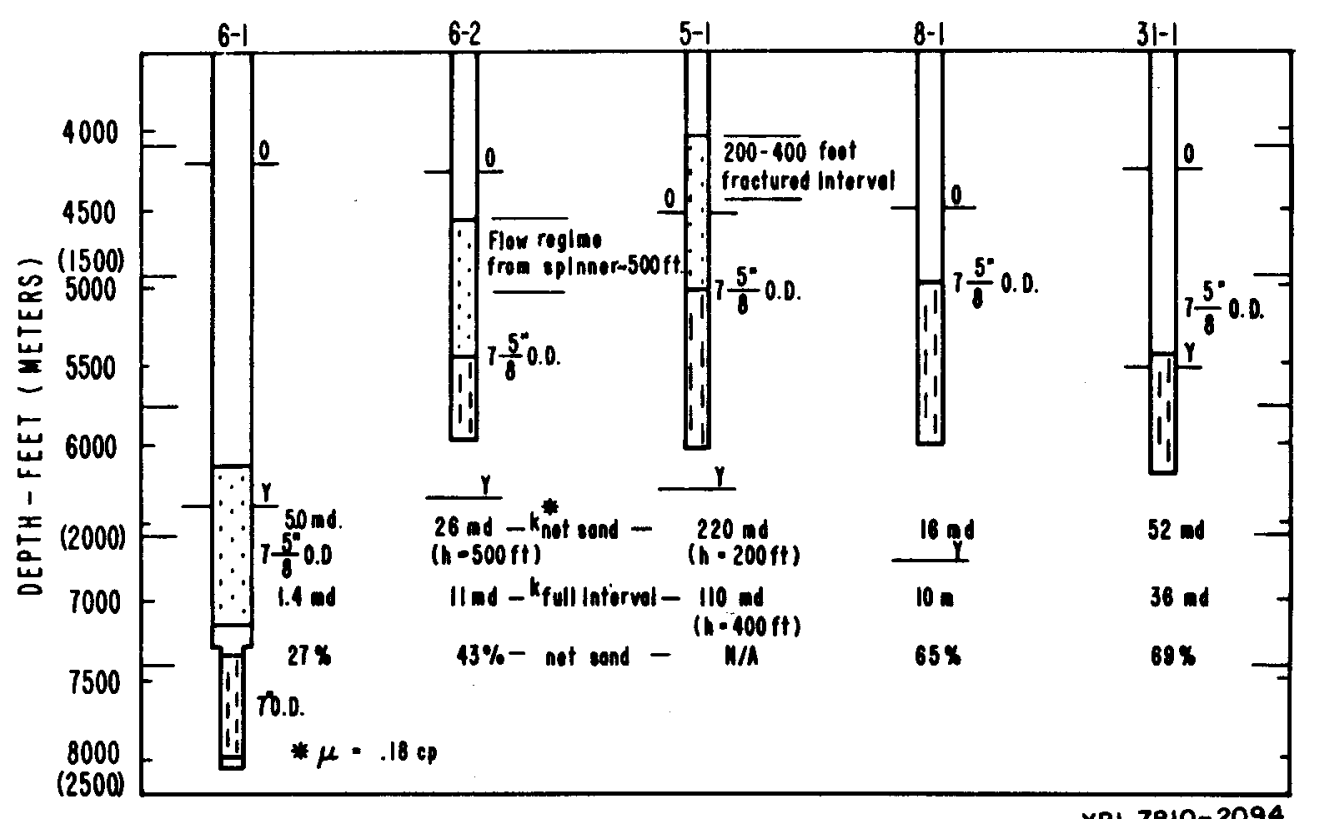

Figure 3.1. Schematic of completion intervals, casing sizes, net sand and full interval permeabilities and seismic marker horizons $O$ and $Y$ for the USBR wells. 
completion interval. Appendix A contains detailed information about each production test.

\section{Discussion of Production Test Results}

The pressure data records for wells $8-1$ and 6-1 are typical of a single production-zone reservoir, and the results from each segment of each well test are generally consistent. However, well-test data for we11s 5-1 and 6-2 display atypical behavior.

The injection test data from well 5-1 show evidence of a vertical fracture. Three independent lines of evidence support this conclusion:

1. A spinner survey shows all flow exiting the well in a 400-ft $(122-m)$ section at the top of the perforated interval. (See Appendix A, Figure A.5.)

2. The wel1 5-1 injection $\log$ for 26 December 1976 (U. S. Bureau of Reclamation, 1977) shows a rapid decrease in wellhead pressure from 1200 to $400 \mathrm{psi}\left(8.3 \times 10^{7}\right.$ to $\left.2.8 \times 10^{7} \mathrm{~Pa}\right)$ concurrent with a constant injection rate of $100 \mathrm{gpm}(6.3$ $\left.x 10^{-3} \mathrm{~m}^{3} / \mathrm{sec}\right)$. Well head pressure of $1200 \mathrm{psi}$ is enough to cause a vertical fracture at the depth of the perforations.

3. The increase of the measured injectivity index with an increased rate of injection suggests a dilation process in the well that is indicative of a fracture. The value of 43,000 md$\mathrm{ft} / \mathrm{cp}\left(1.3 \times 10^{-8} \mathrm{~m}^{3} / \mathrm{sec} / \mathrm{Pa}\right)$ is representative of a fractured interval, and the value of $7.14 \times 10^{-8} \mathrm{ft}^{3} / \mathrm{psi}\left(2.93 \times 10^{-}\right.$ $13 \mathrm{~m}^{3} / \mathrm{Pa}$ ) is associated with a large positive skin effect probably caused by plugging the fracture surface during injection. The low value of the injectivity index is associated with scaling or plugging at the fracture surface.

Pressure data for well 6-2 suggest that two distinct production zones of widely different $\mathrm{kh} / \mathrm{\mu}$ are present. The more permeable zone exists in the upper $500 \mathrm{ft}$ of perforation (see Appendix A, Figure A.13, a spinner survey of 6-2), and the lesser permeable zone is located deeper in the we11. We11-log permeability data are consistent with the 
existence of two production zones in we11 6-2 and their relative locations as stated above. The value of $73,000 \mathrm{md}-\mathrm{ft} / \mathrm{cp}\left(2.2 \times 10^{-8} \mathrm{~m} / \mathrm{sec} / \mathrm{Pa}\right)$ given for we11 6-2 is characteristic of both production zones acting together. Because the productivity index is calculated from the analysis of early-time pressure behavior, it is valid only for those times when both zones act together. However, as the semilog plots in Appendix A indicate, the influence of the less permeable zone becomes dominant at later times when the two zones do not act together as a single reservoir. Thus the pressure changes are greater than those that would be extrapolated solely from early-time pressure behavior. For this reason a productivity index value of $3.8 \mathrm{gpm} / \mathrm{psi}\left(3.5 \times 10^{-8} \mathrm{~m}^{3} / \mathrm{sec} / \mathrm{Pa}\right)$ represents an optimistic upper bound value that is applicable only to early-time behavior.

It is clear from Figure 3.1 and the results of the production tests for wells $6-1$ and 6-2 that the seismic marker beds 0 and $Y$ do not correspond to the vertical boundaries of different aquifers. Well 6-1 showed no evidence of two-production-zone behavior, yet the $Y$ horizon is located in the well's perforated interval. Conversely, well 6-2 does show two-zone behavior, and its interval lies completely between the $O$ and $Y$ horizons. From a comparison of the latest test results (Table 3.4 ) with the pre-1976 test results (Table 3.1 and 3.2 ), we draw the following conclusions.

1. Wel1 8-1 has not changed its character significantly since 1975. Both its transmissivity and productivity index values agree closely between the tests.

2. Wel1 6-1 has been damaged. The transmissivity has decreased five-fold from $70,000 \mathrm{md}-\mathrm{ft} / \mathrm{cp}\left(2.1 \times 10^{-8} \mathrm{~m}^{3} / \mathrm{sec} / \mathrm{Pa}\right)$ measured from the desalting test (after perforation) to $14,000 \mathrm{md}-\mathrm{ft} / \mathrm{cp}$ $\left(4.2 \times 10^{-9} \mathrm{~m}^{3} / \mathrm{sec} / \mathrm{Pa}\right)$ given by the LBL well test. This decrease may be due to plugging or scaling caused by chemical incompatibility of produced fluids. 
3. We11 5-1 has an increased transmissivity value due to the presence of a vertical fracture. The injectivity index has decreased, however, due to plugging of the well by some chemical precipitate mechanism. This plugging mechanism was probably a contributing cause of the initial fracturing of the well.

\section{EAST MESA INTERFERENCE TESTS}

Since early 1976, LBL has completed numerous interference tests at the East Mesa KGRA (Table 3.3). Pressure data were obtained in most instances using Paros scientific wellhead pressure transducers, accurate to $0.01 \mathrm{psi}$, which recorded pressures at intervals of from 4 to 20 minutes on a continuously operating paper printer. Test design ideally included: a stabilized shut-in pressure at all observation wells; a production-well flow rate large enough to create significant drawdowns at all observation wells; and a test of sufficient duration to indicate reservoir inhomogeneities at each of the observation wells. Analysis of the well-test data employed a least-squares pressure-matching computer program developed at LBL (McEdwards and Tsang, 1977) by which data showing the effects of more than one production we11, each of a variable flow rate, may be analyzed. The program computes an analytical solution to the well-test data using properly adjusted values of $\mathrm{kh} / \mu$, $\phi \mathrm{ch}$, and image-we 11 distances, where the distance between an image well and an observation well (image-well distance) may be used to locate either barrier or recharge boundaries. In the program, the production wells are modeled as line sources and the reservoir is considered to be isotropic, laterally infinite, and of constant thickness.

A summary of the chronology, details, and results of all interference tests conducted by LBL at the East Mesa KGRA is presented in Table 3.5. More detailed information concerning these tests is given in Appendix $B$.

Two production tests and one injection test were conducted in conjunction with the interference test at the northern end of the field. Table 3.6 lists the details of these tests. More detailed information is given in Appendix $C$. 
Table 3.5. Interference test and results at East Mesa.

\begin{tabular}{|c|c|c|c|c|c|c|c|}
\hline $\begin{array}{c}\text { Producing } \\
\text { Hell }\end{array}$ & Date & Flow Rate(s) & $\begin{array}{c}\text { Observation } \\
\text { Well }\end{array}$ & 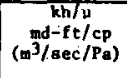 & $\begin{array}{l}\mathrm{pCH} \\
\mathrm{ft} / \mathrm{par} \\
(\mathrm{m} / \mathrm{Pa})\end{array}$ & $\begin{array}{l}\text { Image } \\
\text { We11 }\end{array}$ & Comments \\
\hline $\begin{array}{c}\text { Test } 1 \\
5-2\end{array}$ & $2 / 13 / 76$ to $2 / 24 / 76$ & $90 \mathrm{gpm}$ & 6-1 & $\begin{array}{r}62,000 \\
\left(1.9 \times 10^{-8}\right) \\
\end{array}$ & $\begin{array}{r}5.7 \times 10^{-3} \\
\left(2.5 \times 10^{-7}\right) \\
\end{array}$ & leaky & $\begin{array}{l}\text { Vertical offset between producting } \\
\text { verll and observation well makes } \\
\text { analysis uncertain }\end{array}$ \\
\hline $\operatorname{Test}_{31-1} 2$ & $4 / 1 / 76$ to $4 / 12 / 76$ & $130 \mathrm{gpw}$ & $38-30$ & $\begin{array}{c}136,000 \\
\left(4.09 \times 10^{-8}\right)\end{array}$ & $\begin{array}{c}2.1 \times 10^{-3} \\
\left(9.3 \times 10^{-8}\right)\end{array}$ & barrier & \\
\hline$\underset{6-2}{\text { Test } 3}$ & $2 / 10 / 77$ to $2 / 20 / 77$ & $60 \mathrm{gpm}$ & $\begin{array}{l}6-1 \\
8-1\end{array}$ & $\begin{array}{c}111,000 \\
\left(3.34 \times 10^{-8}\right)\end{array}$ & $\begin{array}{c}6 \times 10^{-3} \\
\left(2.6 \times 10^{-7}\right)\end{array}$ & & $\begin{array}{l}\text { Uncertain initial pressure when } \\
\text { production coomenced } \\
\text { so observable drawdown indicative } \\
\text { of hydraulic barrier }\end{array}$ \\
\hline $\begin{array}{l}\text { Test } 4 \\
n-1,6-2\end{array}$ & $2 / 20 / 77$ to $4 / 13 / 77$ & $\begin{array}{l}\text { Comb1ned Rate } \\
\text { u110 gpm }\end{array}$ & $\begin{array}{l}31-1 \\
38-30 \\
44-7\end{array}$ & $\begin{array}{c}147,000 \\
\left(4.41 \times 10^{-8}\right)\end{array}$ & $\begin{array}{c}2 \times 10^{-3} \\
\left(8.8 \times 10^{-8}\right)\end{array}$ & $\begin{array}{l}10,000 \mathrm{ft} \\
(3,000 \mathrm{~m}) \\
\text { leaky }\end{array}$ & $\begin{array}{l}\text { Total draudoum .2 psi } \\
\text { No observable drawdown } \\
\text { Uncer: aln Initial pressure when } \\
\text { produrtion commenced }\end{array}$ \\
\hline $\begin{array}{l}\text { Test } 5 \\
38-30\end{array}$ & $7 / 14 / 77$ to $7 / 18 / 77$ & $\begin{array}{l}\text { Var1able (step) } \\
500 \mathrm{gpm}, 750 \mathrm{gpm} \\
900 \mathrm{gpm}, 750 \mathrm{gpmw} \\
500 \mathrm{gPm}, 250 \mathrm{gpm}\end{array}$ & $\begin{array}{l}56-30 \\
31-1 \\
16-29\end{array}$ & $\begin{array}{c}146,000 \\
\left(4.40 \times 10^{-8}\right) \\
194,000 \\
\left(5.85 \times 10^{-8}\right) \\
117,000 \\
\left(3.52 \times 10^{-8}\right) \\
\end{array}$ & $\begin{array}{c}6 \times 10^{-4} \\
\left(2.6 \times 10^{-8}\right) \\
2 \times 10^{-3} \\
\left(0.8 \times 10^{-8}\right) \\
4 \times 10^{-3} \\
\left(1.8 \times 10^{-7}\right) \\
\end{array}$ & $\begin{array}{l}4,630 \mathrm{ft} \\
(1,410 \mathrm{~m}) \\
\text { barr1er } \\
2,600 \mathrm{ft} \\
\text { barr1er }\end{array}$ & \\
\hline $\begin{array}{l}\text { Test } 6 \\
16-29\end{array}$ & $7 / 26 / 77$ to $7 / 30 / 77$ & $\begin{array}{l}\text { H1ghly variable } \\
200-700 \mathrm{gpm}\end{array}$ & $\begin{array}{l}56-30 \\
31-1 \\
16-30 \\
\end{array}$ & & & & 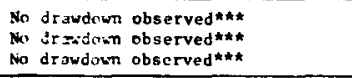 \\
\hline $\begin{array}{l}\text { Te 4t } 7 \\
38-30\end{array}$ & $8 / 26 / 77$ to $10 / 5 / 77$ & \%400 gpm & \begin{tabular}{l|}
$56-30$ \\
$31-1$ \\
$16-30$ \\
$78-30$ \\
\end{tabular} & $\begin{array}{l}131,000 \\
\left(3.94 \times 10^{-8}\right) \\
176,000 \\
\left(5.30 \times 10^{-8}\right)\end{array}$ & $\begin{array}{l}6.4 \times 10^{-4} \\
\left(2.8 \times 10^{-8}\right) \\
\left.2.4 \times 10^{-3}\right) \\
\left(1.1 \times 10^{-7}\right)\end{array}$ & 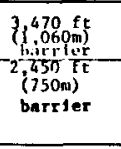 & $\begin{array}{l}\text { No observable drawdown } \\
\text { Non-ty;iteal beliavior, part ial } \\
\text { sarri-r infered }\end{array}$ \\
\hline $\begin{array}{l}\text { Test } 8 \\
44-7\end{array}$ & $9 / 29 / 77$ & & $\begin{array}{l}48-7 \\
46-7\end{array}$ & uncertain & $\therefore$ & & $\begin{array}{l}\text { Smui: arawdown observed } \\
\text { No eif act seen, shallow injection } \\
\text { well (not conclustue) }\end{array}$ \\
\hline $\begin{array}{l}\text { Test 9 } \\
3-1,6-2\end{array}$ & $1 / 6 / 7$ to $1 / 27 / 78$ & $\begin{array}{l}\text { Variable Rate } \\
8-1 \curvearrowright 200 \mathrm{gpm} \\
6-7 \approx 50 \mathrm{gpm}\end{array}$ & $\begin{array}{r}48-7 \\
6-1 \\
\end{array}$ & & & & $\begin{array}{l}\text { No observable draudoum } \\
\text { No obsarvable drawdown }\end{array}$ \\
\hline $\begin{array}{c}\text { Test } 10 \\
3-1,6-2 \\
44-7\end{array}$ & $1 / 27 / 78$ to $3 / 9 / 78$ & $\begin{array}{l}\text { High1y Var lable } \\
8-1 \sim 200 \mathrm{gpm} \\
6-2 \approx 50 \mathrm{gpm} \\
44-7,0-750 \mathrm{gpm}\end{array}$ & $\begin{array}{l}6-1^{\star} \\
48-7 * \star\end{array}$ & $\begin{array}{c}140, n n 0 \\
\left(4,2 \times 10^{-8}\right) \\
250,000 \\
\left(7.5 \times 10^{-8}\right)\end{array}$ & $\begin{array}{c}2 \times 10^{-3} \\
\left(8.8 \times 10^{-8}\right) \\
3 \times 10^{-3} \\
\left(1.3 \times 10^{-7}\right)\end{array}$ & & \\
\hline
\end{tabular}

- So colmunication between we11. 44-7 or 8-1 and 6-1

** Ef fect of 6-2 production and 46-7 injection not certaln. Concurrent production of well $46-7$ obocures the effect, if any, of 8-1 production on the dravdown In Hell 48-7.

k* Interpretation remaing anbiguous due to an unknown quantity of cold water inf1ux into HeIl 16-29 during production.

Table 3.6. Production tests in the northern portion of East Mesa KGRA done by LBL.

\begin{tabular}{|c|c|c|c|c|}
\hline We11 & Description of Test & Instrumentation & $\begin{array}{c}\mathrm{kh} / \mu \\
\mathrm{md}-\mathrm{ft} / \mathrm{cp} \\
\left(\mathrm{m}^{3} / \mathrm{sec} / \mathrm{Pa}\right) \\
\end{array}$ & Comments \\
\hline $38-30$ & $\begin{array}{l}\text { Four days } \\
\text { Vartable rate } \\
\text { Artestan f10w } \\
500 \mathrm{gpm}, 750 \mathrm{gpm}, 900 \mathrm{gpm} \\
750 \mathrm{gpm}, 500 \mathrm{gpw}, 250 \mathrm{gpm}\end{array}$ & $\begin{array}{l}\text { Tubing to } 6100 \mathrm{ft} \text {, } \\
\text { (N1trogen gas filied) } \\
\text { Sperry. Sun pressure } \\
\text { monitor }\end{array}$ & $\begin{array}{c}133,000 \\
\left(4.01 \times 10^{-8}\right)\end{array}$ & P.I, is $5 \mathrm{gpm} / \mathrm{ps} 1$ \\
\hline $16-29$ & $\begin{array}{l}\text { Four days } \\
\text { Variable rate } \\
\text { Artes1an flow } \\
200-700 \mathrm{gpm}\end{array}$ & $\begin{array}{l}\text { Tubing to } 6100 \mathrm{ft} \text {, } \\
\text { (Nitrogen filled) } \\
\text { Sperry Sun pressure } \\
\text { monitor }\end{array}$ & $\begin{array}{c}178,000 \\
\left(5.35 \times 10^{-8}\right)\end{array}$ & $\begin{array}{l}\text { Only build-up data avallable } \\
\text { Cold water influx into well } \\
\text { from top } 150 \text { meters. }\end{array}$ \\
\hline $18-28$ & $\begin{array}{l}\text { Injection Test } \\
7 / 1 / 77 \text { to } 9 / 22 / 77 \\
\text { Varlable rate }\end{array}$ & $\begin{array}{l}\text { Hewlett Packard } \\
\text { Downhole pressure } \\
\text { monitor }\end{array}$ & $\begin{array}{c}76,000 \\
\left(2.3 \times 10^{-8}\right)\end{array}$ & $\begin{array}{l}\text { Well head temperatures range } \\
\text { from } 150^{\circ} \text { to } 200^{\circ} \mathrm{F} \text {. }\end{array}$ \\
\hline
\end{tabular}




\section{Discussion of Interference Test Results}

Interference tests conducted in the northern and central portions of the field yielded transmissivity estimates ranging from 105,000 to $175,000 \mathrm{md}-\mathrm{ft} / \mathrm{cp}\left(3.2 \times 10^{-8}\right.$ to $\left.5.3 \times 10^{-8} \mathrm{~m}^{3} / \mathrm{sec} / \mathrm{Pa}\right)$ and storativity estimates ranging from $2 \times 10^{-3}$ to $6.4 \times 10^{-3} \mathrm{ft} / \mathrm{psi}\left(8.8 \times 10^{-8}\right.$ to $2.8 \times 10^{-7} \mathrm{~m} / \mathrm{Pa}$ ).

Transmissivity estimates obtained for the northern portion of the field are consistently larger than those obtained for the central portion. This reduction of transmissivity may be associated with higher grades of metamorphism in the hotter central portion of the field.

\section{Hydrologic Boundaries and Continuity Between Wells}

The presence of several hydrologic boundaries have been inferred from the numerous interference tests conducted. A barrier (no-flow) boundary with a northeasterly trend is believed to exist between we 11 16-30 and the remainder of the field. Another barrier, possibly discontinuous, is inferred to exist between wel1s 56-30 and 16-29. A partial barrier positioned between wells $38-30$ and $78-30$ is also thought to exist.

Hydrologic continuity between the USBR wells $6-1,6-2$, and $31-1$ was established when we 11 s $6-1$ and $6-2$ were produced and $31-1$ was observed. Interpretation of the test results suggest the existence of a recharge boundary in the area. Due to the small drawdown, low flow rate, and large distance between the observation and the production wells, this interpretation must be reviewed cautiously. Well 8-1 was also monitored. The absence of pressure response at 8-1 while 6-2 was producing, and its lack of response during a previous test (Narasimhan et al., 1977a), indicates a lack of hydrologic continuity between wells 8-1 and 6-2.

In the southern portion of the field, hydrologic continuity between wells 8-1 and 48-7 remains uncertain. If communication does exist, it is of a limited nature. Well 8-1 and both wells 44-7 and 8-1 were producing while well 48-7 was monitored for pressure changes. Interpretation of the test data yields transmissivity estimates that are anomalously large. However, the interpretation of pressure changes in 
we 11 48-7 are complicated by the unknown effects of concurrent fluid injection into we $1146-7$, a shallow (3000-ft, 900-m) well located $1 / 4$ mile away from well 48-7, and by the unknown fluid conductive properties of a geophysically inferred fault that intersects wel1 44-7 (see Figure 1.21).

We11 6-1, which was also monitored, showed a total drawdown of $2.5 \mathrm{psi}$ for the duration of the test. In addition to this anomalously low drawdown, we11 6-1 did not show any build-up after wells 8-1 and 44-7 ceased production. The analysis of this result is complicated by the fact that wel1 6-2 was producing about $50 \mathrm{gpm}$ during the entire time. Although analysis is complicated by the different perforation intervals of we11s $6-1$ and 6-2, late-time pressure data can be approximated by assuming a transmissivity of $140,000 \mathrm{md}-\mathrm{ft} / \mathrm{cp}$ and a storativity of $2 \times 10^{-3} \mathrm{ft} / \mathrm{psi}$. Indications are that wells $8-1$ and 44-7 do not communicate with we 11 6-1.

\section{CONCLUS IONS}

The injection we11 (5-1) measurements indicate that the well is fractured and that the injection interval is a small portion of the open zone in the well (near the top of the perforations). The injectivity index, $\mathrm{Q} / \Delta \mathrm{P}$, is about $0.75 \mathrm{gpm} / \mathrm{psi}\left(\sim 6 \times 10^{-9} \mathrm{~m}^{3} / \mathrm{s} / \mathrm{Pa}\right)$. The reservoir parameters cannot be clearly defined due to the fracture and the apparent formation damage caused by solids plugging and precipitation. The latter material was deposited during early injection tests and resulted in the accidental hydraulic fracturing of the injection we 11 .

The productivity indices of the USBR production wells vary--as would be expected in different wells completed in different ways. Wel1 $8-1$ has the highest productivity index $(\sim 2.8 \mathrm{gpm} / \mathrm{psi})$ and well $6-1$ has the lowest index $(\sim 0.6 \mathrm{gpm} / \mathrm{psi})$. However, wel1 $6-1$ is currently damaged (scaled), probably due to mixing of fluids from different strata (see Section 5, below).

The most reliable values for the mean, effective material parameters-which determine both how readily fluids move and how much fluid is stored in the reservoir--have been obtained from interference tests. The results 
from these tests show that the transmissivity $(\mathrm{kh} / \mu)$ ranges from about 100,000 to $160,000 \mathrm{md}-\mathrm{ft} / \mathrm{cp}$ in the central and northern portions of the field (USBR) to possibly $250,000 \mathrm{md}-\mathrm{ft} / \mathrm{cp}$ in the southern portion (Magma). Since the viscosity ranges from 0.18 to 0.2 , the high and low values of the permeability thickness $(\mathrm{kh})$ are $\sim 50,000 \mathrm{md}-\mathrm{ft}$ and $\sim 18,000 \mathrm{md}-\mathrm{ft}$, respectively. Because the highest value was obtained from sparse data, it would be prudent to use $\approx 30,000 \mathrm{md}-\mathrm{ft}$ as an optimistic mean value for $\mathrm{kh}$. When the short-term production data are analyzed, the value of $\mathrm{kh} / \mu$ are consistently lower than the interference values. This is probably due to a combination of several complicating factors associated with the we11-test analyses. These factors include: wellbore damage; partial penetration; partial hydrological barriers (shale layers, closed factors, etc.); leaky caprock; and shale dewatering. None of these are included in the analyses from which our estimates are derived. The most important effects are probably due to the well damage, partial penetration, and hydrological inhomogeneities.

An estimate of the hydrological continuity is presented in Figure 3.2 and shows possible isolation of wel1 16-30 from the remainder of the field, and apparent isolation of wells $8-1$ and 44-7 from 6-1. The general picture is one of localized barriers and recharge regions, which might be associated with the numerous local features seen in Figures 1.8 to 1.10 of this report.

The parameter that is related to the amount of fluid stored is the quantity $\phi \mathrm{ch}$, sometimes referred to as storativity. To obtain a value of storativity from production tests using our existing analysis methods, the well must not have any damage--or skin. For the USBR East Mesa wells, this requirement is not met and the estimates for $\phi c h$ from interference tests vary widely. The most estimates from tests that had the least complications give a range of $\phi$ ch from $6 \times 10^{-4}$ to $6 \times 10^{-3} \mathrm{ft} / \mathrm{psi}$.

\section{REFERENCES CITED}

Earlougher, R. C., 1977. Advances in well test analysis. Monograph, Dallas, Soc. Petrol. Engin. AIME, v. 5. 


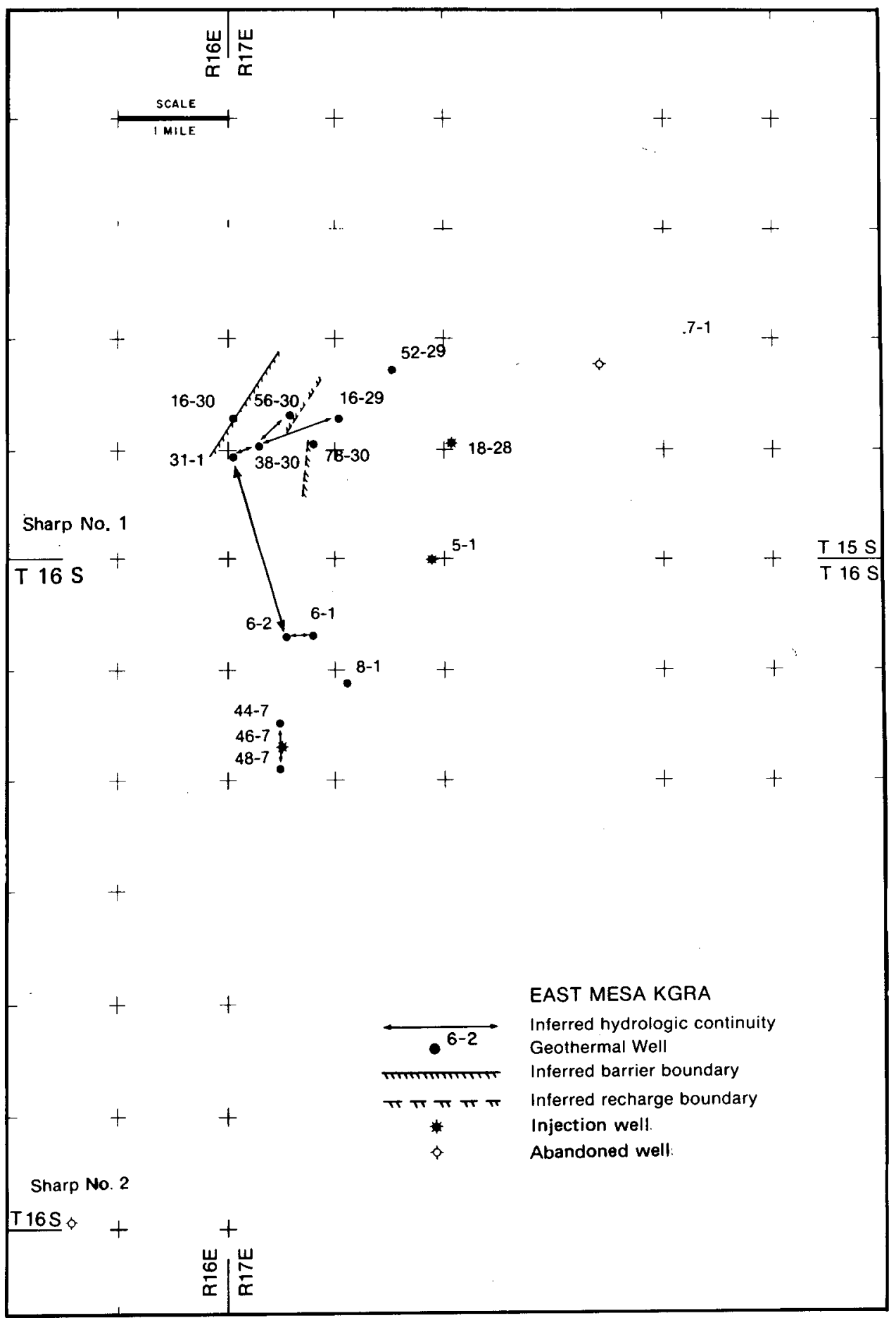

XBL 786-1861A

Figure 3.2. Schematic of hydrologic continuity among wells at the East Mesa KGRA. The values of transmissivity (md-ft/cp) are from interference tests. 
Lippmann, M. J., Bodvarsson, G. S., and Witherspoon, P. A., 1978. Preliminary simulation studies of the Cerro Prieto reservoir, in Proc. first symposium on the Cerro Prieto geothermal field, Baja California, Mexico (September 20-22, 1978). Berkeley, Lawrence Berkeley Laboratory, LBL-7098.

Mathias, K. E., 1975. The Mesa geothermal field--a preliminary evaluation of five geothermal wells, in Proc. second UN symposium on the development and use of geothermal resources. Washington, D.C., U. S. Government Printing Office, v. 3, Pp. 1741-1744.

Matthews, C. S., and Russe1, D. G., 1967. Pressure build-up and flow tests in wells. Monograph, Dallas, Soc. Petrol. Engin. AIME, v. 1. McEdwards, D. G., and Tsang, C. F., 1977. Variable rate multiple well testing analysis, in Proc. invitational well testing symposium, October 19-21, 1977. Berkeley, Lawrence Berkeley Laboratory, LBL-7027, pp. 92-99.

Narasimhan, T. N., McEdwards, D. G., and Witherspoon, P. A., 1977a. Results of reservoir evaluation test, 1976, East Mesa geothermal field in California. Berkeley, Lawrence Berkeley Laboratory, LBL-6369.

Narasimhan, T. N., Schroeder, R. C., Goranson, C. B., McEdwards, D. G., Campbe11, D. A., and Barkman, J. H., 1977b. Recent results from tests on the Republic geothermal wells, East Mesa, California. Berkeley, Lawrence Berkeley Laboratory, LBL-7017.

Narasimhan, T. N., Schroeder, R. C., Goranson, C. B., and Benson, S. M., 1979. Results of reservoir engineering tests, 1977, East Mesa, California. Berkeley, Lawrence Berkeley Laboratory, LBL-7191 U. S. Bureau of Reclamation, 1977. Geothermal resource investigations. East Mesa test site, Imperial Valley, California, status report. Washington, D.C., U. S. Department of the Interior, Bureau of Reclamation.

Witherspoon, P. A., Narasimhan, T. N., and McEdwards, D. G., 1978. Results of interference tests from two geothermal reservoirs. Jour. Petroleum Technology, v. 30, pp. 10-16. 


\section{SECTION 4: RESERVOIR SIMULATION}

T. N. Narasimhan and S. Juprasert

Lawrence Berkeley Laboratory

\section{INTRODUCTION}

This chapter is concerned with certain aspects of the deliverability, at the surface, of the East Mesa geothermal resource in connection with the Colorado River augmentation scheme proposed by the U.S. Bureau of Reclamation (USBR). The primary purpose of the project is to produce fresh water and to use the thermal energy contained in the geothermal fluids for desalination and system operation. In order to optimize system efficiency and cost benefits, the desalting operation requires maximum volume of fluids at maximum temperature. Basically, the simulation studies address the following questions posed by USBR. Will the part of the East Mesa reservoir underlying USBR's lands be able to yield: 100,000 acre-ft/yr of water; 50,000 acre-ft/yr of water; or 25,000 acre-ft/yr of water?

As will become apparent in the following pages, the answer to the question of whether a reservoir can yield water at a certain rate is very much related to economics. Therefore, the final answer can be arrived at only after a detailed economic analysis, duly considering the response of the reservoir to various extraction strategies. The purpose of this simulation study is to provide the relevant reservoir engineering input needed for economics analysis. The actual economics study, however, is beyond the scope of this work.

In charging LBL with the task of answering the above questions, USBR stated the following additional conditions:

- fluid production is to be achieved by downhole pumping, if needed;

- the reservoir will be replenished by injection of Salton Sea water;

- at the wellhead, water will have heat content equivalent to that of $300^{\circ} \mathrm{F}$ water; and

- the reservoir shall remain single-phase (water). 
Inasmuch as the task of the present study is to provide technical input for an overall decision-making process, LBL and USBR decided on the following approach. Based on the available knowledge of the East Mesa geothermal reservoir, a favorable set of reservoir parameters will be assumed. For the assumed favorable conditions, the response of an idealized reservoir under different production and injection scenarios will be computed and the results so obtained wili then be presented, along with a discussion of their implications with reference to various important economic factors.

Within the East Mesa Known Geothermal Resource Area (KGRA), USBR owns about 6720 acres (Figure 4.1 ), about $40 \%$ of which overlies relatively colder regions of the reservoir (if we consider the $300^{\circ} \mathrm{F}$ isotherm at 6000-ft depth). Also, as seen from Figure 4.1, hotter portions of the reservoir extend beyond the limits of USBR's lands, toward the north, northwest, and southwest. Much valuable reservoir data have been collected from these parts of the reservoir lying outside USBR's holdings. In carrying out the simulations, therefore, we will also consider those parts of reservoir extending beyond USBR's lands and interpolate the results to evaluate the potential of the latter. Considering this larger area is also meaningful when studying the peripheral injection scenario, since sweeping heat by peripheral injection has to be planned for the reservoir as a whole rather than for any portion of the reservoir. In particular, we will consider for simulation the area enclosed within the $300^{\circ} \mathrm{F}$ isotherm at a depth of $6000 \mathrm{ft}$ below surface (Figure 4.1), as given by TRW/Intercomp (1976). Additionally, we will consider the area enclosed by the $300 \% \mathrm{~F}$ isotherm at $7000 \mathrm{ft}$, as given in Figure 1.1 of this report. According to our current knowledge, these two cases include a substantial portion of the East Mesa reservoir. However, if further exploration should extend the isotherms beyond these limits, then the potential of the reservoir will indeed increase.

The material in this section will be organized as follows. First, we will set forth the factors that are most relevant from the point of view of reservoir economics. Then, we will state the assumptions used in the simulations and describe the different methods employed 


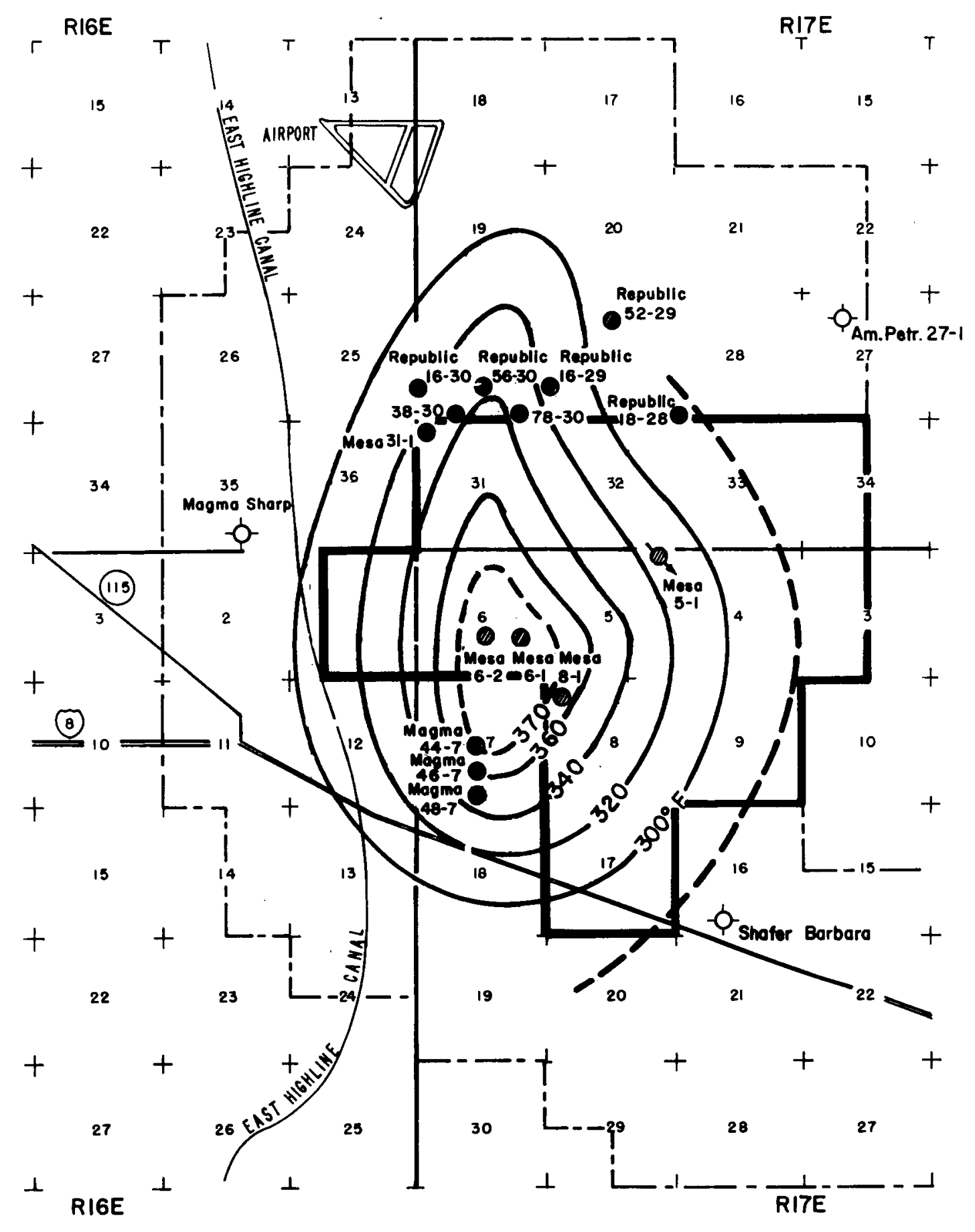

XBL 785-2539A

Figure 4.1. Map of USBR leaseholds at East Mesa. Solid contours show the isotherm at 6000-ft depth; dashed contour shows the $300^{\circ} \mathrm{F}$ isotherm at 7000-ft depth. 
in the computations. Last, we will present our results and discuss their implications.

\section{FACTORS RELEVANT TO ECONOMICS}

As water is produced from a geothermal reservoir, the fluid pressure within the reservoir falls. The decline in the fluid pressure is a direct function of the production rate. Many of the economic factors of interest concern the functional relationship between flow rate and pressure decline, since there are technical and economic limits to the pressure declines that may be acceptable. Furthermore, when one seeks to inject relatively cold water into the geothermal reservoir, in order to either minimize pressure declines or sweep heat energy contained in the rock matrix, the colder water will eventually reach the producing we11, causing a deterioration in the production-well temperature. Therefore, there are several economic factors related to the parameters governing the breakthrough of the injected water to the production we11. The various factors that govern the production vs pressure-decline relationship and the breakthrough of the injected water are discussed below.

The factors that affect the relationship of production to pressure decline include: the number of wells (production or injection) and their depth; their spacing and pattern; the flow rate or injection rate per well; the depth at which deep-well pumps have to be set to attain the desired flow rate; and the energy required to 1 ift water from depth or inject water under pressure. In regard to the breakthrough of the injected fluid at the production wel1, the important factors include the thermal breakthrough of the colder fluid and the hydrodynamic breakthrough. The term hydrodynamic breakthrough denotes the physical arrival of the injected water at the production well. In a groundwater mining problem such as this one, hydrodynamic breakthrough is of fundamental importance. In this case, the Salton Sea water, which is to be used for injection, is of much poorer quality than the reservoir fluid, which is to be extracted to augment the Colorado River.

The reservoir parameters that are crucial to the pressure-decline vs flow-rate relationship include: the permeability of the reservoir, 
$\mathrm{k}$; the thickness of the reservoir, $\mathrm{H}$; the total compressibility of the reservoir material, $c_{t}$; the porosity of the reservoir rock, $\phi$; viscosity of the flowing water, $\mu$; geometry of the reservoir; the flow rate, $Q$; the diameter of the well, d; and the boundary and initial conditions of the reservoir. The parameters critical to breakthrough include flow rate, $Q$; porosity, $\phi$; thickness of the reservoir, $H$; thermal conductivity of the reservoir rock, $\mathrm{K}_{\mathrm{x}}$; specific heat of the rock, $c_{r}$; and specific heat of water, $c_{f}$.

The different factors of interest and the various reservoir parameters considered in the simulations to study those factors are presented in Table 4.1 .

A reservoir simulation study, somewhat similar to the present study, was carried out by Intercomp, Inc., as a subcontractor to TRW, which in turn was a subcontractor to the U. S. Bureau of Reclamation. The study, however, was focussed more toward energy extraction than groundwater mining. The results of the Intercomp study are presented in the report by TRW/Intercomp (1976).

\section{ASSUMPTIONS}

The validity of the present study is intimately related to the various assumptions that need to be made in setting up the simulation model. These assumptions fall into the following categories:

- limits of the production-well field,

- limits of the geothermal reservoir,

- reservoir properties,

- fluid properties, and

- other assumptions.

In accordance with the approach to the problem set forth in the Introduction, we will choose a favorable set of model assumptions. 


\section{Limits of the Production-We1l Field}

As already mentioned, we will consider an area much larger than the lands controlled by USBR and interpolate from the results in order to evaluate the potential of USBR's holdings. Accordingly, we will consider two cases: one in which all the production wells are uniformly distributed within the $300^{\circ} \mathrm{F}$ isotherm at a depth of $6000 \mathrm{ft}$ below ground leve1, and the other in which they are uniformly distributed within the $300^{\circ} \mathrm{F}$ isotherm at a depth of $7000 \mathrm{ft}$. The first case will imply that the wells have a mean depth of $6000 \mathrm{ft}$ while the second will imply a mean depth of $7000 \mathrm{ft}$.

\section{Limits of the Geothermal Reservoir}

For this study we will assume that the reservoir is homogeneous, horizontal, and extends infinitely beyond the $300 \% \mathrm{~F}$ isotherm. This assumption implies that the reservoir has unlimited supplies of stored fluids. This is a favorable assumption from the point of view of providing pressure support during production. To the north of USBR's holdings, interference tests have indicated the presence of one or more "barrier" boundaries of unknown continuity. Within USBR's holdings, interference tests have suggested the possible existence of a "leaky" boundary (Figure 3.2). The disposition of this boundary, however, is difficult to establish. If such a boundary indeed exists, it would provide additional pressure support to production.

Although the reservoir is assumed to be infinite in lateral extent, we will assume that it is vertically bound by impermeable and insulated surfaces. This implies that there is no leakage of water into the reservoir from strata located above or below it. This assumption is reasonable since the interference tests conducted so far have not suggested the presence of an extensive source of leakage, apart from the possibility of a leaky boundary within USBR's holdings already mentioned.

Based on regional geological and geophysical studies, some workers have hypothesized the influx of water into the reservoir from depths through large vertical faults acting as conduits (Goyal, 1978). However, well tests conducted so far have not established the existence of such a regional phenomenon. Although it is conceivable that such a mechanism 
Table 4.1. Factors relevant to economics and the parameters used in the simulations.

\begin{tabular}{ll}
\hline Number of wells & $15,30,60,120$ \\
Mean depth & $6000 \mathrm{ft} ; 7000 \mathrm{ft}$ \\
Pattern & No injection; peripheral \\
& injection, and five-spot \\
Spacing & Wel1s located within $300^{\circ} \mathrm{F}$ \\
& isotherm at $6000 \mathrm{ft}$ \\
& Wells located within $300^{\circ} \mathrm{C}$ \\
& isotherm at $7000 \mathrm{ft}$ \\
& \\
Flow rate: & $250 ; 500 ; 1000 ; 2000$ \\
Total & 100,000 acre-ft/yr \\
& 50,000 acre-ft/yr \\
& 25,000 acre-ft/yr \\
& $100 \%$ volumetric injection \\
& $90 \%$ volumetric injection \\
& $80 \%$ volumetric injection \\
\hline
\end{tabular}

Table 4.2. Model assumptions used in the reservoir simulations.

\begin{tabular}{|c|c|}
\hline Reservoir geometry & $\begin{array}{l}\text { Areally infinite, homogeneous, uniform } \\
\text { thickness, bounded on top and bottom } \\
\text { by impermeable, insulated boundaries }\end{array}$ \\
\hline Material properties & $\begin{aligned} k H & =30,000 \mathrm{md}-\mathrm{ft} \\
\phi c_{\mathbf{t}} \mathrm{H} & =0.001 \mathrm{ft} / \mathrm{psi} \\
\phi & =0.1 ; 0.2 \\
\mathbf{H} & =1000,1500 ; 2000 \mathrm{ft} \\
\rho_{\mathbf{r}} & =2650 \mathrm{~kg} / \mathrm{m}^{3} \\
c_{\mathbf{r}} & =200 \mathrm{cal} / \mathrm{kg}^{\circ} \mathrm{C}\end{aligned}$ \\
\hline Properties of the fluid & $\begin{aligned} \text { Produced water } \\
\rho_{w}=920 \mathrm{~kg} / \mathrm{m}^{3} \\
\mu=0.2 \mathrm{cp} \\
c_{w}=830 \mathrm{cal} / \mathrm{kg}^{\circ} \mathrm{C}\end{aligned}$ \\
\hline Temperature of water & $\begin{array}{l}\text { Produced water }=360^{\circ} \mathrm{F}\left(182^{\circ} \mathrm{C}\right) \\
\text { Injected water }=167^{\circ} \mathrm{F}\left(75^{\circ} \mathrm{C}\right)\end{array}$ \\
\hline Initial conditions & Hydrostatic \\
\hline
\end{tabular}


may be operative on a regional, geological time frame, its importance to the present study does not appear to be significant.

The assumption of the existence of insulated boundaries implies that there is no influx of heat into the system from outside. Although the possibility that some heat influx from the bottom exists, 1ittle quantitative information is currently available. Whatever heat influx may take. place from below will be beneficial in that it will tend to retard the thermal breakthrough times.

In this analysis, we will also ignore the effects of the layers of fine-grained material (clays, silts, shales) that may occur within the reservoir. These interbeds will have two different effects on reservoir response. First, they will drain fluids from storage far more slowly than the sands and experience a more gradual pressure drop than the sands. In shallow groundwater systems fine-grained materials will gradually consolidate, frequently leading to ground subsidence. At East Mesa, however, little is known at present about the compressibility of the fine-grained interbeds within the reservoir. Therefore, no attempt has been made to include these interbeds in the simulations.

The second effect that the interbeds have on the reservoir response relates to extractable energy. During the process of fluid energy production, these interbeds will release the energy stored in them to the produced fluids by conduction. The energy so released will have to retard thermal breakthrough times. In the simulations, the presence of the intereds has been ignored.

\section{Reservoir Properties}

Perhaps the most important parameter governing the pressure vs. flowrate relationship is $\mathrm{kH}$, the product of reservoir permeability and thickness. Several production and interference tests conducted so far (Tables 3.4 through 3.6 ) have shown that within the general area of USBR's holdings, the $\mathrm{kH}$ varies from 11,000 to $20,000 \mathrm{md}-\mathrm{ft} . *$ To the north, in the general area of Republic Geothermal Incorporated's holdings,

* See Appendix D, Conversion Tables, for alternate units. 
the $\mathrm{kH}$ product varies from 23,000 to $35,000 \mathrm{md}-\mathrm{ft}$. In the present study, we will assume a $\mathrm{kH}$ value of $30,000 \mathrm{md}-\mathrm{ft}$. This assumption is optimistic with reference to USBR's holdings.

The storativity parameter, $\phi c_{t} \mathrm{H}$, is a measure of the ability of the reservoir to release water from storage due to decline in pore pressures. The well tests conducted at East Mesa (Tables 3.4 through 3.6) have yielded a range of $6 \times 10^{-4}$ to $6 \times 10^{-3} \mathrm{ft} / \mathrm{psi}$ for $\phi \mathrm{c}_{\mathrm{t}} \mathrm{H}$. For purposes of simulation, we will use a value of $1 \times 10^{-3} \mathrm{ft} / \mathrm{psi}$. When the flow field goes to a steady state or a quasi-steady state, as wil1 be the case when $100 \%$ volumetric injection is considered, the storativity parameter loses importance and the pressure behavior is independent of $\phi c_{t}{ }^{H}$. Hence the assumption of $1 \times 10^{-3} \mathrm{ft} / \mathrm{ps} i$ for storativity is a reasonable one.

In studying the hydrodynamic and thermal breakthroughs under injection scenarios, the parameters $\phi$ and $H$ are important. Unfortuately, these parameters are hard to estimate from well tests and have to be estimated from borehole geophysical and lithological logs. These estimates are subject to considerable uncertainty since very little information is available on the disposition of the sand zones and other intervals that primarily transmit water within the reservoir. For this reason, we will not choose a unique set of $\phi$ and $H$ values to characterize the reservoir. Instead we will choose a few plausible combinations of these parameters. Thus we will consider values of $10 \%$ and $20 \%$ for $\phi$ and 1000,1500 , and $2000 \mathrm{ft}$ for reservoir thickness, $\mathrm{H}$.

In regard to the thermal properties of the reservoir rocks, we will assume a thermal conductivity $\left(K_{r}\right)$ of $4.5 \times 10^{-3} \mathrm{cal} / \mathrm{cm} \cdot \mathrm{sec}^{\circ} \mathrm{C}$ for the sandstones comprising the reservoir. As given by Kappelmeyer and Haenel (1974), the thermal conductivity of sandstones ranges from 5 to $12 \times 10^{-3} \mathrm{cal} / \mathrm{cm}^{\cdot} \mathrm{sec}^{\circ} \mathrm{C}$. Although the assumed value is slightly smaller than the lower limit given by Kappelmeyer and Haenel, it will tend to reduce the spread of the thermal-breakthrough profile and hence will yield a slightly optimistic estimate of the thermal-breakthrough time. Furthermore, during fluid production, the reservoir will be dominated by forced convection and hence conduction effects will be very small. In the simulations, the reservoir rock was assumed to 
have a density of $2.65 \mathrm{gm} / \mathrm{cm}^{3}$ and a specific heat of $0.2 \mathrm{cal} / \mathrm{g}^{\circ} \mathrm{C}$, both of which correspond to the mean values available in the literature.

\section{Fluid Properties}

Fluid density, viscosity, and specific heat are three parameters of the fluid that are required for the simulations. For these quantities, we will assume values of $0.92 \mathrm{~g} / \mathrm{cm}^{3}, 0.2 \mathrm{cp}$, and $0.83 \mathrm{cal} / \mathrm{g}^{\circ} \mathrm{C}$, respectively, all of which correspond to the properties of water at approximately $340^{\circ} \mathrm{F}$. The conductivity of water is in general negligible and hence is ignored.

\section{Other Assumptions}

We will assume that the wells are perfect hydraulic systems. In other words, there will be no "well losses" at the production or injection wells due to degradation of the near-well environment. This assumption is optimistic since, during long-term operation of geothermal wells at large flow rates, increased pressure losses are likely at the wellbore due to such varied causes as scaling, plugging, corrosion, and turbulence. For purposes of simulation, we will assume that the wells have a diameter of $1 \mathrm{ft}$.

The temperature of the injected water is taken to be $167^{\circ} \mathrm{F}$. In point of fact, the Salton Sea water, which is to be used for injection, will be much colder than 1670 F. Since water viscosity increases with decreasing temperature and increased viscosity retards water movement, the assumption of higher injection temperature will lead to optimistic estimates of pressure declines or buildup.

In all the simulations, the reservoir was assumed to be initially under hydrostatic condition and at a uniform temperature of $360^{\circ} \mathrm{F}$. The various model assumptions are given in Table 4.2.

\section{METHODS OF ANALYSIS}

The simulations carried out fall into three categories. These include: pressure transient, thermal breakthrough, and wellbore thermodynamic calculations. The methods used in each of these are discussed below. 


\section{Pressure-Transient Calculations}

A majority of these calculations were made with a technique that essentially superposes the analytical solution of radial flow to a single well in a homogeneous, infinite aquifer. The computer program implementing this technique is called MAXDRAW. As a check of thesecalculations, some of the scenarios considered were repeated using an independent numerical technique embodied in a computer program called TERZAGI. It is pertinent here to briefly describe these two techniques. The central equation in program MAXDRAW is the exponential integral solution,

$$
\Delta p=2420.666 \frac{Q_{\ell}^{\mu}}{\mathrm{kH}} \mathrm{W}(\mathrm{u})
$$

where $\Delta \mathrm{p}$ is pressure drawdown in psi;

$\mathrm{Q}_{\ell}$ is liquid rate of production in $\mathrm{gpm}$;

$\mu$ is dynamic coefficient of viscosity in cp;

$k$ is permeability in $\mathrm{md}$;

$\mathrm{H}$ is reservoir thickness in $\mathrm{ft}$.

In $\mathrm{Eq} .(1), \mathrm{W}(\mathrm{u})$ is the exponential integral, defined by

$$
W(u)=\int_{\mu}^{\infty} \frac{e^{-u}}{u} d u
$$

in which

$$
\mathrm{u}=56,887.45\left(\frac{\phi \mu c_{\mathrm{t}} \mathrm{Hr}^{2}}{\mathrm{kHt}}\right) \text {; }
$$

$\phi$ is porosity;

$c_{t}$ is total compressibility, vol/vol per psi;

$r$ is distance to point of observation, in $\mathrm{ft}$, from the producing we 11 ; and

$t$ is time in min. 
As given in Eq. (1), $\Delta \mathrm{p}$ is the pressure drawdown at a distance $r$ from the producing well at time $t$. By convention, $Q_{\ell}$ is positive for production and negative for injection. When several production and injection wells operate simultaneously in a well field, the pressure drawdown at a desired point in the field at time $t$ can be computed by adding the effect of each well at that point according to Eq. (1). Thus, for a well field with $\mathrm{N}$ wells, the superposition principle yields,

$$
\Delta p=2420.666 \sum_{i=1}^{N} \frac{Q_{\ell, i} \mu}{k H} w\left(u_{i}\right)
$$

where

$$
u_{i}=56,887.45 \frac{\phi c_{t}{ }^{2} r_{i}^{2}}{k H t}
$$

and the subscript $i$ denotes the $i$ th well.

The program assumes constant values of $\mathrm{kH}, \phi c_{t^{H}}, \mu$, and $Q_{l}$, although it can handle variable flow rates. Other input data to the program include the parameters $r_{i}$ and $t$.

The superposition principle can be extended to handle barrier or leaky boundaries, which may be idealized as vertical planes cutting the reservoir. Such boundaries can be treated as planes of reflection giving rise to image wells. The simulation then reduces to superposing the effects of real and image wells.

As a check on this model, consider a well fully penetrating a homogeneous, areally infinite, horizontal reservoir, with $\mathrm{kH}=30,000 \mathrm{md}-\mathrm{ft}$, $\phi \mathrm{cH}=1 \times 10^{-3} \mathrm{ft} / \mathrm{psi}$, and with water viscosity of $0.2 \mathrm{cp}$. The well produces at the rate of $500 \mathrm{gpm}$. For these conditions, program MAXDRAW was used to compute drawdowns at two different points 500 and $1000 \mathrm{ft}$ from the producing well. The drawdowns so computed are presented in Figure 4.2 , as a $\log -\log \mathrm{plot}$ of $t / \mathrm{r}^{2}$ vs $\Delta_{\mathrm{p}}$. As shown in the figure, the computed data agree extremely well with the analytical solution. If one were to use the computed drawdowns and back-compute $\mathrm{kH}$ and $\phi c_{t} H$, the results (as indicated in Figure 4.2) would be $k H=30,260 \mathrm{md}-\mathrm{ft}$ 
and $\phi c_{t^{H}}=1.01 \times 10^{-3} \mathrm{ft} / \mathrm{psi}$, which agrees with the known values within limits of graphical errors.

Some of the pressure transient calculations were also carried out with a numerical model called TERZAGI, partly as an additional check on MAXDRAW calculations and partly to carry out other calculations (e.g., viscosity effects, skin effects) that could not be carried out with MAXDRAW. Program TERZAGI, which was developed from the code TRUMP (Edwards, 1969), employs an Integrated Finite Difference Method (IFDM) in conjunction with an iterative technique to simulate transient fluid flow in multidimensional systems. Computations validating this approach in regard to the exponential integral solution and other problems have been presented by Narasimhan and Witherspoon (1976) and will not be repeated here.

Briefly stated, the program applies the equation of mass conservation to a multidimensional flow region with complex geometry, heterogeneity, and initial conditions in which the material properties may vary with fluid pressures and the boundary conditions may vary with time. In order to solve a specific problem, the flow region is first divided into a convenient number of subregions (volume element). Over each subregion, the fluid pressure (or equivalently, fluid potential) does not vary too rapidly, so that one could associate an "average" value of fluid pressure and other properties with each such volume element. The average value is thus specified at a representative nodal point within the volume element. Having done this, the computer program is used to conserve mass within each volume element as a function of time according to the general equation,

$$
\mathrm{G}_{\mathrm{v}, \ell}+\int_{\Gamma} \frac{\mathrm{k}}{\mu}\left(\rho_{\mathrm{w}} \mathbf{g \nabla z}+\nabla \mathrm{P}\right) \cdot \overrightarrow{\mathrm{n}} \mathrm{d} \Gamma=\rho_{\mathrm{w}} \mathrm{v}_{\ell} \phi \mathrm{c}_{t} \frac{\mathrm{Dp}}{\mathrm{Dt}}
$$

As indicated by Narasimhan and Witherspoon (1976), the surface integral can be split up to handle boundary conditions while the pressure term within the integrand on the left-hand side will duly account for the initial conditions. 


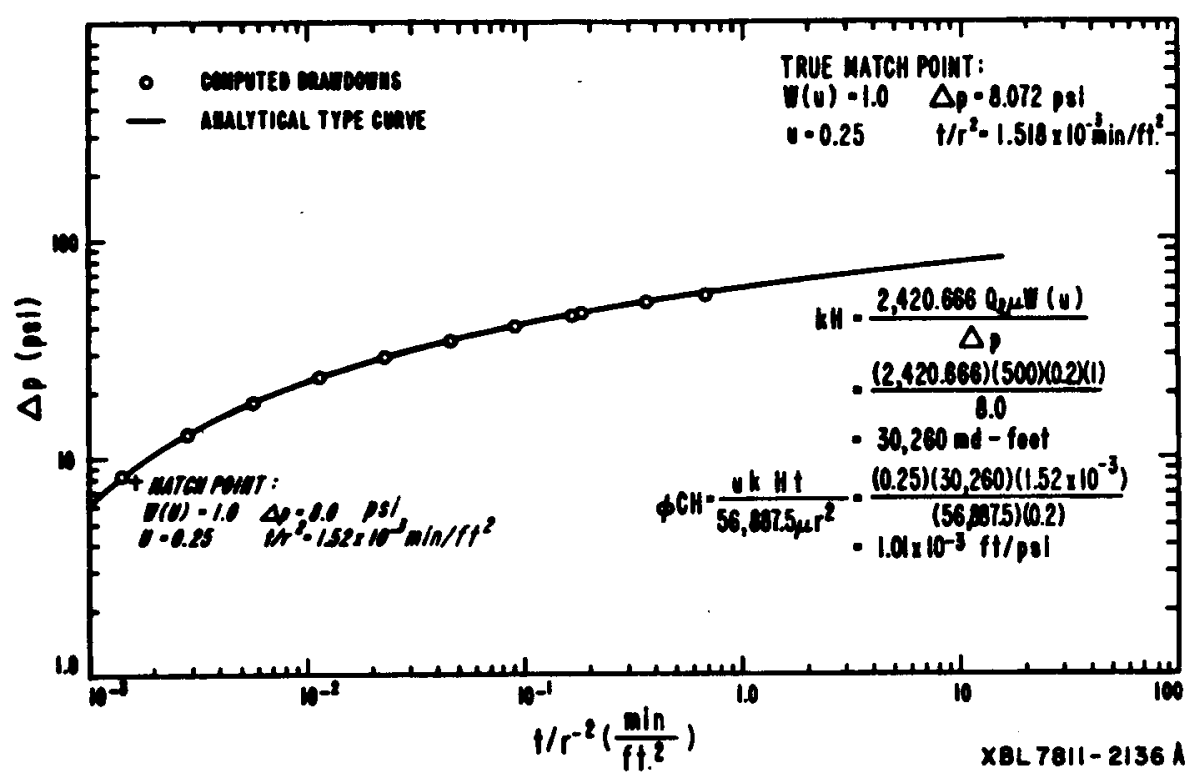

Figure 4.2. Verification of program MAXDRAW. Comparison of computed drawdowns with analytical solution.

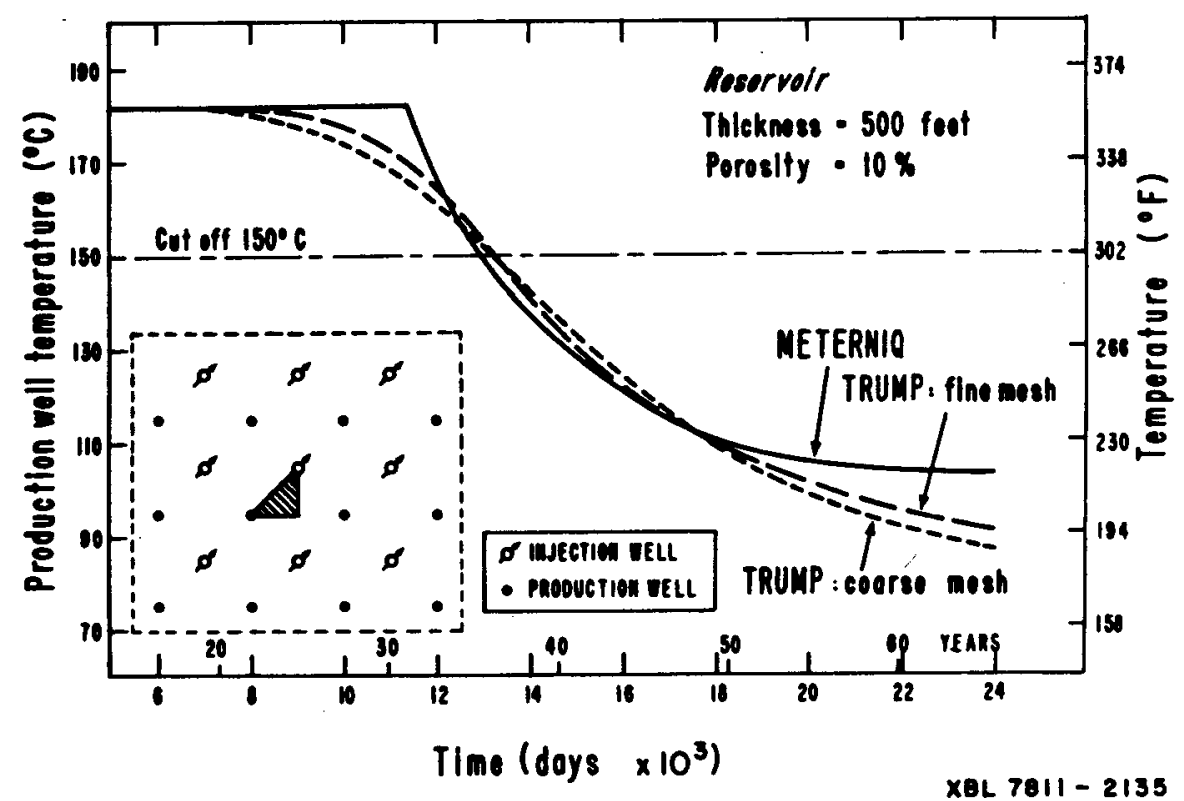

Figure 4.3. Thermal breakthrough calculations for five-spot pattern. Comparison of METERNIQ and TRUMP results. Inset shows five-spot array: production wells; injection well. 


\section{Thermal Breakthrough Calculations}

Two techniques were used to compute thermal-breakthrough times under different production-injection scenarios. Both methods consider the transport of heat in a porous medium with a steady fluid-flow field, an assumption that is reasonable when considering $100 \%$ volumetric injection. The first of these methods, by Gringarten and Sauty (1975), is incorporated into a computer program called METERNIQ developed at the Bureau de Recherches Géologiques et Minières (BRGM) in France. This method is based on computing the fluid velocity field within a prescribed number of stream tubes and transporting heat by pure convection along the stream tubes. In other words, heat conduction is neglected along the path of flow (plug flow). However, leakage of heat into the system (which consists of an areally infinite, horizontal, homogeneous reservoir) across the upper and lower boundaries can be accounted for as known source terms. When a number of wells produce or inject within the reservoir, the velocity field is evaluated by a technique of superposition, which is implemented within the computer program. Because it is based on analytic solution, METERNIQ can be efficiently used for considering well fields with a large number of wells, a task which is difficult with numerical models.

The second method involves the use of program TRUMP developed by Edwards (1969). While METERNIQ neglects heat conduction within the reservoir, TRUMP duly takes it into account. As a check on the METERNIQ calculations and to study the effects of heat conduction within the reservoir, some of the calculations relating to the fivespot pattern were repeated with TRUMP.

Consider an infinite array of production and injection wells distributed in a five-spot pattern (inset Figure 4.3). Under $100 \%$ volumetric injection, the flow field will attain steady state in a short time. Due to symmetry considerations, the heat-transport problem can be studied numerically by considering the shaded region in the inset in Figure 4.3, as was done using program TRUMP. For practical pruposes, the infinte five-spot array can also be reasonably well simulated by METERNIQ by considering a reasonably large number of production and injection wells and directing attention to the results obtained 
for the central portion of the array. A comparison of METERNIQ and TRUMP results is presented in Figure 4.3 .

Specifically, the problem considered relates to a five-spot array with the injection and production wells separated by a distance of $2120 \mathrm{ft}$. The various input parameters were as follows:

$\begin{array}{ll}\text { Flow rate per well } & 1000 \mathrm{gpm} \\ \text { Production temperature } & 182^{\circ} \mathrm{C} \\ \text { Injection temperature } & 75^{\circ} \mathrm{C} \\ \text { Specific heat capacity of water } & 830 \mathrm{cal} / \mathrm{kg}^{\circ} \mathrm{C} \\ \text { Density of water } & 920 \mathrm{~kg} / \mathrm{m}^{3} \\ \text { Density of rock } & 2650 \mathrm{~kg} / \mathrm{m}^{3} \\ \text { Specific heat capacity of rock } & 200 \mathrm{cal} / \mathrm{kg}^{\circ} \mathrm{C} \\ \text { Thickness of reservoir } & 500 \mathrm{ft}\end{array}$

The numerical simulation was carried out assuming the presence of a 6-in.-radius well, using two different meshes: a coarse mesh with 47 volume elements and a finer one with 261. The METERNIQ simulation was carried out with 40 stream tubes.

The results in Figure 4.3 show the variation of production-we 11 temperature as a function of time. Note in this figure that both the coarse and the fine mesh give reasonably close results, indicating that discretization errors in the numerical model are fairly small. A comparison of METERNIQ and TRUMP results in the figure show different breakthrough times, as one would expect. Time of breakthrough is defined as the time at which production-well temperature starts to fall. Thus, due to the presence of heat conduction in the numerical model, temperature fall-off starts much earlier $(\approx 23$ years) than in the other model, which neglects heat conduction in the reservoir ( $\approx 33$ years). However, the rate of temperature fall-off, once breakthrough is initiated, is more gradual in the presence of heat conduction than in the absence of it. Interestingly, if we look at the time taken for the productionwell temperature to drop to $150^{\circ} \mathrm{C}\left(\approx 300^{\circ} \mathrm{F}\right)$, both cases (with or without heat conduction) agree very closely with each other. This example 
establishes the resaonableness and validity of the two approaches in analyzing the problem of heat transport under steady fluid-flow conditions.

\section{Wellbore Thermodynamics}

The purpose of a geothermal wellbore model is to estimate, under conditions of reservoir pressure decline, the wellhead properties (pressure, temperature, enthalpy, stream quality) and the depth to the flash point within the well. Flash point denotes the pressure-temperature condition at which boiling is initiated and steam begins to form from the liquid.

The wellbore model used in the present study was developed by Juprasert and Sanyal (1977). It uses two-component, two-phase pressuredrop correlations that have been used for two-phase flow in oil and gas wells. This model is applied to the one-component, two-phase geothermal system, taking into account heat transfer from the wellbore to the surroundings, phase transfer (vapor-1iquid equilibrium), hold up ("slip") that liquid and vapor may have at different velocities, and the possible existence of several flow regimes along the pipe for a given set of operating conditions. These are single-phase liquid flow, bubble flow, slug flow, transition flow, and annular mist flow. The model uses Duns and Ross (1963), Orkiszewski (1967), Beggs and Bril1 (1973), and Hagedorn and Brown (1965) correlations.

Given the sand-face flow rate; flowing bottom-hole temperature and pressure; the diameter, length, and friction factor of wellbore; and the static temperature profile and overall heat-transfer coefficient, the model calculates a continuous profile of the flowing pressure, temperature, enthalpy, and steam quality in the wellbore.

As an example of the application of the wellbore model, a simulation of the conditions in well 6-1 at East Mesa is presented in Figure 4.4. The simulation was an attempt to duplicate the tests conducted in January 1973 by USBR. During the tests, the well flowed at a constant rate of $250 \mathrm{gpm}$. The computed and measured flowing pressure, temperature, and shut-in temperature profiles are presented in Figure 4.4. The reasonable comparison between the calculated and measured profiles shows that the model is indeed a valid tool of analysis for the present study. 


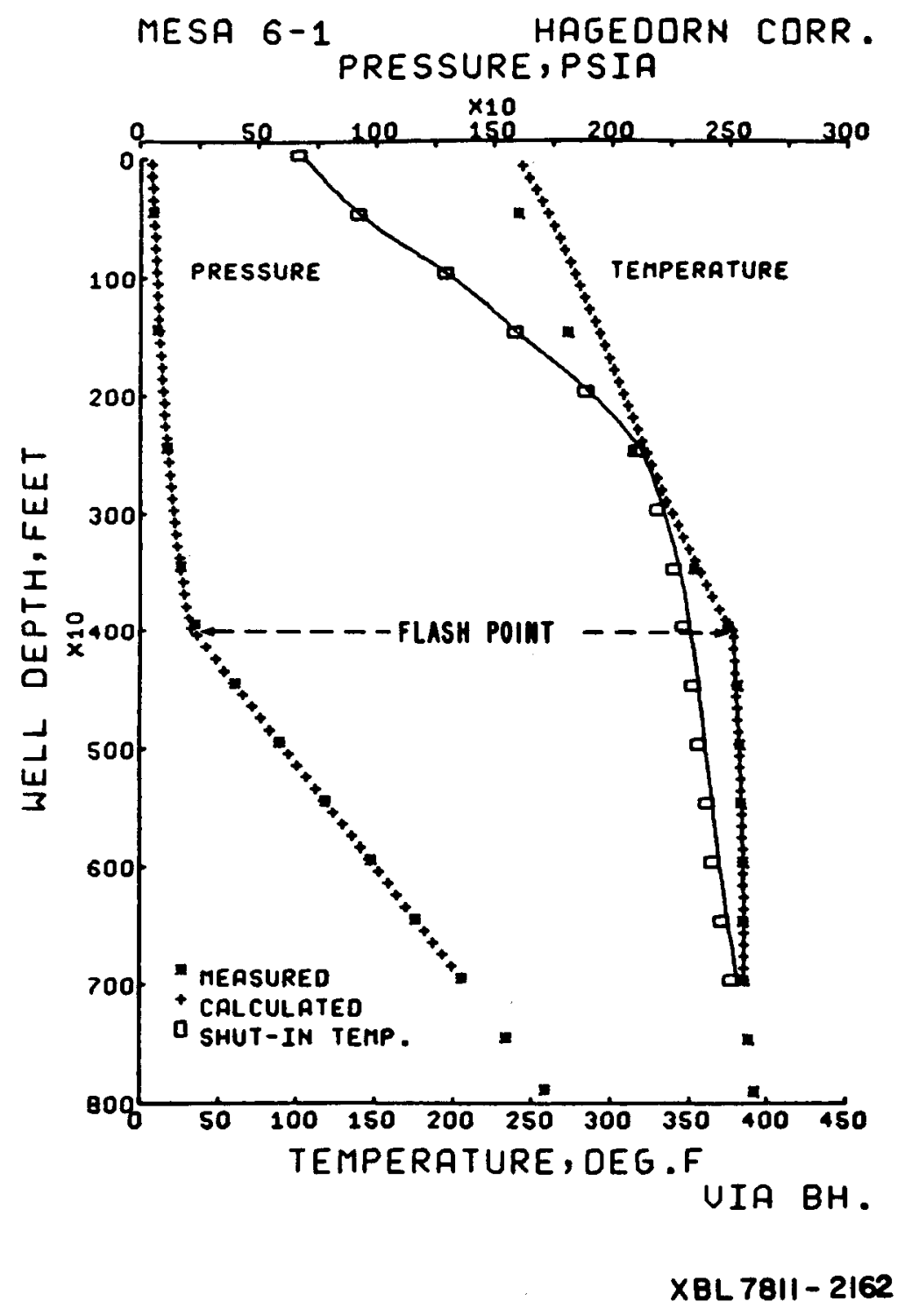

Figure 4.4. Temperature and pressure regimes within well 6-1 at East Mesa. Comparison of computed and measured results. 


\section{CASES STUDIED}

A large number of possible production-injection scenarios were studied. The various cases were selected to quantitatively estimate the influence of the different system parameters on different economic factors, as summarized in Table 4.1.

The cases studied can be divided into three categories: pressure transient calculations, wellbore thermodynamics, and thermal breakthrough calculations. Under each of these categories the scenarios included: no-injection, peripheral-injection, and five-spot configurations. Within each of these scenarios, numerous cases were considered by varying the number of wells, well spacing, flow rates and other parameters. Table 4.3 is a summary of the various cases in the simulation studies.

\section{RESULTS OF SIMULATION}

\section{Pressure Transient Calculations}

The pressure transient calculations were carried out for two wel1field limits. In the first, all the production wells were distributed within the $300^{\circ} \mathrm{F}$ isotherm inferred at the depth of $6000 \mathrm{ft}$ (Figure 4.1). In the second, all the production wells were distributed within the $300^{\circ} \mathrm{F}$ isotherm inferred at a depth of $7000 \mathrm{ft}$ Figure 1.29. In each case, the wells were distributed uniformly at equal spacing, in an idealized fashion. The spacing between the production wells varied depending on the number of wells. In general, the spacing for the 7000-ft case was 1.4 times the corresponding spacing for the 6000-ft case. The production-well spacing for the various cases is presented in Table 4.4 .

No injection. First consider the simplest case, assuming no reinjection. The configuration of the production wells for this case is illustrated in Figure 4.5, for $3000 \mathrm{~F}$ isotherm at $6000 \mathrm{ft}$. As an example of the output obtained, Figure 4.6 shows the drawdowns computed at the different we $11 \mathrm{~s}$ after 1.4 years for the 30 -production-well case. In Figure 4.7 a contour map and an isometric view of the drawdown data are shown for the cases considered in Figure 4.6. 
Table 4.3. Summary of the cases studied in the reservoir simulation.

\begin{tabular}{|c|c|c|c|c|c|c|c|c|c|c|c|c|c|c|c|c|c|}
\hline \multirow{3}{*}{$\begin{array}{l}\text { PROBLEM } \\
\text { TYPE }\end{array}$} & \multirow{3}{*}{ TECHWI QUE } & \multirow{3}{*}{$\begin{array}{l}\text { NUMBER OF } \\
\text { PRODUCTION } \\
\text { KELLS }\end{array}$} & \multicolumn{4}{|c|}{ NO INJECTION } & \multicolumn{4}{|c|}{ PERI PHERAL INJECTION } & \multicolumn{4}{|c|}{ FIVE-SPr:i PATTERN } & \multicolumn{3}{|c|}{ OTHER } \\
\hline & & & \multirow{2}{*}{\multicolumn{2}{|c|}{\begin{tabular}{c}
\multicolumn{2}{c}{ SPACING } \\
(feet) $\mid$ (acres)
\end{tabular}}} & \multicolumn{2}{|c|}{ FLOW RATE } & \multirow{2}{*}{$\begin{array}{c}\text { NUMBER } \\
\text { OF } \\
\text { INJECTION } \\
\text { WELLS }\end{array}$} & \multirow{2}{*}{ 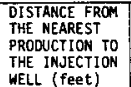 } & \multirow{2}{*}{$\begin{array}{l}\text { INJUECTIOON } \\
\text { RATE } \\
\text { PER } \\
\text { WELL } \\
\text { (gPm) }\end{array}$} & \multirow{2}{*}{\begin{tabular}{|l} 
PERCENTAGE \\
InJECTION
\end{tabular}} & \multirow{2}{*}{\begin{tabular}{|c|} 
NUMBEER OF \\
INJECTION \\
WELLS
\end{tabular}} & \multicolumn{2}{|c|}{ SPACING } & \multirow{2}{*}{$\begin{array}{l}\text { PERCENTAGE } \\
\text { INJECT IION }\end{array}$} & \multirow{2}{*}{$\begin{array}{c}\text { VISCOSITY } \\
\text { EFFECTS }\end{array}$} & \multirow{2}{*}{$\begin{array}{c}\text { MELL-BORE } \\
\text { DAMAGE }\end{array}$} & \multirow{2}{*}{$\begin{array}{l}\text { EFFECT OF } \\
\text { IMPERMEABLE } \\
\text { BARRIER }\end{array}$} \\
\hline & & & & & $\begin{array}{l}\text { per wel1 } \\
\text { (gpm) }\end{array}$ & $\begin{array}{l}\text { Total } \\
\text { (acre-ft/yr) }\end{array}$ & & & & & & (feet) & (acres) & & & & \\
\hline \multirow{6}{*}{$\begin{array}{l}\text { PRESSURE } \\
\text { TRANSIENT }\end{array}$} & \multirow{4}{*}{$\begin{array}{l}\text { ANALYTICAL } \\
\text { (MAXDRAW) }\end{array}$} & 15 & 4,200 & 405 & $\begin{array}{l}1,000 \\
(2,000) \\
(4,000)\end{array}$ & $\begin{array}{c}25 \times 10^{3} \\
\left(50010^{3}\right) \\
\left(100 \times 10^{3}\right)\end{array}$ & 14 & 4,200 & 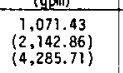 & 100 & 15 & 2,970 & 203 & $\begin{array}{l}100 \\
90 \\
80\end{array}$ & & & $\begin{array}{l}\text { One Impermeable } \\
\text { Barrifer Bound- } \\
\text { ary. }\end{array}$ \\
\hline & & 30 & 3,000 & 207 & $\begin{array}{r}(500) \\
(5,000) \\
(2,000)\end{array}$ & $\begin{array}{r}\left(25 \times 10^{3}\right) \\
5 \times 0 \times 10^{3} \\
\left(100 \times 10^{3}\right)\end{array}$ & $20 ; 24$ & 3,$000 ; 4,743.42 \mid$ & \begin{tabular}{|c|}
$(7500 ; 625)$ \\
1,$500 ; 1,250$ \\
$(3,000 ; 2,500)$
\end{tabular} & 100 & 30 & 2,120 & 103 & $\begin{array}{l}100 \\
90 \\
80\end{array}$ & & & $\begin{array}{l}\text { One Impermeable } \\
\text { Barrier Bound- } \\
\text { ary. }\end{array}$ \\
\hline & & 60 & 2,100 & 100 & $\begin{array}{r}(500) \\
1,000\end{array}$ & $\left\{\begin{array}{l}\left(50 \times 10^{3}\right. \\
\left.100 \times 10^{3}\right)\end{array}\right.$ & 27 & 2,100 & \begin{tabular}{|c|c|}
$(1,1111.11)$ \\
$2,222.22$
\end{tabular} & 100 & 60 & 1.485 & 51 & $\begin{array}{l}100 \\
90 \\
80\end{array}$ & & & $\begin{array}{l}\text { One Inpermeable } \\
\text { Barrier Bound- } \\
\text { ary }\end{array}$ \\
\hline & & 120 & 1,500 & 52 & $\begin{array}{r}\quad(500) \\
1,000\end{array}$ & $\begin{array}{c}\left(100 \times 10^{3}\right) \\
200 \times 10^{3}\end{array}$ & 39 & 1,500 & $\begin{array}{c}(1,538.46) \\
3,076.92\end{array}$ & 100 & 120 & 1,060 & 26 & $\begin{array}{r}100 \\
90 \\
80\end{array}$ & & & $\begin{array}{l}\text { One Inpermeable } \\
\text { Barrier Bound- } \\
\text { ary }\end{array}$ \\
\hline & \multirow{2}{*}{$\begin{array}{l}\text { Munerical } \\
\text { (TERZAGI) }\end{array}$} & 30 & & & & & & & & & 30 & 2,120 & 103 & 100 & Studied & studied & \\
\hline & & 60 & & & & & & & & & 60 & 1,485 & 51 & 100 & Studied & Studied & \\
\hline $\begin{array}{l}\text { WELL-BORE } \\
\text { HHEPOO- } \\
\text { OYFAMICS }\end{array}$ & $\begin{array}{l}\text { WELL-BORE } \\
\text { MODEL }\end{array}$ & $\begin{aligned} \text { Two cases } \\
\text { I. } \\
\text { II. } \\
\text { II. } \\
\text { ho } \\
\text { ho } \\
\text { ID }\end{aligned}$ & $\begin{array}{l}\text { studied: } \\
\text { representa } \\
\text { ture of } 36 \\
\text { represento } \\
\text { spoerature } \\
72 ; 11.15 \\
500 \text { to } 2.0\end{array}$ & 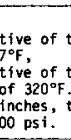 & $\begin{array}{l}\text { the central, } \\
\text { the peripher } \\
\text { theth case } \\
\text { the flow rat }\end{array}$ & $\begin{array}{l}\text { hot portion } \\
\text { ral, cooler po } \\
\text { es were conduc } \\
\text { te of } 1.000 \text { gp }\end{array}$ & $\begin{array}{l}\text { of the reser } \\
\text { irtion of the } \\
\text { ted with tw } \\
\text { mo, and the }\end{array}$ & $\begin{array}{l}\text { Ivoir, with the } \\
\text { le reservoir, wit } \\
\text { od different size } \\
\text { bottom-ho le pres }\end{array}$ & $\begin{array}{l}\text { bottom-hole } \\
\text { in the bottom- } \\
\text { sof of casing } \\
\text { sure varied }\end{array}$ & & & & & & & & \\
\hline \multirow{5}{*}{$\begin{array}{l}\text { THERPAL } \\
\text { BREAK- } \\
\text { THROUGH }\end{array}$} & \multirow{5}{*}{ 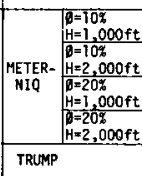 } & 30 & & & & & 20, & 3,000 & $\begin{array}{l}1,500 \\
1,070 \\
, 070\end{array}$ & 100 & 30 & 2,120 & 103 & 100 & & & \\
\hline & & 30 & & & & & 20 & 3,000 & $\begin{array}{l}1,000 \\
, 500 \\
3,070\end{array}$ & 100 & 30 & 2.120 & 103 & 100 & & & \\
\hline & & 30 & & & & & $\frac{28}{20,}$ & 3,000 & $\begin{array}{l}1,070 \\
1,500 \\
1,070\end{array}$ & 100 & 30 & 2,120 & 103 & 100 & & & \\
\hline & & 30 & & & & & $\begin{array}{l}-\frac{20}{20} \\
28\end{array}$ & 3,000 & $\begin{array}{l}1,500 \\
1,5070 \\
1,070\end{array}$ & 100 & 30 & 2,120 & 103 & 100 & & & \\
\hline & & $\frac{30}{60}$ & & & & & & & & & $\frac{30}{60}$ & $\begin{array}{l}2.120 \\
1.485\end{array}$ & $\frac{103}{51}$ & $\frac{100}{100}$ & & & \\
\hline
\end{tabular}


Table 4.4. Production-well spacing used in pressure-transient calculations for wells distributed within $300^{\circ} \mathrm{F}$ isotherm.

Well spacing ( $\mathrm{ft}$ ) at

\begin{tabular}{ccc} 
No. of wells & $6000-\mathrm{ft}$ depth & 7000-ft depth \\
\hline 15 & 4200 & 5880 \\
30 & 3000 & 4200 \\
60 & 2100 & 2940 \\
120 & 1500 & 2100 \\
\hline
\end{tabular}

(A)

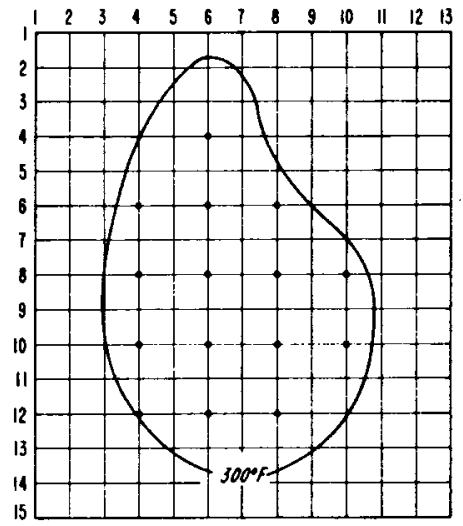

(c)

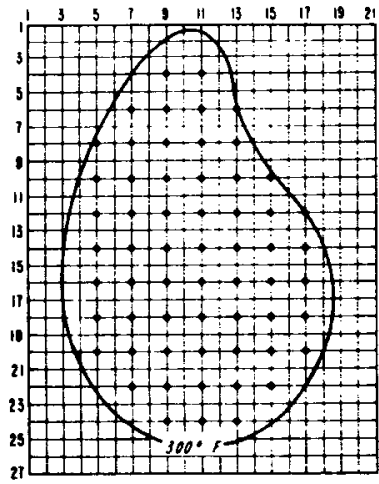

(8)

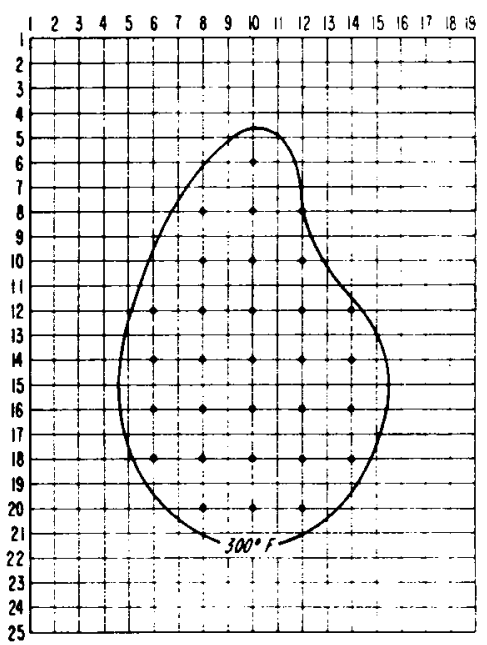

(D)

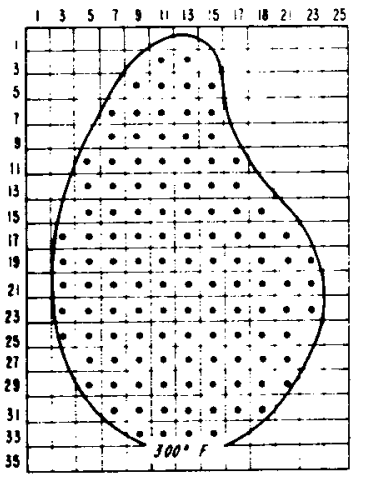

XBL $7811-12933$

Figure 4.5. Distribution of wells within the $300^{\circ} \mathrm{F}$ isotherm at $6000-\mathrm{ft}$ depth for the no-injection case: (A) 5 , (B) 30 , (C) 60 , and (D) 120 production wells. 
PRESSURE(PSI) DRAWDOWN( +) AND BUILDUP( - ) AFTER 1.40 YEAR( S )

\begin{tabular}{|c|c|c|c|c|c|c|c|c|c|c|c|c|c|c|c|c|c|c|c|}
\hline & 1 & 2 & 3 & 4 & 5 & 6 & 7 & 8 & 9 & 10 & 11 & 12 & 13 & 14 & 15 & 16 & 17 & 18 & 19 \\
\hline 1 & 464 & 493 & 521 & 547 & 573 & 595 & 614 & 629 & 638 & 642 & 638 & 629 & 614 & 595 & 573 & 547 & 521 & 493 & 464 \\
\hline 2 & 502 & 534 & 567 & 598 & 628 & 655 & 679 & 697 & 709 & 714 & 709 & 697 & 679 & 655 & 628 & 598 & 567 & 534 & 502 \\
\hline 3 & 541 & 578 & 615 & 652 & 688 & 721 & 750 & 774 & 790 & 796 & 790 & 774 & 750 & 721 & 688 & 652 & 615 & 578 & $54 i$ \\
\hline 4 & 581 & 623 & 666 & 709 & 752 & 792 & 829 & 861 & 883 & 892 & 883 & 861 & 829 & 792 & 752 & 709 & 666 & 623 & 581 \\
\hline 5 & 622 & 670 & 719 & 769 & 820 & 869 & 916 & 957 & 992 & 1009 & 992 & 957 & 916 & 869 & 820 & 769 & 719 & 670 & 622 \\
\hline 6 & 662 & 716 & 772 & 831 & 890 & 951 & 1010 & 1063 & 1111 & 1379 & 1111 & 1063 & 1010 & 951 & 890 & 831 & $T T 2$ & 716 & 662 \\
\hline 7 & 702 & 762 & 826 & 892 & 962 & 1035 & 1111 & 1181 & 1227 & 1252 & 1227 & 1181 & 1111 & 1035 & 962 & 892 & 826 & 762 & 702 \\
\hline 8 & 740 & 806 & 877 & 953 & 1033 & 1118 & 1212 & 1538 & 1344 & 1605 & 1344 & 1538 & 1212 & 1118 & 1033 & 953 & 877 & 806 & 740 \\
\hline 9 & 775 & 848 & 927 & 1011 & 1101 & 1196 & 1297 & 1388 & 1433 & 1456 & 1433 & 1388 & $129 T$ & 1196 & 1101 & 1011 & 927 & 848 & 775 \\
\hline 10 & 807 & 886 & 972 & 1066 & 1167 & 1271 & 1379 & 1712 & 1520 & 1781 & 1520 & 1712 & 1379 & 1271 & 1167 & 1066 & 972 & 886 & 807 \\
\hline 11 & 834 & 918 & 1012 & 1116 & 1230 & 1348 & 1449 & 1537 & 1580 & 1602 & 1580 & 1537 & 1449 & 1348 & 1230 & 1116 & 1012 & 918 & 834 \\
\hline 12 & 855 & 944 & 1044 & 1156 & 1286 & 1656 & 1514 & 1834 & 1636 & 1896 & 1636 & 1834 & 1514 & 1656 & 1286 & 1156 & 1044 & 944 & 55 \\
\hline 3 & 869 & 961 & 1065 & 1183 & 1316 & 1450 & 1545 & 1624 & 1663 & 1684 & 1663 & 1624 & 1545 & 1450 & 1316 & 1183 & 1065 & 961 & 869 \\
\hline 4 & 875 & 969 & 1075 & 1195 & 1333 & 1710 & 1567 & 1883 & 1683 & 1941 & 1683 & 1883 & 1567 & 1710 & 1333 & 1195 & 1075 & 969 & 875 \\
\hline & 873 & 967 & 1073 & 1193 & 1328 & 1463 & 1557 & 1635 & 1672 & 1692 & 1672 & 1635 & 1557 & 1463 & 1328 & 1193 & 1073 & 967 & 73 \\
\hline 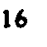 & 862 & 955 & 1058 & 1176 & 1312 & 1685 & 1540 & 1854 & 1652 & 1910 & 1652 & 1854 & 1540 & 1685 & 1312 & 1176 & 1058 & 955 & 862 \\
\hline & 844 & 933 & 1032 & 1145 & 1272 & 1400 & 1490 & 1565 & 1600 & 1620 & 1600 & 1565 & 1490 & 1400 & 1272 & 1145 & 1032 & 933 & 44 \\
\hline & 819 & 902 & 995 & 1100 & 1221 & 1582 & 1430 & 1742 & 1539 & 1797 & 1539 & 1742 & 1430 & 1582 & 1221 & 1100 & 995 & 902 & 819 \\
\hline & 788 & 865 & 949 & 1042 & 1144 & 1248 & 1335 & 1410 & 1446 & 1465 & 1446 & 1410 & 1335 & 1248 & 1144 & 1042 & 949 & 865 & 788 \\
\hline & 752 & 821 & 896 & 977 & 1061 & 1146 & 1233 & 1547 & 1342 & 1599 & 1342 & 1547 & 1233 & 1146 & 1061 & 977 & 896 & 821 & 752 \\
\hline & 712 & 774 & 840 & 909 & 979 & 1049 & 1117 & 1176 & 1206 & 1220 & 1206 & 1176 & 1117 & 1049 & 979 & 909 & 840 & 774 & 12 \\
\hline & 671 & 726 & 783 & 841 & 899 & 956 & 1007 & 1048 & 1074 & 1083 & 1074 & 1048 & 1007 & 956 & 899 & 841 & 763 & 726 & 671 \\
\hline & 628 & 676 & 726 & 775 & 824 & 869 & 909 & 940 & 960 & 967 & 960 & 940 & 909 & 869 & 824 & 775 & 726 & 676 & 628 \\
\hline A & 586 & 628 & 671 & 712 & 753 & 789 & 821 & 845 & 861 & 866 & 861 & 845 & 821 & 789 & 753 & 712 & 671 & 628 & 586 \\
\hline 25 & 544 & 581 & 618 & 653 & 687 & 717 & 743 & 762 & 774 & 778 & 774 & 762 & 743 & 717 & 687 & 653 & 618 & 581 & 544 \\
\hline
\end{tabular}

XBL 7810-11848

Figure 4.6. Sample printout of drawdowns computed for the no-injection case showing 30 we $11 \mathrm{~s}$ within $300^{\circ} \mathrm{F}$ isotherm at $6000-\mathrm{ft}$ depth. Flow rate is $1000 \mathrm{gpm}$ per well. 
(A)

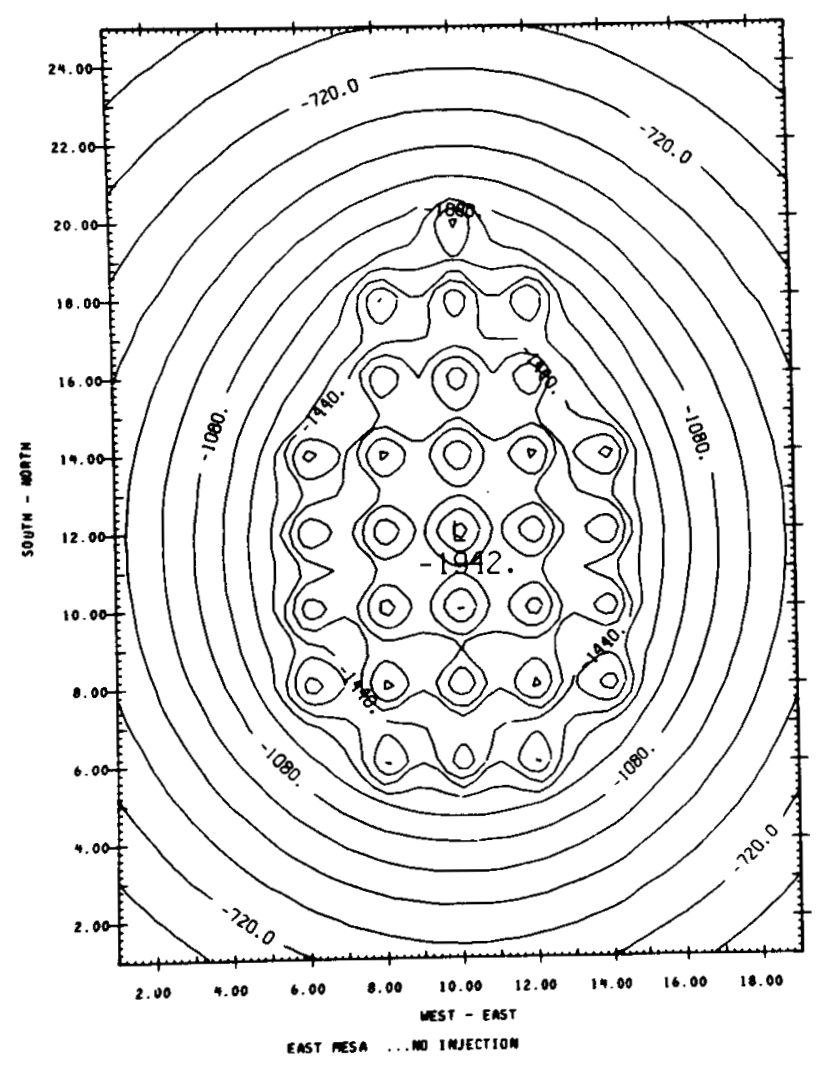

(B)

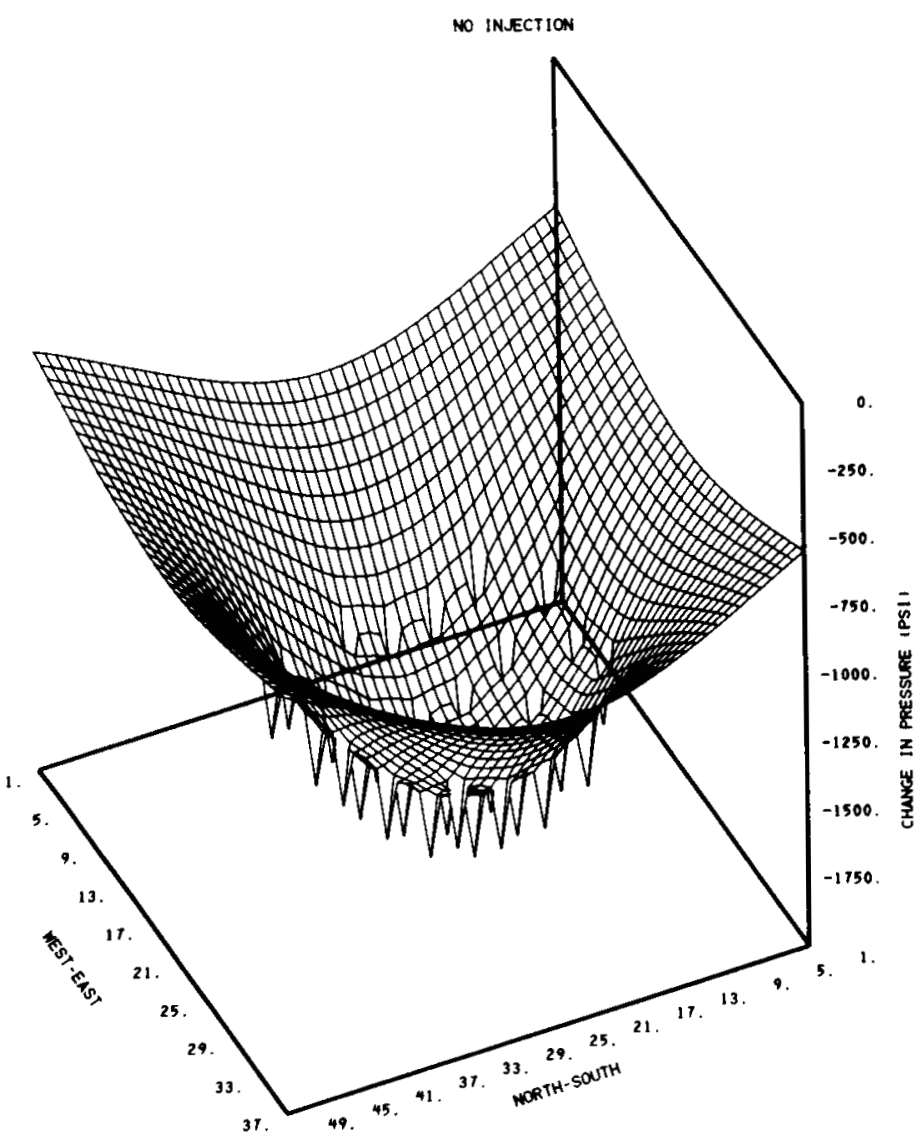

XBL $7811-12934$

Figure 4.7. Two-dimensional (A) and three-dimensional (B) plots of pressure drawdown contours for the no-injection case considered in Figure 4.6. 
The results from all the different runs studied for the no-injection case are summarized in Figure 4.8. Since there is no replenishment by injection, the flow field will forever be nonsteady. The results in Figure 4.8 are presented at an arbitrary time of 11.22 years after production started. The banded regions indicate the range of drawdowns computed for the different parts of the well field. Note the following in Figure 4.8.

1. The computed drawdowns are consistently in excess of $2100 \mathrm{psi}$ for the $50,000 \mathrm{acre}-\mathrm{ft} / \mathrm{yr}$ case and $4250 \mathrm{psi}$ for the 100,000 acre-ft/yr case. Although the 25,000 acre-ft/yr case is omitted in Figure 4.8 for clarity, the drawdowns for this case will be equal to $50 \%$ of the corresponding 50,000 acre-ft/yr run. If we consider that $1 \mathrm{psi}$ is approximately equivalent to $2.5 \mathrm{ft}$ of water, it immediately becomes apparent that for drawdowns inexcess of $2000 \mathrm{psi}$, the flash-point depth in the well should drop below the top of the reservoir, initiating boiling within the reservoir, which will invalidate the basic singlephase assumption of the present study. Therefore, the actual significance of Figure 4.8 is to show that production has to be suitably scaled down if the reservoir is to sustain it. Conversely, if large production is forced on the reservoir, the production will eventually decline due to the inability of the reservoir to transmit enough fluids to match the discharge.

2. Both the drawdown bands are more or less horizontal when the number of wells is greater than or equal to 30 . This simply shows that, by and large, withdrawal of water at a given total rate from an area will lead to approximately the same pressure drawdowns, irrespective of the number of wells.

In summary, then, for an annual flow rate of 25,000 acre-ft, one could expect average drawdowns of about $1250 \mathrm{psi}$ in the production wells. For the 50,000 and the 100,000 acre-ft/yr cases, the drawdowns will be proportionately higher.

Peripheral injection. From the point of view of sweeping heat into the central portions of the well field, peripheral injection is a very good strategy. Several possible scenarios were considered in this regard. In the basic case, the injection wells were located beyond 


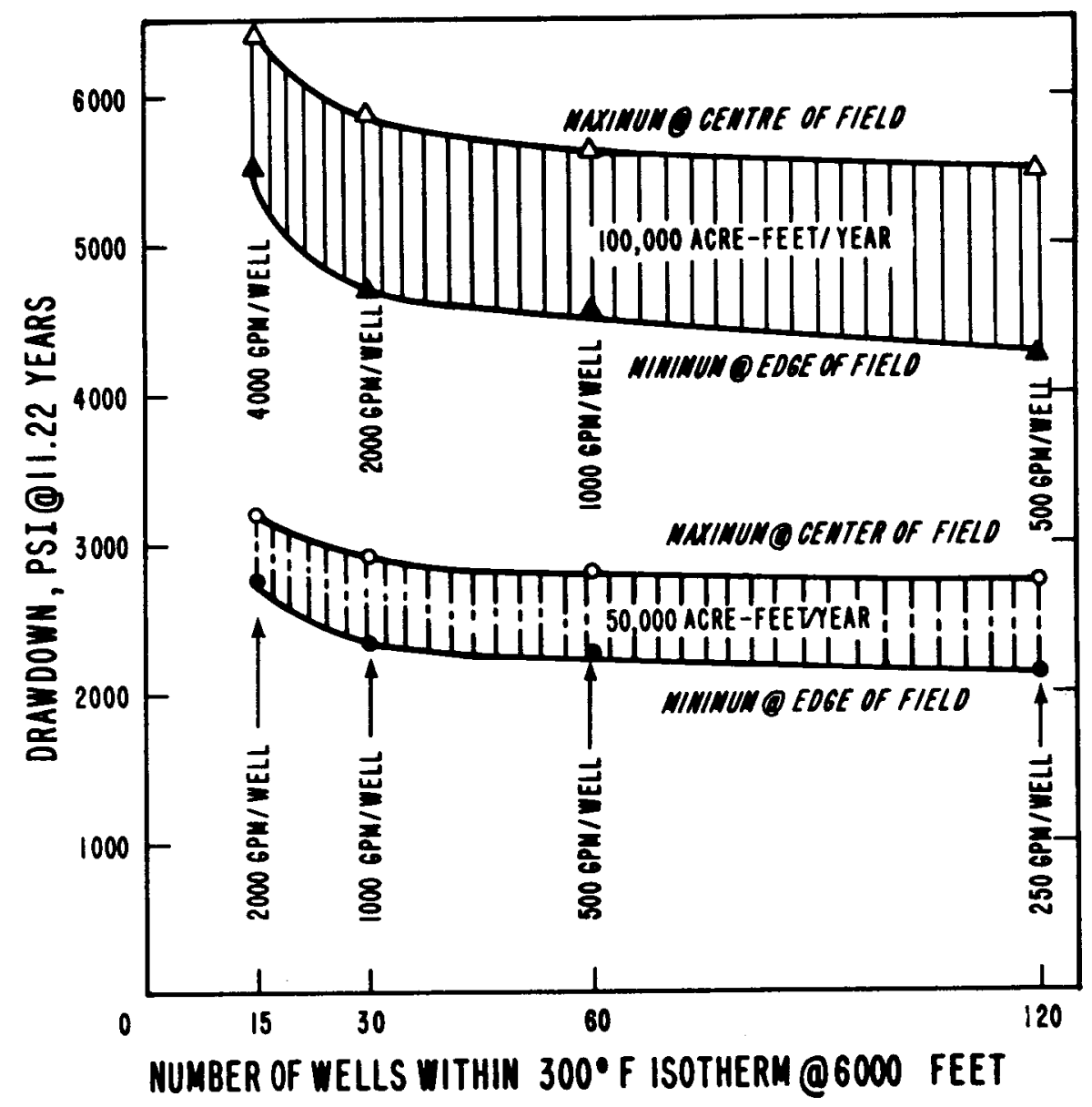

$X 8\llcorner 7811-2169$

Figure 4.8. Summary of results for the no-injection case. Wells located within $300^{\circ} \mathrm{F}$ isotherm at 6000-ft depth. Drawdowns for 25,000 acre-ft omitted for clarity (see text). 
the outermost producing wells at a spacing equal to the production well spacing within the well field. We will call this case the closein injection ring, as illustrated in Figure 4.9. Although this configuration leads to fewer injection we11s, in order to assure $100 \%$ injection, the per-well injection flow rates have to be proportionately large.

In order to evaluate the effects of the proximity of the injection ring to the production wells, a few simulations were carried out with the injection wells located much farther away from the outermost production wells than is seen in Figure 4.9. A comparison of the results quickly showed that although moving the injection wells farther away increases thermal breakthrough times, it greatly reduces pressure support to wells within the reservoir. Since, in the present study, pressure drawdowns appear to be of greater concern than temperature breakthroughs, we will direct our attention primarily to the close-in peripheral injection case, which is more advantageous for reservoir pressure support than a more distant ring of injection wells.

A sample computer printout of the quasi-steady static pressure drawdowns and injection pressures in excess of the static pressures are presented in Figure 4.10 for the particular problem of 30 production and 20 injection wells within the $300 \%$ isotherm at $6000 \mathrm{ft}$. A contour plot and an isometric view of the data from Figure 4.10 are shown in Figure 4.11.

A summary of the various cases studied in presented in Figure 4.12. In this figure, the drawdowns for the 25,000 acre-ft/yr case are omitted for clarity. The drawdowns for the 25,000 acre-ft/yr case will be $50 \%$ of the corresponding 50,000 acre-ft/yr case.

One can easily see from Figure 4.12(A) that for the 50,000 acre$\mathrm{ft} / \mathrm{yr}$ case, the average drawdowns decrease from about 950 psi for 15 production wells to about $300 \mathrm{psi}$ for 120 production wells, while corresponding maximum drawdowns of 1000 to 700 psi could be expected in the central portions of the well field. These values are to be multiplied by a factor of 2 for the 100,000 acre-ft/yr case. Similarly, Figure 4.12(B) shows that for an annual injection rate of 
(A)

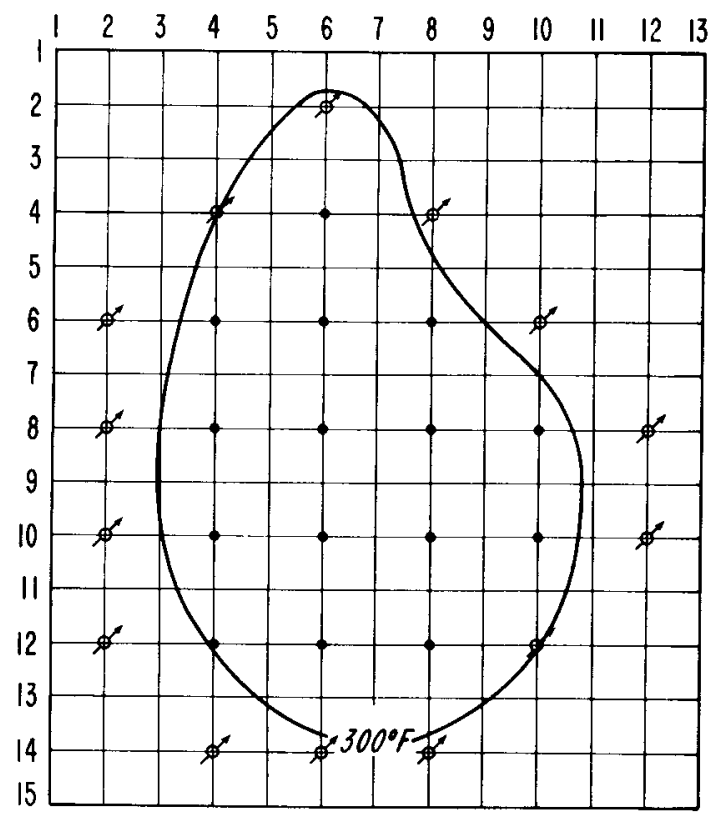

(c)

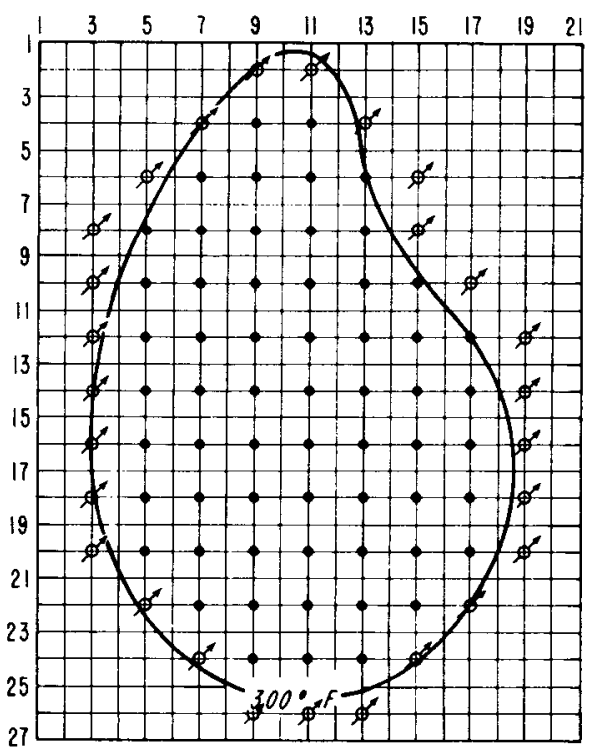

(B)

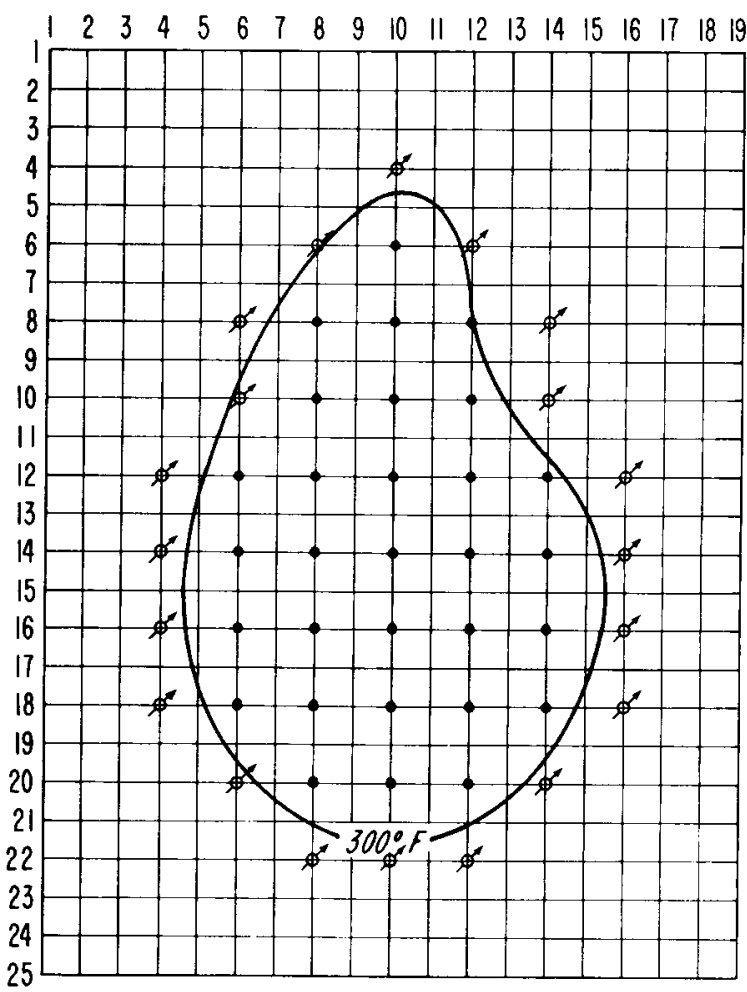

(D)

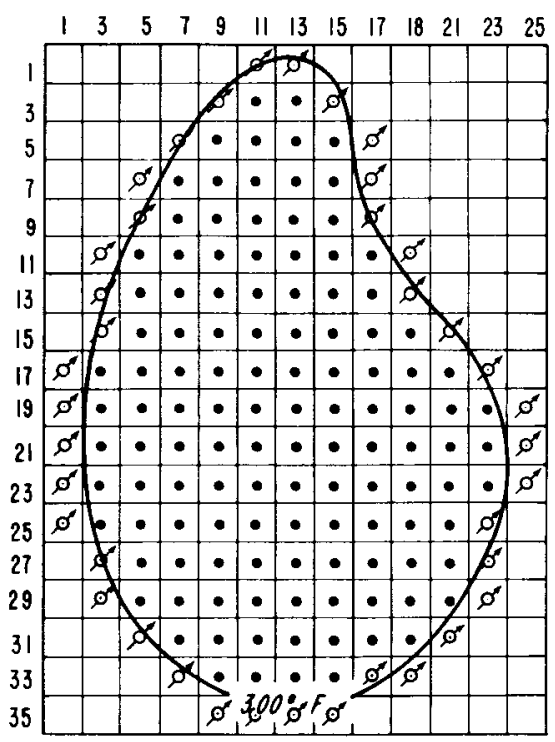

XBL 7811-2134A

Figure 4.9. Configuration of production and injection wells for closein peripheral injection. (A) 15, (B) 30, (C) 60 , (D) 120 production wells. Production wells located within $300 \%$ isotherms at 6000-ft depths. 
PAESSURE(PSI) DAAWDOWN( +) AND BUILDUP( - ) AFTER 11.22 YEAR(S)

\begin{tabular}{|c|c|c|c|c|c|c|c|c|c|c|c|c|c|c|c|c|c|c|}
\hline & 1 & 2 & 3 & 4 & 5 & 6 & 7 & 8 & 9 & 10 & 11 & 12 & 13 & 14 & 15 & 16 & 17 & 18 \\
\hline 1 & -6 & -7 & -9 & -11 & -14 & -18 & -22 & -26 & -30 & -31 & -30 & -26 & -22 & -18 & -14 & -11 & -9 & -7 \\
\hline 2 & -5 & -6 & -8 & -10 & -14 & -18 & -23 & -30 & -37 & -41 & -37 & -30 & -23 & -18 & -14 & -10 & -8 & -6 \\
\hline 3 & -4 & -5 & -6 & -9 & -12 & -16 & -23 & -32 & -47 & -61 & -47 & -32 & -23 & -16 & -12 & -9 & -6 & -5 \\
\hline 4 & -2 & -3 & -4 & -6 & -9 & -13 & -20 & -29 & -48 & -428 & -48 & -29 & -20 & -13 & -9 & -6 & -4 & -3 \\
\hline 5 & 0 & 0 & -1 & -3 & -5 & -8 & -15 & -22 & -7 & -1 & -7 & -22 & -15 & -8 & -5 & -3 & -1 & 0 \\
\hline 6 & 1 & 1 & 1 & 0 & 0 & 0 & 0 & -356 & 55 & 332 & 55 & -356 & 0 & 0 & 0 & 0 & 1 & 1 \\
\hline 7 & 4 & 5 & 5 & 4 & 1 & 6 & 47 & 96 & 148 & 178 & 148 & 96 & 47 & $\leq$ & 1 & 4 & 5 & 5 \\
\hline 8 & 6 & 8 & 11 & 12 & 5 & -343 & 103 & 439 & 250 & 514 & 250 & 439 & 103 & -343 & 5 & 12 & 11 & 8 \\
\hline 9 & 8 & 12 & 17 & 24 & 32 & 60 & 163 & 271 & 326 & 352 & 326 & 271 & 163 & 60 & 32 & 24 & 17 & 12 \\
\hline 10 & 9 & 13 & 21 & 37 & 60 & -252 & 226 & 585 & 403 & 667 & 403 & 585 & 226 & -252 & 60 & 37 & 21 & 13 \\
\hline 11 & 9 & 11 & 16 & 36 & 103 & 194 & 304 & 406 & 459 & 484 & 459 & 406 & 304 & 194 & 103 & 36 & 16 & 11 \\
\hline 12 & 8 & 9 & 5 & -331 & 139 & 513 & 377 & 706 & 515 & 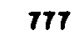 & 515 & 706 & 377 & 513 & 139 & -331 & 5 & 9 \\
\hline 13 & 7 & 8 & 10 & 41 & 164 & 308 & 413 & 500 & 544 & 566 & 544 & 500 & 413 & 308 & 164 & 41 & 10 & 8 \\
\hline 14 & 6 & 7 & 7 & -318 & 174 & 569 & 438 & 762 & 566 & 827 & 566 & 762 & 438 & 569 & 174 & -318 & 7 & 7 \\
\hline 15 & 5 & 6 & 10 & 46 & 176 & 327 & 433 & 518 & 559 & 581 & 559 & 518 & 433 & 327 & 176 & 46 & 10 & 6 \\
\hline 16 & 4 & 4 & 2 & -325 & 165 & 557 & 421 & 742 & 544 & 804 & 544 & 742 & 421 & 557 & 165 & -325 & 2 & 4 \\
\hline 17 & 4 & 3 & 2 & 29 & 146 & 283 & 380 & 459 & 498 & 518 & 498 & 459 & 380 & 283 & 146 & 29 & 2 & 3 \\
\hline 18 & 4 & 2 & -4 & $-34 t$ & 114 & $4 T t$ & $32 T$ & 642 & 442 & 700 & 442 & 642 & 327 & 477 & 114 & $-34 T$ & -4 & 2 \\
\hline 19 & 4 & 4 & 5 & 19 & 75 & 149 & 236 & 316 & 352 & 371 & 352 & 316 & 236 & 149 & 75 & 19 & 5 & 4 \\
\hline 20 & 6 & 7 & 12 & 22 & 35 & -299 & 142 & 460 & 252 & 506 & 252 & 460 & 142 & -299 & 35 & 22 & 12 & 7 \\
\hline 21 & 6 & 8 & 12 & 17 & 21 & 30 & 65 & 95 & 115 & 120 & 115 & 95 & 65 & 30 & 21 & 17 & 12 & 8 \\
\hline 22 & 6 & 7 & 9 & 12 & 14 & 15 & 7 & -366 & 2 & -361 & 2 & -366 & 7 & 15 & 14 & 12 & 9 & 7 \\
\hline 23 & 5 & 6 & 7 & 7 & 7 & 4 & -7 & -21 & -20 & -24 & -20 & -21 & -7 & 4 & 7 & 7 & 7 & 6 \\
\hline 24 & 4 & 4 & 4 & 4 & 3 & 0 & -6 & -12 & -15 & -16 & -15 & -12 & -6 & 0 & 3 & 4 & 4 & 4 \\
\hline 25 & 3 & 3 & 3 & 2 & 0 & -1 & -5 & -9 & -11 & -11 & -11 & -9 & -5 & -1 & 0 & 2 & 3 & 3 \\
\hline
\end{tabular}

XBL $7810-11849$

Figure 4.10. Sample printout of drawdowns and injection pressures in excess of static for close-in peripheral injection with wells within $300 \% \mathrm{~F}$ isotherm at 6000-ft depth. Negative numbers indicate injection pressure in excess of static pressure. 


\section{(A)}

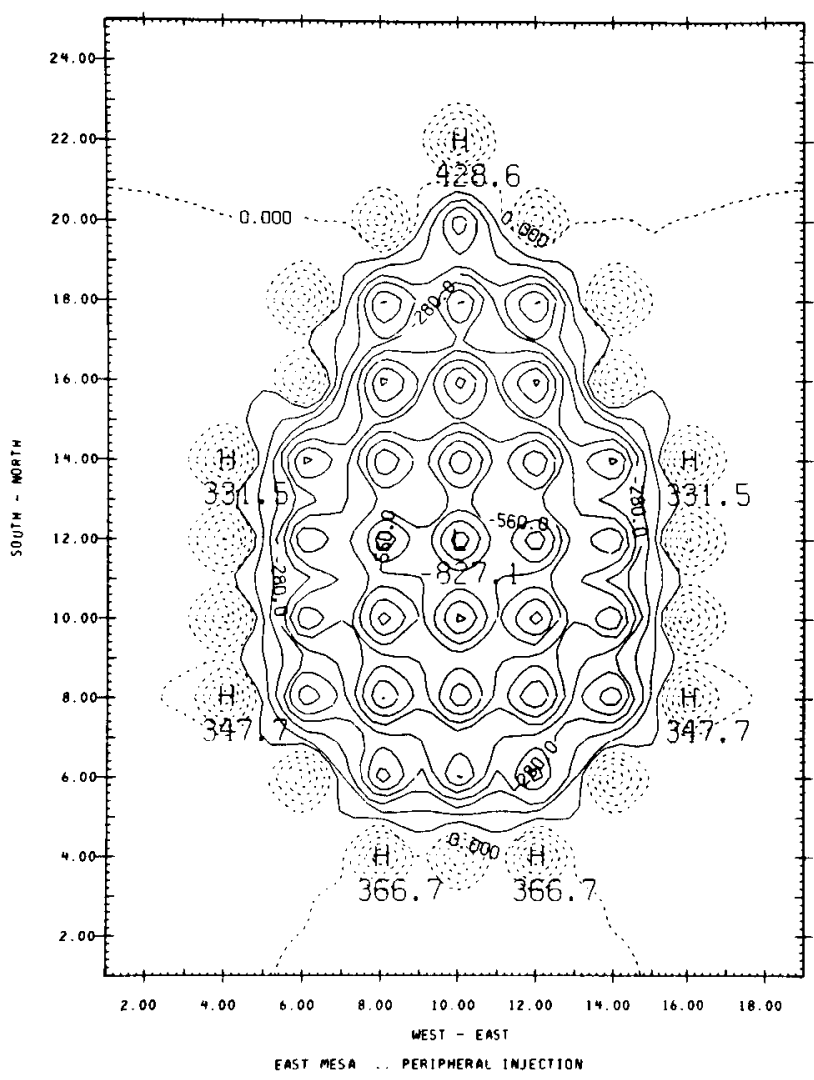

(B)

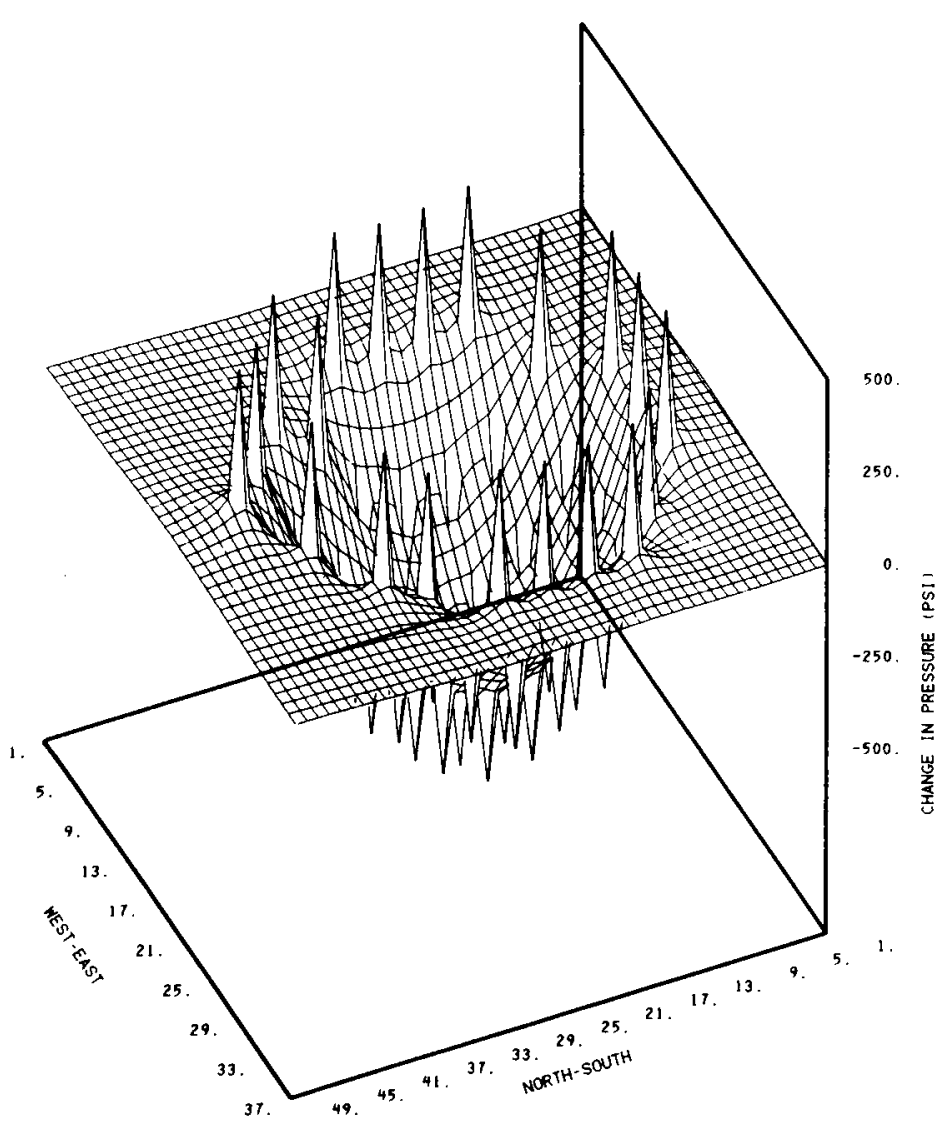

XBL $7811-12936$

Figure 4.11. Two-dimensional (A) and three-dimensional (B) contour plots of the results shown in Figure 4.10 for peripheral injection. 
Table 4.5. Close-in peripheral injection case: comparison of drawdown ranges for production well within $300^{\circ} \mathrm{F}$ isotherm at 6000- and 700-ft depth. Total production is 50,000 acre-ft/yr in all cases.

\begin{tabular}{|c|c|c|c|c|c|c|c|c|}
\hline \multirow[b]{3}{*}{$\begin{array}{l}\text { No. of } \\
\text { Wells }\end{array}$} & \multicolumn{4}{|c|}{ Minimum Drawdown } & \multicolumn{4}{|c|}{ Maximum Drawdown } \\
\hline & \multicolumn{2}{|c|}{ 6000-ft depth } & \multicolumn{2}{|c|}{ 7000-ft depth } & \multicolumn{2}{|c|}{ 6000-ft depth } & \multicolumn{2}{|c|}{ 7000-ft depth } \\
\hline & $\begin{array}{l}\text { Spacing } \\
(\mathrm{f} t)\end{array}$ & $\begin{array}{l}\text { Drawdown } \\
\text { (psi) }\end{array}$ & $\begin{array}{c}\text { Spacing } \\
(\mathrm{ft})\end{array}$ & $\begin{array}{c}\text { Drawdown } \\
\text { (psi) }\end{array}$ & $\begin{array}{c}\text { Spacing } \\
(\mathrm{ft})\end{array}$ & $\begin{array}{l}\text { Drawdown } \\
\text { (psi) }\end{array}$ & $\begin{array}{c}\text { Spacing } \\
(\mathrm{ft})\end{array}$ & $\begin{array}{c}\text { Drawdown } \\
\text { (psi) }\end{array}$ \\
\hline 15 & 4200 & 748 & 5880 & 768 & 4200 & 1138 & 5880 & 1156 \\
\hline 30 & 3000 & 332 & 4200 & 341 & 3000 & 827 & 4200 & 835 \\
\hline 60 & 2100 & 196 & 2940 & 200 & 2100 & 660 & 2940 & 663 \\
\hline 120 & 1500 & 43 & 2100 & 44 & 1500 & 580 & 2100 & 580 \\
\hline
\end{tabular}
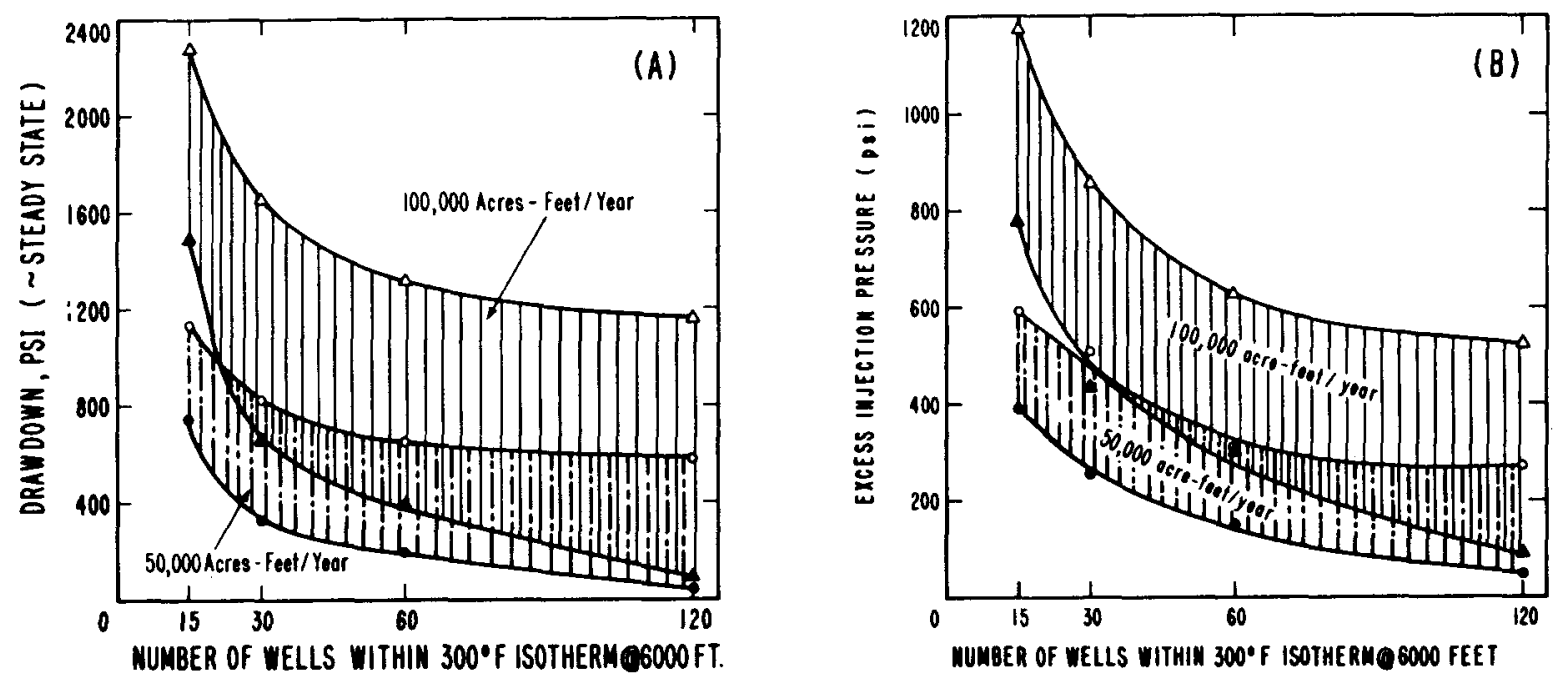

$X B \perp 7811-2167$

Figure 4.12. Summary of results for the close-in peripheral injection case. Production wells are within $300^{\circ} \mathrm{F}$ isotherm at 6000-ft depth. Drawdowns for 25,000 acre-ft/yr are omitted for clarity. (A) Drawdowns, (B) injection pressures in excess of static pressure. 
50,000 acre-ft, the excess injection pressures over static pressures decrease from about 450 to about $150 \mathrm{psi}$, as the number of wells increases.

In another series of peripheral injection scenarios, the wells were distributed within the $300^{\circ} \mathrm{F}$ isotherm inferred at a depth of $7000 \mathrm{ft}$ below land surface. Since the area enclosed by this isotherm is about 1.9 times the size of the area enclosed by the same isotherm at $6000 \mathrm{ft}$, the well spacing in this case had to be 1.4 times the spacing used in the other case (Figure 4.9). The results of these simulations are summarized in Table 4.5. These studies reveal that insofar as peripheral injection is concerned, enlarging the area with the same we11-field configuration has no effect on the pressure distribution. As shown in Table 4.5, although the spacing between the production wells is increased when considering $3000 \mathrm{~F}$ isotherm at $7000 \mathrm{ft}$ (and hence interference effects should decrease), the injection wells are pushed farther back and the pressure support from them decreases. Quantitatively these two effects seem to complement each other exactly, so increased spacing of wells does not lead to reduction in drawdowns. As an added check on the calculations, a few of the simulations were repeated by increasing the spacing to 1.9 times that in Figure 4.9 . These also gave almost the same results as are presented in Table 4.5.

In a third series of models, the possibility of a barrier boundary was considered. It is well known that wells located close to barrier boundaries will experience higher pressure drawdowns than would be the case if no barrier boundaries were present. In the case of peripheral injection, the actual location of the barrier and its orientation will have a great effect on the system response. However, inasmuch as we are simulating an idealized reservoir, let us consider the effect of a barrier trending northwest-southeast, as in Figure 4.13. In this case, the barrier divides the well field into two parts, each of which have 10 injection wells. Of the 30 production wells, the northern part has only 13 production wells and the southern block the remaining 17 . The drawdown and excess injection pressures (over static pressure) calculated are presented in Figure 4.14. As can be seen from the figure (in comparison with Figure 4.10), the block to the south of the barrier is characterized in general by higher drawdowns and lower injection 


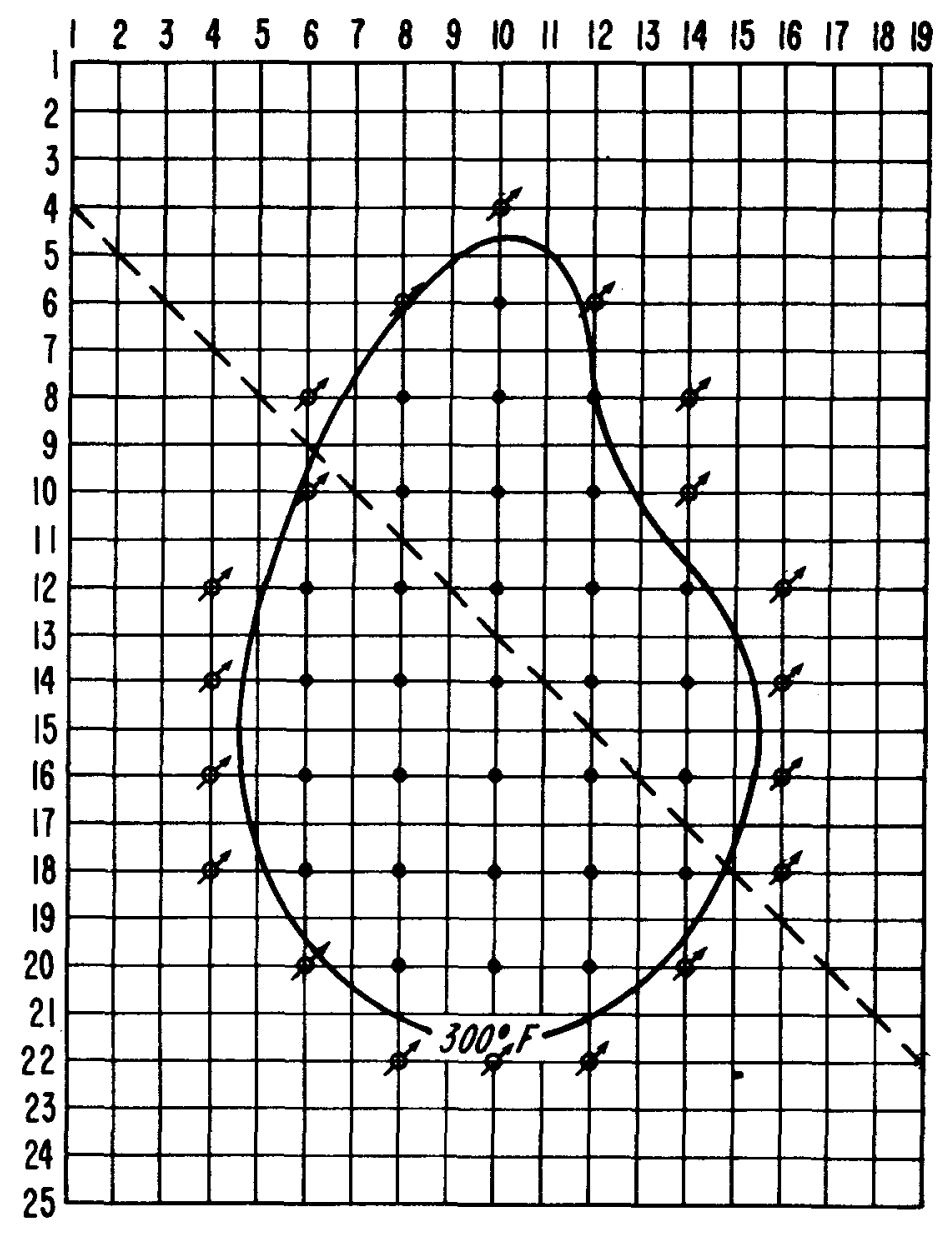

XBL7810-2129

Figure 4.13. Effect of barrier boundary on close-in peripheral injection: disposition of the assumed boundary. 
PRESSURE(PSI) DRAWDOWN(+) AND BUILDUP( - ) AFTER 11.22 YEAR(S)

\begin{tabular}{|c|c|c|c|c|c|c|c|c|c|c|c|c|c|c|c|c|c|c|c|}
\hline & & 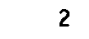 & 3 & 4 & & 6 & I & & & 10 & 1 & $?$ & 3 & 4 & 15 & 6 & 7 & 8 & \\
\hline & 54 & 8 & 62 & 6 & - & - & -182 & -189 & -194 & 98 & -197 & -195 & -191 & 88 & -184 & -181 & -178 & -175 & $5-$ \\
\hline 2 & 8 & -162 & -166 & -171 & -176 & -182 & -190 & -198 & -208 & -213 & -211 & -205 & -200 & -195 & -191 & -187 & -184 & -181 & -1 \\
\hline 3 & 162 & -166 & -170 & 175 & -180 & -187 & -195 & -2 & -224 & 40 & - & 15 & -207 & 02 & 97 & -194 & -190 & -187 & $7-184$ \\
\hline 4 & & & -174 & 78 & -183 & -189 & -198 & -209 & -231 & -614 & -237 & -220 & -213 & -207 & -203 & -200 & -197 & -193 & $3-190$ \\
\hline 5 & 166 & 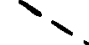 & -177 & -181 & -185 & -189 & -198 & -207 & -196 & -194 & -204 & -221 & -217 & -211 & -208 & -206 & -203 & -200 & -19 \\
\hline 6 & 171 & 178 & & -184 & -187 & -185 & -188 & -546 & -138 & 132 & -148 & -565 & -212 & -212 & -214 & -212 & -209 & -206 & $6-2.03$ \\
\hline 7 & 176 & 123 & 191 & 1 & -193 & -183 & -141 & -96 & -51 & -28 & -66 & -123 & -175 & -218 & -224 & -219 & -216 & -213 & $3-210$ \\
\hline 8 & 80 & 188 & 197 & $20 t$ & & -53 & -81 & 247 & 46 & 298 & 25 & 207 & -133 & -582 & -233 & -225 & -223 & -221 & $1-21 \varepsilon$ \\
\hline 9 & 184 & 193 & 203 & 215 & 20 & & -2 & 84 & 117 & 12 & 88 & 24 & -88 & -194 & -221 & -226 & -230 & -230 & -227 \\
\hline & Q7 & 196 & 208 & 226 & 244 & -86 & & 399 & 183 & 426 & 147 & 319 & -43 & -524 & -210 & -230 & -240 & -241 & $1-2$ \\
\hline & 189 & 197 & 206 & 229 & 295 & 381 & 489 & & 217 & 221 & 180 & 11 & 11 & -99 & -186 & -248 & -261 & -257 & $7-250$ \\
\hline & 191 & 198 & 200 & -1 & 342 & 122 & 597 & 9 & & 40 & 207 & 390 & 8 & 196 & -173 & - & -288 & -274 & +-264 \\
\hline & 93 & 200 & 210 & 248 & 379 & 534 & 654 & 763 & 834 & & 7 & 15 & 63 & -36 & -172 & -283 & -302 & -290 & -27 \\
\hline & 95 & 204 & 212 & -104 & 3 & 8 & 94 & 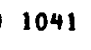 & 4 & 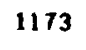 & & 27 & 53 & 192 & -189 & -667 & -324 & -306 & -290 \\
\hline & 年 & 206 & 19 & 266 & 408 & 574 & 9 & 806 & 8th & 3. & 945 & & 4 & -85 & -217 & 6 & - & -322 & 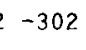 \\
\hline & 97 & 206 & 214 & -101 & 401 & 809 & 692 & 1035 & 863 & 1153 & 930 & 1171 & & 106 & -262 & -724 & -366 & -337 & -313 \\
\hline & & 200 & 215 & 254 & 385 & 537 & 652 & $75 ?$ & 815 & & & P7? & 830 & & 1 & -396 & -383 & -349 & -321 \\
\hline & 94 & 205 & 209 & -121 & 353 & 31 & 998 & 933 & 754 & 1037 & 806 & 1037 & 755 & 94 & & & -400 & 355 & 323 \\
\hline & 98 & 207 & 218 & 244 & 313 & 100 & 03 & 601 & 657 & 97 & 701 & 689 & 635 & 574 & 5 & & & -348 & -319 \\
\hline & 3 & 207 & 223 & 245 & $26 \%$ & -52 & 404 & 738 & 370 & 319 & 583 & 811 & 3 & 86 & 7 & $T_{1}$ & & 3 & -310 \\
\hline & 16 & 7 & 20 & 36 & 52 & 73 & 320 & 364 & 199 & 420 & 430 & 424 & 407 & 383 & 37 & 371 & 3 & & \\
\hline & 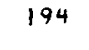 & (n) & 15 & (2) & 3 & 52 & 254 & 06 & 7 & -10 & 7 & -57 & 325 & 341 & 3 & 336 & $3 / n$ & 311 & \\
\hline & 190 & 199 & 208 & 218 & 227 & 33 & 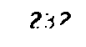 & 8 & 40 & 246 & 260 & $26 R$ & 290 & 306 & . & 8 & $n ?$ & 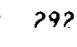 & the \\
\hline & . & (12 & 201 & 209 & 216 & & & $? 21$ & 234 & 241 & 250 & 260 & 272 & 281 & 285 & 185 & 1 & 274 & s. \\
\hline & 181 & (n) & n & $20 \mathrm{i}$ & 08 & 2 & 17 & ?? & ?? & 234 & 24 & 249 & h & $2 A ?$ & $26 k$ & Pho & $2+3$ & 251 & 1 \\
\hline
\end{tabular}

$X B L 7811-2165$

Figure 4.14. Effect of barrier boundary on close-peripheral injection. Sample printout of drawdowns. 
pressures; the northern block is characterized by higher excess injection pressures and lower drawdowns. The presence of barriers tends to increase drawdowns and excess injection pressures. An isometric view of the results in Figure 4.14 are presented in Figure 4.15 .

In summary, for peripheral injection, pressure drawdowns may vary from about $950 \mathrm{psi}$ for 15 production wells to about $300 \mathrm{psi}$ for 120 production wells for a total annual flow rate of 50,000 acre-ft. The pressure drawdowns can be directly scaled for 25,000 and 100,000 acre$\mathrm{ft} / \mathrm{yr}$. Distributing the same number of wells over a larger area will not enhance pressure support. Finally, barrier boundaries, if present, will increase drawdowns and excess injection pressures.

Five-spot pattern. In a five-spot pattern, the injection wells are interspersed uniformly with production wells, as in Figure 4.16. Because of the proximity of production and injection wells, the fivespot pattern is perhaps the most beneficial for reservoir pressure support .

In dealing with five-spot pattern, one commonly uses the term "acre per we11," as a quantitative measure of well spacing. By convention, acreage per well is given by the equation

Acreage per we $11=D_{i}^{2} / 9 \times 4840$

where $D_{i}$ is the distance, in feet, between a production well and the nearby injection well in the five-spot configuration.

A sample printout of the drawdowns and excess injection pressures computed for a five-spot case with 30 pairs of wells is given in Figure 4.17. A contour map and an isometric view of the same results are given in Figure 4.18.

The results obtained with various five-spot simulation studies are presented in Figures 4.19 through 4.21 . The results presented in Figures 4.19 and 4.20 relate to $100 \%$ volumetric reinjection; those in Figure 4.21 show the effect of unbalanced injection on pressure drawdowns . 


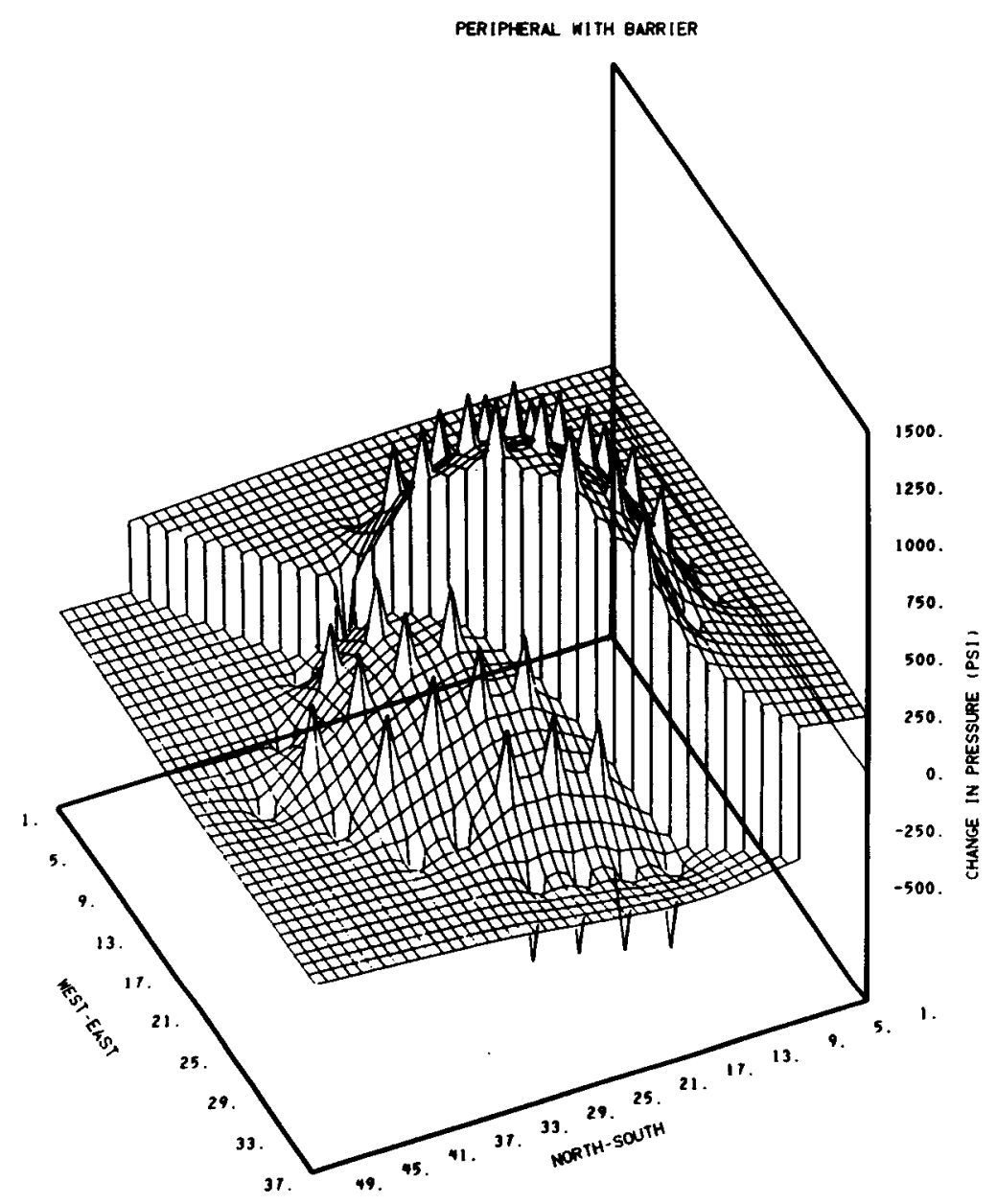

XBL $7812-14018$

Figure 4.15. Effect of barrier boundary on close-in peripheral injection. Three-dimensional plot of data in Figure 4.14 . 
(A)

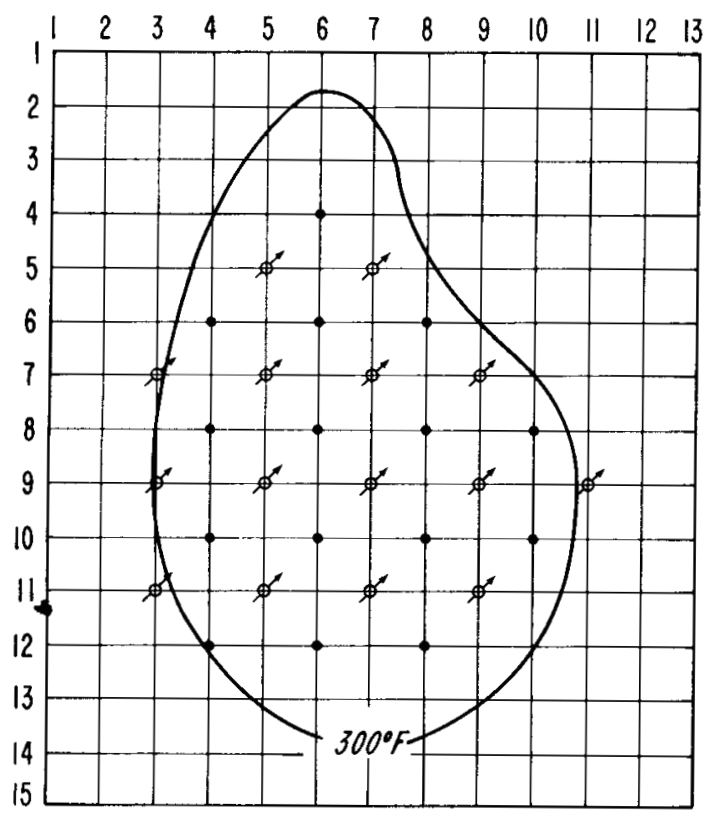

(c)

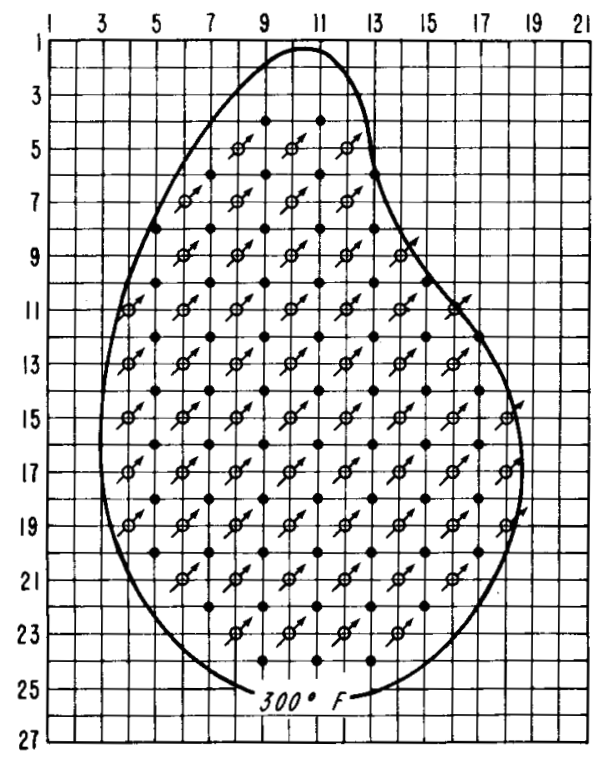

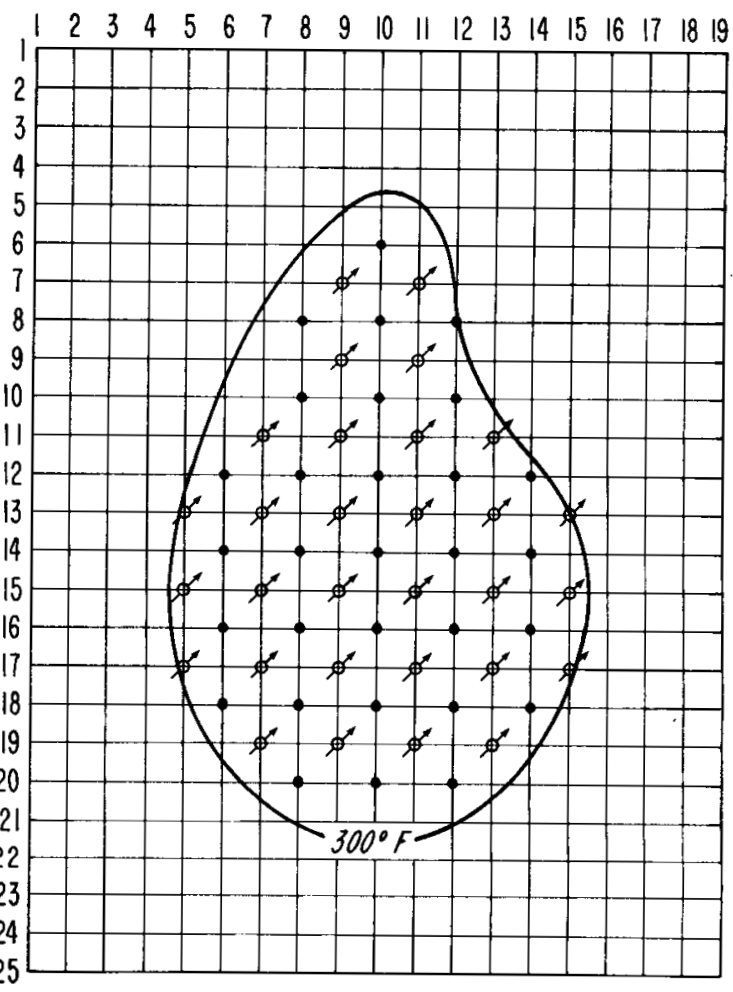

(D)

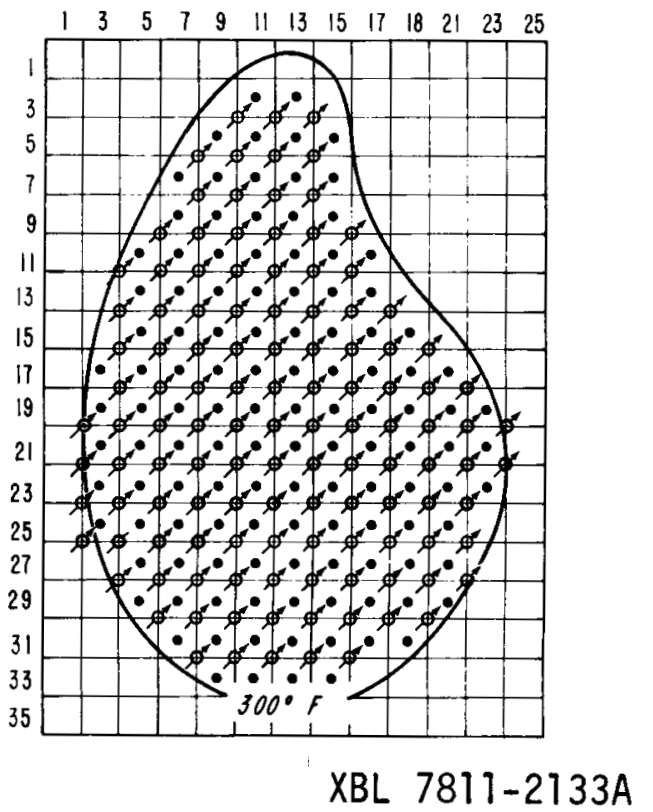

Figure 4.16. Production and injection well configurations for fivespot pattern: (A) 15, (B) 30 , (C) 60 , and (D) 120 production wells. Wells are located within $300^{\circ} \mathrm{F}$ isotherm at 6000-ft depth. 
PRESSURE(PSI) DRAWDDWN( +) AND BUILDUP( -) AFTER 11.22 YEAR(S)

\begin{tabular}{|c|c|c|c|c|c|c|c|c|c|c|c|c|c|c|c|c|c|c|c|}
\hline & 1 & 2 & 3 & 4 & 5 & 6 & $T$ & 8 & 9 & 10 & 11 & 12 & 13 & 14 & 15 & 16 & 17 & 18 & 19 \\
\hline 1 & 7 & 8 & 10 & 12 & 14 & 15 & 17 & 19 & 20 & 20 & 20 & 19 & 17 & 15 & 14 & 12 & 10 & 8 & \\
\hline 2 & 6 & 8 & 10 & 12 & 15 & 17 & 19 & 21 & 23 & 23 & 23 & 21 & 19 & 17 & 15 & 12 & 10 & 8 & 6 \\
\hline 3 & 6 & 8 & 10 & 13 & 15 & 18 & 22 & 4 & 27 & 28 & 27 & 24 & 22 & 18 & 15 & 13 & 10 & 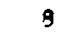 & \\
\hline 4 & 5 & 7 & 10 & 13 & 16 & 20 & 24 & 28 & 33 & 35 & 33 & 28 & 24 & 20 & 16 & 13 & 10 & 7 & 5 \\
\hline 5 & 4 & 6 & 9 & 13 & 17 & 21 & 26 & 31 & 40 & 49 & 40 & 31 & 26 & 21 & 17 & 13 & 9 & 6 & 4 \\
\hline 6 & 2 & 4 & 7 & 12 & 17 & 23 & 29 & 31 & 37 & 295 & 37 & 31 & 29 & 23 & 17 & 12 & 7 & 4 & 2 \\
\hline 7 & 0 & 2 & 5 & 10 & 16 & 25 & 35 & 36 & -215 & 37 & -215 & 36 & 35 & 25 & 16 & 10 & 5 & 2 & 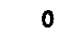 \\
\hline 8 & -3 & -1 & 1 & 6 & 13 & 24 & 43 & 293 & 36 & 284 & 36 & 293 & 43 & 24 & 13 & 6 & 1 & -1 & -3 \\
\hline 9 & -7 & -6 & -3 & 0 & 7 & 17 & 33 & 42 & -217 & 29 & $-21 T$ & 42 & 33 & 17 & 7 & 0 & -3 & -6 & -7 \\
\hline 10 & -12 & -12 & -11 & -7 & -2 & 2 & 14 & 272 & 21 & 270 & 21 & 272 & 14 & 2 & -2 & -7 & -11 & -12 & -12 \\
\hline 11 & -17 & -19 & -20 & -19 & -11 & -7 & -251 & 6 & -240 & 10 & -240 & 6 & -251 & -7 & -11 & -19 & -20 & -19 & -17 \\
\hline 12 & -23 & -27 & -32 & -36 & -28 & 232 & -11 & 244 & 0 & 250 & 0 & 244 & -11 & 232 & -28 & -36 & -32 & -27 & -23 \\
\hline 13 & -28 & -34 & -43 & -57 & -299 & -32 & -270 & -12 & -257 & -6 & $-25 T$ & -12 & -270 & -32 & -299 & -57 & -43 & -34 & -28 \\
\hline 14 & -31 & -39 & -50 & -64 & -64 & 207 & -27 & 231 & -12 & 239 & -12 & 231 & -27 & 207 & -64 & -64 & -50 & -39 & -31 \\
\hline 15 & -32 & -41 & -52 & -70 & -314 & -44 & -278 & -18 & -262 & -10 & -262 & -18 & -278 & -44 & -314 & -70 & -52 & -41 & -32 \\
\hline 16 & -31 & -39 & -50 & -64 & -63 & 208 & -25 & 234 & -8 & 242 & -8 & 234 & -25 & 208 & -63 & -64 & -50 & -39 & -31 \\
\hline 17 & -29 & -35 & -43 & -57 & -299 & -30 & -267 & -7 & -250 & 1 & -250 & -7 & -267 & -30 & -299 & -57 & -43 & -35 & -29 \\
\hline 18 & -24 & -28 & -33 & -37 & -28 & 234 & -6 & 253 & 10 & 262 & 10 & 253 & -6 & 234 & -28 & -37 & -33 & -29 & -24 \\
\hline 19 & -19 & -21 & -22 & -20 & -12 & -5 & -246 & 18 & -222 & 30 & -222 & 18 & -246 & -5 & -12 & -20 & -22 & -21 & -19 \\
\hline 20 & -15 & -15 & -14 & -10 & -4 & 1 & 17 & 287 & 52 & 302 & 52 & 287 & 17 & 1 & -4 & -10 & -14 & -15 & -15 \\
\hline 21 & -11 & -10 & -8 & -4 & 1 & 11 & 27 & 47 & 53 & 59 & 53 & 47 & 27 & 11 & 1 & -4 & -8 & -10 & -11 \\
\hline 22 & -7 & -6 & -3 & 0 & 5 & 13 & 24 & 34 & 40 & 43 & 40 & 34 & 24 & 13 & 5 & 0 & -3 & -6 & -7 \\
\hline 23 & -5 & -3 & 0 & 2 & 7 & 13 & 20 & 26 & 31 & 32 & 31 & 26 & 20 & 13 & 7 & 2 & 0 & -3 & -5 \\
\hline 24 & -3 & -1 & 1 & 4 & 8 & 12 & 17 & 21 & 24 & 25 & 24 & 21 & 17 & 12 & 8 & 4 & 1 & -1 & -3 \\
\hline 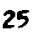 & -1 & 0 & 2 & 4 & 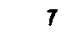 & 11 & 14 & 17 & 19 & 20 & 19 & 17 & 14 & 11 & 7 & 4 & 2 & 0 & -1 \\
\hline
\end{tabular}

XBL $7810-11850$

Figure 4.17. Sample printout of five-spot pattern for 30 pairs of wells within $300 \% \mathrm{~F}$ isotherm at 6000 - ft depth. 
(A)

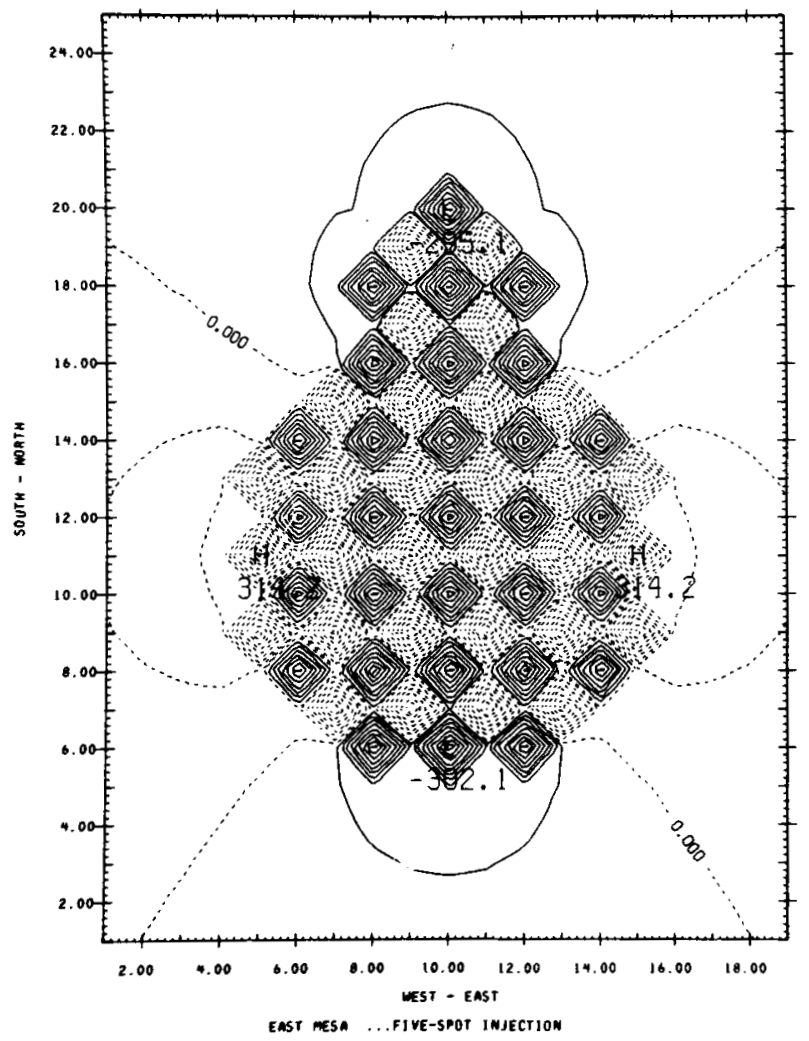

(B)

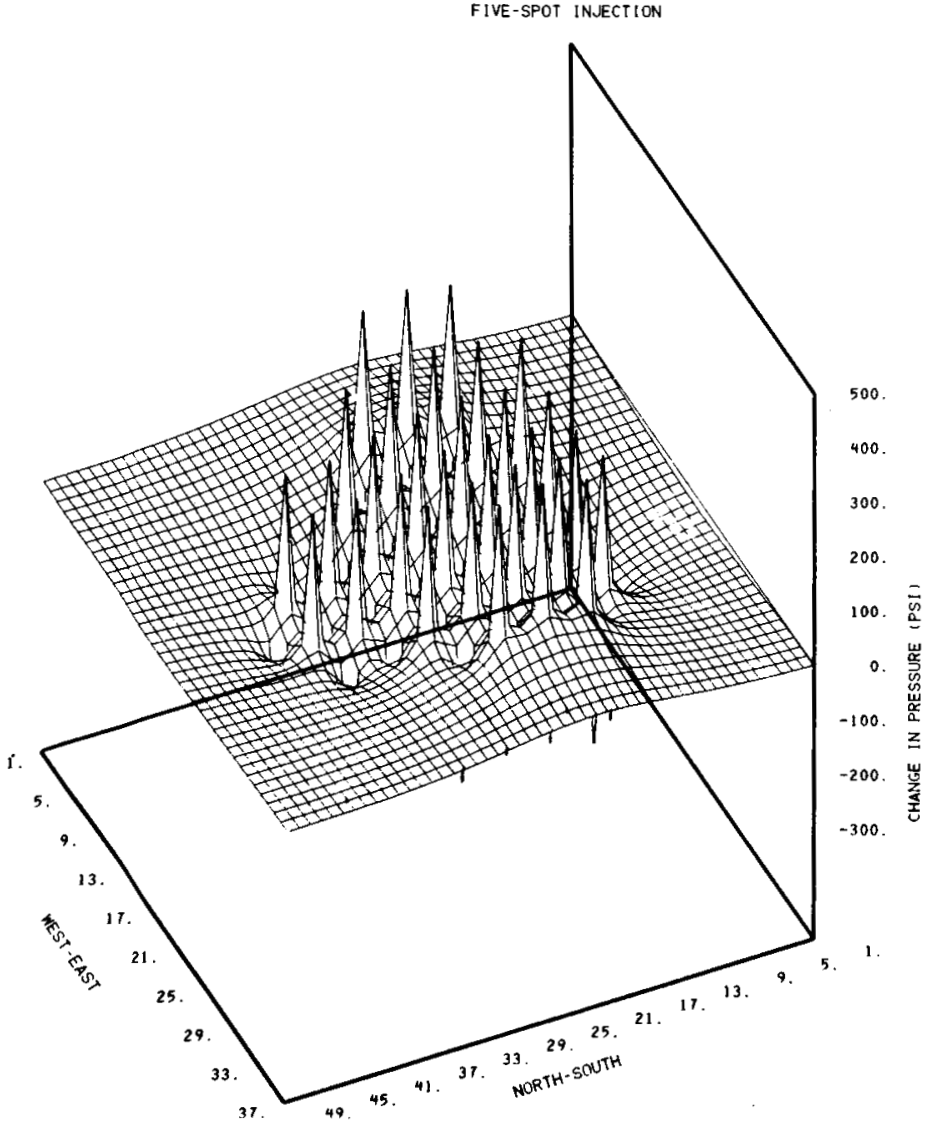

Figure 4.18. Five-spot pattern. Two-dimensional (A) and three-dimensional XBL 7811-12935 (B) plots of results shown in Figure 4.17 . 


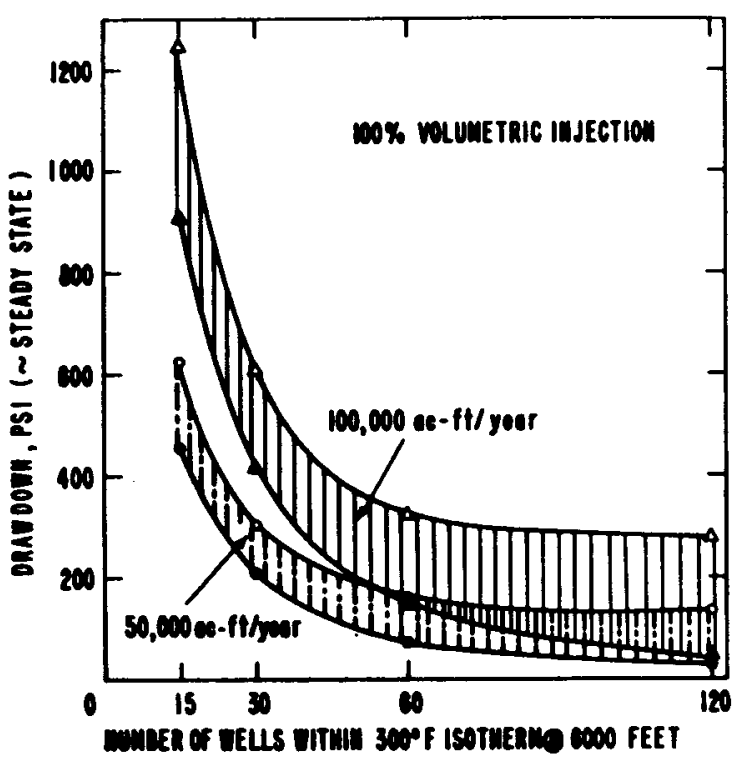

XBL 7811-2158

Figure 4.19. Five-spot pattern. Drawdowns as a function of total flow rate for production wells located within $300 \% \mathrm{~F}$ isotherm at 6000-ft depth.
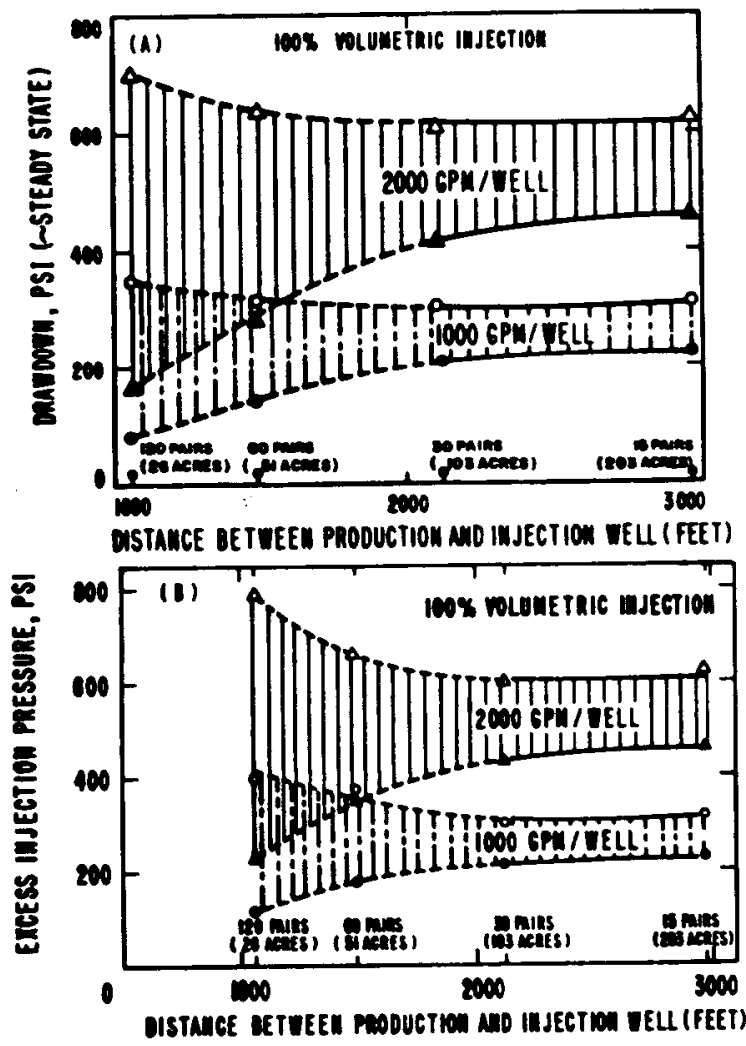

Figure 4.20. Five-spot pattern. Relation of pressure response to two different, per-well flow rates. (A) Drawdown, and (B) excess injection pressure, assuming same viscosity for produced and injected water. Wells are located within $300^{\circ} \mathrm{F}$ isotherm at 6000-ft depth. 


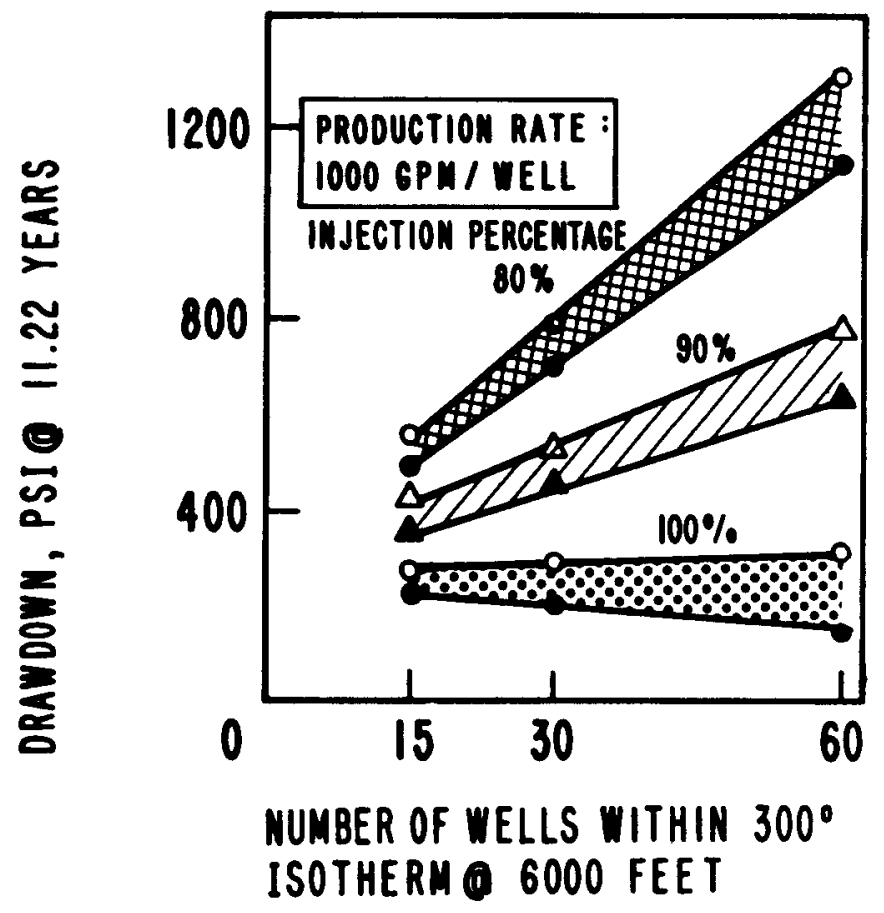

XBL 7811-2159

Figure 4.21. Study of unbalanced injection for five-spot pattern. 
The results presented in Figure 4.19 show that for a given total production, the average drawdown in production wells declines as the number of wells increases. The rate of this decline is rapid as the number of wells is increased from 15 to 30 , but tends to stabilize as the number of wells is increased from 30 to 120. For a total annual flow rate of 50,000 acre-ft, the drawdown declines, on an average, from 520 psi for 15 wells, to 260 psi for 30 wells, to about 90 psi for 120 wells. However, an annual rate of 50,000 acre-ft from 120 wells means $250 \mathrm{gpm}$ per we11. It seems reasonable to expect that there may be certain lower limits to acceptable production rates from individual geothermal wells in a well field. In such an event it is perhaps more desirable to study the pressure response at given production rates per well than the total production from the field. This implies that for a given flow rate per well the total production will increas with the number of wells.

The drawdown response for different spacings in the five-spot configuration is presented in Figure 4.20(A). The ranges of drawdown suggested by the hatching result from the fact that the arrays used in the simulation were finite. Consequently, wells in different parts of the array responded differently to production. The hatched bands in Figure 4.20(A) are very nearly horizontal, indicating that in a five-spot pattern, drawdowns are generally insensitive to spacing. Thus, one could theoretically increase the number of production-injection pairs in a given well field, and enhance total production without unduly increasing pressure drawdowns. Note also from Figure 4.20(A) that for a flow rate of about $1000 \mathrm{gpm}$, one could expect drawdowns of approximately $250 \mathrm{psi}$ or about $500 \mathrm{psi}$ for flow rates of $2000 \mathrm{gpm}$ per well.

For the same conditions considered in Figure 4.20(A), the excess injection pressure over static pressure are presented in Figure 4.20(B), assuming that both produced and injected water have the same viscosity. Since viscosity effects are ignored, it is not surprising that the range of excess injection pressures are approximately the same as the drawdowns. The effect of viscosity changes on injection pressures will be analyzed in a subsequent section. 
The fact that pressure drawdowns are insensitive to wel1 spacing [Figure 4.20(A)] in the five-spot configuration suggests that one could greatly increase total production by merely increasing the number of production-injection pairs and reducing the spacing within a given area. In choosing to increase the number of wells and decrease the spacing, it is important to consider whether or not enough fluid is available for $100 \%$ injection. The calculations presented so far are based on the assumption of $100 \%$ volumetric injection. It is worthwhile to explore the possible consequences, in the event that the required volumes of fluids are not available for reinjection. Toward this end, several simulations were carried out to study the pressure response at injection rates that were $90 \%$ and $80 \%$ of total production. The results of such unbalanced injection scenarios are presented in Figure 4.21. Note from this figure that unbalanced injection indeed leads to increased drawdowns and, the greater the number of productioninjection pairs, the greater the increase in the drawdown. Thus, for the case of 30 production-injection pairs, the average drawdown increases from about 250 to about 480 psi when volumetric injection is reduced from 100 to $90 \%$. Under the same conditions, when there are 60 pairs of we11s, the drawdown increases from about $240 \mathrm{psi}$ to about $700 \mathrm{psi}$. The results presented in Figure 4.21 stress the fact that (a) ideally one would require $100 \%$ volumetric injection for maximum pressure support; and (b) if one cannot assure $100 \%$ volumetric injection, the effects of unbalanced injection can be reduced by increasing the spacing between we11s and decreasing the total number of production wells.

A few simulations were also carried out, in the five-spot configuration, to study the possible effect of a barrier boundary, if one should exist. The results, not presented here, showed that the pressure drawdown pattern over the well field was not affected significantly by the barrier. This is to be expected since the five-spot array is more or less symmetrical and the pattern of images will be very similar to the real well distribution.

Effect of viscosity on pressure distribution. In all the discussions so far, we have assumed that the injected water and the produced water have the same viscosity of $0.2 \mathrm{cp}$, which corresponds to the viscosity 
of water at approximately $340^{\circ} \mathrm{F}$. However, the viscosity of water is very much dependent on temperature. At the assumed injection temperature of $167^{\circ} \mathrm{F}\left(75^{\circ} \mathrm{C}\right)$, the viscosity of water is about $0.38 \mathrm{cp}$ or, about 1.9 times that of hot water. If we refer to Eq. (1), which relates $\Delta p$ to the other parameters, we immediately see that pressure drawdown is directly proportional to viscosity, other factors remaining constant. Physically this simply means that colder water moves more slowly through a porous medium than hot water due to increased viscosity. To be realistic in the pressure transient calculation, therefore, it is necessary to have a quantitative appreciation of the role of water viscosity on the drawdown and injection pressures.

Perhaps the most rigorous way to study the influence of viscosity on the pressure behavior is to carry out coupled energy-mass transport calculations. We will take a less rigorous approach using decoupled calculations that are adequate for our purpose, which is to get some quantitative idea of the role of viscosity on fluid pressures. This approach was implemented using the program TERZAGI for the five-spot pattern.

As the injection of cooler water proceeds, a region of cool water will form around the injection well. Within this region, the reservoir has essentially cooled down to the temperature of the injected fluids. The outer boundary of this region can be idealized as the isotherm corresponding to the temperature of the injected water. As injection continues, this boundary will migrate toward the production well. The region occupied by the injected water will have a mobility (defined as the ratio $\mathrm{k} / \mu$ ) about $1 / 1.9$ times that of the region occupied by hot water. For simulation purposes, the flow region can be treated as a heterogeneous one, containing materials of contrasting mobility. The expansion of the colder regon as injection progresses can be approximated by several steady-state runs with the colder region occupying larger and larger portions of the flow field.

Specifically, viscosity effects were numerically studied for the five-spot pattern configuration. On symmetry consideration (e.g., inset Figure 4.3), only a triangular region need be considered, as in Figure 4.22. The flow region was discretized into 47 volume elements 


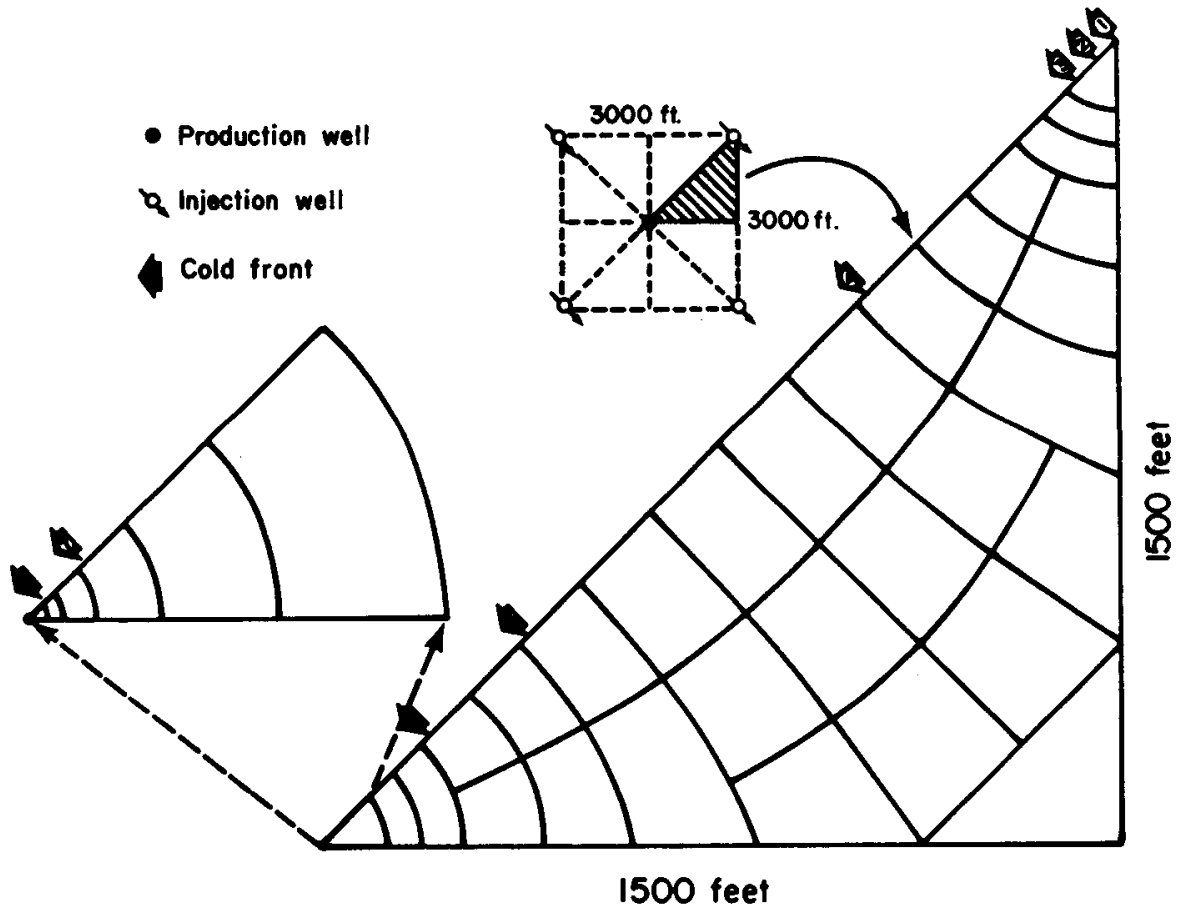

XBL $785-2540$

Figure 4.22. Five-spot pattern. Triangular region numerically modeled for evaluating viscosity effects. 
and the wells themselves were modeled as volume elements represented by a 45-degree arc of a 6-in. radius circle. The calculations were carried out assuming that the injected water had a viscosity 1.9 times that of hot water. The results are summarized in Figure 4.23. Figure 4.23(A) shows the pressure build-up (excess injection pressure) profiles from the injection well to a point approximately midway between the production and injection wells along a line joining them. The family of curves shows the profiles corresponding to the position of the cold front 20,125, 265, 690 and $1000 \mathrm{ft}$ from the injection well. As the cold region expands, the pressure at the injection wells builds up quickly and attains a theoretical maximum 1.9 times the value of the hot reservoir by the time the cold front reaches a point midway between the we11s. As the cold front migrates further toward the production wel1, the drawdown in the production well gradually begins to increase, as in Figure 4.23(B). (Pressure profiles are shown with the cold front at $530,262,75,15$, and $0 \mathrm{ft}$ from the production well.) Thus, although one would expect the pressure field to stablized with $100 \%$ volumetric injection, it is probably realistic to expect gradual increase in drawdowns and excess injection pressures as a function of time. These values will gradually tend toward those corresponding to the higher viscosity case.

The drawdown and excess injection pressures of the hot reservoir in Figure 4.23 were found to agree very closely with the values calculated with the program MAXDRAW.

Effect of wellbore damage. Another important assumption made in the preceding calculations was that the geothermal well was a perfect mechanical system. In practice this is likely to be an unrealistic assumption. More common1y, one would expect a geothermal well to be damaged, either during construction or during production. In the petroleum literature, it is customary to treat wellbore damage in terms of an equivalent "skin" effect. A skin can be thought of as a region of reduced permeability immediately surrounding a well. Due to this reduced permeability, additional head losses (pressure drawdowns or excess injection pressures) will be induced as water crosses this region. Based on the width of this region and its permeability, it is customary 

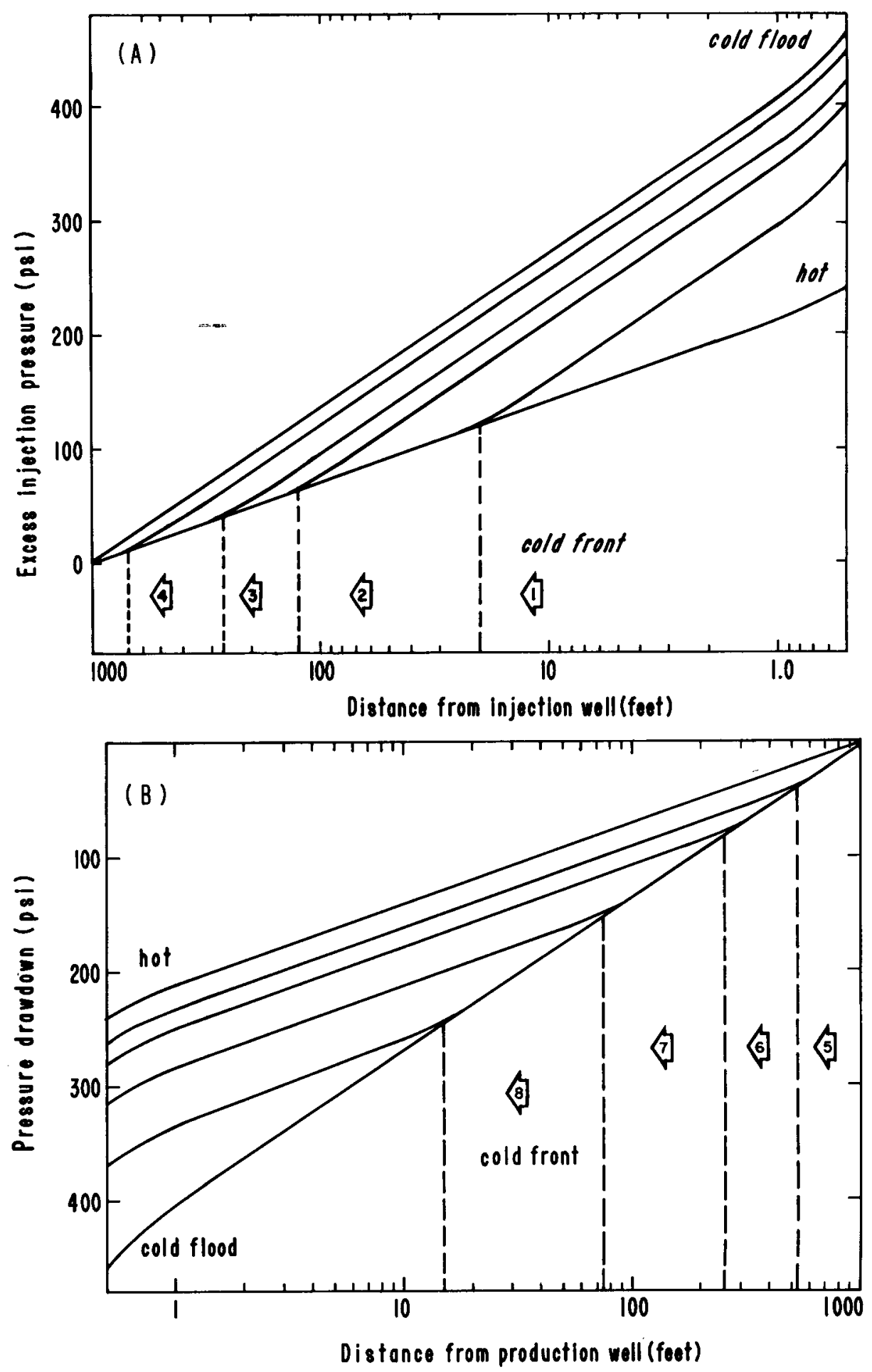

X8L 7812-2191

Figure 4.23. Effect of viscosity on pressure regime for five-spot pattern: (A) effect on excess injection pressure; (B) effect on pressure drawdown. 
to define a skin factor (Earlougher, 1977) as

$$
S=\left[\left(k / k_{s}\right)-1\right] \ln \left(r_{s} r_{w}\right)
$$

where $S$ is skin factor, $k_{s}$ is permeability of skin, $r_{s}$ is radius of skin, $r_{W}$ is radius to well, and $1 n$ is the natural logarithm.

In order to gain a quantitative idea of the effect of skin on pressure drawdown, the same mesh used in Figure 4.22 (five-spot case) was used here. The computations were made for different skin factors assuming the produced and injected waters to have the viscosity of hot water. The results are presented in Figure 4.24. As seen from this figure, drawdown varied linearly with skin factor. For a skin factor of 3 , the drawdowns increase by as much as $42 \%$. Although we do not have any reliable estimate for the range of skin factors found in geothermal wells, skin factors of 5 or more are common in the petroleum literature.

\section{Wellbore Pressure-Temperature Calculations}

In order to efficiently operate a geothermal well and decide on the depths of downhole pumps, it is necessary to know the pressure and temperature profiles within the well under expected conditions of flow. Toward this end, a few computations were made using the we11bore model of Juprasert and Sanyal (1977). Two cases were considered: (a) a well representative of the central, hot portion of the reservoir, synthesized from the shut-in temperature profiles of wells 6-1, 6-2, and $8-1$; and (b) a well representative of the cooler, peripheral portion of the reservoir, synthesized from the shut-in temperature profiles of we11s 5-1, 31-1, and Republic 16-29. The synthesized temperature profiles are given in Figure 4.25. In both cases, the static bottomhole pressure was assumed to be $2500 \mathrm{psi}$ at a depth of $6000 \mathrm{ft}$. The calculations were made for a flow rate of $1000 \mathrm{gpm}$ for two different casing diameters: 8.75 in. and 11.15 in. I.D. The downhole flowing temperatures for the two cases were $367^{\circ} \mathrm{F}$ and $320^{\circ} \mathrm{F}$, respectively. In the different simulation runs, bottom-hole pressures were allowed to decline from 2500 to $2000 \mathrm{psi}$. The results, summarized in 


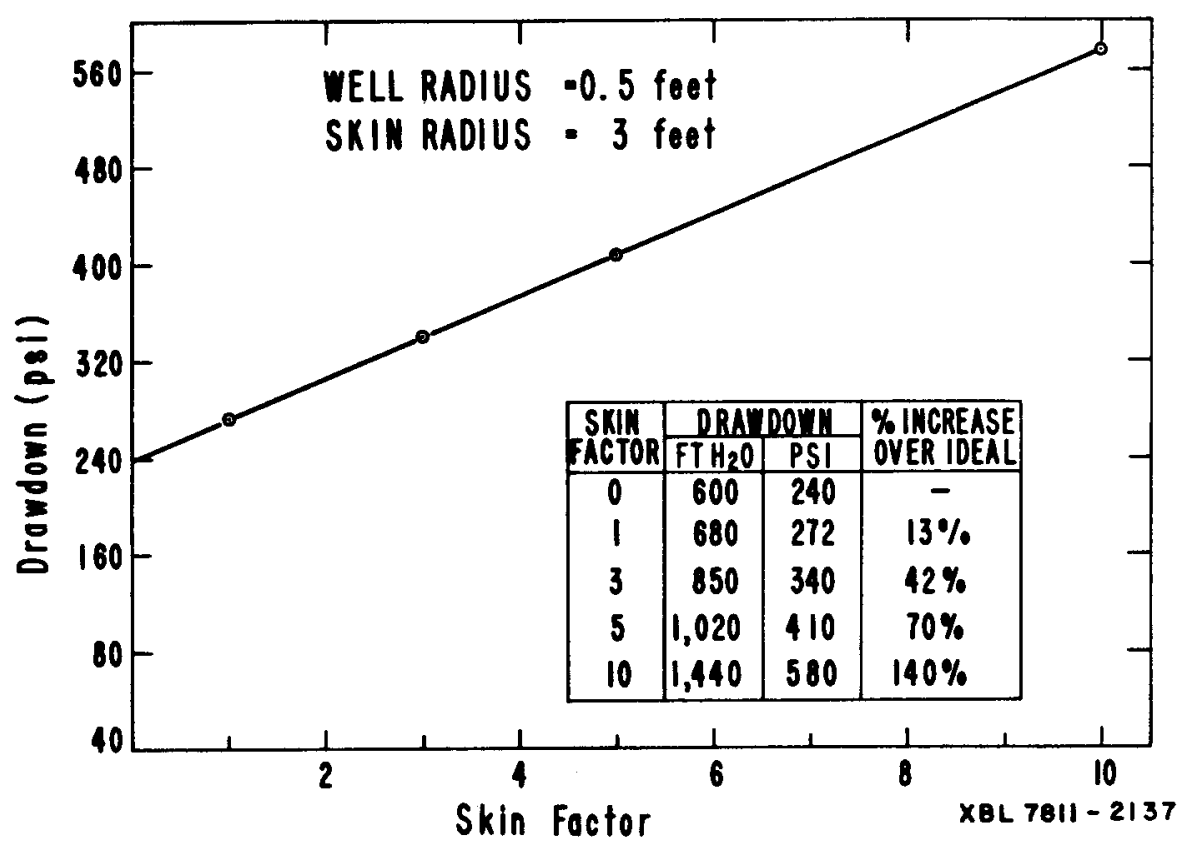

Figure 4.24. Effect of skin factor on drawdown for five-spot pattern.

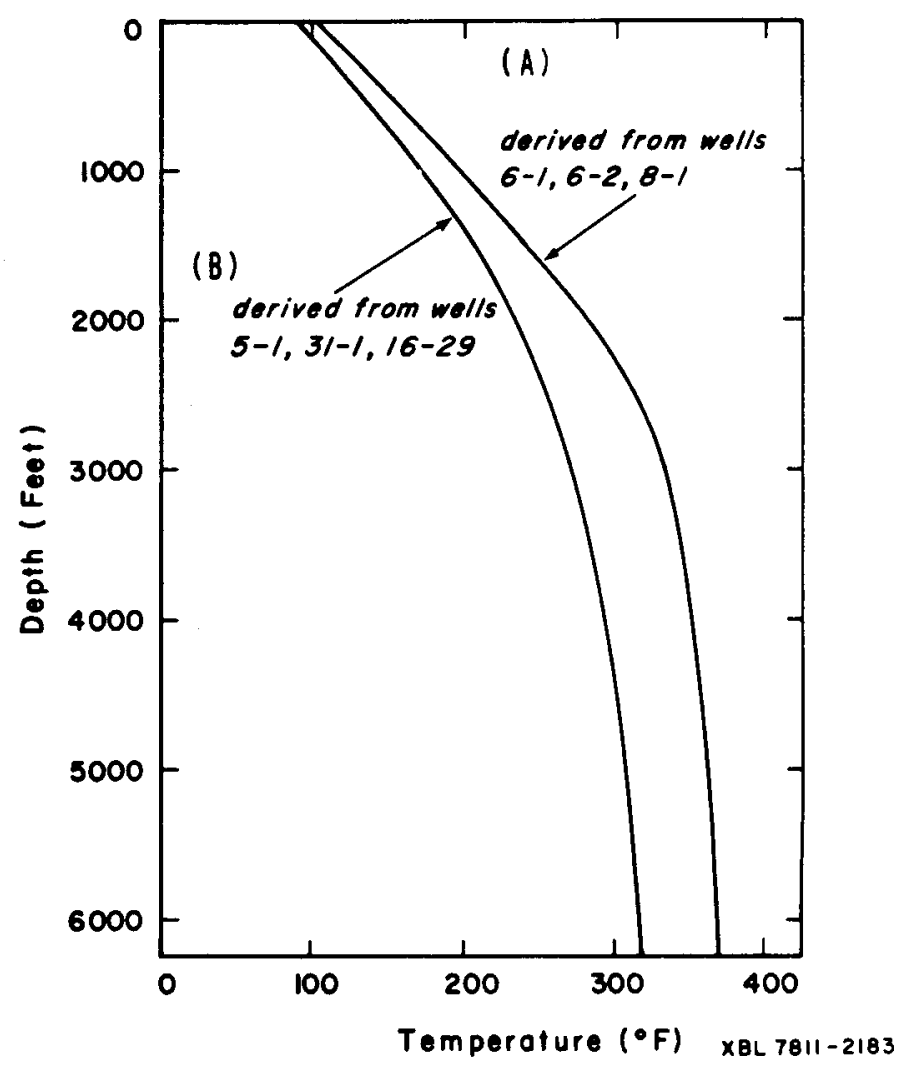

Figure 4.25. Wellbore simulation showing synthesized shut-in temperature profiles: (A) well representative of hotter part of the reservoir; (B) well representative of colder part of the reservoir. 
Figures 4.26 and 4.27 , show flash-point depth as we11 as temperature, pressure, and steam quality at the wellhead as functions of reservoir pressure decline. For example, the values of these parameters for a bottom-hole pressure of $2200 \mathrm{psi}$ (drawdown of $300 \mathrm{psi}$ ) can be read off from the figures as indicated by the arrows.

Note that in both cases, the wellhead pressures corresponding to a reservoir pressure of $2500 \mathrm{psi}$ are in excess of $100 \mathrm{psi}$ and are realistic with reference to East Mesa field conditions. Also, as seen from the figures, flash-point depth increases linearly with decreasing bottom-hole pressures. Quantitatively, a pressure drawdown of 500 psi approximately corresponds to a flash depth of $1200 \mathrm{ft}$. Therefore, when drawdowns are in excess of a few hundred psi, it seems reasonable to estimate flash-point depth by simply multiplying drawdown (in psi) by 2.4 . Incidentally, the factor 2.4 corresponds roughly to head of hot water in $\mathrm{ft} / \mathrm{psi}$.

The aforesaid calculations took into account water salinity but not the presence of noncondensible gases such as carbon dioxide. Noncondensible gases will be released from the fluids when the fluid pressure declines below the "bubble point." In fact, to avoid cavitation, the pump has to be set below the bubble-point depth, which may be greater than the flash-point depth. Also, the calculations did not consider "net positive suctionhead," which should be properly included in the pump design.

Hydrodynamic and Temperature Breakthrough $\mathrm{Calculations}$

Hydrodynamic breakthrough occurs when the injected fluid arrives at the production we11; thermal breakthrough occurs when the productionwell temperature begins to drop. Because the desalination project includes mining the better-quality geothermal reservoir water at the expense of Salton Sea water, consideration must be given to hydrodynamic and thermal breakthroughs.

Hydrodynamic breakthrough. Theoretically, the life of the groundwater mining scheme depends on the total volume of reservoir water present within the system 1 imits and the rate at which fluid is produced. 


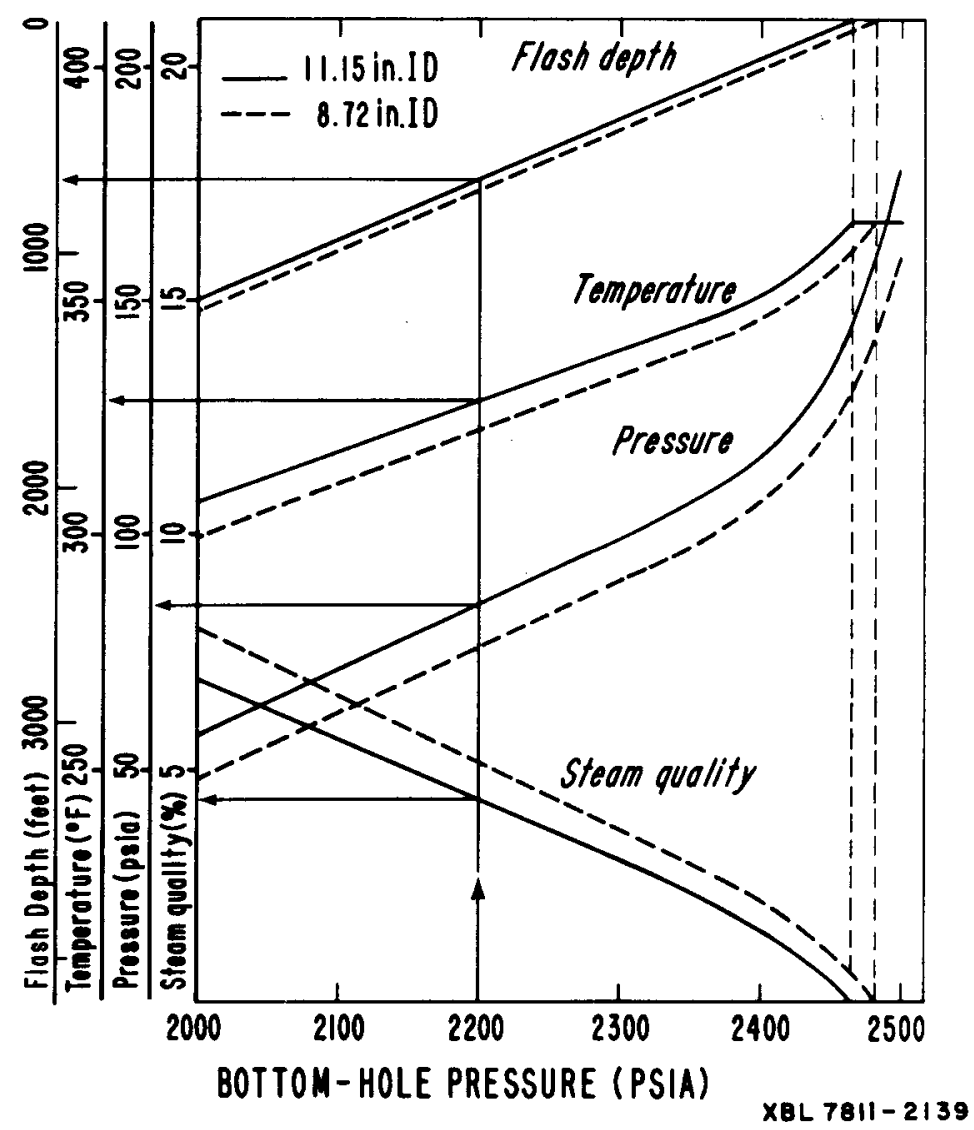

Figure 4.26. Wellhead temperature and pressure calculations for a well in the relatively hotter portion of the reservoir.

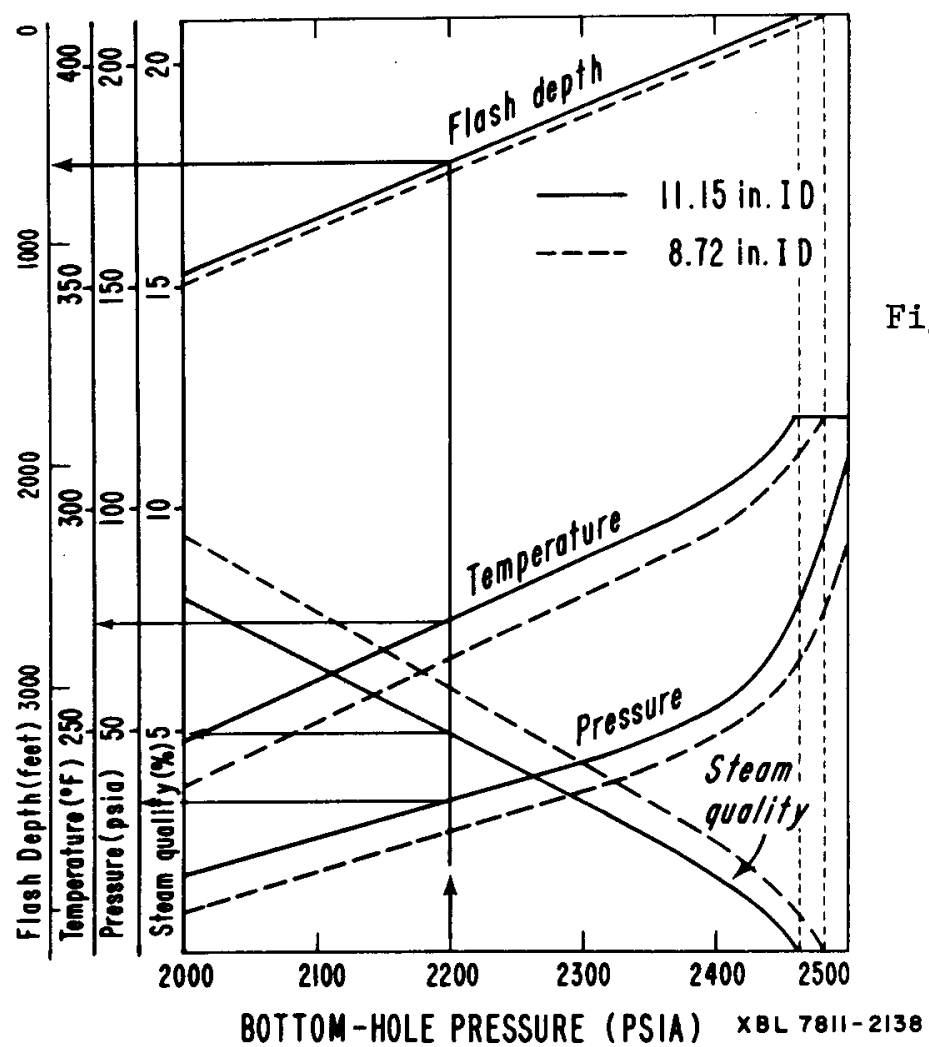

Figure 4.27. Wellhead temperature and pressure calculations for a well in the peripheral parts of the field. 
If we assume, for simplicity, that the injected water and the reservoir water do not mix chemically and that the injected water will, given sufficient time, fully displace all the reservoir water, then the total "mineable" life of the reservoir can be computed by dividing the volume of fluid in the reservoir by the injection rate. The volume of the fluid contained in the reservoir depends on the reservoir thickness and the effective porosity of the reservoir rocks. If we consider the effective portion of the reservoir contained within the $300^{\circ} \mathrm{F}$ isotherm at 6000 $\mathrm{ft}$, its area can be measured to be approximately 12.0 square miles or 7680 acres. Therefore, the mineable reservoir life can be computed by

$$
\mathrm{R}_{\mathrm{L}}=\frac{7680 \mathrm{H} \phi}{\mathrm{Q}_{\mathrm{TAF}}}
$$

where $R_{L}$ is mineable reservoir 1 ife in years,

$\mathrm{H}$ is reservoir thickness in $\mathrm{ft}$,

$\phi$ is porosity expressed as a fraction, and

QTAF is total field production in acre-ft/year.

The relation between $\mathrm{H}, \phi$ and QTAF according to Eq. ( 9 ) is depicted in Figure 4.28. As can be seen from the figure, $R_{L}$ may vary from a few years to as much as 150 years depending on the combination of $\phi, H$ and QTA. If the reservoir has a thickness of $1500 \mathrm{ft}$ and a porosity of $15 \%$, then for 50,000 acre-ft/yr production and injection rate, the mineable reservoir 1 ife will be about 36 years.

Note that the above calculations as sume the region within $300 \%$ isotherm at $6000 \mathrm{ft}$. Instead, if one were to include the deeper parts of the reservoir within the $300^{\circ} \mathrm{F}$ isotherm at $7000 \mathrm{ft}$, the $R_{L}$ values in Figure 4.28 would be multiplied by a factor of 2 since the 7000-ft region encompases an area almost twice as large as the 6000-ft region.

The $R_{L}$ values in Figure 4.28 , are very optimistic. In reality, there will be some chemical mixing of produced and injected water and the production-well water quality will gradually decline with time, Moreover, it is highly unlikely that the injected water will ever com- 

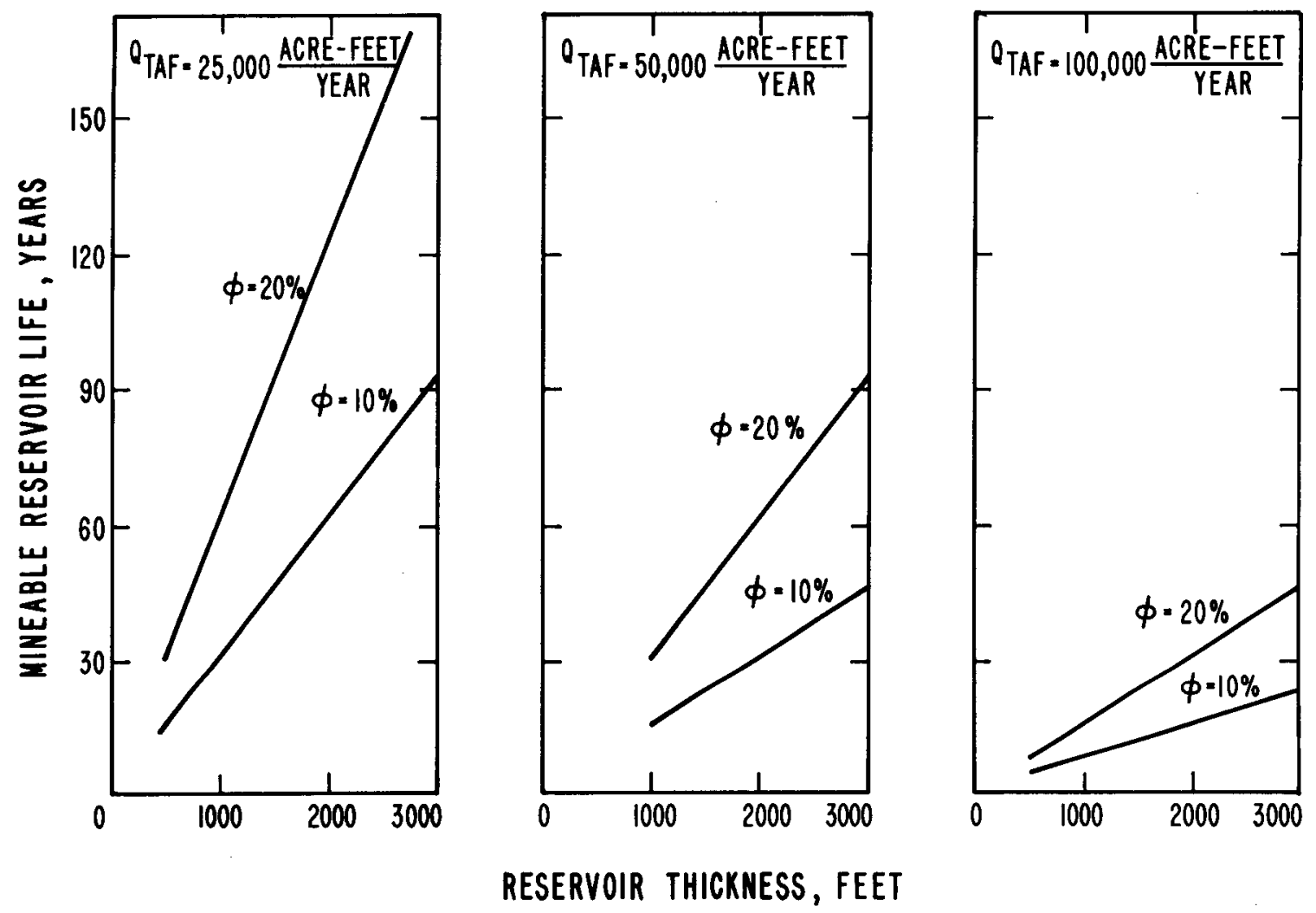

XBL 7812-2189

Figure 4.28. Mineable reservoir 1 ife, $\mathrm{R}_{\mathrm{L}}$, as a function of $\phi, H$ and QTAF. Region is within $300^{\circ} \mathrm{F}$ isotherm at 6000-ft depth. For the case of $300^{\circ} \mathrm{F}$ isotherm at 7000-ft depth, indicated $\mathrm{R}_{\mathrm{L}}$ values are to be multiplied by 2 . 
pletely displace all the reservoir fluid. Therefore it is very likely that the actual reservoir 1 ife, insofar as mining fresh water is concerned, may be far smaller than the $\mathrm{R}_{\mathrm{L}}$ values indicated in Figure 4.28 .

Thermal breakthrough. Thermal breakhrough calculations were carried out for the peripheral injection as well as the five-spot pattern scenarios using programs METERNIQ and TRUMP. In all the calculations, 30 production we $11 \mathrm{~s}$ were distributed within the $300 \% \mathrm{~F}$ isotherm at $6000-\mathrm{ft}$ depth, with a spacing of $3000 \mathrm{ft}$ between production wells. The simulations were carried out for different combinations of $\phi=10 \%, 20 \%$ and $\mathrm{H}=1000$ and $2000 \mathrm{ft}$. The flow rate was assumed to be 50,000 acre$\mathrm{ft} / \mathrm{yr}$ and the production and injection temperatures were $360^{\circ} \mathrm{F}\left(182^{\circ} \mathrm{C}\right)$ and $167^{\circ} \mathrm{F}\left(75^{\circ} \mathrm{C}\right)$, respectively.

At the outset, the calculations revealed that for a given thickness (H) varying the porosity had very little effect on the thermal breakthrough pattern. This is to be expected, since changing the porosity only slightly alters the heat capacity of the fluid-filled porous medium. Furthermore, for the steady fluid-flow conditions considered, increasing the reservoir thickness proportionately increased the thermal breakthrough. Thus, most of the simulation results could be conveniently scaled to obtain estimates for other parameter combinations. Depending on the local disposition of production and injection wells, the breakthroughs varied from one part of the reservoir to the other.

A map showing the well configurations and well numbers used in the METERNIQ simulations is given in Figure 4.29 .

Thermal breakthrough is not sensitive to porosity, other factors remaining constant (see Figure 4.30 for the case of peripheral injection). In this case, two values of $\phi$ were considered: $\phi=10 \%$ and $20 \%$, other features remaining constant. It is clear from the figure that the results are insensitive to $\phi$, within the range of values considered. Other results, not included here, showed that the same was true for wells in the five-spot configuration.

Thermal breakthrough is significantly affected, however, by reservoir thickness (H). If porosity is constant, increased reservoir thickness proportionately increases the heat capacity of the rock-water mixture and hence the breakthrough time scale is altered proportionately. 
(A)

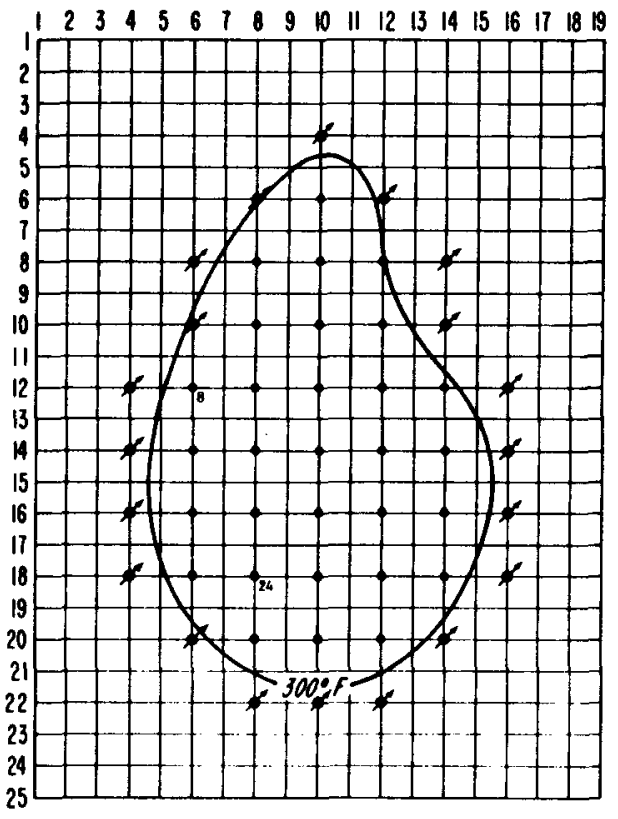

(B)

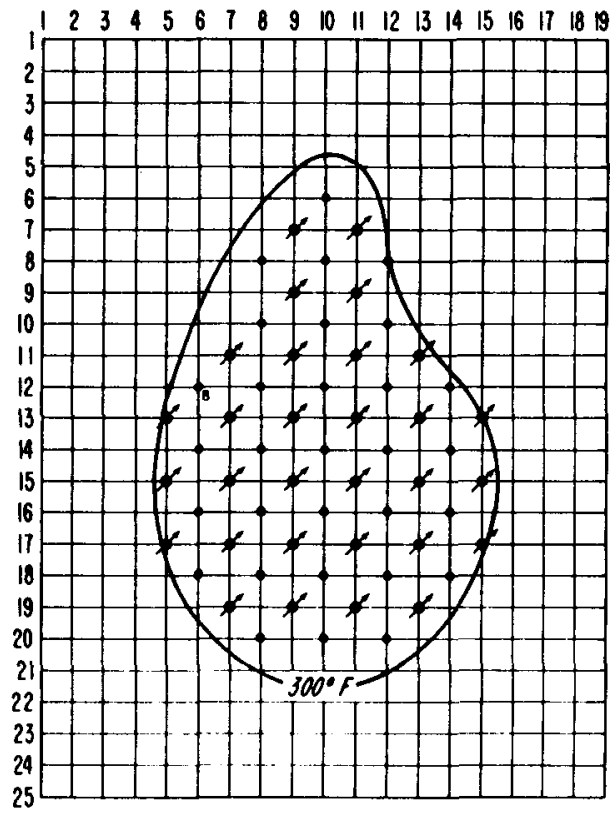

XBL 7812-14019

Figure 4.29. Thermal breakthrough calculations for well configurations and numbering used in simulation: (A) close-in peripheral injection; (B) five-spot pattern.

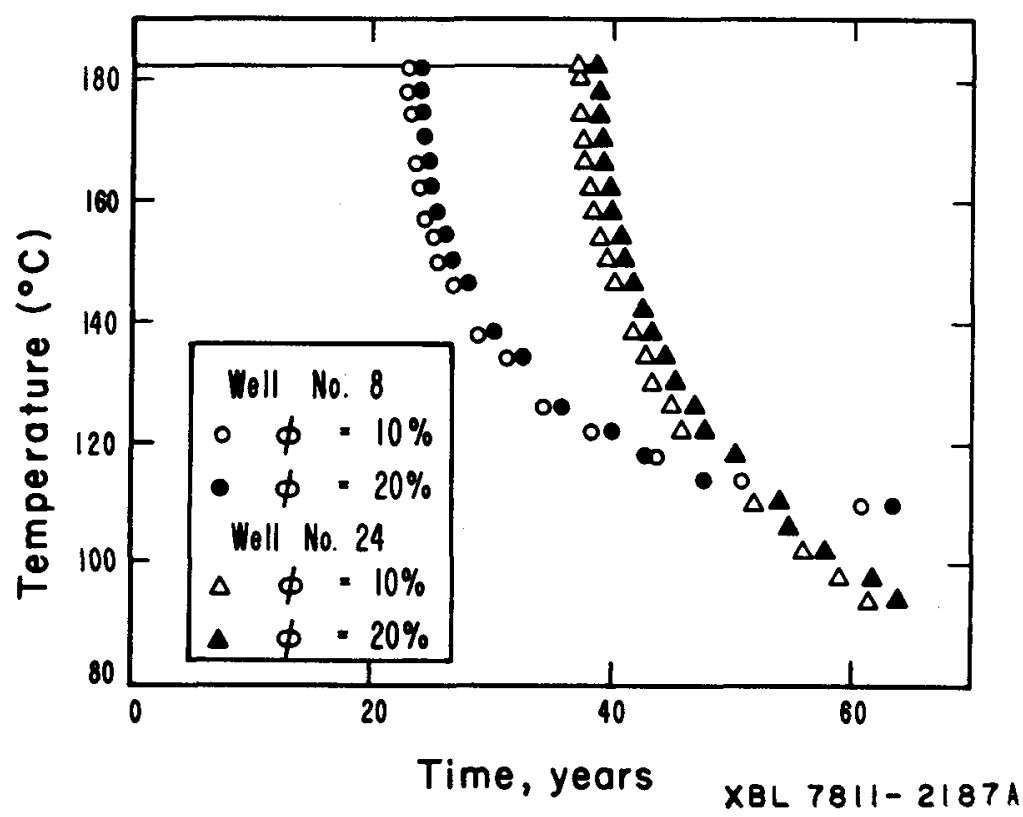

Figure 4.30. Temperature decline in two wells as a function of time for two values of porosity in peripheral injection case (production $=50,000 \mathrm{acre}-\mathrm{ft} / \mathrm{yr}, \mathrm{H}=500 \mathrm{ft}$ ). 
This is illustrated in Figure 4.31 , where the results of two computer runs are plotted on a time scale normalized with reference to reservoir thickness (production-well temperature as a functionof time/H).

We have seen (Figure 4.3) that the actual pattern of temperature decline in a production well may vary with the nature of heat conduction present. For the purposes of the present study, these variations are inconsequential. It is far more relevant, however, to know the time elapsed before the production-well temperature declines from $360^{\circ} \mathrm{F}$ to some critical temperature. Figure 4.32 plots the time for temperature to decline to $300^{\circ} \mathrm{F}$ versus $\mathrm{H}$, for peripheral injection and five-spot pattern cases. The annual flow rate is assumed to be 50,000 acre-ft. Note that the times seen in Figure 4.32 are generally much larger than the corresponding mineable life of the reservoir (Figure 4.28). This means that if good quality water can be used for reinjection, it can be recycled several times to sweep the heat from the rock. Because groundwater mining is the prime theme here, hydrodynamic breakthrough is of greater concern than thermal breakthrough (compare Figures 4.28 and 4.32 ).

In the foregoing, we have used the parameters $H$ and $\phi$. It must be emphasized here that these parameters actually denote the "effective" reservoir thickness and "effective" reservoir porosity. The former denote the net sand (or pay section) while the latter represents the interconnected pores through which the reservoir waters move.

\section{GROUND SUBS IDENCE}

In considering the potential of ground subsidence at East Mesa due to geothermal fluid withdrawal, two basic questions have to be addressed: (a) what the maximum subsidence is likely to be, and (b) what will be the spatial configuration of the subsidence bow1?

The magnitude of subsidence that is likely in a sedimentary system such as East Mesa depends on the pressure drawdown, the compressibility of the reservoir rocks and associated fine-grained materials (clays, shales), and the manner in which the volumetric deformations occurring in the reservoir are transmitted to the land surface through the overburden. The spatial distribution of the subsidence bowl is a function of the 


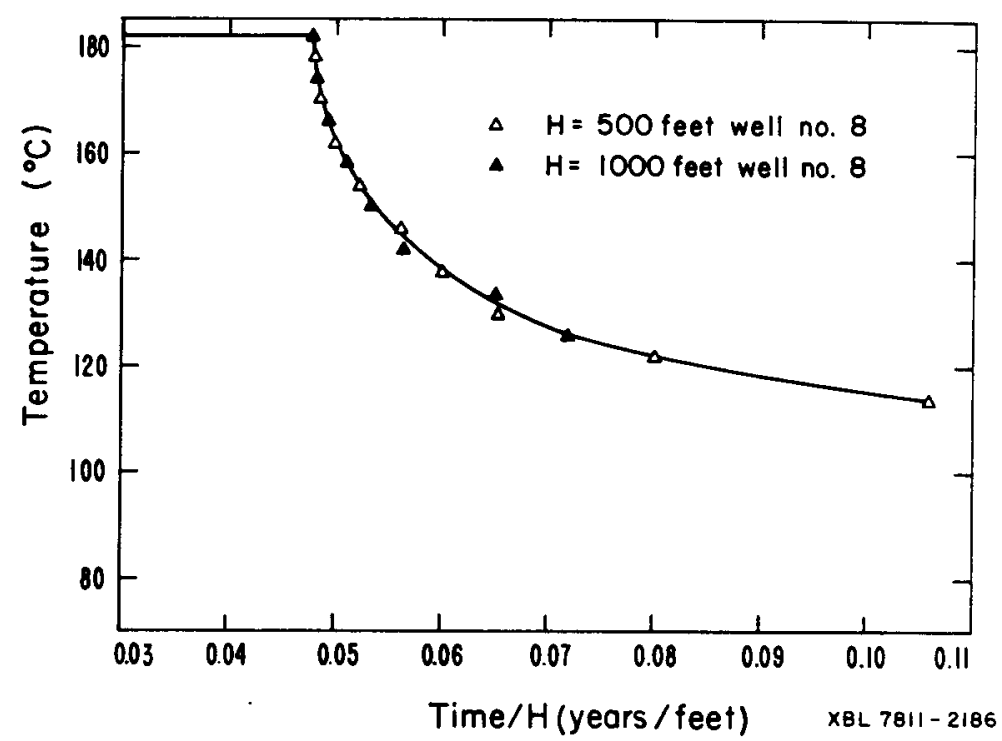

Figure 4.31. Temperature decline as a function of time/H for five-spot pattern.

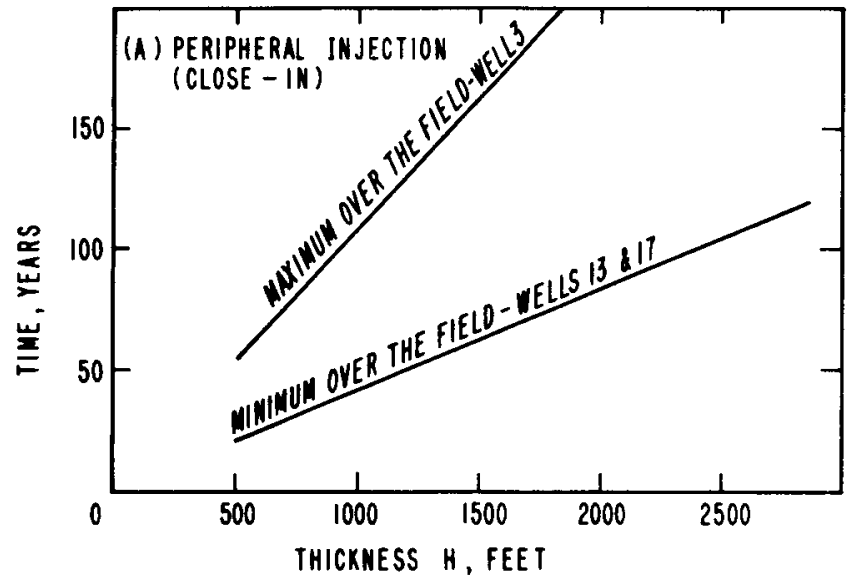

Figure 4.32. Effect of $H$ on time elapsed for production temperature to decline to $300^{\circ} \mathrm{F}$ :

(A) peripheral

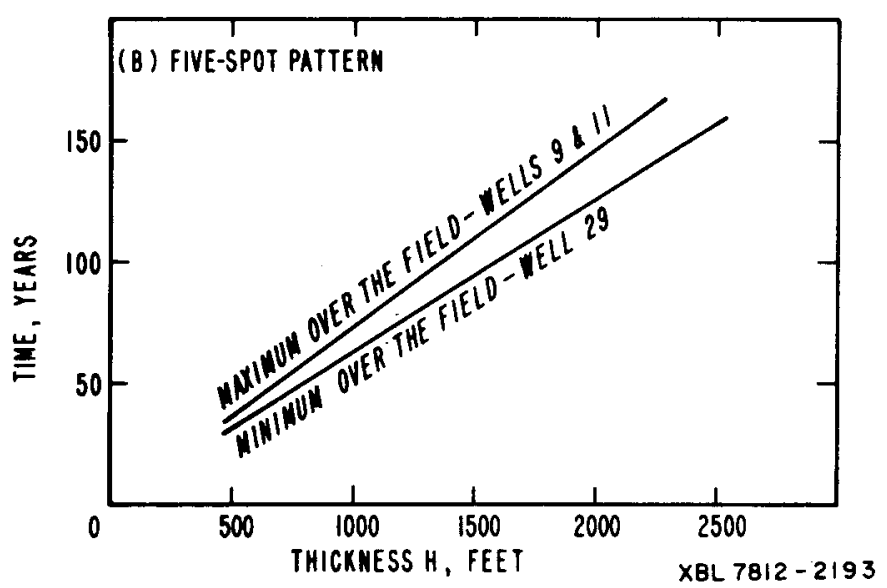

injection, (B) fivespot pattern. Flow rate is 50,000 acre$\mathrm{ft} / \mathrm{yr}$. 
production-injection strategy used, and the heterogeneity and geological structure of the reservoir. Thus, if the reservoir were homogeneous, a single large subsidence bowl could form over the center of the field under the peripheral injection scenario. If, however, a five-spot pattern is followed, several isolated subsidence bowls, distributed through the field, may result.

In general, experience in shallow groundwater systems indicates that fine-grained sediments such as clays are far more compressible (by a factor of 10 or more) than sands (Helm, 1975). In such environments, most of the subsidence can be accounted for by the gradual consolidation of the clay zones, as they release water into the depressuring aquifer.

At the present time, estimates of the magnitude and distribution of ground subsidence over the East Mesa reservoir cannot be made reliably for two reasons. First, very little in-situ or other data are presently available on the properties and subsurface distribution of the materials constituting the reservoir. Second, the simulation studies carried out in the present project have assumed a highly idealized system. In the absence of refined field data, it is not worthwile to attempt sophisticated computations with an idealized model. We will therefore attempt to arrive at a very rough estimate of the land subsidence potential at East Mesa caused by the proposed desalination project.

Recent studies of the subsurface geophysical logs at East Mesa (Peter Van de Camp, personal communication) suggest that the density of shales and other fine-grained sediments in the 5000- to 8000-ft depth range vary between 2.4 and 2.6. If we consider that the density of minerals making up the shales is approximately 2.6 to 2.7 , the high density of the shales implies that they have drained most of their contained water and have already compacted significantly. If we could ignore the possibility of shale compaction, then subsidence at East Mesa would be governed mainly by reservoir compressibility.

The interference tests conducted over the East Mesa field (Table 3.5) have yielded $\phi c_{t} \mathrm{H}$ values varying from $6 \times 10^{-4}$ to $6 \times 10^{-3} \mathrm{ft} / \mathrm{psi}$. The term $c_{t}$ in $\phi c_{t}{ }^{H}$ denotes the "total compressibility" (Earlougher, 1977) of the saturated reservoir, given by 


$$
c_{t}=c_{w}+c_{f}
$$

where $c_{t}$ is total compressibility (vol/vol)/psi; $c_{W}$ is compressibility of water given by

$$
c_{\mathrm{w}}=\frac{1}{\Delta \mathrm{p}} \frac{\Delta \mathrm{v}_{\mathrm{w}}}{\mathrm{V}_{\mathrm{w}}},(\mathrm{vol} / \mathrm{vol}) / \mathrm{psi}
$$

where $V_{w}$ is volume of water, and $c_{f}$ is pore volume compressibility of the formation given by

$$
c_{f}=\frac{1}{p} \frac{\Delta v_{v}}{v_{v}},\left(\operatorname{vol} / v_{0} 1\right) / p s i
$$

where $V_{v}$ is volume of voids in the rock.

In view of $\mathrm{Eq} .(10)$, we could estimate $c_{f}$ provided that we know $\phi$ and $\mathrm{H}$. Thus,

$$
c_{f}=c_{t}-c_{w}=\left[\left(\phi c_{t} H / \phi H\right)-c_{w}\right]
$$

It is known empirically (Earlougher, 1977, p. 231) that the compressibility of water is approximately $3 \times 10^{-6} 1 / \mathrm{psi}$ at temperatures in excess of $220^{\circ} \mathrm{F}$. If we assume this value for $c_{w}$, then,

$$
c_{\mathrm{f}}=\left(\frac{\phi / c_{\mathrm{t}} \mathrm{H}}{\phi \mathrm{H}}-3 \times 10^{-6}\right), \mathrm{psi}^{-1}
$$

For computing volume changes in the reservoir (and hence, subsidence), it is more convenient to use the "coefficient of volume change" $\left(\mathrm{m}_{\mathrm{v}}\right)$ defined by Lambe and Whitman (1969)

$$
\mathrm{m}_{\mathrm{v}}=\frac{1}{\Delta \mathrm{p}} \frac{\Delta \mathrm{v}_{\mathrm{b}}}{\mathrm{v}_{\mathrm{b}}}
$$


where $\mathrm{V}_{\mathrm{b}}$ is bulk volume and $\Delta \mathrm{V}_{\mathrm{b}}=\Delta \mathrm{V}_{\mathrm{v}}$ if rock gains are assumed to have negligible compressibility.

In view of Eqs. (13) and (15), one could show by simple algebra that

$$
\mathrm{m}_{\mathrm{v}}=\phi c_{\mathrm{f}}=\phi\left(\frac{\phi c_{\mathrm{t}} \mathrm{H}}{\phi \mathrm{H}}-3 \times 10^{-6}\right), \mathrm{psi}^{-1} \text {. }
$$

If we assume, for simplicity, a vertical prism of the reservoir with unit cross-sectional area and thickness $H$, with all the reservoir deformation in the vertical direction, then, in view of the definition of $\mathrm{m}_{\mathrm{v}}$,

$$
\mathrm{d}_{\mathrm{v}}=\left(\mathrm{m}_{\mathrm{v}}\right)(\mathrm{H})(\Delta \mathrm{p}), \mathrm{ft}
$$

where $d_{v}$ is vertical reservoir deformation in $f t$ and $\Delta p$ is reservoir pressure drop in psi. Combining Eqs. (16) and (17) we finally get

$$
d_{v}=\left[\phi c_{t} H\left(3 \times 10^{-6} \phi H\right)\right] \Delta p, \text { ft } .
$$

Based on the interference tests, $\phi c_{t}{ }^{H}$ is known to vary between $6 \times 10^{-4}$ to $6 \times 10^{-3} \mathrm{ft} / \mathrm{psi}$ while subsurface geological data suggests that $\phi$ and $\mathrm{H}$ may vary from 10 to $20 \%$ and 500 to $2000 \mathrm{ft}$, respectively. Or, $\phi \mathrm{H}$ may vary from 50 to $400 \mathrm{ft}$. The variation of vertical reservoir compaction $\mathrm{d}_{\mathrm{v}}$ as a function of $\phi \mathrm{H}, \Delta \mathrm{p}$, and $\phi \mathrm{cH}$, according to Eq. (18) is presented in Figure 4.33.

Figure 4.33 shows that the reservoir compaction may range from less than $0.1 \mathrm{ft}$ to a little more than $5 \mathrm{ft}$ over the range of values considered for the various parameters. For example, if the reservoir thickness is $2000 \mathrm{ft}, \phi=10 \%(\phi \mathrm{H}=200)$, and $\phi \mathrm{cH}=6 \times 10^{-3} \mathrm{ft} / \mathrm{psi}$, then for a pressure drawdown of $500 \mathrm{psi}$, the expected compaction may be about $2.7 \mathrm{ft}$. If $\phi \mathrm{H}$ were $1 \times 10^{-3} \mathrm{ft} / \mathrm{psi}$, then the expected compaction will only be about $0.2 \mathrm{ft}$.

Note, in Figure 4.33(B) that the compaction contours are restricted to the region to the left $\phi \mathrm{H}=400$. This simply means that for a $\phi \mathrm{H}=400$, water expansivity alone should give rise to a $\phi c_{t}{ }^{H}>$ $1 \times 10^{-3} \mathrm{ft} / \mathrm{psi}$ and that the assumed value of $\phi \mathrm{cH}$ is too low to be 

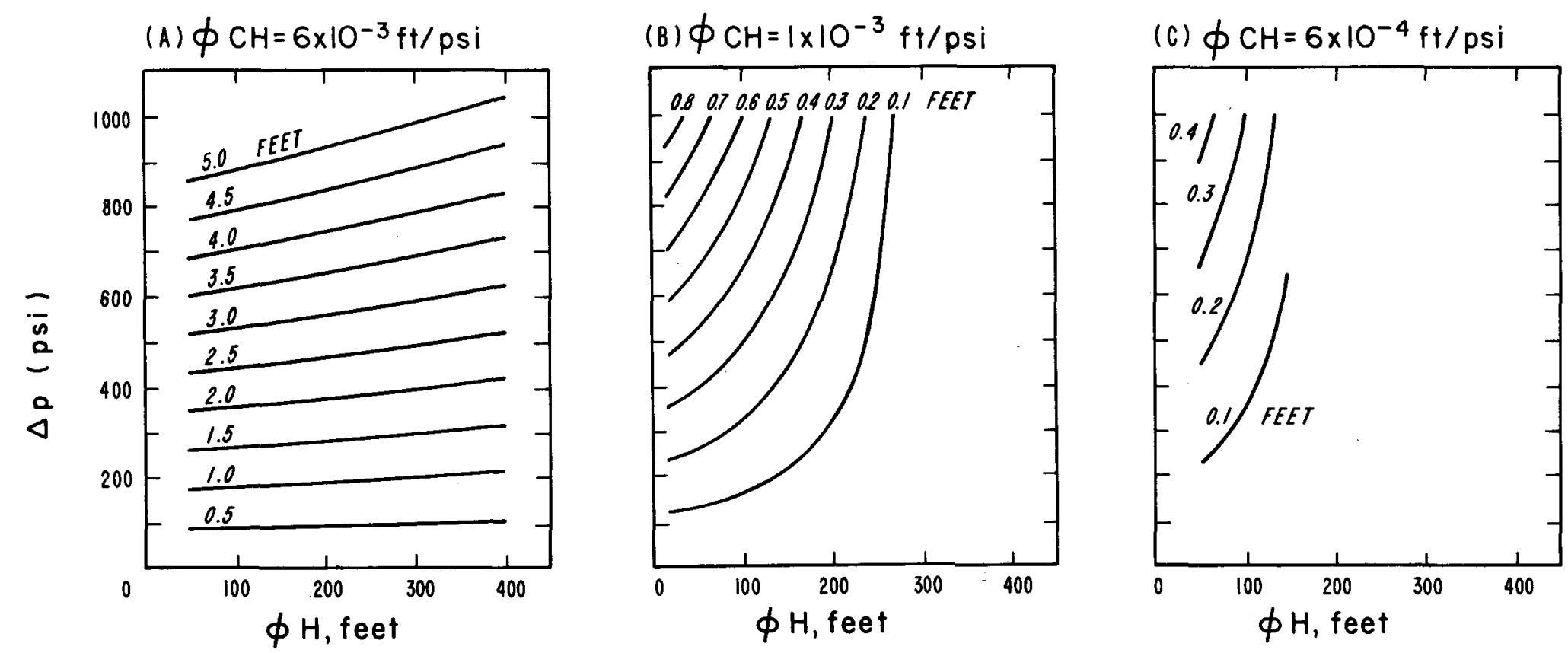

XBL 791-2165

Figure 4.33. Variation of estimated reservoir compaction as a function of $\Delta \mathrm{p}_{t}$ and $\phi \mathrm{H}$. (A) $\phi \mathrm{cH}=6 \times 10^{-3} \mathrm{ft} / \mathrm{psi} ;$ (B) $\phi \mathrm{cH}=1 \times 10^{-3} \mathrm{ft} / \mathrm{psi}$; and (C) $6 \times 10^{-4} \mathrm{ft} / \mathrm{psi}$. 
realistic. The same explanation applies to Figure 4.33(c) for the region with $\phi \mathrm{H}>200$.

The results in Figure 4.33 only represent reservoir compaction. Whether all the reservoir compaction will be expressed at the 1 and surface as ground subsidence or whether there will be some alternation of the displacements as they are transmitted through the overburden cannot be predicted at present due to lack of data for describing the overburden.

\section{INDUCED SEISMICITY}

A very real environmental concern in large-scale reinjection of fluids into geological systems is that of induced seismicity. The association between seismicity and fluid injection has been dramatically established at Rangely, Colorado (Evans, 1967). In geologic systems where structural discontinuities (faults) are present, increase of pore fluid pressure within the discontinuities may often lead to decreased normal stresses and a reduction in the shear-strength of the discontinuity leading to seismic activity. The quantitative prediction of such movements is a problem of great complexity and is beyond the scope of the present study. Among the important factors that govern induced seismicity, one should mention in situ tectonic stresses, magnitude of the injection pressures and shear strength of individual planes of discontinuity. If we consider that lithostatic pressures increase at the rate of about 1 psi per foot depth and hydrostatic pressures increase at the rate of about $0.4 \mathrm{psi}$, the effective vertical stresses at a deptof $5000 \mathrm{ft}$ may be expected to be about 3000 psi. Compared with this, an injection of 600 psi implies a perturbation of in situ stresses by as much as $20 \%$. Under the circumstances, considerable caution is warranted if injection pressures of several hundred psi are contemplated. The caution is particularly relevant at East Mesa, which lies very close to the geologically active San Andreas fault system.

\section{DISCUSSION OF RESULTS}

In this section we will study the results presented in the previous sections in regard to an overall economic analysis. 
Pressure Transient Calculations

Basically, the pressure transient calculations led to estimates of pressure drawdowns and excess injection pressures at the various production and injection wells. These results raise two important issues. The first is whether or not currently available downhole pumps can bring up the required quantities of water from appropriate depths (dictated by pressure drawdowns). The second issue is the availability of the power required to operate downhole and injection pumps. In our discussions we will not be concerned with the technical feasibility of installing and operating the pumps. We will assume that pumps are available and can move the required quantities of fluid from the relevant depths. We will therefore restrict our discussion to the pressure changes in relation to power requirements for pump operation.

In our discussion of wellbore thermodynamics (Figures 4.26 and 4.27) we showed that the depth of flash point is a function of reservoir pressure decline; and a presure drawdown of $300 \mathrm{psi}$ corresponds to a flash-point depth of roughly $720 \mathrm{ft}$. That is, for approximate calculations one could estimate flash-point depth by multiplying pressure drawdown by a factor of 2.4. Physically, flash point in the wellbore is the depth at which water begins to boil and steam begins to form at the prevalent temperature. As a result, the bow1 assembly (impellers) of downhole pumps have to be placed at a safe depth below the flash point in order to prevent steam entry into the impellers and consequent cavitation.

The purpose of having a downhole pump is to assure single-phase fluid at the wellhead, and additional head to transmit the fluids beyond the wellhead. In order to achieve this, the pump has to develop enough pressure to maintain the wellbore pressure corresponding to singlephase water flow at the wellhead. Computations based on the wellbore model suggest that for a given flow rate, this pressure could be effectively achieved by developing a pressure at the pump equal to the reservoir pressure drop. The work done by the pump in developing this pressure is equivalent to lifting the produced water against gravity from the flash-point depth. 
The excess injection pressure is the amount of pressure required, in excess of the static reservoir pressure, to push the injected water into the reservoir. If we convert the excess pressure into an equivalent injection head, then the work done by the injection pump can be treated as equivalent to moving the fluids against gravity over a distance equivalent to the injection head.

If we consider a scenario involving $100 \%$ volumetric injection, and if we know the combined average drawdown and injection heads, then we can easily estimate the overall power required to produce and inject the geothermal fluids at the flow rate of interest. Suppose the flow rate is $Q_{\ell}$ (production and injection). For simplicity assume that the average weight of water is $8 \mathrm{lb} / g a 1$. Corresponding to this case, let 1 psi of water be equivalent to $2.4 \mathrm{ft}$ of water. Then, if the total head (drawdown + injection) is $\Delta_{\mathrm{Pt}}$, the power required (in $\mathrm{MW}$ ) can be derived by

$$
\mathrm{P}_{\mathrm{MW}}=\frac{1}{1000} \frac{\left(8 \mathrm{Q}_{\ell}\right)(2.4) \Delta \mathrm{P}_{t}}{44,236}=4.3404 \times 10^{-7} \mathrm{Q}_{\ell} \Delta \mathrm{P}_{\mathrm{t}}
$$

where $P_{M W}$ is power required in $M W$ at $100 \%$ pump efficiency, $Q_{\ell}$ is the rate of fluid flow in $\mathrm{gPm}$, and $\Delta \mathrm{pt}$ is total pressure differential (drawdown + excess injection pressure in psi). Thus, for example, the power required to move $1000 \mathrm{gpm}$ at $800 \mathrm{psi}$ pump differential pressure is $0.347 \mathrm{MW}$.

The power requirements for different total annual flow rates are given in Figure 4.34(A). Suppose we are interested in finding the total power requirements for the peripheral injection case, for an annual flow rate of 50,000 acre-ft of water (or $30,000 \mathrm{gpm}$ ) with 60 production we 11 s and 40 peripheral injection we11s. From Figure 4.12(A), the average drawdown is about $450 \mathrm{psi}$ and the average excess injection pressure is about $230 \mathrm{psi}$ at a viscosity of $0.2 \mathrm{cp}$, corresponding to water at approximately $347^{\circ} \mathrm{F}$. Since injected water at $75^{\circ} \mathrm{C}$ has a viscosity about 1.9 times that of hot water, the total pressure differential is $\Delta \mathrm{p}_{t}=450+(1.9 \times 230)=887 \mathrm{psi}$. For this set of circumstances 


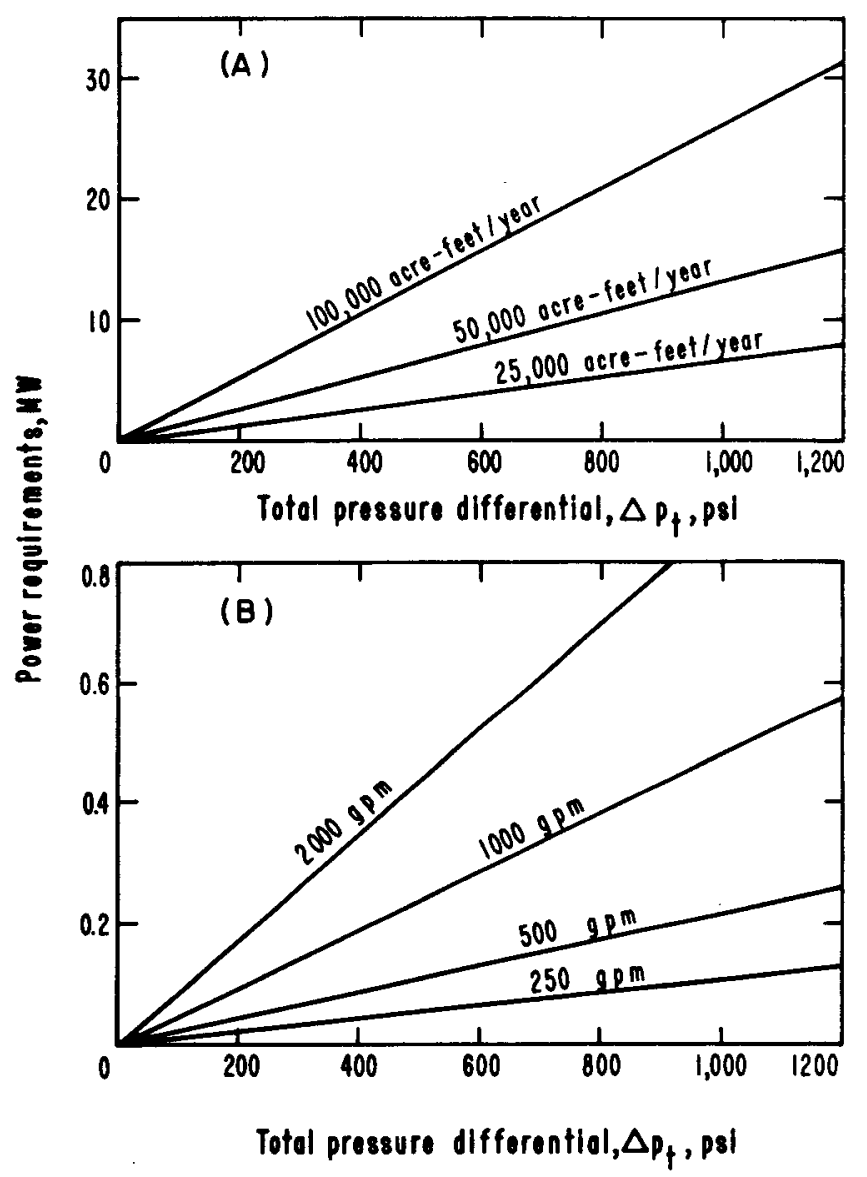

XBL 7B12-2192

Figure 4.34. Power requirement for lifting and injection water as a function of flow rate and total pressure differential, $\Delta \mathrm{p}_{\mathrm{t}}$ : (A) total flow rate from field, (B) flow rate per injection-production pair in the five-spot case. 
we can see (Figure 4.34) that the total power requirement is about $11.6 \mathrm{MW}$ at a pump efficiency of $100 \%$.

For the five-spot case under similar circumstances $(50,000$ acre$\mathrm{ft} / \mathrm{yr}, 60$ production wells) the average drawdown is about $120 \mathrm{psi}$ (Figure 4.19). Once again, considering viscosity effects, $\Delta p_{t}$ for this case is $(120+120 \times 1.9)=350 \mathrm{psi}$. Figure 4.34 shows that the total power requirements are about $4.5 \mathrm{MW}$ at $100 \%$ pump efficiency.

In considering the power requirements for a five-spot case, it is important to consider production-injection pairs. Since these pairs may have lower minimum flow rates, the viability of the five-spot configuration may depend on their economics. The power requirements for production-injection pairs are given in Figure 4.34(B).

Suppose we consider a $1000 \mathrm{gpm}$ flow rate for a doublet at 51-acre spacing (which is equivalent to $100,000 \mathrm{acre}-\mathrm{ft} / \mathrm{yr}$ from 60 we11s). The average drawdown and excess injection pressure for this case (Figure 4.20) is approximately $225 \mathrm{psi}$. Including effects of viscosity, this implies a total pressure differential of about 650 psi. For this case, the power requirements per pair are $0.31 \mathrm{MW}$ at $100 \%$ pump efficiency. [Figure 4.34(B)].

As was pointed out earlier, pressure drawdowns for five-spot injection patterns are relatively insensitive to spacing (Figure 4.20). Thus if an optimal five-spot spacing is chosen, one could use it throughout the wel1-field to obtain maximum possible flow rates, assuming that the reservoir is uniform and extensive.

\section{Hydrodynamic and Temperature Breakthroughs}

Because groundwater mining is proposed in this project, the mineable reservoir life $\left(R_{L}\right)$ is a critical aspect in the overall development of the fracture. As seen from $\mathrm{Eq}$. (9), $\mathrm{R}_{\mathrm{L}}$ is directly related to reservoir thickness and porosity $(\phi)$. Because the injected fluid cannot fully displace all the reservoir fluids, we are primarily concerned with the effective reservoir thickness $(H)$ and porosity $(\phi)$, characteristic of those stratigraphic layers through which most of the injected or produced water moves. Moreover, even if the effective porosity is known, it is doubtful if the injected Salton Sea water can displace all the reservoir fluids from the effective pores. Rather, we expect 
some portion of the reservoir fluid to be permanently locked up in the pores and remain unavailable for mining. At present, we cannot predict what portion of the total resource this unavailable reservoir fluid may constitute. We can only state that the mineable 1 ife presented in Figure 4.28 is a possible upper bound.

Yet another factor in hydrodynamic breakthrough is the possibility of mixing between the injected and produced fluids. As the injected fluid begins to arrive at the production well through various flow paths, the salinity of the produced fluids will gradually begin to increase. The rate at which the salinity increases will considerably influence the desalination process itself. Although we cannot predict this salinity variation as a function of time with the limited data currently available, it is reasonable to state that the practical life of the project will be shorter than the upper bound provided by mineable reservoir life. If careful water quality monitoring is carried out during the life of the proposed project, a better and clearer picture may emerge.

The thermal breakthrough calculations provide insight into the possible energy-producing life of the reservoir. From this point of view, the acceptable lower limit for temperature (or heat content) of the produced fluids will determine the project life. Of course, the time taken for the temperature of the produced fluids to fall below the critical level will vary from one part of the reservoir to another, depending upon the particular production-injection strategy used.

We have to recall that energy production is of secondary importance here. Energy is a by-product of the primary objective--groundwater mining. In general, under a given set of conditions, the thermal breakthrough will lag significantly behind the hydrodynamic breakthrough, by a factor of 2 to 5 or more. As a result, it is reasonable to infer that the life of the desalination project will depend more on the hydrodynamic than the thermal breakthrough. Hence, the latter is less important in the present study. 


\section{Ground Subsidence}

Ground subsidence includes horizontal and vertical displacements caused at the land surface due to fluid production at depth. In a location such as the Imperial Valley, where civil engineering structures such as canals have very close alignment and gradient tolerances, subsidence is an important enonmental consideration. The effect of subsidence on engineering structures will depend on its absolute magnitude and on the spatial variation of subsidence (differential subsidence). Thus, large values of subsidence over a wide area may sometimes be acceptable and rapid variation of even small absolute subsidence over short distances may not be. Thus the magnitude as well as the pattern of subsidence are important environmental considerations.

Because of the paucity of data on material properties and distributions within the East Mesa reservoir, the estimates of subsidence presented earlier are very preliminary. Here again, a detailed subsidence monitoring program during the operation of the reservoir will be the only way to achieve a proper subsidence management program for the project. The results presented earlier in this chapter do, however, show that due to the large fluid withdrawals planned and the large pressure declines (of the order of several hundred psi), subsidence is likely to be an important environmental problem. Also, due to the proximity of the site to the San Andreas fault system, induced seismicity is a real concern if large fluid injection is to be implemented.

\section{INTERPOLATION OF RESULTS TO USBR'S LEASEHOLD}

All the results presented so far were developed for a much larger portion of the East Mesa reservoir than is held by the U. S. Bureau of Reclamation. The total area of the reservoir contained within the $300^{\circ} \mathrm{F}$ isotherm at $600 \mathrm{ft}$ is approximately 7700 acres; the area contained within the same isotherm at a depth of $7000 \mathrm{ft}$ is approximately 14,000 acres. Of this, USBR holds about 4400 acres within the limits of the $300^{\circ} \mathrm{F}$ isotherm at the $600-\mathrm{ft}$ depth and about 5900 acres within the limits of the same isotherm at the 7000-ft depth (Figure 4.1). Therefore, the quantity of water that could be produced from USBR's property will only constitute a portion of the larger area. 
The results of the calculations carried out so far clearly show that without any reinjection whatsoever, the pressure drawdowns are likely to be too large to be economical. Hence, some form of injection has to be carried out. The calculations also show that for maximum pressure support to the reservoir, $100 \%$ volume injection is most desireable.

In general, two injection patterns can be considered: peripheral injection and five-spot injection. The peripheral injection scheme seeks to sweep the reservoir fluids and heat toward the center of the reservoir. Considering the fairly regular, oval shape of the East Mesa thermal anomaly, it is clear that to be most successful, the injection wells have to be placed along a line parallel to and outside of the required isotherm (300\% here). Many of these injection we1ls will necessarily lie outside of the USBR's leasehold. Along with these, many production wells will also lie outside of the USBR's property. If the peripheral injection strategy is implemented in collaboration with other leaseholders, then the actual portion of the reservoir production assignable to USBR's lands can be estimated as equal to the ratio of the area of USBR's holdings to the total area within the $300^{\circ} \mathrm{F}$ isotherm. If we consider the $300^{\circ} \mathrm{F}$ isotherm at $6000-\mathrm{ft}$ depth, this ratio works out to be approximate $1 y 60 \%$ of the total. For the same isotherm at 7000 -ft depth, the ratio amounts to about $42 \%$.

The implication of this is as follows. In Figure 4.12(A) for the case of 60 production wells and 50,000 acre-ft/yr production, the average drawdown is approximately $440 \mathrm{psi}$. Therefore, for about the same average drawdown, one could expect about 30,000 acre-ft/yr $(60 \%$ of 50,000 acre-ft/yr) from the wells located within USBR's holdings. Conversely, if $50,000 \mathrm{acre}-\mathrm{ft} / \mathrm{yr}$ of water are needed from USBR wells, the total production (and hence, the total drawdowns) will have to be suitably increased. That is, production of 50,000 acre$\mathrm{ft} / \mathrm{yr}$ from the USBR wells implies a mean pressure drawdown of $440 / 0.6 \approx 730 \mathrm{psi}$. For $25,000 \mathrm{acre}-\mathrm{ft} / \mathrm{yr}$ production under the same conditions, the mean drawdown can be expected to be 365 psi.

For the five-spot production-injection strategy, the productivity of USBR's property is easier to evaluate. If we neglect the fact that 
the peripheral wells in a finite five-spot array will have pressure responses slightly different from those in the center of the array, then we could associate an average pressure drawdown (or excess injection pressure) with each production-injection pair. The total production from USBR's property will be equal to the flow rate per well times the number of pairs within the USBR property. A study of the well distributions in conjunction with a map showing the limits of USBR's holdings (Figure 4.35 ) shows that about $60 \%$ of the total number of production-injection pairs occur within the USBR's holdings. Hence, in order to estimate the quantity of flow that can be obtained from USBR's lands, one can take the flow rate per pair of wells for a given spacing (Figure 4.20) and multiply this by the number of wells that can be accommodated within the USBR's lands. For example, in Figure 4.20(A) consider the 51 acre spacing case at $100 \mathrm{gpm}$ per we 11 . This corresponds to 60 production-injection pairs in the total area. For this case, the average pressure drawdown is about 230 psi. Since 36 such pairs $(60 \%$ of 60) can be accommodated within the USBR's lands, it follows that about $36,000 \mathrm{gpm}$ of water $(60,000$ acre-ft/yr) can be produced at an average drawdown of $230 \mathrm{psi}$. Conversely, the 36 wells within USBR's lands may be able to yield about $50,000 \mathrm{acre}-\mathrm{ft} / \mathrm{yr}$ at an average drawdown of 192 psi.

The various flow rates that can be obtained from wells distributed solely within USBR's leasehold and the corresponding pressure-transient and breakthrough implications are summarized in Tables 4.6 and 4.7 , respectively. The results in Table 4.7 are graphically presented in Figures 4.35, 4.36 and 4.37. The figures and tables show that producing fluids at a certain rate from the reservoir can lead to different pressure responses, reservoir 1 ife, and temperature breakthroughs depending on the number of wells, their spacing, and pattern. The final economic decision will lie in choosing the best combination of the number of wells, their spacing, pattern, and flow rates so that for a given flow rate the outcome will be acceptable. Tables 4.6 and 4.7 strive to provide the information required to do this. In attempting this optimization, one has to define the acceptable limits of each condition (e.g., the amount of money that can be set aside for drilling wells; 
Table 4.6. Flow rates obtainable from within the USBR leasehold at East Mesa for various reinjection schemes. A summary of pressure-transient results.

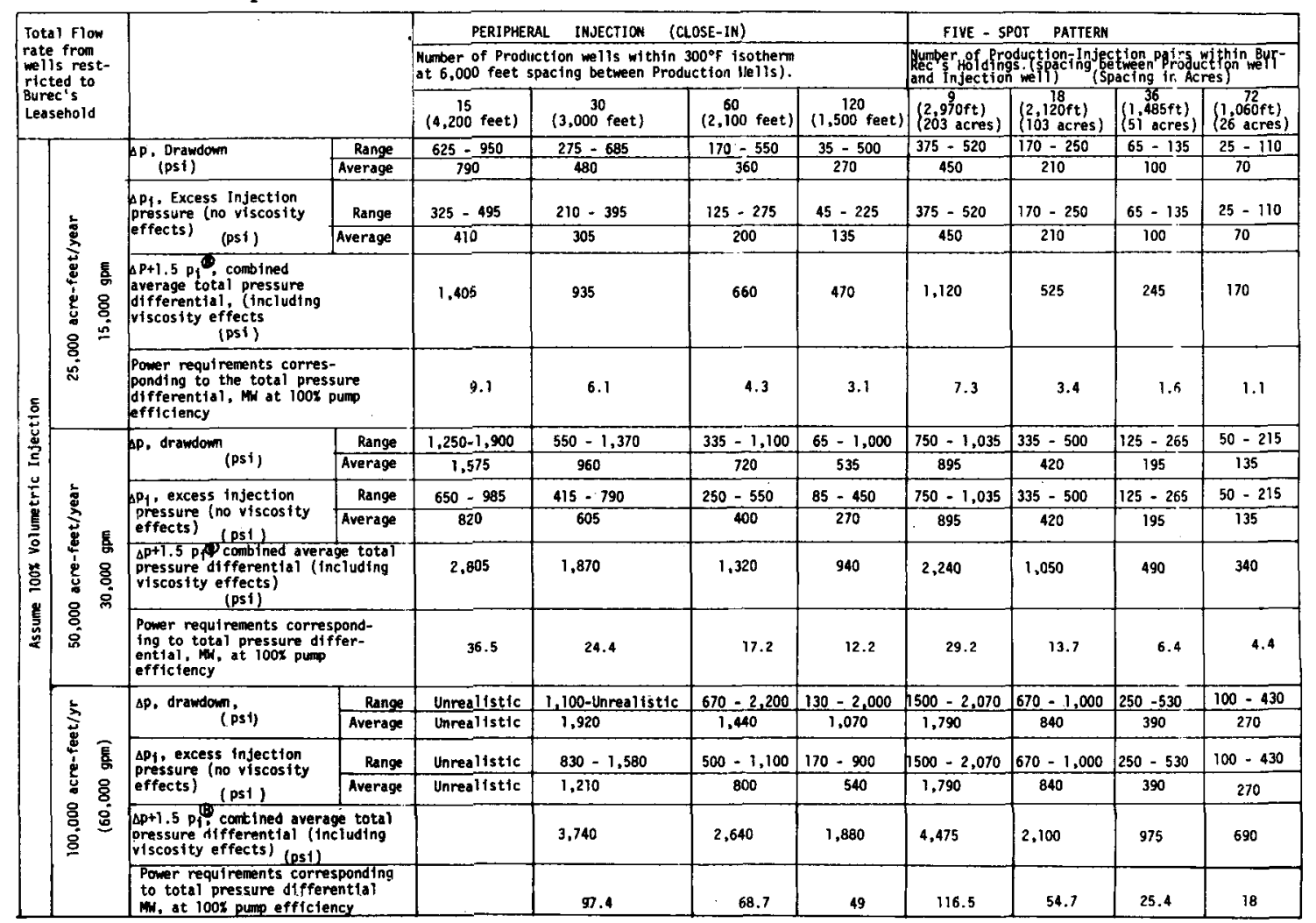

Mote: A. It has been assumed in preparing this Table that at the $6,000 \mathrm{ft}$. level, 60 percent of the area within the $300^{\circ} \mathrm{F}$ isotherm falls within the Bureau's Holdings. Although the injected water has a viscosity injch 15 about 1.9 times that of the reservoir water at os $345^{\circ} \mathrm{F}$, we will use a smaller factor of 1.5 in

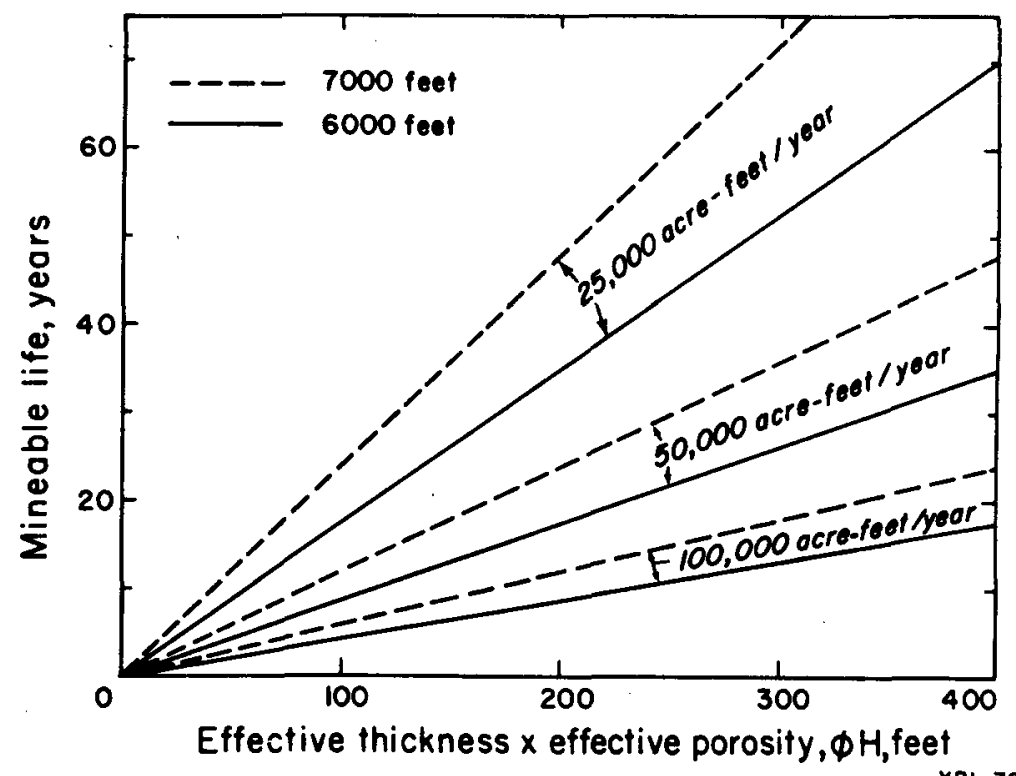

$X 8 L 7811-2185$

Figure 4.35. Mineable life of the reservoir contained within the USBR's leasehold as a function of $\phi H$ and rate of fluid production. 
Table 4.7. Flow rates available from USBR leaseholds: hydrodynamic and temperature breakthrough implications.

\begin{tabular}{|c|c|c|c|c|c|c|c|c|c|c|c|c|}
\hline \multirow{3}{*}{$\begin{array}{l}\text { ANMUAL FLOW } \\
\text { RATE FRON WELLS } \\
\text { RESTRICTED TO } \\
\text { THE BUREC'S } \\
\text { LEASEHOLD }\end{array}$} & \multirow{3}{*}{$\begin{array}{l}\text { ASSUMED } \\
\text { EFECTIVE } \\
\text { RESERYOIR } \\
\text { THICKNESS } \\
\text { (feet) }\end{array}$} & \multirow{3}{*}{$\begin{array}{l}\text { ASSUMED } \\
\text { EFFECTIVE } \\
\text { RESEVOIR } \\
\text { POROSITY } \\
\text { (Percent) }\end{array}$} & \multicolumn{2}{|c|}{ MIMEABLE RESERVOIR LIFE, R, YEARS } & \multicolumn{8}{|c|}{ TIME ELAPSED BEFORE RESERVOIR TEMPERATURE DECLINES FROM $360^{\circ} \mathrm{F}$ to $300^{\circ} \mathrm{F}$} \\
\hline & & & \multirow{2}{*}{$\begin{array}{l}\text { Considering } 300^{\circ} \mathrm{F} \\
\text { Isotherm at } 6,000 \\
\text { ft. depth } \\
\text { (4,400 acres) }\end{array}$} & \multirow{2}{*}{$\begin{array}{l}\text { Considering } 300^{\circ} \\
\text { Isotherm at } 7,000 \\
\text { ft. depth } \\
\text { (6,000 acres) }\end{array}$} & \multicolumn{4}{|c|}{ Peripheral (close-in) injection } & \multicolumn{4}{|c|}{ Five-spot pattern } \\
\hline & & & & & $\begin{array}{l}4,200 \mathrm{ft}^{0} \\
405 \text { acres }\end{array}$ & $\begin{array}{l}3,000 \mathrm{ft}^{\circ} \\
207 \text { acres }\end{array}$ & $\begin{array}{l}2,100 \mathrm{f}^{0} \\
100 \text { acres }\end{array}$ & $\begin{array}{l}1,500 \mathrm{ft} \\
52 \text { acres }\end{array}$ & $\begin{array}{l}2,970 f \oplus \\
203 \text { acres }\end{array}$ & $\begin{array}{l}2,120 \mathrm{ft} \\
103 \text { acres }\end{array}$ & $\begin{array}{l}1,485 \mathrm{ft}^{\mathbb{( 1 )}} \\
5\}^{\text {acres }}\end{array}$ & $\begin{array}{l}1,0600 \mathrm{D} \\
26 \text { acres }\end{array}$ \\
\hline \multirow{6}{*}{$\begin{array}{l}25,000 \text { acre-feet } \\
(15,000 \mathrm{gpm})\end{array}$} & \multirow{2}{*}{1,000} & 10 & 17.6 & 24 & 705.2 & 52.6 & 26.3 & $130^{2}$ & 161.8 & 8 to $^{9}$ & 40.5 & 20.2 \\
\hline & & 20 & 35.2 & 48 & 210.4 & 105.2 & 52.6 & 26.3 & 183.4 & 91.7 & 45.8 & 22.9 \\
\hline & \multirow{2}{*}{1,500} & 10 & 26.4 & 36 & $\begin{array}{c}157.6 \\
\text { to }\end{array}$ & $\begin{array}{c}78.8 \\
\text { to }\end{array}$ & 39.9 & 20 & 242.6 & 121.3 & $\begin{array}{c}60.6 \\
t 0\end{array}$ & $\begin{array}{c}30.3 \\
\text { to }\end{array}$ \\
\hline & & 20 & 52.8 & 72 & 30.2 & 157.6 & 78.8 & $\begin{array}{l}39.9 \\
5\end{array}$ & $\begin{array}{r}275.0 \\
\end{array}$ & $\begin{array}{r}137.5 \\
\end{array}$ & 68.8 & 34.4 \\
\hline & \multirow[b]{2}{*}{2,000} & 10 & 35.2 & 48 & 210.4 & $105.0^{2}$ & $5 t_{0}^{6}$ & $260^{3}$ & 323.6 & $761_{0}^{8}$ & 80.9 & 40.5 \\
\hline & & 20 & 70.4 & 96 & 420.8 & 210.4 & 105.2 & 52.6 & 366.8 & 183.4 & 91.7 & 45.8 \\
\hline \multirow{6}{*}{$\begin{array}{c}50,000 \text { acre-feet } \\
(30,000 \mathrm{gpm})\end{array}$} & \multirow{2}{*}{1,000} & 10 & 8.8 & 12 & $\begin{array}{l}52.6 \\
\text { to }\end{array}$ & $\begin{array}{c}26.3 \\
\text { to }\end{array}$ & 73.2 & $\begin{array}{l}6.6 \\
\text { to }\end{array}$ & 80.9 & $\begin{array}{c}40.5 \\
\text { to }\end{array}$ & $\begin{array}{c}20.2 \\
\text { to }\end{array}$ & $\begin{array}{c}10.1 \\
\text { to }\end{array}$ \\
\hline & & 20 & 17.6 & 24 & 105.2 & $\begin{array}{c}52.6 \\
52.6\end{array}$ & 26.3 & 13.2 & 91.7 & 45.8 & 22.9 & 11.5 \\
\hline & \multirow{2}{*}{1,500} & 10 & 13.2 & 18 & $\begin{array}{c}78.8 \\
\text { to }\end{array}$ & $\begin{array}{c}39.4 \\
\text { to }\end{array}$ & 19.2 & 9.6 & $\begin{array}{l}121.6 \\
\text { to }\end{array}$ & $\begin{array}{c}60.8 \\
\text { to }\end{array}$ & $\begin{array}{c}30.4 \\
\text { to }\end{array}$ & $\begin{array}{l}15.2 \\
\text { to }\end{array}$ \\
\hline & & 20 & 26.4 & 36 & 157.6 & 78.8 & 39.4 & 19.2 & 137.6 & 68.8 & 34.4 & 17.2 \\
\hline & \multirow{2}{*}{2.000} & 10 & 17.6 & 24 & 105.2 & 52.6 & 26.3 & 13.2 & 161.8 & 80.9 & $\frac{40.5}{40.5}$ & 20.2 \\
\hline & & 20 & 35.2 & 48 & 210.4 & 105.2 & $\begin{array}{r}10 \\
52.6 \\
\end{array}$ & $\begin{array}{r}200 \\
26.3 \\
\end{array}$ & $\begin{array}{c}20 \\
183.4 \\
\end{array}$ & 91.7 & $\begin{array}{l}10.8 \\
45.8\end{array}$ & 22.9 \\
\hline \multirow{6}{*}{$\begin{array}{c}100,000 \text { acre-feet } \\
(60,000 \mathrm{gpm})\end{array}$} & \multirow{2}{*}{1.000} & 10 & 4.4 & 6 & $\begin{array}{c}26.3 \\
t 0^{3}\end{array}$ & $\begin{array}{c}13.1 \\
\text { to }\end{array}$ & $\begin{array}{l}6.6 \\
\text { to }\end{array}$ & $\begin{array}{l}3.3 \\
\text { to }\end{array}$ & 40.5 & 20.2 & $\begin{array}{l}10.1 \\
\text { to }\end{array}$ & $\begin{array}{l}5.1 \\
\text { to }\end{array}$ \\
\hline & & 20 & 8.8 & 12 & 52.4 & 26.2 & 13.1 & 6.6 & 45.8 & 22.9 & 11.5 & 5.8 \\
\hline & \multirow{2}{*}{1.500} & 10 & 6.6 & 9 & 39.4 & 19.7 & 9.9 & 5.0 & 60.6 & 30.3 & 15.2 & 7.6 \\
\hline & & 20 & 13.2 & 18 & $\begin{array}{l}78.8 \\
78.8\end{array}$ & $\begin{array}{l}50 . \\
39.4\end{array}$ & $\begin{array}{l}10.7 \\
19.7\end{array}$ & 9.9 & 68.8 & 34.4 & 17.2 & 8.6 \\
\hline & \multirow{2}{*}{2,000} & 10 & 8.8 & 12 & 52.6 & $\begin{array}{c}26.2 \\
\text { to }\end{array}$ & $\begin{array}{c}13.1 \\
\text { to }\end{array}$ & $\begin{array}{l}6.6 \\
\text { to }\end{array}$ & $\begin{array}{c}80.9 \\
\text { to }\end{array}$ & $\begin{array}{c}40.5 \\
\text { to }\end{array}$ & $\begin{array}{c}20.2 \\
\text { to }\end{array}$ & $\begin{array}{c}10.1 \\
\text { to }\end{array}$ \\
\hline & & 20 & 17.6 & 24 & 105.2 & 52.6 & 26.3 & 13.1 & 91.7 & 45.8 & 22.9 & 11.5 \\
\hline
\end{tabular}

(1) R pertains, in this table, only to BuRec Lands.

(B) Simulations were carried out for 50,000 acre-feet/year flow rate for 30 production wells within $300^{\circ} \mathrm{F}$ isotherm at 6,000 ft. depth. (103-acre spacing). Results for 25,000 acre-feet and 100,000 acre-feet annual flow rates obtained by scaling 50,000 acre-feet results by factors of 2 and 0.5 respectively.
Results for other spacings obtained using the fact that breakthroughs are inversely proportional to the square of

(1) Spacing between adjacent production wells.

(1) Spacing between adjacent production and injection mells.

(1) All thermal breakthrough calculations are for the $20 \%$ porosity case. 

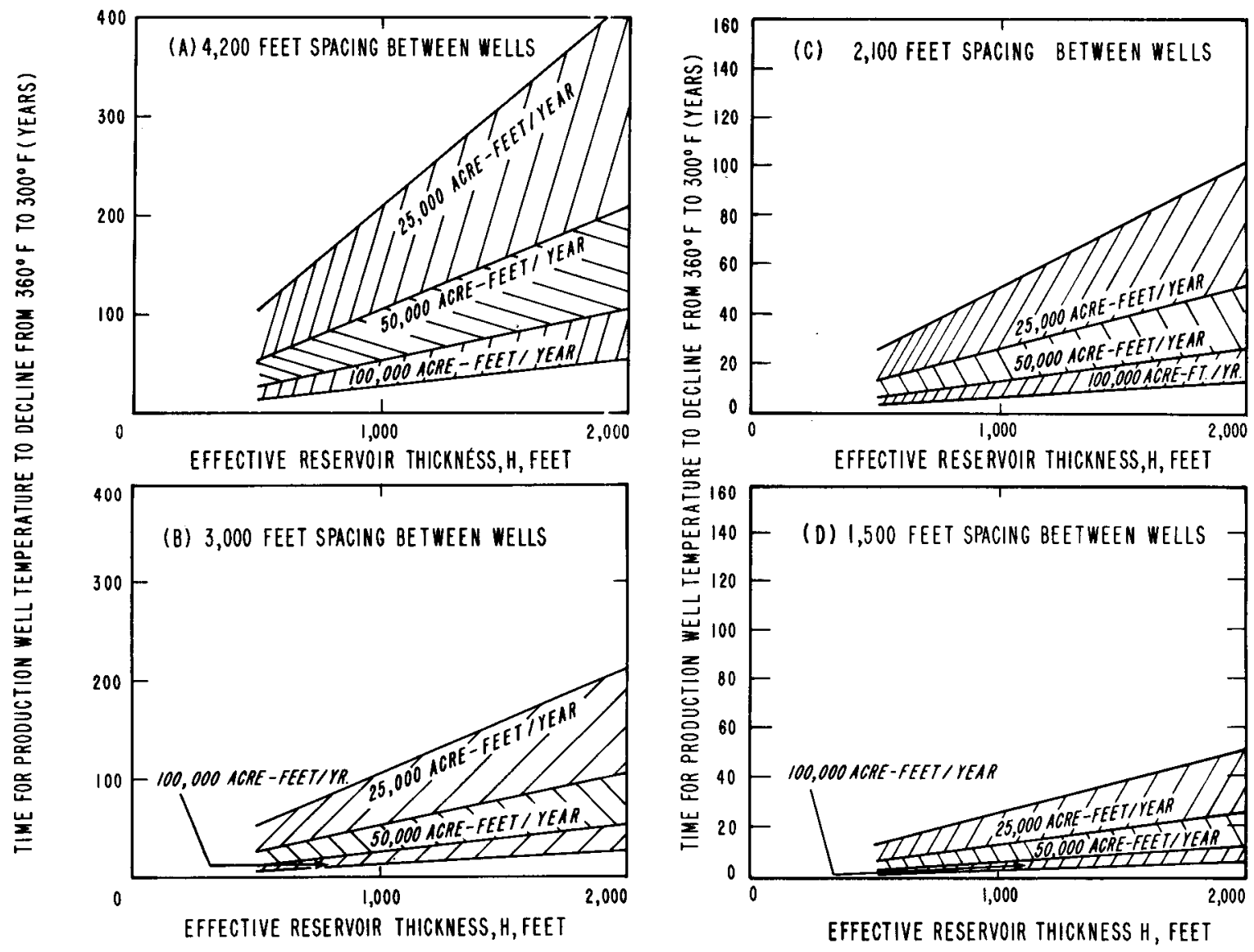

$\times B L 791-2188$

Figure 4.36. Time for production-well temperature to decline from $360^{\circ} \mathrm{F}$ to $300^{\circ} \mathrm{F}$ as a function of $\mathrm{H}$, well-spacing, and total production rate from wells located within the USBR leasehold for peripheral injection case: (A) 4200- $\mathrm{ft}$, (B) 3000-ft, (C) 2100-ft, and (D) 1500-ft well spacing. 

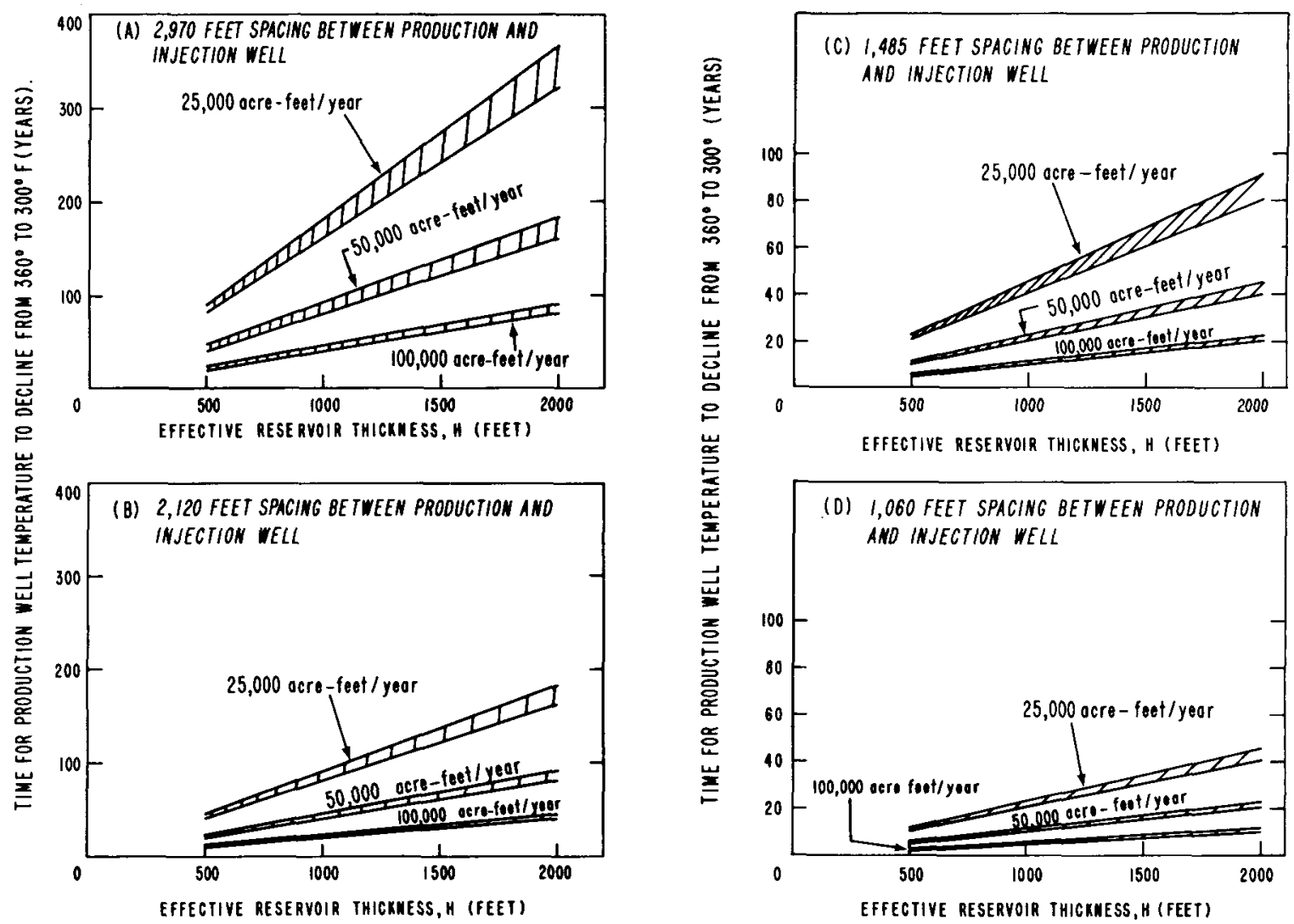

$X B L 7811-2171 \mathrm{~A}$

Figure 4.37. Time for production-well temperature to decline from $360 \circ$ to $300 \%$ as a function of $\mathrm{H}$, well-spacing, and total flow rate from wells within USBR leasehold for fivespot pattern: (A) 206-acre, (B) 103-acre, (C) 51.5-acre, and (D) 26-acre well spacing. 
the depth at which pumps could be successfully installed and operated; the lower limit for acceptable flow rates from individual we11s, and so on). As we have pointed out at the beginning of this chapter, optimization and economic evaluation are outside the scope of this study.

\section{LIMITATIONS OF THIS STUDY}

We have attempted to provide a realistic evaluation of the East Mesa reservoir performance under various production rates to help USBR evaluate the feasibility of the desalination project. Because of the nature of the decision to be made, our task has not been to model the East Mesa reservoir in precise detail. Rather, our task has been to study a great many possible scenarios with relatively simple mathematical models--emphasising variety rather than sophistication. Hence, the calculations have been made on a highly idealized model. This limitation has to be recognized at the outset in interpreting the various results presented in this chapter. Because the system parameters chosen represent the reservoir optimistically, the results presented should be considered as indicating the reservoir performance under favorable conditions.

In discussing the other limitations of this study, it is perhaps best to answer the following questions. Is it possible for the reservoir to perform better than the idealized model indicates? What level of risk should be associated with the ranges of results obtained?

First, there are two aspects in which the reservoir performance may improve. The reservoir pressure response may prove to be better, or the mineable resrvoir life may increase. Insofar as pressure response is concerned, the model assumptions are extremely favorable: $\mathrm{kH}$ of $30,000 \mathrm{md}-\mathrm{ft}$ as compared with 10,000 to $20,000 \mathrm{md}-\mathrm{ft}$ within the USBR leasehold; ignore barrier boundary effects; areally infinite aquifer; ignore well-bore damage, and so on.

Perhaps the only model that might be less favorable for pressure support is the assumption of no water influx from the top or bottom of the idealized reservoir. In fact, if the sediments below the reservoir were to possess significant (fracture?) permeability and exist at a relatively high hydraulic potential, it is quite conceivable that large 
influx of hot fluids may migrate upward to the reservoir and provide strong pressure support. Interference tests conducted in 1976 and 1977 between wel1s $6-2,6-1,31-1$, and 8-1 have suggested a possible "leaky" boundary within the USBR leasehold area. Nevertheless, very little data are currently available to establish this leaky boundary with any degree of confidence. For practical purposes, therefore, it is reasonable not to rely on this leady source in making the final decision. It is very likely that the other favorable assumptions will more than compensate for the leaky source uncertainty.

The question of uncertainty and $r$ isk assessment is even more difficult to answer. It is certainly extremely difficult to quantitatively associate a "factor of safety" or "factor of risk" with the results so far presented. However, considering the favorable assumptions made and the general lack of experience in pumping large amounts of fluids over prolonged periods of time, it is likely that the actual reservoir performance will be less optimistic than that suggested by the results of the present study. Consequently, some risk factor needs to be incorporated into the final decision-making procedure in this regard. This factor will also be governed in part by the risk that the decision maker is willing to associate with the overall desalination project.

\section{SUMMARY AND CONCLUSIONS}

The present study is an attempt to provide the necessary reservoir engineering input on the feasibility of augmenting the Colorado River with desalted geothermal fluids from the East Mesa reservoir. Specifically, the study seeks to predict the response of the reservoir under various production-injection scenarios for annual flow rates varying from 25,000 to 100,000 acre-ft $(15,000$ to $60,000 \mathrm{gpm})$.

We propose a method of obtaining the desired annual flow rates by using downhole pumps with simultaneous reinjection of Salton Sea water to replenish the reservoir and provide pressure support. The reservoir will remain single-phase (water) at all times.

Our philosophy of analysis is to choose a set of reservoir parameters that are optimistic, given the present status of knowledge of East Mesa, and to study the response of an idealized reservoir to different 
exploitation strategies. The responses will then be presented to illustrate their significance on the economics of the overall project. The actual economic analysis, however, is beyond the scope of the present study.

The factors that are most relevant to economic analysis include: pressure drawdowns and excess injection pressures; hydrodynamic breakthroughs; and thermal breakthroughs. The parameters that strongly affect these factors are the 1 imits of the well field; the pattern of well distribution; well spacing; the geometry and size of the reservoir; total rate of fluid production; reservoir permeability, storativity; and the effective reservoir thickness and porosity. The assumptions made in regard to these parameters are summarized in Table 4.2.

The simulations carried out in the present study fall into three categories: pressure-transient calculations, well-bore thermodynamic calculations and thermal breakthrough calculations. The pressuretransient calculations were carried out with program MAXDRAW, which essentially superposes a set of analytic solutions. Some of these calculations are also carried out with a numerical model TERZAGI. The wellbore two-phase calculations were carried out with a model developed by Juprasert and Sanyal (1977). The thermal breakthrough calculations were carried out with a program called METERNIQ, based on an analytic approach. To check the results, some calculations were repeated with an independent numerical model called TRUMP.

Al1 the simulations pertained to a homogeneous, infinite, horizontal reservoir. A majority of the calculations were directed to the case in which the production wells were distributed within the $300 \% \mathrm{~F}$ isotherm at a depth of $6000 \mathrm{ft}$. Some simulations were also run with the production wells distributed within the $3000 \mathrm{~F}$ isotherm at a depth of $7000 \mathrm{ft}$.

Three types of production-injection scenarios were considered: no injection peripheral injection; and five-spot pattern. For each of these scenarios, the following spacings between production wells were considered: $4200,3000,2100$, and $1500 \mathrm{ft}$. In addition, calculations were carried out to study the effect of viscosity changes, wellbore damage, and barrier boundary effects. The various cases studied are given in Table 4.3. 
The results of pressure transient calculations are summarized graphically in Figures 4.8 through 4.21. Results of the no-injection scenario given in Figure 4.8 show that for 50,000 acre-ft annual production the average drawdown declines from about 3000 psi for a spacing of $4200 \mathrm{ft}$ to about $2500 \mathrm{psi}$ for a spacing of $1500 \mathrm{ft}$ between production wells. For annual flow rates of 25,000 and 100,000 acre-ft, the drawdown range can be scaled by factors of 0.5 and 2 , respectively. The computed drawdown ranges are unrealistic since, at these drawdowns, the reservoir will flash and become two-phase, which violates the basic assumption of a single-phase system. Rather, the large drawdown ranges computed simply show that the indicated flow rates are too large for the reservoir to sustain under single-phase flow conditions.

The aim of peripheral injection is primarily to sweep the heat from the reservoir toward the central portion of the well field, where fluid is extracted. To a lesser extent, peripheral injection will also help minimize the pressure drawdowns by providing reservoir pressure support. Although three different peripheral injection rings were studied (close-in, intermediate, and farthest), the close-in ring (where the injection ring was closest to the production field) was found to be most favorable for providing reservoir pressure support and hence, is of greatest interest.

Results summarized in Figure 4.12(A) show that for close-in peripheral injection scheme, the average drawdown varies from about 950 psi for 4200-ft spacing to about 310 psi for 1500-ft spacing for an annual flow rate of 50,000 acre-ft. For 25,000 and 100,000 acre-ft annual rates, the aforesaid values could be scaled by factors of 0.5 and 2 , respectively. Figure $4.12(B)$ shows that for an annual flow rate of 50,000 acre-ft, the excess injection pressure ranges from 480 to $150 \mathrm{psi}$ depending on well spacing.

In another series of simulations, the peripheral injection scenario was repeated with the production wells distributed within the 1 imits of the $300^{\circ} \mathrm{F}$ isotherm at the $7000-\mathrm{ft}$ depth. The results showed that the pressure drawdowns and excess injection pressures in these were essentially the same as the corresponding cases for the $300 \%$ isotherm at 6000-ft depth (Table 4.5). This shows that as far as peripheral 
injection is concerned, distributing the same number of wells over a larger area will not significantly increase pressure support.

It is known that the existence of barrier boundaries will lead to pressure drawdowns and excess injection pressures that are greater than when such boundaries are absent. In the case of peripheral injection, the actual pattern and magnitude of such increases will depend on the location and orientation of such boundaries. However, computations do show that if such boundaries are present, they could significantly increase pressure drawdowns and excess injection pressures (compare Figures 4.14 and 4.10 ).

Calculations carried out for the five-spot pattern (Figure 4.19) show that for 50,000 acre-ft annual production, the average pressure drawdowns decline rather significantly from about 530 psi at a spacing of 203 acres to about 800 psi for a spacing of 26 acres. This suggests that for a given annual rate of production it is more efficient to have a large number of closely spaced wells. In this regard, two points should be borne in mind. First, obtaining the same total flow rate from a large number of wells implies decreased flow rates per we 11. For example, 50,000 acre-ft annual production from 206-acre spacing implies $2000 \mathrm{gpm}$ per well, whereas obtaining the same flow rate from a 26-acre spacing implies $250 \mathrm{gpm}$ per well. Secondly, reduction of well spacing will lead to faster thermal breakthrough times.

For five-spot pattern injection, it is also instructive to study the response of a single pair of production and injection wells to different flow rates. These responses are illustrated in Figure 4.20. These figures show that for a given flow rate per well (e.g., 1000 or $2000 \mathrm{gpm}$ ) the average pressure drawdown (or excess injection pressure) is insensitive to spacing. Thus for a flow rate of $1000 \mathrm{gpm}$, the average pressure drawdown is approximately 250 psi, for we11-spacing ranging from 26 to 203 acres.

This finding is encouraging in that one could conceivably increase the total number of well pairs to increase overall flow rate from the well field. A word of caution is in order here: the calculations are based on $100 \%$ volumetric injection. However, it is pertinent to examine the consequences if $100 \%$ volumetric injection cannot be assured. 
The influence of unbalanced injection on pressure drawdowns for various we11 spacings for $100 \mathrm{gpm}$ production well is presented in Figure 4.21. This figure implies that (a) pressure drawdowns increase as injection decreases below production; and (b) for a given, decreased injection, drawdowns increase more for smaller well spacing and larger number of wells than for larger well spacing and smaller number of wells.

The pressure-transient calculations were all carried out with the assumption that the viscosity of the injected water was the same as that of the produced hot water $(0.2 \mathrm{cp})$. However, viscosity of water at $167^{\circ} \mathrm{F}\left(75^{\circ} \mathrm{C}\right)$ is about 1.9 times higher than that of water at approximately $340^{\circ} \mathrm{F}$. Higher viscosity means decreased water mobility and implies proportionate increase in pressure drawdowns. The effect of viscosity on pressure drawdowns for the five-spot pattern is illustrated in Figure 4.23. As the cold front migrates outward from the injection well, the excess injection pressures increase rather rapidly above the value of to hot-water pressures and reach their peak when the cold front is midway between the production and injection wells. At this maximum value, the injection well behaves as though the entire reservoir were filled with the colder injected fluid. As the cold front migrates beyond the midway point to the production well, the production well drawdowns will begin to increase due to the advance of the less mobile cold water toward it. Although one could normally expect the pressure field to stabilize under $100 \%$ volumetric injection, in actuality the viscosity effects will render it unsteady. As a result, one should expect the injection pressures and drawdowns to gradually increase with time throughout the life of the project. This should have important implications on the design and setting of different pumps needed for operating the well field.

An important assumption made in the pressure-transient simulations is that the wells are perfect hydraulic systems. However, experience from hydrogeology and petroleum engineering shows that significant head losses at production or injection wells invariably occur in almost all field situations. Such losses are especially likely to occur in geothermal wells due to such causes as corrosion, scaling, and formation plugging. To provide some clues to the role of wel1 losses in pressure 
drawdowns, a few calculations were carried out for the five-spot pattern. The results, given in Figure 4.24, indicate that a skin factor of 5 can increase pressure drawdowns by as much as $70 \%$. A skin factor of 5 may not be unusual for geothermal wells.

An important feature of producing geothermal wells is that the fluid invariably flashes, boils, or migrates up the well bore. The depth at which boiling begins (with the formation of steam) may be called the flash point. When downhole pumps are contemplated, the flash-point depth is of critical importance since the bowl assembly of the deep-well pump has to be lowered safely below the flash point. The location of flash point within the wellbore is a function of flowing reservoir temperature and pressure, well diameter and friction factor, and flow rate. Computations on well-bore thermodynamics (Figures 4.26 and 4.27) suggest that for the conditions likely at East Mesa, flashpoint depth varies directly as reservoir pressure drops. Moreover, as a rough approximation, one could estimate flash-point depth by multiplying pressure drawdown in psi by a factor of 2.4 .

Because the proposed desalination project includes groundwater mining at the expense of relatively poor-quality Salton Sea water, the feasibility of the project depends on hydrodynamic and thermal breakthroughs. In regard to hydrodynamic breakthrough, the "mineable reservoir life" $\left(R_{L}\right)$ is the time required, at a given flow rate, to mine all the fluid contained within the reservoir. Obviously, $R_{L}$ is equal to the volume of water within the reservoir divided by the flow rate. Thus, $R_{L}$ is a function of the effective reservoir porosity, extent, and thickness. Very little data are currently available on the overall values of effective reservoir porosity and thickness. The values of $R_{L}$ corresponding to a range of values of $\phi$ and $H$ are given in Figure 4.28 for the portion of the reservoir contained within the $3000 \mathrm{~F}$ isotherm at $6000-\mathrm{ft}$ depth. Because the area enclosed by the $300 \% \mathrm{~F}$ isotherm at $7000-\mathrm{ft}$ depth is roughly twice as large as the area at $6000-\mathrm{ft}$ depths, one could easily scale the results in Figure 4.28 by a factor of 2 to obtain $R_{L} s$ for the 7000-ft depth. As shown in Figure 4.28 , $R_{L}$ may vary from a few to as many as 150 years, depending 
on the combination of parameters chosen. For example, assuming $\mathrm{H}=$ $1500 \mathrm{ft}, \phi=15 \%$, and annual flow rate $=50,000 \mathrm{acre}-\mathrm{ft}$, then $\mathrm{R}_{\mathrm{L}}$ is 36 years for the $6000-\mathrm{ft}$ case.

It must be noted here that $\mathrm{R}_{\mathrm{L}}$ suggests only an upper bound for the reservoir life. The actual life is likely to be much smaller. It is extremely doubtful that the injected water can successfully displace all the in situ reservoir fluids from the reservoir pores. And, with the arrival of the poor-quality injected fluid at the production wells along flow paths of increasing lengths, there will ensue a gradual decline in the chemical quality of the produced fluids. Thus, long before the entire quantity of reservoir fluid is mined out, the chemical quality of the produced fluids will so deteriorate as to seriously affect the efficiency of the desalination process.

Thermal breakthrough occurs when cold injected fluid reaches the production well and production-well temperature begins to decline. The life of a geothermal production well very much depends on the time elapsed before the production-well temperature falls below an acceptable leve1. This depends on the effective reservoir porosity and thickness, flow rate, initial reservoir temperature, well spacing, and so on. All the thermal breakthrough simulation runs assumed an initial reservoir temperature of $360^{\circ} \mathrm{F}$. The computations showed that, other factors remaining constant, thermal breakthroughs were not very sensitive to porosity. However, for a given set of conditions, thermal breakthroughs were directly proportional to effective reservoir thickness $(H)$ and inversely proportional to the square of the distance between production and injection wells. The effect of $\mathrm{H}$ on the time elapsed for production well temperature to decline to $300^{\circ} \mathrm{F}$ from $360 \% \mathrm{~F}$ is illustrated in Figure 4.32 for peripheral injection and five-spot scenarios. Increasing $H$ by a factor of 2 also increases the time elapsed by a factor of 2 . In this connection, $H$ is the effective reservoir thickness rather than the total thickness.

Ground subsidence denotes the displacements occurring at the land surface due to various causes such as tectonic movements and fluid withdrawal from the subsurface. Our concern here is the potential for ground subsidence caused exclusively by geothermal fluid withdrawal. 
Ground subsidence occurs due to the reduction in the bulk volume of the reservoir rocks due to fluid withdrawal and transmission of the effects of volume change to the land surface through the overburden. The magnitude of reservoir volume change depends on the compressibility of the reservoir rocks and the pressure changes caused by fluid withdrawal. Experience with shallow groundwater systems indicates that, in general, fine-grained sediments such as clays and shales are far more compressible than coarse-grained materials such as sands. Nevertheless, study of geophysical logs from boreholes at East Mesa suggests that the shales within the reservoir are quite dense and may not be very compressible. If this is indeed correct, then reservoir compaction at East Mesa should be largely governed by the compressibility of the coarse-grained reservoir rocks. Interference tests so far conducted indicate the reservoir $\phi c_{t} \mathrm{H}$ ranges from $6 \times 10^{-4}$ to $6 \times 10^{-3} \mathrm{ft} / \mathrm{psi}$. Computations based on this range (Figure 4.33) indicate that reservoir compaction may vary from less than $1 \mathrm{ft}$ to as much as $5 \mathrm{ft}$, depending on $\phi, H$, and pressure drawdown.

Because there are costly irrigation structures close to the geothermal field at East Mesa, the effects of subsidence are of significant environmental interest. In this regard, the magnitudes of maximum and differential subsidence are equally important. Unfortuately, the idealized models used in this study do not incorporate the details of reservoir geometry and heterogeneity needed for predicting land subsidence very accurately. The detailed data of the reservoir that are needed to attempt a sophisticated subsidence model are not available. Due to the several hundred psi of drawdown likely to occur at East Mesa, if 25,000 to 100,000 acre-ft/yr of water are produced, ground subsidence could be a significant environmental problem. A carefully controlled subsidence-monitoring program is essential from the beginning of the exploitation program if ground subsidence is to be kept under control.

Considering that the East Mesa site lies close to the geologically active San Andreas fault system, induced seismicity may be a real concern if injection pressures of several hundred psi are contemplated. 
So far, we have summarized the reservoir response for various scenarios for wells distributed within the $300^{\circ} \mathrm{F}$ isotherm, which occupies a region larger than the area under the USBR leasehold. To get an idea of the reservoir response for wells restricted to the USBR leasehold, one has to interpolate from the results presented so far. About 4400 acres of USBR's property falls within the $300^{\circ} \mathrm{F}$ isotherm at $6000 \mathrm{ft}$. This area is about $60 \%$ of the total area within the $300 \% \mathrm{~F}$ isotherm at that depth. For the peripheral injection scenario (which has to be considered for the reservoir as a whole) and the five-spot pattern, one could therefore calculate only about $60 \%$ of the total flow rate from wells located within USBR's lands for the pressure drawdown ranges presented earlier. For example, looking at Figure 4.12(A), which relates to peripheral injection, the average pressure drop for 60 production wells for an annual flow rate is approximately $410 \mathrm{psi}$. Of these 60 production wells, about 36 lie within USBR's lands and should yield, at the same average drawdown, about 30,000 acre-ft/yar $(60 \%$ of 50,000 acre-ft/yr). Conversely, if one desires to obtain 50,000 acre-ft/yr from the 36 wells within USBR's lands, the production rate has to be stepped up by a factor of 1.67 . This increased production rate will lead to an average drawdown of $440 \times 1.67=730$ psi. Similar reasoning will also apply when interpolating hydrodynamic or thermal breakthrough. The results of these interpolations are summarized in Tables 4.6, 4.7, and Figures 4.35 through 4.37 .

The various mathematical simulations carried out in this study have provided quantitative information on the response of the geothermal reservoir to annual flow rates of 25,000, 50,000, and 100,000 acre$\mathrm{ft} / \mathrm{yr}$ under a variety of production and injection scenarios. The answer to whether or not the reservoir will sustain a given annual flow rate can only be obtained through a process of optimization and economic analysis. The optimization has to evaluate trade-offs among several alternate possibilities. For example, should one obtain a given total flow rate with a few widely spaced wells at large drawdowns or with many closely spaced wells? Several factors must be considered to make this decision: the cost of drilling, installing, and maintaining pumps; the faster breakthrough times; the possibility of enhanced drawdowns 
due to unbalanced injection; wellbore damage; viscosity effects; and the minimum acceptable economic flow rate per well. In addition, maximum acceptable drawdowns and power required to lift or inject water against gravity must be considered. Apart from the economic considerations, there are technical problems such as whether efficient pumps could be installed and maintained effectively over prolonged periods of time at the desired depths.

In a study such as the present one where an idealized reservoir has been considered, it is necessary to be aware of the limitations of analysis. Almost all of the reservoir parameters used in the simulation have been chosen optimistically in the light of available field data, especially with reference to the USBR leasehold. The actual reservoir response should normally be expected to be poorer than what the results might indicate at the outset. Hence, a risk factor should be considered when using the results for economic analysis. Quantitatively, this risk factor is very difficult to establish. This difficulty is attributable to several reasons, not the least of which is that very little information is currently available on the operation of large well fields in geothermal reservoirs with downhole pumps and with reinjection at large flow rates over prolonged periods of time. To some extent, the risk involved will also depend on how much effort one is willing to spare to get this new technology of geothermal resource utilization to a workable stage.

We must consider whether or not the response of the reservoir could be much better than the results presented in this study would suggest. Specifically, the simulation studies have ignored the possible influx of geothermal fluids from greater depths as the reservoir pressure drops due to production. Although such a possibility exists, field evidence is lacking at present to establish the magnitude of such influx. It may be necessary to wait until the reservoir is stressed sufficiently before the existence of such influx and its magnitude can be established. At present, therefore, one cannot rely on this possibility in evaluating the overall feasibility of the desalination project. 
The choice of the $300^{\circ} \mathrm{F}$ isotherm does not clearly limit the geothermal reservoir at East Mesa. According to our present knowledge, it encompasses a reasonable portion of the geothermal reservoir and provides a basis for interpolating to the USBR's property. If future exploration reveals that the isotherms extend much beyond their present inferred positions, then a more favorable picture of the reservoir will emerge.

Finally, we have concentrated on the problem of groundwater mining and replenishing the reservoir fluids with relatively cold Salton Sea water. We have not addressed the problem of energy extraction from the geothermal fluids through recycling, by injection of relatively warm (2100F) fluids. In this case, the responses should be somewhat better due to diminished viscosity effects and the absence of the chemical quality problem associated with Salton Sea water. Caution should therefore be exercised in extrapolating the results of the present study to the problem of energy extraction. It is advisable to carry out an independent evaluation of that issue.

In conclusion, we have strived to present, in as clear as fashion as possible, the expected response of the geothermal reservoir at East Mesa to various flow rates under different exploitation strategies. We hope that these results will help USBR arrive at a rational decision on the feasibility of the desalination project. 
NOMENCLATURE

\begin{tabular}{|c|c|c|c|}
\hline Symbo1 & Property & Dimensions & Units \\
\hline$c_{\mathrm{f}}$ & Specific heat of water & Energy/mass·deg & $\mathrm{cal} / \mathrm{kg}^{\circ} \mathrm{C}$ \\
\hline$c_{p}$ & $\begin{array}{l}\text { Pore volume compressibility } \\
\text { of rock }\end{array}$ & $\mathrm{LT}^{2} / \mathrm{M}$ & $1 / p s i$ \\
\hline$c_{\mathbf{r}}$ & $\begin{array}{l}\text { Specific heat of reservoir } \\
\text { rock }\end{array}$ & Energy/mass $\cdot \mathrm{deg}$ & $\mathrm{cal} / \mathrm{kg}^{\circ} \mathrm{C}$ \\
\hline$c_{w}$ & Compressibility of water & $\mathrm{LT}^{2} / \mathrm{M}$ & $1 / \mathrm{psi}$ \\
\hline d & Diameter of the wel1 & $\mathrm{L}$ & \\
\hline $\mathrm{D}_{\mathbf{i}}$ & $\begin{array}{l}\text { Distance between production } \\
\text { and injection well }\end{array}$ & $\mathrm{L}$ & $\mathrm{ft}$ \\
\hline $\mathrm{D} / \mathrm{Dt}$ & Total derivative & & \\
\hline$g$ & Gravitationa1 constant & $\mathrm{L} / \mathrm{T}^{2}$ & \\
\hline $\mathrm{G}_{\mathrm{v}}, 1$ & $\begin{array}{l}\text { Volumetric generation rate } \\
\text { from volume element } 1\end{array}$ & $\mathrm{~L}^{3 / \mathrm{T}}$ & gpm \\
\hline $\mathrm{H}$ & Thickness of the aquifer & $\mathrm{L}$ & ft \\
\hline $\mathbf{k}$ & Permeability of the reservoir & $\mathrm{L}^{2}$ & md \\
\hline $\mathbf{k}_{\mathbf{s}}$ & Permeability of skin & & \\
\hline $\mathrm{k}_{\mathbf{r}}$ & Thermal conductivity of rock & Energy/LT·deg & \\
\hline $\mathrm{K}_{\mathrm{f}}$ & $\begin{array}{l}\text { Thermal conductivity of the } \\
\text { fluid }\end{array}$ & Energy/LT·deg & $\mathrm{cal} / \mathrm{cm} \cdot \sec ^{\circ} \mathrm{C}$ \\
\hline $\overrightarrow{\mathrm{n}}$ & Unit outer normal & & \\
\hline $\mathbf{p}$ & Reservoir pressure & $\mathrm{M} / \mathrm{LT}^{2}$ & psi \\
\hline$P i$ & Initial reservoir pressure & $\mathrm{M} / \mathrm{LT}^{2}$ & psi \\
\hline$\Delta_{\mathrm{p}}$ & Change in reservoir pressure & $\mathrm{M} / \mathrm{LT}^{2}$ & psi \\
\hline pt & $\begin{array}{l}\text { Total pressure differential, } \\
\text { drawdown }+ \text { excess injection } \\
\text { pressure }\end{array}$ & & psi \\
\hline$P_{D}$ & $\begin{array}{l}\text { Dimensionless pressure used } \\
\text { in petroleum literature. } \\
P_{D}=0.5 \mathrm{~W}(\mathrm{U})\end{array}$ & & \\
\hline $\mathrm{Q}_{\mathrm{m}}$ & Mass flow rate & $\mathrm{M} / \mathrm{T}$ & \\
\hline $\mathrm{Q}_{1}$ & Liquid flow rate & $\mathrm{L}^{3} / \mathrm{T}$ & gpm \\
\hline QTAF & Total fluid production & $\mathrm{L}^{3} / \mathrm{T}$ & acre-ft/yr \\
\hline
\end{tabular}




\section{$r_{\mathbf{s}}$}

$r_{W}$

t

u

1

$u=\left(\phi c_{t} H \mu r^{2} / 4 k H t\right)$ where all

the quantities are expressed

in their fundamental units

$\mathrm{u}=56,887.45\left(\phi \mathrm{c}_{\mathrm{t}} \mathrm{H} \mu \mathrm{r}^{2} / \mathrm{kHt}\right)$

as actual units used in this

report .

$V_{1} \quad$ Volume of a volume element

$v_{v} \quad$ Volume of voids

$V_{w} \quad$ Volume of water

$\mathrm{V}_{\mathrm{b}} \quad$ Bulk volume

W(u) Well function of $u$.

$W(u)=\int_{u}^{\infty} \frac{e^{-u}}{u} d u=2 P_{D}$

$z \quad$ Elevation

$\Gamma \quad$ Surface bounding a volume

element

$\begin{aligned} \rho_{r} & \text { Density of rock } \\ \rho_{w} & \text { Density of water } \\ \phi & \text { Porosity } \\ \mu & \text { Viscosity }\end{aligned}$

L

L

$\mathrm{T}$

ft

ft

min
$\mathrm{L}^{3}$

$\mathrm{L}^{3}$

$\mathrm{L}^{3}$

$\mathrm{L}^{3}$
L

$\mathrm{L}^{2}$

$M / L^{3}$

$M / L^{3}$

1

M/LT $f t$

$\mathrm{kg} / \mathrm{m}^{3}$

$\mathrm{kg} / \mathrm{m}^{3}$

$c p$ 


\section{REFERENCES CITED}

Beggs, H. D., and Bri11, J. P., 1973. A study of two-phase flow in inclined pipes. Trans. AIME, v. 255, pp. 607-617.

Duns, H., Jr., and Ros, N. C. J., 1963. Vertical flow of gas and liquid mixtures in wells. Proc. Sixth World Pet. Cong., Frankfurt, v. II, pp. 451-465.

Earlougher, R. C., Jr., 1977. Advances in well test analysis. Monograph, Henry L. Doherty Series, Soc. Petrol. Engin. of AIME, v. 5.

Edwards, A. L., 1969. TRUMP: a computer program for transient and steady-state temperature distributions in multidimensional systems. Springfield, Nat. Tech., Info. Serv., Report UCRL-14754, Ref. II, $265 \mathrm{pp}$.

Evans, D. M., 1967. Man-made earthquakes, a progress report. Geotimes, v. 12 , no. 6 , pp. 19-20.

Goyal, K. P., 1978. Heat and mass transfer in a saturated porous medium with applications to geothermal reservoirs. PhD thesis, Boulder, University of Colorado, Dept. Mechanical Engineering.

Gringarten, A. C., and Sauty, J. P., 1975. A theoretical study of heat extraction research from aquifers with uniform regional flow. J. Geophys. Res., v. 80, no. 35, pp. 4956-4962.

Hagedorn, A. R., and Brown, K. E., 1965. Experimental study of pressure gradients occurring during continuous two-phase flow in smal1diameter vertical conduits. Trans. AIME, v. 234, pp. 475-484.

Helm, D. C., 1975. One-dimensional simulation of aquifer systems compaction near Pixley, California: 1, Constant parameters. Water Resource Res., v. 11, no. 3, pp. 465-478.

Juprasert, S., and Sanyal, S. K., 1977. A numerical simulator for flow in geothermal wellbores. Geothermal Resources Council., Trans. v. 1, Pp. 159-161.

Kappelmeyer, 0., and Haene1, R., 1944. Geothermics with special reference to application. Berlin and Stuttgart, Geopublication Associates.

Lambe, T. W., and Whitman, R. V., 1969. Soil mechanics. New York, John Wiley. 
Narasimhan, T. N., and Witherspoon, P. A., 1976. An integrated finite difference method for analyzing fluid flow in porous media. Water Resources Res., v. 12, no. 1, pp. 57-64.

Orkiszewski, J., 1967. Predicting two-phase pressure drops in vertical pipe. Trans. AIME, v. 240, pp. 829-838.

TRW/Intercomp, Inc., 1976. Study of the geothermal reservoir underlying the East Mesa area, Imperial Valley, California. U. S. Dept. Interior, Bureau of Reclamation, Lower Colorado Region Office, Report no. 28859-6001-RU-00, vol. 1 . 


\section{SECTION 5: GEOCHEMISTRY \\ R. W. Taylor, ${ }^{1}$ D. D. Jackson, ${ }^{1}$ T. Wolery, ${ }^{1}$ and J. A. Apps ${ }^{2}$ \\ 'Lawrence Livermore Laboratory \\ 2Lawrence Berkeley Laboratory}

\section{INTRODUCTION}

The East Mesa geothermal field has been under development by the U.S. Bureau of Reclamation (USBR) since 1968 with the goal of producing fresh water and power (USBR, 1971, 1973, and 1974). Since the drilling and testing of the first well in 1972, production and desalting of geothermal fluids has been hindered by formation of mineral scales consisting prinarily of calcite. Table 5.1 lists the principal activities at East hesa during the last 10 years. The table is by no means complete but emphasizes those tests that contribute to the background information on scaling. Five geothermal wells have been drilled by the USBR at East Mesa, referred to as $6-1,6-2,31-1,8-1$, and 5-1, respectively. The locations of these wells at the test site are given in Figure 5.1. The depth, bottom-hole temperature, and approximate salt content of the well fluids are summarized in Table 5.2.

The proposed desalination plant at East Mesa is intended to produce approximately 25,000 acre-ft of distilled water per year. Geothermal fluids from a number of wells would be combined before entering the desalination plant. Chemical evidence from existing producing wells at East Mesa suggests that mixing nay lead to precipitates, possibly causing scaling in the production pipelines feeding the plant. Geothermal fluids would be recovered from wells through the use of downhole pumps, obviating carbonate scaling due to flashing* in the wellbores, however, rapid scaling would be expected upon steari separation in the desalination plant.

The exploitation of geothermal fluids would probably lead to subsidence of the land surface above the reservoir. Because of the flatness of the terrain and the proximity of agricultural land served by irrigation canals, subsidence would have to be prevented by injecting residual fluids and make-up water from the Salton Sea. Salton Sea water would be pumped to East Mesa using the power produced incidentally to the desalination process. The

*The term "flashing" is used here in the sense of vapor separation from the aqueous phase. Limited flashing of East Mesa geothermal fluids will result in a vapor phase consisting primarily of carbon dioxide. More extensive flashing will produce a vapor phase in which water is dominant. 


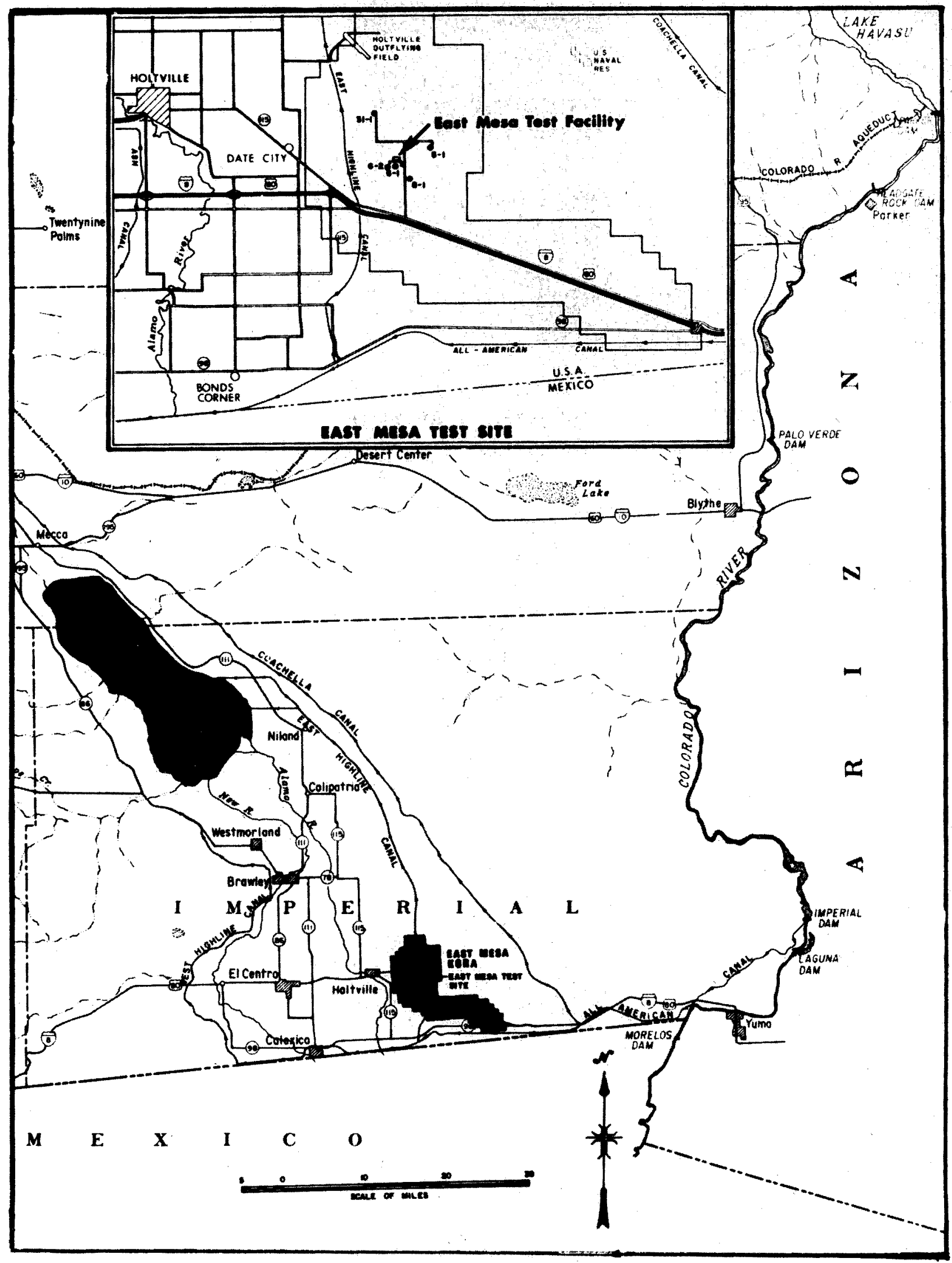

Figure 5.1. Map of southeastern California showing location of East Mesa, a Known Geothermal Resource Area (KGRA), and locations of U.S. Bureau of Reclamation leaseholds (source, USBR). 
Table 5-1. Principal activities at the East Mesa geothermal field 1968 to 1978. Year Principal Activities

1968 USBR and Division of Saline Water authorized to appraise geothermal resources for fresh-water production.

U.C. Riverside geophysics defines anomaly at East Mesa.

1970

1971

1972

Holes drilled to measure temperature gradient. U.C. Riverside geophysics report (1970).

First USBR status report (1971b). Resistivity survey by U.C. Riverside. Site location for report for 6-1 (USBR, 1971a). U.C. Riverside report (1971) on desalination potential.

Well 6-1 drilled and tested. Well 6-1 flashed to $4000 \mathrm{ft}$ at $100 \mathrm{gal} / \mathrm{min}$. Development concepts report (U.C. Riverside, 1972).

Well 6-2 drilled and tested. MSF shakedown test produced 10,000 gal fresh water. Report on 6-1 testing (USBR, 1973b) Site selection report for well 6-2 (USBR, 1973a).

1974

Wells 5-1, 8-1 and 31-1 drilled. Well 6-1 tested and perforated. Single-stage VTE tested $900 \mathrm{hr}$ using well 6-1. Contract to Bechtel for desalting. Wah1 (1975) report on Garrett sçaling, USBR status report (USBR, 1974).

Commercial interest in East Mesa, Republic and Magma drill-wells. Second perforation of well 6-1. Eight day test of MSF. Well 5-1 tested and injection started. USBM operates materials testfacility on well 6-1, which seals itself. Well 6-2 perforated.

Bechtel operates VTE and MSF. Injection into well 5-1, from we11s $6-2$ and $8-1$.

1977 USBR status report (1977a); and desalting report (1977b). Fluted Ti tubes scaled (VTE). Reports on site operation by Bechtel Corp. (1977a, 1977b). Battelle PNL corrosion studies in well 6-1, which plugs; Watson initiates Round Robin sample. LBL starts production tests. Aerojet and Allied test heat-exchangers on well $6-1$.

1978 LBL reservoir testing. BNL tests polymer pipes in well 6-2. Turbine tests by DDS Engineering Co. ORNL tests condensers. Turbine tests (DSS). Down-hole pump tests by Barber Nicols. DOE takes over site; Westec managing. 
Table 5.2 East Mesa well data (USBR)*

\begin{tabular}{clccc}
\hline $\begin{array}{c}\text { Well } \\
\text { number }\end{array}$ & \multicolumn{2}{c}{$\begin{array}{c}\text { Depth } \\
\text { (feet) }\end{array}$} & $\begin{array}{c}\text { Reservoir } \\
\text { (formation) } \\
\text { temp }\left({ }^{\circ} \mathrm{C}\right)\end{array}$ & $\begin{array}{c}\text { Total dissolved } \\
\text { solids (TDS) } \\
(\mathrm{mg} / 1)\end{array}$ \\
\hline $6-1$ & $2448+$ & 8030 & 204 & 20,000 \\
$6-2$ & 1830 & 6005 & 193 & 4,000 \\
$31-1$ & 1899 & 6231 & 154 & 2,000 \\
$8-1$ & 1891 & 6205 & 179 & 2,500 \\
$5-1$ & 1834 & 6016 & 157 & 2,000 \\
\hline
\end{tabular}

* See USBR, 1977, and Appendix E.

+ Presently open only to a depth of $1294 \mathrm{~m}(7200 \mathrm{ft})$.

water would also be used to cool the desalination-plant heat exchangers. Several problems might arise from the use of Salton Sea water. These include scaling in the heat exchangers, scaling due to mixing with residual brines, and scaling due to heating by and reaction with the rocks in the reservoir after injection. Scaling may even occur in the transmission pipelines between the Salton Sea and the desalination plant.

Potential problems in the operation of a desalination plant can thus be summarized as scaling:

(a) due to mixing of incompatible geothermal fluids, whether in the production wells or in the production pipelines ;

(b) caused by flashing, concentration and cooling of the geothermal fluids in the desalination plant;

(c) caused by heating Salton Sea water in heat exchangers;

(d) by mixing Salton Sea water with residual geothermal fluids; or

(e) by injecting residual geothermal fluids and Salton Sea water in the geothermal reservoir.

Scaling may or may not be operationally significant depending on where it occurs, its quantity, and physical characteristics. With this knowledge USBR can take corrective action, either by modifying plant design, or treating the working fluids to prevent or retard precipitation of scale formers.

The purpose of this section is to evaluate the potential for scaling under the conditions expected in an operating desalination plant at East Mesa. This section is divided into eight parts. The second part reviews 
the available data on the chemical compositions of geothermal well fluids at East Mesa and the Salton Sea. Succeeding parts deal with the problem of flashing and fractionation of volatiles from East Mesa geothermal fluids; the potential for scaling caused by the use of geothermal fluids and Salton Sea water, respectively; scaling predictions compared with operating experience obtained from pilot-plant studies at East Mesa; and scale control techniques. Finally, our conclusions and recommendations are presented.

CHEMICAL COMPOSITION OF FLUIDS FROM EAST MESA AND THE SALTON SEA

\section{Selection Criteria and Sampling Problems}

Many samples of fluid have been taken for chemical analysis from the East Mesa wells, particularly wells 6-1 and 6-2. Chemical analysis of wellhead samples taken in an "unflashed" condition are tabulated in Appendix $\mathrm{E}$. Actual concentrations of key scale-forming elements remain uncertain due to difficulties in taking samples, sample instability, and to a lesser extent, inaccurate analytical techniques. During early investigations at East Mesa, only flashed samples were collected; some of these are included in the tabulations. Some downhole samples are also included, even though most of them seem to have been mixed with drilling mud. Also, recent analyses of flashed fluids from Republic vells are included, data for unflashed samples not being available (Michels, 1978).

In retrospect it probably was not known if a well being sampled was flowing as a single phase (unflashed) or if the sample remained a single phase in the sampling tube (Riley et al., 1979). Occasionally the individuals collecting samples commented in their notebooks that gas bubbles were seen escaping from the sampling tube. Even so, such samples were classified as unflashed.*

Flashing can change the chemical composition of the fluid in several ways. Loss of steam results in a general concentration of all nonvolatile elements. This can lead to the precipiation of solid phases, particularly

* Chemistry laboratory notebook and data sheets, and records of wellhead temperature, pressure, and flow rate are presently stored at USBR, Boulder City, Nevada. 
those that have a decreasing solubility with decreasing temperature, for flashing cools the fluid. The loss of carbon dioxide $\left(\mathrm{CO}_{2}\right)$ during the flashing causes carbonate precipitation, as discussed below. The formation of calcium carbonate $\left(\mathrm{CaCO}_{3}\right)$ while a sample is being taken results in a low value for the calcium (Ca) concentration. Once solid $\mathrm{CaCO}_{3}$ is present as scale, particles may be carried into the sample resulting in a high $\mathrm{Ca}$ concentration. This is one reason for the variability of the tabulated values for $\mathrm{Ca}$ and other scaleforming elements.

The most recent and most common sampling technique used by USBR at East Mesa is fluid removal through a coil of tubing submerged in an ice bath. The cooled fluid is released (depressurized) through a valve at the end of the tube. Both copper and stainless steel have been used, and both have disadvantages: copper reacts with the fluid and stainless steel is a poor conductor of heat.

Another sampling method was occasionally used. The hot fluid was discharged through a $0.4-\mathrm{mm}-$ diameter hole directly into a weighed amount of ice and water. Wells $6-1$ and 6-2 were sampled by both methods on 30 April 1974 (Appendix E). The sample collected by the cooling-coil method had lower concentrations of calcium, magnesium ( $\mathrm{Mg}$ ), strontium ( $\mathrm{Sr}$ ), and silica $\left(\mathrm{SiO}_{2}\right)$ than the other method (Appendix E, wells 6-1 and 6-2). It is possible that precipitation took place in the cooling coil. The differences observed by the two sampling methods range from $10 \%$ for $\mathrm{Sr}$ to nearly $60 \%$ in the case of $\mathrm{Ca}$. Thus it appears that sampling remains an unsolved problem (Battelle, 1978; Kryukov and Larionov, 1970; and Hill and Morris, 1975). It is the greatest source of error in determining concentrations of scaleforming elements at East Mesa.

\section{Change in $\mathrm{pH}$ with Sample Age}

Measurements of the $\mathrm{pH}$ of samples from well 6-2, said to be "unflashed," show a range from 5.9 to 7 and higher. This depends mostly on the amount of gas released before the measurement was made. Loss of $\mathrm{CO}_{2}$ occurs even in "sealed" sample bottles. Table 5.3 shows the increase in pH of "unflashed" samples between the time they were collected (field $\mathrm{pH}$ ) and the time laboratory measurements were made, an interval of approximately 20 days. 
Table 5.3. Change of $\mathrm{pH}$ of well 6-2 fluid samples with time ("sealed" containers).*

\begin{tabular}{ccc}
\hline Sample & Field & Laboratory \\
description & $\mathrm{pH}$ & $\mathrm{pH}(20$ days $)$ \\
\hline \multirow{2}{*}{ "Unflashed" pipeline } & 6.2 & 6.7 \\
& 6.1 & 6.9 \\
& 6.2 & 6.8 \\
Flashed transfer pump & 9.4 & 9.1 \\
& 9.2 & 9.1 \\
& 9.3 & 9.1 \\
Flashed injection well (5-1) & 9.3 & 9.0 \\
& 9.1 & 9.0 \\
& 9.1 & 9.1 \\
\hline
\end{tabular}

*USBR, 1977a; Tables 5.7 and 5.8 .

\section{Analytical Errors vs. Sampling Problems}

In addition to sampling techniques and aging, different ways of measuring the concentration of an element give different results. Even the "same" method applied by different analysts in different laboratories yields different results. This was demonstrated by an analysis of a prepared control sample and a single sample of we11 6-2 fluid by 18 different laboratories in an experiment by J. C. Watson of Battelle Pacific Northwest Laboratories (unpublished data). The scatter of the analyses of the control sample was much less than for the geothermal fluid. Some of the results for the fluid are shown in Table 5.4 .

The variability is so large in some cases, ( $\mathrm{Ca}$ and $\mathrm{Ba}$, for instance), that the problem is almost certainly precipitation of solids rather than analytical errors. The variability in the value of suspended solids among laboratories, $9 \pm 9 \mathrm{mg} / 1$, also suggests this possibility. By comparison, the control sample contained $13.0 \mathrm{mg} / 1 \mathrm{Ca}$. The value determined by 10 laboratories using atomic absorption spectroscopy (AA) was $13.0 \pm 2$ with extreme values of 10.1 and 17.3. Four laboratories measured the $\mathrm{Ba}$ in the control sample by atomic absorption spectroscopy; the mean was $0.32 \pm 0.02$. The sample was made up to contain $0.30 \mathrm{mg} / 1 \mathrm{Ba}$. 
Table 5.4. Partial chemical composition of well 6-2 fluid, sampled on 8 July $1977 . *$

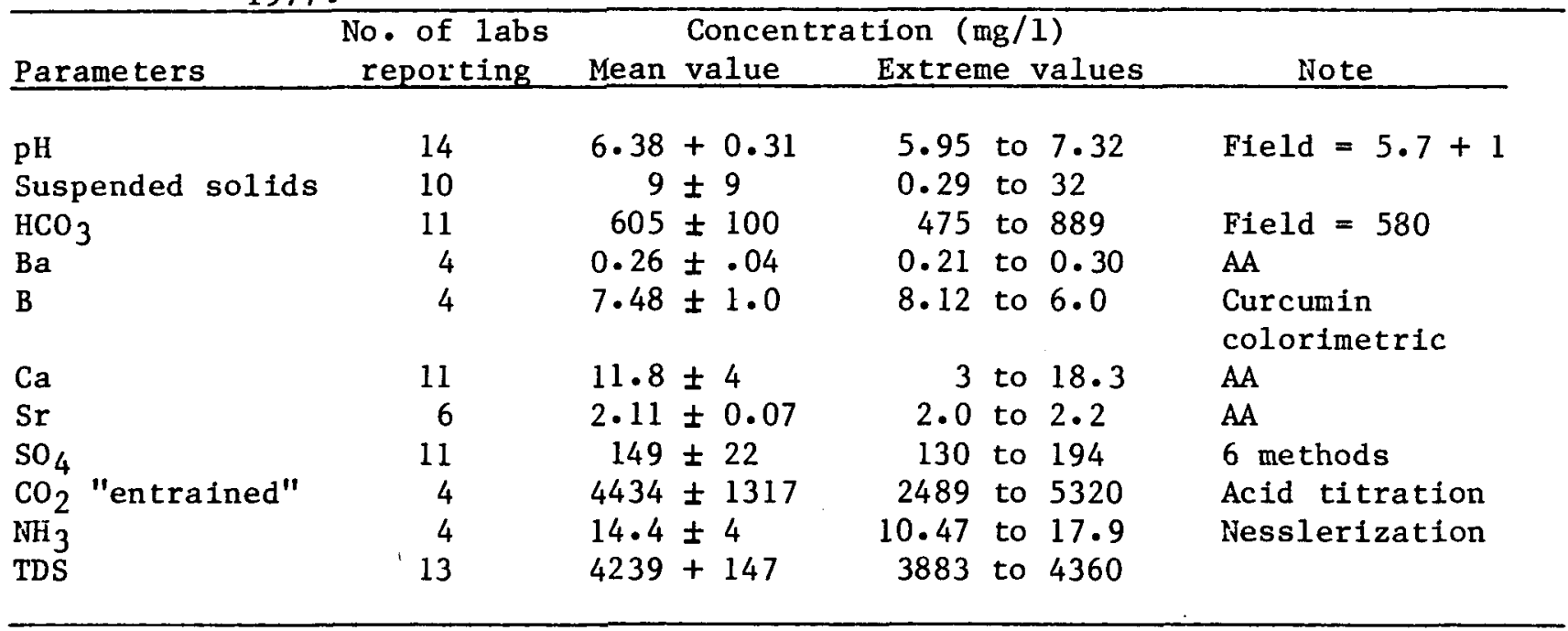

*Source: J.C. Watson, Battelle Pacific Northwest Laboratories

\section{Composition Trends}

In order to design plants to use the East Mesa fluids, it is important to know if the fluids change in composition with time or with volume of fluid produced. The total volume of fluid removed from each well is known as a function of time on a monthly basis (Westec Services, Inc., 1978). This information is shown in tables of chemical composition for each well in Appendix $E$. We see no systematic change in fluid composition with either time or production.

From 2 to 25 October 1974, well 6-1 was produced at a relatively steady rate of $2901 / \mathrm{min}(63 \mathrm{ga} 1 / \mathrm{min}$ ) at a wellhead pressure of 0.74 to 0.76 $\mathrm{MPa}^{\dagger}$ (92 to $96 \mathrm{psig}$ ), and a temperature of $165^{\circ} \mathrm{C}\left(330^{\circ} \mathrm{F}\right)$. The fluid stream was sampled every 4 hours, and the chloride (C1), calcium, bicarbonate $\left(\mathrm{HCO}_{3}\right)$, silica, sulfate $\left(\mathrm{SO}_{4}\right)$, total dissolved solids (TDS), and $\mathrm{pH}$ were measured in each sample. Variations in some parameters were large but not systematic with time or production $(\mathrm{C} 1=12,684$ to $15,305 \mathrm{mg} / 1, \mathrm{Ca}=500$ to $1100 \mathrm{mg} / 1$, and $\mathrm{pH}=6.9$ to 7.7$)$.

During 1976 and early 1977, well 6-2 was produced most of the tine, but at variable rates, as shown in Figure 5.2. - The $\mathrm{Na}, \mathrm{Ca}$, and $\mathrm{CO}_{2}$ concentrations in the fluid are also shown in the figure. No clear trends

\footnotetext{
Tegapascals (MPa). The S.I. pressure unit is pascal (Pa); to convert from standard atmospheres to $\mathrm{Pa}$, multiply by $1.013 \times 10^{5}$.
} 
are evident. During September 1976, when the well was closed each day and then opened to a flow of $411 / \mathrm{min}(9 \mathrm{gal} / \mathrm{min})$, the $\mathrm{Ca}$ concentration exceeded $100 \mathrm{mg} / 1$ at times, probably due to transient dissolution of previously precipitated calcite scale.

The minimum values of the $\mathrm{CO}_{2}$ concentration (1500 $\mathrm{mg} / 1$ ) are independent of the flow rate. The greatest variable in $\mathrm{CO}_{2}$ concentration occurred at the highest flow rates. This is consistent with the view that at high flow rates the well was flashing and bubbles of $\mathrm{CO}_{2}$ were sampled more frequently.

\section{Conclusions}

In view of the uncertainty in fluid composition due to sampling, aging, and analytical errors, it is difficult to choose one analysis over another as typical of the fluid from a given well. We have, however, selected a set of analyses to represent various wells, as shown in Table 5.5. The analyses selected were arbitrary. We chose the most recent chemical analysis for each well, providing the analysis was nearly complete and was not very different from most previous analyses.

\section{Chemical Composition of the Salton Sea}

Development of the East Mesa geothermal field for fresh water and power production will require a source of additional water for cooling and to replace fluid lost by the reservoir. This is necessary to maintain reservoir pressure and to prevent subsidence of the land surface.

Table 5.5 Chemical analysis selected to represent wells.*

We11 Date of sampling Comments

\begin{tabular}{|c|c|c|}
\hline $6-1$ & 12 April 1977 & $\mathrm{CO}_{2}$ probably $\sim 760 \mathrm{mg} / 1$ \\
\hline $6-2$ & $12 \mathrm{July} 1977$ & $\begin{array}{l}\mathrm{Ba} \text { assumed to be } 0.25 \mathrm{mg} / \mathrm{l} \text { and } \\
\mathrm{Sr}=6 \mathrm{mg} / 1 \text { based on other } \\
\text { analyses }\end{array}$ \\
\hline $1-1$ & 18 August 1976 & \\
\hline $8-1$ & 15 April 1977 & $\begin{array}{l}\mathrm{H}_{2} \mathrm{~S} \text { assumed to be } \sim 1.5 \mathrm{mg} / 1 \\
\text { on basis of other analyses }\end{array}$ \\
\hline $5-1$ & 31 May 1974 & Probably flashing \\
\hline
\end{tabular}

*See Appendix E. 


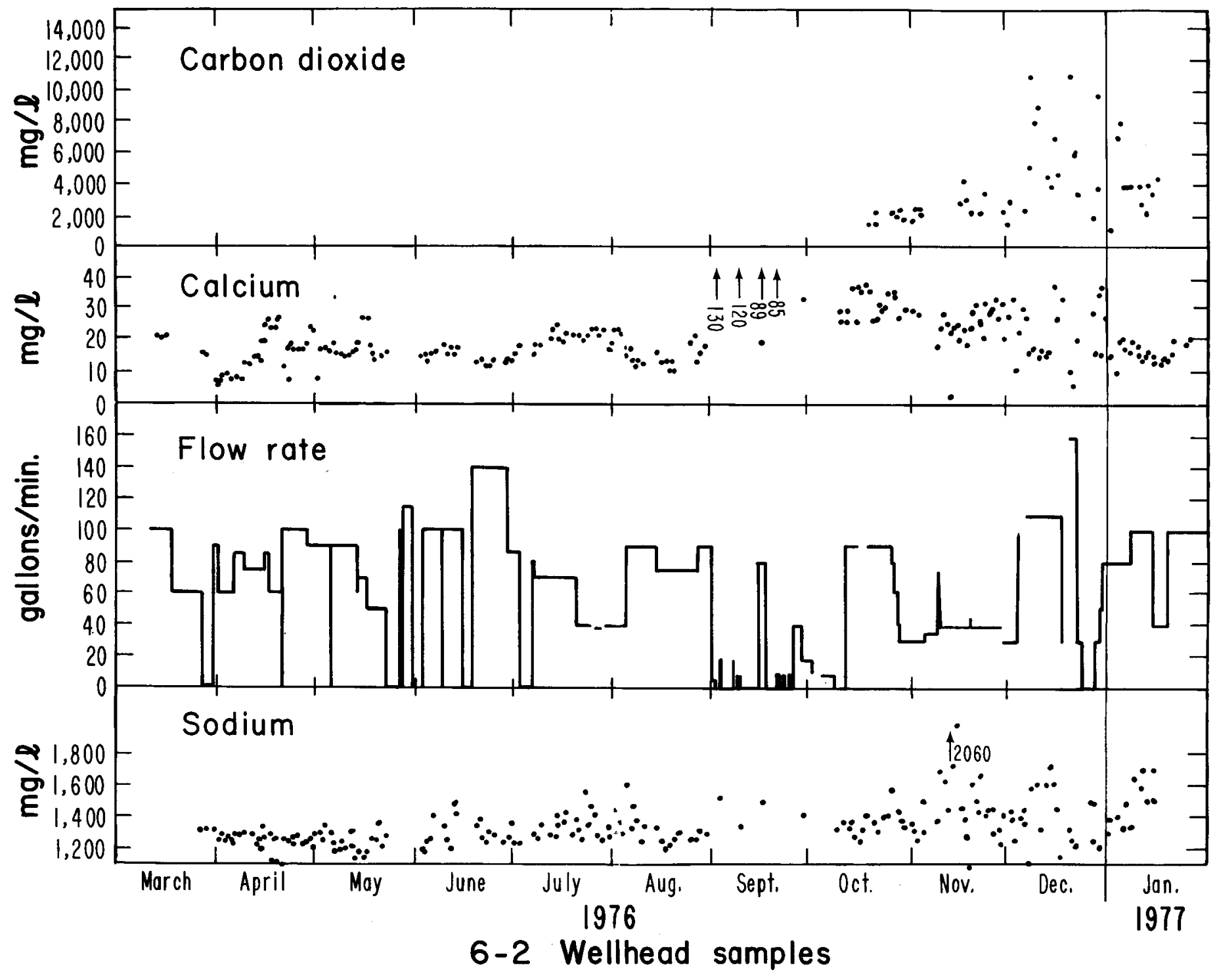

XBL $789-2267$

Figure 5.2. Flow rate and composition of well 6-2 fluids. 
The Salton Sea, originally a fresh-water lake formed by the flood of the Colorado River in 1905, was almost as saline as ocean water by the year 1929. This was a result of solution of salts that existed in the basin before the flood and also because of intense evaporation from the surface of the lake (Henley et al., 1966).

Figure 5.3 shows changes in major chemical components from 1907 through 1977. The Sea was chemically monitored by the Carnegie Institute of Washington from 1907 through 1929. The Imperial Irrigation District of the Imperial Valley has monitored the Salton Sea from 1945 through the present time. Although $\mathrm{Na}$ and $\mathrm{Cl}$ appear to have been stabilized since 1945, there has been a slow continual increase in the concentration of $\mathrm{Ca}, \mathrm{Mg}$, and $\mathrm{SO}_{4}$ to the present time. Table 5.6 shows a more complete chemical analysis obtained in June 1967, which will be used in the subsequent parts of this report.

\section{FLASHING AND FRACTIONATION OF VOLATILES}

Flashing takes place when the vapor pressure of the fluid exceeds the confining pressure. Because it provides the heat for vaporization, the fluid cools during flashing. Without heat exchange the maximum fraction of East Mesa fluids that can be flashed to steam is $19 \%$ per $100^{\circ} \mathrm{C}$ of cooling, as shown in Figure 5.4. (The salt concentration is too low to make much difference in yield.) With heat exchange, desalting plants have been tested that convert as much as $70 \%$ of the geothermal fluid into fresh water. However, because of the potential for silica scale formation when fluids are concentrated more than a factor of 2 , a yield of $50 \%$ was common during testing (Figure 5.5).

\section{Contribution of $\mathrm{CO}_{2}$ to Flashing}

Flashing of East Mesa fluids can be predicted from temperatures and $\mathrm{CO}_{2}$ content alone since they are low in volatile components (except for $\mathrm{CO}_{2}$ ). The pressure below which flashing occurs is given in Figure 5.6 as a function of temperature and $\mathrm{CO}_{2}$ concentration. The solubility of $\mathrm{CO}_{2}$ at high temperatures was taken from Helgeson (1969). If a well at $160^{\circ} \mathrm{C}$ $\left(320^{\circ} \mathrm{F}\right)$ and $0.6 \mathrm{MPa}(73 \mathrm{psig})$ were sampled, and the sample contained $1500 \mathrm{mg} / 1$ 


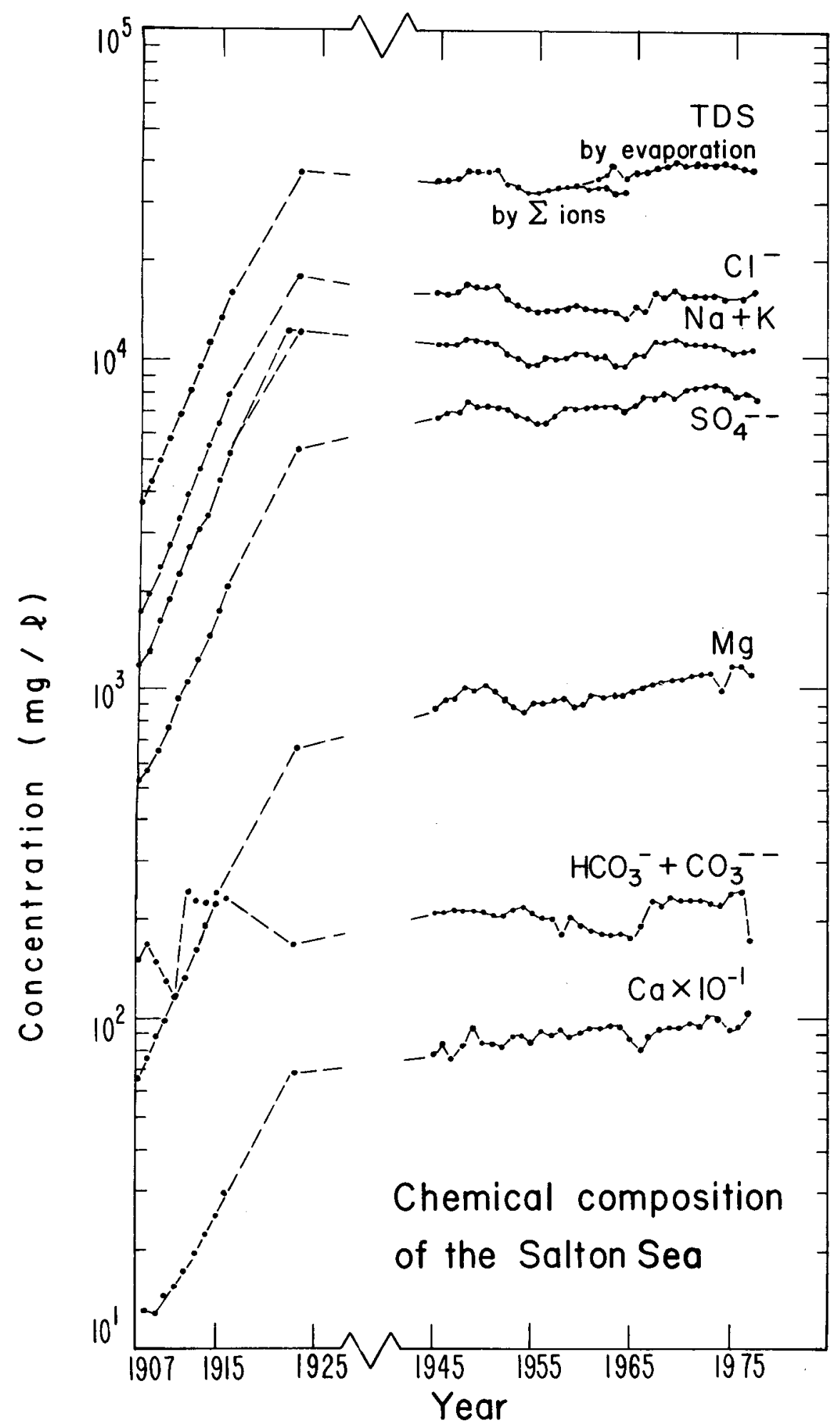

XBL $789-2266$

Figure 5.3. Trends in chemical composition of Salton Sea water from 1907 to 1977. 


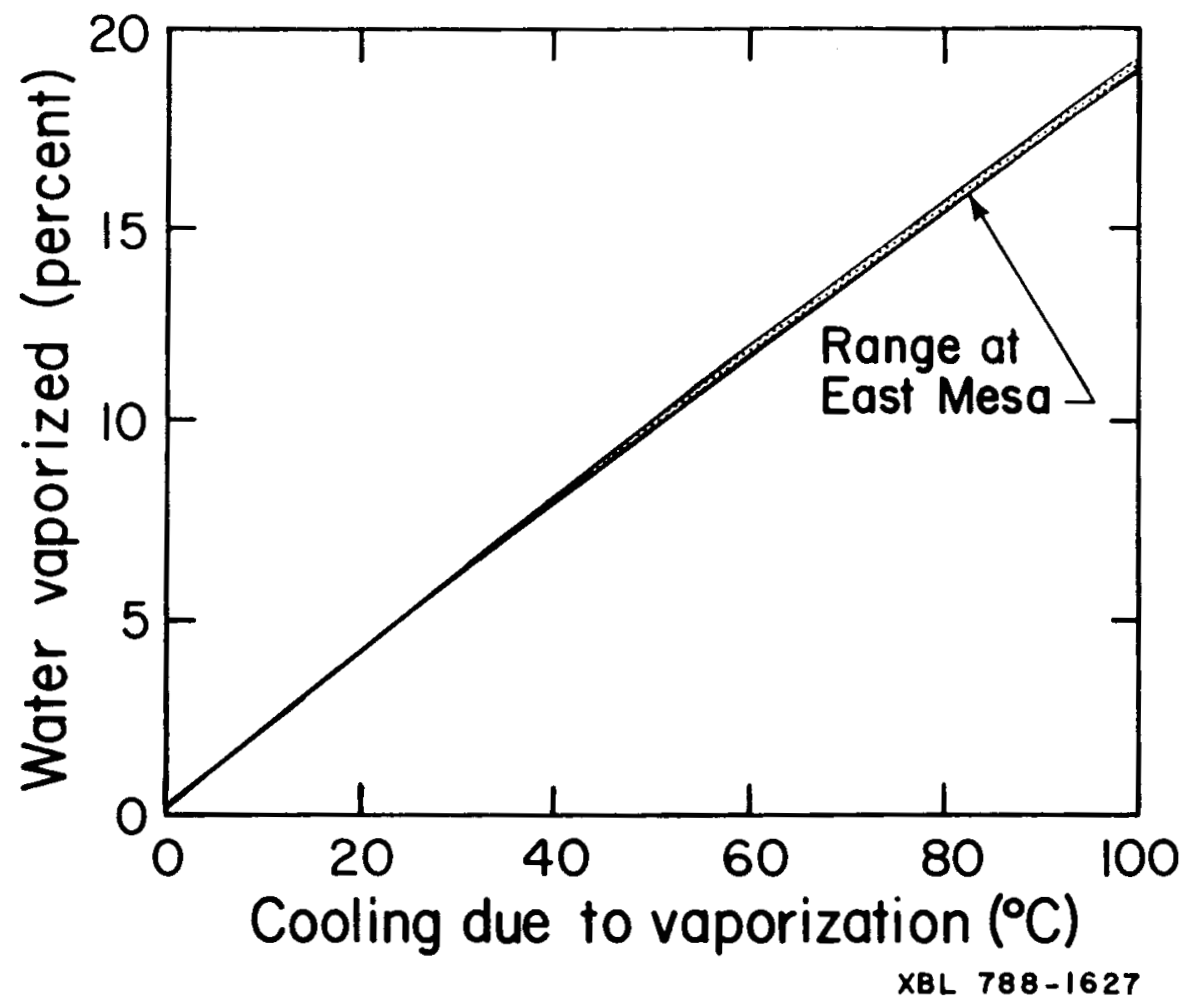

Figure 5.4. Self-vaporization of hot geothermal fluid by expansion.

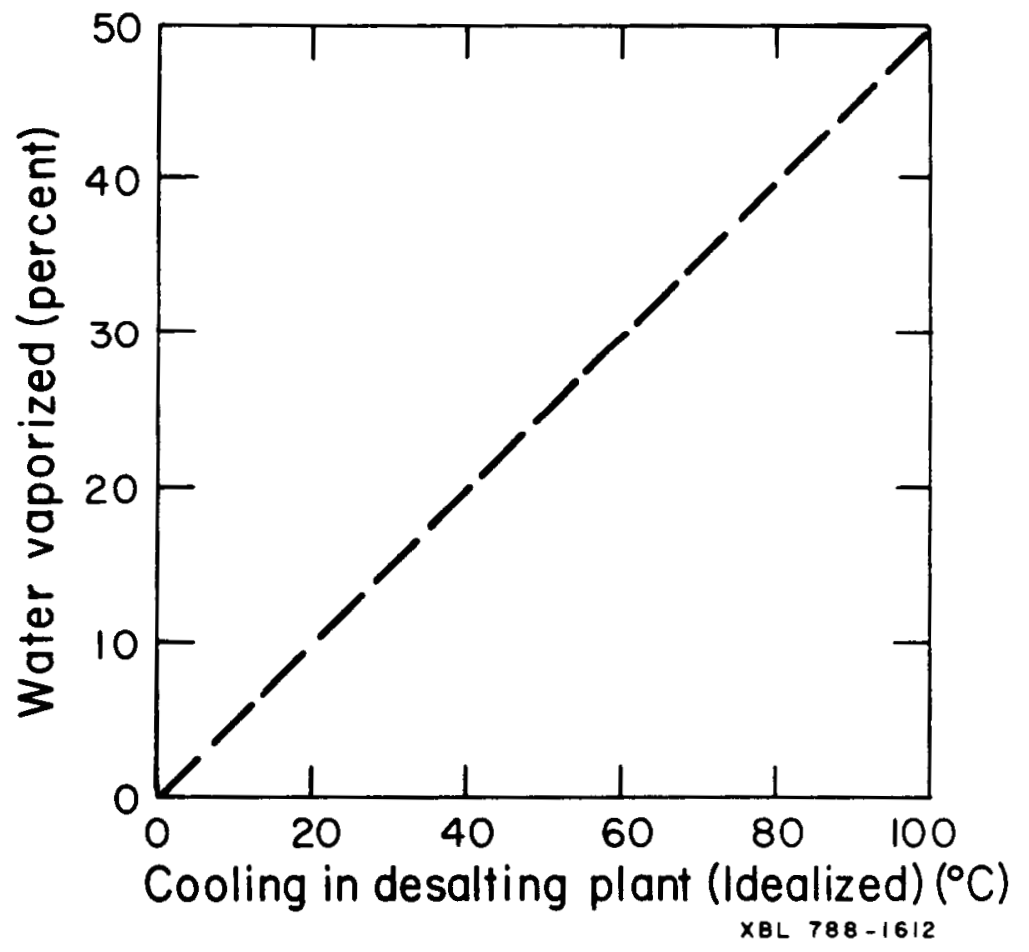

Figure 5.5. Idealized relation between cooling and percent of water vaporized in a desalination plant. 


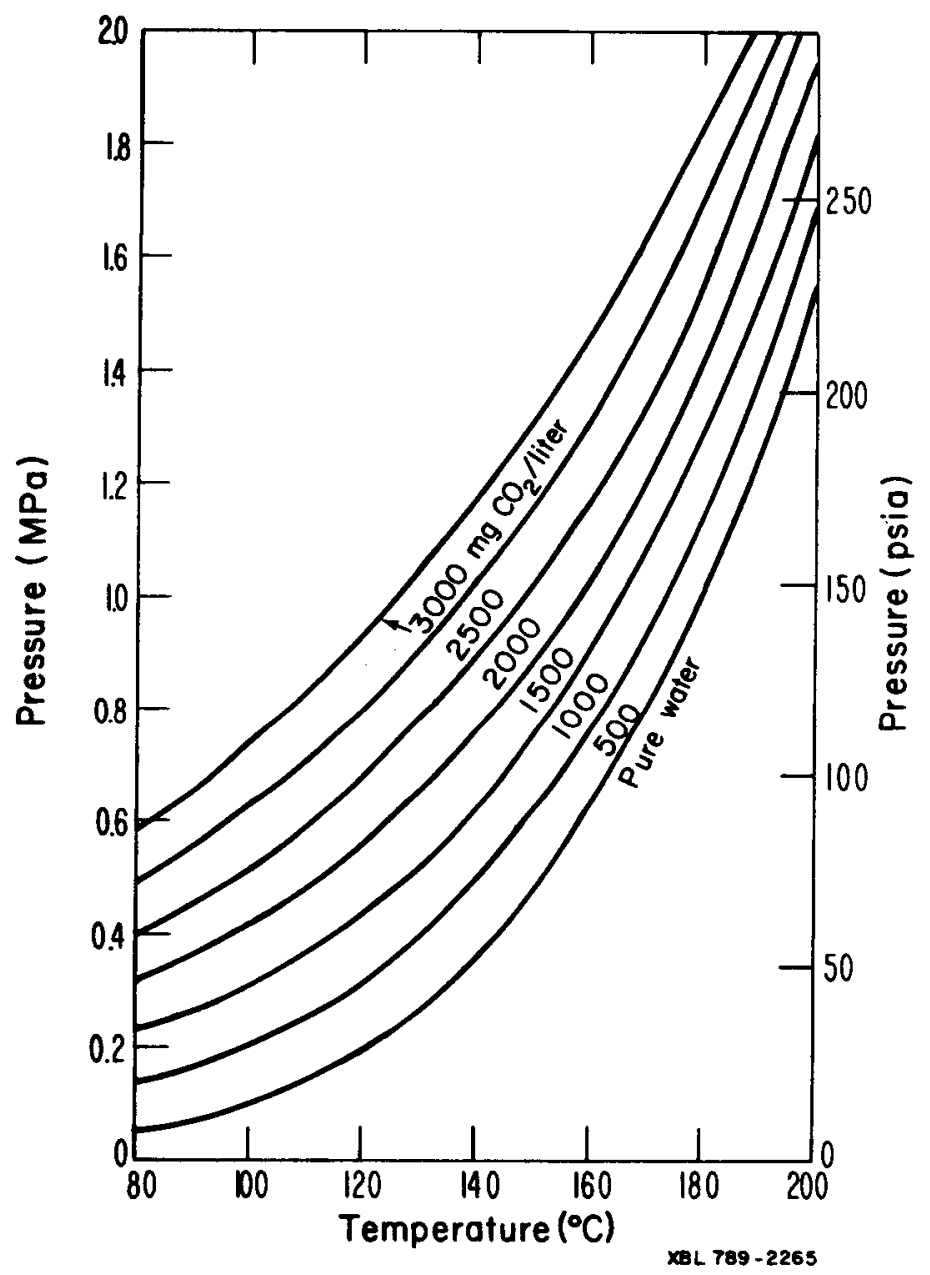

Figure 5.6. Pressure-temperature relations for the system $\mathrm{H}_{2} \mathrm{O}-\mathrm{CO}_{2}$ showing boundaries between the single-phase (liquid) and two-phase (1iquid + gas) regions, data from Helgeson (1969). 
of $\mathrm{CO}_{2}$, the well would probably be flashing below the sampling point. Conversely, if one could determine the flow rate where flashing occurs by other means (for example, $\mathrm{pH}$ measurements), the $\mathrm{CO}_{2}$ content could be estimated from the temperature and pressure using Figure 5.6.

Table 5.6. Chemical composition of the Salton Sea, 8 June 1967.*

\begin{tabular}{|c|c|}
\hline Parameter & Concentration (mg/1) \\
\hline $\mathrm{Na}$ & 10,500 \\
\hline $\mathrm{K}$ & 172 \\
\hline $\mathrm{Ca}$ & 954. \\
\hline $\mathrm{Mg}$ & 1,078 \\
\hline $\mathrm{Li}$ & 3.2 \\
\hline $\mathrm{C} 1$ & 15,000 \\
\hline $\mathrm{CO}_{3}$ & 0 \\
\hline $\mathrm{HCO}_{3}$ & 203. \\
\hline $\mathrm{SO}_{4}$ & 8,146 \\
\hline $\mathrm{NO}_{3}$ & 14 \\
\hline $\mathrm{NH}_{4}$ & - \\
\hline $\mathrm{B}^{4}$ & 9.20 \\
\hline F & 3.20 \\
\hline As & 0.0 \\
\hline $\mathrm{Ba}$ & $<1$ \\
\hline $\mathrm{Cd}$ & $<0.005$ \\
\hline Co & 0.0050 \\
\hline $\mathrm{Cu}$ & 0.0100 \\
\hline $\mathrm{Fe}$ & $<.2$ \\
\hline Mn & 0.01 \\
\hline $\mathrm{Ni}$ & 0.003 \\
\hline $\mathrm{Pb}$ & $<0.002$ \\
\hline $\mathrm{Rb}$ & - \\
\hline $\mathrm{Se}$ & - \\
\hline $\mathrm{Sr}$ & 11. \\
\hline $\mathrm{Zn}$ & 0.062 \\
\hline Total dissolved solids (TDS) & $37,082.0$ \\
\hline Specific conductance at $25^{\circ} \mathrm{C}$ ( mho) & $42,100.0$ \\
\hline Temperature $\left({ }^{\circ} \mathrm{C}\right)$ & 25.0 \\
\hline $\mathrm{pH}$ & 7.7 \\
\hline
\end{tabular}

* California Department of Water Resources, 1970. Location: TIIS, RIIE. 
Fractionation of $\mathrm{CO}_{2}$ and $\mathrm{NH}_{3}$ During Flashing

Flashing results in loss of volatiles by the fluid. The distribution of volatile materials between liquid and vapor can be calculated by assuming that the vapor phase is in equilibrium with the liquid phase. It is, of course, necessary to take into account the increase in volume of the vapor phase due to nonsteam components. In the present case, such calculations were made with the assistance of a computer program named FLOCAL (D. D. Jackson, unpublished data). The degree of saturation of a fluid with respect to the principal scaleforming minerals can be calculated during flashing by this code as well as the fractionation of $\mathrm{CO}_{2}, \mathrm{NH}_{3}$, and $\mathrm{H}_{2} \mathrm{~S}$ between fluid and vapor phases. The data base and the methods of calculating activity products are those of Helgeson. Minor flashing results in the loss of most of the dissolved $\mathrm{CO}_{2}$ to the vapor phase as shown in Table 5.7 and Figure 5.7. The figure is expressed in terms of degrees of cooling to make it generally applicable to flashing at East Mesa.

Because ammonia $\left(\mathrm{NH}_{3}\right)$ is more soluble in water than $\mathrm{CO}_{2}$, it is not as rapidly fractionated into the vapor phase during flashing, as shown in Figure 5.7. Likewise when the product gas stream is condensed, $\mathrm{NH}_{3}$ will tend to redissolve. This explains the absence of $\mathrm{NH}_{3}$ in the gas analyses reported below and the high concentrations of $\mathrm{NH}_{3}$ in the product water, $50 \mathrm{mg} / 1$ (USBR, 1977a). In fact, $\mathrm{NH}_{3}$ will be retained by the liquid phase to a greater extent than shown here because its interaction with dissolved carbon dioxide has not been taken into account.

Table 5.7. Fraction of dissolved $\mathrm{CO}_{2}$ in vapor phase due to flashing from $200^{\circ} \mathrm{C}$.

\begin{tabular}{ccc}
$\begin{array}{c}\text { Temperature drop } \\
\left({ }^{\circ} \mathrm{C}\right)\end{array}$ & $\begin{array}{c}\text { Final temperature } \\
\left({ }^{\circ} \mathrm{C}\right)\end{array}$ & $\begin{array}{c}\text { Fraction of total } \mathrm{CO}_{2} \text { in } \\
\text { vapor phase }(\%)\end{array}$ \\
\hline 0 & 200 & 0 \\
5 & 195 & 84.1 \\
10 & 190 & 92.2 \\
20 & 180 & 96.9 \\
40 & 160 & 99.0 \\
60 & 140 & 99.6 \\
80 & 120 & 98.8 \\
100 & 100 & 99.9 \\
\hline
\end{tabular}


Table 5.8. Dry gas composition flashed from well 6-1 in 1977.*

\begin{tabular}{lcccc}
\hline Element & March & $\begin{array}{c}\text { Concentration } \\
17 \text { March }\end{array}$ & $\begin{array}{r}\text { (mole \%) } \\
\text { 12 April }\end{array}$ & 5 May \\
\hline $\mathrm{CO}_{2}$ & 62.5 & 87.5 & 85.6 & 90.3 \\
$\mathrm{Ar}$ & 0.29 & 0.04 & 0.05 & 0.04 \\
$\mathrm{O}_{2}$ & 5.53 & 0.02 & 0.03 & 0.07 \\
$\mathrm{~N}_{2}$ & 23.0 & 2.12 & 2.36 & 1.56 \\
$\mathrm{CO}$ & $<0.10$ & $<0.10$ & $<0.10$ & $<0.10$ \\
$\mathrm{He}$ & $<0.01$ & $<0.01$ & $<0.01$ & $<0.01$ \\
$\mathrm{H} 2$ & 0.23 & 0.12 & 0.36 & 0.11 \\
$\mathrm{CH} 4$ & 8.44 & 10.2 & 11.6 & 7.77 \\
\end{tabular}

* Battelle analyses, collected at separator (Parry and Sullivan, 1977).

$\dagger$ Possible air leak.

\section{Observed Composition of Dry Gas From Well 6-1}

The composition of water-free gas flashed from well 6-1 fluid is shown in Table 5.8. The sample was collected at the separator; and the absence of $\mathrm{NH}_{3}$ is probably due to its solution in condensed steam. The principal component is $\mathrm{CO}_{2}$. The well was flashing even at a $561 / \mathrm{mm}$ (15 gal/min) flow (Perry and Sullivan, 1977). The relatively high concentration of methane $\left(\mathrm{CH}_{4}\right)$ was unexpected and has not been taken into account in estimating vapor pressure; thus the actual vapor pressure of 6-1 fluid may be a little higher than estimated when based on $\mathrm{CO}_{2}$ content alone. Nitrogen has also been found in the Republic wells at East Mesa at approximately the same range of concentration as methane (Michels, 1978).

\section{Chemical Change in a Flashing Fluid}

The loss of $\mathrm{CO}_{2}$ by flashing leads to the following chemical reactions among dissolved species:

$$
\text { dissolved } \begin{aligned}
\mathrm{CO}_{2}\left(\mathrm{H}_{2} \mathrm{CO}_{3}\right) & =\mathrm{CO}_{2}(\mathrm{~g})+\mathrm{H}_{2} \mathrm{O} \\
\mathrm{HCO}_{3}^{-}+\mathrm{H}^{+} & =\mathrm{H}_{2} \mathrm{CO}_{3}
\end{aligned}
$$

The ratio of the concentration of $\mathrm{H}_{2} \mathrm{CO}_{3}$ to $\mathrm{HCO}_{3}^{-}$is related to $\mathrm{H}^{+}$by $\mathrm{K}_{2}$, the equilibrium constant for Equation (2) as follows:

$$
\left(\mathrm{H}^{+}\right)=\left(\mathrm{H}_{2} \mathrm{CO}_{3}\right) /\left(\mathrm{HCO}_{3}^{-}\right) \mathrm{K}_{2}
$$

The value of $\mathrm{K}_{2}$ at $25^{\circ} \mathrm{C}$ is $4 \times 10^{7}$. Equation (3) is plotted as a function of temperature in Figure 5.8 . 


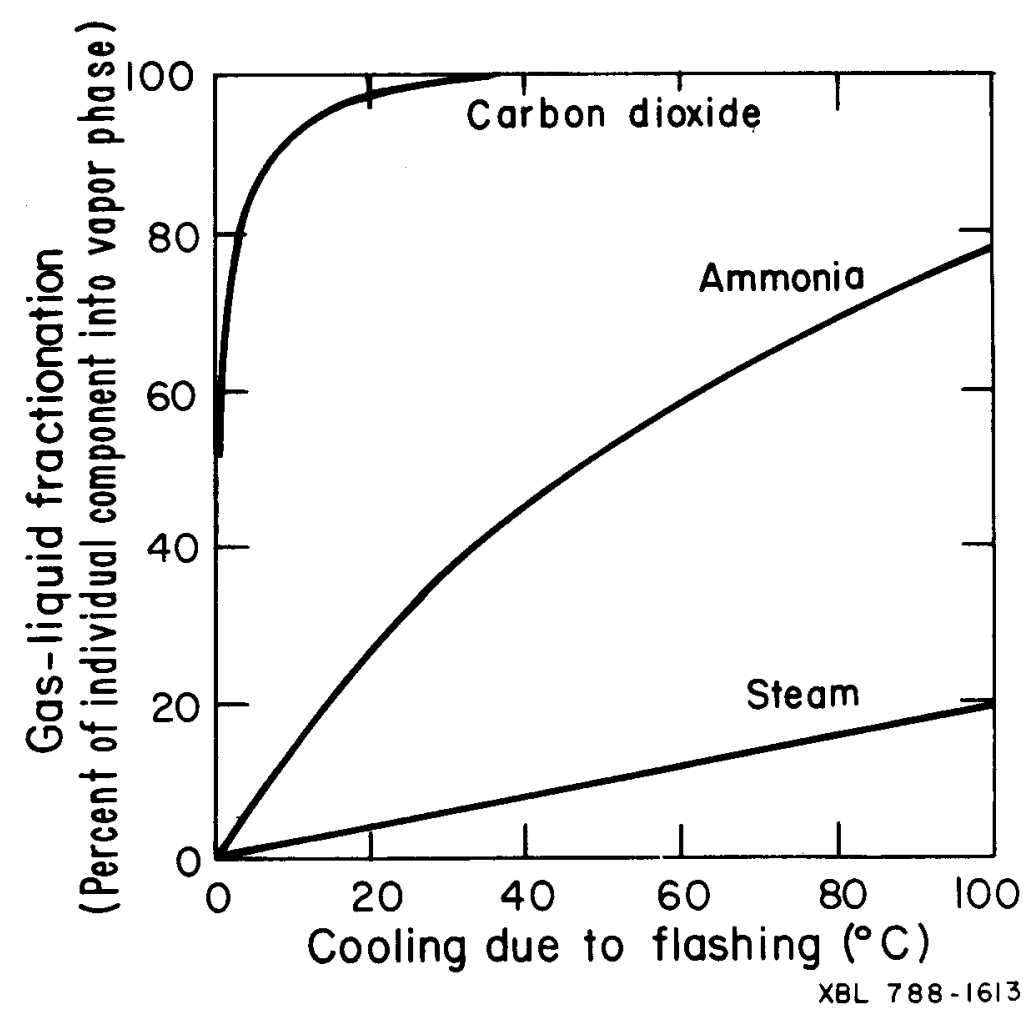

Figure 5.7. Fractionation of $\mathrm{CO}_{2}$ on $\mathrm{NH}_{3}$ in $i$ ts vapor phase when the geothernal fluid at East Mesa is flashed.

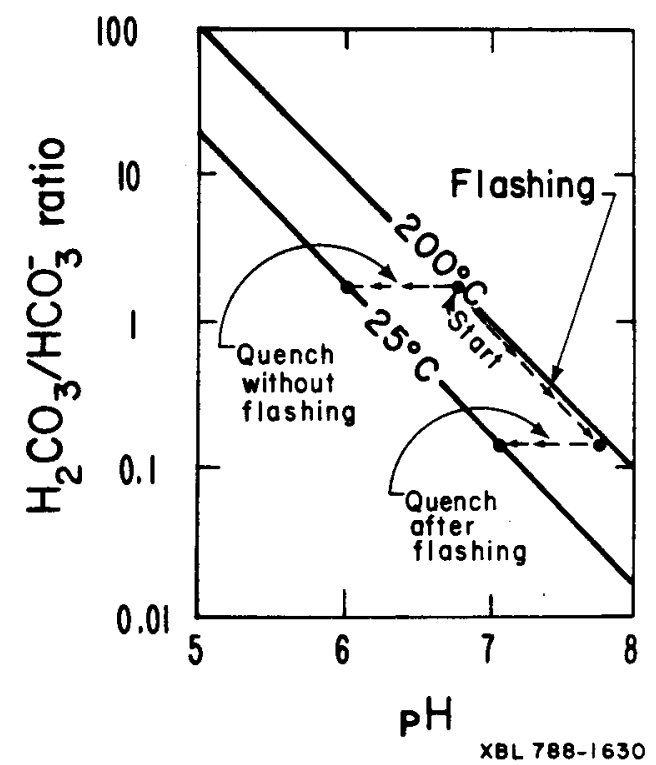

Figure 5.8. Schematic diagram showing relations among $\mathrm{pH}$, temperature, and the distribution of dissolved carbon dioxide in East Mesa fluids. 
As shown above, "unflashed" East Mesa fluids tend to have a $\mathrm{pH}$ of $\sim 6$ and some have a $\mathrm{H}_{2} \mathrm{CO}_{3} / \mathrm{HCO}_{3}^{-}$ratio of 2 , as predicted. (In practice, the concentration of dissolved $\mathrm{CO}_{2}$ is of ten calculated from measured $\mathrm{pH}$ and $\mathrm{HCO}_{3}$ concentration, particularly when the concentration of dissolved $\mathrm{CO}_{2}$ is high and loss of $\mathrm{CO}_{2}$ cannot be avoided during sampling•)

Measured only at ambient temperature, the $\mathrm{pH}$ at reservoir temperature can be estimated from Figure 5.8 because the $\mathrm{H}_{2} \mathrm{CO}_{3} / \mathrm{HCO}_{3}^{-}$ratio changes little when East Mesa fluids are quenched. This was found by calculating species distribution as a function of temperature using the computer code EQ3 (Wolery, 1978). Thus an East Mesa fluid of $\mathrm{pH} 6.0$ at $25^{\circ} \mathrm{C}$ has a $\mathrm{pH}$ of $\sim 6.75$ at $200^{\circ} \mathrm{C}$. Flashing $10^{\circ} \mathrm{C}$ reduces the $\mathrm{H}_{2} \mathrm{CO}_{3} / \mathrm{HCO}_{3}^{-}$ratio from $\sim 2$ to 0.2 and the $\mathrm{pH}$ increases accordingly. Quenched, the measured $\mathrm{pH}$ would be $\sim 7$, as shown in the figure.

Equations (4) and (5) show that a decrease in the concentration of $\mathrm{H}^{+}$by flashing results in an increase in the amount of $\mathrm{CO}_{3}^{2-}$, even though there is an overall renoval of $\mathrm{CO}_{2}$ from the fluid.

$$
\begin{aligned}
\mathrm{HCO}_{3}^{-} & =\mathrm{H}^{+}+\mathrm{CO}_{3}^{2-} \\
\mathrm{K}_{5} & =\left(\mathrm{H}^{+}\right)\left(\mathrm{CO}_{3}^{2-}\right) /\left(\mathrm{HCO}_{3}^{-}\right) \\
\mathrm{K}_{5} & =10^{-10.4} \text { at } 25^{\circ} \mathrm{C}
\end{aligned}
$$

Thus the precipitation of calcite by reaction (6) takes place upon flash cooling in spite of an increasing solubility with decreasing temperature:

$$
\mathrm{Ca}^{2+}=\mathrm{CO}_{3}^{2-}=\mathrm{CaCO}_{3}
$$


SCALING POTENTIAL OF GEOTHERMAL FLUIDS

\section{Computational Methods}

When a fluid becomes supersaturated with respect to a mineral, scaling can take place. Supersaturation does not necessarily mean that the mineral will precipitate, or actually form a scale. Some precipitation rates, such as that of silica from solution, can be exceedingly slow at moderate levels of supersaturation. Others can be very fast. Unfortunately, we cannot predict the kinetics of many reactions of interest to geothermal plant operations at this time, and therefore, we must base our evaluation on thermodynamic criteria. On the other hand, if thermodynamic arguments indicate that a potential scale former will be undersaturated, there is no conceivable way in which a scale could form.

The potential for scaling by a particular mineral can be expressed as the ratio of activity product to solubility product. A ratio of 1 represents saturation values, $>1$ indicates supersaturation, and $<1$, undersaturation. For example, Figure 5.9 is divided into a lower unsaturated field and an upper supersaturated field by a horizontal dashed line. Using the methods and data of Helgeson (1969), calculations of scaling potential were

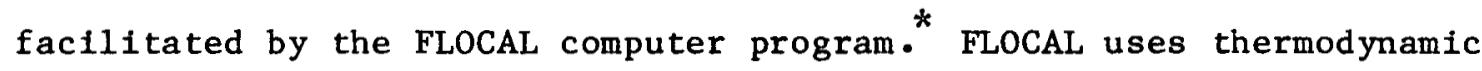
properties of steam to calculate composition, volume, enthalpy, and mass of the vapor phase at each degree centigrade of volume, enthalpy, and mass of the vapor phase at each degree centigrade of cooling during flashing. Increasing salt concentration and decreasing temperatures in the residual field are taken into account to calculate new activity-product to solubilityproduct ratios for each mineral during flashing.

The number of minerals treated by Helgeson is large but by no means exhaustive. To look for other potential scale-forming minerals, three other aqueous-solution computer codes were used: SOLMNEQ (Kharaka and Barnes, 1973), MINEQL (Westall et al., 1976), and EQ3/EQ6 (Wolery, 1978). At least 30 solid phases (minera1s) could form from East Mesa-Salton Sea fluids during production. Most of them are possible only if the trace of aluminum (Al) in some of the chemical analyses is taken into account and 
would produce only small amounts of solids. Only six minerals have sufficient stability and can be formed in significant amounts to be of practical importance. These minerals are calcite $\left(\mathrm{CaCO}_{3}\right)$, silica $\left(\mathrm{SiO}_{2}\right)$, barite $\left(\mathrm{BaSO}_{4}\right)$, celestite $\left(\mathrm{SrSO}_{4}\right)$, anhydrite $\left(\mathrm{CaSO}_{4}\right)$, and gypsum $\left(\mathrm{CaSO}_{4} \cdot 2 \mathrm{H}_{2} \mathrm{O}\right)$.

The ions $\mathrm{Ba}^{2+}$ and $\mathrm{Sr}^{2+}$ were assumed to have the same dependence of stoichiometric individual ion activity coefficients on $\mathrm{SO}_{4}^{2-}$, as Helgeson gives for $\mathrm{Ca}^{2+}$. Although solid solutions among $\mathrm{CaSO}_{4}, \mathrm{SrSO}_{4}$, and $\mathrm{BaSO}_{4}$ are known, and in fact were found as scale at East Mesa, no thermodynamic data exist for them.

The minerals dolomite $\left[\mathrm{CaMg}\left(\mathrm{CO}_{3}\right)_{2}\right]$, magnesite $\left(\mathrm{MgCO}_{3}\right)$, and talc $\left[\mathrm{Mg}_{3} \mathrm{Si}_{4} \mathrm{O}_{10}(\mathrm{OH})_{2}\right]$ may also be "scale formers" if magnesium-rich Salton Sea water is injected into the reservoir to balance fresh water production.

\section{Scaling Potential of Individual Wells During Production and Flashing}

To calculate the scale-forming potential of fluids in pipelines and the desalination plant, both conductive cooling and flash cooling must be taken into account. Flashing, the self-vaporization of hot geothermal fluid by reduction of pressure, produces an amount of steam that varies with fluid temperature, salt content, and the design of the desalting plant.

This section presents results of calculations of the scale-forming compositions of fluld samples collected on the dates given in Table 5.5 .

Calcite and quartz saturation at reservoir temperatures $\left(-200^{\circ} \mathrm{C}\right)$ are clearly implied by the occurrence of these minerals in the reservoir rocks (Fournier, 1973, 1976; Hoagland, 1976a, 1976b). This was confirmed by calculations. Calcite supersaturation results from flashing. Carbonatescale formation at flash points has been a particularly troublesome feature of production at East Mesa. In addition, saturation was found with respect to amorphous silica at lower temperatures. All unflashed wells were unsaturated with respect to $\mathrm{CaSO}_{4}$ and $\mathrm{SrSO}_{4}$.

Some fluid analyses show traces of aluminum, zinc $(\mathrm{Zn})$, and iron ( $\mathrm{Fe})$ (Appendix E). On this basis East Mesa fluids were calculated to be supersaturated with many aluminosilicates, sphalerite $(\mathrm{ZnS})$, smithsonite $\left(\mathrm{ZnCO}_{3}\right)$, pyrrhotite $(\mathrm{FeS})$, and siderite $\left(\mathrm{FeCO}_{3}\right)$. The results of one calculation for 
an aluminium-bearing fluid are shown to illustrate the point, but one should bear in mind the questionable significance of these analyses. The total amount of scale which these elements can form is small.

Considering the chemical analysis of well 6-1 (sampled on 12 April 1977) as typical, the degree of calcite saturation is shown in Figure 5.9. The lower solid curve shows a decreasing activity-product to solubilityproduct ratio as the fluid is cooled without flashing. This is due to the increasing solubility of calcite with decreasing temperature. Flash-induced cooling, on the other hand, leads to a sudden $\mathrm{pH}$ increase and supersaturation, as shown by the upper curve. Thus wherever flashing takes place, calcite scale formation is possible, be it in a producing well, pipeline, or desalting plant.

Fluid from well 6-1 is calculated to be supersaturated with quartz at all temperatures, but supersaturation with respect to amorphous silica occurs only below $80^{\circ} \mathrm{C}$ (Figure 5.10). We11 6-1, however, is unsaturated with $\mathrm{CaSO}_{4}$ and $\mathrm{SrSO}_{4}$ (Figure 5.11).

The upper, dashed curves in Figures 5.10 and 5.11 show how the ratio of activity to solubility products changes with temperature when flashing occurs augmented by the use of heat exchangers. By this means approximately half of the fluid is reclaimed as fresh water, as discussed above. Both the role of temperature and concentration have been taken into account and there is an increase in the minimum temperature for saturation by amorphous silica and $\mathrm{BaSO}_{4}{ }^{\circ}$

We1l 6-2 is calculated to be supersaturated with calcite and approximately saturated with respect to quartz $\left(\mathrm{SiO}_{2}\right)$ at the bottom-hole temperature $\left(180^{\circ} \mathrm{C}\right)$, as shown in Figures 5.12 and 5.13. Saturation with amorphous silica at $<190^{\circ} \mathrm{C}$ is shown. Unsaturation with $\mathrm{BaSO}_{4}, \mathrm{SrSO}_{4}$, and $\mathrm{CaSO}_{4}$ is calculated for 6-2 fluid at all temperatures--even when the concentration of these minerals in the fluid doubles due to flash-evaporation in a desalination plant.

Figure 5.14 shows the effect of traces of Al on saturation calculations for geothermal fluid from well 6-2. The fluid is supersaturated with respect to several aluminosilicates at all temperatures below $\sim 150^{\circ} \mathrm{C}$ (based on EQ6 calculation). Similar results can be expected for other well fluids. The Al concentration in well 6-2 fluid, measured by four laboratories using atomic absorption, was $0.0,0.11,0.24$, and $<0.7 \mathrm{mg} / 1$ 
J.C.Watson, unpubl. data). Thus analyses for trace amounts of Al are uncertain. In any case, the total amount of aluminosilicate that can precipitate is small.

Only one complete chemical analysis of unflashed brine from well $31-1$ is available. Of the principal scale formers at East Mesa, this we11 appears to be saturated only with respect to $\mathrm{SiO}_{2}$ (both forms) and $\mathrm{CaCO}_{3}$ (Figures 5.15 and 5.16). The fluid is calcite-saturated at bottom-hole temperature and when the well is flashed. Under the latter conditions the fluid demonstrates a high calcite scaling potential. Saturation with respect to $\mathrm{BaSO}_{4}$ is probable at temperatures below $50^{\circ} \mathrm{C}$-for example in the concentrated waste stream of desalination plants.

The chemical composition of fluid from well 8-1 is similar to that from well 31-1. Quartz exists at saturation temperatures at the bottom of the we11, and the degree of supersaturation increases with cooling, as shown in Figure 5.17. Based on a single Ba analysis, the fluid appears to be unsaturated with $\mathrm{BaSO}_{4}$. The saturation temperature for amorphous silica increases from $\sim 80^{\circ}$ to $125^{\circ} \mathrm{C}$ with flashing.

The 8-1 fluid, like the other East Mesa geothermal fluids, is saturated with calcite at reservoir temperatures: it becomes supersaturated when it is flashed, and undersaturated when cooled without flashing (Figure 5.18).

\section{Potential for Scaling Due to Mixing Geothermal Fluids}

In order to produce fresh water or power economically at East Mesa, simultaneous production and mixing of fluids from many wells will be necessary. Evaluation of the effects of mixing fluids from different wells indicates that serious scaling may result. In particular, mixing well 6-1 fluid with fluid from other wells increases the degree of saturation both with respect to carbonates and sulfates. Figures 5.19, 5.20, and 5.21 show that a $1 / 1$ mixture of well $6-1$ and well 6-2 fluids has a higher potential for scaling with respect to calcite, barite, quartz, and amorphous silica than either fluid alone. Figure 5.22 shows that only at temperatures above $150^{\circ} \mathrm{C}$ can fluids from wells $6-1$ and $6-2$ be mixed together in all proportions without the risk of $\mathrm{BaSO}_{4}$ scale formation. At $50^{\circ} \mathrm{C}$, for example, the addition of more than $10 \%$ fluid from well 6-1 to fluid from well 6-2 results in $\mathrm{BaSO}_{4}$ saturation. 


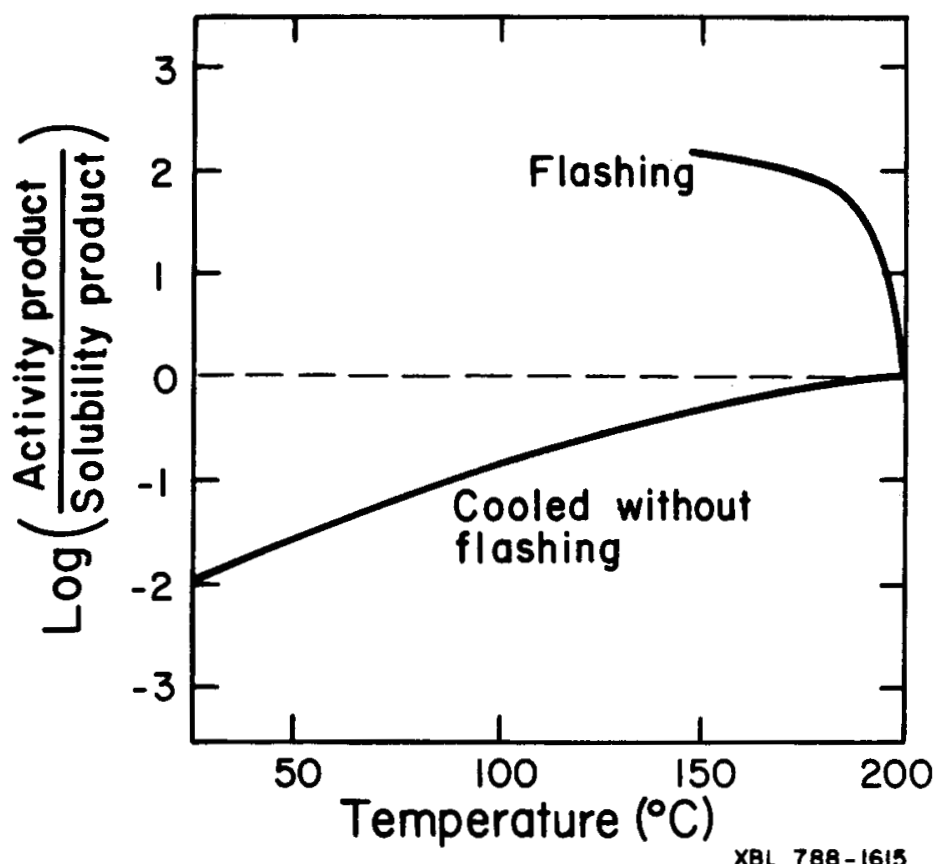

Figure 5.9. Calcite supersaturation due to flashing-induced $\mathrm{CO}_{2}$ loss, and and calcite undersaturation when we11 6-1 fluid is cooled with flashing as shown by upper and lower curves, respectively.

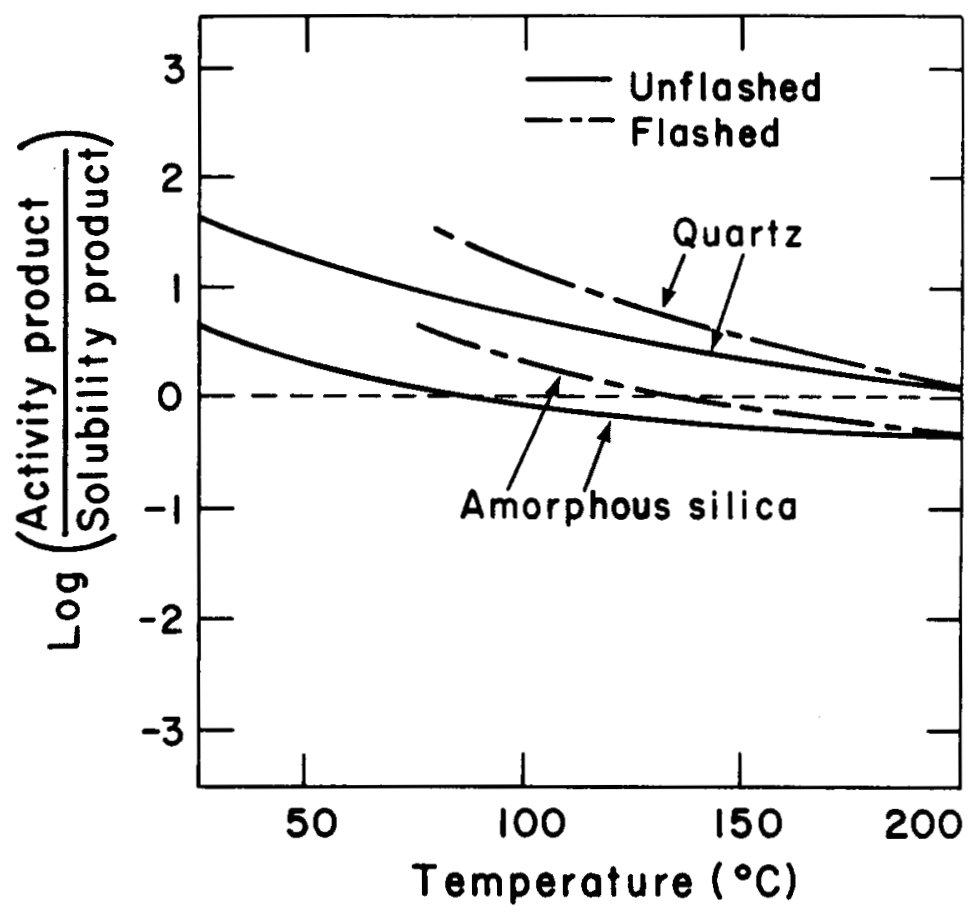

$X B L 78||-2146$

Figure 5.10. Silica scaling potential of geothermal fluid from well 6-1 showing quartz saturation at all temperatures below $200^{\circ} \mathrm{C}$ (formation temperature). 


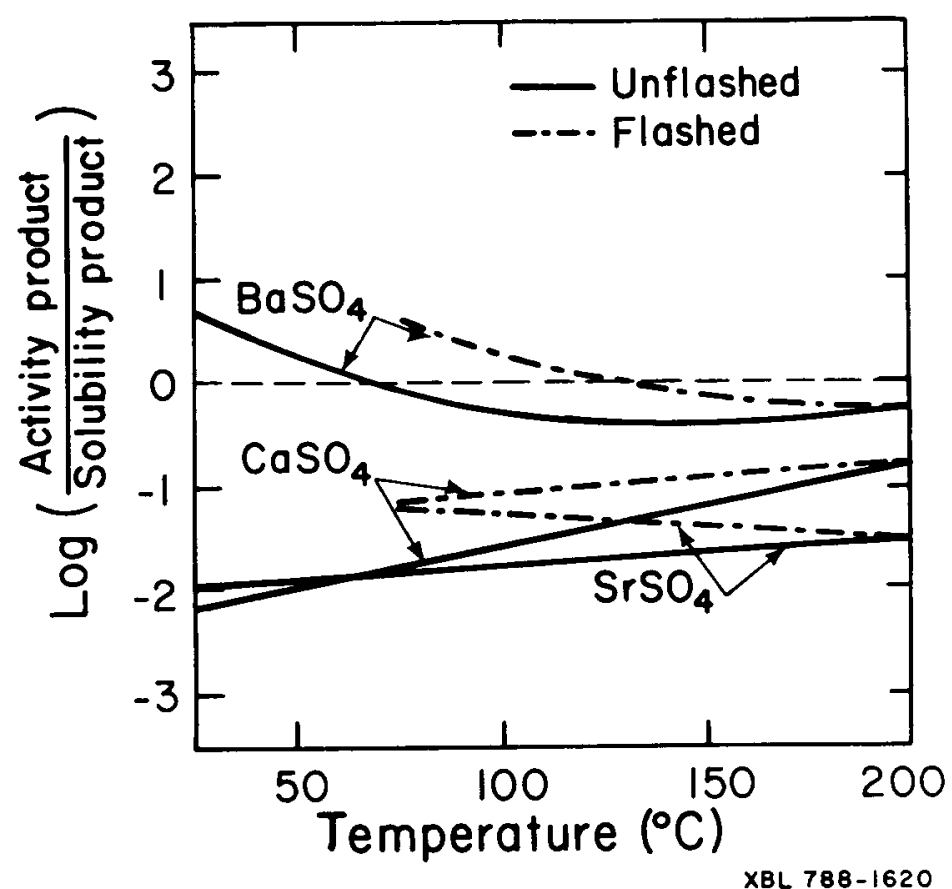

Figure 5.11. Scale-forming potential of geothermal fluid from well 6-1 with respect to three sulfate ninerals.

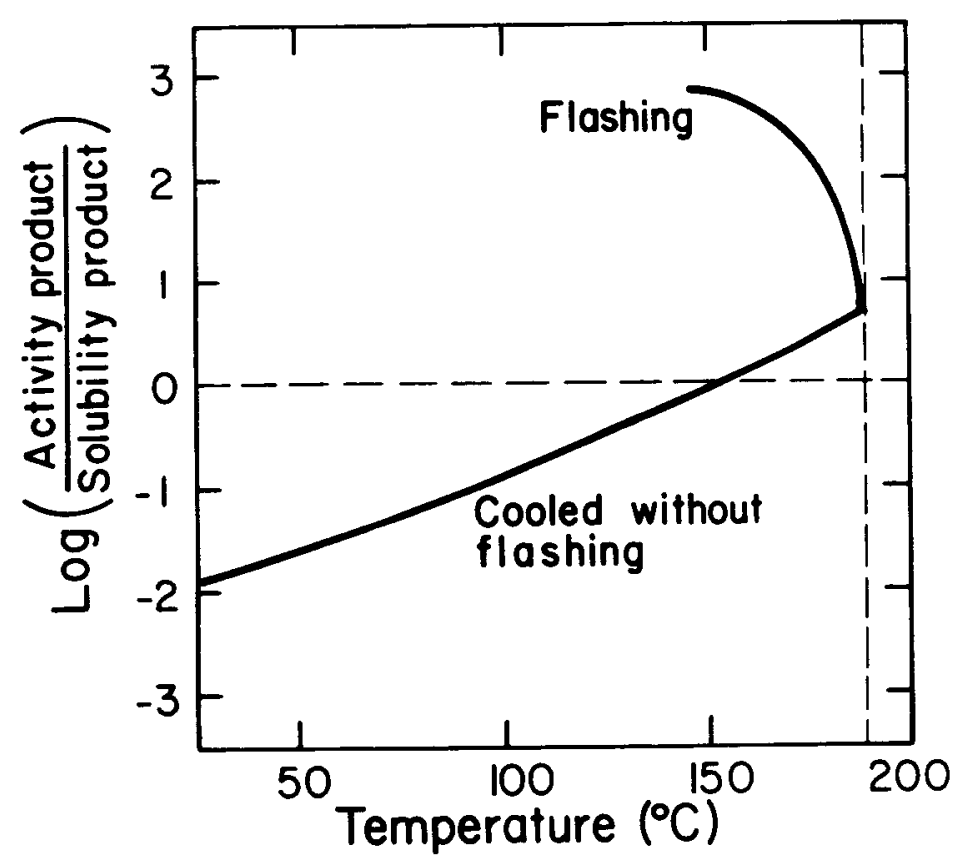

XBL $788-1619$

Figure 5.12. Calcite scaling potential of geothermal fluid from well 6-2 (downhole temperature indicated by vertical dashed line). 


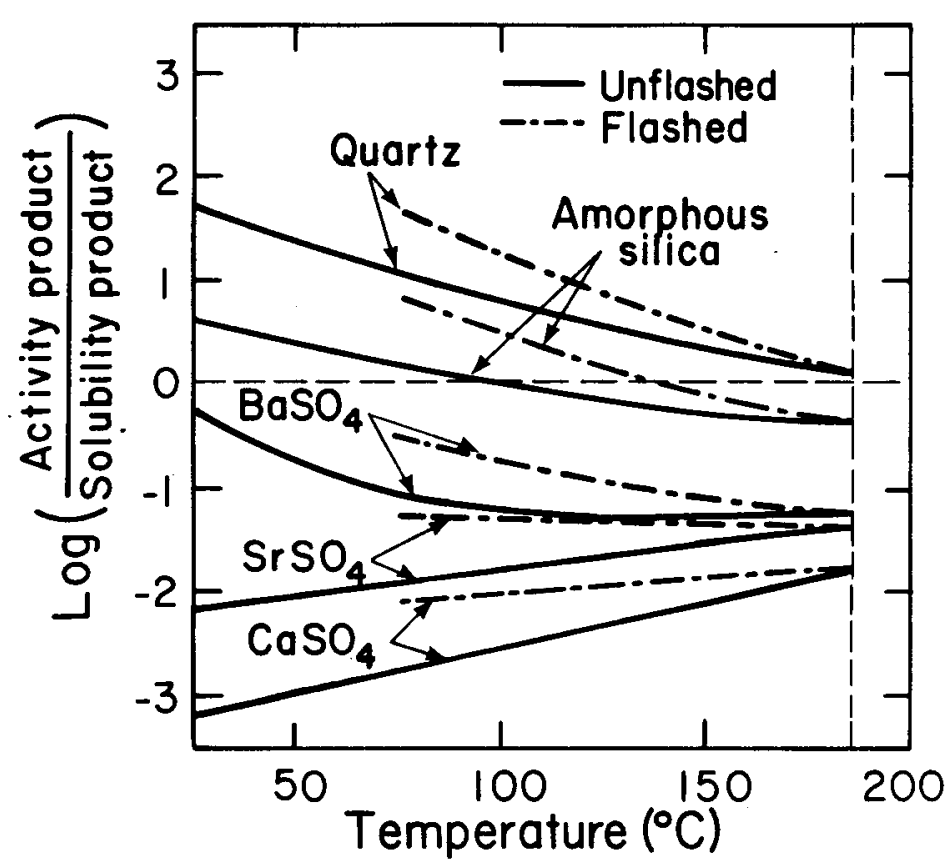

XBL $788-1621$

Figure 5.13. Scale-forming potential of geothermal fluid from well 6-2 with respect to quartz, amorphous silica, and sulfate minerals.

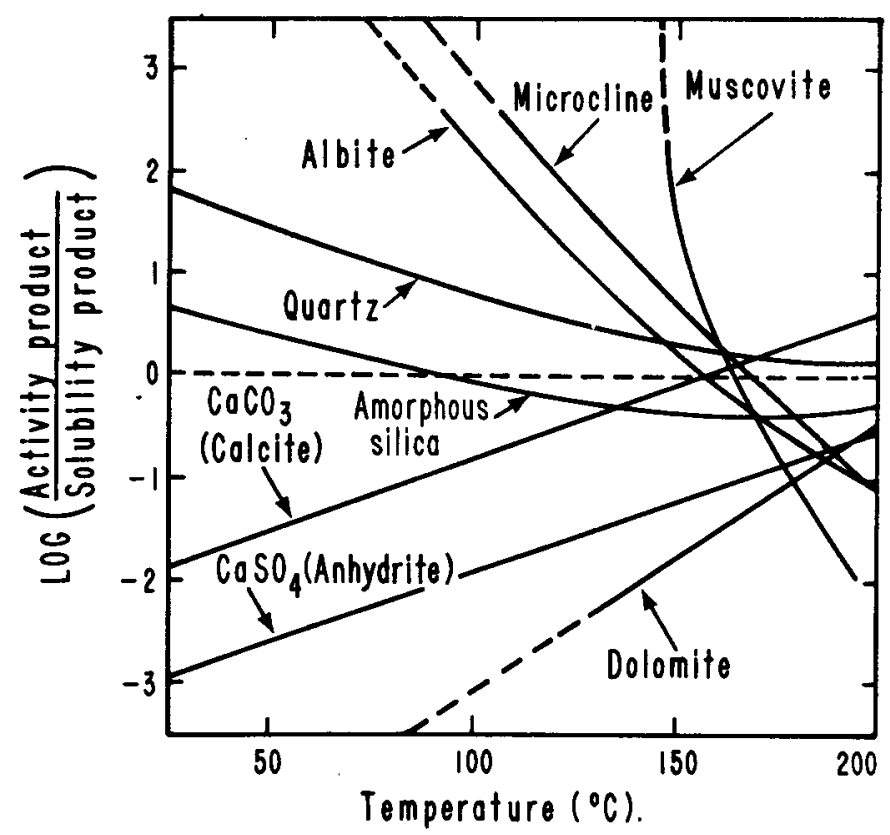

XBL 789-2072

Figure 5.14. Scale-forming potential of geothermal fluids from well 6-2,

- calculated on the assumption that well 6-2 fluid contained $006 \mathrm{mg} \mathrm{Al}$, using the EQ6 code. 


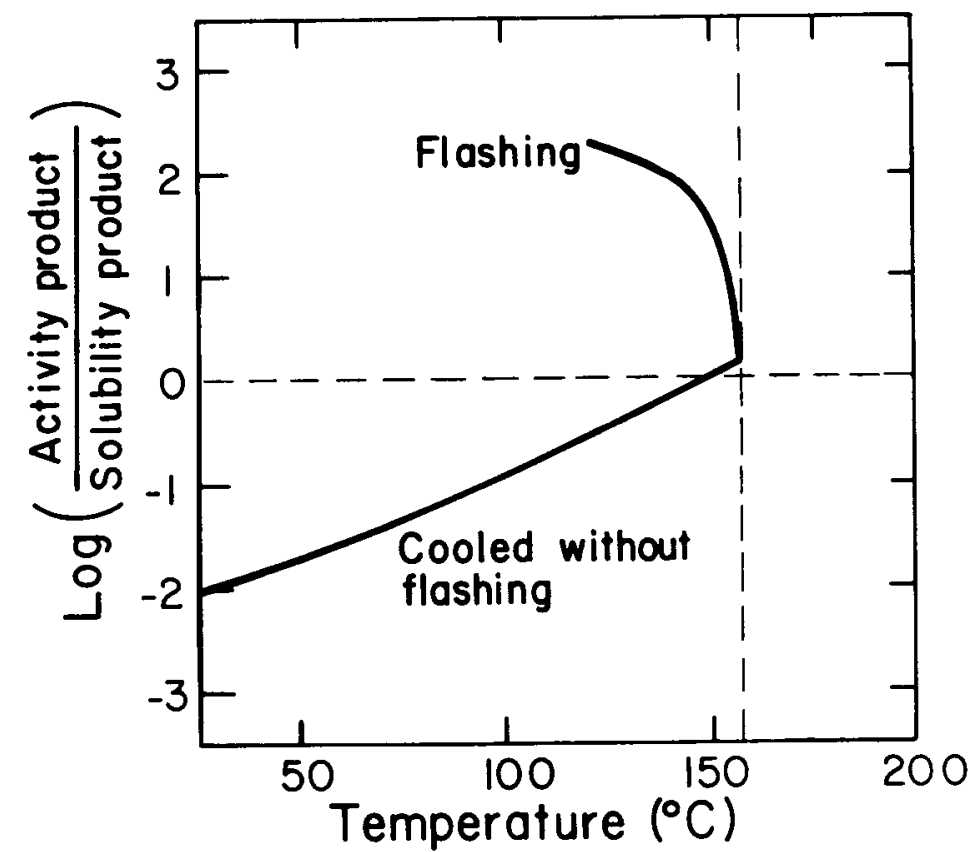

XBL $78 B-1616$

Figure 5.15. Calcite scaling potential in well $31-1$ geothermal fluid.

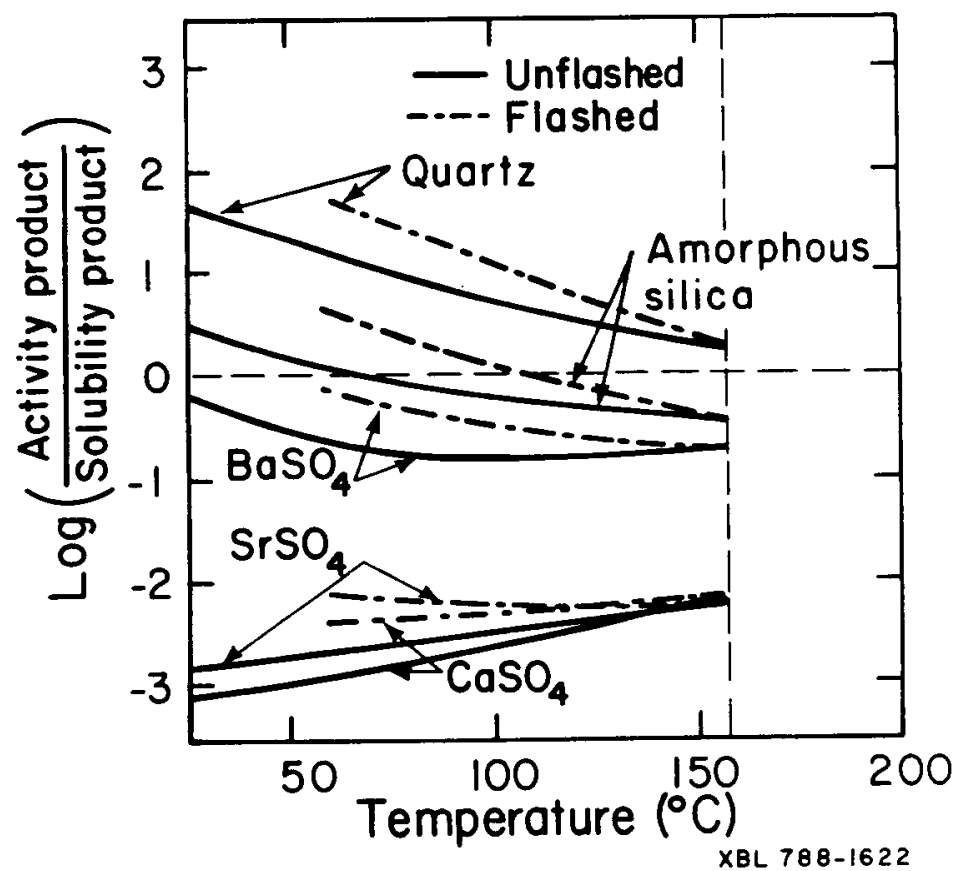

Figure 5.16. Scale-forming potential for geothermal fluid from we11 31-1. 


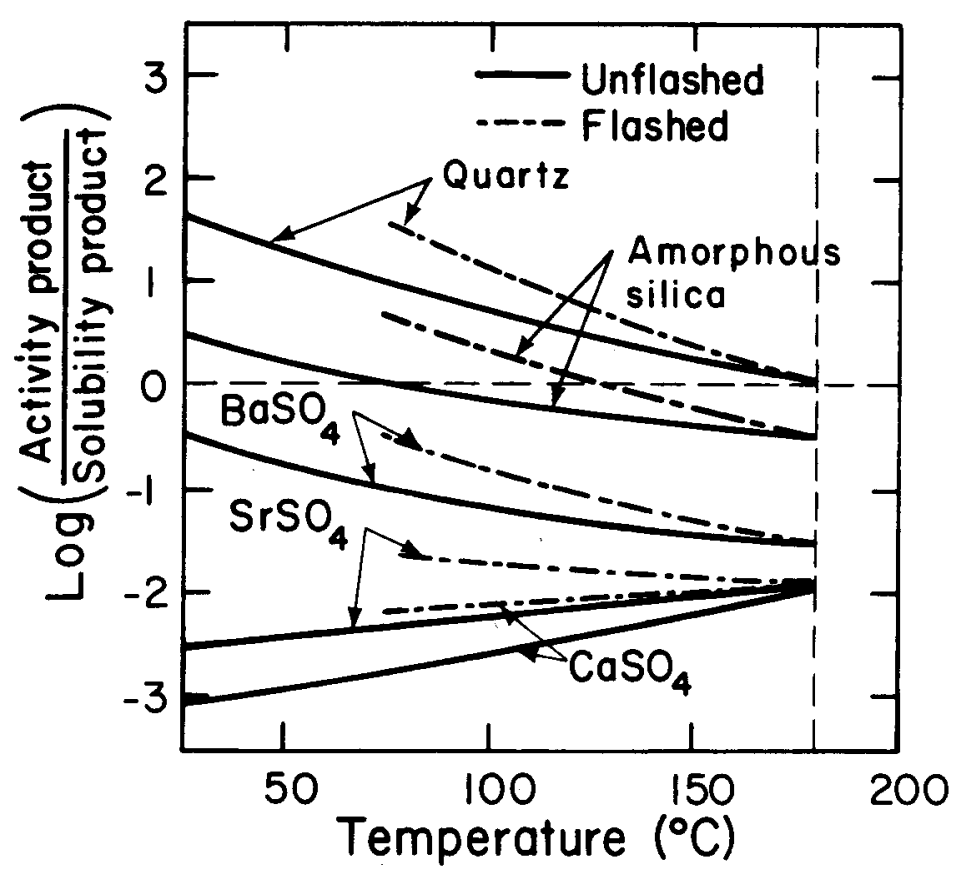

XBL $788-1623$

Figure 5.17. Scale-forming potential for geothermal fluid from well 8-1.

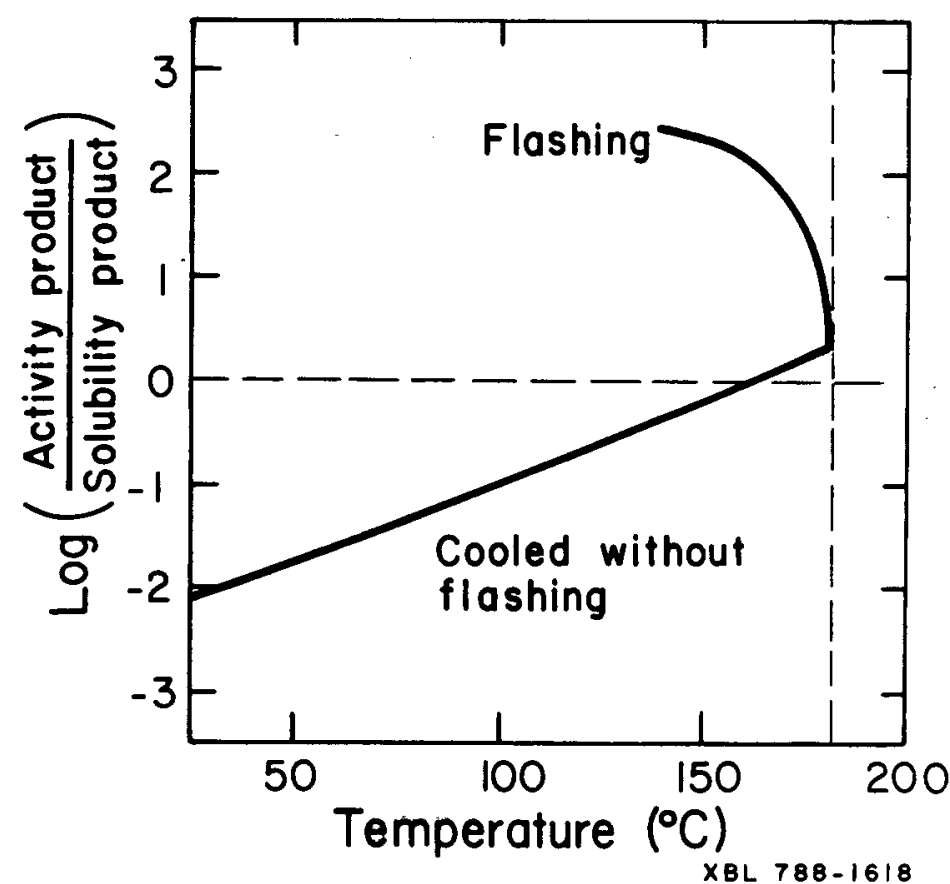

Figure 5.18. Calcite scaling potential in we11 8-1 geothermal fluid. 


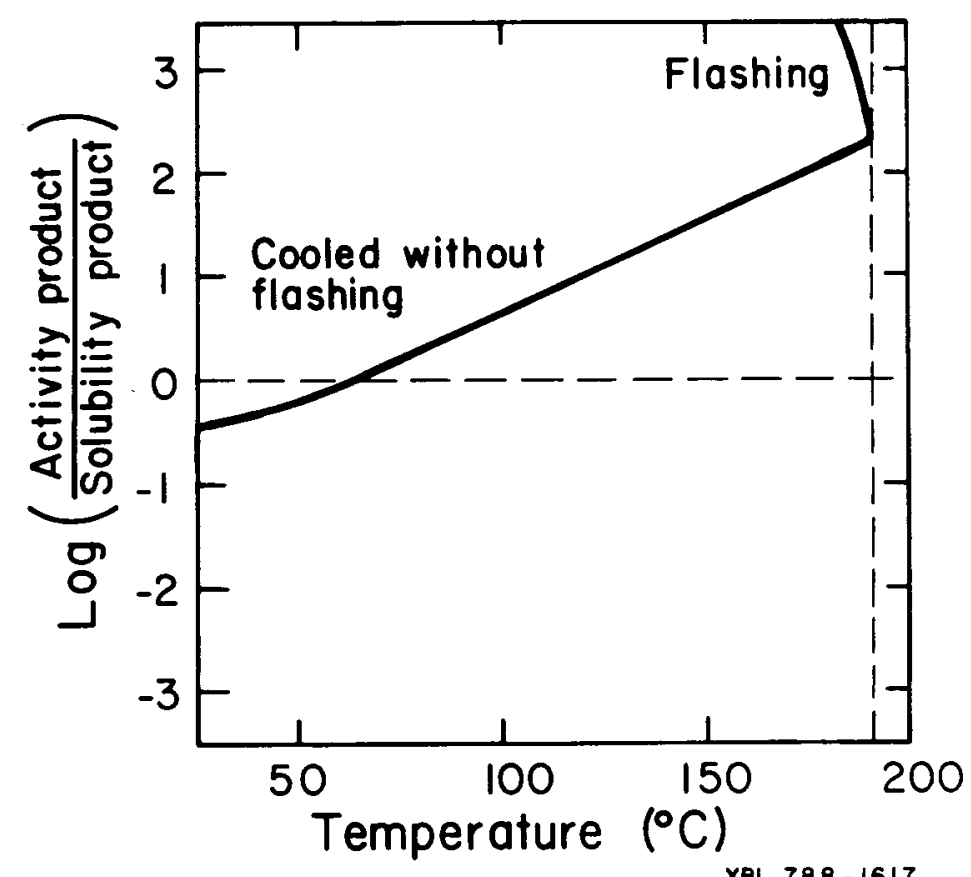

Figure 5.19. Calcite scaling potential for a $1 / 1$ mixture of wel1 6-1 and well 6-2 geothermal fluids.

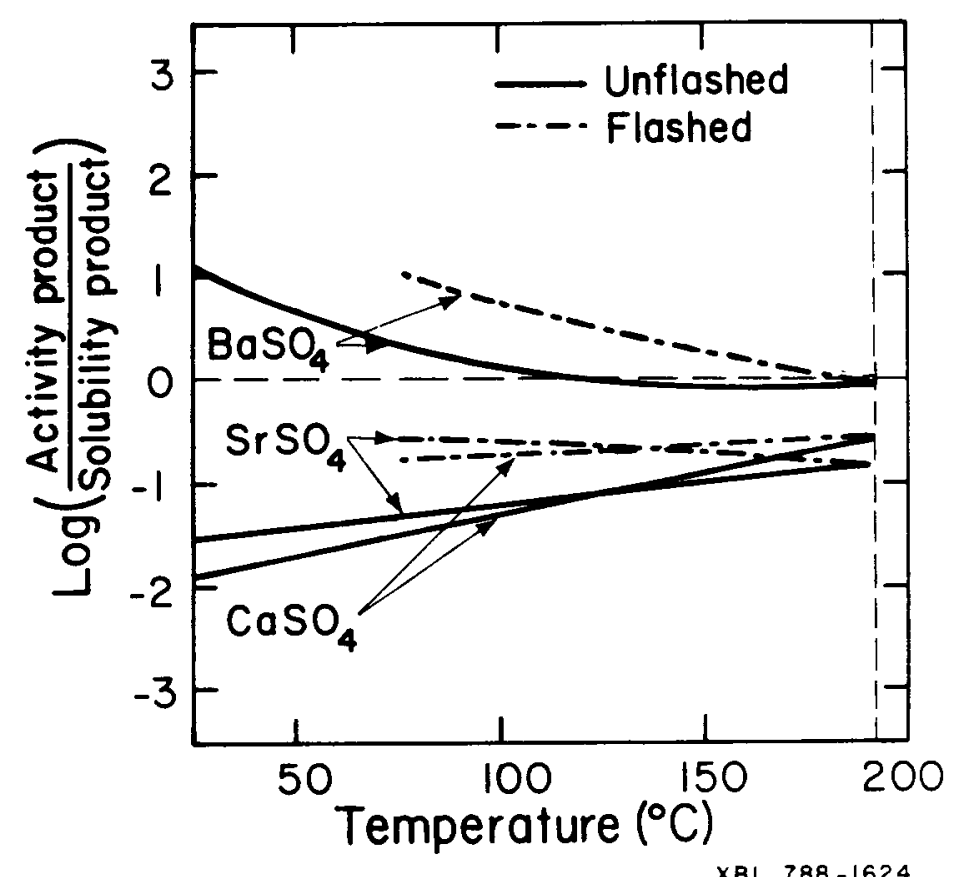

Figure 5.20. Sulfate scaling potential for a $1 / 1$ mixture of well $6-1$ and well 6-2 geothermal fluids. 


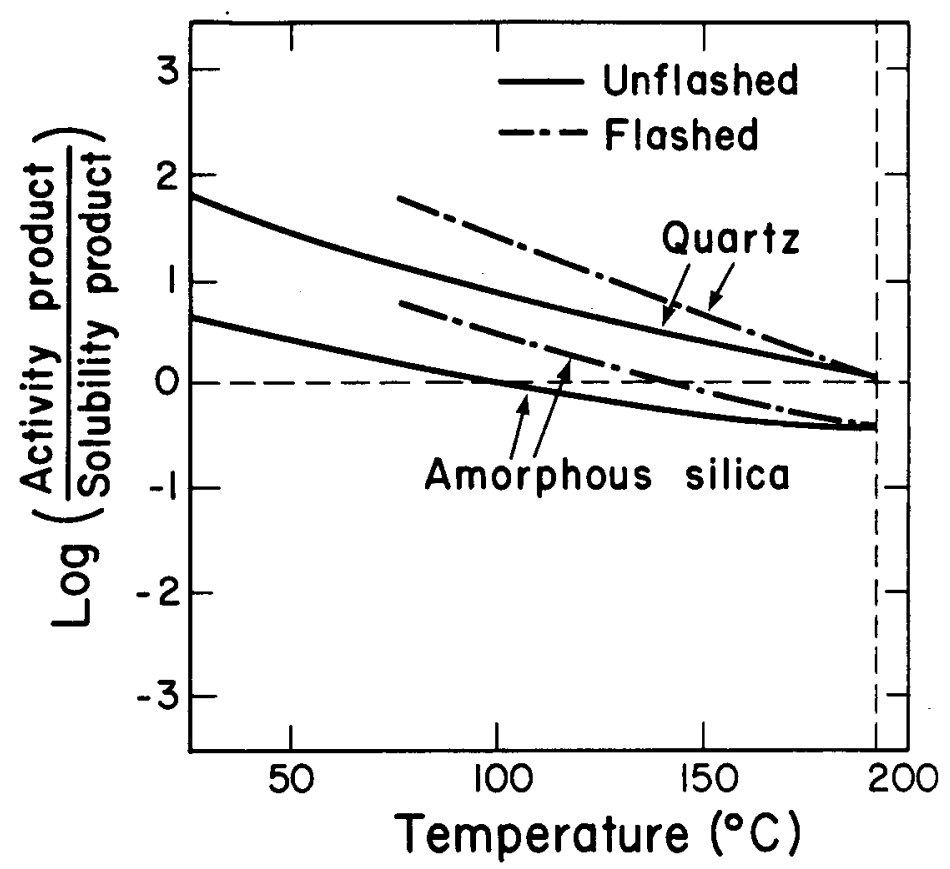

XBL $7810 \cdot 6580$

Figure 5.21. Silica scaling potential for a $1 / 1$ mixture of we11 6-1 and well 6-2 geothermal fluids.

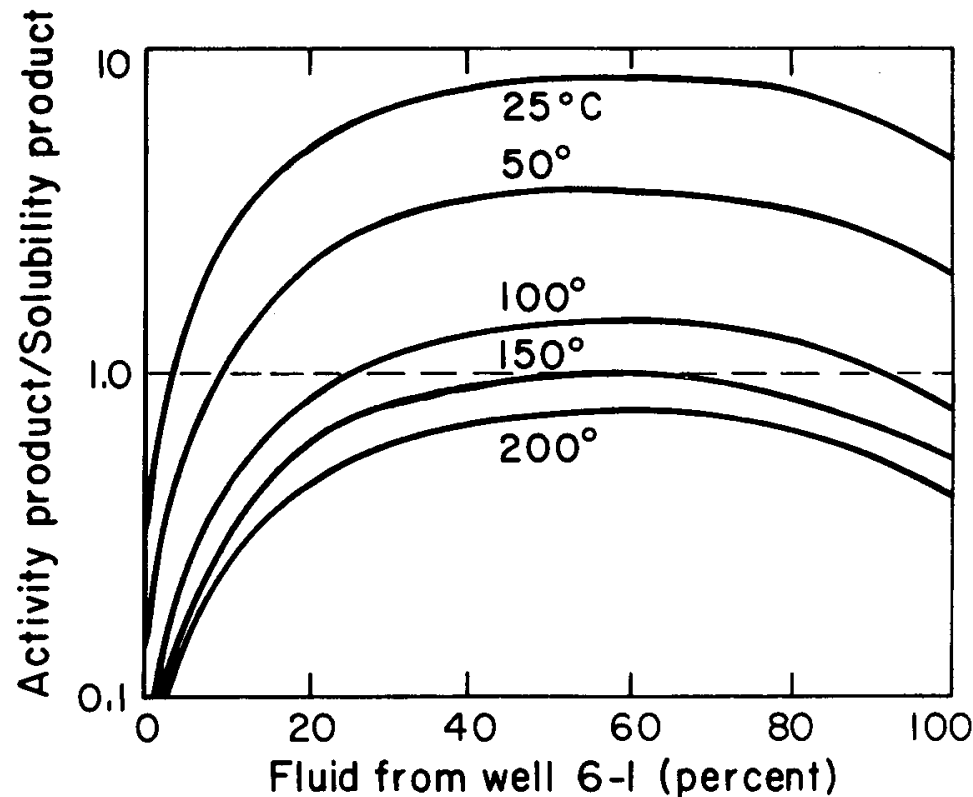

XBL $788-1607$

Figure 5.22. Barite $\left(\mathrm{BaSO}_{4}\right)$ saturation between $20^{\circ}$ and $200^{\circ} \mathrm{C}$ in mixtures of well 6-1 and well 6-2 geothermal fluids. 
POTENTIAL FOR SCALE FORMATION FROM THE USE OF SALTON SEA WATER

Development of East Mesa for the production of either power or fresh water will require a supply of additional water. Cooling water is needed for power production and when fresh water is produced from geothermal fluids, an equivalent volume of fluid should be injected to maintain reservoir pressure and to prevent ground subsidence.

The Salton Sea is the principal potential source of available water for these purposes. Thus it is necessary to consider the chemical characteristics of this water, and in particular, the potential problems of transporting, heating, and mixing it with spent geothermal fluids, and injecting it into the geothermal reservoir.

The Salton Sea is calculated to be saturated with respect to at least 10 minerals. The principal ones are gypsum $\left(\mathrm{CaSO}_{4} \cdot \mathrm{H}_{2} \mathrm{O}\right)$, magnesite $\left(\mathrm{MgCO}_{3}\right)$, dolomite $\left[\mathrm{CaMg}\left(\mathrm{CO}_{3}\right)_{2}\right]$, calcite $\left(\mathrm{CaCO}_{3}\right)$, and celestite $\left(\mathrm{SrSO}_{4}\right)$. These minerals are potential scale formers in the transport and low-temperature concentration of Salton Sea water. At temperatures above $\sim 90^{\circ} \mathrm{C}$, anhydrite $\left(\mathrm{CaSO}_{4}\right)$ becomes the stable phase rather than gypsum.

Two different computer codes using different sources of information were used to make this prediction. In all cases the two codes were in agreement on the calculated saturation with respect to the same mineral. For example, Table 5.9 shows the distribution of species in Salton Sea water at $25^{\circ} \mathrm{C}$. Saturation by a mineral is indicated by capital letters. This calculation is based on MINEQL (Westa11, 1976). A part1y different array of possible saturating phases was examined by EQ3/EQ6. Those that saturate the fluid are shown in Table 5.10. The code EQ3/EQ6 does not consider celestite, and MINEQL does not consider dolomite, gypsum, and some of the other less abundant minerals.

Supersaturation with respect to the iron oxides (Table 5.10) is probably fictive, because analyses of dissolved iron in natural waters are usually too high due to interference from colloidal ferric hydroxide. Supersaturations with respect to the carbonates are probably real, because these are well documented for surface ocean water. The small gypsum supersaturation may also be real. 
Table 5.9. Species distribution in the Salton Sea at $25^{\circ} \mathrm{C} *$

\begin{tabular}{|c|c|c|c|c|}
\hline Component & ${ }_{(\mathrm{ppm})}^{\text {Conc }}$ & $\begin{array}{l}\text { ration } \\
\quad(\mathrm{mole} / \mathrm{kg})\end{array}$ & $\begin{array}{c}\text { Species or } \\
\text { phase } †\end{array}$ & $\begin{array}{c}\text { Distribution } \\
(\%)\end{array}$ \\
\hline $\mathrm{Ca}$ & 945.0 & $2.36 \times 10^{-2}$ & $\begin{array}{l}\text { ANHYDRITE } \\
\mathrm{CaSO}_{4}{ }^{\circ} \\
\mathrm{CALCITE} \\
\mathrm{Ca}^{2+} \\
\mathrm{CaHCO}_{3} \mathrm{O}\end{array}$ & $\begin{array}{r}65.8 \\
16.9 \\
8.9 \\
8.3 \\
-\end{array}$ \\
\hline Mg & 172.0 & $4.43 \times 10^{-2}$ & $\begin{array}{l}\mathrm{Mg} \mathrm{SO}_{4}{ }^{\circ} \\
\mathrm{Mg}^{2+} \\
\mathrm{MgHCO}_{3}+\end{array}$ & $\begin{array}{c}71 \cdot 3 \\
27 \cdot 8 \\
-\end{array}$ \\
\hline $\mathrm{K}$ & 172.0 & $4.42 \times 10^{-3}$ & $\begin{array}{l}\mathrm{K}^{+} \\
\mathrm{KSO}_{4}^{-}\end{array}$ & $\begin{array}{l}88 \cdot 5 \\
11 \cdot 5\end{array}$ \\
\hline $\mathrm{Na}$ & $10,500 \cdot 0$ & $4.57 \times 10^{-1}$ & $\begin{array}{l}\mathrm{Na}^{+} \\
\mathrm{NaSO}_{4}^{-}\end{array}$ & $\begin{array}{r}95.1 \\
4.9\end{array}$ \\
\hline $\mathrm{Sr}$ & 11.0 & $1.26 \times 10^{-4}$ & $\begin{array}{l}\text { CELESTITE } \\
\mathrm{Sr}^{2+}\end{array}$ & $\begin{array}{r}96.1 \\
3.9\end{array}$ \\
\hline $\mathrm{Li}$ & 3.2 & $4.61 \times 10^{-4}$ & $\begin{array}{l}\mathrm{Li}^{+} \\
\mathrm{LiSO}_{4}^{-}\end{array}$ & $\begin{array}{r}96.0 \\
4.0\end{array}$ \\
\hline $\mathrm{Fe}$ & 0.1 & $1.79 \times 10^{-7}$ & $\mathrm{Fe}(\mathrm{OH})_{3}(\mathrm{~S})$ & 100.0 \\
\hline $\mathrm{Zn}$ & 0.062 & $9.48 \times 10^{-7}$ & $\begin{array}{l}\mathrm{ZnSO}_{4}{ }^{\circ} \\
\mathrm{Zn}^{2+} \\
\mathrm{ZnC1}^{+} \\
\mathrm{ZnCl}^{-} \\
\mathrm{Zn}(\mathrm{OH})_{3} \\
\mathrm{Zn}(\mathrm{OH})_{2}\end{array}$ & $\begin{array}{r}60.2 \\
29.6 \\
3.9 \\
2.2 \\
2.3 \\
1.2\end{array}$ \\
\hline $\mathrm{Mn}$ & 0.01 & $1.8 \times 10^{-7}$ & $\begin{array}{l}\mathrm{MnCl}^{+} \\
\mathrm{MnCl}_{2}{ }^{\circ} \\
\mathrm{InSO}_{4}^{\circ} \\
\mathrm{Mn}^{\circ}{ }^{\circ} \\
\mathrm{MnCl}_{3}{ }^{\circ} \\
\mathrm{Mn} \mathrm{HCO}_{3}{ }^{+}\end{array}$ & $\begin{array}{r}48.4 \\
20.3 \\
18.8 \\
9.2 \\
2.7 \\
-\end{array}$ \\
\hline $\mathrm{Cu}$ & 0.005 & $7.81 \times 10^{-8}$ & $\begin{array}{l}\mathrm{Cu}\left[\mathrm{B}(\mathrm{OH})_{4}\right]_{2} \\
\mathrm{Cu}(\mathrm{OH})_{2} \\
\mathrm{Cu}\left(\mathrm{CO}_{3} \mathrm{O}\right)\end{array}$ & $\begin{array}{c}84.7 \\
1.6 \\
-\end{array}$ \\
\hline B & 9.2 & $8.51 \times 10^{-4}$ & $\begin{array}{l}\mathrm{HB}(\mathrm{OH})_{4} \mathrm{O} \\
\mathrm{B}(\mathrm{OH})_{4}\end{array}$ & $\begin{array}{r}96.1 \\
3.9\end{array}$ \\
\hline $\mathrm{Cl}$ & $15,000.0$ & $4.23 \times 10^{-1}$ & $\mathrm{Cl}^{-}$ & 100.0 \\
\hline
\end{tabular}

* Calculated by MINEQL from the chemical composition given in Table 5.6.

† Capita1 letters indicate saturation. 
Table 5.9. Species distribution in the Salton sea at $25^{\circ} \mathrm{C} *$ (continued)

\begin{tabular}{|c|c|c|c|c|}
\hline Component & $\begin{array}{l}\text { Con } \\
\text { (ppm) }\end{array}$ & $\begin{array}{l}\text { ration } \\
\qquad(\mathrm{mole} / \mathrm{kg})\end{array}$ & $\begin{array}{c}\text { Species or } \\
\text { phaset }\end{array}$ & $\begin{array}{c}\text { Distribution } \\
(\%)\end{array}$ \\
\hline $\mathrm{SO}_{4}$ & $8,146.0$ & $8.48 \times 10^{-2}$ & $\begin{array}{l}\mathrm{Mg} \mathrm{SO}_{4}{ }^{\circ} \\
\mathrm{NaSO}_{4}^{-} \\
\mathrm{ANHYDR}^{-} \\
\mathrm{SO}_{4}{ }^{2-} \\
\mathrm{CaSO}_{4}{ }^{\circ}\end{array}$ & $\begin{array}{r}37 \cdot 3 \\
26 \cdot 6 \\
18 \cdot 3 \\
12 \cdot 4 \\
4 \cdot 7\end{array}$ \\
\hline $\mathrm{CO}_{2}$ & 146.0 & $3.32 \times 10^{-3}$ & $\begin{array}{l}\mathrm{CALCITE} \\
\mathrm{HCO}_{3}^{-} \\
\mathrm{MgHCO}_{3}{ }^{+} \\
\mathrm{MgCO}_{3} \mathrm{O}^{-} \\
\mathrm{CaHCO}_{3}{ }^{+} \\
\mathrm{CaCO}_{3} \mathrm{O}^{\circ} \\
\mathrm{NaCO}_{3} \mathrm{O} \\
\mathrm{H}_{2} \mathrm{CO}_{3}^{\circ}\end{array}$ & $\begin{array}{c}63.2 \\
24.8 \\
7.6 \\
1.5 \\
1.2 \\
- \\
- \\
-\end{array}$ \\
\hline $\mathbf{F}$ & 3.2 & $1.68 \times 10^{-4}$ & $\begin{array}{l}\mathrm{F}^{-} \\
\mathrm{MgF}^{+} \\
\mathrm{CaF}^{+} \\
\text {FLUORITE }\end{array}$ & $\begin{array}{c}55.8 \\
42.8 \\
1.4 \\
-\end{array}$ \\
\hline $\mathrm{NO}_{3}$ & $14 \cdot 0$ & $2.26 \times 10^{-4}$ & $\mathrm{NO}_{3}^{-}$ & 100.0 \\
\hline
\end{tabular}

* Calculated by MINEQL from the chemical composition given in Table 5.6.

+ Capital letters indicate saturation. 
Table 5.10. Ninerals saturating Salton Sea water at $25^{\circ} \mathrm{C.*}$

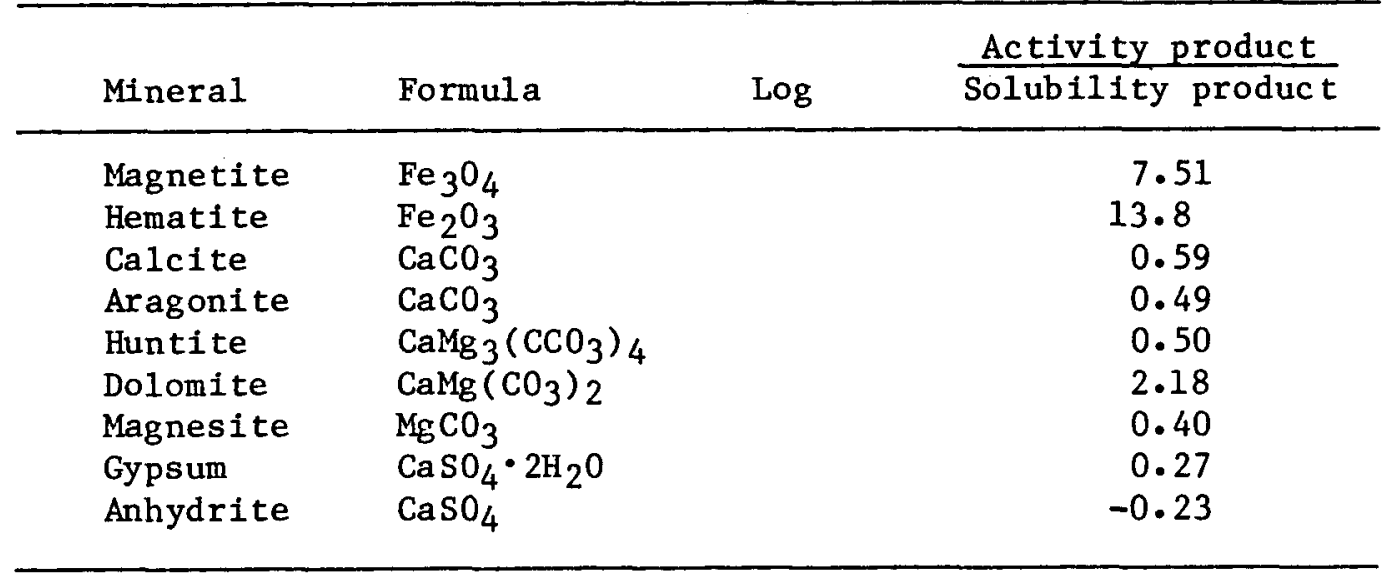

* Based on EQ3/EQ6 calculations.

\section{Scale Formation by Heating Salton Sea Water}

Precipitation of phases from Salton Sea water during heating to $260^{\circ} \mathrm{C}$ in a closed system (as in a sealed laboratory pressure vesse1) is shown in Figure 5.23. The mass of each precipitate is plotted semilogarithmically according to the scale on the left; the combined precipitate volume is shown by the scale on the right. Gypsum is replaced by anhydrite near $96^{\circ} \mathrm{C}$, and dolomite by magnesite near $135^{\circ} \mathrm{C}$.

The use of Salton Sea water as a cooling fluid in power production will almost certainly lead to the formation of scale deposits composed of some or all of these minerals, and the same appears to be the case during injection.

As a fluid flows through a heat exchanger or the reservoir and is heated, equilibrium causes those minerals that precipitate and form scales to be left behind as the fluid moves on through the temperature gradient. For example, in the case of the Salton Sea water, gypsum will form, but will not be heated to the temperature for transformation into anhydrite. The precipitation sequence based on this "flow-through" heating has also been calculated and the results are shown in Figure 5.24. The amounts of minerals that form are shown with the total volume of precipitate. This prediction is a thermodynamic (equilibrium) sequence--not necessarily kinetically favored. For additional information on mass transport of this kind see the pioneering work by Helgeson et al. (1970) and Needham et a1. (1976). 


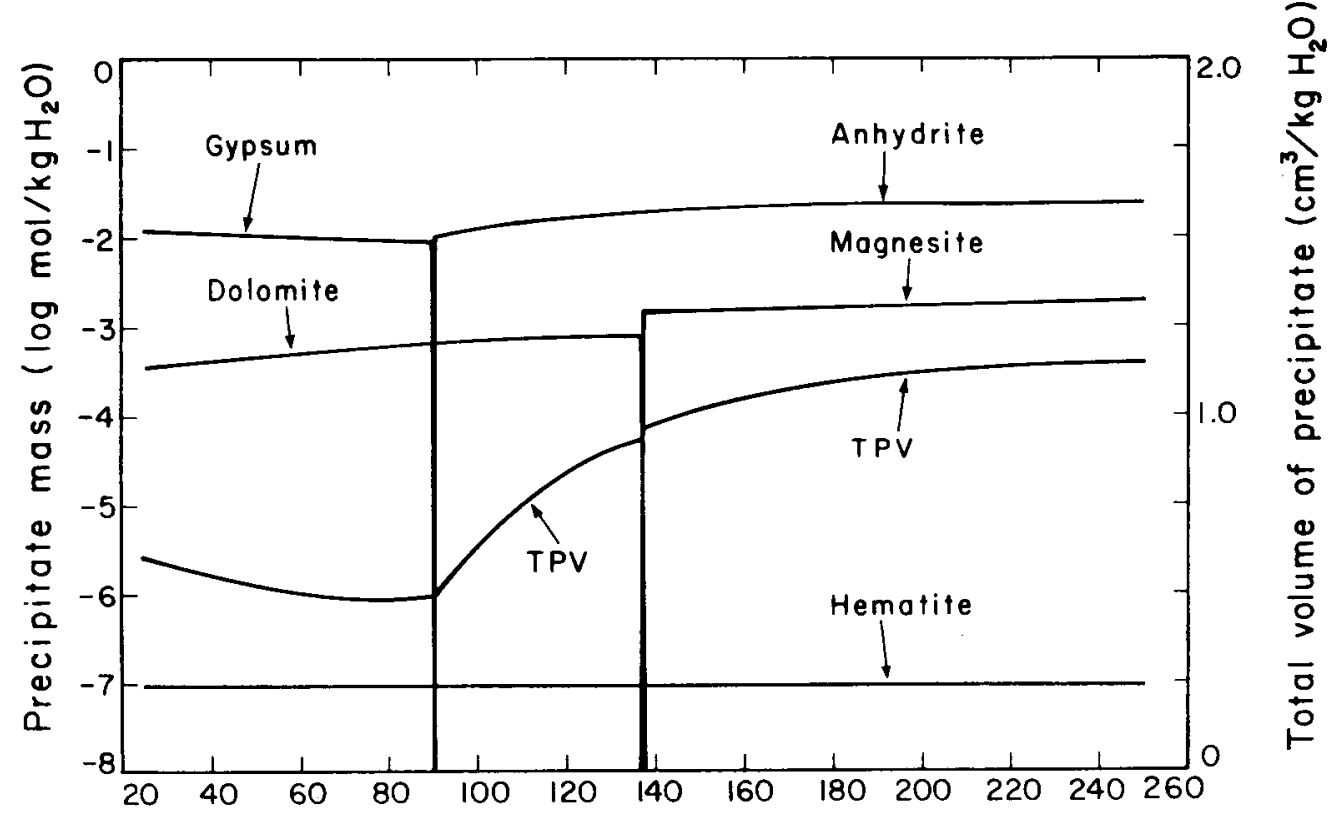

Temperature $\left({ }^{\circ} \mathrm{C}\right)$

XBL $789-2075$

Figure 5.23. Closed-system heating of Salton Sea water showing precipitate masses.

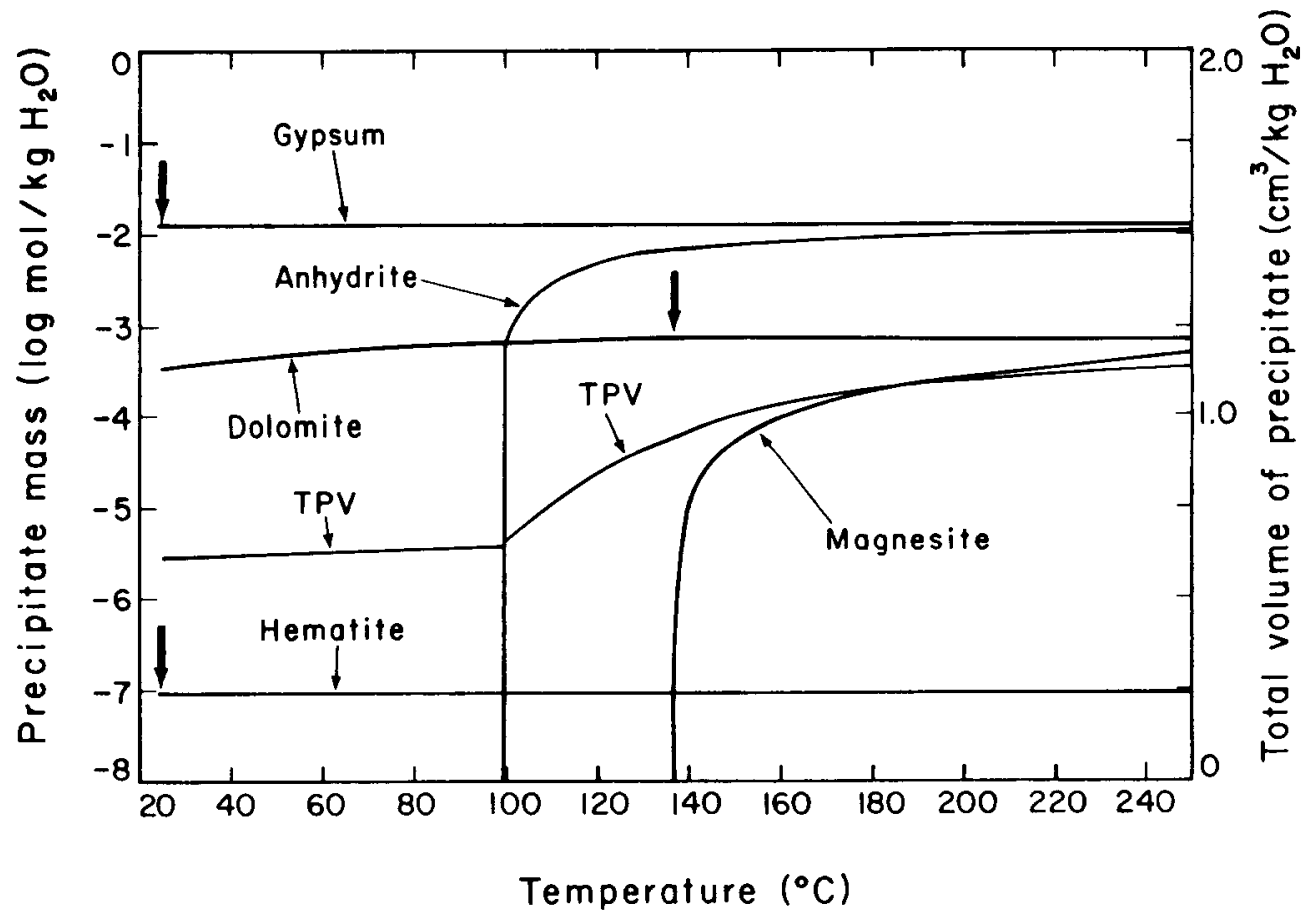

XEL $789-2074$

Figure 5.24. Precipitation sequence of minerals from heated Salton Sea water based on a flow-through model in which precipitates are removed from the system and cannot redissolve. 


\section{Mixing Salton Sea Water with Geothermal Fluids}

Mixing Salton Sea water with geothermal fluids can lead to supersaturation even when one of the fluids alone is undersaturated. The amount of Salton Sea water that can be added to spent fluid from well 6-1 before $\mathrm{CaSO}_{4}$ saturation results is shown in Figure 5.25. For example, mixtures of the two fluids containing more than $35 \%$ Salton Sea water become $\mathrm{CaSO}_{4}$ saturated at temperatures above $50^{\circ} \mathrm{C}$.

When more than $55 \%$ Salton Sea water is mixed with well 6-2 fluid at $50^{\circ} \mathrm{C}$, saturation with respect to $\mathrm{CaSO}_{4}$ will occur (Figure 5.26). The potential for $\mathrm{CaSO}_{4}$ precipitation increases with increasing temperature for all mixtures, a fact that could lead to a plugging of the reservoir during injection.

If more than $10 \%$ Salton Sea water is mixed with well 6-2 fluid at $50^{\circ} \mathrm{C}$, the mixture becomes saturated with $\mathrm{BaSO}_{4}$; above $100^{\circ} \mathrm{C}$ no saturation is predicted for any mixture (Figure 5.27). These mixtures will become unsaturated with $\mathrm{BaSO}_{4}$ when injected into the reservoir and heated to reservoir temperature.

Mixtures of well 6-1, well 6-2, and Salton Sea water with a high potential for scale formation are shown by shaded areas in Figures 5.28 and 5.29. Because the fluid from wells $8-1$ and $31-1$ is similar in composition to that of well 6-2, these qualitative diagrams can also be considered to apply to fluid mixtures from well $8-1$ or $31-1$, rather than $6-2$.

When fluid mixtures are injected, they will be heated as they flow. Scale-forming precipitates will be removed from the fluid. A "flow-through" model has been applied to a $1 / 1$ mixture of spent well 6-2 fluid and Salton Sea water. Figure 5.30 shows the amounts of various minerals that could separate upon heating. Barite and celestite may also form, but they are not presently available for consideration in the EQ6 data base. Only when anhydrite becomes stable does the total volume of precipitate (scale) become significant. Antigorite is a serpentine mineral having the composition $\mathrm{Mg}_{3} \mathrm{Si}_{2} \mathrm{O}_{5}(\mathrm{OH})_{4}$ •

\section{Reactions of Injected Fluids with Reservoir Minerals}

The minerals composing the reservoir rocks can react with injected fluids, creating new minerals and altering others. The mineralogy of the 


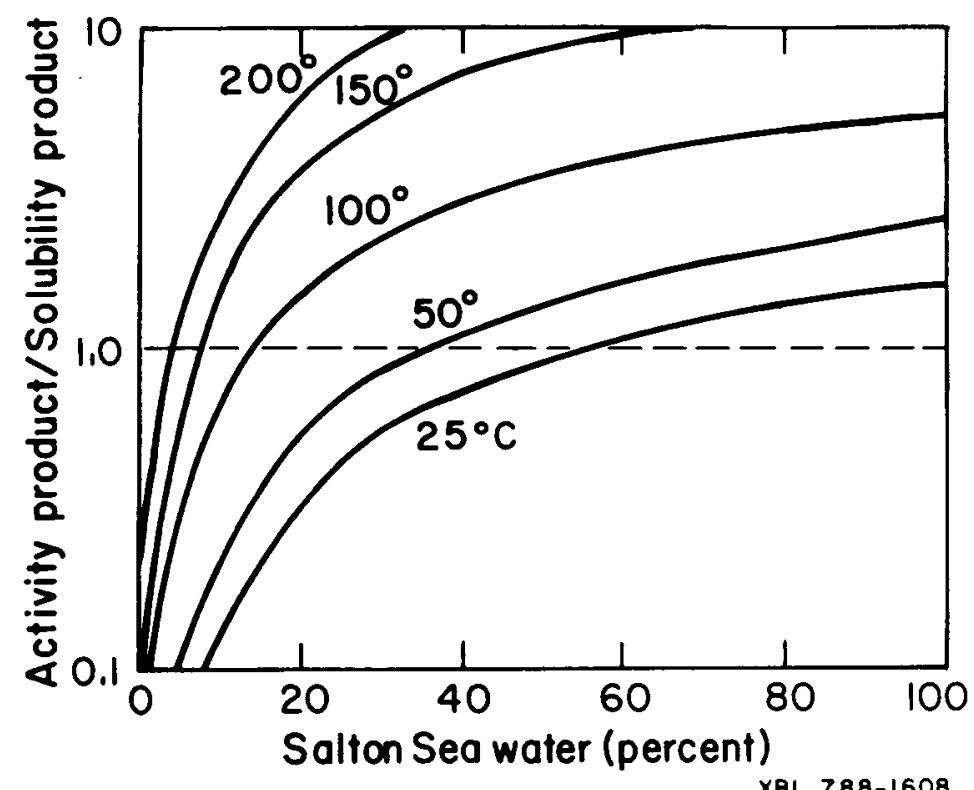

Figure 5.25. Anhydrite $\left(\mathrm{CaSO}_{4}\right)$ saturation between $25^{\circ}$ and $200^{\circ} \mathrm{C}$ in mixtures of Salton Sea water and well 6-1 geothermal fluid.

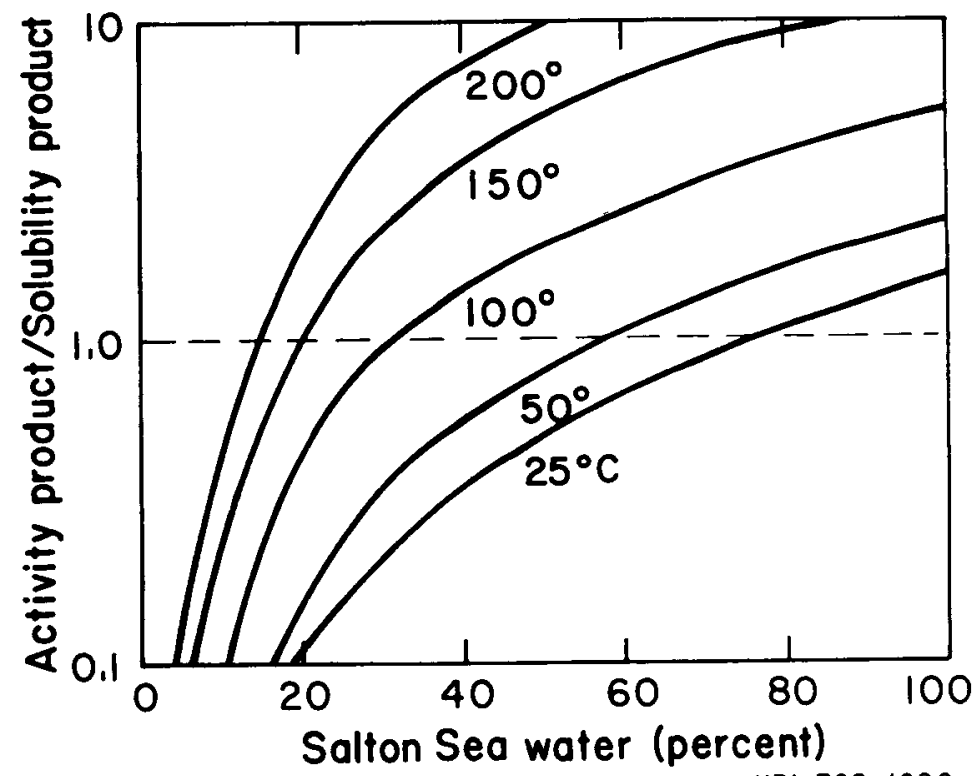

Figure 5.26. Anhydrite $\left(\mathrm{CaSO}_{4}\right)$ saturation between $25^{\circ}$ and $200^{\circ} \mathrm{C}$ in mixtures of Salton Sea water and well 6-2 geothermal fluid. 


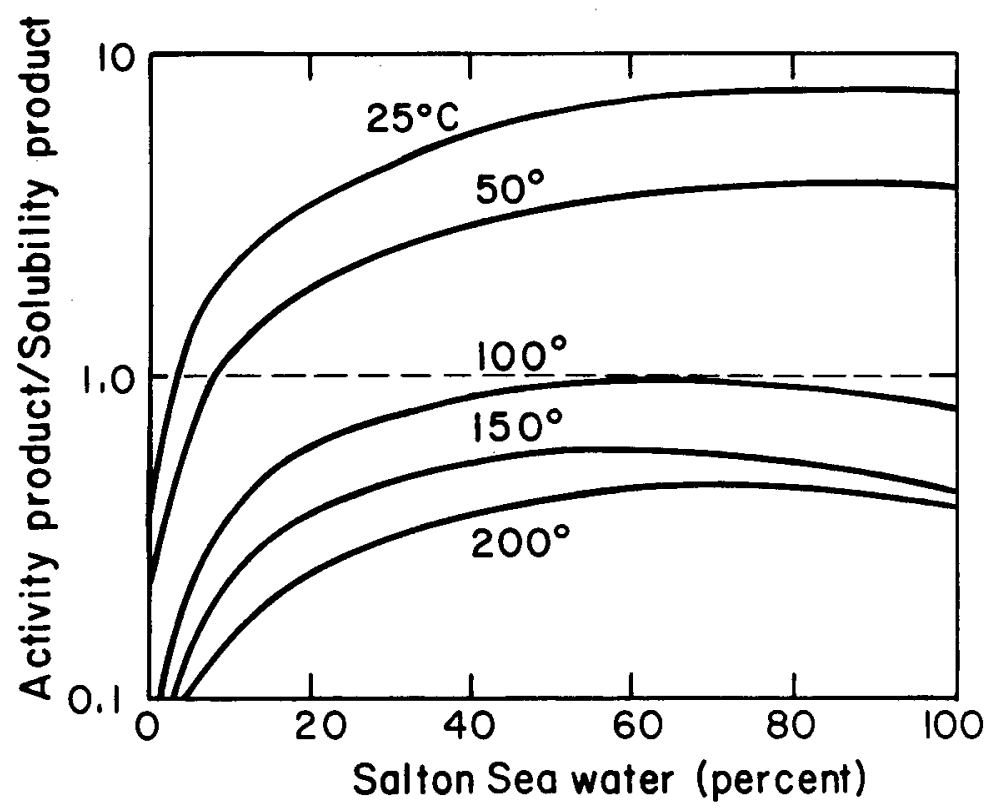

XBL $788-1606$

Figure 5.27. Barite $\left(\mathrm{BaSO}_{4}\right)$ saturation between $25^{\circ}$ and $200^{\circ} \mathrm{C}$ in mixtures of Salton Sea water and well 6-2 geothermal fluid.
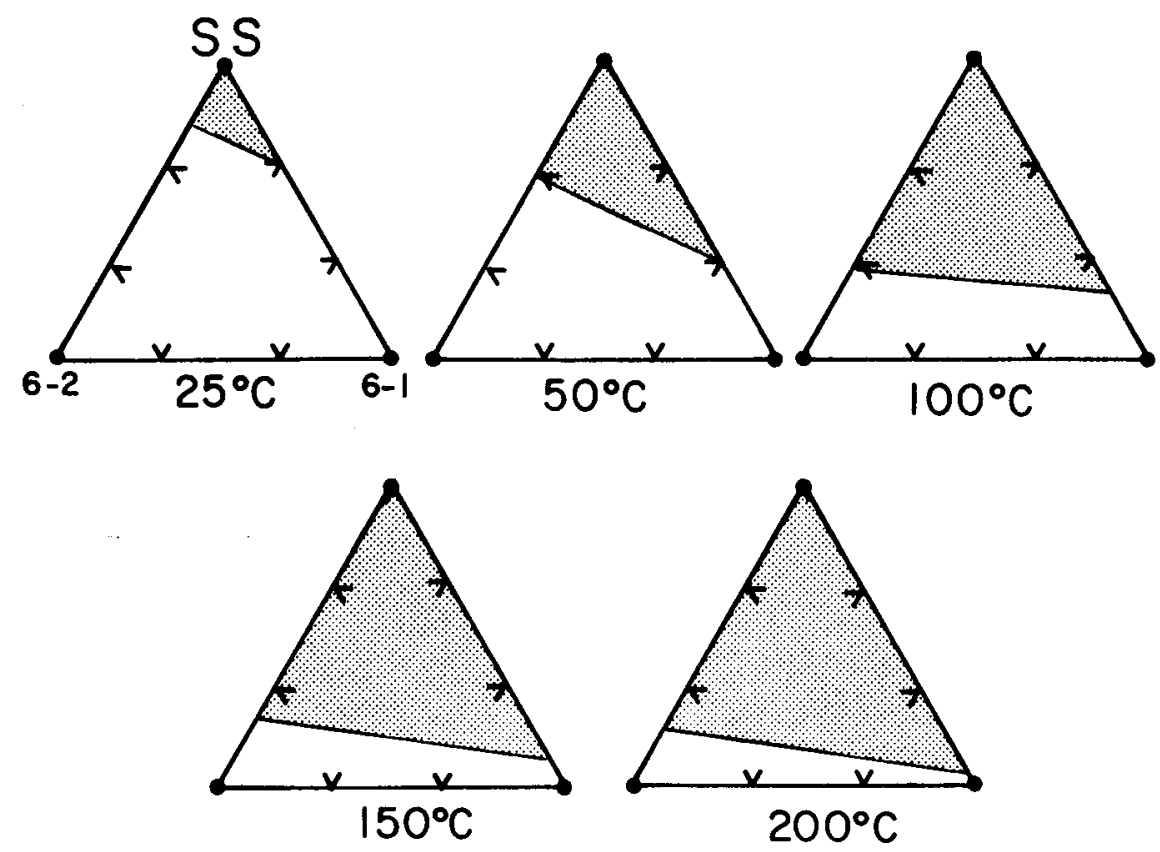

XBL $788-1628$

Figure 5.28. Anhydrite $\left(\mathrm{CaSO}_{4}\right)$ saturation in mixtures of fluids from well $6-1,6-2$, and the Salton Sea (SS) at various temperatures. 

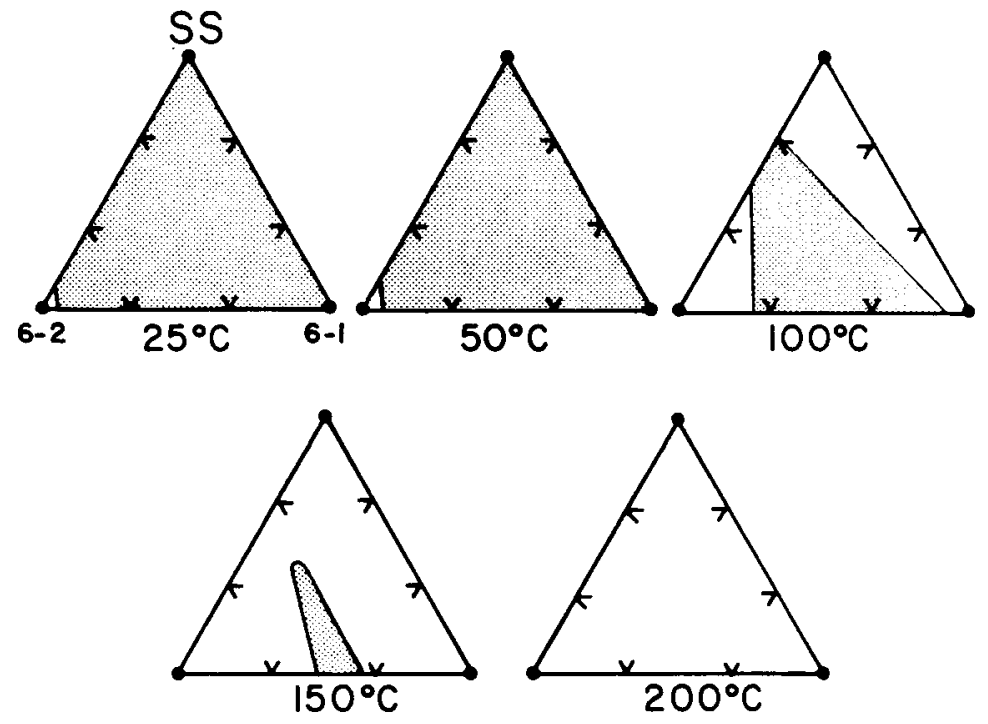

XBL $788-1629$

Figure 5.29. Barite $\left(\mathrm{BaSO}_{4}\right)$ saturation in mixtures of fluids from well $6-1,6-2$, and the Salton Sea (SS) at various temperatures. Stippled areas show composition supersaturated with barite.

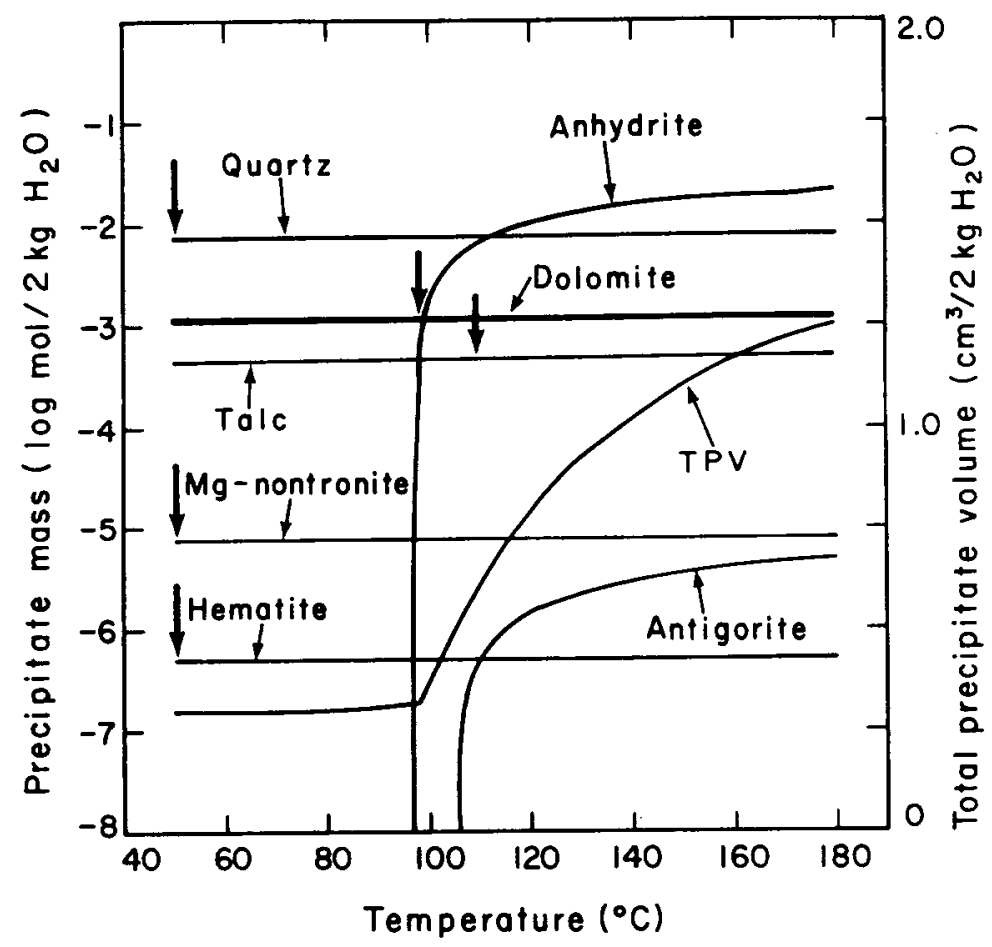

XBL 789-2073

Figure 5.30. Minerals precipitating by heating a $1 / 1$ mixture of Salton Sea water and spent 6-2 fluid (calculated assuming a flow-through model in which each mineral is removed when it forms). 
Table 5.11. Estimated mineralogy, wel1 5-1.*

\begin{tabular}{lcc}
\hline \multicolumn{1}{c}{ Mineral } & \multicolumn{2}{c}{ Concentration } \\
$(\mathrm{g} / \mathrm{kg})$ & $885 \mathrm{~kg})$ \\
\hline Quartz & 175 & 8.072 \\
Calctte & 41 & 1.748 \\
Dolomite & 175 & 0.222 \\
Microcline & 124 & 0.629 \\
Albite & 0.473 \\
\hline * Fournier, 1973, 1976; Hoagland, 1976a, 1976b
\end{tabular}

geothermal reservoir near injection well 5-1 has not been studied. Table 5.11 is an estimate based on studies of samples recovered from other East Mesa wells (Fournier, 1973, 1976; Hoagland, 1976a, 1976b). The concentrations in the table represent typical mineral proportions and reflect neither the probable error in analyses nor the observed scatter among various samples.

Figure 5.31 shows the mass transfer of minerals by the irreversible reaction between original rock components and fluid at a constant temperature of $180^{\circ} \mathrm{C}$. The fluid is a $1 / 1$ mixture of Salton sea and spent $6-2$ fluid.

Saturation of fluid by the minerals originally present in the rock is shown by an arrow $(t)$ along the bottom of the diagram. The net dissolution of a reacting solid is shown by $(-)$, and net precipitation by $(+)$. When enough rock has been added to reach albite saturation, there is a net creation of two original reactants, quartz and calcite, and there was previously a transient net creation of dolomite. At the end, all reactants are saturated and calcite is formed at the expense of anhydrite and dolomite.

Since calcite and quartz precipitate as cements, the rock would presumably become less permeable. But the solution of anhydrite helps lead to a small net mineral-volume decrease of $1 \mathrm{~cm}^{3} / 2 \mathrm{~kg} \mathrm{H}_{2} 0$. In the early part of the reaction, cement minerals are dissolving and hydrous minerals such as muscovite are precipitated. During this phase, the rock probably weakens and a net increase in mineral volume occurs. This may cause plugging of the reservoir and loss of permeability. However, changes in reservoir permeability are not directly related to the amount of solid that is added or removed any more than permeability is related to porosity. It is the way 


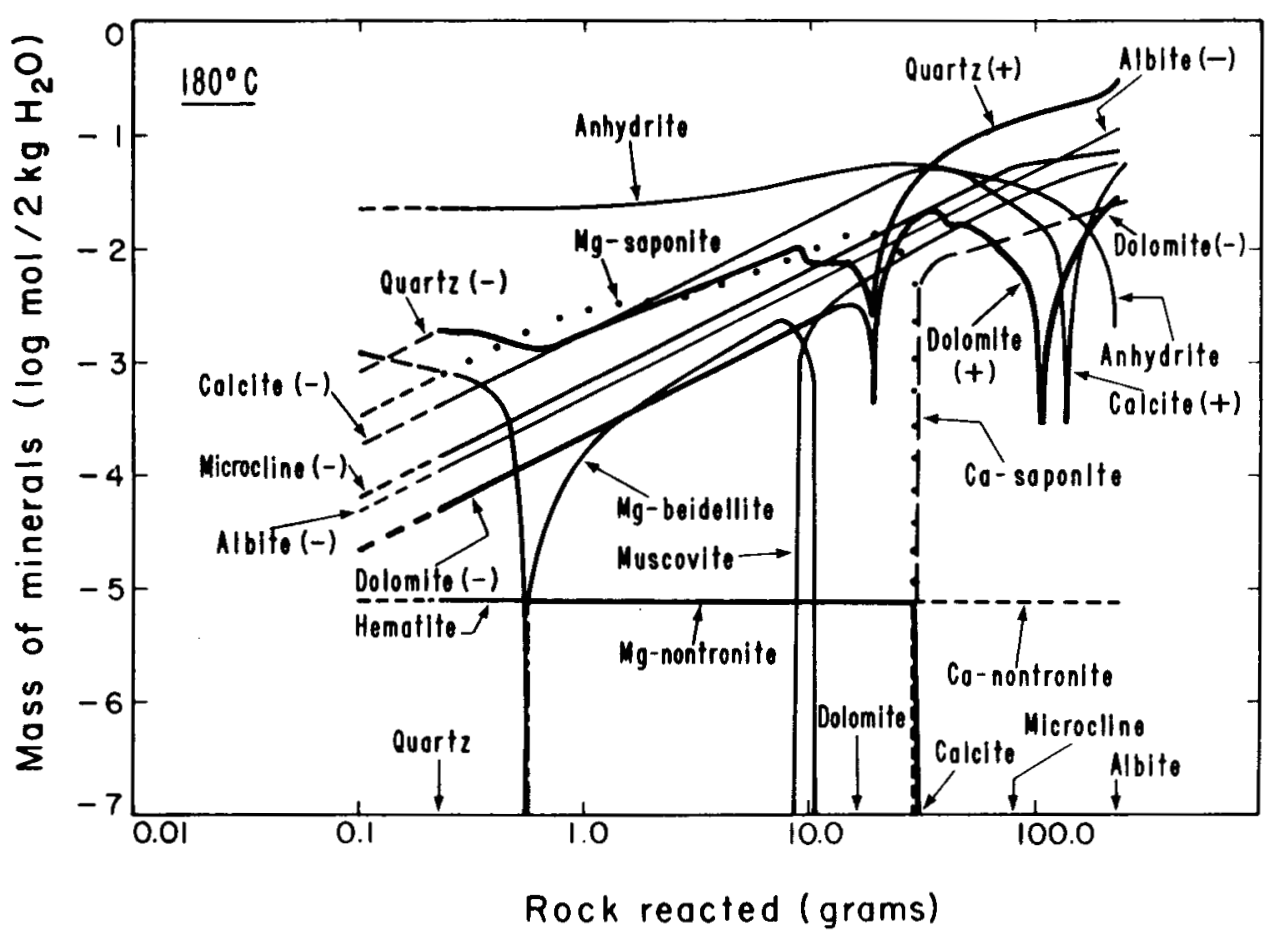

$\times B L 789 \cdot 2076$

Figure 5.31 Diagram simulating closed system reaction of a $1 / 1$ mixture of Salton Sea water and spent fluid from well 6-2 with reservoir minerals at $180^{\circ} \mathrm{C}$. The equilibrium calculation was made assuming a "reaction" of $2 \mathrm{~kg}$ of fluid with increasing amounts of reservoir rock. 
Table 5.12. Chemical compositions of clay minerals formed by reaction of injected fluid with reservoir rock.

Formula Mineral

\begin{tabular}{|c|c|}
\hline 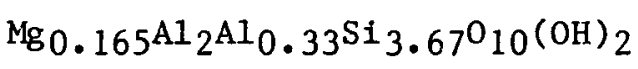 & Mg-beidellite \\
\hline $\mathrm{Ca}_{0} \cdot 165^{\mathrm{Mg}} 3^{\mathrm{Al}_{0}} 0.33^{\mathrm{Si}} 3.67^{0}{ }_{10}(\mathrm{OH})_{2}$ & Ca-saponite \\
\hline $\mathrm{Mg}_{0.165} \mathrm{Mg}_{3} \mathrm{Al}_{0.33 \mathrm{Si}_{3.670_{10}}(\mathrm{OH})_{2}}$ & Mg-saponite \\
\hline 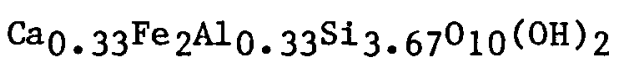 & Ca-nontronite \\
\hline $\mathrm{Mg}_{0.33} \mathrm{Fe}_{2} \mathrm{Al}_{0.33} \mathrm{Si}_{3.67} \mathrm{O}_{10}(\mathrm{OH})_{2}$ & Mg-nontronite \\
\hline
\end{tabular}

solution or deposition changes the geometry of the fluid flow that is important. At the present time we do not know the geometry of the paths of fluid flow at East Mesa. Table 5.12 gives the chemical composition of clay minerals formed during injection.

\section{SCALE-FORMING EXPERIENCE}

In this section we review the history of scaling at East Mesa and compare these data with the predictions of the first parts of this report. The comparisons are not as valuable as they might be if the chemical composition and structure of scales were better known.

Our ability to predict downhole scaling in nonflashing wells is poor. For example, we find supersaturation of well 6-1 fluid only with respect to quartz and amorphous silica, yet the scale found was partly $\mathrm{BaSO}_{4}-$ with which the well is not calculated to be saturated except at $<60^{\circ} \mathrm{C}$.

We are able to predict carbonate and sulfate scale formation in desalting plants. Estimates of scaling rates based on equilibrium precipitation of minerals agree with observed scaling rates.

The conditions under which silica scale forms remains poorly understood. It seems possible that quartz sand, carried by the fluid from the reservoir, may be the source of some of the quartz scales found at relatively low temperatures at East Mesa. 
Downhole Scaling in We11 6-1

Well 6-l has a history of sealing itself at a depth of $\sim 1860 \mathrm{~m}$, a depth too great for scaling to have occurred by flashing-induced precipitation (Mathias, 1976). Called plugging or bridging, it first happened after the initial zone of production was doubled in length by two subsequent wellcasing perforations. The history of production, perforation, and plugging in well $6-1$ is outlined in Table 5.13.

Little is known about the structure, chemistry, or mineralogy of the plugs of scale--which is surprising in view of the cost and inconvenience they have caused. Table 5.14 shows what is known about this downhole scaling. From samples taken at the time the first plug was drilled out, the U.S. Bureau of Mines has learned the plug was probably half calcite, and the remainder contained barite, mica, and quartz (Needham et al., 1976, Bechtel Corp, 1977a). No direct samples of the second plug were recovered. A tool located near the plug for 22 hours was covered with scale when brought to the surface. An x-ray diffraction analysis showed that the acid insoluble fraction was a single mineral; the chemical analysis gave the composition $\mathrm{Ba}_{0 .}{ }_{46} \mathrm{Sr}_{0} .38 \mathrm{Ca}_{0.14} \mathrm{SO}_{4}$. The carbonate content of this plug was not determined.

The best guess that can be made with this limited information is that two scale plugs were formed of the same material, which was approximately half calcite and half $(\mathrm{Ba}, \mathrm{Sr}, \mathrm{Ca}) \mathrm{SO}_{4}$.

Table 5.13. Downhole plugging history of well 6-1.

Events

Production, $10 \times 10^{4} \mathrm{~m}^{3 *}$

Perforation, 2075 to $2179 \mathrm{~m}+$

Production, $7.2 \times 10^{4} \mathrm{~m}^{3 *}$

Perforation, 1868 to $2075 \mathrm{~m}$

Production, $2.1 \times 10^{4} \mathrm{~m}^{3}$ *

Plugged 1860 to $870 \mathrm{~m}^{\neq}$

Production, $5.3 \times 10^{4} \mathrm{~m}^{3 *}$

Plugged, $1861 \mathrm{~m} \S$

Production, $0.5 \times 10^{4} \mathrm{~m}^{3}$ *

Plugging, $5 \times 104 \mathrm{~m}^{3}$

Dates

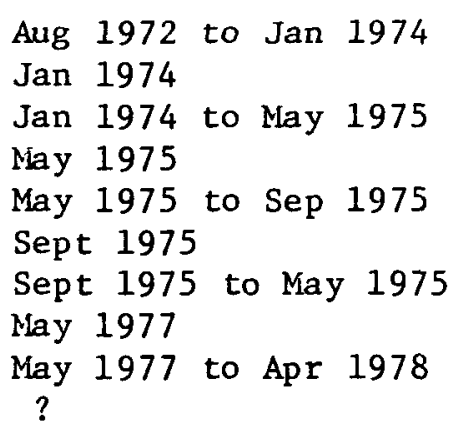

*Production records (Westec, 1978).

toriginal casing was slotted from 2222 to $2433 \mathrm{~m}$ (7292 to $8015 \mathrm{ft}$ ).

See USBR, 1977a.

\#Drilled out (USBR, 1977a).

§Treated with $19 \mathrm{~m}^{3}$ of $10 \% \mathrm{HCl}$ (USBR, 1977a). 
Table 5.14. Chemistry and mineralogy of scale in well 6-1.

\begin{tabular}{|c|c|c|c|c|c|}
\hline \multirow[b]{2}{*}{$\begin{array}{l}\text { Depth of } \\
\text { sample (m) }\end{array}$} & \multicolumn{3}{|c|}{ First plugging* } & \multicolumn{2}{|r|}{$\begin{array}{l}\text { Second plugging }{ }^{+} \\
27 \text { May } 1977\end{array}$} \\
\hline & 0 & $\begin{array}{l}80 \text { to } \\
90\end{array}$ & 182 & $\begin{array}{l}2164 \text { to } \\
2286\end{array}$ & 1830 \\
\hline $\begin{array}{l}\text { Sample } \\
\text { type }\end{array}$ & $\begin{array}{l}\text { Scale on } \\
\text { flange surface }\end{array}$ & \multicolumn{2}{|c|}{$\begin{array}{l}\text { Recovered during } \\
\text { recording }\end{array}$} & & $\begin{array}{l}\text { Scale on tool in well } \\
\text { at depth for } 24 \mathrm{hr}\end{array}$ \\
\hline $\begin{array}{l}\mathrm{CaCO}_{3} \\
\mathrm{TGA} \text { (wt\%) }\end{array}$ & 95 & 97 & 92 & 50 & Unknown \\
\hline $\begin{array}{l}\text { Other } \\
\text { minerals } \\
\text { (X-ray) }\end{array}$ & Quartz $\ddagger$ & ragonite & Quartz & $\begin{array}{l}\text { Barite } \\
\text { Mica } \\
\text { Quartz }\end{array}$ & $\begin{array}{l}\text { Acid insoluble fraction } \\
\text { was }\left(\mathrm{Ba}_{0.46} \mathrm{Sr}_{0.38} \mathrm{Ca}_{0.14}\right)_{\mathrm{SO}_{4}}\end{array}$ \\
\hline
\end{tabular}

*Analysis by U.S. Bureau of Mines, College Park Nietallurgy Research Center tChemical and $x$-ray analysis by E. M. Gordon, LBL, June 1977 . †Quartz is not generally formed as scale in geothermal fluids, the more common form of silica is amorphous.

Chemical analyses of fluid from well 6-1 before and af ter the second perforation show no clear changes. (Analyses before the first perforation are far too variable to set a trend.) However, a probable cause of this plugging is the mixing of incompatible fluids from different levels in the reservoir. Recall, for example, that well 6-1 contains 4 to 5 times more dissolved solids than the other wells--clear evidence that fluids of very different concentrations exist in the reservoir.

It seems possible that surface $\mathrm{pH}$ measurements may aid in predicting downhole scaling. Further work is clearly needed, but evidence in the case of well $6-1$ is as follows.

During March through May 1977, well 6-1 was produced at a rate of 6000 to $10,000 \mathrm{~m}^{3}$ (5 to 8 acre-ft) per month at a we11head pressure of $0.77 \mathrm{MPa}$ (97 psig; USBR, unpublished data). On 27 May, the well partly sealed itself, as noted.

Four chemical analyses of fluid taken up to 45 days before "plugging" showed a pH of $\sim 6, \mathrm{HCO}_{3}$ - contents of 80 to $130 \mathrm{ppm}$, and $\mathrm{Ca}$ contents between 720 and $900 \mathrm{ppm}$. These fluids are calculated to be supersaturated with respect to calcite at temperatures above $-115^{\circ} \mathrm{C}$, that is, "downhole" (shown by the upper band in Figure 5.32). 


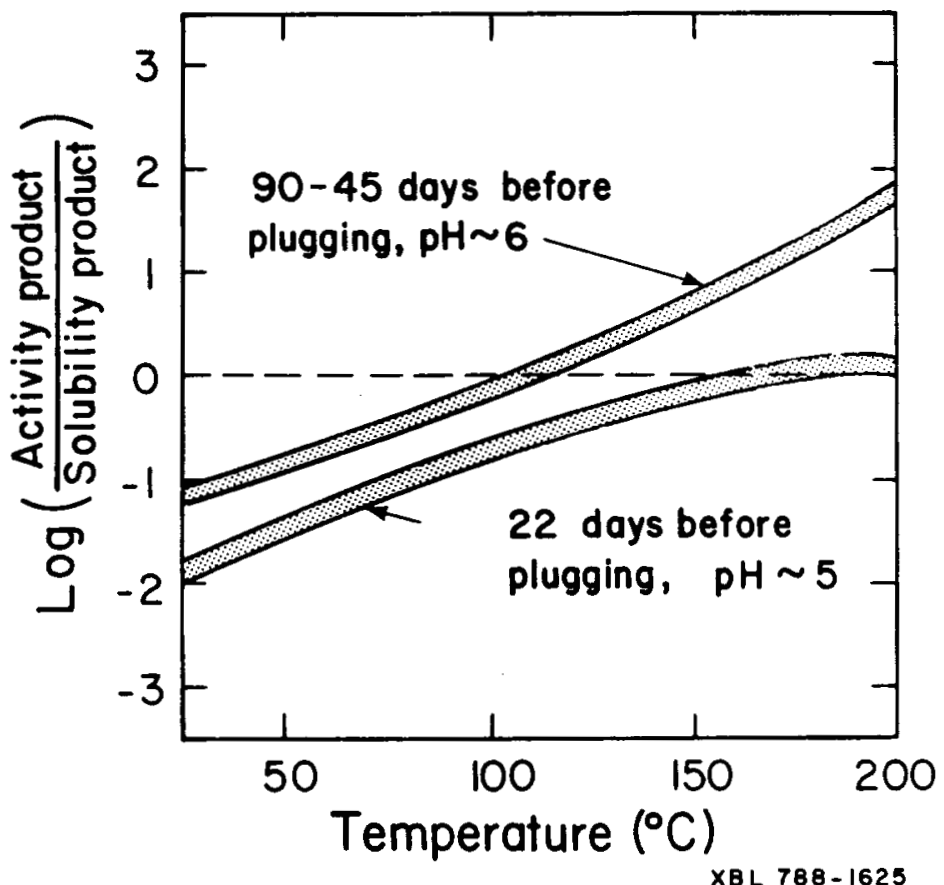

Figure 5.32. Degree of calcite saturation before plugging of wel1 6-1. 
Sometime between 45 and 22 days before the plug was found, the pH changed to $\sim 5$ and the fluid no longer demonstrated such a high calculated downhole calcite supersaturation. This condition was documented by three chemical analyses up to and on the day the well bridge was found (shown by the lower band in the figure).

Scale Formation in the Multistage Flash-Evaporator Plant

In the multistage flash-evaporator (MSF) plant, hot fluid is flashed to steam in a series of three tanks (stages) by the reduction of pressure. Approximately $10 \%$ of the fluid is flashed per cycle through the three stages, and $90 \%$ of the spent fluid is recycled. Recycling is accomplished by reheating the fluid in a series of three heat exchangers. Each heat exchanger is a condenser for the product steam. As much as $60 \%$ of the fluid is converted to fresh water by recycling (Bechtel Corp., 1977a, 1977b).

In the MSF plant, flashing takes place in separator tanks where large thicknesses of carbonate scale can accumulate without restricting flow. The inlet nozzles do require an occasional cleaning with acid, however. In another type of desalting plant tested at East Mesa, using vertical tube evaporators (VTE), flashing takes place on heat exchange surfaces where even thin deposits of scale seriously reduce plant efficiency. The MSF process therefore possesses a major advantage over the VTE when scaling is possible.

Each MSF heat exchanger contains a total of 40 tubes, which are $4.6-\mathrm{m}$ $(15-f t)$ long and $2.29-\mathrm{cm}(0.901-i n \cdot)$ inside diameter. The inner surface of each tube has an area of $3310 \mathrm{~cm}^{2}$. During one test, the flow rate through each tube was $0.15 \mathrm{~kg} / \mathrm{sec}(2.3 \mathrm{gal} / \mathrm{min})$ corresponding to an average flow velocity of $\sim 0.36 \mathrm{~m} / \mathrm{cc}(1 \mathrm{ft} / \mathrm{s})$.

The approximate fluid temperature increase in each heat exchanger was $8.3^{\circ} \mathrm{C}\left(15^{\circ} \mathrm{F}\right)$ as shown in Table 5.15. Scaling on heat-exchange surfaces can be expected by those phases with which the fluid is just saturated as it enters the heat exchanger if also the phases become less soluble as temperature is increased. Only calcite appears to neet both of these criteria. The fluid is probably saturated with calcite because of flashing and because calcite has a retrograde solubility. The decrease in the equilibrium amount 
of calcite (no supersaturation allowed), which can be dissolved by the fluid as 1 it is heated by each successive heat exchanger, is given in Table 5.15 . The calculated average monthly accumulation of calcite scale would be equivalent to a layer $0.1-\mathrm{mm}$ thick, assuming a uniform scale coating.

The heat-exchanger tubes should be expected to be covered with a uniform thickness of calcite over the entire inner surface because of the uniform temmerature gradient. A scale thickness of $0.1 \mathrm{~mm}$ is equal to $10 \%$ of the thickness of the tube wa11. The thernal conductivity of calcite is 15 times less than that of steel. Thus, the calcite layer is easily noticed because it will reduce the heat transfer by approximately half. Observations on scaling of the MSF heat exchangers support these theoretical calculations only in part. The principal scale found was indeed calcite. It was "thin" (no thickness measurements were reported), it was uniformly deposited along all of the tubes, and it decreased the heat transfer $30 \%$ (and increased the heat exchange pressure drop) during the first 30 days of testing. However, silica was also reported in the scale and the heat-transfer coefficient decreased very little during subsequent tests at higher temperatures. (No actual scale analyses were reported; the method of determining the scale composition is not known.)

Table 5.15. Calculated calcite-scale thickness in VTE heat-exchange tubes.

\begin{tabular}{llccc}
$\begin{array}{c}\text { Heat } \\
\text { exchanger } \\
\text { number }\end{array}$ & $\begin{array}{c}\text { Fluid temperature* } \\
\text { In } \\
\left({ }^{\circ} \mathrm{C}\right)\end{array}$ & $\begin{array}{c}\text { Out } \\
\left({ }^{\circ} \mathrm{C}\right)\end{array}$ & $\begin{array}{c}\text { Decrease in } \\
\text { calcite } \\
\text { solubility } \\
(\mathrm{mg} / \mathrm{kg} \text { fluid })+\end{array}$ & $\begin{array}{c}\text { Calculated thick- } \\
\text { ness of monthly } \\
\text { calcite scale } \\
\text { accumulation }(\mathrm{mm}) \neq\end{array}$ \\
\hline 307 & 115 & 124 & 0.26 & 0.13 \\
308 & 124 & 132 & 0.21 & 0.11 \\
309 & 132 & 140 & 0.18 & 0.094 \\
\hline
\end{tabular}

* Average, Bechte1, 1977a, pp. 57, 59, and 61.

+ Helgeson, 1969.

† Based on a calcite density of $3 \mathrm{~g} / \mathrm{cm}^{3}$. 
Silica scale formation cannot be due to simple equilibrium crystalization because silica becomes more soluble with increasing temperature. The form of the silica was not identified, but because the silica concentration in the fluid stream was 600 to $900 \mathrm{mg} / 1$, the fluid was supersaturated with respect to quartz and amorphous silica. Two factors may have contributed to the formation of this silica scale. The nucleation and growth of calcite could have formed surfaces on which colloidal amorphous silica could adhere. The scale in the heat exchangers also contained some iron. This may have been simply contamination of the scale by the tubes-iron carried along by the scale samples when they were chipped off during sampling . On the other hand, the fluid contains some iron in solution at the wellhead and doubtless picks up more during recirculation through the plant. Rapid precipitation of amorphous silica from iron-hydroxide-containing solutions has been previously noted when the silica concentration is in excess of the amorphous silica (Wahl et al., 1975; Fournier and Rowe, 1962) concentration limit of $400 \mathrm{mg} / \mathrm{I}$ at $100^{\circ} \mathrm{C}$ (Figure 5.33 ).

The heat transfer coefficient did not decrease much during the second high temperature test. The tubes were not cleaned between tests, and the second $0.1 \mathrm{~mm}$ of scale layer cannot reduce the heat transfer by the same fraction as the first. Another possibility is that the scale layer did not grow as rapidly during the test at higher temperature because the differential solubility of calcite decreases with increasing temperature.

\section{Scaling in the Vertical-Tube Evaporator Plant}

Fresh water has been produced from geothermal fluids at East Mesa by means of a vertical tube evaporator (VTE) pilot plant. Resembling a tubetype heat exchanger mounted vertically, a VTE can be used with either downward or upward fluid flow. In the East Mesa plant, three evaporators or "effects," as they are called, were used in series. The first two were of the down-flowing type--a film of fluid cascaded down along the inside tube walls. In the third effect, fluid was passed upward and evaporated by a percolating action. In all three effects, steam was introduced to the outside of the tubes, where it condensed, contributing heat to flash the fluid. Each effect obtained steam from the next upstream (hotter) effect and the first effect was heated by steam from the wellhead separator (Bechte1 Corp., 1977a, 1977b). 


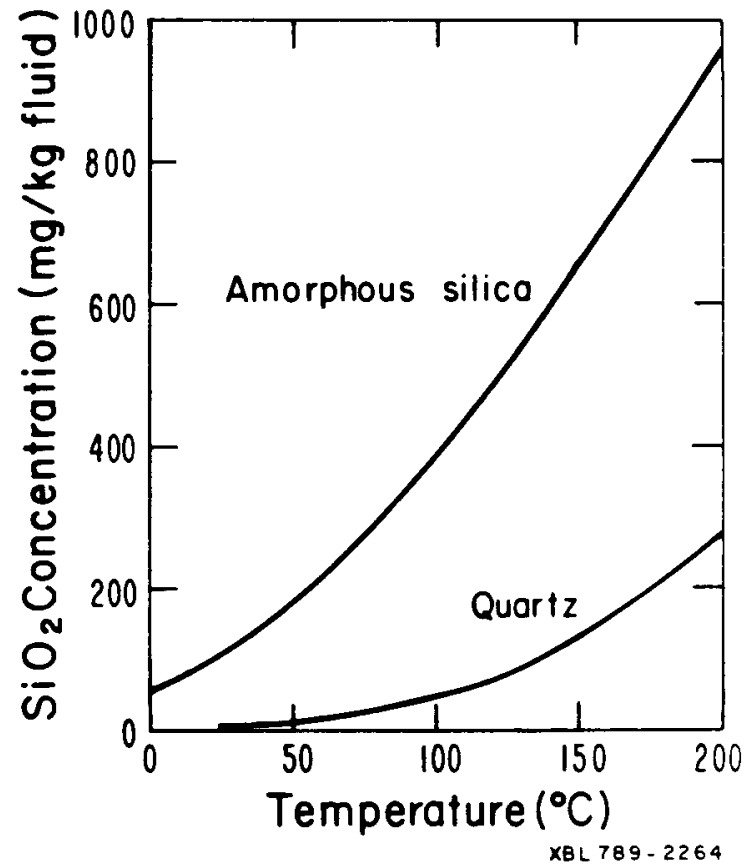

Figure 5.33. Solubility diagram for quartz and amorphous silica (data from Fournier and Rowe, 1962). 
It is essential to prevent scale from forming on the tube wall because it reduces the flow of heat and thus the rate of fresh-water production. Three scale-forming processes take place on the inner surfaces of the tubes, making scale control difficult. Vaporization releases $\mathrm{CO}_{2}$, causing continued $\mathrm{CaCO}_{3}$ supersaturation. Loss of fresh water causes a concentration of salt in the remaining fluid. The fluid cools as it flows through the plant so that minerals that become less soluble at low temperatures may precipitate.

When a single effect was tested for 900 hours in 1974 by flowing fluid from well 6-1 upward through it, a tenacious layer of barite formed inside all of the tubes. When all three effects were operated using 6-1 fluid, $\mathrm{BaSO}_{4}$ formed in all effects, but the scaling was most severe in the lowest temperature effect (E-3). When fluid from well 6-2 was used, no $\mathrm{BaSO}_{4}$ scale was formed in the VTE.

This experience agrees with predictions (shown in Figures 5.10 and 5.12); well 6-1 fluid becomes saturated with $\mathrm{BaSO}_{4}$ during flashing at temperatures below $130^{\circ} \mathrm{C}\left(265^{\circ} \mathrm{F}\right)$, and well 6-2 fluid remains unsaturated with $\mathrm{BaSO}_{4}$ during flashing. The composition of the barite scale was not reported; it is said to have contained "trapped" $\mathrm{SrSO}_{4}$ (Bechtel, 1977a). It seems possible that this is the same ( $\mathrm{Ba}, \mathrm{Sr}, \mathrm{Ca}) \mathrm{SO}_{4}$ phase that was found in the downhole plug . Fluid from well 6-1 is not saturated with $\mathrm{SrSO}_{4}$, yet it appears that $\mathrm{Sr}$ may contribute to scale-forming this solid solution with barite.

As predicted, $\mathrm{CaSO}_{4}$ did not form scale during the use of fluids from either well 6-1 or 6-2.

Quartz supersaturation in all fluids was calculated, which defines a potential for quartz scale formation. Quartz is known to be very slow to form, and we expected to find amorphous-silica scale. We found quartz, which will be discussed later.

During the 900-hour test with well 6-1 fluid, calcite scale was not formed inside the tubes. However, the fluid was flashed to $150^{\circ} \mathrm{C}$ in a wellhead separator before it was passed up through the evaporator. Presumably, most of the available calcite was deposited in the separator and the 
fluid may have become unsaturated with respect to calcite by the time it entered the evaporator due to cooling. This behavior may be similar to that of the fluid from the Namafjall and Svartsengi wells in Iceland, as discussed by Arnorsson (1978).

When fluid from well 6-2 was used without wellhead separation, rapid calcite scaling resulted in the evaporator tubes. In order to overcome this serious problem, well 6-2 fluid was flashed to $140^{\circ} \mathrm{C}$ in a separator before use--a strategy which appears to have been only partly successful because the use of calcite scale inhibitors was tested extensively during the next year. Without inhibitors, 70 to $90 \%$ of the $\mathrm{Ca}$ is reported to have been deposited as calcite in the separator. The addition of $10 \mathrm{mg} / 1$ of thresholdtype scale inhibitor upstream of the separator greatly reduced calcite scaling in the separator (Bechtel, 1977a). Scaling on heat-transfer surfaces was also said to be reduced by the use of scale inhibitors, but this is not certain due to lack of baseline data showing the heat-transfer coefficient using flashed fluid without additives.

Thirteen minerals have been identified in scales of the VTE plant when it was operated on flashed 6-2 fluid from March to June 1976. During this period, all three effects were used and the tubes were made of smooth titanium. The principal objective of these tests was to evaluate various scale inhibitors. Nineteen samples of scale were taken for $x$-ray and chemical analysis. The results are included in Appendix $F$.

There seems to be no relation between the scale inhibitor used and the scale mineralogy. In order to find trends of scale mineralogy with temperature (with the hope of casting some light on the occurrence of silica scales) the minerals are tabulated in terms of the temperature zones in which they were found (Table 5.16).

The principal scale-forming minerals are calcite, magnetite, and aragonite $\left(\mathrm{CaCO}_{3}\right.$, a polymorph of calcite). One sample contained a major amount of noncrystalline material, presumably amorphous silica. Most of the samples that contained iron oxides in abundance were taken from the head or bottom plates of the evaporators (which were made of stee1). Thus these minerals are probably corrosion products rather than phases precipitating from the fluid. 
Table 5.16. Scale distribution in the VTE using well 6-2 fluid.

\begin{tabular}{|c|c|c|c|c|c|c|c|c|c|}
\hline \multirow[b]{2}{*}{ Scale minerals $\ddagger$} & \multicolumn{3}{|c|}{$\begin{array}{l}\text { Presence } \\
\text { Major }\end{array}$} & \multicolumn{2}{|c|}{$\begin{array}{r}\text { temperature } \\
\text { Moderate }\end{array}$} & \multicolumn{3}{|c|}{ zones (effects) } & \multirow[b]{2}{*}{$E-3$} \\
\hline & $\mathrm{E}-1^{\dagger}$ & $\mathrm{E}-2$ & $E-3$ & $E-1$ & $\mathrm{E}-2$ & $E-3$ & $E-1$ & $\mathrm{E}-2$ & \\
\hline Calcite & $00++o$ & $+\infty$ & + & & & + & ... & + & 0 \\
\hline Magnetite & oooot & + & + & & & & + & + & .t \\
\hline Quartz & ... & + & & - & & + & ott & + & + \\
\hline Aragonite &.+ & & & & & + & & & \\
\hline Hematite & & & + & & & & H+oo & Hoo & .t \\
\hline Feldspar & & & & & & & + & + & + \\
\hline Halite & & & & & & & $\ldots+$ & + & + \\
\hline Noncrystalline & & & - & & & & & & \\
\hline Maghemite & & & + & & & & $\bullet++$ & + & \\
\hline Dolomite & & & & & & & $\cdots$ & & \\
\hline Magnesite & & & & & & & $\cdots$ & & \\
\hline Siderite & & & & - & & & - & & \\
\hline Clay & & & & & & & $H$ & + & \\
\hline
\end{tabular}

* See Appendix E.

+ Temperature in $\mathrm{E}-1$ was $120^{\circ} \mathrm{C}, \mathrm{E}-2$ was 110 to $120^{\circ} \mathrm{C}$, and $\mathrm{E}-3$ was 100 to $110^{\circ} \mathrm{C}$.

† Identified by $x$-ray diffraction.

- Plant running at a concentration factor of 2.

+ Plant running at a concentration factor of 3 .

o Plant running at an unknown concentration factor.

Major amounts of quartz seem to occur more frequently (compared with calcite) in the highest-temperature $\left(120^{\circ} \mathrm{C}\right)$ effect, and the sample with major concentrations of amorphous silica was taken from E-3, the lowest-temperature $\left(100^{\circ} \mathrm{C}\right)$ effect. Major amounts of quartz were not found in E-3. Quartz was also found in scale scraped from well 6-1 after it had plugged. Scale sampled by Wahl (1975) downstream from the 6-1 separator was a black glass with an Fe/Si atom ratio of 1 , which is similar to glass found at the Salton Sea geothermal field. Quartz has not been found in the scales formed by the very hot fluids from the Salton Sea field, and it was not expected at East Mesa.

It is possible that this quartz did not precipitate from the fluid but was carried as sand grains from the reservoir to be trapped in the scale. Indeed, feldspar was a pervasive minor "scale" mineral in all effects, an observation that can also be explained by this mechanism. The occurrence of insects in one scale sample (Appendix F) shows that samples could have been contaminated by wind-blown minerals. 
In any case, silica scaling was not a significant problem, for at the conclusion of each of these tests the scale could be cleaned out of the evaporator tubes with acid. The rate of scaling was slow; it was estimated that a full-sized VTE desalting plant would have to be cleaned only yearly if it were designed to handle a certain amount of scale.

A striking acceleration in the rate of scaling was observed when the smooth $T i$ tubes were replaced by fluted $T i$ tubes in a final VTE test. Af ter only four days, the heat transfer decreased by half--more than projected for a year of operation with smooth-wall $\mathrm{TI}$ tubes. The scale was reported to be "more than 80 percent silica," and difficult to remove (Wahl, 1975). It is not known if this scale was amorphous silica or quartz, and the actual chemical composition has not been published.

The reason for this rapid formation of silica scale is puzzling. It has been assumed that silica scale starts to form when the silica concentration exceeds $500 \mathrm{mg} / 1$, corresponding to a concentration factor of $\sim 2.5$ at East Mesa. This is saturated with respect to amorphous silica at $130^{\circ} \mathrm{C}$, as shown in Figure 5.33. During testing of fluted Ti tubes, the silica concentration in the second effect was as high as $520 \mathrm{mg} / 1$ and the spent fluid at the end of the third effect (blown down) reached $813 \mathrm{mg} / 1$. However, the highest measured concentration of silica in the first effect was 428 $\mathrm{mg} / 1$, and the average of 13 daily measurements was $342 \mathrm{mg} / 1$. The rate of scale formation in all three effects was approximately equal, based on the measured decrease in heat-transfer coefficient. The addition of $\mathrm{NaOH}$ to the fluid in the third effect maintained a high heat-transfer coefficient by preventing silica-scale formation (USBR, 1977b).

The growth rate of scale (silica?) has been estimated as $0.022 \mathrm{~mm} /$ day $(0.00087 \mathrm{in} . /$ day) based on the rate of decrease of heat transfer. This rate is from 1 to $10 \%$ of the maximum rate of scaling that would have occurred with equilibrium precipitation of silica due to the temperature drop through the effects.

The increased surface area of the fluted tubes no doubt resulted in a higher inftial heat flux and vaporization rate than observed for smooth tubes. Perhaps very high local silica concentrations resulted. The initial rate of scaling with fluted tubes was so rapid that no values of heat transfer were observed corresponding to what was expected for clean tubes. 
The correct explanation for this unexpected and serious silica scaling may be discovered with more experience at East Mesa and from results of the recent experimental work on the kinetics of silica precipitation by 0 .Weres, LBL, and by H.Barnes (unpub1. data; Phillips et a1., 1977). Examination of the scale by scanning electron microscopy might also be helpful.

\section{Scaling During Transport and Injection of Spent Fluids}

Injection of spent geothermal fluids into the East Mesa geothermal reservoir is necessary in order to avoid expensive surface ponding, to prevent subsidence of the ground surface, to maintain reservoir pressure and production, and to increase the fraction of the heat energy in the reservoir that can be recovered. (The reservoir is $\sim 80$ volume-percent rock, which contains $44 \%$ of the enthalpy of the reservoir.)

Well 5-1 was selected as the injection well because it is at the edge of the field. The temperature at the bottom of we $115-1$ was $170^{\circ} \mathrm{C}\left(335^{\circ} \mathrm{F}\right)$ before injection of spent brine began. This well is located $2.1 \mathrm{~km}(1.4$ miles) northeast of the East Mesa Test Site, to which it is connected by a buried asbestos-cement pipeline 25.4-cm (10-in.) in diameter. Fluid is pumped through this pipeline by a transfer pump at the test site. A second high-pressure injection pump is located at the 5-1 wellhead.

Appoximately $89,000 \mathrm{~m}^{3}\left(2.3 \times 10^{7} \mathrm{gal}\right)$ of fluid were injected into well 5-1 before January 1977. One-third of this came from the storage pond and two-thirds came from wells $6-1$ and $6-2$, as shown in Table 5.17.

Table 5.17. Volume of fluid injected into well 5-1.

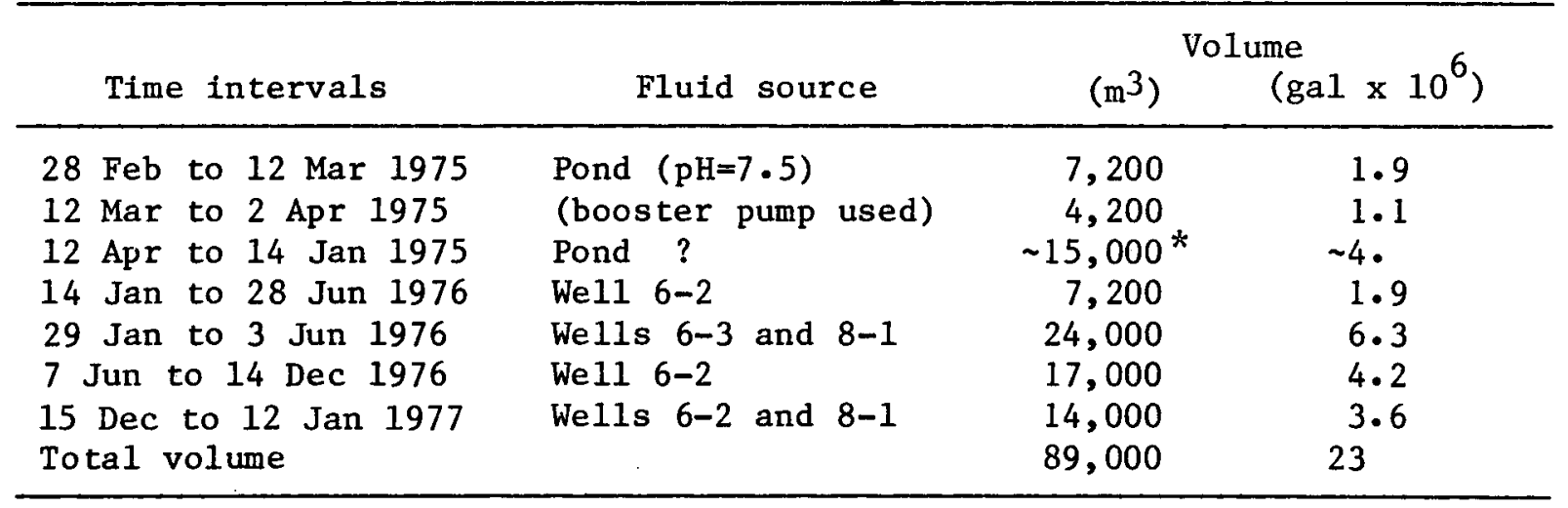

* Estimate based on a $3.21 / \mathrm{sec}(\sim 50 \mathrm{gal} / \mathrm{min})$ flow rate for 40 hours each week (USBR, 1977a, p. 47). 
During early 1976, well 6-2 was produced for the principal purpose of testing the capacity of well 5-1 for injection. The chemical composition of fluids sampled at three key locations during the production, flashing, and injection of fluid from well 6-2 is shown in Table 5.18. Sampling at all three locations was repeated on three consecutive days $(26,27$, and 28 January 1976).

The Ca concentration decreased $-50 \%$ and the $\mathrm{Na}$ concentration increased $15 \%$ as the fluid passed from the pipeline sampling point to the sampling point at the injection transfer pump. These changes in concentration are the result of flashing. Some $36 \mathrm{~kg}$ of calcite probably accumulated at the flash points in the system and the separator during January 1976 when $7260 \mathrm{~m}^{3}$ of fluid was flashed before being injected. Unfortunately no measurements of the rate of calcite accumulation were made during this period to confirm this estimate.

The flashed fluid cooled $10^{\circ}$ to $20^{\circ} \mathrm{C}$ during the 5 hours it took to flow through the $2.1-\mathrm{km}-$ long pipeline from the test site to the injection well. Because of the increasing solubility of calcite with decreasing temperature, the calcite-saturated fluid that left the test site should have arrived at the injection well unsaturated. However, this was not the case because filters at the injection well were plugged by calcite. In addition, the chemical composition of the spent fluid at the wellhead shown in Table 5.18 indicates that calcite and quartz were supersaturated, based on the data of Helgeson (1969). (The activity-product to solubility-product ratio for calcite is calculated to be 1.4.)

Saturation of the fluid with respect to calcite may have been due to the entrainment of small calcite crystals.

Calcite precipitation can be expected as the injected fluid is heated by the hot rocks in the reservoir. Soon after the start of injection, the fluid will be heated within the well, particularly when the flow rate is low. Once the well has been cooled, the injected fluid will be heated within the reservoir.

There are many factors that can change the permeability of the reservoir during injection. Factors that tend to plug up the reservoir are the 
Table 5.18. Chemistry of reinjection of well 6-2 fluid during 1976 (three-day sampling, $100 \mathrm{gal} / \mathrm{min}$ flow rate).

\begin{tabular}{|c|c|c|c|c|}
\hline & \multicolumn{4}{|c|}{ Sampling location } \\
\hline & & $\begin{array}{l}\text { "Unflashed" } \\
\text { pipeline }\end{array}$ & $\begin{array}{l}\text { Injection } \\
\text { transfer pump }\end{array}$ & $\begin{array}{l}\text { We11head } \\
\text { tank }(5-1)\end{array}$ \\
\hline $26 \mathrm{Jan}$ & $\begin{array}{l}\text { Temp }\left({ }^{\circ} \mathrm{C}\right) \\
\mathrm{pH} \\
\mathrm{TDS}(\mathrm{mg} / 1) \\
\mathrm{Ca} \quad(\mathrm{mg} / 1) \\
\mathrm{Na} \quad(\mathrm{mg} / 1) \\
\mathrm{HCO}_{3}(\mathrm{mg} / 1) \\
\mathrm{SiO}_{2}(\mathrm{mg} / 1)\end{array}$ & $\begin{array}{c}170 \\
6.2 \\
3860 \\
5.0 \\
1306 \\
595 \\
240 *\end{array}$ & $\begin{array}{c}73 \\
9.4 \\
4560 \\
3.0 \\
1542 \\
383 \\
158 \star\end{array}$ & $\begin{array}{c}52 \\
9.3 \\
4620 \\
2.6 \\
1546 \\
458 \\
150 *\end{array}$ \\
\hline $27 \mathrm{Jan}$ & $\begin{array}{l}\text { Temp }\left({ }^{\circ} \mathrm{C}\right) \\
\mathrm{pH} \\
\mathrm{TDS}(\mathrm{mg} / 1) \\
\mathrm{Ca}(\mathrm{mg} / 1) \\
\mathrm{Na}(\mathrm{mg} / 1) \\
\mathrm{HCO}_{3}(\mathrm{mg} / 1) \\
\mathrm{SiO}_{2}(\mathrm{mg} / 1)\end{array}$ & $\begin{array}{c}170 \\
6.1 \\
3920 \\
4.8 \\
1317 \\
623 \\
191 *\end{array}$ & $\begin{array}{c}79 \\
9.2 \\
4580 \\
2.4 \\
1534 \\
462 \\
152 \star\end{array}$ & $\begin{array}{c}66 \\
9.1 \\
4540 \\
2.0 \\
1524 \\
464 \\
147 \star\end{array}$ \\
\hline $28 \mathrm{Jan}$ & $\begin{array}{l}\text { Temp }\left({ }^{\circ} \mathrm{C}\right) \\
\mathrm{pH} \\
\mathrm{TDS}(\mathrm{mg} / 1) \\
\mathrm{Ca}(\mathrm{mg} / 1) \\
\mathrm{Na}(\mathrm{mg} / 1) \\
\mathrm{HCO}_{3}(\mathrm{mg} / 1) \\
\mathrm{SiO}_{2}(\mathrm{mg} / 1)\end{array}$ & $\begin{array}{c}170 \\
6.2 \\
3880 \\
5.0 \\
1314 \\
611 \\
221 \star\end{array}$ & $\begin{array}{c}76 \\
9.3 \\
4560 \\
1.8 \\
1540 \\
449 \\
152 *\end{array}$ & $\begin{array}{c}68 \\
9.1 \\
4580 \\
2.6 \\
1542 \\
461 \\
152 \star\end{array}$ \\
\hline
\end{tabular}

* Note loss of $\mathrm{SiO}_{2}$ at $\mathrm{T}>80^{\circ} \mathrm{C}$ and no less at $\mathrm{T}<80^{\circ} \mathrm{C}$, in spite of slow cooling in pipeline.

precipitation of calcite and alteration of reservoir mineralogy that result in a net volume increase (Figure 5.31). Factors that tend to increase the permeability are dissolution of silica and alteration of reservoir minerals that result in net volume decreases.

If chemical equilibrium were the only consideration, the volume of silica that would be dissolved by the injection of cool fluid (as it is heated by the reservoir) would exceed the volume of calcite that can be deposited due to the same change in temperature. In fact, injected fluid is not at equilibrium with silica but contains a considerable excess due to the slow rate of silica precipitation at low temperatures. One cannot overlook the possibility that coprecipitation of silica and calcite can take place in 
the reservoir as the fluid is heated, but before it is hot enough to be undersaturated with silica (behavior similar to that observed in the MSF heat exchangers). It is a good idea to reduce the silica concentration of injection fluids to as low a value as possible.

Changes in reservoir permeability are not directly related to the amount of solid that is added or removed any more than permeability is related to porosity. It is the way solution or deposition changes the geometry of fluid flow that is important, and this is presently an unknown factor.

\section{Preclpitation of Scale-Forming Minerals in Fluid-Mixing Experiment}

In this report, we have pointed out that fluids from many wells will have to be mixed in order to develop the East Mesa field. We have also shown the theoretical scale-forming potential that resulted from mixing. In this section we report on laboratory experiments in which the amounts and kinds of scale formed as a result of mixing were measured. (This work was done at East Mesa before the current contract.)

Before to collecting samples for these mixing tests, wells $31-1$ and 8-1 were flowed for 24 hours through a 5-cm-diam pipeline $\sim 24 \mathrm{~m}$ long. We11 6-1 was flowing at a very low rate for 3 to 4 days, and 6-2 was flowed for several months at $3801 / \mathrm{min}$.

Approximately 5.7 liters of unflashed, "flashed-at-the-wellhead," and "pipeline-flashed" fluid samples were taken at each well. The unflashed fluid was taken using the usual cooling-coll method; the wellhead-flashed fluid sample was taken without a cooling coil; and the pipeline-flashed sample was taken from the end of the 5-cm pipeline for wells $31-1$ and $8-1$. For well 6-1, the pipeline-flashed sample was taken from the open flash tank in use on the well. A pipeline-flashed sample of well 6-2 was obtained from the line after the separator. These two kinds of flashed-fluid samples were taken because the degree of flashing is not related to the length of pipe through which the fluid flows, and can indicate scale deposition along the pipe. The sample of Salton Sea water used in the mixing experiments was collected about $1.6 \mathrm{~km}$ offshore at a depth of $3 \mathrm{~m}$. The sample had a conductivity of 60,000 umhos and a $\mathrm{pH}$ of 8.2. (Similar values were measured for five other water samples taken in the southeastern portion of the Salton Sea.) 
A 400-ml sample of each kind of well fluid from the four wells and from the Salton Sea was set aside as a standard. By this means, the amount of precipitation resulting from mixing could be compared with the amount formed wi thout mixing •

Fluids were mixed in equal amounts to make up a total volume of $800 \mathrm{ml}$. Well fluids were mixed while still above ambient temperature. After standing for 24 hours under ambient conditions, each container was examined and any precipitate that had formed was filtered, dried in an oven at $110^{\circ} \mathrm{C}$, and weighed. Most of the precipitates were investigated by $\mathrm{x}$-ray diffraction and the results are given in Table 5.19.

The flashed samples from well 6-1 were gray-black colored and had a black precipitate. After standing for about one hour, the fluid became yellow and a yellow precipitate formed; it was mostly calcite. Another sample was taken at the well and filtered during the gray-black phase. A black precipitate was obtained on the filter paper. Upon drying the filter paper in the oven, the fluid became yellow, and the precipitate gave a positive test for $\mathrm{Fe}^{3+}$ and a negative test for $\mathrm{So}_{4}^{2-}$. During this same period, well 6-1 fluid was used in a heat exchanger where a black precipitate formed. About $20 \%$ of this precipitate was magnetic and assumed to be magnetite. The remainder contained FeS-ZnS.

Unflashed fluid from well 6-1 was clear but with a yellow tint. After boiling for two minutes a yellow precipitate formed, equivalent in concentration to $70 \mathrm{mg} / 1$; it was identified as calcite.

The occurrence of quartz and sphalerite in flashed we11s 6-2 and 8-1 fluids but not in well 6-1 may only mean that the larger quantity of calcite found in well 6-1 hid these less abundant minerals.

Quartz, although predicted by equilibrium calculations, was not expected. This has been discussed in connection with the identification of quartz in the VTE scale and in scale from within the 6-1 wellhole. In only one $x$-ray pattern did we find broad peaks associated with amorphous silica. It probably was not a major phase in these precipitates. 
Table 5.19. Amounts and kinds of precipitates formed by sampling and mixing fluids.

\begin{tabular}{|c|c|c|c|}
\hline Sample & $\begin{array}{l}\text { Unflashed } \\
(\mathrm{mg} / 1)\end{array}$ & $\begin{array}{l}\text { Wellhead flashed } \\
(\mathrm{mg} / 1)\end{array}$ & $\begin{array}{c}\text { Pipeline flashed } \\
(\mathrm{mg} / 1)\end{array}$ \\
\hline $\begin{array}{l}6-1 \\
6-2 \\
31-1 \\
8-1\end{array}$ & $\begin{array}{l}\text { clear } \\
\text { clear } \\
\text { clear } \\
\text { clear }\end{array}$ & $\begin{array}{l}14 \mathrm{C} \\
2 \mathrm{Q}, \mathrm{C}, \mathrm{S} \\
\text { clear } \\
\text { trace }\end{array}$ & $\begin{array}{c}27 \mathrm{C} \\
3 \\
\text { clear } \\
\text { trace } \\
\mathrm{C}, \mathrm{Q}, \mathrm{H}\end{array}$ \\
\hline $\begin{array}{l}S S+, 6-1 \\
S S, 6-2 \\
S S, 8-1 \\
S S, 31-1\end{array}$ & $\begin{array}{l}22 \mathrm{~B} \\
\text { clear } \\
\text { clear } \\
\text { clear }\end{array}$ & $\begin{array}{l}58 \mathrm{~B} \\
27 \mathrm{C}, \mathrm{B} \\
\text { clear } \\
\text { clear }\end{array}$ & $\begin{array}{l}\text { 63B } \\
\text { clear } \\
30 \mathrm{C} \\
30 \mathrm{C}\end{array}$ \\
\hline $\begin{array}{l}6-1,6-2 \\
6-1,8-1 \\
6-1,31-1 \\
6-2,8-1 \\
6-2,31-1 \\
8-1,31-1\end{array}$ & $\begin{array}{l}\text { clear } \\
\text { clear } \\
22 \mathrm{C}, \mathrm{B} \\
\text { clear } \\
\text { clear } \\
\text { clear }\end{array}$ & $\begin{array}{l}95 \mathrm{C}, \mathrm{B} \\
69 \mathrm{C}, \mathrm{B} \\
88 \mathrm{C}, \mathrm{B} \\
\text { clear } \\
\text { trace } \\
\text { trace }\end{array}$ & $\begin{array}{c}88 \mathrm{C} \\
166 \mathrm{C}, \mathrm{B} \\
123 \mathrm{C} \\
4 \\
\text { clear } \\
2 \mathrm{H}\end{array}$ \\
\hline $\begin{array}{l}6-1,6-2,8-1 \\
6-1,6-2,31-1 \\
6-1,8-1,31-1 \\
6-2,8-1,31-1\end{array}$ & $\begin{array}{l}\text { clear } \\
\text { cloudy } \\
\text { trace } \\
\text { clear }\end{array}$ & $\begin{array}{c}38 \mathrm{C}, \mathrm{B} \\
122 \mathrm{C}, \mathrm{B} \\
96 \mathrm{C} \\
2\end{array}$ & $\begin{array}{c}141 \mathrm{C} \\
\neq \\
155 \mathrm{C} \\
2\end{array}$ \\
\hline $6-1,6-2,8-1,31-1$ & clear & $90 \mathrm{C}, \mathrm{B}$ & $110 \mathrm{C}$ \\
\hline
\end{tabular}

* X-ray identification by H. Ruben, LBL, 1977, as follows:

$$
\begin{aligned}
& \mathrm{C}=\text { calcite }\left(\mathrm{CaCO}_{3 \mathrm{E}}\right) \\
& \mathrm{Q}=\text { quartz }\left(\mathrm{SiO}_{2}\right) \\
& \left.\mathrm{B}=(\mathrm{Ba}, \mathrm{Sr}) \mathrm{SO}_{4}\right) \\
& \mathrm{H}=\text { hematite }\left(\mathrm{Fe}_{2} \mathrm{O}_{3}\right) \\
& \mathrm{S}=\text { sphalerite }(\alpha+\beta \mathrm{ZnS}) .
\end{aligned}
$$

+ SS $=$ Salton Sea water.

$\neq$ Not tested. 


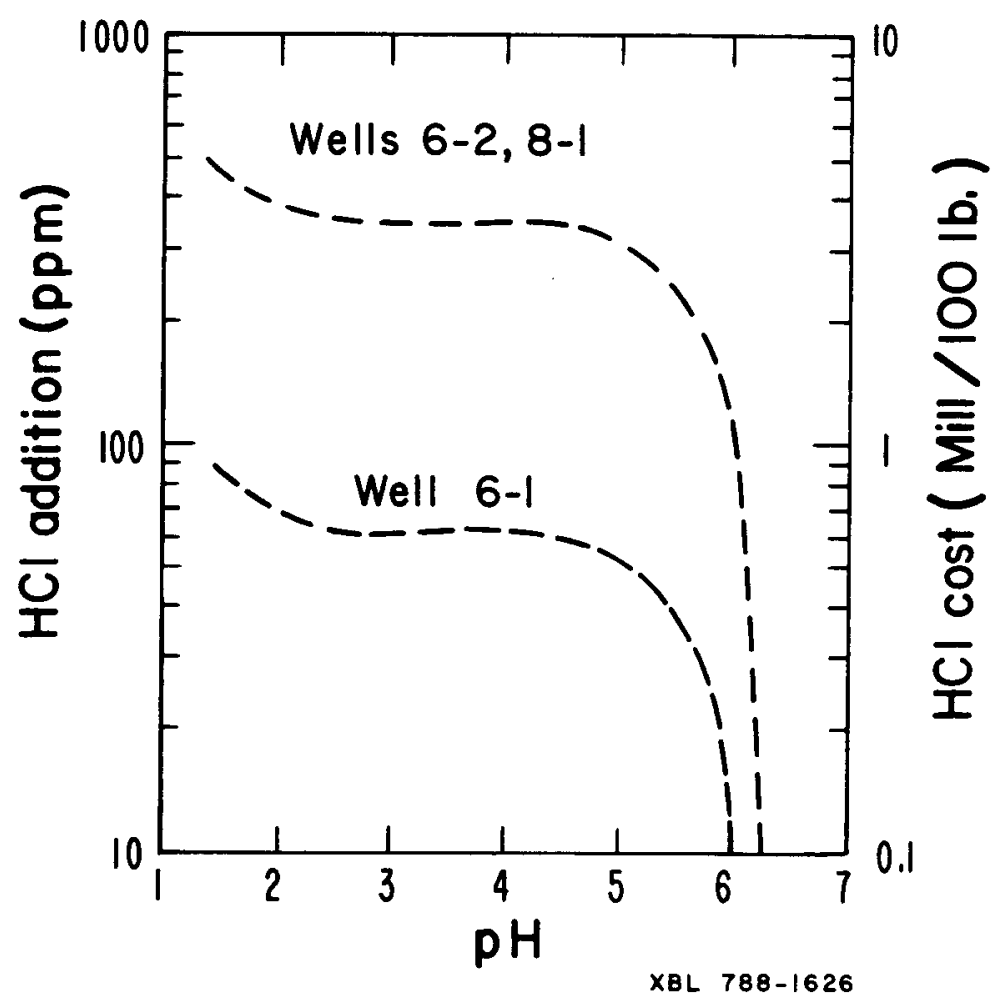

Figure 5.34. Calculated titration curves for East Mesa fluids. 
The general trends observed in these mixing experiments are in agreement with predictions. The amount of precipitate formed by mixing is greater than that formed by the component fluids themselves. Fluid from well 6-1 appears to be incompatible with the other fluids. Fluids from wells $6-2,8-1$, and 31-1 have very similar scaling tendencies. The major minerals that were observed to form are the minerals predicted from calculations - with a few exceptions. Salton Sea water was predicted to be saturated with gypsum and anhydrite. Even when boiled for several minutes to increase the degree of supersaturation, neither mineral precipitated.

The geothermal fluids were calculated to be saturated both with FeS and $\mathrm{ZnS}$. However, because of the questionable significance of the iron analyses of geothermal fluids produced from iron pipes, and because of the very small concentration of $\mathrm{Zn}(0.1 \mathrm{mg} / 1)$ the amounts calculated to form were not considered to be significant. The occurrence of a mineral with the sphalerite structure, in amounts that were detectable by $x$-ray diffraction, was unexpected. The chemical composition of this phase should be determined.

\section{SCALE CONTROL}

The most effective first step in scale control is knowing the chemistry and structure of the scales that form, the rate at which they form, and where they form under known conditions of well flow rate, temperature, and pressure. With our present knowledge, we can suggest certain measures for reducing scaling and plugging.

Prevention of carbonate-scale formation in flashing geothermal fluids can be accomplished by adding acid. Hydrochloric acid (HC1) is preferred over less expensive sulfuric acid $\left(\mathrm{H}_{2} \mathrm{SO}_{4}\right)$ in order to avoid aggravated sulfate precipitation. The amount that must be added to East Mesa fluids to prevent calcite scaling upon flashing is the amount necessary to lower the $\mathrm{pH}$ to $\sim 4$. For well $6-1$ this is $60 \mathrm{mg} / 1 \mathrm{HCl}$ (Figure 5.34). The cost would be $0.6 \mathrm{mill} / 100 \mathrm{lb}$ of fluid if $\mathrm{HCl}$ costs $\$ 0.10 / 1 \mathrm{~b}$. Wells $6-2,8-1$, and $31-1$ contain considerably more $\mathrm{HCO}_{3}$ - than well 6-1, and calcite-scale prevention requires $\sim 400 \mathrm{mg} / \mathrm{HCl}$, at a cost of $4 \mathrm{mill} / 100 \mathrm{lb}$. This is probably far too expensive and other ways must be explored to prevent scaling in these high-bicarbonate brines. 
Carbonate scale inhibition by the use of phosponate-type materials, particulary "Dearborn 8010" was explored by Bechtel (1977a). They concluded that although longer term testing was needed, 10 to $12 \mathrm{mg} / 1$ added to unflashed well 6-2 fluid reduced scaling in the vertical-tube evaporator. The cost of this inhibitor is 1 mill/100 $\mathrm{lb}$ of fluid.

Thus, the cost of carbonate-scale prevention by acidification is more than the cost of phosphonate inhibitors in high- $\mathrm{HCO}_{3}^{-}$wells. In well 6-1 the reverse may be true, but no experimental work has been done. However, inhibitors probably only delay scaling and it may occur later in the formation, where it is inaccessible.

Removal of carbonate scale by thermal shock was demonstrated in small heat exchangers by Wahl et al . (1975) and Phillips et al . (1977), but further work is needed to find out whether it would be practical to subject larger equipment to such treatment.

Silica scaling can generally be avoided by keeping the concentration of $\mathrm{SiO}_{2}$ below $-500 \mathrm{mg} / 1$. This rule is based on experience but it can be rationalized by the following facts: the rate of precipitation of silica at temperatures below $130^{\circ} \mathrm{C}$ tends to be slow compared with the time a fluid remains in most processing equipment; amorphous silica, not quartz, is usually precipitated during the production and processing of geothermal fluids; and the solubility of amorphous silica at $130^{\circ} \mathrm{C}$ is $500 \mathrm{mg} / 1$ compared to a quartz solubility of $90 \mathrm{mg} / 1$ at the same temperature (Figure $5.33)$.

This rule appears to have been violated at East Mesa during the testing of fluted $T i$ tubes in the VTE when rapid silica scaling occurred at $T$ $\leq 110^{\circ} \mathrm{C}$ from fluids containing $\leq 500 \mathrm{mg} \mathrm{SiO} 2 / 1$. It is not known if this scale was amorphous silica or quartz. During earlier experiments (also using well 6-2 fluid but with smooth Ti tubes in the VTE) quartz was found in the scale although the rate of deposition was slow. Quartz was also discovered in scale from deep in the 6-1 well and in laboratory mixing experiments (Table 5.19). It is possible that this quartz came from the reservoir as solid particles rather than in solution. Further studies of these scales need to be made to learn the origin of the quartz. 
Plugging of the geothermal reservoir during injection of spent fluids can also be considered to be a scaling problem. It may be prevented by the removal of all particulate matter and as much dissolved calcite and silica as possible at the surface. Calcite is removed by flashing and silica may be removed (to a certain extent) in the holding pond, if the residence time is long and where the formation of other precipitates can form nuclei for accelerated silica precipitation.

Removal of $\mathrm{SiO}_{2}$ by the addition of $\mathrm{Ca}(\mathrm{OH})_{2}$ to precipitate calcium silicates is a well-known and reliable method, but it is probably too expensive for this application.

\section{CONCLUSIONS AND RECOMMENDATIONS}

The chemical composition of fluid produced from each East Mesa well of ten varied from sample to sample. The variability was greatest for the scale-forming elements $\mathrm{Ca}, \mathrm{C}, \mathrm{Sr}, \mathrm{Ba}, \mathrm{Fe}$, and $\mathrm{S}$. These changes showed no clear trends with time or with the total volume of fluid taken from a given we11.

The main reason for this variability was probably the formation of scale in the well and in the sampling tube. Scale can cause either an increase or decrease in the concentration of some elements in the fluid depending upon whether scale is forming or dissolving. This causes considerable difficulties in predicting the scale-forming potential of geothermal fluids. The samples on which the predictions are based are not representative of the reservoir because of the formation of the very scales being predicted.

Relations among scaling, fluid composition, flow rate in the well, fluid temperature, and fluid pressure may be postulated, but they must be systematically explored. As yet no well testing dedicated to this purpose has been done; this is needed. Continuous on-line measurements of as many variables as possible, including conductivity, $\mathrm{pH}$, and $\mathrm{CO}_{2}$ concentration, would be helpful in this task.

Downhole scaling and plugging have been troublesome in well 6-1. On two occasions the well plugged at a depth of $\sim 1820 \mathrm{~m}$. This problem appears to be the result of mixing of incompatible fluids in the wells. 
The presence of various fluids in the East Mesa reservoir was first indicated by the striking difference of we11 6-1 fluid (20,000 mg/1 TDS) from other well fluids ( 2000 to $5000 \mathrm{mg} / 1 \mathrm{TDS}$ ). When the initial producing zone of well 6-2 was extended upward, the salt concentration of the fluid doubled. New evidence for downhole scaling due to the mixing of different fluids was the high degree of calcite supersaturation found in well 6-1 fluid before the well plugged.

In order to confirm this mechanism for downhole scaling, samples of fluids should be taken as a function of depth within producing zones. This information, in addition to detailed chemical analyses of downhole scale, can be used to design scale-prevention techniques. It is possible, for example, that periodic injections of small amounts of $\mathrm{HCl}$ or other chemicals at the bottom of wells will prevent downhole plugging.

If incompatible fluids are found, and if downhole chemical modification is too costly, methods should be considered to produce these fluids separately.

When all East Mesa wells are flashed, immediate calcite supersaturation results. Less than $5^{\circ} \mathrm{C}$ cooling, due to flashing, is all that is necessary. Because of the very small amount of flashing necessary for supersaturation, calcite scale forms in limited zones--it does not pervade fluid-processing equipment when formed by this mechanism.

Bechtel experiments showed that the formation of flash-induced scaling was inhibited by the use of phosphonate additives to well 6-2 fluid. The cost was $1 \mathrm{mill} / 45 \mathrm{~kg}(100 \mathrm{lb})$ of fluid. Carbonate scale formation can probably be prevented in flashing well 6-2 fluid by the addition of HCl at cost of $3 \mathrm{mill} / 45 \mathrm{~kg}$ of fluid. The cost for carbonate scale prevention in well $6-1$, by $\mathrm{HCl}$, would be less $(\sim 0.6 \mathrm{mill} / 45 \mathrm{~kg})$. The Bechtel results need to be confirmed by longer term testing and $\mathrm{HCl}$ addition should be tested.

Calcite scaling is not expected during production and use of East Mesa fluids as long as flashing is avoided, for example by using pressurized heat exchangers and downhole pumps.

All East Mesa fluids are saturated with quartz at formation temperature, and they become gradually supersaturated with quartz as they cool. Thus, in principle, quartz scale should pervade the walls of wells, pipes, and geothermal plants. Practical experience in other geothermal areas shows 
that amorphous silica rather than quartz is the scale former in silica-rich fluids. Furthermore, amorphous silica scale forms only when the silica concentration exceeds the saturation value for quartz many times (the factor increases with decreasing temperature as shown in Figure 5.33). The discovery of quartz in scales at East Mesa is therefore puzzling. The microstructure of quartz-bearing scales should be studied to be certain that the quartz came from solution and was not simply sand grains carried in the fluid.

According to our calculations, well 6-1 fluid becomes supersaturated with respect to $\mathrm{BaSO}_{4}$ at $\mathrm{T}<75^{\circ} \mathrm{C}$; when concentrated by flashing this supersaturation occurs at $\mathrm{T}<125^{\circ} \mathrm{C}$. This is in agreement with the occurrence of $\mathrm{BaSO}_{4}$ scale in the VTE. The scale that formed the plugs deep in well 6-1 probably contained a mineral with the composition $\mathrm{Ba}_{0 .} \mathrm{Sr}_{0.4} \mathrm{Ca}_{0.1} \mathrm{SO}_{4}$. We did not expect this, for two reasons: the temperature was too high for $\mathrm{BaSO}_{4} \mathrm{satura-}^{-}$ tion, and the fluid is undersaturated with respect to both $\mathrm{SrSO}_{4}$ and $\mathrm{CaSO}{ }_{4}$. This discovery suggests that the solubility data for $\mathrm{SrSO}_{4}$ may be in error, or that this complex sulfate mineral may be less soluble than its end-member components.

Mixing hot or cold East Mesa fluids with one another or with Salton Sea water increases chances for scaling. In particular, mixing unflashed fluid from well 6-1, which is unsaturated with $\mathrm{BaSO}_{4}$, with unflashed fluid from well 6-2 (or other wells) which are also unsaturated with $\mathrm{BaSO}_{4}$, will result in a large $\mathrm{BaSO}_{4}$ supersaturation and great potential for scale formation. Indeed, when mixed in the laboratory, water from wells $6-1$ and 6-2, and from well 6-1 and the Salton Sea did form a barite-like scale, which also contained $\mathrm{Sr}$.

Salton Sea water has a calculated potential for scale formation that may complicate its use at East Mesa. When heated (for example if injected into the reservoir or used as a cooling fluid in a heat exchanger), it becomes saturated with $\mathrm{CaSO}_{4} \cdot 2 \mathrm{H}_{2} \mathrm{O}, \mathrm{CaSO}_{4}, \mathrm{BaSO}_{4}, \mathrm{SrSO}_{4}$, and $\mathrm{CaMg}\left(\mathrm{CO}_{3}\right)_{2} \cdot$ However, when Salton Sea water was boiled for several minutes and allowed to stand, no precipitation of solids was observed. Further experiments need to be made simulating the specific use of the Salton Sea water before its scale-forming potential is discounted. 


\section{ACKNOWLEDGMENTS}

We would like to thank Ken Mathias, Jack Haynes, and Sus Suemoto of the U.S. Bureau of Reclamation for help in sorting out early chemistry and production records of East Mesa.

Bil1 Riley and Frank McCawley gave us unpublished information on the U.S. Bureau of Mines work at East Mesa, and we also thank Donald Michels of Republic Geothermal, Inc., for recent unpublished chemical analyses of their wells.

\section{REFERENCES CITED}

Arnorsson, Stefan, 1978. Precipitation of calcite from flashed geothermal waters in Iceland. Contrib. Mineral. Petrol., v . 66, pp. 21-28.

Bechtel Corp., 1977a. Operation and maintenance of the East Mesa Test Site, technical results March to October 1976. U. S. Dept. of the Interior, Bureau of Reclamation, Final Report, Phase I, 154 p. , 1977b. Operation and maintenance of the East Mesa Test site, technical results November 1976 to January 1977, Operation and maintenance functions February 1976 to January 1977. U.S. Department of the Interior, Bureau of Reclamation.

California Dept. Water Resources, 1970. California water resources. Sacramento, California Dept. Water Res., Bull 143-7.

Fournier, R.0., 1973. An x-ray and optical study of cuttings from the USBR East Mesa 6-1 drill hole, Imperial County, California. USGS Open-file Report, $35 \mathrm{p}$.

, 1976. A study of the mineralogy and 1ithology of cuttings from the USBR Mesa 6-2 drill-hole, Imperial County, California, including comparisons with Mesa 6-1 drill-hole. USGS Open-file Report 76-88, 57 p.

Fournier, R.O., and Rowe, I.I., 1962. The solubility of quartz in water in the temperature interval from $25^{\circ}$ to $300^{\circ} \mathrm{C}$. Geochim. et Cosmochim. Acta, v. 26, p. 1029 .

Heley, A.C., Hughes, G.H., and Irelan, B., 1966. Hydrological regimen of Salton Sea, California. USGS Professional Paper 486-C.

Helgeson, H.C., 1968. Evaluation of irreversible reactions in geochemical processes involving minerals and aqueous solutions, I, Thermodynamic relations. Geochim. et' Cosmochim. Acta, v. 32, pp . 853-857. 
, 1969. Thermodynamics of hydrothermal systems at elevated temperatures and pressures. Am. Jour. Sci., v . 267, pp . 729-804.

Helgeson, H.C., Brown, T.H., Nigrini, A., and Jones, T.A., 1970. Calculation of mass transfer in geochemical processes involving aqueous solutions. Geochim. et Cosmochim. Acta, v • 34, pp - 569-592. Hill, J.H., and Morris, C.J., 1975. Sampling a two-phase geothermal brine flow for chemical analyses. Livermore, Lawrence Livermore Laboratory, UCRL-77544.

Hoagland, J.R., 1976a. Petrology and geochemistry of hydrothermal alterations in bore-hole Miesa 6-2, East Mesa geothermal area, Imperial Valley, California. M.S. thesis, Riverside, Inst. Geophys. and Planet. Phys., Dept. Earth Sci., Univ - of California, 90 p.

, 1976b. Preliminary evaluation of fluid chemistry in the East Mesa KGRA. Riverside, Inst. Geophys, and Planet. Phys., Univ • of California • Kharaka, Y.K., and Barnes, I., 1973. SOLMNEQ: solution-mineral equilibrium computations. U.S. Dept. Interior, Geol. Survey Computer Contribution PB 215-899.

Kryukov, P.A., and Larionov, E.G., 1970. Physico-chemical sampling of high-temperature wells in connection with their encrustation by calcium carbonate, in Proceedings, UN symposium on the development and utilization of geothermal resources, Pisa, 1970. Geothermics, Spec. Issue 2, v. 2, no. 2, pp. 1624-1628.

Mathias, K.E., 1976. The Mesa geothermal field--a preliminary evaluation of five geothermal wells, in Proceedings, second UN symposium on the development and use of geothermal resources, 20-29 May 1975, San Francisco. Washington, D.C., U.S. Government Printing office, v. 3, PP. 1741-1747.

Michels, D., 1978. Personal communication (Republic Geothermal, Inc.). Needham, P.B., Jr•, Murphy, A.P•, and McCrawley, F.X., 1976. Scaling in both high- and low-salinity brines. Presented at conference on scale management in geothermal energy development, San Diego, California. Springfield, National Technical Information Service, ERDA publication C0O-2607-4.

Parry, H.L•, and Sullivan, R.G., 1977. Geothermal corrosion test facilty description design features and initial operating experience. Richland, Battelle Pacific Northwest Laboratories, Preliminary Report. 
Phillips, S.L., Mathur, A.K., and Doebler, R.E., 1977. A study of brine treatment. Berkeley, Lawrence Berkeley Laboratory, LBL-6371.

Riley, W.D., Walters, R.T., MacCawley, F.X., and Needham, P.B., Jr., 1979. Physical and chemical effects on analysis of geothermal brines. College Park, Md., U.S. Dept. of Interior, Bureau of Reclamation, Report of Investigations series.

University of California, Riverside, 1970. Geophysical investigations for geothermal energy sources, Imperial Valley, California. Riverside, University of California, Technical Report No. 3, Phase I of 1968 Field Project.

, 1971. A cooperative investigation of geothermal resources in the Imperial Valley area and their potential value for desalination of water and other purposes. Riverside, University of California.

, 1972. A cooperative investigation of geothermal resources in the Imperial Valley area and their potential value for desalting of water and other purposes. Riverside, Inst. Geophys. and Planet. Phys., University of California, UCR Report 72-7.

U.S. Bureau of Reclamation, 1971a. Geothermal resource investigations, Imperial Valley, California: site location report, deep geothermal test we11. U.S. Dept. of Interior, Bureau of Reclamation. , 1971b. Geothermal resource investigations, Imperial Valley, California: status report. U.S. Dept. of Interior, Bureau of Reclamation. -1973a. Geothermal resource investigations, Imperial Valley, California: geothermal test well Mesa 6-2. U.S. Dept. of Interior, Bureau of Reclamation .

- 1973b. Geothermal resources investigations, Imperial Valley, California: Test well Mesa 6-1. U.S. Dept. of Interior, Bureau of Reclamation.

, 1974. Geothermal resources investigations, Imperial Valley, California: status report. U.S. Dept. of Interior, Bureau of Reclamation. , 1977a. Geothermal resource investigations, East Mesa Test

Site, Imperial Valley, California: status report. U.S. Dept. Interior, Bureau of Reclamation.

, 1977b. Geothermal resource investigations, East Mesa Test Site, Imperial Valley, California: desalting 1974-1976. U.S. Dept. of Interior, Bureau of Reclamation. 
Wahl, E.F., Yen, I.K., and Bartel, W.J., 1975. Silicate scale control in geothermal brines--final report. LaVerne, California, Garrett Res. and Devel. Co., Inc., report for USBR.

Watson, J.C., 1978. Sampling and analysis methods for geothermal fluids and gases. Richland, Battelle Pacific Northwest Laboratory PNL-MA-572. Westal1, J., Zachary, J., and Morel, F., 1976. MINEQL, a computer program for calculation of chemical equilibrium composition of aqueous systems. Cambridge, Mass. Inst. Tech., Dept. Civil Eng., Tech. Note no. 18. Westec Services, Inc., 1978. Historical summary of the Bureau of Reclamation geothermal wells at the East Mesa test site, East Mesa, California. San Diego, Westec Services, Inc.

Wolery, T.J., 1978. Some chemical aspects of hydrothermal processes at mid-oceanic ridges--a theoretical study, Part II, Calculations of chemical equilibrium between aqueous solutions and minerals. Ph.D. thesis, Evanston, Northwestern University. 


\section{SECTION 6: SUMMARY}

R. C. Schroeder

Lowrence Berkeley Laboratory

A comprehensive project study has been completed for the U. S. Department of the Interior, Bureau of Reclamation, in cooperation with the U. S. Department of Energy, Imperial Magma Co., and Republic Geothermal, Inc., on the U. S. Bureau of Reclamation leaseholds at the East Mesa KGRA. The purpose of the study was to assess the resource, determine the production and injection capacities of the resource, and assess the likelihood of chemistry-related problems during fluid production and injection, and during desalination. The resource assessment and production behavior studies depend heavily upon the geological and hydrothermal model of the reservoir. Because no coherent model of the reservoir was available, one of the important tasks was to review all available geological and geophysical data and to construct a comprehensive geological model of the resource. To determine the maximum rate of fluid withdrawal requires both well-testing information and reservoirsimulation calculations. The well-test data provide estimates for well behavior, reservoir flow characteristics, and material parameters--such as permeabilities. When the geological model and the flow characteristics are estimated, calculations can be made to study the implications of various production/injection strategies, and different choices of wel1 completions and patterns. Since the chemical stability of geothermal brines depends strongly upon temperature and pressure, the chemistry studies are dependent not only on fluid sampling and analysis, but also on the thermodynamic state of the brine during crucial phases of production and injection. The reservoir definition (geology, geophysics), reservoir engineering, and geochemistry are interdependent, and each contributes to the accurate assessment of the capacity, productivity, and associated chemistry of the resource.

The major conclusions reached during the geological synthesis and modeling are that at least three marker horizons can be mapped (as shown in Figures 1.8 to 1.10 ). A deep, poorly reflecting zone (for seismic signals) was identified on the basis of velocity analyses and well logs as relatively dense rocks. This poorly reflecting zone (PRZ) was penetrated by a few wells and showed significantly lower 
porosity and permeability compared with shallower zones. Since the PRZ corresponds to both the gravity high and the thermal high, it is interpreted to be a dense, thermally altered region that could, however, be substantially fractured.

In Section 1, a volumetric calculation was made to estimate the heat content of the fluid and the heat content of the rock, within the boundaries of the USBR leasehold. Since the $3000 \mathrm{~F}$ isotherm is inside the lease boundary (in some places) the volume included in the calculation is smaller than the volume of the entire leasehold to the depth chosen $(7500 \mathrm{ft}$ ). A much larger volume would result by including rock and fluid to a greater depth, but the tables in Section 1 show that: (a) the porosity decreases significantly below 7500 feet; and (b) there is very little information available below this depth. Including deeper zones would simply increase the estimates proportionately. For example, if evidence of substantial fractures were obtained, it might be appropriate to extend the estimates accordingly.

The specific conclusions from the volumetric study are that the total volume of fluid at temperatures above $300 \circ \mathrm{F}$ is $\approx 3 \times 10^{9} \mathrm{~m}^{3}$ $\left(1.1 \times 10^{11} \mathrm{ft}^{3}\right)$; the total mass of fluid is $\approx 2.8 \times 10^{12} \mathrm{~kg}\left(6.1 \times 10^{12} 1 \mathrm{~b}\right)$; the total heat in the fluid is $\approx 1.8 \times 10^{18} \mathrm{~J}\left(1.7 \times 10^{15} \mathrm{Btu}\right)$; the total volume of sand is $\approx 1.4 \times 10^{10} \mathrm{~m}^{3}\left(5 \times 10^{11} \mathrm{ft}^{3}\right)$; and the total heat in the sand is $\approx 4.6 \times 10^{18} \mathrm{~J}\left(4.4 \times 10^{15} \mathrm{Btu}\right)$. The volume of sand was obtained by including all formation material having porosity greater than $10 \%$ (from the SARABAND logs). The heat contents were calculated relative to $60 \% \mathrm{~F}$.

The geophysical work covered in this report (Section 2) is based upon data acquired in 1977 and 1978 from the microseismic net shown in Figure 2.1. The interesting and somewhat surprising observation from these studies is that there is an apparent total lack of any current microseismic activity within the East Mesa KGRA. This holds for all observable activity above a Richter magnitude, $\mathrm{M}_{\mathrm{L}}=1$. Most of the observed microseismic activity was identified with events such as the major Brawley swarms (1977). At present there does not appear to be any relationship between the seismic activity believed to originate near the Imperial-Brawley fault system and the East Mesa KGRA. 
The well testing portion of the report (Section 3 ) includes analyses of data from well tests before 1978, and a review of tests carried out under contract to the U. S. Bureau of Reclamation. A comprehensive picture of the reservoir's hydrological characteristics has emerged from these measurements and analyses. The picture is one of scattered hydrological discontinuities within the anomaly as a whole. This is demonstrated in Figure 3.2, where apparent barriers to flow have been found near we11s $16-30$ and 6-1. In Figures 1.8 through 1.10, numerous features have been mapped, suggesting that the geological and hydrological discontinuities may be related to one another. In addition to the inhomogeneous nature of the geology, the flow parameters also indicate a nonuniform distribution of permeability and porosity. In the central portion of the field, the early well-test analyses gave relatively low values for the transmissivity, $\mathrm{kh} / \mu$. More recently-from data obtained during well tests at higher flow rates--the analyses gave values of transmissivity in the central portion of the anomaly that were not as low as the preliminary estimates. Nevertheless, the center of the anomaly appears to have relatively low $\mathrm{kh} / \mathrm{\mu}$ compared with the northern and southern extremes. Figure 1.24 through 1.29 show that the central portion of the KGRA corresponds to a relatively high-temperature region. The temperatures are relatively lower in the northern and southern portions of the anomaly, at a given depth. The crude correlation of temperature, depth, and transmissivity may be related to hydrothermal mineralization, although this has not been verified.

The well testing has also provided indications of the conditions of the wells in the USBR leasehold. The wells have been tested only in a self-flowing mode, and at greater than $120 \mathrm{gpm}$ these wells flash in the wellbore. In addition to the temperature drop due to vaporization, there is also a large amount of $\mathrm{CO}_{2}$, which is released from solution during flashing. As a result, the wells have all scaled to some degree. This was quite apparent during the production testing and resulted in difficulty removing the downhole tools that had been used to monitor transient pressure. It appears that all of the USBR wells are damaged (scaled) to some extent, and 6-1 has had additional 
problems below $3600 \mathrm{ft}$, where a scale plug formed--apparently due to mixing of fluids from different strata (see discussion of chemistry, below). The well with the highest productivity index is $8-1$ ( $P I \approx 2.8 \mathrm{gpm} / \mathrm{psi}$ ), and we11 6-1 has the poorest ( $P I \approx 0.6 \mathrm{gpm} / \mathrm{psi}$ ). The well testing throughout the anomaly has indicated that the transmissivity is probably at least $100,000 \mathrm{md}-\mathrm{ft} / \mathrm{cp}$ throughout most of the anomaly, and could be twice that number in the northern and southern portions of the KGRA.

Section 4, the reservoir simulation portion of the report, covers calculations made to determine the conditions that would exist in the reservoir and boreholes when specified amounts of water are withdrawn for desalination. The desalinated water would be used for augmenting the Colorado River and makeup water is assumed to be available (from the Salton Sea, for example). Specifically, the study seeks to predict the response of the reservoir for annual flow rates of 25,000 to 100,000 acre-ft $(15,000$ to $60,000 \mathrm{gpm})$.

The calculations included three types: pressure transient, thermal breakthrough, and wellbore flow. The calculations were made assuming several simplifications--such as homogeneity--as discussed in Section 4 , above. The principal transient pressure considerations are related to well patterns (number of wells), type of injection (peripheral or regular pattern), and effects of viscosity (for cold-water injection). The effect of gravity on the thermal breakthrough has not been included in the calculations. The wellbore-flow calculations were made to determine the flash point in the well for the given reservoir conditions obtained from the pressure-transient calculations.

Two cases were included in the numerical transient-pressure calculations. One was for average well depths of $6000 \mathrm{ft}$ and the second for well depths of $7000 \mathrm{ft}$. The values of the material parameters and the assumptions used in the numerical calculations are summarized in Table 4.2. The thermal breakthrough calculations were made for a quadrant of a fivespot well pattern and for both peripheral injection and for five-spot patterns. The material and thermal properties used in the calculations are also given in Section 4.

Three injection strategies were studied numerically: no injection, peripheral injection, and injection in a uniform five-spot well pattern. 
In Figure 4.8, the drawdowns after 11.2 years are shown as functions of the number of we11s, and for both 50,000 and 100,000 acre-ft/yr withdrawal rates. The withdrawal for both 6000- and 7000-ft wells is from within the $300^{\circ} \mathrm{F}$ temperature contour. This was chosen as the calculation area because USBR required this minimal temperature constraint as input to their desalination system. For the 100,000 acre-ft/yr withdrawal rate, the drawdowns are more than 5500 psi at the center of the field, and more than 4250 psi at the edge of the field. For 50,000 acre-ft/yr these numbers decrease by about a factor of 2 .

For peripheral injection, the injection wells can be located at arbitrary distances from the production field. When the wells are placed farther from the field, more wells must be drilled to give similar sweep patterns and pressure support. Since pressure support was shown to be desirable for the "no-injection" case, peripheral injection was calculated using injection-well spacings equal to the production-well spacing. In Figure 4.12 the production-well drawdowns and injectionwell excess pressures are shown as functions of the number of wells and rate of production (injection equals production). In these cases the dependence of the maximum drawdown on the number of wells is important. The spread between the minimum drawdowns and maximum drawdowns is also more pronounced, although the absolute magnitudes are reduced appreciably in comparison with the no-injection case. However, the center of the field still shows greater than $\approx 1200$ psi drawdown for the 100,000 acre-ft/yr case. For the 50,000 acre-ft/yr case, the drawdowns do not exceed 1200 psi even for the case of 15 producing and 15 injection wells. Drawdowns are much less than 1200 psi in most of the field. From Table 4.5, we see that the above summary conclusions hold for the case of $7000-\mathrm{ft}$ and $6000-\mathrm{ft}$ well depths. The assumptions inherent in these conclusions give a "best-case" result. When barriers, shale lenses or layers, and other complications are considered, the results will probably be less favorable with respect to the magnitude of the drawdowns. An example of a barrier dividing the entire field is given in Figures $4.13,4.14$, and 4.15 as an example. 
For the five-spot calculations, the well spacing was dictated by the combination of the bounding $300^{\circ} \mathrm{F}$ isotherm and the number of wells in the pattern. the drawdowns and excess injection pressures are shown in Figures 4.19 and 4.20. For $1000 \mathrm{gpm} /$ we 11, the drawdowns do not exceed $350 \mathrm{psi}$ (even for $100,000 \mathrm{acre}-\mathrm{ft} / \mathrm{yr}$ ) anywhere in the field. Although $2000 \mathrm{gpm} / \mathrm{we} 11$ is also shown, the results from well testing do not make this case a serious possibility in the East Mesa field. For 60 wells the flow rates are $500 \mathrm{gpm} / \mathrm{we} 11$. The excess injection pressures are of the same magnitude as the drawdowns (excluding any complications due to scaling or plugging). Calculations were made to quantitatively show the effects of a skin factor. For evaluation of the results we note that a "skin factor" of 5 is quite large. Figure 4.24 shows that the skin effect for large skin factor could double the drawdowns.

Wellbore calculations were made for wells similar to $6-1$ or $8-1$, and the results are given in Figures 4.26 and 4.27. They show that the flashpoint depth in feet is approximately 2.4 times the drawdown in psi for typical USBR wells at East Mesa. When pumps are used they must be set deeper than the flash-point depth, since $\mathrm{CO}_{2}$ is released from solution below the phase-change point, and a static heat is also required for most pumps to operate.

In the calculations for breakthrough from injection to production wells, both the hydrodynamic and thermal breakthrough were calculated since the desalination requires known chemical composition, and the composition (at least initially) would be the current brine chemistry. The estimated hydrodynamic breakthrough times were greater than 36 years for a reservoir of from 1500- to 6000-ft thick, or 12 years for a reservoir thickness of $500 \mathrm{ft}$. The number is about twice as large when the $300 \% \mathrm{~F}$ isotherm bounds the reservoir at a depth of $7000 \mathrm{ft}$.

Thermal breakthrough was calculated for both peripheral and fivespot well patterns. The parameters used in the calculations are summarized in Section 4, and the results are presented graphically in Figures 4.29 and 4.30 for peripheral injection and five-spot injection, respectively. The figures show that, for the parameters and assumptions described in the text, the thermal breakthrough does not occur until 
after at least $\approx 22$ years for peripheral injection and at least $\approx 42$ years for five-spot injection. These calculations were for the case of 50,000 acre-ft/yr production-injection and a reservoir height of $500 \mathrm{ft}$. Clearly, anisotropies or inhomogeneities might result in very different values. The minimum numbers quoted here are for the minimum likely "average" reservoir height in the field (500 ft). Note that this is the thickness of permeable sand, not the geometric height. It may be possible that the effective reservoir thickness is two or more times this number, in which case the breakthrough may be 60 to $80 \% 1$ onger (see Figure 4.32). The numbers for drawdowns and breakthrough times can be scaled (approximately) to estimate the withdrawal within the USBR leasehold, rather than the entire volume bounded by the $300 \circ$ isotherm at either 6000 or $7000 \mathrm{ft}$. The approximate scaling factor is $60 \%$ for the volume and $\approx 1.67$ for drawdowns or breakthrough times.

The chemistry section of this report (Section 5) is devoted to determinating the conditions to be expected during desalination to East Mesa. The important aspects include evaluation of existing data, the potential for scaling, a comparison of predictions with the experience from the demonstration desalination plant, and scale-control techniques.

The existing chemistry data show great variability and the conditions associated with the sampling were not always known. In addition, scaling and gas evolution occurred during some of the sampling periods. There are data, however, that suggest mixing of incompatible fluids during production of East Mesa brines. Both the change in chemical composition when extending the production interval and the high degree of calcite supersaturation have been cited as examples in wells 6-2 and 6-1, respectively.

Calcite scaling will not occur if flashing is prevented through the use of downhole pumps and pressurized heat exchangers. However, $\mathrm{BaSO}_{4}$ scaling may be a possible problem even for unflashed mixtures of brines from different production zones. The potential scaling 
problems when injecting Salton Sea water into the reservoir require additional studies, since calculations indicate possible supersaturation of $\mathrm{CaSO}_{4} \cdot 2 \mathrm{H}_{2} \mathrm{O}, \mathrm{BaSO}_{4}$, and $\mathrm{CaMg}\left(\mathrm{CO}_{3}\right)_{2}$ under typical injection conditions (i.e., eventual heating of the injected fluid). 


\section{APPENDIX A: PRODUCTION TEST DATA AND DISCUSSION}

\section{WELL 5-1 INJECTION TEST}

A plot of the injection rate, wellhead pressure, and downhole pressure measurements made during the well test is shown in Figure A.1. The injected water was at about $70^{\circ} \mathrm{F}$. No unusual difficulties were encountered during the test. The injection pump(s) quit for a short time on several occasions due to a lack of feed water from the storage tank, but these flow interruptions did not seriously affect the test as a whole. The flow rate, measured injectivity index, and analytical results for each test segment are listed in Table A.1.

Test segments 3, 4 and 5 display good pressure behavior. Annotated semilog plots of pressure vs elapsed time used in these analyses are given as Figures A.2, A.3, and A.4. The disparity of kh/ $\mu$ values among the test segments can be explained by the dilation process of a hydraulic (vertical) fracture that is believed to communicate with the well in a 400-ft section at the top of the perforations. Figure A.5 shows the results of a spinner survey taken in well 5-1 on 8 December 1977. This survey, combined with hysteretic behavior of the injectivity indices and the drop of 1200 to $400 \mathrm{psi}$ wellhead pressure recorded in the injection $\log$ on 26 December 1977, indicates that the we 11 is fractured.

Test segment 3 best represents well operating conditions. The measured injectivity index (I.I.) of $0.84 \mathrm{gpm} / \mathrm{psi}$ agrees closely with the calculated 18 hour I.I. of $0.79 \mathrm{gpm} / \mathrm{psi}$. The test results of segment 3 are therefore believed to most closely represent the behavior of the well in its present condition.

\section{WELL 8-1 PRODUCTION TEST}

A plot of wellhead temperature and pressure, flow rate, and downhole pressure measurements made during the production test is shown in Figure A.6. The flow rate variation, calculated productivity index, and results for each analyzable test segment are given in Table A.2.

Constant flow rates could not be maintained because the well is artesian, and when free flowing it suffers a progressive pressure 
decline concurrent with a decrease in flow rate. In addition, flashing occurs in the well bore so that the resultant scale build up contributes to progressive flow rate decay. For these reasons, the three build-up tests, test segments 4,7 and 11 , are considered the best representative well tests. Annotated semilog plots of pressure vs elapsed time for these three tests are given as Figures A.7 through A.9. The results of these three tests are in close agreement. Average parameter values for we11 $8-1$ based on these tests are: $\mathrm{kh} / \mu=60,000 \mathrm{md}-\mathrm{ft} / \mathrm{cp}$ $\left(1.8 \times 10^{-8} \mathrm{~m}^{3} / \mathrm{sec} / \mathrm{Pa}\right), \phi \mathrm{chr}_{\mathrm{e}}^{2}=0.037 \mathrm{ft}^{3} / \mathrm{psi}\left(1.52 \times 10^{-7} \mathrm{~m}^{3} \mathrm{~Pa}\right)$; and P.I. $=2.54 \mathrm{gpm} / \mathrm{psi}\left(2.32 \times 10^{-8} \mathrm{~m}^{3} / \mathrm{sec} / \mathrm{Pa}\right)$.

\section{WELL 6-2 PRODUCTION TEST}

A plot of production rate, wellhead pressure and downhole pressure is shown in Figure A.10. As the graph indicates, constant flow rates could not be maintained. That flashing occurred in the we 11 is evidenced by the small, apparently random fluctuations in wellhead pressure recorded at the higher flow rates.

Flashing caused the deposition of carbonate scale on the capillary tube (nitrogen filled) to a depth of approximately $400 \mathrm{ft}$. Scale deposited during previous flow periods narrowed the base of the wellhead to 3 inches in diameter. (This was determined by running dummy tools of various sizes into the we11.)

Results of all useful test segments are given in Table A.3.

Test segments 5 and 7 are the most representative and the average reservoir parameter values were obtained from the results of these two segments. Semilog plots of pressure vs elapsed time for these segments are given as Figures $A .11$ and $A .12$. The average reservoir parameter estimates are: $\mathrm{kh} / \mu=73,000 \mathrm{md}-\mathrm{ft} / \mathrm{cp}\left(2.2 \times 10^{-8} \mathrm{~m}^{3} / \mathrm{sec} / \mathrm{Pa}\right)$; $\phi \operatorname{chr}_{\mathrm{e}}^{2}=0.105 \mathrm{ft}^{3} / \mathrm{psi}\left(4.31 \times 10^{-7} \mathrm{~m}^{3} / \mathrm{Pa}\right) ;$ and $\mathrm{P} . \mathrm{I} .=3.38 \mathrm{gpm} / \mathrm{psi}$ $\left(3.09 \times 10^{-8} \mathrm{~m}^{3} / \mathrm{sec} / \mathrm{Pa}\right)$.

Figure A.13 shows the results of a spinner survey. The figure indicates that the flow occurs in the upper $500 \mathrm{ft}(150 \mathrm{~m})$ of perforations. Well log porosities and permeabilities for this interval agree closely with the production test estimates. 


\section{WELL 6-1 PRODUCTION TEST}

A plot of wellhead temperature and pressure, production rate and downhole pressure measurements is shown in Figure A.14. The absence of wellhead pressure and temperature response during periods of production rate changes, combined with the low wellhead temperature value, indicate that flashing occurred in the well throughout the entire test. The well also produced considerable amounts of $\mathrm{CO}_{2}$ and small quantities of sand and organic material. Scale was deposited on the capillary tube (oil filled) to a depth of approximately $800 \mathrm{ft}(240 \mathrm{~m})$.

The results of usable test segments are presented in Table A.4. Semilog plots of pressure vs elapsed time for segments 2, 5, and 7 are shown in Figures A.15, A.16, and A.17. Average reservoir estimates for these segments are: $\mathrm{kh} / \mathrm{\mu}=14,000 \mathrm{md}-\mathrm{ft} / \mathrm{cp}\left(4.2 \times 10^{-9} \mathrm{~m}^{3} / \mathrm{sec} / \mathrm{Pa}\right)$; $\phi \mathrm{chr}_{\mathrm{e}}^{2}=1.01 \mathrm{ft}^{3} / \mathrm{psi}\left(4.15 \times 10^{-7} \mathrm{~m}^{3} / \mathrm{Pa}\right) ;$ and P.I. $=0.83 \mathrm{gpm} / \mathrm{psi}$ $\left(7.6 \times 10^{-9} \mathrm{~m}^{3} / \mathrm{sec} / \mathrm{Pa}\right)$. 
5-1 Injection test. 1977

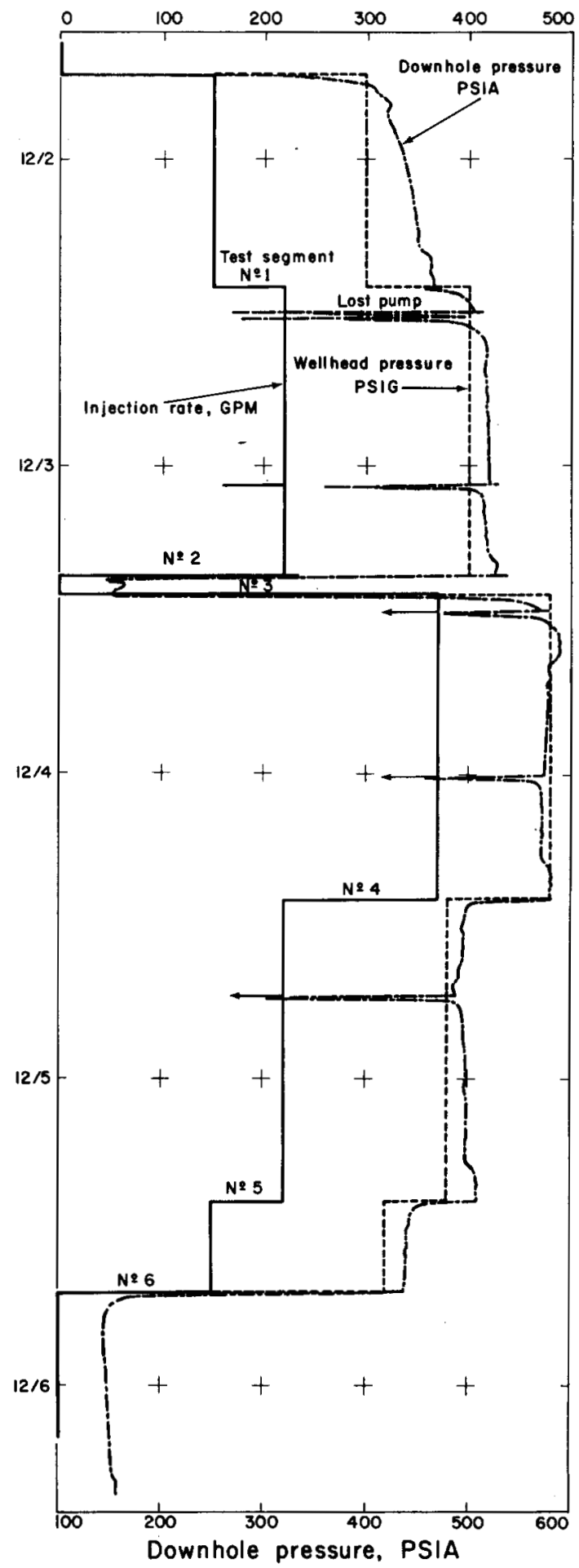

XBL 789-2057

Figure A.1. Plot of injection rates, wellhead pressures, and downhole pressures recorded during the well 5-1 injection test. Top scale is injection rate (gpm) and wellhead pressure (psig). 
Table A.1. Wel1 5-1 injection test segments and test results, December 1977 .

\begin{tabular}{|c|c|c|c|c|c|}
\hline DATE & SEGMENT & $\begin{array}{l}\text { INJECTION } \\
\text { RATE-gpm }\end{array}$ & $\begin{array}{c}\mathrm{kh} / \mu \\
\mathrm{md}-\mathrm{ft} / \mathrm{cp} \\
\left(\mathrm{m}^{3} / \mathrm{sec} / \mathrm{Pa}\right)\end{array}$ & $\begin{array}{c}\phi \operatorname{chr}^{2} \\
\mathrm{ft}^{3} / \mathrm{psi} \\
\left(\mathrm{m}^{3} / \mathrm{Pa}\right)\end{array}$ & $\begin{array}{c}\text { I.I. } \\
\text { gpm/psi } \\
\left(\mathrm{m}^{3} / \mathrm{sec} / \mathrm{Pa}\right)\end{array}$ \\
\hline $12 / 1$ & - & $0-150$ & - & - & $\left(4.3 \times 10^{-9}\right)$ \\
\hline $12 / 2$ & 1 & $150-220$ & - & - & $\left(\begin{array}{c}.58 \\
\left(5.3 \times 10^{-9}\right)\end{array}\right.$ \\
\hline $12 / 3$ & 3 & $0-370$ & $\begin{array}{c}43,000 \\
\left(1.3 \times 10^{-8}\right)\end{array}$ & $\begin{array}{c}7.14 \times 10^{-8} \\
\left(2.93 \times 10^{-13}\right)\end{array}$ & $\left(7.7 \times 10^{-9}\right)$ \\
\hline $12 / 4$ & 4 & $370-220$ & $\begin{array}{l}100,000 \\
\left(3.0 \times 10^{-8}\right)\end{array}$ & $\begin{array}{c}6.74 \times 10^{-9} \\
\left(2.77 \times 10^{-14}\right)\end{array}$ & $\left(5.5 \times 10^{-9}\right)$ \\
\hline $12 / 5$ & 5 & $220-150$ & $\begin{array}{c}57,000 \\
\left(1.7 \times 10^{-8}\right)\end{array}$ & $\begin{array}{c}2.15 \times 10^{-8} \\
\left(8.83 \times 10^{-14}\right)\end{array}$ & $\left(4.7 \times 10^{-9}\right)$ \\
\hline
\end{tabular}




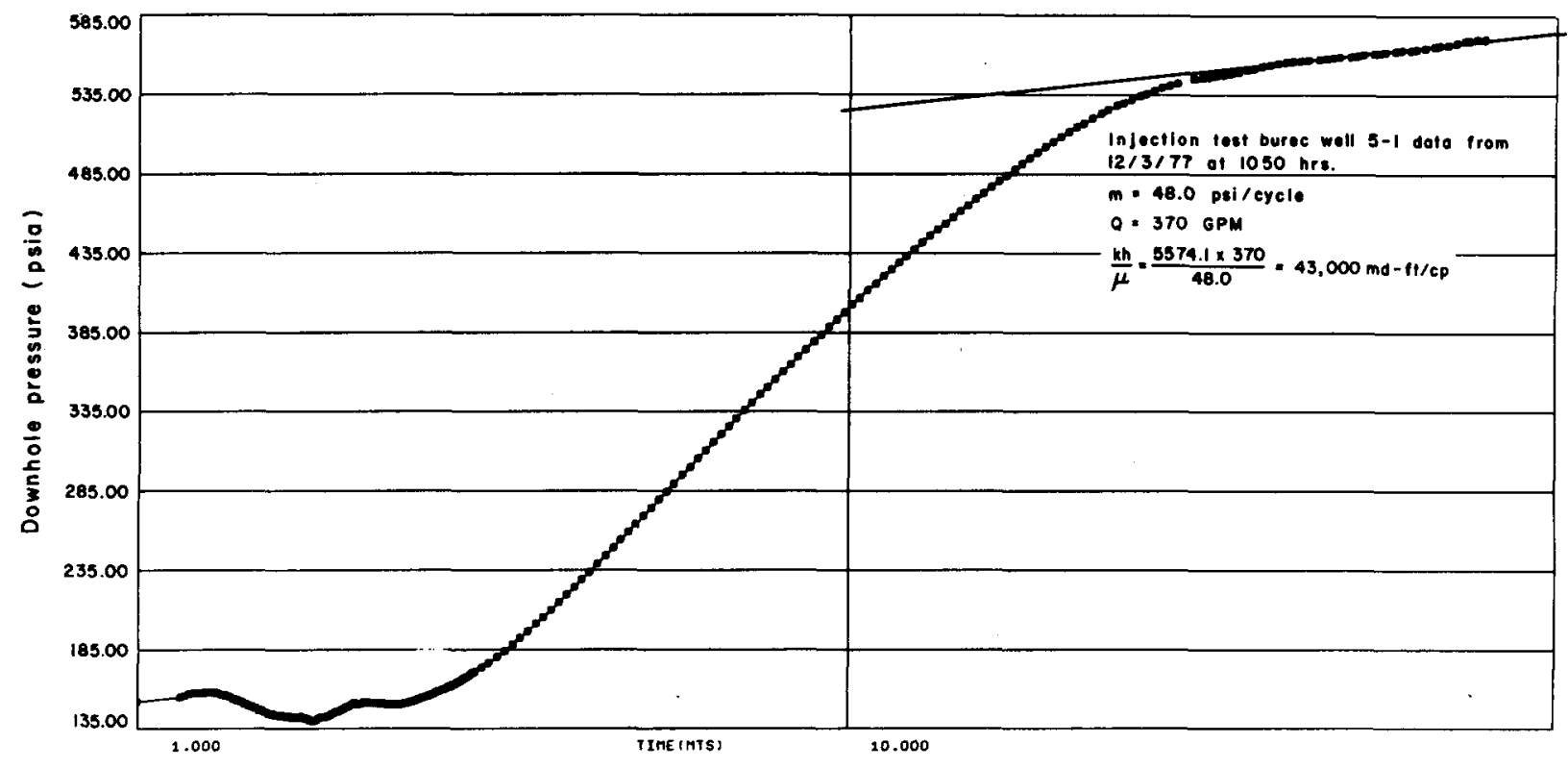

XBL 789-2063

Figure A.2. Downhole pressure vs $\log$ of elapsed time for test segment 3 of the wel1 5-1 injection test.

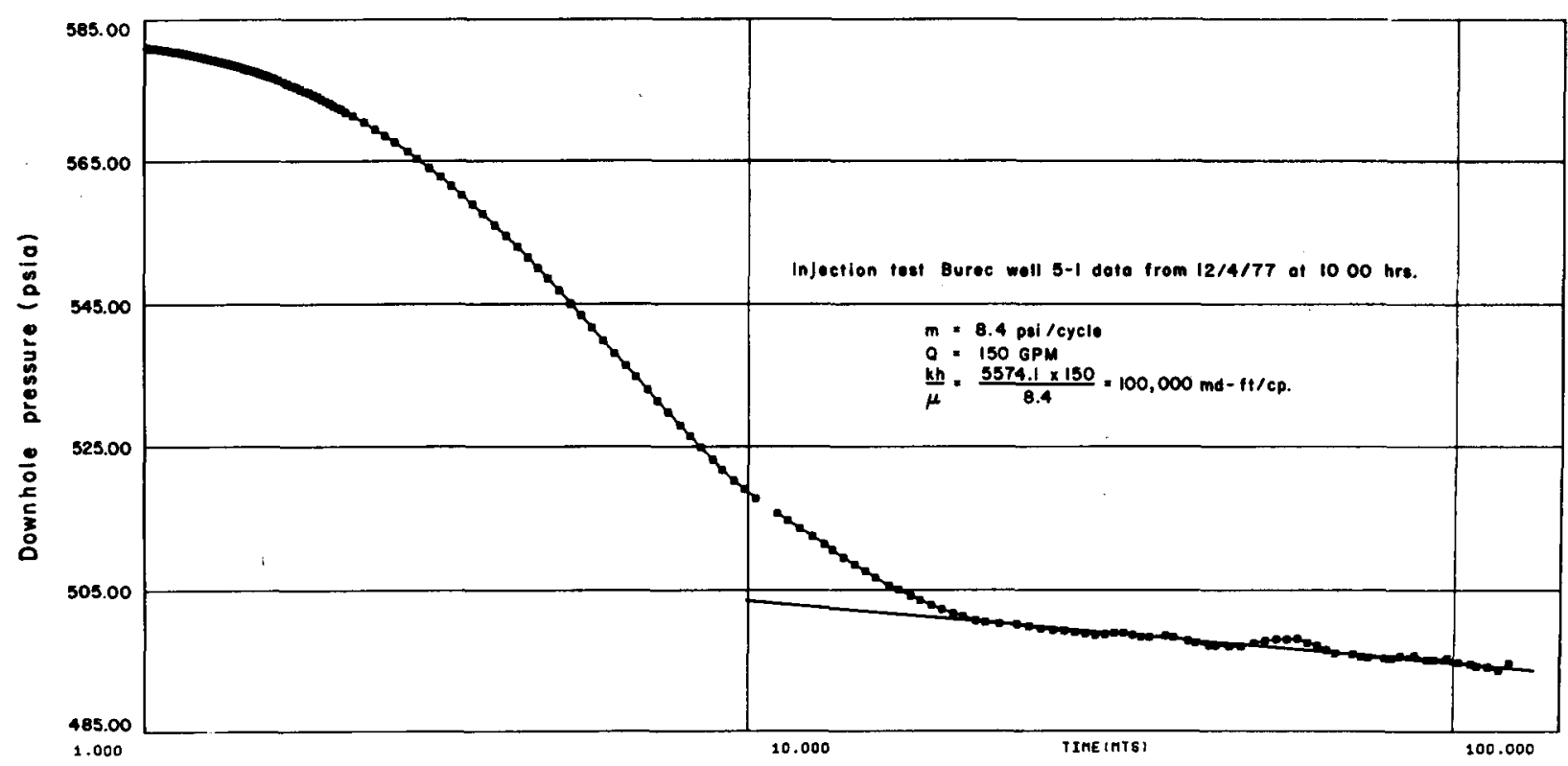

XBL $789-2064$

Figure A.3. Downhole pressure vs $\log$ of elapsed time for test segment 4 of the well 5-1 injection test. 


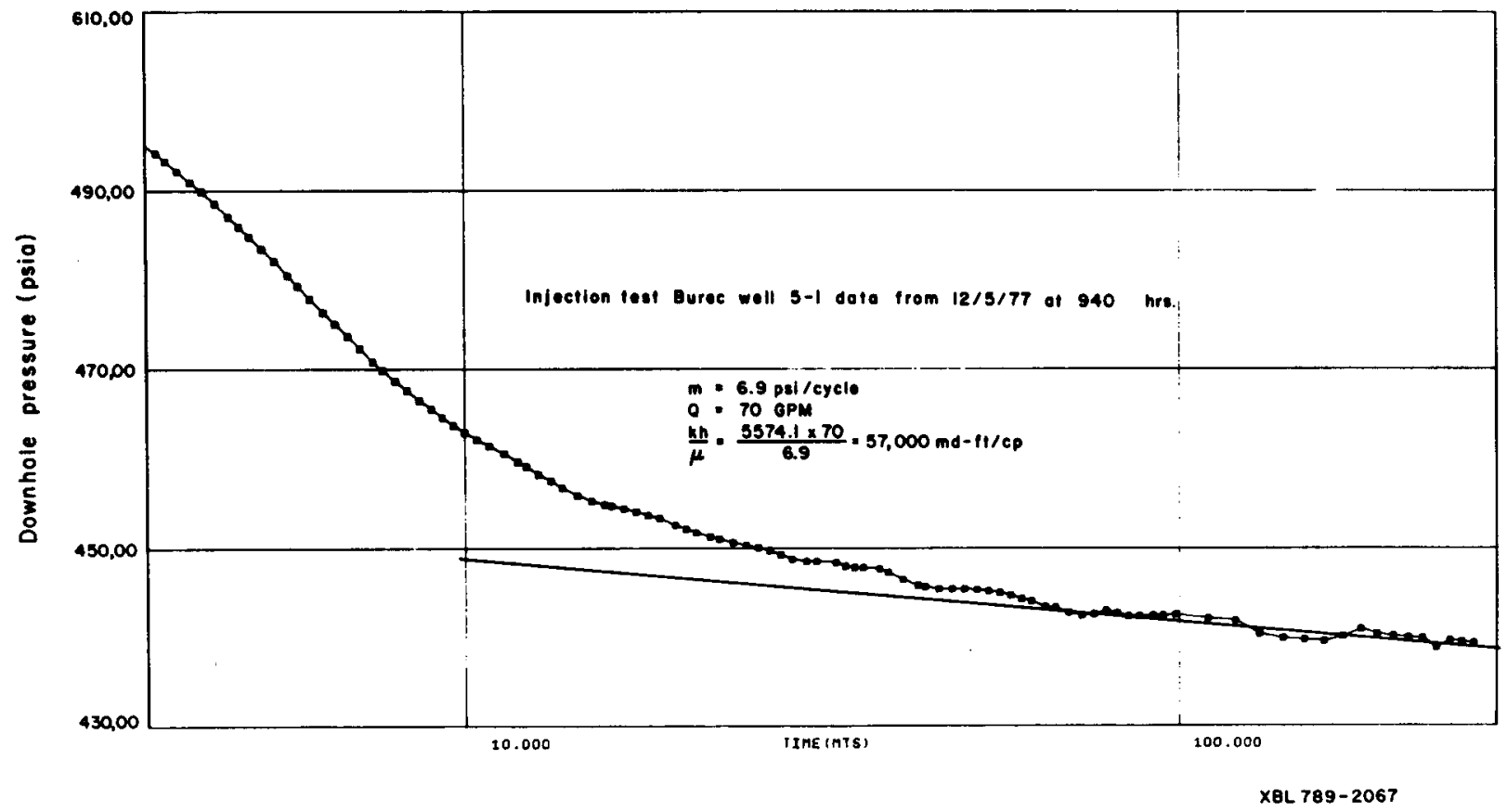

Figure A.4. Downhole pressure vs log of elapsed time for test segment 5 of the wel1 5-1 injection test. 


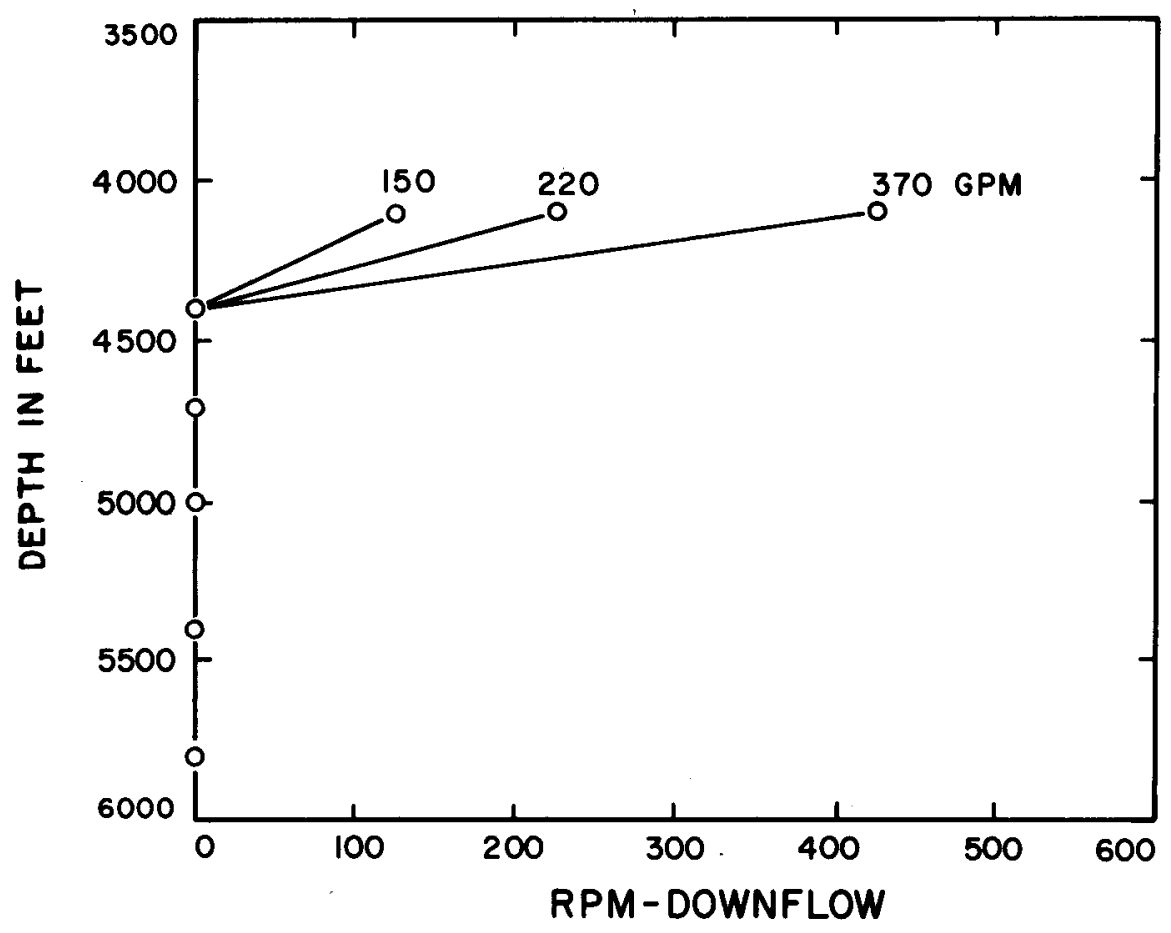

XBL $789-2082$

SURVEY DATA - well injecting

$\begin{array}{ccccc} & & \text { RPM }- \text { low rate } & \text { medium rate } & \text { high rate } \\ \text { Stops } & 4100 & 125 & 225 & 425 \\ & 4400 & 0 & 0 & 0 \\ 4700 & 0 & 0 & 0 \\ 5000 & 0 & 0 & 0 \\ 5400 & 0 & 0 & 0 \\ 5800 & 0 & 0 & 0\end{array}$

Open intervals 4061' to 5276' perforations

5003' to 6003' slotted

Figure A.5. Results of a spinner survey taken in we11 5-1. 


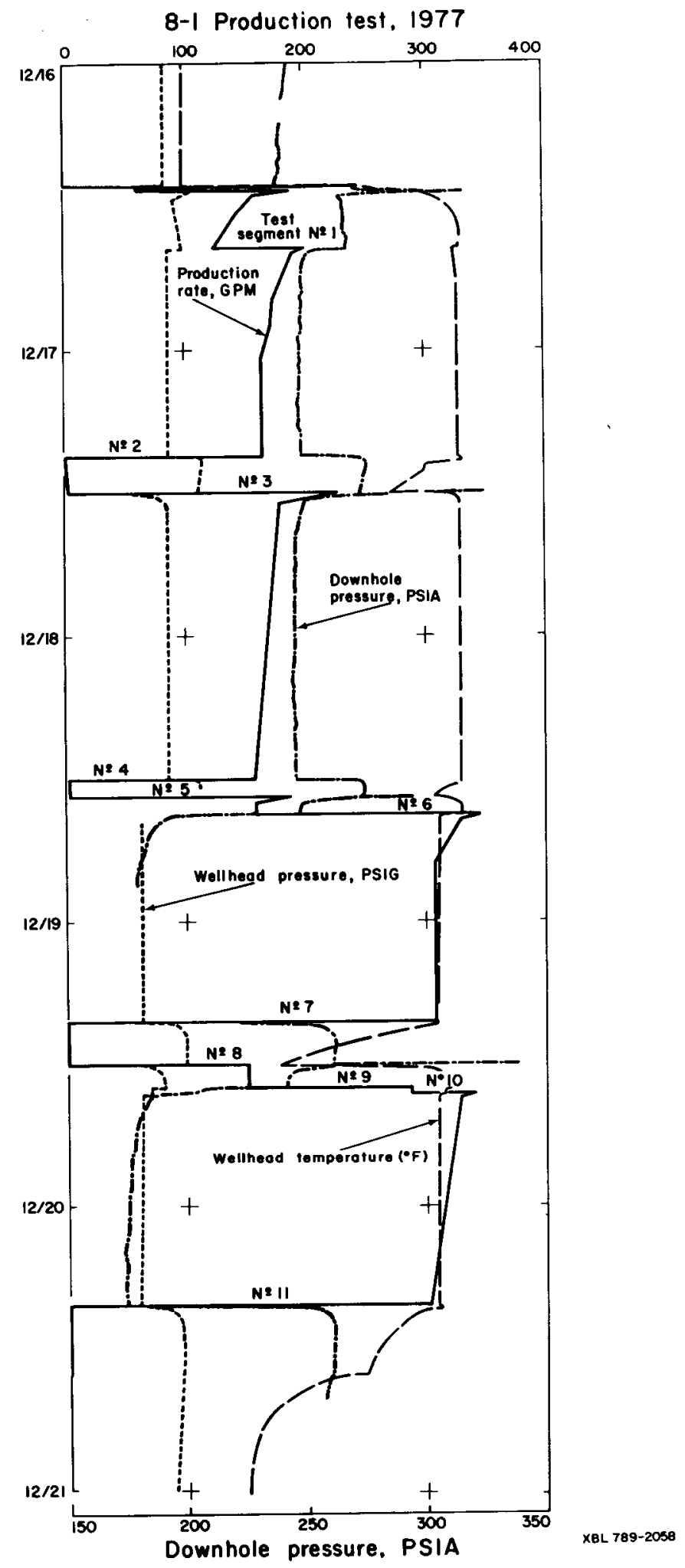

Figure A.6. Plot of wellhead temperatures and pressures, production rates, and downhole pressures recorded during the well 8-1 production test. The top scale is production rate (gpm), wellhead pressure (psig), and wellhead temperature $\left({ }^{\circ} \mathrm{F}\right)$. 
Table A.2. Wel1 8-1 injection production test segments and test results, December 1977.

\begin{tabular}{|c|c|c|c|c|c|}
\hline DATE & SEGMENT & $\begin{array}{l}\text { PRODUCTION } \\
\text { RATE-gpm }\end{array}$ & $\begin{array}{c}\mathrm{kh} / \mu \\
\mathrm{md}-\mathrm{ft} / \mathrm{cp} \\
\left(\mathrm{m}^{3} / \mathrm{sec} / \mathrm{Pa}\right)\end{array}$ & $\begin{array}{c}\phi \operatorname{chr}^{2} \\
\mathrm{ft}^{3} / \mathrm{psi} \\
\left(\mathrm{m}^{3} / \mathrm{Pa}\right)\end{array}$ & $\begin{array}{c}\text { P.I. } \\
\text { gpm/psi } \\
\left(\mathrm{m}^{3} / \mathrm{sec} / \mathrm{Pa}\right)\end{array}$ \\
\hline \multirow[t]{2}{*}{$12 / 16$} & 1 & $0-165$ & $\begin{array}{c}45,000 \\
\left(1.3 \times 10^{-8}\right)\end{array}$ & $\begin{array}{c}.224 \\
\left(9.20 \times \times 10^{-7}\right)\end{array}$ & $\begin{array}{l}2.42 \\
\left(2.21 \times 10^{-8}\right)\end{array}$ \\
\hline & 2 & $165-0$ & $\begin{array}{c}120,000 \\
\left(3.6 \times 10^{-8}\right)\end{array}$ & $\left(3.00 \times 10^{-8}\right)$ & $\begin{array}{l}4.09 \\
\left(3.74 \times 10^{-8}\right)\end{array}$ \\
\hline $12 / 18$ & 4 & $180-0$ & $\begin{array}{c}63,000 \\
\left(1.9 \times 10^{-8}\right)\end{array}$ & $(3.075)$ & $\begin{array}{c}2.86 \\
\left(2.62 \times 10^{-8}\right)\end{array}$ \\
\hline \multirow[t]{2}{*}{$12 / 19$} & 6 & $158-308$ & $\begin{array}{c}92,000 \\
\left(2.7 \times 10^{-8}\right)\end{array}$ & $\left(5.3 \times 10^{-8}\right)$ & $\begin{array}{c}3.38 \\
\left(3.09 \times 10^{-8}\right)\end{array}$ \\
\hline & 7 & $308-0$ & $\begin{array}{c}62,000 \\
\left(1.9 \times 10^{-8}\right)\end{array}$ & $\begin{array}{l}.015 \\
\left(6.2 \times 10^{-8}\right)\end{array}$ & $\begin{array}{c}2.40 \\
\left(2.20 \times 10^{-8}\right)\end{array}$ \\
\hline $12 / 20$ & 11 & $303-0$ & $\begin{array}{c}55,000 \\
\left(1.6 \times 10^{-8}\right)\end{array}$ & $\begin{array}{c}.023 \\
\left(9.4 \times 10^{-8}\right)\end{array}$ & $\begin{array}{c}2.24 \\
\left(2.05 \times 10^{-8}\right)\end{array}$ \\
\hline
\end{tabular}




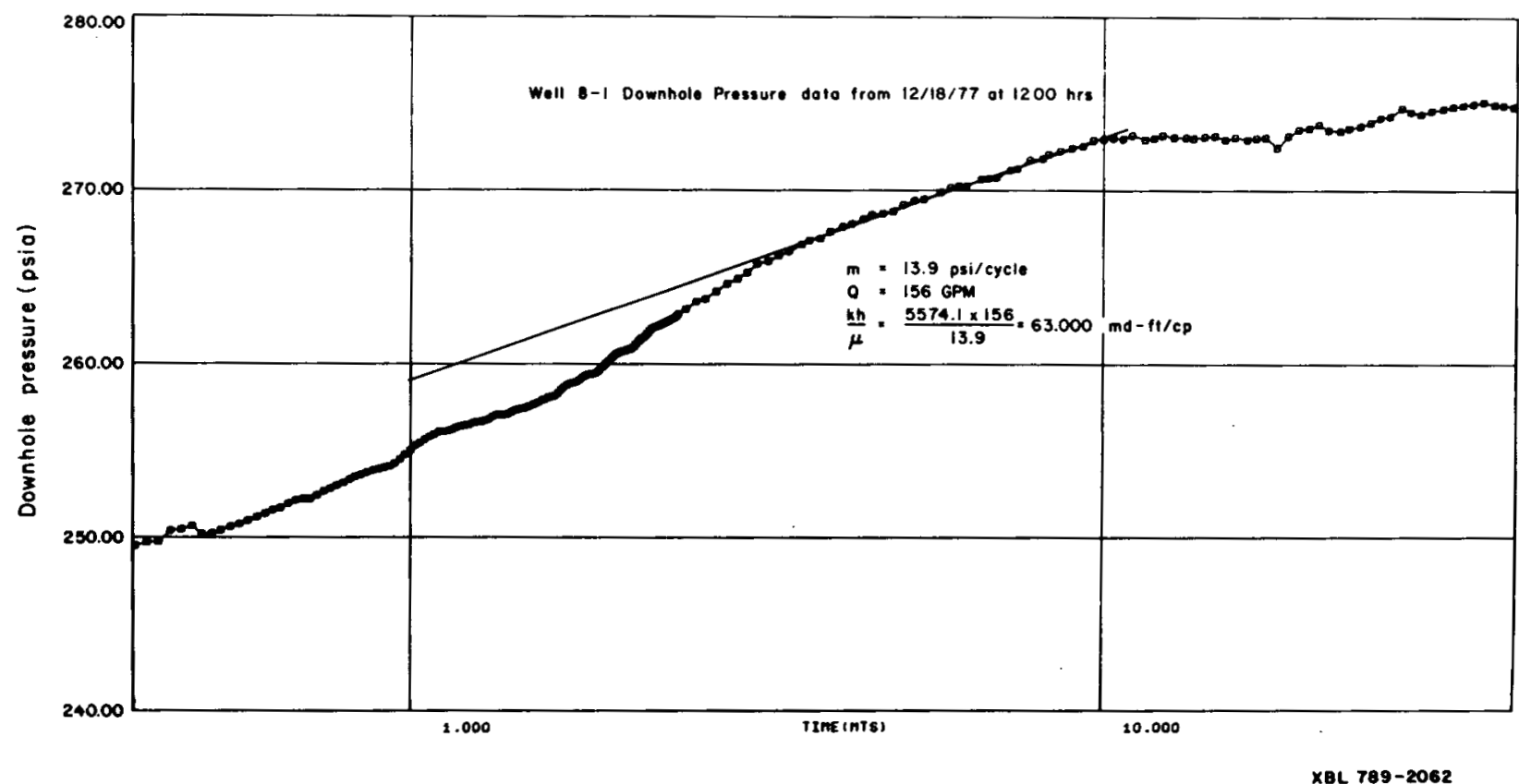

Figure A.7. Downhole pressure vs $l o g$ of elapsed time for test segment 4 of the wel1 8-1 production test.

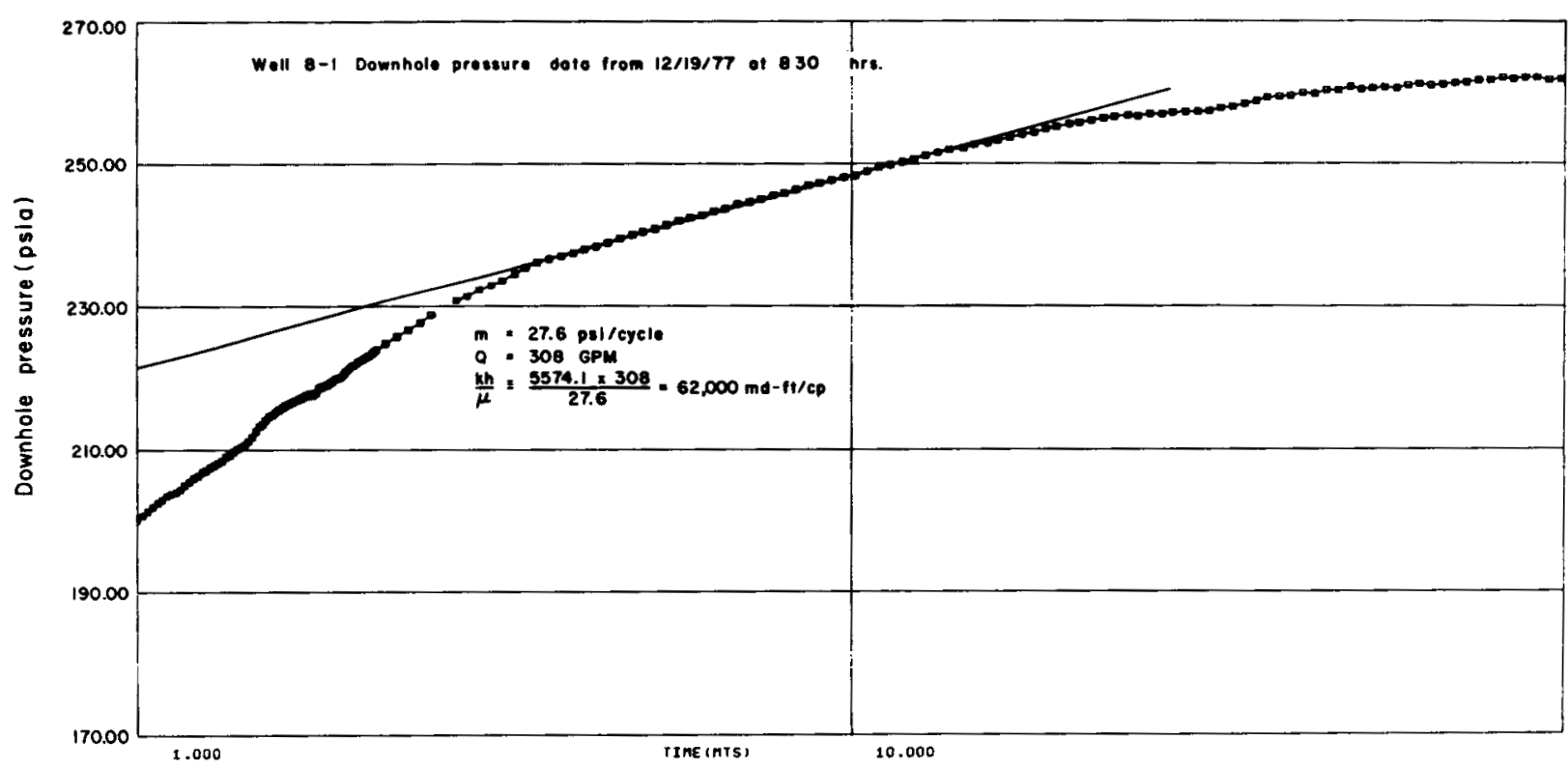

XBL 789-2071

Figure A.8. Downhole pressure vs $\log$ of elapsed time for test segment 7 of the well 8-1 production test. 


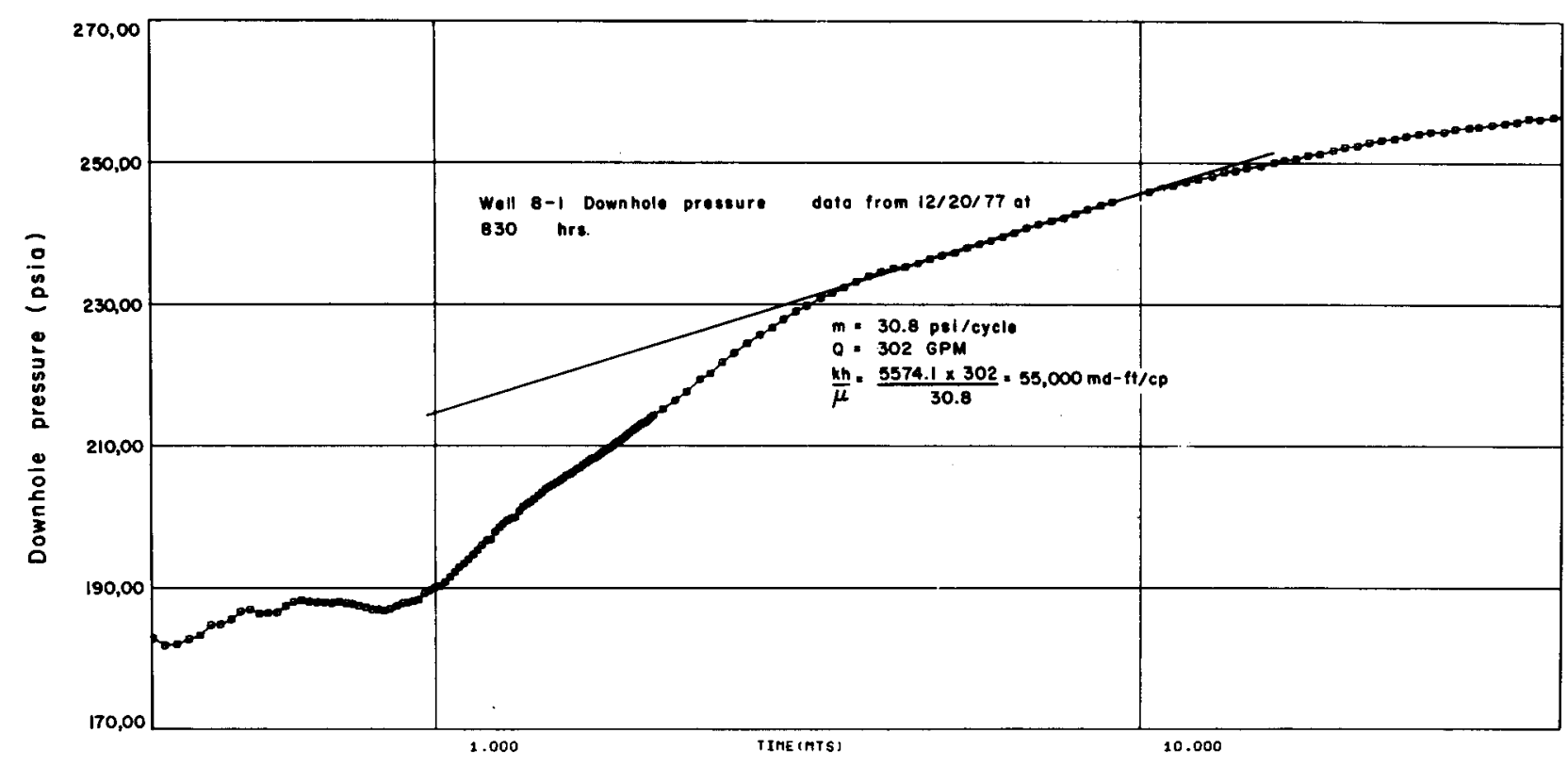

$X B L 789-2068$

Figure A.9. Downhole pressure vs log of elapsed time for test segment 11 of the wel1 8-1 production test. 
6-2 Production test. 1978

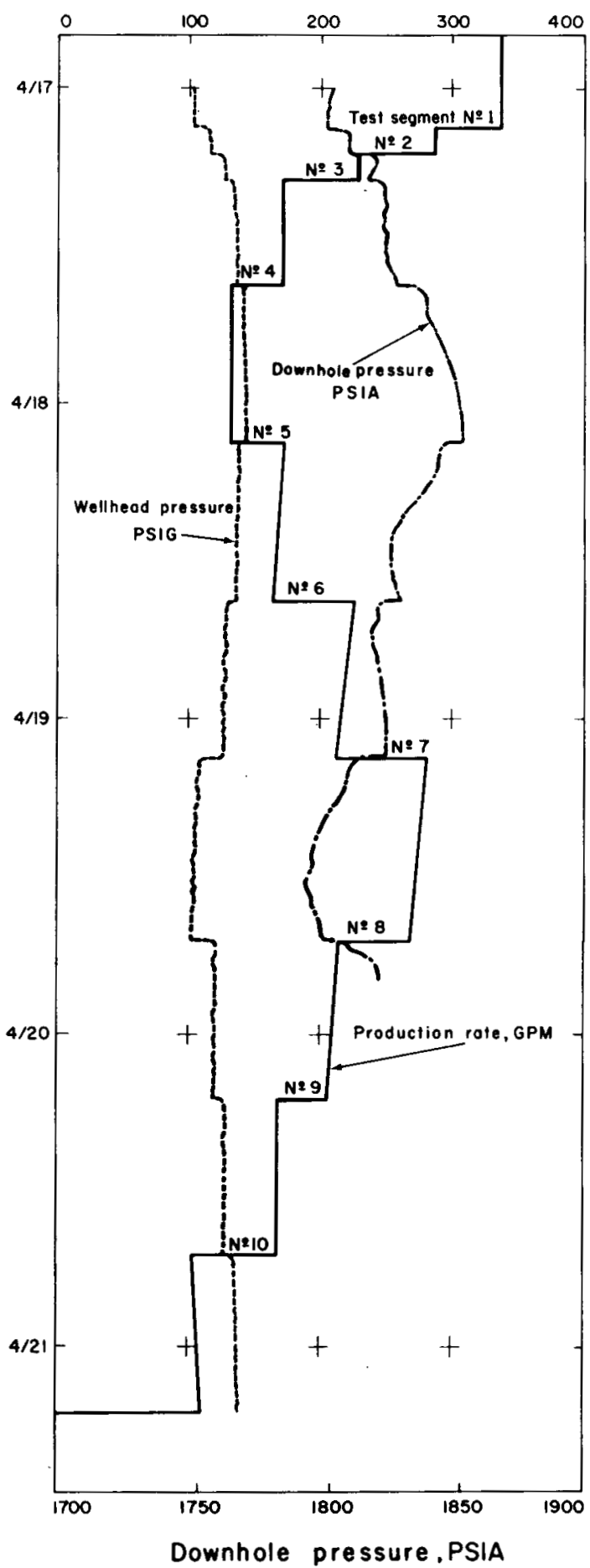

X日L 789-2060

Figure A.10. Plot of wellhead pressures, downhole pressures, and production rates recorded during the well 6-2 production test. Top scale is production rate ( $\mathrm{gpm}$ ), wellhead pressure (psig), and wellhead temperature $\left({ }^{\circ} \mathrm{F}\right)$. 
Table A.3. We11 6-2 production test segments and test results, April 1977.

\begin{tabular}{|c|c|c|c|c|c|}
\hline DATE & SEGMENT & $\begin{array}{l}\text { PRODUCTION } \\
\text { RATE-gpm }\end{array}$ & $\begin{array}{c}\mathrm{kh} / \mu \\
\mathrm{md}-\mathrm{ft} / \mathrm{cp} \\
\left(\mathrm{m}^{3} / \mathrm{sec} / \mathrm{Pa}\right)\end{array}$ & $\begin{array}{c}\phi \operatorname{chr}_{\mathrm{e}}^{2} \\
\mathrm{ft} \mathrm{t}^{3} / \mathrm{psi} \\
\left(\mathrm{m}^{3} / \mathrm{Pa}\right)\end{array}$ & $\begin{array}{c}\text { P.I. } \\
\text { gpm/psi } \\
\left(\mathrm{m}^{3} / \mathrm{sec} / \mathrm{Pa}\right)\end{array}$ \\
\hline \multirow[t]{3}{*}{$4 / 17$} & 1 & $339-286$ & $\begin{array}{c}70,000 \\
\left(2.1 \times 10^{-8}\right)\end{array}$ & $\left(3 . \dot{9} 7 \times 10^{-6}\right)$ & $\begin{array}{c}4.35 \\
\left(3.98 \times 10^{-8}\right)\end{array}$ \\
\hline & 3 & $228-169$ & $\begin{array}{l}111,000 \\
\left(3.3 \times 10^{-8}\right)\end{array}$ & $\left(3.08 \times 10^{-7}\right)$ & $\begin{array}{c}4.74 \\
\left(4.34 \times 10^{-8}\right)\end{array}$ \\
\hline & 4 & $169-131$ & $\begin{array}{c}47,000 \\
\left(1.4 \times 10^{-8}\right)\end{array}$ & $\left(4.11 \times 10^{-8}\right)$ & $\begin{array}{c}1.79 \\
\left(1.64 \times 10^{-8}\right)\end{array}$ \\
\hline \multirow[t]{2}{*}{$4 / 18$} & 5 & $131-172$ & $\begin{array}{c}73,000 \\
\left(2.2 \times 10^{-8}\right)\end{array}$ & $\left(4.07 \times 10^{-7}\right)$ & $\begin{array}{c}3.36 \\
\left(3.07 \times 10^{-8}\right)\end{array}$ \\
\hline & 6 & $164-225$ & $\begin{array}{c}142,000 \\
\left(4.27 \times 10^{-8}\right)\end{array}$ & $\left(4.11 \times 10^{-8}\right)$ & $\begin{array}{c}4.92 \\
\left(4.5 \times 10^{-8}\right)\end{array}$ \\
\hline $4 / 19$ & 7 & $212-281$ & $\begin{array}{c}73,000 \\
\left(2.2 \times 10^{-8}\right)\end{array}$ & $\left(4.56 \times 10^{-7}\right)$ & $\begin{array}{c}3.41 \\
\left(3.12 \times 10^{-8}\right)\end{array}$ \\
\hline
\end{tabular}




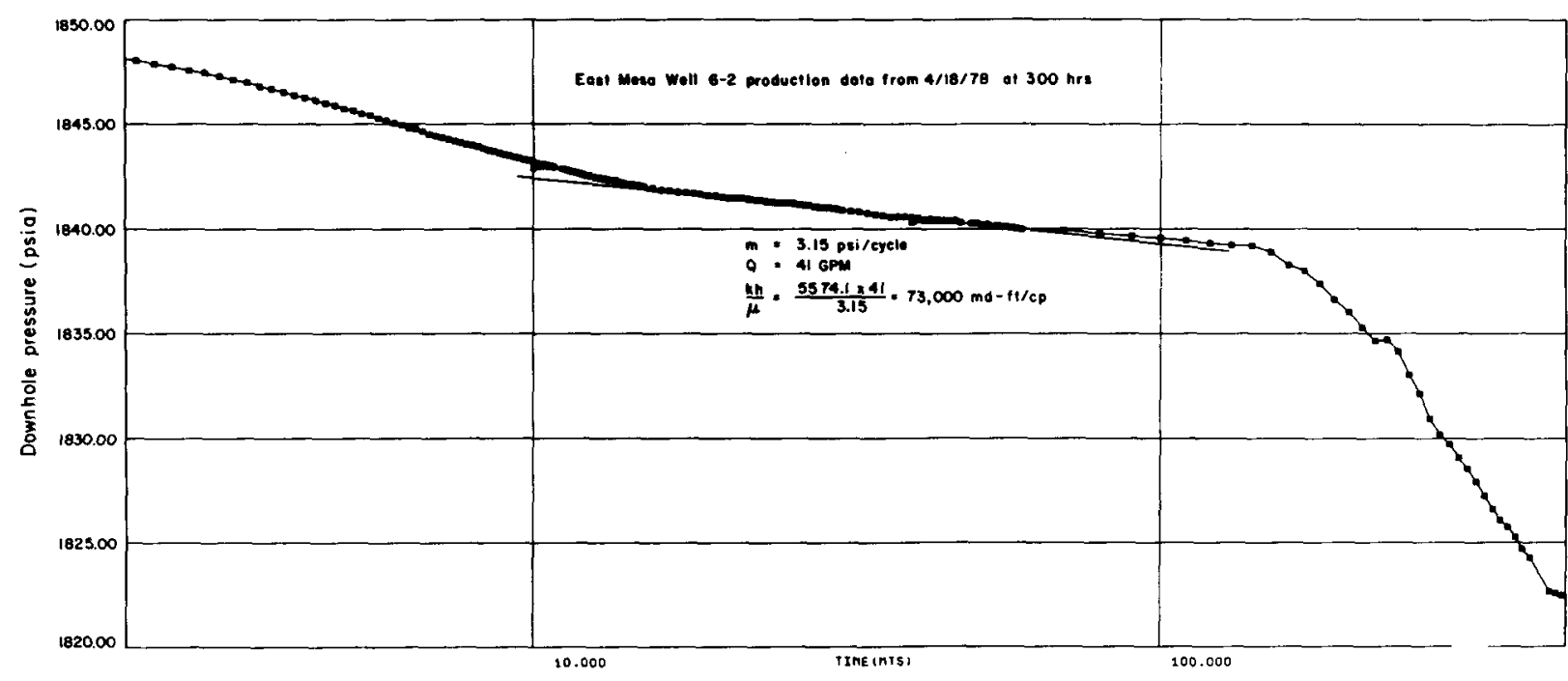

$X B L 789-2070$

Figure A.11. Downhole pressure vs $10 \mathrm{~g}$ of elapsed time for test segment 5 of the well 6-2 production test.

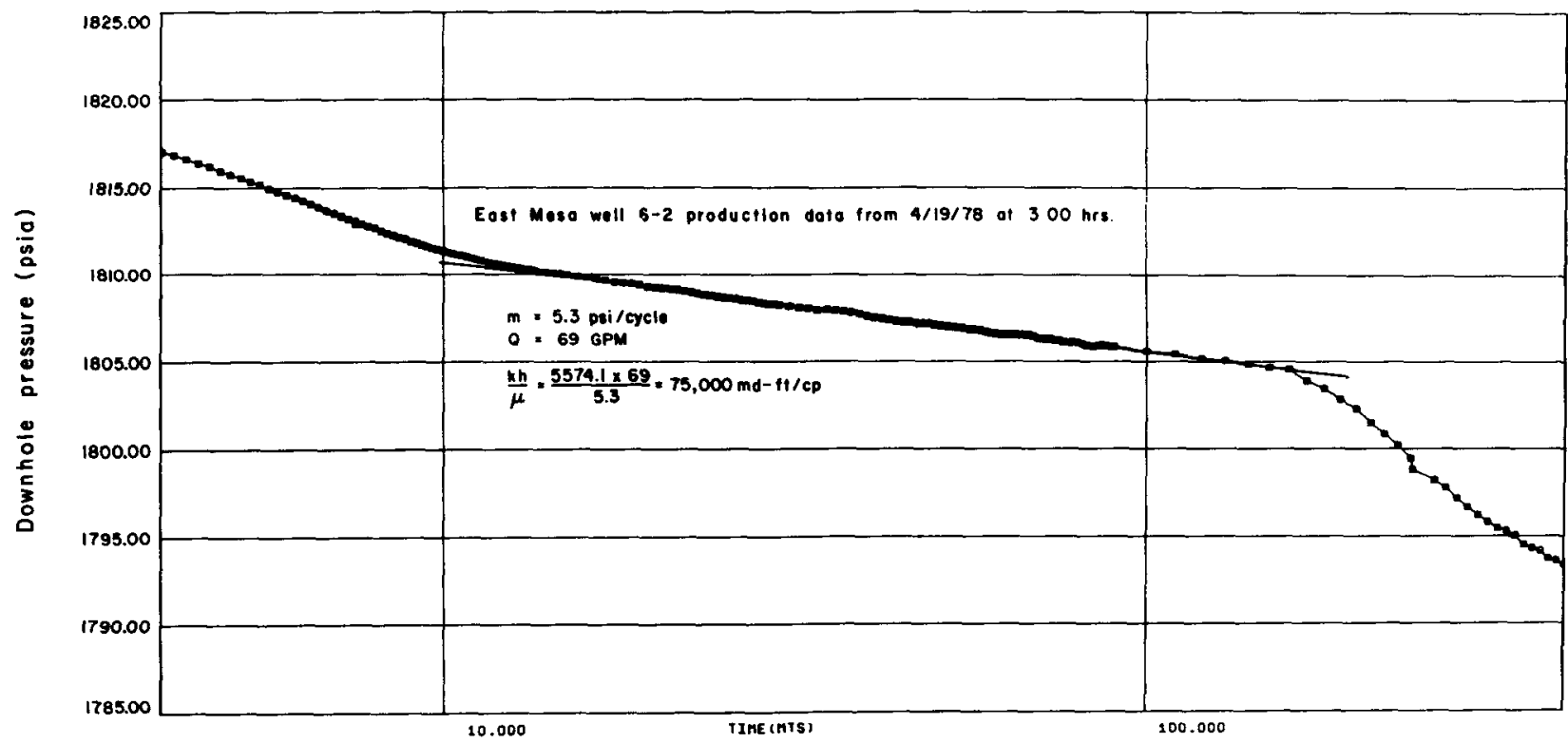

XEL $789-2069$

Figure A.12. Downhole pressure vs $10 \mathrm{~g}$ of elapsed time for test segment 7 of the we11 6-2 production test. 


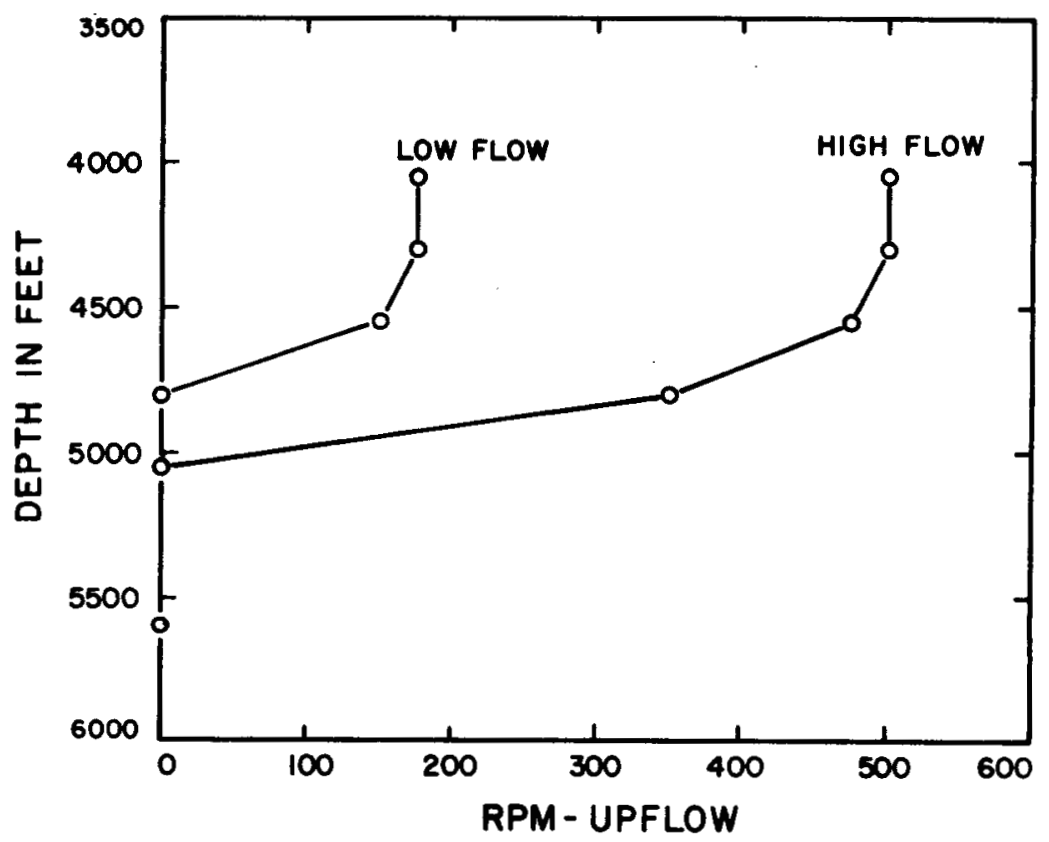

XEL 789-2083A

STEVY DATA - WEL FIOWTG

\begin{tabular}{|c|c|c|c|}
\hline \multirow{2}{*}{ Stops } & & RPM - low rate & high rate \\
\hline & 4050 & 175 & 500 \\
\hline & 4300 & 175 & 500 \\
\hline & 4550 & 150 & 475 \\
\hline & 4800 & 0 & 350 \\
\hline & 5050 & 0 & 0 \\
\hline & 5600 & 0 & 0 \\
\hline
\end{tabular}

Open intervals 4567' to $5455^{\prime}$ perforations

$5456^{\prime}$ to $5957^{\prime}$ 'slotted

Figure A.13. Results of a spinner survey taken in well 6-2. 
6-1 Production test. 1978

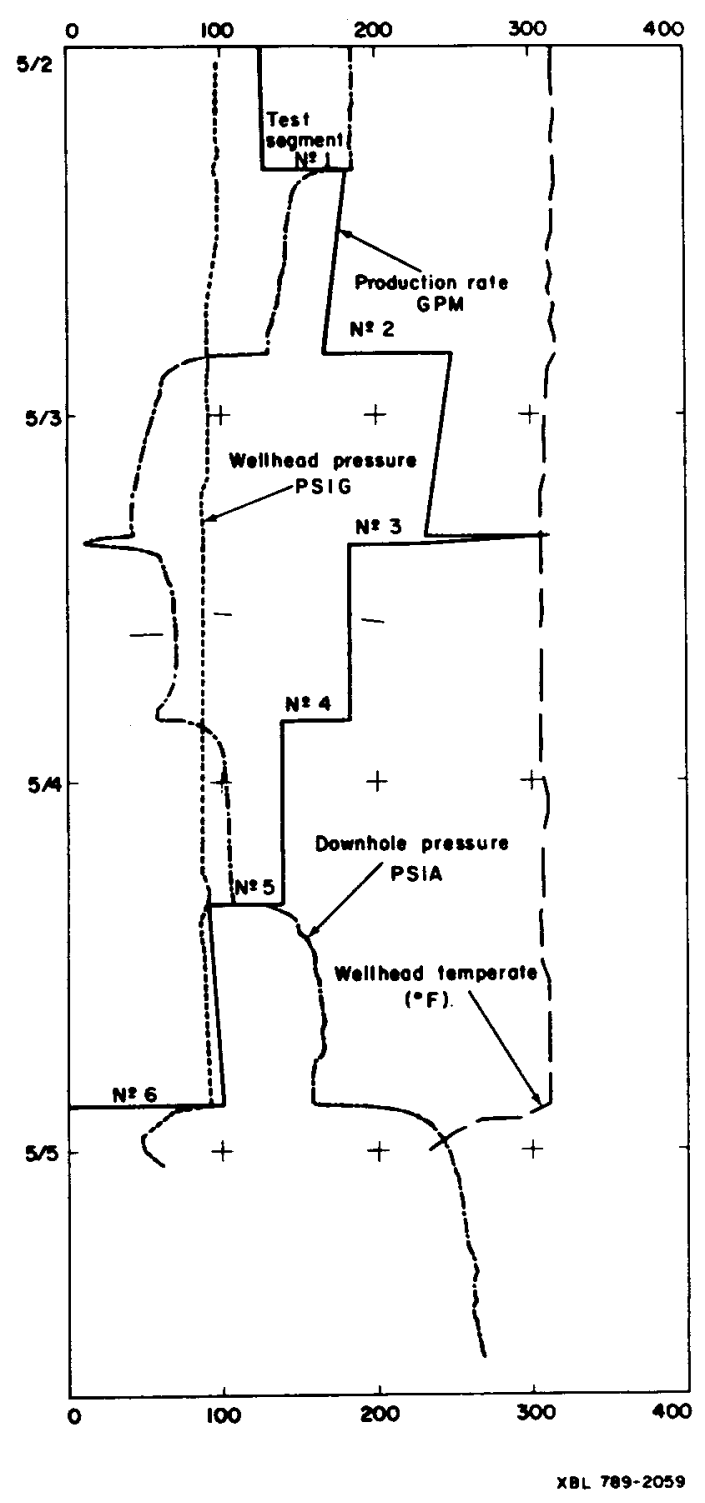

Figure A.14. Plot of wellhead temperature and pressure, production rate and downhole pressure recorded during the well 6-1 production test. Both scales refer to production rate $(\mathrm{gpm})$, wellhead pressure (psig), wellhead temperature $\left({ }^{\circ} \mathrm{F}\right)$, and relative downhole pressure (psia). 
Table A.4. We11 6-1 production test segments and test results, May 1977 .

\begin{tabular}{|c|c|c|c|c|c|}
\hline DATE & $\begin{array}{c}\text { TEST } \\
\text { SEGMENT }\end{array}$ & $\begin{array}{l}\text { PRODUCTION } \\
\text { RATE-gPm }\end{array}$ & $\begin{array}{c}\mathrm{kh} / \mu \\
\mathrm{md}-\mathrm{ft} / \mathrm{cp} \\
\left(\mathrm{m}^{3} / \mathrm{sec} / \mathrm{Pa}\right)\end{array}$ & $\begin{array}{c}\phi c h r_{e}^{2} \\
\mathrm{ft}^{3} / \mathrm{psi} \\
\left(\mathrm{m}^{3} / \mathrm{Pa}\right)\end{array}$ & $\begin{array}{c}\text { P.I. } \\
\text { gpm/psi } \\
\left(\mathrm{m}^{3} / \mathrm{sec} / \mathrm{Pa}\right)\end{array}$ \\
\hline \multirow[t]{2}{*}{$5 / 2$} & 1 & $123-183$ & $\begin{array}{c}15,000 \\
\left(4.5 \times 10^{-9}\right)\end{array}$ & $\left(5.83 \times 10^{-7}\right)$ & $\left(8.1 \times 10^{-9}\right)$ \\
\hline & 2 & $167-250$ & $\begin{array}{c}14,000 \\
\left(4.2 \times 10^{-9}\right)\end{array}$ & $\left(5.83 \times 10^{-7}\right)$ & $\left(7.6 \times 10^{-9}\right)$ \\
\hline $5 / 3$ & 5 & $183-139$ & $\begin{array}{c}14,000 \\
\left(4.2 \times 10^{-9}\right)\end{array}$ & $\left(3.33 \times 10^{-7}\right)$ & $\left(7.1 \times 10^{-9}\right)$ \\
\hline \multirow[t]{2}{*}{$5 / 4$} & 6 & $139-91$ & $\begin{array}{c}13,000 \\
\left(3.9 \times 10^{-9}\right)\end{array}$ & $\begin{array}{c}.109 \\
\left(4.48 \times 10^{-7}\right)\end{array}$ & $\begin{array}{c}1.11 \\
\left(1.0 \times 10^{-8}\right)\end{array}$ \\
\hline & 7 & 91.0 & $\begin{array}{c}12,000 \\
\left(3.6 \times 10^{-9}\right)\end{array}$ & $\begin{array}{c}0.59 \\
\left(2.42 \times 10^{-6}\right)\end{array}$ & $\left(6.0 \times 10^{-9}\right)$ \\
\hline
\end{tabular}




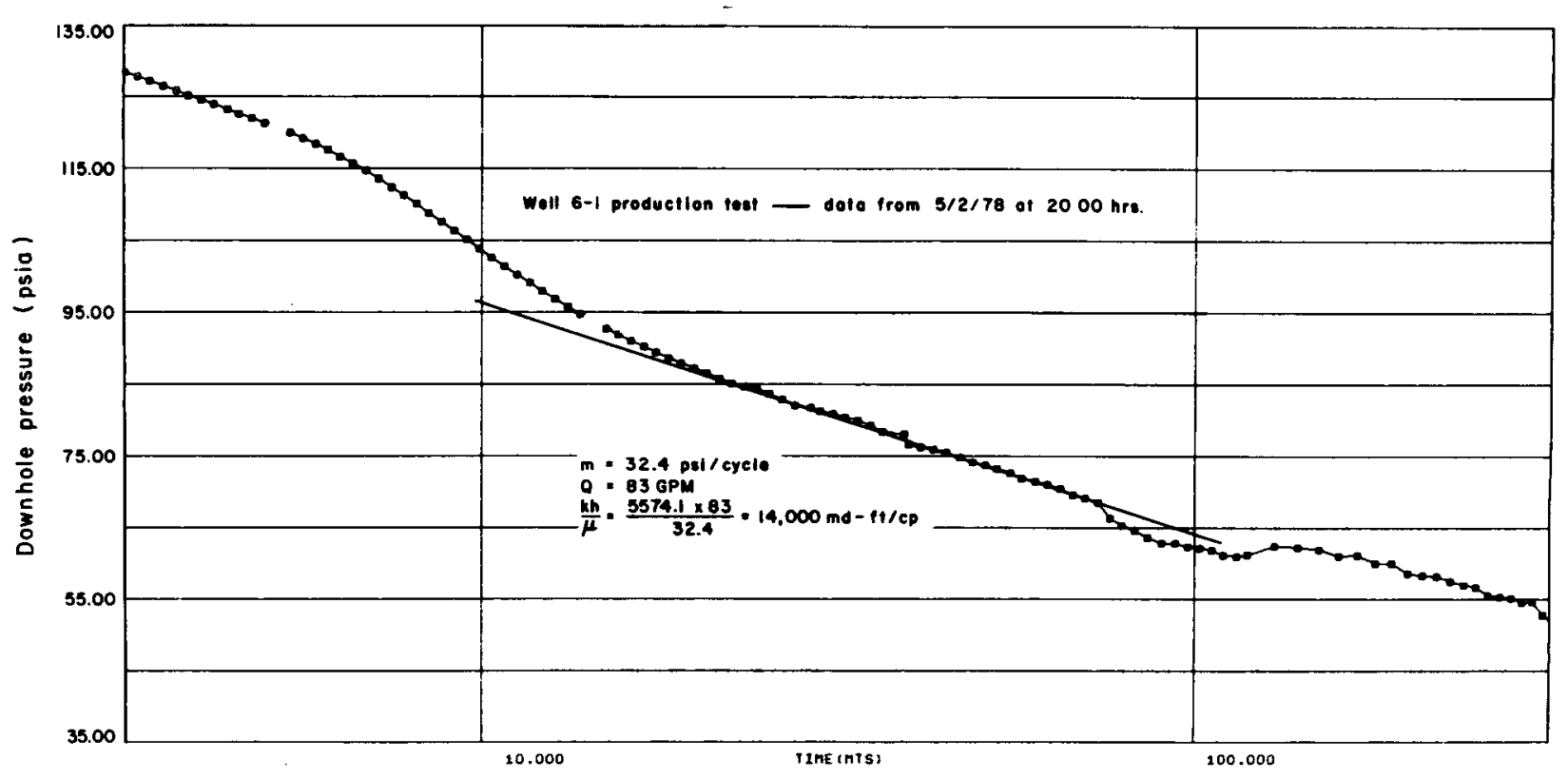

XBL 789-2065

Figure A.15. Downhole pressure vs $10 \mathrm{~g}$ of elapsed time for test segment 2 of the well 6-1 production test.

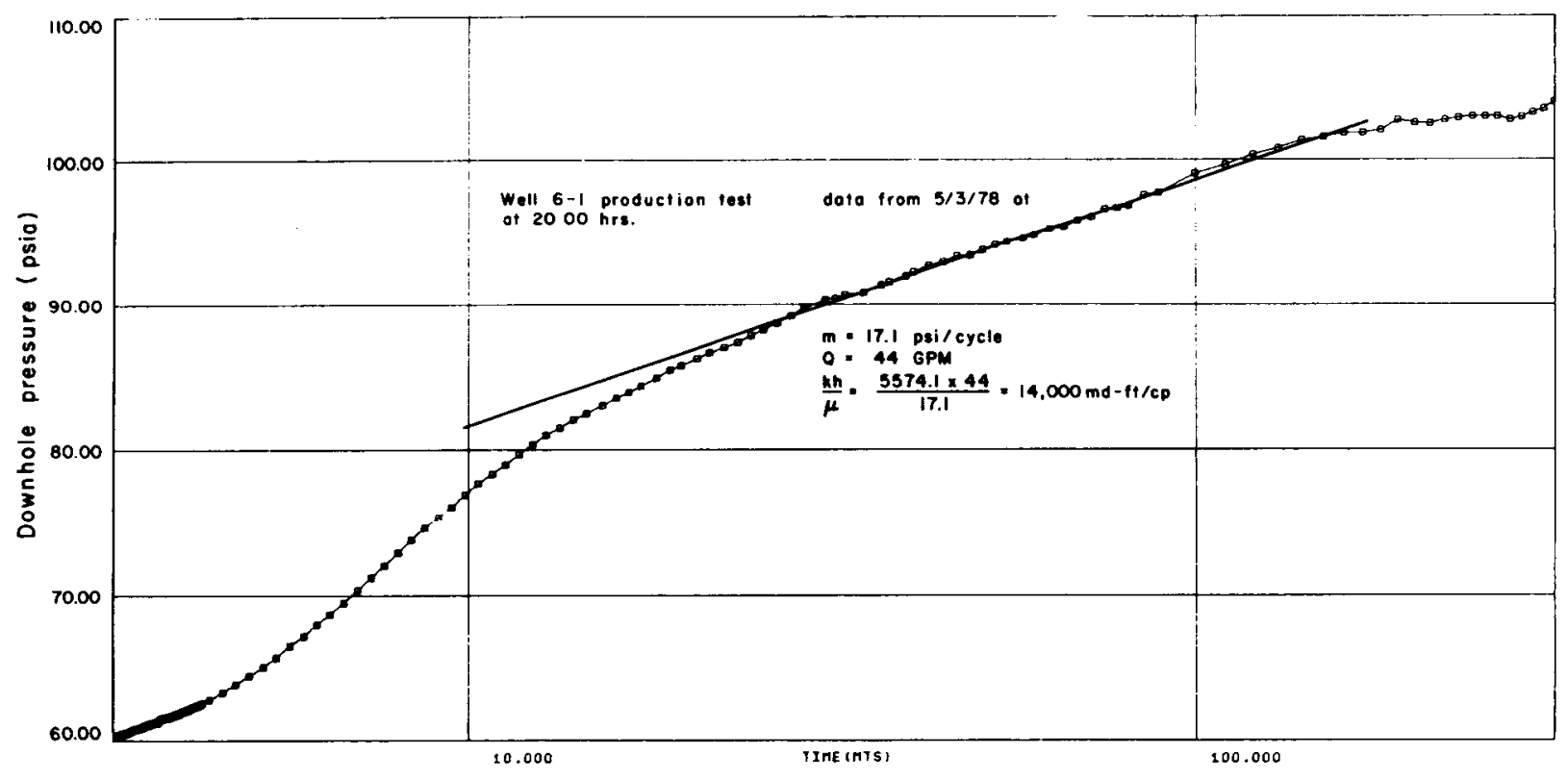

XBL 789-2061

Figure A.16. Downhole pressure vs log of elapsed time for test segment 5 of the well 6-1 production test. 


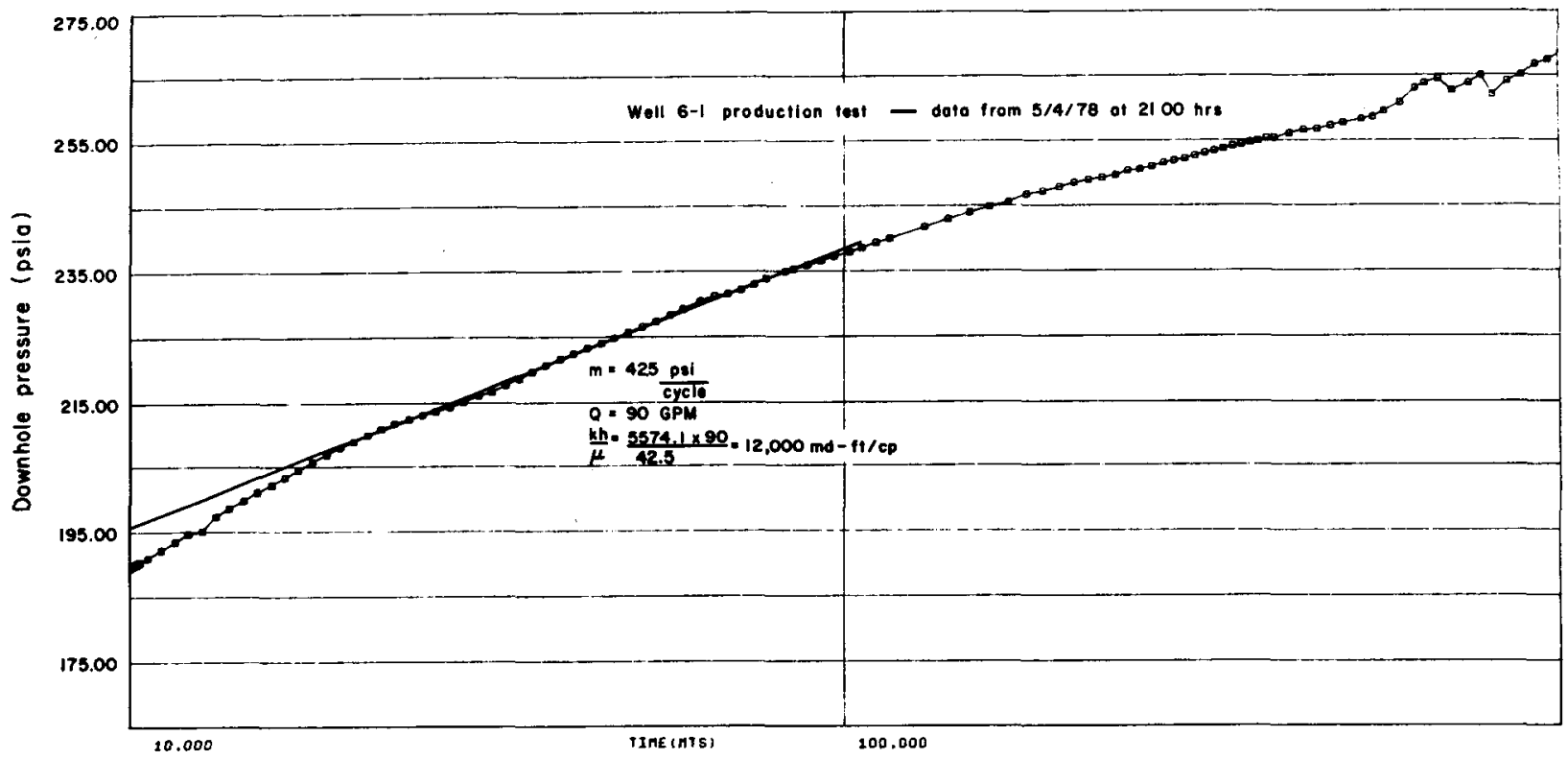

XBL 789-2066

Figure A.17. Downhole pressure vs $\log$ of elapsed time for test segment 7 of the we11 6-1 production test. 


\section{APPENDIX B: INTERFERENCE TESTS}

INTRODUCTION

Interference test data are analyzed using a least-squares computer matching program that can solve for transmissivity, storativity, and the distance to an image wel1.* The program employs an analytical solution, which models the well as a line source that fully penetrates the reservoir. In addition, it assumes the reservoir is isotropic, vertically bounded, of constant thickness, isothermal, and areally infinite. Using the superposition principle, the program can analyze pressure data that are affected by the production of many wells, each with a variable production rate.

Interference data are obtained using a sensitive ( $0.01 \mathrm{psi})$ wellhead transducer. Wellhead pressure is recorded continuously by a digital paper printer for the duration of the test. Diurnal pressure variations of approximately $0.2 \mathrm{psi}$, assumed to be caused by earthtides, are present in the data. Data processing before analysis consists of smoothing the data by eye to eliminate these diurnal variations. Representative pressure points are then selected for analysis.

Flow rate data are obtained using orifice flow meters with chart recorders or weir plate flow meters with chart recorders. Due to the difficulties inherent in measuring two-phase flow and the problem of scaling in geothermal systems, the accuracy of the flow rate data is far less than the accuracy of the pressure data. Thus the accuracy of reservoir parameters obtained from any analysis can be, at best, only as accurate as the flow-rate measurements.

Interference test data analyses are complicated by the effect of different completion and perforation intervals between observation and production wells. In this case, lateral inhomogeneities such as

\footnotetext{
* An image well is used to mathematically represent a linear hydrologic vertical boundary in the reservoir. The sign of an image well and its distance to an observation well is equivalent information about the type (barrier or leaky) and location of a linear boundary.
} 
shale lenses can strongly effect the local vertical permeability of the reservoir, leading to misinterpretation of the data. The analytical solution employed by the program does not account for partially penetrating production wells or inhomogeneity of any kind in the reservoir. Thus it must be used cautiously to avoid misinterpretation of the data. Conversely, in some cases the lack of a good match of pressure data has led to the inference that the reservoir model used by the program is not accurate enough to permit meaningful analysis.

\section{INTERFERENCE TESTS IN USBR AND MAGMA POWER PROPERTIES}

Interference tests in this area are complicated by the different completion and perforation intervals of the wells. They are further complicated by the complex geology, the different local permeabilities associated with each we11, and the complex fault system in the area. Two interference tests have been conducted in the USBR and Magma Power portions of the East Mesa KGRA. They are discussed in separate sections below.

\section{TEST 1}

Test 1 involved six wells; two producing we11s (6-1 and 6-2) and five observation wel1s $(8-1,38-30,6-1,44-7$ and $31-1)$. Table B.1 is a schematic of the various production and observation periods of these wells and Table B.2 is a summary of the characteristics of the observation data obtained.

Due to the low production rates of wells $6-1$ and $6-2$, observed drawdowns at all observation wells were small. Wells $8-1$ and $38-30$ experienced no observable drawdown due to the production of wells 6-1 and 6-2. Wells 6-1, 44-7, and 31-1 had noticeable drawdowns. However, for none of these wells were the pressure data readily analyzable.

\section{We11 6-1}

Analysis of pressure data from we11 6-1 was complicated because it was flowed briefly before the test. When production of well 6-2 began (10 February 1977), well 6-1 was still losing wellhead pressure due to the cooling of the well, thus causing uncertainty in its initial 
pressure (Figure B.1). Analysis is further complicated by the different completion intervals of well 6-1 (1980 m to $2444 \mathrm{~m})$ and well 6-2 (1460 m and $1816 \mathrm{~m}$ ). The best estimates of the transmissivity and storativity of the reservoir between these two wells, ignoring the abovementioned difficulties, are $140,000 \mathrm{md}-\mathrm{ft} / \mathrm{cp}\left(4.2 \times 10^{-8} \mathrm{~m}^{3} / \mathrm{sec} / \mathrm{Pa}\right)$ and $2 \times 10^{-3}$ $\mathrm{ft} / \mathrm{psi}\left(9.0 \times 10^{-8} \mathrm{~m} / \mathrm{Pa}\right)$.

\section{We11 44-7}

Interpretation of pressure data from well 44-7 is not straightforward due to the unknown effects of injection into and production from well 46-7 before and during the test. Well 46-7 is a shallow (934 m) well located approximately $400 \mathrm{~m}$ from well 44-7. The increase in wellhead pressure at we11 44-7 after injection into well 46-7 (see Figure B.2), creates uncertainty in the initial pressure of $44-7$ and seems to indicate communication between the shallow and deep zones of the reservoir. In a separate test, designed to determine whether such vertical communication does exist, we 11 44-7 was produced and wells 48-7 and 46-7 were monitored. Whereas well 48-7, a deep well located approximately $800 \mathrm{~m}$ from well 44-7, showed a drawdown of approximately $0.2 \mathrm{psi}$, well 46-7 showed no pressure response. However, due to the short duration of this test ( $\sim 12$ hours of production) no conclusion was drawn regarding communication between the shallow (well 46-7) and deep (wel1 44-7) reservoir zones. In addition, a later test (Interference Test 2) indicates that well 6-1 does not communicate with well 44-7, thus indicating that we11 6-2 production alone is responsible for the pressure response of we 11 44-7.

We $1131-1$

During the test, wel1 31-1 experienced a drawdown of 0.2 psi (Figure B.3). Although this indicates hydraulic continuity between the northern and southern portions of the reservoir, it is difficult to obtain estimates of the reservoir parameters or reservoir geometry for such small drawdowns. In addition, diurnal and bi-weekly fluctuations of the reservoir pressure, presumably caused by earth-tides, partially obscure the pressure response. If an homogeneous reservoir 
with a transmissivity of $160,000 \mathrm{md}-\mathrm{ft} / \mathrm{cp}\left(4.8 \times 10^{-8} \mathrm{~m} / \mathrm{sec} / \mathrm{Pa}\right)$ is assumed, it is necessary to postulate the existence of recharge in the reservoir to account for the small drawdown observed.

TEST 2

Test 2 involved six wel1s; four production wells $(6-2,8-1,44-7$, and 46-7) and two observation wells (6-1 and 48-7). Table B.3 is a schematic of production and observation periods of the we $11 \mathrm{~s}$ and Table B.4 summarizes the characteristics of the observation data obtained.

\section{We11 6-1}

Wel1 6-1 had a maximum drawdown of 2.5 psi during the test (Figure B.4). Calculations using the actual flow-rate data from wells 44-7, 6-2, and 8-1 were made. Assuming a reservoir transmissivity of $160,000 \mathrm{md}-\mathrm{ft} / \mathrm{cp}\left(4.8 \times 10^{-8} \mathrm{~m}^{3} / \mathrm{sec} / \mathrm{Pa}\right)$; a reservoir storativity of $2 \times 10^{-3} \mathrm{ft} / \mathrm{psi}\left(9.8 \times 10^{-8} \mathrm{~m} / \mathrm{Pa}\right)$; and reservoir homogeneity, calculations predict maximum drawdowns of 4 psi due to well 8-1 production, 7 psi due to well 44-7 production, and 2.1 psi due to well 6-2 production. The small drawdown actually observed at well 6-1, combined with the absence of any build-up at the cessation of production of wel1s 8-1 and 44-7 (see Table B.3) indicate a lack of communication between well 6-1 and both wells 44-7 and 8-1. Assuming that the drawdown at 6-1 is caused only by we11 6-2, the analysis still remains difficult due to the different completion intervals of wells 6-1 and 6-2. Production tests on wel1 6-1 yield anomalously low values of the reservoir transmissivity in the vicinity of well 6-1, thus further complicating analysis. Late-time pressure data can be matched assuming a transmissivity of $140,000 \mathrm{md}-\mathrm{ft} / \mathrm{cp}\left(4.2 \times 10^{-8} \mathrm{~m}^{3} / \mathrm{sec} / \mathrm{Pa}\right)$ and a storativity of $2 \times 10^{-3}$ $\mathrm{ft} / \mathrm{psi}\left(9 \times 10^{-8} \mathrm{~m} / \mathrm{Pa}\right)$ for the reservoir between wells $6-1$ and $6-2$.

\section{We11 48-7}

Wel1 48-7 experienced a maximum drawdown of 17 psi (Figure B.5). It is not clear whether there is communication between we $11 \mathrm{~s} 8-1$ and 48-7. A test of longer duration or with higher flow rates and with well 8-1 as the sole producer would be necessary to determine this. 
Analysis of pressure data from well 48-7 was done first by assuming that only wells 44-7 and 8-1 affected the drawdown. A reservoir transmissivity of $250,000 \mathrm{md}-\mathrm{ft} / \mathrm{cp}\left(75 \times 10^{-8} \mathrm{~m}^{3} / \mathrm{sec} / \mathrm{Pa}\right)$ and a reservoir storativity of $1 \times 10^{-3} \mathrm{ft} / \mathrm{psi}\left(5 \times 10^{-8} \mathrm{~m} / \mathrm{Pa}\right)$ were obtained. The analysis was repeated with the assumption that only we11 44-7 communicated with well 48-7. The values of the reservoir parameters obtained were similar. Analysis of we11 48-7 data in both cases did not indicate the presence of any recharge or barrier boundaries in the reservoir. As injection into well 46-7 was not accounted for in the analysis, the relatively good match of the pressure data by the computer matching program lends credence to the assumption that there is limited communication between the shallow and deep reservoirs.

\section{INTERFERENCE TESTS IN THE REPUBLIC GEOTHERMAL PROPERTY}

Three interference tests were conducted on the Republic Geothermal, Inc. (RGI) wel1s in 1977. Each test consisted of producing a single well at variable flow rates of up to $1000 \mathrm{gpm}$. Several observation wells were monitored during each test. Produced fluids were injected into wel1 18-28, which is located far enough from the observation wells to assure that the effect of injection on observed pressures is negligible. In each test, analysis of pressure data was facilitated by sufficiently large drawdowns at each of the communicating observation wells.

\section{Test 1}

We11 38-30 was produced for four days with a variable flow rate, which consisted of seven step-rate changes $(250,500,900,750,500$, 250 and $0 \mathrm{gpm}$ ). Wells 56-30, 31-1, and 16-29 were monitored for pressure response (Figures B.6, B.7, and B.8). Table B.5 lists the distance from we11 38-30 and maximum drawdowns recorded for each of the observation wells.

Analysis of pressure data gives reservoir transmissivity values ranging from $120,000 \mathrm{md}-\mathrm{ft} / \mathrm{cp}\left(3.6 \times 10^{-8} \mathrm{~m}^{3} / \mathrm{sec} / \mathrm{Pa}\right)$ to $160,000 \mathrm{md}-\mathrm{ft} / \mathrm{cp}$ $\left(4.8 \times 10^{-8} \mathrm{~m} 3 / \mathrm{sec} / \mathrm{Pa}\right)$ and a reservoir storativity ranging from $6 \times 10^{-4}$ $\mathrm{ft} / \mathrm{psi}\left(3.7 \times 10^{-8} \mathrm{~m} / \mathrm{Pa}\right)$ to $1 \times 10^{-3}\left(4 \times 10^{-8} \mathrm{~m} / \mathrm{Pa}\right)$. The analysis of pressure data from both wells 56-30 and 31-1 indicates the presence 
of a barrier boundary in the reservoir. Good computer matches to observed pressure data were obtained from all of the observation we11s.

Test 2

We11 16-29 was produced at a variable rate for four days. Wells 56-30, 31-1, and 16-30 were monitored for pressure response (Figures B.6, B.7 and B.9). None of the observation wells incurred any drawdown due to the production of wel1 16-29. Wel1s $31-1$ and 16-30 are far enough $(1330 \mathrm{~m}$ and $1610 \mathrm{~m})$ from the production well that the lack of presure response can be expected. Well 56-30 however, is $800 \mathrm{~m}$ from well 16-29 and the lack of response (Figure B.6) seems to indicate the pressure of an hydraulic barrier between the two wells. This interpretation must be viewed cautiously because of the uncertainty of the flow rate data of 16-29 caused by the influx of an unknown quantity of cold water into the we11 from the upper $150 \mathrm{~m}$ during production.

\section{Test 3}

We11 38-30 was pumped at a rate of approximately $400 \mathrm{gpm}$ for 40 days. We11s 56-30, 31-1, 16-30, and 78-30 were monitored for pressure response (Figures B.6, B.7, B.9, and B.10). Table B.6 lists the distances to well 38-30 and the maximum drawdown recorded for each of the observation wells.

Analysis of pressure data from wells $56-30$ and $31-1$ yield reservoir transmissivity ranging from $140,000 \mathrm{md}-\mathrm{ft} / \mathrm{cp}\left(4.2 \times 10^{-8} \mathrm{~m}^{3} / \mathrm{sec} / \mathrm{Pa}\right)$ to $160,000 \mathrm{md}-\mathrm{ft} / \mathrm{cp}\left(4.8 \times 10^{-8} \mathrm{~m}^{3} / \mathrm{sec} / \mathrm{Pa}\right)$ and reservoir storativity values ranging from $6 \times 10^{-4} \mathrm{ft} / \mathrm{psi}\left(3 \times 10^{-8} \mathrm{~m} / \mathrm{Pa}\right)$ to $1 \times 10^{-3} \mathrm{ft} / \mathrm{psi}$ $\left(4 \times 10^{-8} \mathrm{~m} / \mathrm{Pa}\right)$. As in Test 1 , analysis of data from these two wells indicates the presence of a barrier boundary in the reservoir. We11 16-30 showed no pressure decline due to the production of well 38-30 (Figure B.9). The transducers used during the test were switched to verify the lack of communication. The lack of communication between wells $16-30$ and 38-30, together with information obtained about image well distances in the analysis of wells 56-30 and 31-1, indicated that a barrier is located between we11s $31-1$ ad 16-30 (see section 3, Figure 3.2).

Analysis of pressure data from well 78-30 yielded a reservoir transmissivity of $115,000 \mathrm{md}-\mathrm{ft} / \mathrm{cp}\left(3.5 \times 10^{-8} \mathrm{~m}^{3} / \mathrm{sec} / \mathrm{Pa}\right)$. The 
anomalously low value of the reservoir transmissivity and the poor computer match of the pressure data indicate that the assumption of reservoir isotropy is incorrect. Clearly communication exists between we11s 78-30 and 38-30 but there appears to be some impediment to the communication. The existence of a partial barrier between the wells is thus inferred.

\section{SUMMARY}

Reservoir transmissivity values obtained from interference tests in the northeastern portion of the East Mesa KGRA range between $120,000 \mathrm{md}-\mathrm{ft} / \mathrm{cp}\left(3.6 \times 10^{-8} \mathrm{~m}^{3} / \mathrm{sec} / \mathrm{Pa}\right)$ to $160,000 \mathrm{md}-\mathrm{ft} / \mathrm{cp}$ $\left(4.8 \times 10^{-8} \mathrm{~m}^{3} / \mathrm{sec} / \mathrm{Pa}\right)$. Reservoir storativity values obtained range from $6 \times 10^{4} \mathrm{ft} / \mathrm{psi}\left(3 \times 10^{-8} \mathrm{~m} / \mathrm{Pa}\right)$ to $1 \times 10^{-3} \mathrm{ft} / \mathrm{psi}\left(4 \times 10^{-8} \mathrm{~m} / \mathrm{Pa}\right)$. Several hydraulic barriers have been located in the northern portion of the reservoir. The repeatability of the test and the consistency of the results give credibility to the values obtained for the reservoir parameters.

The southern portion of the East Mesa KGRA is more perplexing than the northern part of the reservoir. The low flow rates of the production wells and the small drawdowns observed at the observation wells made analysis more difficult at less credible. Analysis was also complicated by pressures at observation wells being affected by the production of more than one well. An estimate of the reservoir transmissivity of $140,000 \mathrm{md}-\mathrm{ft} / \mathrm{cp}\left(4.2 \times 10^{-8} \mathrm{~m}^{3} / \mathrm{sec} / \mathrm{Pa}\right)$ is obtained for the reservoir between wells 6-1 and 6-2. The transmissivity in the Magma property to the south appears to be higher, approximately $250,000 \mathrm{md}-\mathrm{ft} / \mathrm{cp}$ $\left(7.5 \times 10^{-8} \mathrm{~m}^{3} / \mathrm{sec} / \mathrm{Pa}\right)$. 
Table B.1. Schematic of Interference Test 1.

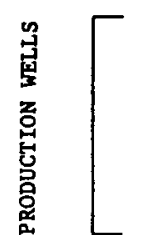

\begin{tabular}{|cccc} 
Well 6-2 Production $250 \mathrm{gpm}$ & $4 / 13 / 77$ \\
$2 / 22 / 77$ & Well 6-1 Production $250 \mathrm{gpm}$ & $4 / 13 / 77$
\end{tabular}

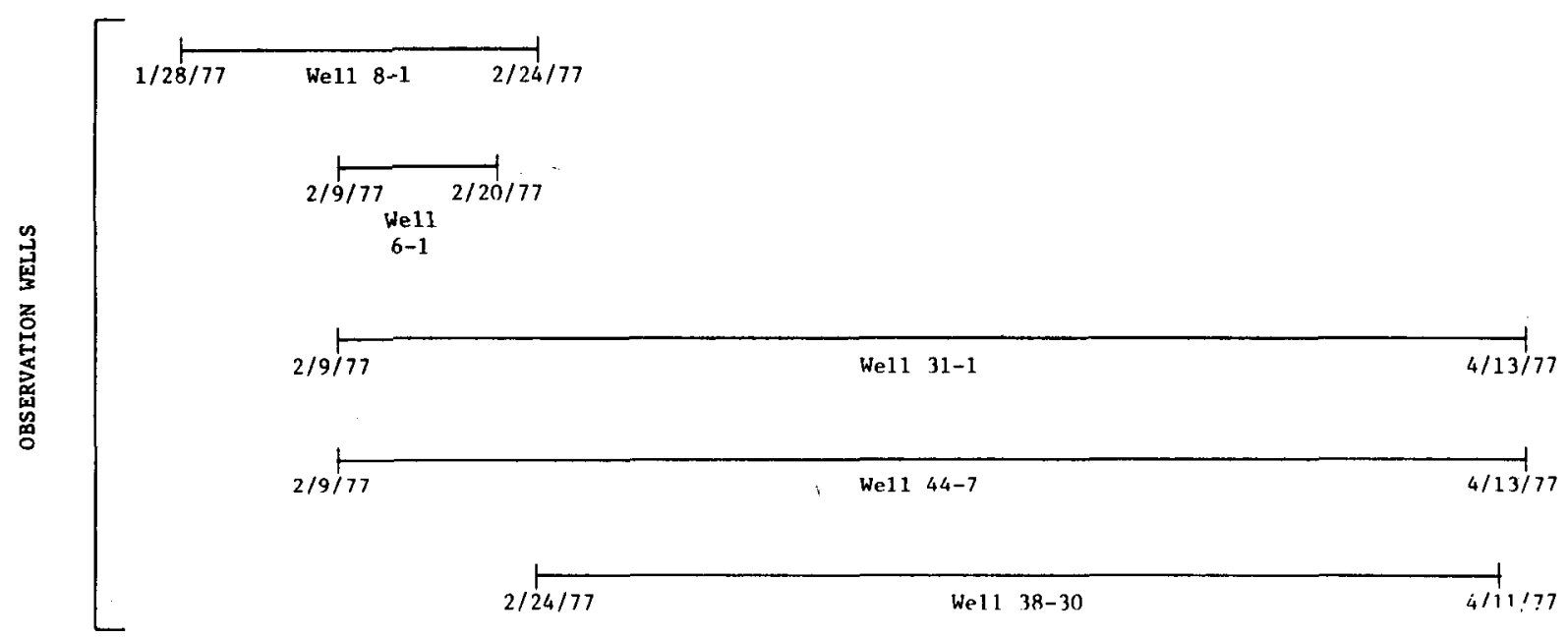

Table B.2. Summary of observation data of Interference Test 1.

\begin{tabular}{|c|c|c|c|c|}
\hline OBSERVATION WELL & $\begin{array}{l}\text { DISTANCE T } \\
6-1\end{array}$ & $\begin{array}{l}\text { TION WELL } \\
6-2\end{array}$ & $\begin{array}{l}\text { MAXIMUM } \Delta P \\
\text { (psi) }\end{array}$ & COMMENTS \\
\hline $6-1$ & & $450 m$ & 0.7 & $\begin{array}{l}\text { Uncertain initial pressure. } \\
\text { Different completion intervals } \\
\text { between observation and produc- } \\
\text { tion wells. }\end{array}$ \\
\hline $8-1$ & $710 \mathrm{~m}$ & $1,120 \mathrm{~m}$ & 0.0 & Hydraulic barrier infered. \\
\hline $31-1$ & $2,900 \mathrm{~m}$ & $2,700 \mathrm{~m}$ & 0.2 & \\
\hline $44-7$ & $970 \mathrm{~m}$ & $900 \mathrm{~m}$ & 0.7 & Uncertain Initial pressure. \\
\hline $38-30$ & $3,000 \mathrm{~m}$ & $2,900 \mathrm{~m}$ & 0.0 & $\begin{array}{l}\text { Ton far from the production wells } \\
\text { to have observable drawdown with } \\
\text { glven production rates. }\end{array}$ \\
\hline
\end{tabular}




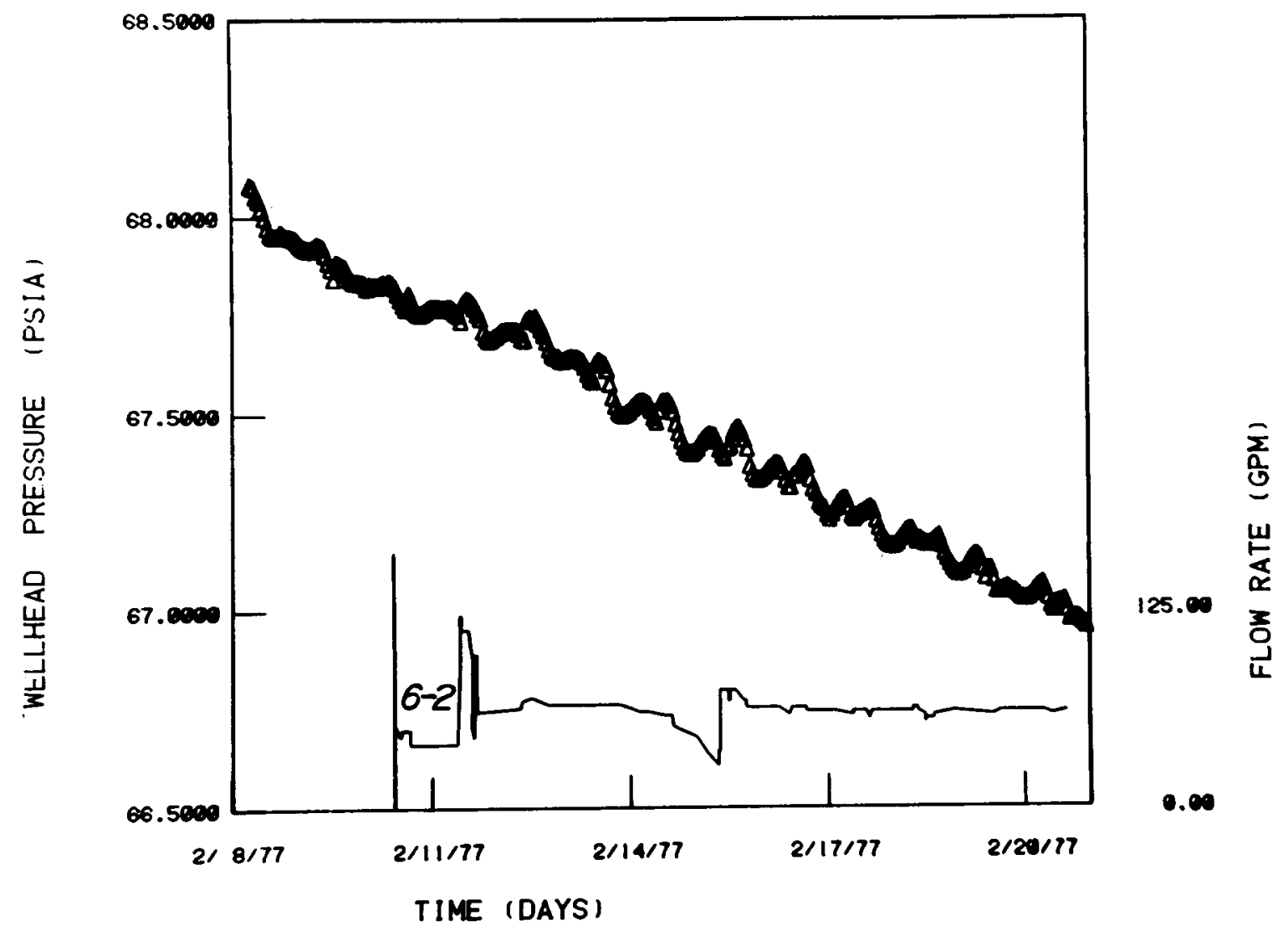

XBL 789-10778 A

Figure B.1. Wellhead pressure of well 6-1 and flow rate of well 6-2 during Interference Test 1, USBR and Magma properties. 


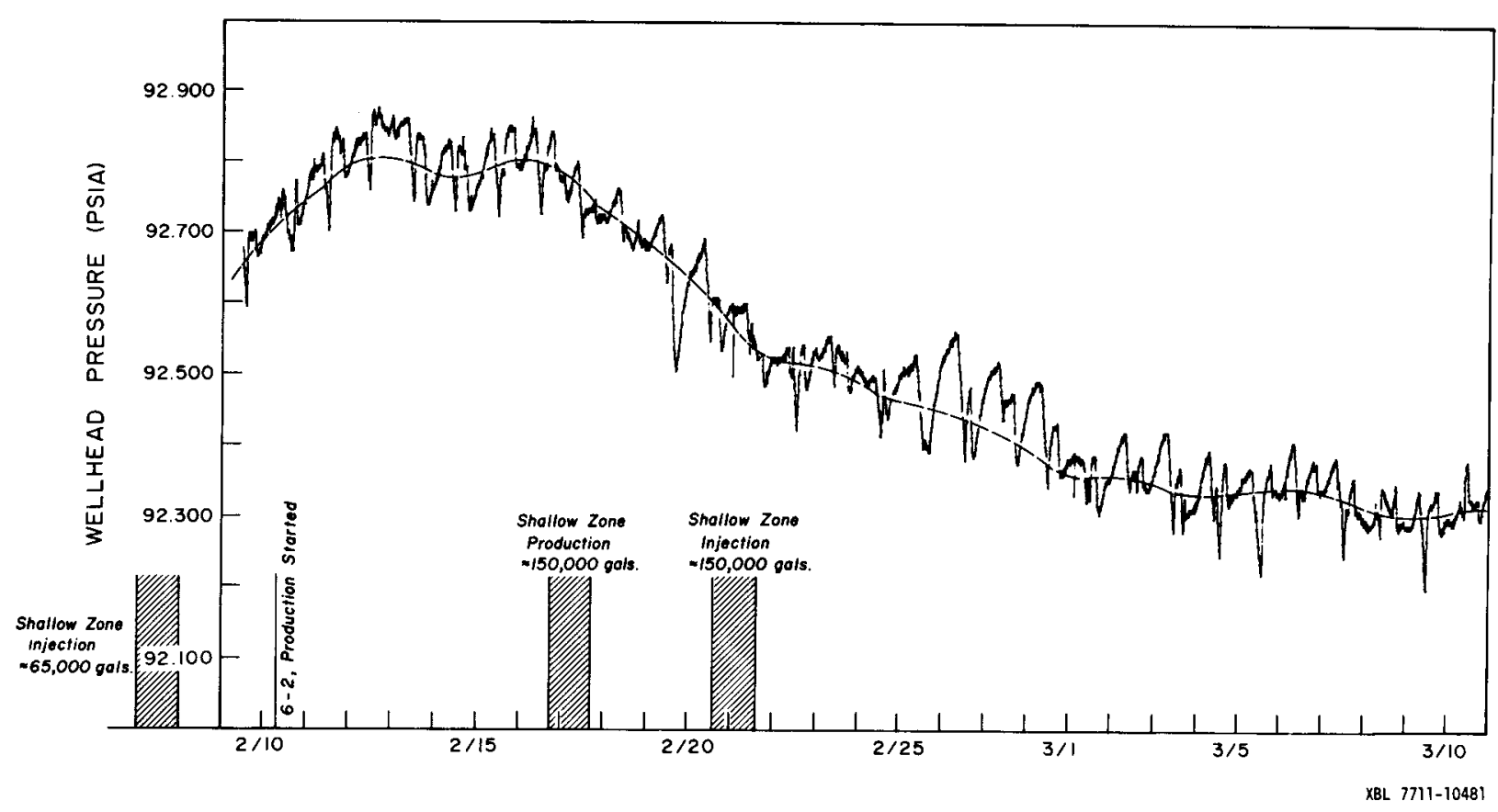

Figure B.2. Wellhead pressures of well 44-7 during Interference Test 1 , USBR and Magma properties.

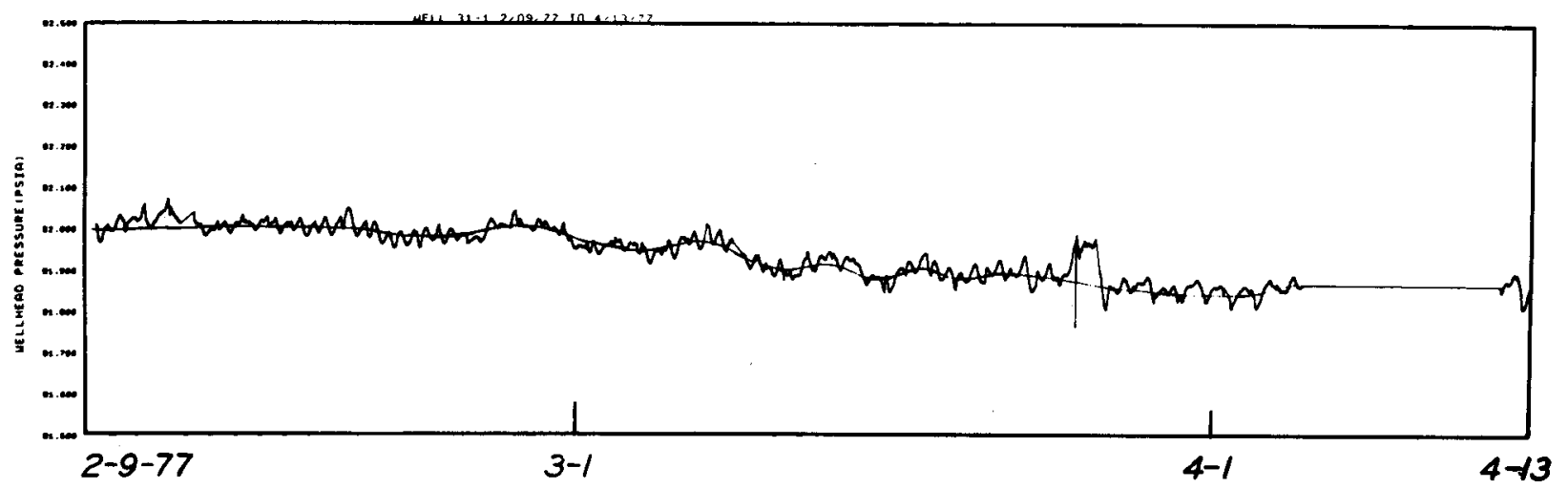

XBL 789-10773-I

Figure B.3. Wellhead pressure of well 31-1 during Interference Test 1 , USBR and Magma properties. 
Table B.3. Schematic of Interference Test 2.

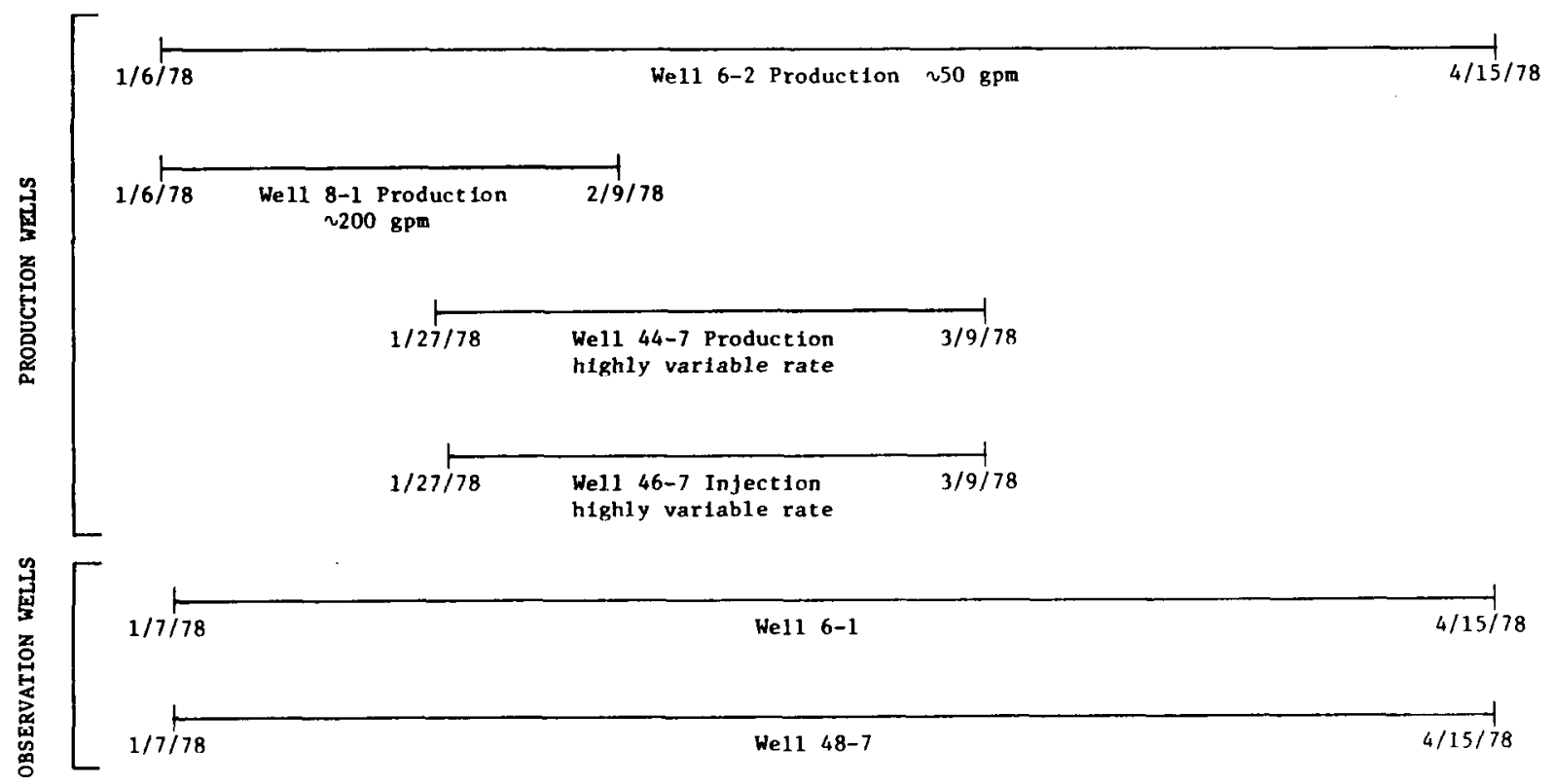

Table B.4. Summary of observation data of Interference Test 2 .

\begin{tabular}{|c|c|c|c|c|c|}
\hline OBSERVATION WELL & $6-2$ & $\begin{array}{c}\text { TANCE T } \\
8-1\end{array}$ & 44-7 & $\underset{\Delta \mathrm{P}}{\operatorname{MAXIMUM}}$ & COMMENTS \\
\hline $6-1$ & 450m & 710m & 970m & $2.5 \mathrm{psi}$ & $\begin{array}{l}\text { 1. No response to } 8-1 \text { production. } \\
\text { 2. No response to } 44-7 \text { production. }\end{array}$ \\
\hline $48-7$ & $1900 m$ & 1600 m & $800 \mathrm{~m}$ & $17 \mathrm{ps} 1$ & $\begin{array}{l}\text { 1. Too far from Well } 6-2 \text { to have notice- } \\
\text { able drawdown due to } 6-2 \text { production. } \\
\text { 2. The existence of hydraulic continuity } \\
\text { between Well 8-1 and } 48-7 \text { remains } \\
\text { uncertain. } \\
\text { 3. It is uncertain what the effect of } \\
\text { concurrent injection into the shallow } \\
\text { Well } 46-7 \text { ( } 930 \text { m deep) is on Well } 48-7 \text {. }\end{array}$ \\
\hline
\end{tabular}




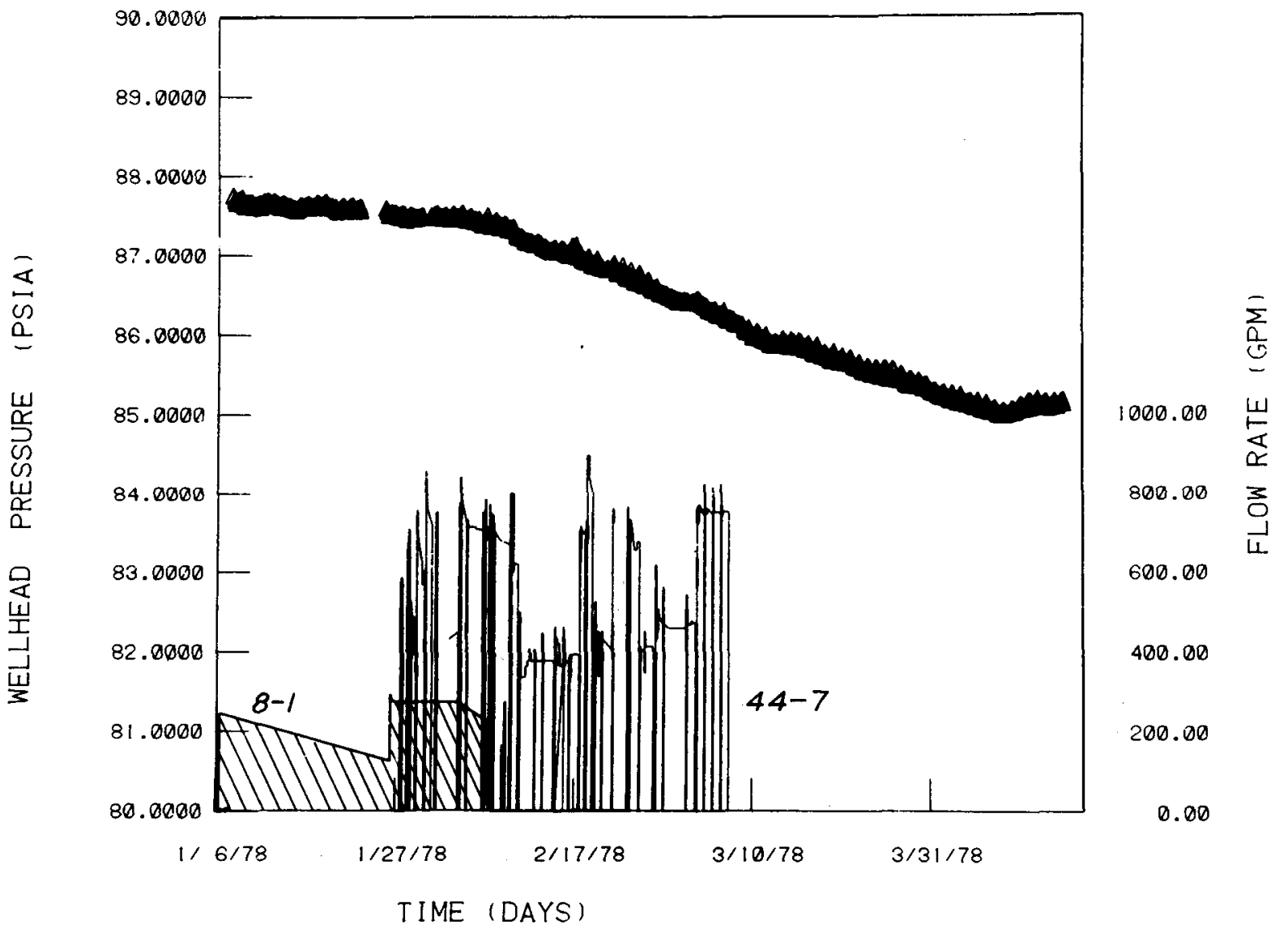

XBL 7810-11832A

Figure B.4. Wellhead pressure of we11 6-1 and flow rates of wells 8-1 and 44-7 during Interference Test 2, USBR and Magma properties. 


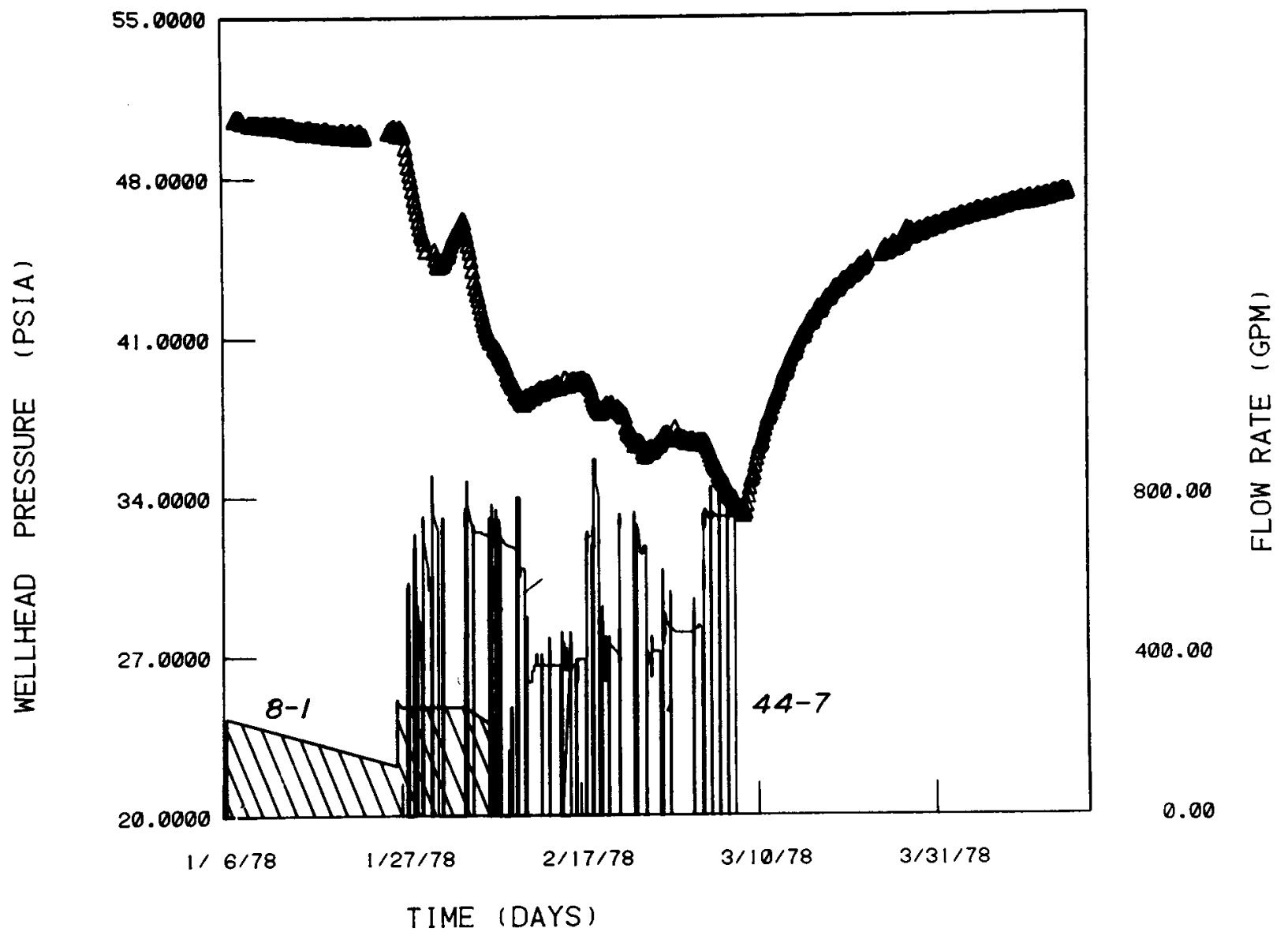

XBL. 7810-11831 A

Figure B.5. Wellhead pressure of well 48-7 and flow rates of wells 8-1 and 44-7 during Interference Test 2, USBR and Magma properties. 


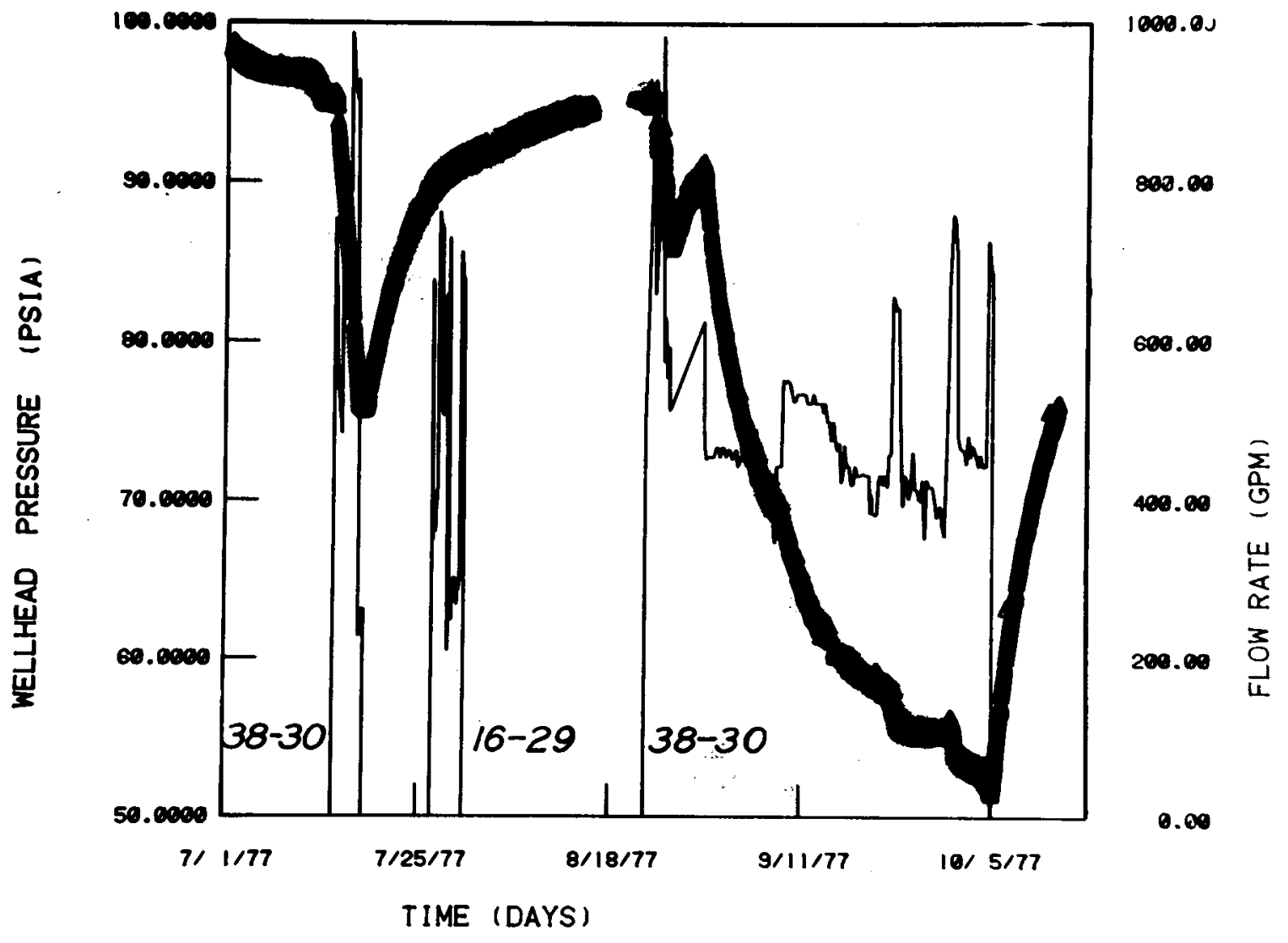

XBL 789-10777 A

Figure B.6. Wellhead pressure of well 56-30 and flow rates of wells 38-30 and 16-29 during Interference Tests 1, 2, and 3, Republic property. 


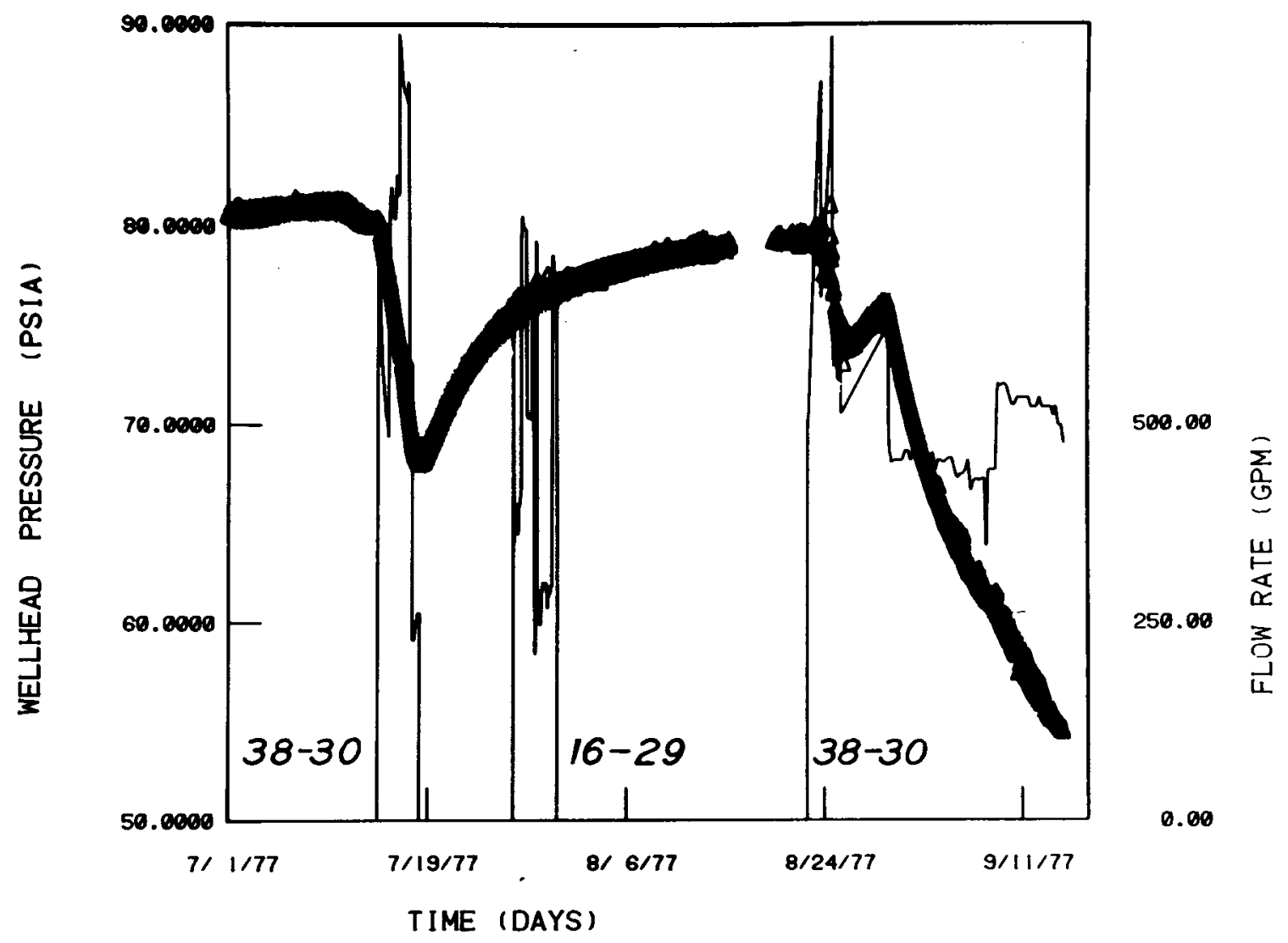

XBL $789-10773$ A

Figure B.7. Wellhead pressure of well $31-1$ and flow rates of wells 38-30 and 16-29 during Interference Tests 1, 2, and 3, Republic property. 


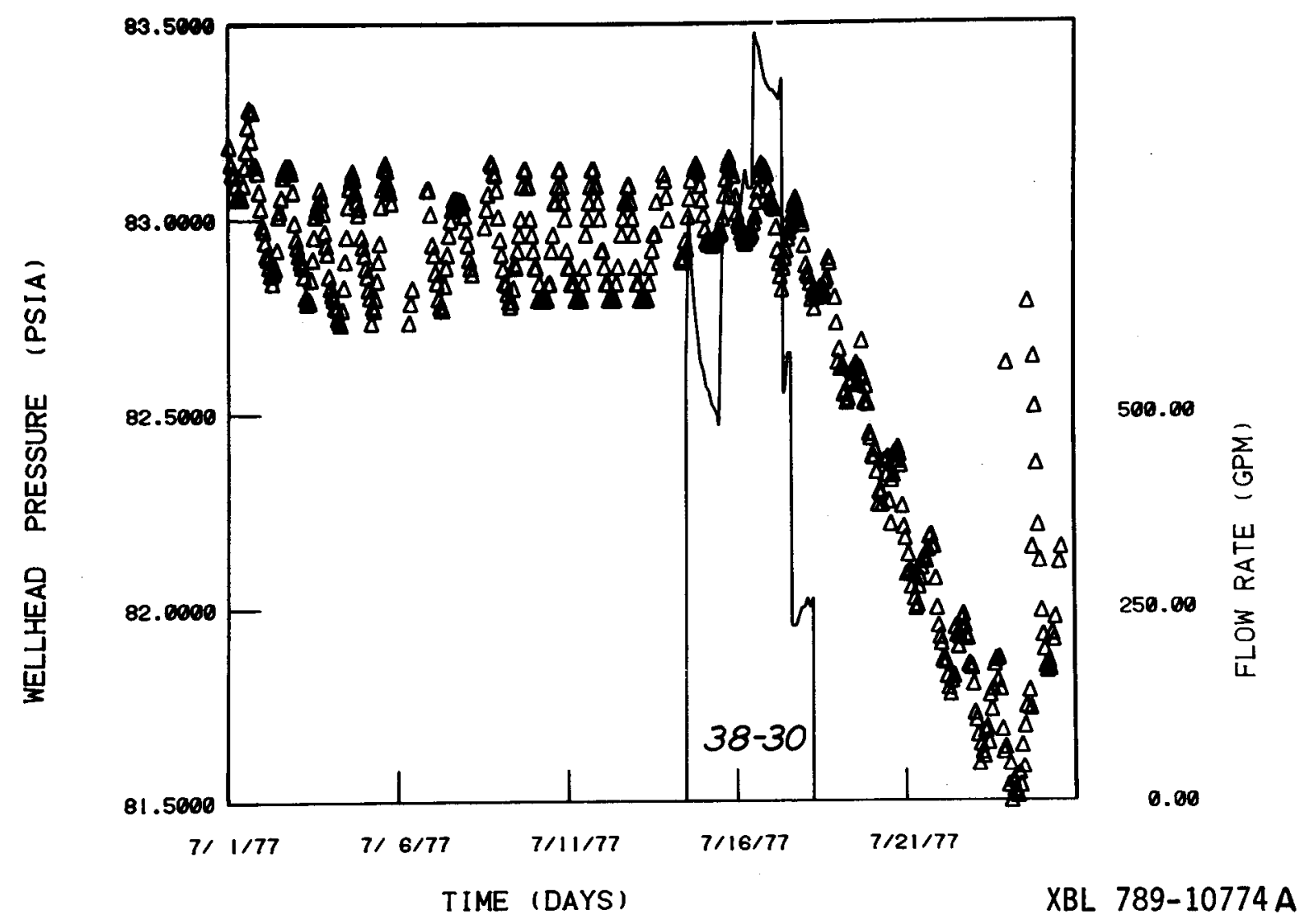

Figure B.8. Wellhead pressure of well $16-29$ and flow rates of wells 38-30 during Interference Test 1, Republic property.

Table B.5. Distance to well 38-30 and maximum drawdown recorded for each observation wel1 used in Interference Test 1 (Republic Geothermal property).

\begin{tabular}{|c|c|c|}
\hline OBSERVATION WELL & DISTANCE TO 38-30 & MAXIMUM $\triangle \mathrm{P}$ \\
\hline $56-30$ & $580 \mathrm{~m}$ & $23 \mathrm{psi}$ \\
$31-1$ & & $12 \mathrm{psi}$ \\
$16-29$ & $380 \mathrm{~m}$ & $1.5 \mathrm{psi}$ \\
\hline
\end{tabular}




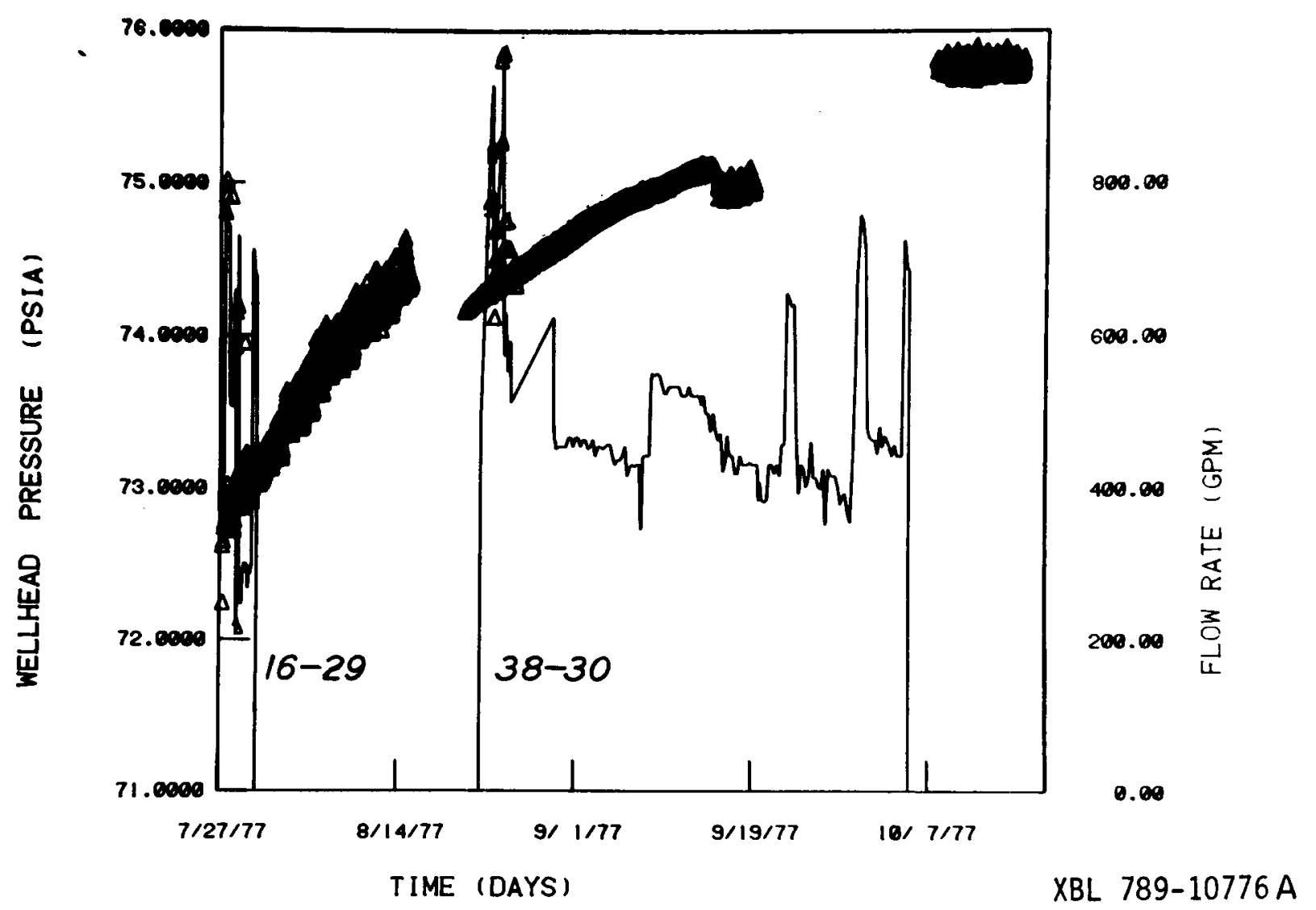

Figure B.9. Wellhead pressure of we11 16-30 and flow rates of wells 16-19 and 38-30 during Interference Tests 2 and 3, Republic property.

Table B.6. Distance to wel1 38-30 and maximum drawdown recorded for each observation we11 used in Interference Test 2 (Republic Geothermal property).

\begin{tabular}{|c|c|c|c|}
\hline OBSERVATION WELL & DISTANCE TO 38-30 & MAXIMUM $\triangle \mathrm{P}$ & COMMENTS \\
\hline $56-30$ & $580 \mathrm{~m}$ & $45 \mathrm{psi}$ & \\
$16-30$ & $580 \mathrm{~m}$ & 0. & No communication \\
$31-1$ & $380 \mathrm{~m}$ & 25 psi & No data after $9 / 20 / 77$ \\
$78-30$ & $800 \mathrm{~m}$ & 12 psi & $\begin{array}{l}\text { Atypical pressure response } \\
\text { to } 38-30 \text { production }\end{array}$ \\
\hline
\end{tabular}




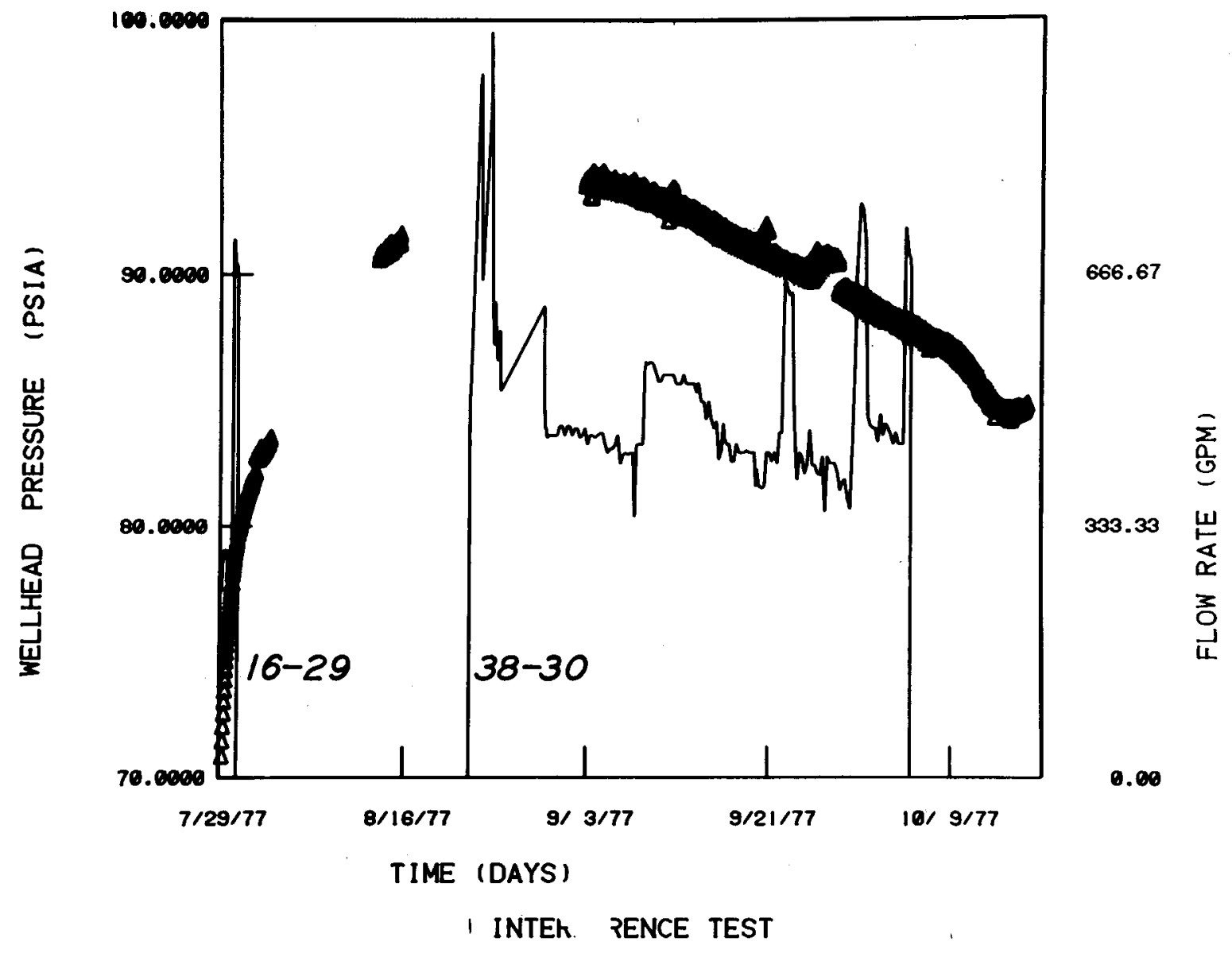

XBL 789-10775 A

Figure B.10. Wellhead pressure of well $78-30$ and flow rates of wells 16-29 and 38-30 during Interference Test 3, Republic property. 


\section{APPENDIX C: PRODUCTION TESTS IN THE NORTHERN PORTION OF THE EAST MESA KGRA DONE BY LBL}

WELL 38-30 PRODUCTION TEST

We11 38-30 production data (Figure C.1) were obtained using nitrogenfilled tubing to a depth of $6100 \mathrm{ft}$. Pressure was taken from a Sperry Sun pressure gauge and recorded by hand at 15-sec intervals at the time of rate changes, and less frequently as the pressure changes occurred more slowly. Early-time data are not considered very reliable due to the slow response of the nitrogen gas to large pressure changes. Analysis of late-time data was done with the computer matching program. Analyses yielded a $\mathrm{kh} / \mu$ value of $\sim 140,000 \mathrm{md}-\mathrm{ft} / \mathrm{cp}\left(4.2 \times 10^{-8} \mathrm{~m}^{3} / \mathrm{sec} / \mathrm{Pa}\right)$ and $a \operatorname{chr}_{\mathrm{e}}^{2}$ of $0.477 \mathrm{ft}^{3} / \mathrm{psi}\left(2.37 \times 10^{-6} \mathrm{~m}^{3} / \mathrm{Pa}\right)$.

WELL 18-28 INJECTION TEST

We11 18-28 injection data (Figure C.2) were obtained using a Hewlett Packard downhole pressure gauge at a depth of $5000 \mathrm{ft}$. Pressure data were recorded at 10 -min intervals on a digital paper printer. Flow data were obtained using orifice plate meters and circular chart recorders. The injection temperature at the wellhead ranged from $1500 \mathrm{~F}$ to $2000 \mathrm{~F}$.

The injection test consisted of three separate segments. The first two were each of 4 days duration and the third of 40 days duration. The data were analyzed for the reservoir transmissivity $(\mathrm{kh} / \mu)$ and relative skin values associated with each test segment. A11 three segments of the test yielded reservoir transmissivity values of $\sim 76,000 \mathrm{md}-\mathrm{ft} / \mathrm{cp}\left(2.3 \times 10^{-8} \mathrm{~m}^{3} / \mathrm{sec} / \mathrm{Pa}\right)$. As one would expect during injection, skin values obtained became increasingly positive for successive segments of the test, thus indicating that a scaling or plugging mechanism was occurring in the well. The skin values obtained for three segments ranged from 0.28 to 1.96 . These skin values were calculated by assuming the value of $2.0 \times 10^{-3} \mathrm{ft}^{3} / \mathrm{psi}$ for $\phi \mathrm{chr}_{\mathrm{w}}$.

\section{WELL 16-29 PRODUCTION TEST}

A transmissivity value of $178,000 \mathrm{md}-\mathrm{ft} / \mathrm{cp}\left(5.3 \times 10^{-8} \mathrm{~m}^{3} / \mathrm{sec} / \mathrm{Pa}\right)$, given in Table 3.6 for this test, is a very approximate estimate. These 
results are of poor quality because of complications such as cold water flux and lack of pretest stabilized pressures. The test result is given for completeness only.

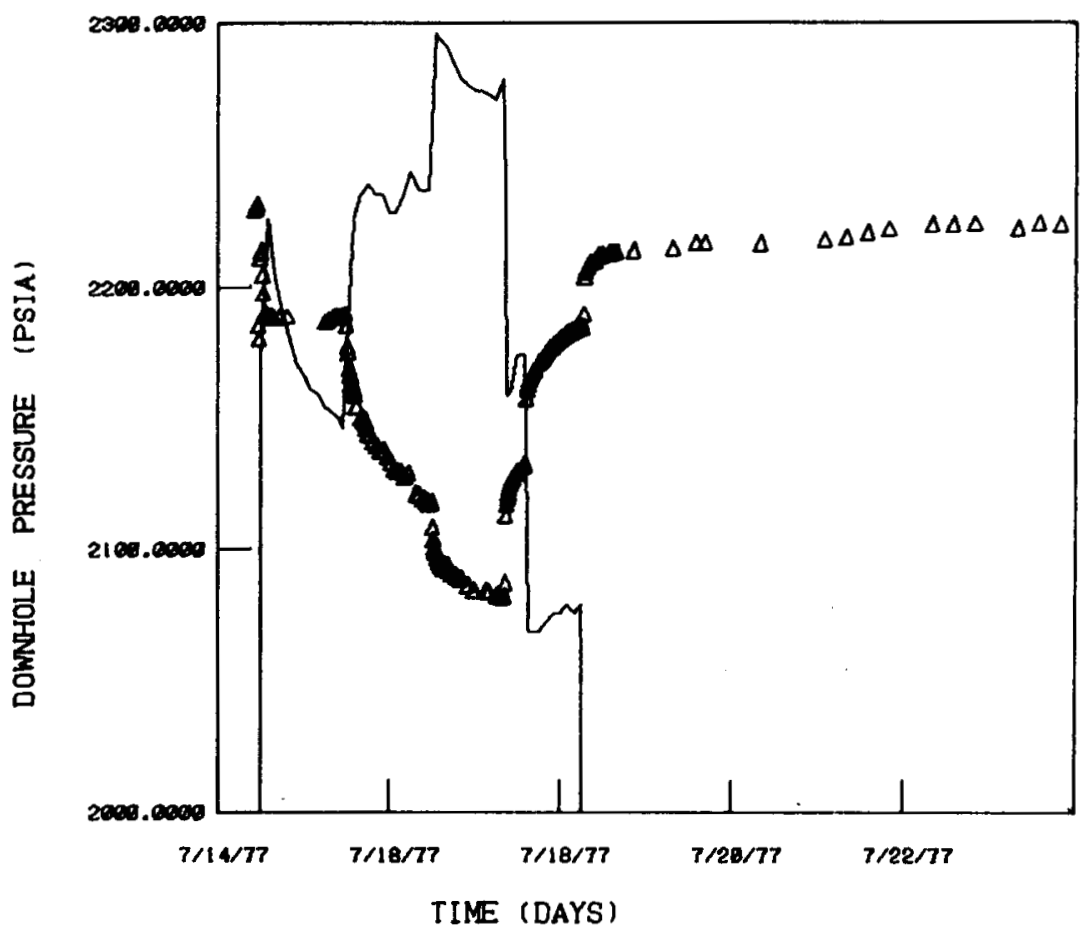

WELL 38-30 PRODUCTION TEST
1000.0

666.67

总

333.33

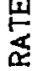

高

0.20

XBL $788-10124$

Figure C.1. Downhole pressure and flow rate of wel1 38-30, Republic property. 


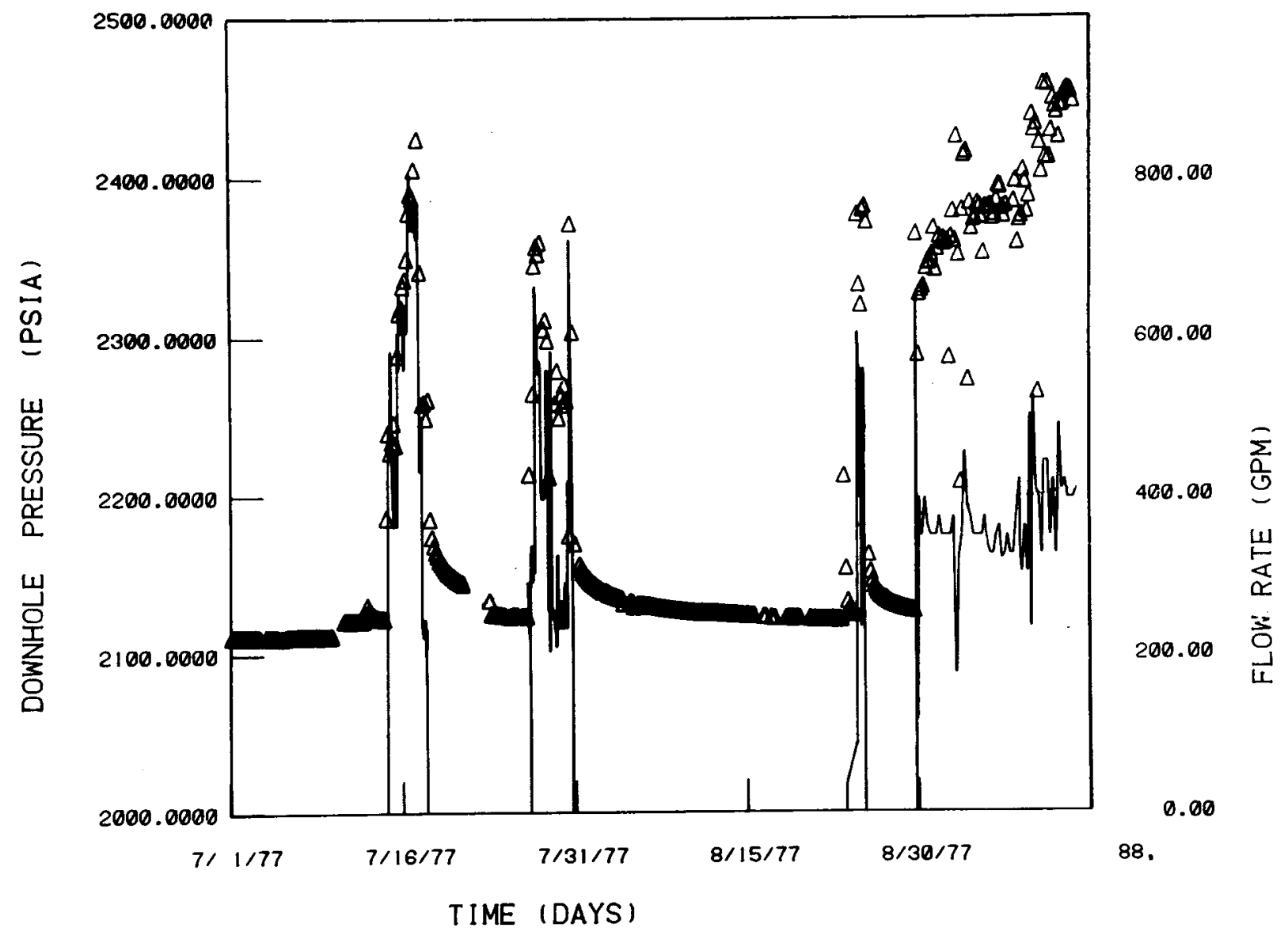

WELL 18-28 INJECTION TEST

XBL $7810-11833$

Figure C.2. Downhole pressure and injection flow rate of well 18-28, Republic property. 


\section{APPENDIX D: CONVERSION TABLES}

Tabie 1.

PERMEABILITY

viscosity = I centipoise

\begin{tabular}{|c|c|c|c|c|c|c|c|c|c|c|}
\hline & $\mathrm{cm}^{2}$ & $m^{2}$ & $\mathrm{ft}^{2}$ & Darcy & $\mathrm{cm} / \mathrm{sec}$ & $\mathrm{ft} / \mathrm{sec}$ & ft/year & $\begin{array}{l}\text { litres/ } \\
\text { sec } \cdot m^{2}\end{array}$ & $\begin{array}{l}\mathrm{gPd}\left[\mathrm{U} .5 . \mathrm{f} / \mathrm{ft}^{2}\right. \\
\text { (Meinzer) E }\end{array}$ & Ebhim" \\
\hline $\mathrm{cm}^{2}$ & 1 & $10^{-4}$ & $1.076 \times 10^{-3}$ & $1.014 \times 10^{8}$ & $9.804 \times 10^{4}$ & $3.216 \times 10^{3}$ & $1.015 \times 10^{11}$ & $8.698 \times 10^{5}$ & $1.845 \times 10^{9}$ & 0.9 \\
\hline$m^{2}$ & $10^{4}$ & 1 & $1.076 \times 10^{1}$ & $1.014 \times 10^{12}$ & $9.804 \times 10^{8}$ & $3.216 \times 10^{7}$ & $1.015 \times 10^{15}$ & $8.69 \times 10^{9}$ & $1.845 \times 10^{13}$ & 0.8 \\
\hline $\mathrm{ft}^{2}$ & $9.294 \times 10^{2}$ & $9.294 \times 10^{-2}$ & 1 & $9.417 \times 10^{10}$ & $9.109 \times 10^{7}$ & $2.988 \times 10^{6}$ & $9.430 \times 10^{13}$ & $8.080 \times 10^{8}$ & $1.714 \times 10^{12}$ & 0.7 \\
\hline Darcy & $9.862 \times 10^{-9}$ & $9.862 \times 10^{-13}$ & $1.062 \times 10^{-11}$ & 1 & $9.66 \times 10^{-4}$ & $3.173 \times 10^{-5}$ & $1.001 \times 10^{3}$ & $8.58 \times 10^{-3}$ & $1.82 \times 10^{1}$ & 0.6 \\
\hline $\mathrm{cm} / \mathrm{sec}$ & $1.020 \times 10^{-5}$ & $1.020 \times 10^{-9}$ & $1.09 \times 10^{-8}$ & $1.035 \times 10^{3}$ & 1 & $3.281 \times 10^{-2}$ & $1.035 \times 10^{6}$ & $9.985 \times 10^{0}$ & $2.118 \times 10^{4}$ & 0.5 \\
\hline $\mathrm{ft} / \mathrm{sec}$ & $3.109 \times 10^{-4}$ & $3.109 \times 10^{-8}$ & $3.347 \times 10^{-7}$ & $3.152 \times 10^{4}$ & $3.048 \times 10^{1}$ & 1 & $3.156 \times 10^{7}$ & $2.704 \times 10^{2}$ & $5.736 \times 10^{5}$ & 0.4 \\
\hline $\mathrm{ft} /$ year & $9.852 \times 10^{-12}$ & $9.852 \times 10^{-16}$ & $1.060 \times 10^{-14}$ & $9.990 \times 10^{-1}$ & $9.602 \times 10^{-7}$ & $3.169 \times 10^{-8}$ & 1 & $8.570 \times 10^{-6}$ & $1.818 \times 10^{-2}$ & 0.3 \\
\hline litres $/ \mathrm{sec} \cdot \mathrm{m}^{2}$ & $1.150 \times 10^{-6}$ & $1.150 \times 10^{-10}$ & $1.238 \times 10^{-9}$ & $1.106 \times 10^{2}$ & $1.001 \times 10^{-1}$ & $3.698 \times 10^{-3}$ & $1.167 \times 10^{5}$ & 1 & $2.121 \times 10^{3}$ & 0.2 \\
\hline $\begin{array}{l}\operatorname{gpd}\left[\text { [u.S. ] } / \mathrm{ft}^{2}\right. \\
\text { (Neinzer) }\end{array}$ & $5.420 \times 10^{-10}$ & $5.420 \times 10^{-14}$ & $5.834 \times 10^{-13}$ & $5.494 \times 10^{-2}$ & $4.721 \times 10^{-5}$ & $1.743 \times 10^{-6}$ & $5.500 \times 10^{1}$ & $4.714 \times 10^{-4}$ & 1 & 0.1 \\
\hline EbhIm" & 0.9 & 0.8 & 0.7 & 0.6 & 0.5 & 0.4 & 0.3 & 0.2 & 0.1 & 1 \\
\hline
\end{tabular}

"Standard Ethiopian buckets per hectare per lunar month.

Dimensions: $\quad k$, Absolute Permeability $\left[L^{2}\right]$

$K$, Hydraulic Conductivity $(\mathrm{L} / \mathrm{t})$

$k / u$, Mbbilit) $\left[\mathrm{L}^{3} \mathrm{t} / \mathrm{M}\right]$

Table 2 .

COMPRESS I B I L I TY

$\left[L t^{2} / M\right]$

\begin{tabular}{|c|c|c|c|c|c|c|c|}
\hline & $\begin{array}{c}\mathbf{m}^{2} / \mathrm{N} \\
\text { (Pascals) }^{-1}\end{array}$ & $\mathrm{~m}^{2} / \mathrm{kg}_{\mathrm{f}}$ & $\begin{array}{l}\mathrm{in}^{2} / 1 b_{f} \\
(p s i)^{-1}\end{array}$ & Bars $^{-1}$ & $A_{t m}^{-1}$ & $\begin{array}{l}\text { (ft of } \\
\text { water) } \\
\text { at } 68^{\circ} \mathrm{F}\end{array}$ & $\begin{array}{l}\text { (m of } \\
\text { water) } \\
\text { at } 68^{\circ} \mathrm{F}\end{array}$ \\
\hline $\begin{array}{l}\mathrm{m}^{2} / \mathrm{N} \\
\text { (Pascals) }^{-1}\end{array}$ & 1 & 9.807 & $6.897 \times 10^{3}$ & $10^{5}$ & $1.0133 \times 10^{5}$ & $2.984 \times 10^{3}$ & $9.794 \times 10^{3}$ \\
\hline $\mathrm{m}^{2} / \mathrm{kg}_{\mathrm{f}}$ & $1.020 \times 10^{-1}$ & 1 & $7.031 \times 10^{2}$ & $1.0197 \times 10^{4}$ & $1.0332 \times 10^{4}$ & $3.042 \times 10^{2}$ & $9.980 \times 10^{2}$ \\
\hline $\begin{array}{l}\text { in. }{ }^{2} / 1 b_{f} \\
(p s i)^{-1}\end{array}$ & $1.450 \times 10^{-4}$ & $1.4223 \times 10^{-3}$ & 1 & 14.504 & 14.696 & 0.4327 & 1.419 \\
\hline Bars $^{-1}$ & $10^{-5}$ & $9.8068 \times 10^{-5}$ & $6.895 \times 10^{-2}$ & 1 & 1.01325 & $2.984 \times 10^{-2}$ & $9.790 \times 10^{-2}$ \\
\hline $\operatorname{Atm}^{-1}$ & $9.8692 \times 10^{-6}$ & $9.6787 \times 10^{-5}$ & $6.805 \times 10^{-2}$ & 0.98692 & 1 & $2.945 \times 10^{-2}$ & $9.662 \times 10^{-2}$ \\
\hline $\begin{array}{c}\text { (ft of water) } \\
\text { at } 68^{\circ} \mathrm{F}\end{array}$ & $3.351 \times 10^{-4}$ & $3.287 \times 10^{-3}$ & 2.311 & 33.512 & 33.956 & 1 & 3.281 \\
\hline $\begin{array}{l}\text { (m of water) } \\
\text { at } 68^{\circ} \mathrm{F}\end{array}$ & $1.02110^{-4}$ & $1.00210^{-3}$ & 7044 & 10.214 & 10.349 & 0.3048 & 1 \\
\hline
\end{tabular}


Table 3.

TEMPERATURE

${ }^{\circ} \mathrm{C}$ to ${ }^{\circ} \mathrm{F}$

\begin{tabular}{|c|c|c|c|c|c|c|c|c|c|}
\hline${ }^{\circ} \mathrm{C}$ & ${ }^{\circ} \mathrm{F}$ & ${ }^{\circ} \mathrm{C}$ & ${ }^{\circ} \mathrm{F}$ & ${ }^{\circ} \mathrm{C}$ & ${ }^{\circ} \mathrm{F}$ & ${ }^{\circ} \mathrm{C}$ & ${ }^{\circ} \mathrm{F}$ & ${ }^{\circ} \mathrm{C}$ & ${ }^{\circ} \mathrm{F}$ \\
\hline 0 & 32 & 100 & 212 & 200 & 392 & 300 & $\$ 72$ & 400 & 752 \\
\hline 5 & 41 & 105 & 221 & 205 & 401 & 305 & 581 & 405 & 761 \\
\hline 10 & 50 & 110 & 230 & 210 & 410 & 310 & 590 & 410 & 770 \\
\hline 15 & 59 & 115 & 239 & 215 & 419 & 315 & 599 & 415 & 779 \\
\hline 20 & 68 & 120 & 248 & 220 & 428 & 320 & 608 & 420 & 788 \\
\hline 25 & 77 & 125 & 257 & $225^{\circ}$ & 437 & 325 & 617 & 425 & 797 \\
\hline 30 & 86 & 130 & 266 & 230 & 446 & 330 & 626 & 430 & 806 \\
\hline 35 & 95 & 135 & 275 & 235 & 455 & 335 & 635 & 435 & 815 \\
\hline 40 & 104 & 140 & 284 & 240 & 464 & 340 & 644 & 440 & 824 \\
\hline 45 & 113 & 145 & 293 & 245 & 473 & 345 & 653 & 445 & 833 \\
\hline 50 & 122 & 150 & 302 & 250 & 482 & 350 & 662 & 450 & 842 \\
\hline 55 & 131 & 155 & 311 & 255 & 491 & 355 & 671 & 455 & 851 \\
\hline 60 & 140 & 160 & 320 & 260 & 500 & 360 & 680 & 460 & 860 \\
\hline 65 & 149 & 165 & 329 & 265 & 509 & 365 & 689 & 465 & 869 \\
\hline 70 & 158 & 170 & 338 & 270 & 518 & 370 & 698 & 470 & 878 \\
\hline 75 & 167 & 175 & 347 & 275 & 527 & 375 & 707 & 475 & 887 \\
\hline 80 & 176 & 180 & 356 & 280 & 536 & 380 & 716 & 480 & 896 \\
\hline 85 & 185 & 185 & 365 & 285 & 545 & 385 & 725 & 485 & 905 \\
\hline 90 & 194 & 190 & 374 & 290 & 554 & 390 & 734 & 490 & 914 \\
\hline 95 & 203 & 195 & 383 & 295 & 563 & 395 & 743 & 495 & 923 \\
\hline
\end{tabular}

Table 4

VOLUME

$\left[\mathrm{L}^{3}\right]$

\begin{tabular}{|c|c|c|c|c|c|c|}
\hline & $\mathrm{m}^{3}$ & litre & bbl & $\begin{array}{l}\text { Gallon } \\
\text { (U.S.) }\end{array}$ & $\begin{array}{l}\text { Gallon } \\
\text { (Imp.) }\end{array}$ & $\mathrm{ft}^{3}$ \\
\hline $\mathrm{m}^{3}$ & 1 & $10^{3}$ & 6.289 & $2.642 \times 10^{2}$ & $2.20 \times 10^{2}$ & 35.315 \\
\hline litre & $10^{-3}$ & 1 & $6.289 \times 10^{-3}$ & 0.2642 & 0.220 & $3.5315 \times 10^{-2}$ \\
\hline bbl & .1590 & $1.590 \times 10^{2}$ & 1 & 42.0 & 34.97 & 5.6146 \\
\hline $\begin{array}{c}\text { gallons } \\
\text { (U.S.) }\end{array}$ & $3.7854 \times 10^{-3}$ & 3.7854 & $2.381 \times 10^{-2}$ & 1 & 0.8327 & 0.13368 \\
\hline $\begin{array}{l}\text { gallons } \\
\text { (IMP) }\end{array}$ & $4.546 \times 10^{-3}$ & 4.546 & $2.860 \times 10^{-2}$ & 1.2009 & 1 & 0.16054 \\
\hline $\mathrm{ft}^{3}$ & $2.832 \times 10^{-2}$ & 28.32 & 0.178 & 7.481 & 6.229 & 1 \\
\hline
\end{tabular}


Table 5.

FLON RATE $\left[L^{3} / \mathrm{t}\right]$ or $[\mathrm{M} / \mathrm{t}]$

\begin{tabular}{|c|c|c|c|c|c|c|c|c|}
\hline & $\mathrm{m}^{3} / \mathrm{sec}$ & litres/min & bb1/day & $\underset{(U . S .)}{\text { gallons/min }}$ & $\begin{array}{l}\text { gallans/min } \\
\text { (Imp.) }\end{array}$ & $\mathrm{ft}^{3} / \mathrm{sec}$ & $\begin{array}{c}k 1 b / h r \\
\left(o_{w}=1.0\right)\end{array}$ & $\begin{array}{c}\mathrm{klb} / \mathrm{hr} \\
\left(\mathrm{O}_{w^{*}}=9\right)\end{array}$ \\
\hline $\mathrm{m}^{3} / \mathrm{sec}$ & 1 & $6 \times 10^{4}$ & $5.434 \times 10^{5}$ & $1.585 \times 10^{4}$ & $1.320 \times 10^{4}$ & 35.315 & $7.94 \times 10^{3}$ & $7.15 \times 10^{3}$ \\
\hline litres/min & $1.60 \times 10^{-5}$ & 1 & 9.058 & 0.2642 & 0.220 & $5.885 \times 10^{-4}$ & $1.32 \times 10^{-1}$ & $1.19 \times 10^{-1}$ \\
\hline $\mathrm{bb} 1 / \mathrm{day}$ & $1.840 \times 10^{-6}$ & $1.10 \times 10^{-1}$ & 1 & $2.917 \times 10^{-2}$ & $2.428 \times 10^{-2}$ & $0.498 \times 10^{-5}$ & $1.46 \times 10^{-2}$ & $1.31 \times 10^{-2}$ \\
\hline $\begin{array}{l}\text { gallons/min } \\
\text { (U.S.) }\end{array}$ & $0.31 \times 10^{-5}$ & 3.785 & 34.28 & 1 & 0.8327 & $2.2280 \times 10^{-3}$ & 0.50 & 0.45 \\
\hline$\underset{\text { (Imp.) }}{\text { gallons/min }}$ & $7.58 \times 10^{-5}$ & 4.540 & 41.19 & 1.2009 & 1 & $2.676 \times 10^{-3}$ & 0.601 & 0.541 \\
\hline $\mathrm{ft}^{3} / \mathrm{sec}$ & $2.8317 \times 10^{-2}$ & $1.699 \times 10^{3}$ & $1.539 \times 10^{4}$ & $4.488 \times 10^{2}$ & $3.737 \times 10^{2}$ & 1 & $2,25 \times 10^{2}$ & $2.05 \times 10^{2}$ \\
\hline $\begin{array}{l}k \notin b / h r \\
\rho_{w}=1.0\end{array}$ & $1.26 \times 10^{-4}$ & 7.56 & 68.5 & 2.00 & 1.66 & $4.45 \times 10^{-3}$ & 1 & 0.900 \\
\hline $\begin{array}{l}k 1 b / h r \\
0_{w}=0.9\end{array}$ & 1. $.40 \times 10^{-4}$ & 8.42 & 8.2 & 2.22 & 1.85 & $4.93 \times 10^{-3}$ & 1.11 & 1 \\
\hline
\end{tabular}

Table 6 .

\begin{tabular}{|c|c|c|c|c|c|c|c|}
\hline \multicolumn{8}{|c|}{$\begin{array}{r}\text { PRESSURE } \\
{\left[M / L t^{2}\right]}\end{array}$} \\
\hline & $\begin{array}{c}\mathrm{N} / \mathrm{m}^{2} \\
\text { (Pascals) }\end{array}$ & $\mathrm{kg}_{\mathrm{f}} / \mathrm{m}^{2}$ & $\begin{array}{c}\mathrm{bb}_{\mathrm{f}} / \mathrm{in}^{2} \\
(\mathrm{psi})\end{array}$ & Bars & Atm & $\begin{array}{c}\mathrm{ft} \text { of water } \\
\left.\text { (at } 68^{\circ} \mathrm{F}\right)\end{array}$ & $\begin{array}{l}\text { m of water } \\
\left.\text { (at } 68^{\circ} \mathrm{F}\right)\end{array}$ \\
\hline $\begin{array}{c}\mathrm{N} / \mathrm{m}^{2} \\
\text { (Pascals) }\end{array}$ & 1 & $1.020 \times 10^{-1}$ & $1.450 \times 10^{-4}$ & $10^{-5}$ & $9.8692 \times 10^{-6}$ & $3.351 \times 10^{-4}$ & $1.021 \times 10^{-4}$ \\
\hline $\mathrm{kg}_{\mathrm{f}} / \mathrm{m}^{2}$ & 9.804 & 1 & $1.4223 \times 10^{-3}$ & $9.8068 \times 10^{-5}$ & $9.6787 \times 10^{-5}$ & $3.287 \times 10^{-3}$ & $1.002 \times 10^{-3}$ \\
\hline $\begin{array}{c}1 b_{f} / i n^{2} \\
(p s i)\end{array}$ & $6.895 \times 10^{3}$ & $7.031 \times 10^{2}$ & 1 & $6.895 \times 10^{-2}$ & $6.805 \times 10^{-2}$ & 2.311 & 0.7042 \\
\hline Bars & $10^{5}$ & $1.0197 \times 10^{4}$ & 14.504 & 1 & 0.98692 & 33.512 & 10.214 \\
\hline Atm & $1.0133 \times 10^{5}$ & $1.0332 \times 10^{4}$ & 14.696 & 1.01325 & 1 & 33.956 & 10.349 \\
\hline $\begin{array}{l}\mathrm{ft} \text { of water } \\
\left(\text { at } 68^{\circ} \mathrm{F}\right)\end{array}$ & $2.984 \times 10^{3}$ & $3.042 \times 10^{2}$ & 0.4328 & $2.984 \times 10^{-2}$ & $2.945 \times 10^{-2}$ & 1 & 0.3048 \\
\hline $\begin{array}{l}m \text { of water } \\
\left.\text { (at } 68^{\circ} \mathrm{F}\right)\end{array}$ & $9.794 \times 10^{3}$ & $9.980 \times 10^{2}$ & 1.419 & $9.790 \times 10^{-2}$ & $9.662 \times 10^{-2}$ & 3.281 & 1 \\
\hline
\end{tabular}


Table 7: Viscosity (dynamic)

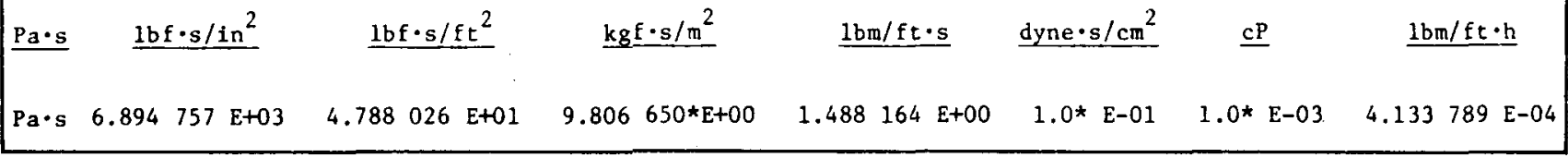

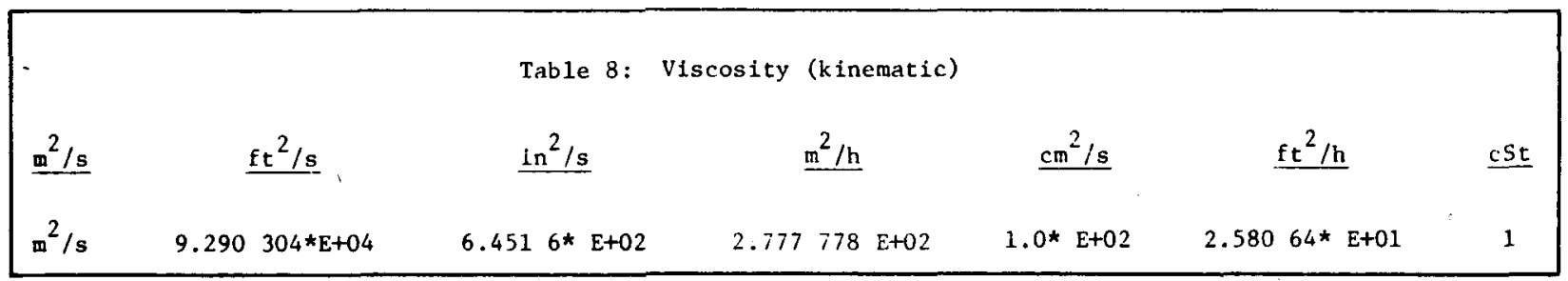

Table 9: Diffusivity
$\mathrm{m}^{2} / \mathrm{s}$
$\underline{\mathrm{ft}} \mathrm{t}^{2} / \mathrm{s}$
$\mathrm{cm}^{2} / \mathrm{s}$
$\underline{\mathrm{f}} \mathrm{t}^{2} / \mathrm{h}$
$\mathrm{m}^{2} / \mathrm{s}$
$9.290304 * E+04$
$1.0 * \mathrm{E}+02$
$2.58064 *$ E+01

Table 10: Thermal Conductivity

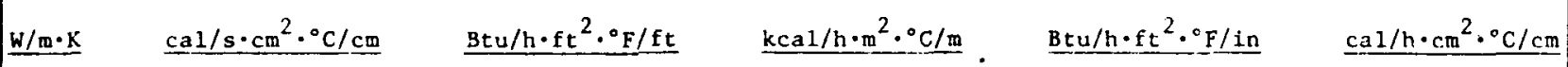
$\mathrm{W} / \mathrm{m} \cdot \mathrm{K}$
$4.184^{*} \mathrm{E}+02$
$1.730735 \mathrm{E}+00$
$1.162222 E+00$
$1.442 \quad 279 \quad E-01$
1.162222 E-01

Table 11: Density (1iquids)

\begin{tabular}{|c|c|c|c|c|c|}
\hline $\mathrm{kg} / \mathrm{m}^{3}$ & $1 \mathrm{bm} / \mathrm{U} \cdot \mathrm{S}$. gal & $\mathrm{Lbm} / \mathrm{U} \cdot \mathrm{K} \cdot \mathrm{gal}$ & $1 \mathrm{bm} / \mathrm{ft}^{3}$ & ${\mathrm{~g} / \mathrm{cm}^{3}}^{3}$ & ${ }^{\circ} \mathrm{API}$ \\
\hline $\mathrm{kg} / \mathrm{m}^{3}$ & $\begin{array}{lll}1.198 & 264 & \mathrm{E}+02 \\
1.198 & 264 & \mathrm{E}-01\end{array}$ & 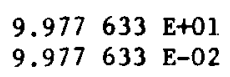 & $\begin{array}{lll}1.601 & 846 & E+01 \\
1.601 & 846 & E-02\end{array}$ & $\begin{array}{l}1.0 * \mathrm{E}+03 \\
1\end{array}$ & \\
\hline
\end{tabular}

Table 12: Specific Heat Capacity (mass basis)

\begin{tabular}{llll}
$\mathrm{J} / \mathrm{kg} \cdot \mathrm{K}$ & $\underline{\mathrm{kW} \cdot \mathrm{h} / \mathrm{kg} \cdot{ }^{\circ} \mathrm{C}}$ & $\underline{\mathrm{Btu} / 1 \mathrm{bm} \cdot{ }^{\circ} \mathrm{F}}$ & $\underline{\mathrm{kcal} / \mathrm{kg} \cdot{ }^{\circ} \mathrm{C}}$ \\
$\mathrm{J} / \mathrm{Kg} \cdot \mathrm{K}$ & $3.6 * \mathrm{E}+03$ & $4.1868 * \mathrm{E}+00$ & $4.184 * \mathrm{E}+00$ \\
\hline
\end{tabular}

Table 13: linthalpy Calorific Value on (mass basis)

$\begin{array}{ccccc}\mathrm{J} / \mathrm{kg} & \underline{\mathrm{Btu} / 1 \mathrm{bm}} & \underline{\mathrm{cal} / \mathrm{g}} & \text { cal/1bm } \\ \mathrm{J} / \mathrm{kg} & 2.326000 \mathrm{E}-03 & 4.184 * \mathrm{E}+00 & 9.224141 \mathrm{E}+00 \\ & 2.325000 \mathrm{E}+00 \\ & 6.461 & & & \end{array}$


APPENDIX E:

Chemical aNALYSES OF FLUIDS from eAst MESA WELUS 
Table E.1 (continued)

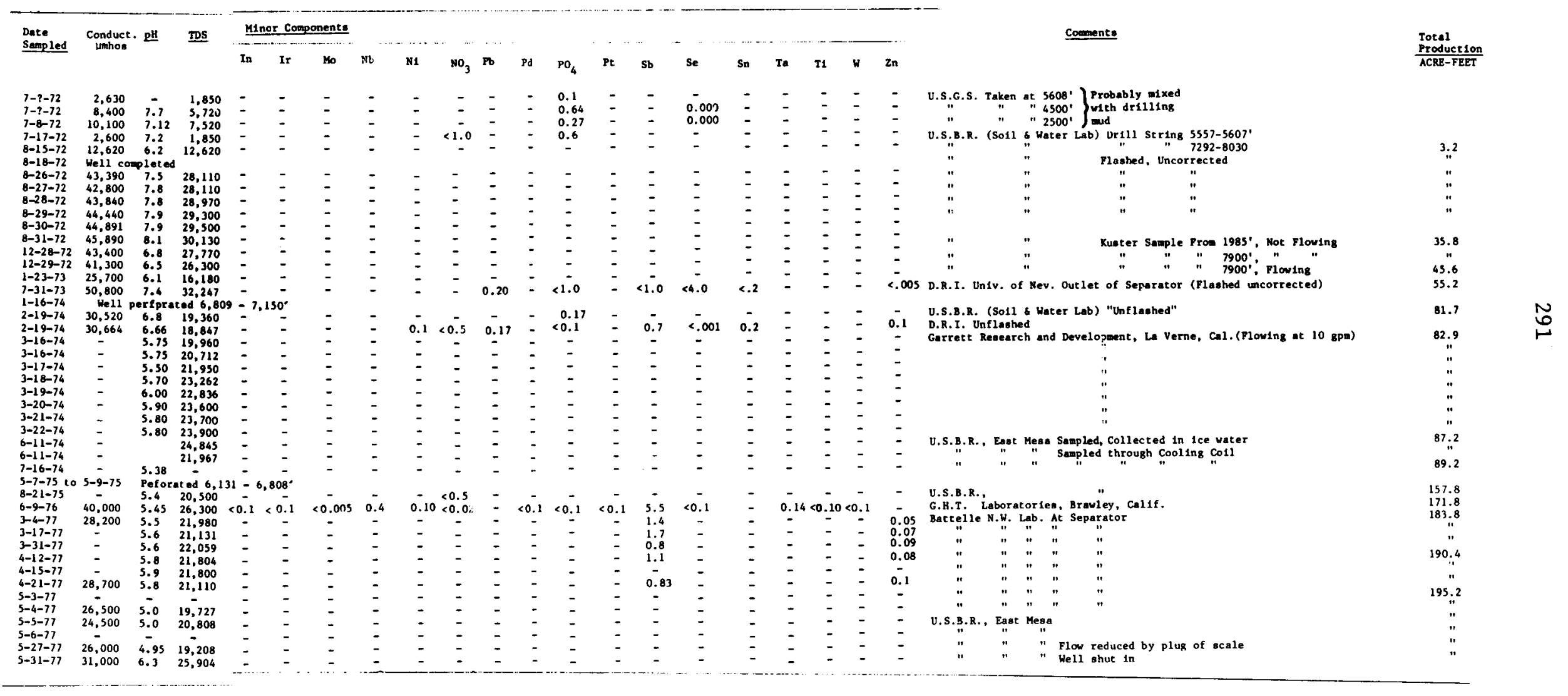


Table E.2. Chemical analyses of well 6-2 (concentration mg/l).

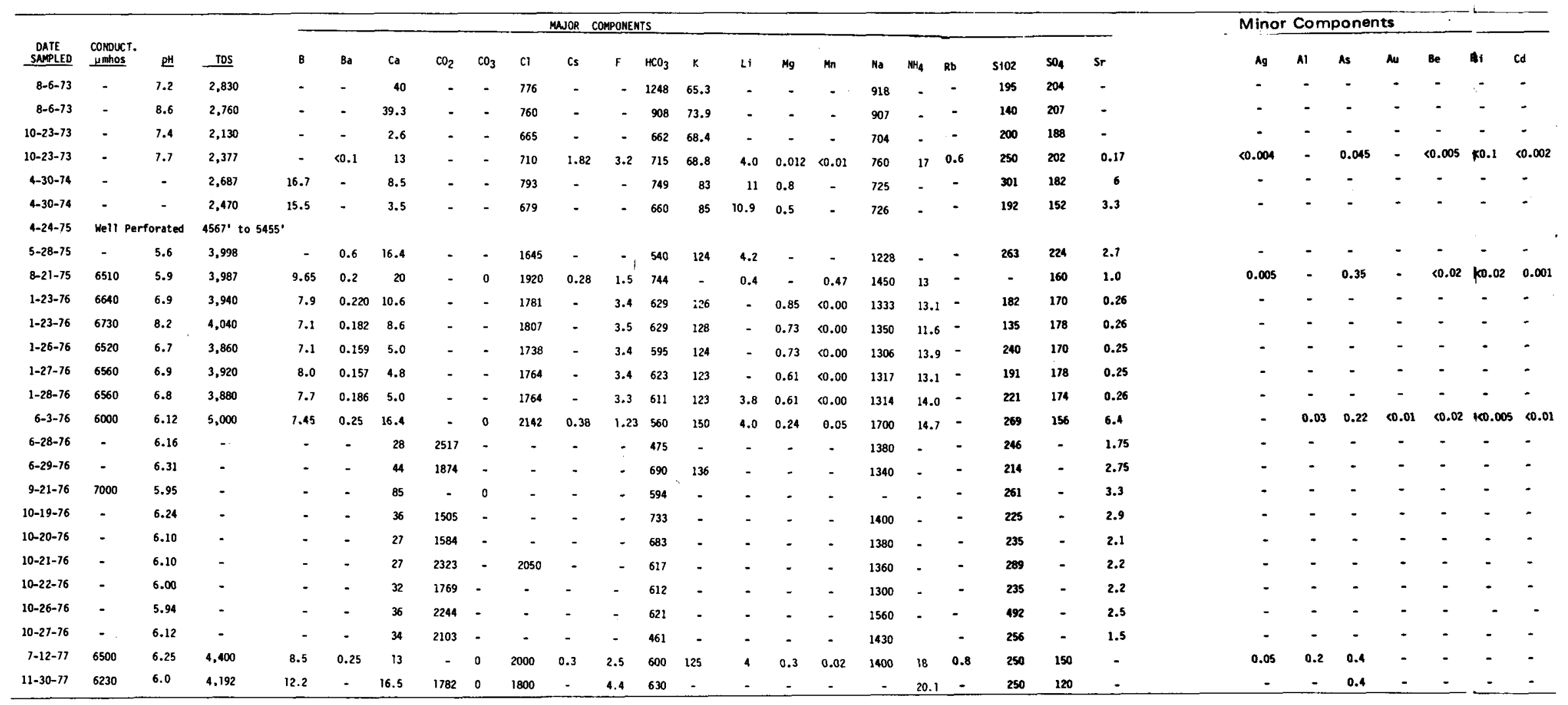


Table E.3. Chemical analyses of Republic wells (concentration $\mathrm{mg} / \mathrm{l}$ ).

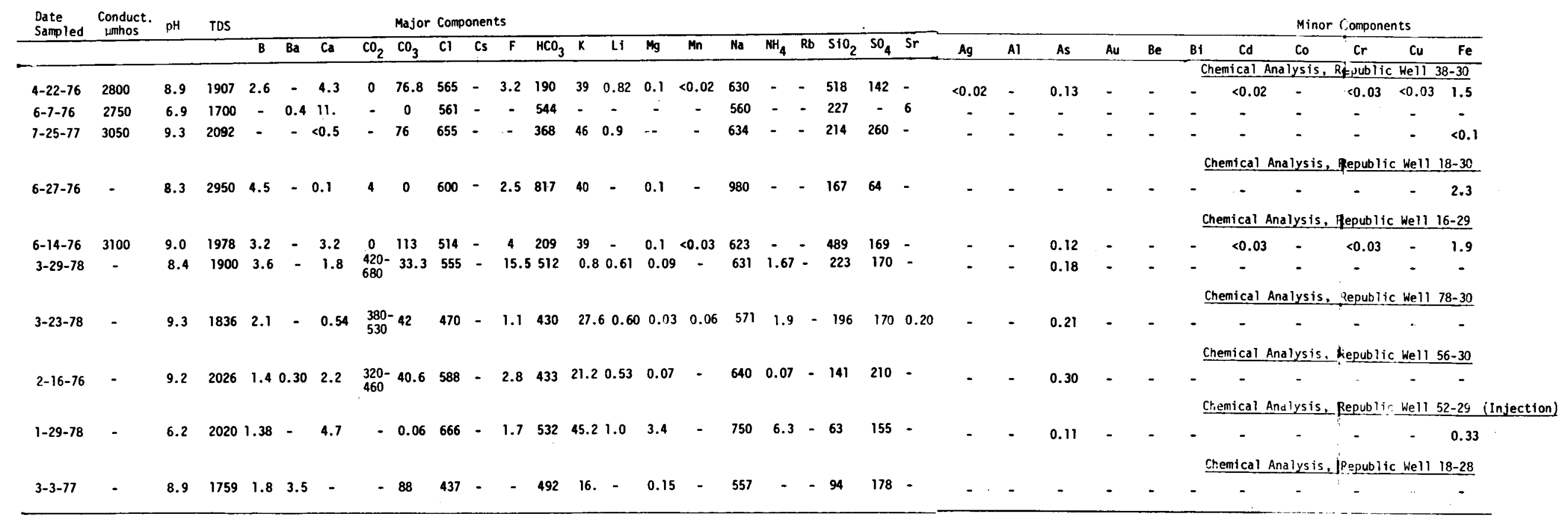


Table E.3 (continued)

\begin{tabular}{|c|c|c|c|c|c|c|c|c|c|c|c|c|c|c|c|c|c|c|c|c|c|c|c|c|c|}
\hline $\begin{array}{l}\text { Date } \\
\text { Sampled }\end{array}$ & $\begin{array}{l}\text { Conduct. } \\
\text { umhos }\end{array}$ & $\mathrm{pH}$ & TDS & & Compone & & & & & & & & & & & & & & & & & & & Comments & $\begin{array}{l}\text { Total } \\
\text { Production }\end{array}$ \\
\hline & & & & Ge & $\mathrm{Hg}$ & $\mathrm{H}_{2} \mathrm{~S}$ & In & Ir & no & Mb & $\mathrm{Ni}^{\top}$ & $\mathrm{NO}_{3}$ & $\overline{\mathrm{Pb}}$ & Pd & $\mathrm{PO}_{4}$ & $\overline{p t}$ & Sb & Se & $5 n$ & $\mathrm{Ta}$ & $T i$ & $\bar{W}$ & $2 n$ & & Acre-feet \\
\hline $4-22-76$ & 2800 & 8.9 & 1907 & - & 0.002 & - & - & - & - & - & $<0.03$ & - & $<0.05$ & - & 0.7 & - & $<0.1$ & $<0.01$ & - & - & - & - & $<0.02$ & $8 \mathrm{r}$ content was $0.7 \mathrm{mg} / \mathrm{kg}$ & - \\
\hline $7-25-77$ & 3050 & 9.3 & 2092 & - & - & - & - & $\cdot$ & - & - & - & - & - & - & - & - & - & - & - & - & - & - & - & & - \\
\hline $6-27-76$ & - & 8.3 & 2950 & - & - & - & - & - & - & - & - & - & - & - & 0.4 & - & - & - & - & - & - & - & - & & \\
\hline $6-14-76$ & 3100 & 9.0 & 1978 & - & 0.006 & - & - & - & - & - & - & - & $<0.05$ & - & 0.9 & - & - & $<0.01$ & - & - & - & - & $<0.05$ & & - \\
\hline $3-29-78$ & - & 8.4 & 1900 & - & - & - & - & - & - & - & - & - & - & - & 0.31 & - & - & - & - & - & - & - & - & Flashed, uncorrected for 10.78 loss & - \\
\hline $3-23-78$ & - & 9.3 & 1836 & - & - & - & - & - & - & - & - & - & - & - & - & - & - & - & - & - & - & - & - & Flashed, uncorrected for $10.8 \mathrm{x}$ loss & - \\
\hline $2-16-76$ & - & 9.2 & 2026 & - & - & - & - & - & - & - & - & - & - & - & 0.08 & - & - & - & - & - & - & - & - & Flashed, uncorrected for $9.9 \%$ loss & - \\
\hline $1-29-78$ & - & 6.2 & 2020 & - & - & - & - & - & - & - & - & - & - & - & 2.3 & - & - & - & - & - & - & - & - & & - \\
\hline $3-3-77$ & - & 8.9 & 1759 & - & - & - & - & - & - & - & - & - & - & - & - & - & - & - & - & - & - & - & - & Flashed, est. loss - $9 x$ & - \\
\hline
\end{tabular}


Table E.4. Chemical analyses of wells 8-1, 31-1, and 44-7 (concentration mg/l).

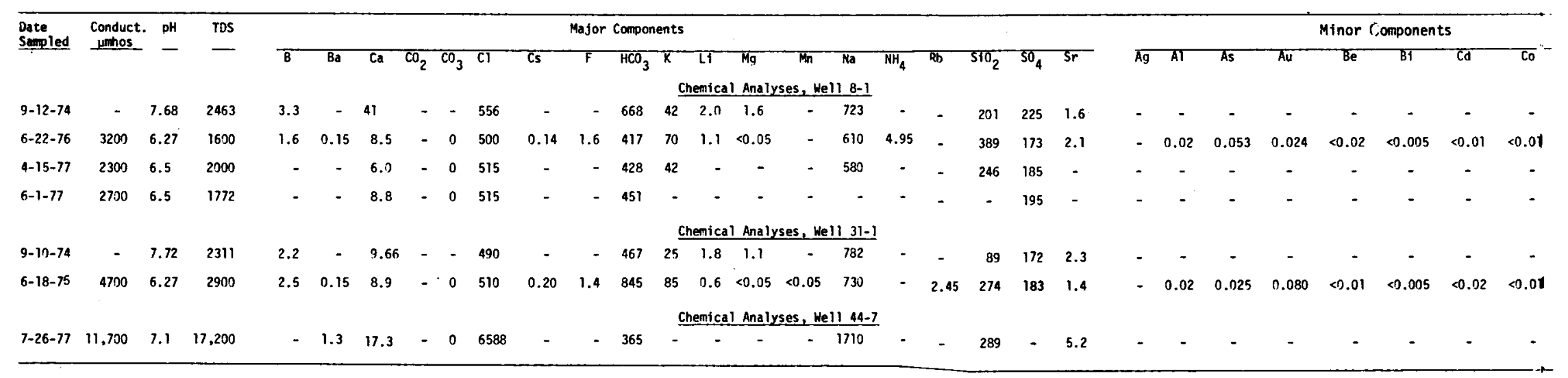


Table E.4 (continued)

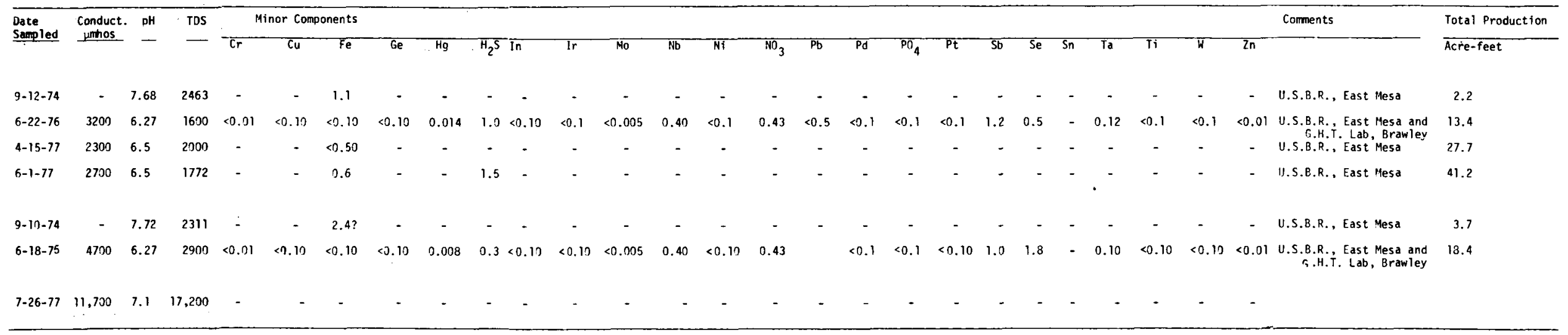

XBL 789-11414 
Table E.5. Chemical analyses of well 5-1 (concentration $\mathrm{mg} / \mathrm{l}$ ).

\begin{tabular}{|c|c|c|c|c|c|c|c|c|c|c|c|c|c|c|c|c|c|c|c|c|c|c|c|c|c|c|c|c|c|c|c|c|c|}
\hline \multirow{2}{*}{$\begin{array}{l}\text { Date } \\
\text { Sampled }\end{array}$} & \multirow{2}{*}{$\begin{array}{l}\text { Conduct. } \\
\text { umhos }\end{array}$} & \multirow[t]{2}{*}{$\mathrm{pH}$} & \multirow[t]{2}{*}{ TOS } & \multicolumn{19}{|c|}{ Major Components } & \multicolumn{11}{|c|}{ Minor Components } \\
\hline & & & & B & $\mathrm{Ba}$ & $\mathrm{Ca}$ & $\mathrm{CO}_{2}$ & $\mathrm{CO}_{3}$ & Cl & Cs & $\mathbf{F}$ & $\mathrm{HCO}_{3}$ & k & LI & $\mathrm{Mg}$ & Mn & $\mathrm{Na}$ & $\mathrm{NH}_{4}$ & $\mathbf{R b}$ & $\mathrm{SiO}_{2}$ & $\mathrm{SO}_{4}$ & $S r$ & Ag & Al & As & $\mathrm{Au}$ & $\mathrm{Be}$ & $B \mathbf{i}$ & $\mathrm{Cd}$ & Co & $\mathrm{Cr}$ & $\mathrm{Cu}$ & $\mathrm{Fe}$ \\
\hline $4-25-74$ & - & 6.7 & 2390 & - & - & 46.5 & - & - & 825 & - & - & 705 & 48.9 & - & 4.01 & - & 798 & - & - & 130 & 196 & - & - & - & - & - & - & - & - & - & - & - & - \\
\hline $4-25-74$ & - & 6.7 & 2390 & - & - & 46.5 & - & - & 825 & - & - & 717 & 48.9 & - & 4.01 & - & 798 & - & - & 130 & 196 & - & - & - & - & - & - & - & - & - & - & - & - \\
\hline $5-20-74$ & - & - & 1567 & - & - & - & - & - & 387 & - & - & - & - & - & - & - & - & - & - & - & 136 & - & - & - & - & - & - & - & - & - & - & - & - \\
\hline $5-20-74$ & - & - & 1572 & - & - & - & - & - & 381 & - & - & - & - & - & - & - & - & - & - & - & 124 & - & - & - & - & - & - & - & - & - & - & - & - \\
\hline $5-31-74$ & - & 9.12 & 1575 & - & - & 16.2 & - & - & 454 & - & - & 331.5 & 29 & - & 2.1 & - & 593 & - & - & 201 & 102 & - & - & - & - & - & - & - & - & - & - & - & - \\
\hline $1-9-75$ & - & 5.99 & 1161 & - & - & 16.5 & - & - & 252 & - & - & 429 & 31.8 & - & - & - & 381 & - & - & 136 & - & - & - & - & - & - & - & - & - & - & - & - & - \\
\hline
\end{tabular}


Table E.5 (continued)

\begin{tabular}{|c|c|c|c|c|c|c|c|c|c|c|c|c|c|c|c|c|c|c|c|c|c|c|c|c|c|}
\hline \multirow{2}{*}{$\begin{array}{l}\text { Date } \\
\text { Sampled }\end{array}$} & \multirow{2}{*}{$\begin{array}{l}\text { Conduct. } \\
\text { umhios }\end{array}$} & \multirow[t]{2}{*}{$\mathrm{pH}$} & \multirow[t]{2}{*}{ TDS } & \multicolumn{20}{|c|}{ Minor Components } & \multirow[b]{2}{*}{ Comments } & \multirow{2}{*}{$\begin{array}{l}\text { Total } \\
\text { Praduction } \\
\text { Acre - Feet }\end{array}$} \\
\hline & & & & Be & $\mathrm{Hg}$ & $\mathrm{H}_{2} \mathrm{~S}$ & In & Ir & no & Nb & Ni & $\mathrm{NO}_{3}$ & Pb & Pd & $\mathrm{PO}_{4}$ & Pt & Sb & Se & Sn & Ta & Ti & w 2 & $2 n$ & & \\
\hline $4-25-74$ & - & 6.7 & 2390 & - & - & - & - & - & - & - & - & - & - & - & - & - & - & - & - & - & - & -- & - & Drill Stem Test & 0 \\
\hline $4-25-74$ & - & 6.7 & 2390 & - & - & - & - & - & - & - & - & - & - & - & - & - & $\cdot$ & - & - & - & - & - & - & Drill Stem Test & 0 \\
\hline $5-20-74$ & - & - & 1567 & - & - & - & - & - & - & - & - & - & - & - & - & - & - & - & - & - & - & - & - & Flowing (2-phase) & 2.6 \\
\hline $5-20-74$ & - & - & 1572 & - & - & - & - & - & - & - & - & - & - & - & - & - & - & - & - & - & - & - & - & & 2.6 \\
\hline $5-31-74$ & - & 9.12 & 1575 & - & - & - & - & - & - & - & - & - & - & - & - & - & - & - & - & - & - & - & - & & 2.6 \\
\hline $1-9-75$ & - & 5.99 & 1161 & - & - & - & - & - & - & - & - & - & - & - & - & - & - & - & - & - & - & - & - & & 17.9 \\
\hline
\end{tabular}

XBL $789-11412$ 


\section{APPENDIX F: RESULTS OF LABORATORY STUDIES OF SCAIE SAMPLES TAKEN FROM THE VTE}

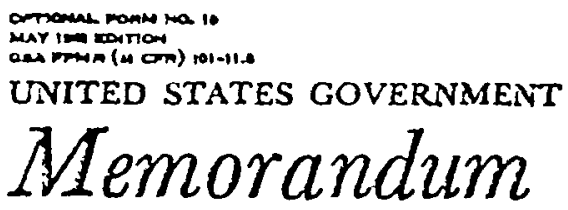

To

: Head, Physlcal Sclences and Chemlcal

Engineering Section $\sigma G b$

FROM : E. F. Monk

surject: Scale Samples - VTE Operations - East Mesa Geothermal Site, Holtville, Califoraia

(see letters dated June 29 and August 26, 1976)

Petrographic referral code: $76-39$

\section{INTRODUCTION}

Nineteen scale samples were received from Mr, James C. Watson, East Mesa Geothermal Site, for examination and identification.

The scale samples and their locations are as follows:

Sample

$\underline{\text { Location }}$
A
E-3 tubes after Test 1-4 day Test on Dearborn 80101800 hrs $3 / 15$ to 1100 hrs $3 / 19$
B
Orffice plate - Downstream after Test 3-4 day Test on Calgon Chelant SL-500 3/24 - 3/28
C E-1 deposit around carbon steel hold down bolts for the nozzles after Test 3
D E-1 deposit on top head near the tubes after Test 3
E E-1 loose fluffy deposit near the tubes - after Test 3
F E-3 deposit scraped 2-6 feet down from the top - after Test 3
G
E-3 deposit as per $\underline{F}$ after Test 4 Drewplex 502
J Nozzles from E-1 after Test G-3 $6 / 14$
K Nozzles from E-2 after Test G-3 $6 / 14$
L Al1 4 tubes E-1 6/14 after Test G-3
M
All 4 tubes E-2 $6 / 14$ after Test G-3 


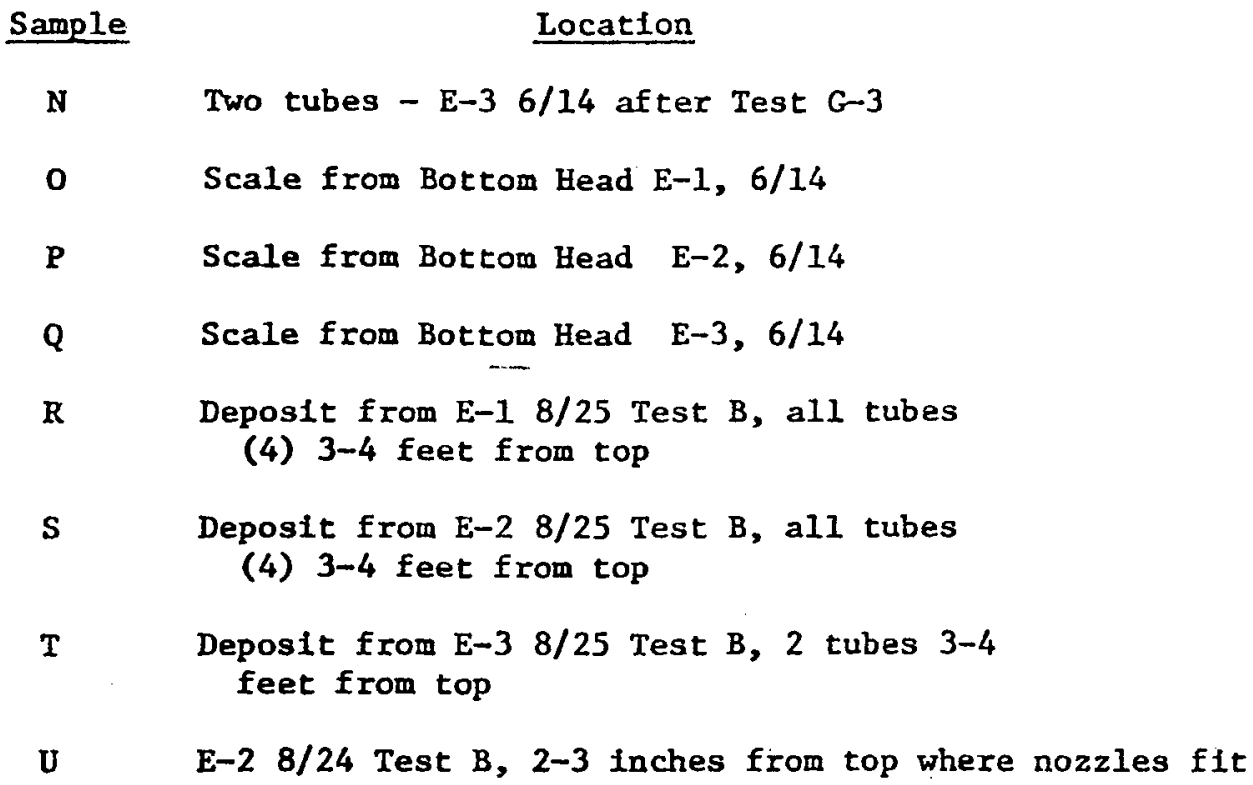

The purpose of the examination is to ascertain the chemical compositions of the scale samples.

\section{EXAMINATION AND RESULTS}

The scale samples were examined by X-ray powder diffraction (XRD) analyses for their crystalline compounds and by X-ray spectrographic (XRS) analyses for their elemental compositions.

The results of the analyses are enclosed in table 1.

\section{DISCUSSION AND REMARKS}

The scale samples varied from white to gray to brown to black in color,

The white and gray samples are slightly to nonmagnetic. The brown and black samples are moderately to highly magnetic.

The white and gray samples consist chiefly of calcium carbonate. The brown and black samples consist chiefly of iron oxides $\left(\mathrm{Fe}_{3} \mathrm{O}_{4}\right.$ - magnetite $\checkmark \mathrm{Fe}_{2} \mathrm{O}_{3}$ - maghemite and $\alpha \mathrm{Fe}_{2} \mathrm{O}_{3}$ - hematite) and vary from well to poorly crystalline.

Most samples contain some organic fiber strands and bundles (clear, pale yellow, and pale green in color) and fresh, silvery metallic colored fragments. The metal fragments vary from flat to curved to curled in shape, are highly magnetic to nonmagnetic, and probably were obtained from the pipe walls during the scale sampling process. Sample $M$ contained (about 
30 percent by volume) some small bugs or Insects (one ( 1 ) gray "locustlike" Insect and eight ( 8 ) black "beetle-like" bugs).

Moderate to minor amounts of potassium (K) were detected in the elemental form, but no potassium crystalline compounds were detectable by $X-r a y$ diffraction analysis. The potassium probably occurs in minor amounts as the hallde mineral, sylvite (KC1).

No phosphates were detected (reference your letter on samples $O, P$, and $Q$ ).

No sulfates were detected by $X$-ray powder diffration analyses; however, minor amounts of elemental sulf ar (S) were detected by $X$-ray spectrographic analyses. The sulfur present is probably combined with bariun, strontiun, and/or calcium, but is below detectable limits of our X-ray diffractometer.

Samples $J, K$, and $L$ contained minor amounts of unidentified interlayered clay minerals with broad peaks at $12-14 \AA, 4.55 \AA$, and $2.56 \AA$. These X-ray diffraction peak positions and characteristics did not change when the samples were treated with glycerol.

The mineralogy (crystalline compounds) and elemental analyses results are reported in table $I$ in relative amounts (1.e., major, moderate, and minor) rather than in percent. Reliable percentage estimations could not be made because of poor crystallinity of some of the compounds, contamination materials, and the heterogeneous mixture of minor to trace amounts of numerous elements and compounds.

\section{Enclosure}

Copy to: 1523 (Petrographic Files) 


\begin{tabular}{|c|c|c|}
\hline 8ample & $\begin{array}{l}\text { Eetloned } \\
\text { smounte }\end{array}$ & $\begin{array}{l}\text { XRD - X-ray diffraction analyses } \\
\text { (crystalilne compounds or mineralogy) }\end{array}$ \\
\hline$\Lambda$ & $\begin{array}{l}\text { Minfor } \\
\text { Moderate } \\
\text { MInor }\end{array}$ & $\begin{array}{l}\text { Noncrystalline } \\
\text { None } \\
\text { Hearite, magnetite, calcite, and mlacellaneous } \\
\text { and unidentifled }\end{array}$ \\
\hline D & $\begin{array}{l}\text { Mafor } \\
\text { Moderate } \\
\text { Minor }\end{array}$ & $\begin{array}{l}\text { Calcite and aragonite } \\
\text { None } \\
\text { Dolomite, hallte, magnaste, and miscellaneous } \\
\text { and unidentifled }\end{array}$ \\
\hline C & $\begin{array}{l}\text { Major } \\
\text { Moderate } \\
\text { Minor }\end{array}$ & $\begin{array}{l}\text { Magnetito } \\
\text { Siderite } \\
\text { Hemstite, calcita, quarts, and miscollaneous } \\
\text { and unidentifled }\end{array}$ \\
\hline D & $\begin{array}{l}\text { Major } \\
\text { Moderate } \\
\text { Minor }\end{array}$ & $\begin{array}{l}\text { Magnetlte } \\
\text { Quarce } \\
\text { Calcite, feldopar, hematite, siderite, and } \\
\text { miscellaneous and unldentified }\end{array}$ \\
\hline $\mathbf{B}$ & $\begin{array}{l}\text { Major } \\
\text { Moderete } \\
\text { Minor }\end{array}$ & $\begin{array}{l}\text { Kagnetite and quarts } \\
\text { None } \\
\text { Calcite, feldopar, hematite, maghemite, and } \\
\text { miscellaneous and unidentifled }\end{array}$ \\
\hline$P$ & $\begin{array}{l}\text { Major } \\
\text { Moderate } \\
\text { Minor }\end{array}$ & $\begin{array}{l}\text { Calcite and quarts } \\
\text { None } \\
\text { Feldspar, hematite, magnetite, dolomite - ?; } \\
\text { halfte, and mlscellageous and unidentified }\end{array}$ \\
\hline C & $\begin{array}{l}\text { Major } \\
\text { Moderate } \\
\text { Minor }\end{array}$ & $\begin{array}{l}\text { Calcite and quarts } \\
\text { None } \\
\text { Peldapar, hematite, mangeite, hallte, dolomite, } \\
\text { and trace of mlacellaneous and unldentifled }\end{array}$ \\
\hline 3 & $\begin{array}{l}\text { Major } \\
\text { Moderate } \\
\text { Minor }\end{array}$ & $\begin{array}{l}\text { Calcite and aragonlta } \\
\text { None } \\
\text { Quartz, feldspar, clays and miscellaneous and } \\
\text { unidentlfled }\end{array}$ \\
\hline$x$ & $\begin{array}{l}\text { Major } \\
\text { Moderate } \\
\text { MInor }\end{array}$ & $\begin{array}{l}\text { Calelte } \\
\text { None } \\
\text { Quarte, feldspar, magnatite, clay, and } \\
\text { miscellencous and unidentified }\end{array}$ \\
\hline to & $\begin{array}{l}\text { Major } \\
\text { Moderate } \\
\text { MInor }\end{array}$ & $\begin{array}{l}\text { Calcito } \\
\text { None } \\
\text { Quartz, feldspar, hamatite, clay, and } \\
\text { miscellancous and unidentificd }\end{array}$ \\
\hline
\end{tabular}

XRS - X-ray opectrographlc analyses (heavy elcments)

(11ght elements)

$\mathrm{Fe}$
$\mathrm{Sr}$

Ba, $2 n, M n$, and $I I$

$$
\begin{gathered}
\text { Sx } \\
\text { None } \\
\text { Ba and Fe }
\end{gathered}
$$$$
\text { Fe }
$$

$\mathrm{Be}, \mathrm{Sr}, 2 \mathrm{n}, \mathrm{Cu}, \mathrm{N} 1, \mathrm{Kn}$, and $\mathrm{II}$ - ?

$$
\begin{gathered}
\text { Ee } \\
\text { None }
\end{gathered}
$$

Be, Sr, Cu, Zn, Ni, Mn, and $T$

$$
\text { Fe }
$$

Be, $\mathrm{Sr}, \mathrm{Zn}, \mathrm{Cu}, \mathrm{Ml}$, and $\mathrm{TI}$ - ?

$\mathrm{Ba}, \mathrm{Zn}, \mathrm{Cu}, \mathrm{Sr}, \mathrm{NL}, \mathrm{Kn}$, and $\mathrm{IL}$

$$
\text { Pe }
$$

B1, $\mathrm{Cu}, \mathrm{N1}, \mathrm{Mn}$, and $\mathrm{II}$

$$
\text { Fe }
$$

Be, Sr, Cu, $\mathrm{Kr}$, and $\mathrm{Zn}$

\section{Fe}

$\mathrm{Ba}, \mathrm{2n}, \mathrm{Cu}, \mathrm{Sr}$, and $\mathrm{kn}$

$$
\begin{gathered}
\text { Fe } \\
\text { Sx and } \mathrm{Mn} \\
\text { Be, } 2 n \text {, and } \mathrm{Tl}
\end{gathered}
$$

$x, C 1$, and 81

$\mathrm{C}$

si

Ce

$X$ and $s i$

Ce

C1 and S1

$\mathrm{Cs}$

CI and st

Nane

$\pi, C 1$, and $\$ 1$

Ca

None

Ca

None

$\mathrm{K}, \mathrm{CI}$, and $\mathrm{s}$

Ca

$\mathrm{x}, \mathrm{Cl}$, and $\mathrm{s}$ 
Table 1 - Continued

\begin{tabular}{|c|c|c|c|c|}
\hline \multirow[b]{2}{*}{ Semple } & \multirow{2}{*}{$\begin{array}{l}\text { Eaclouted } \\
\text { amounte }\end{array}$} & \multirow{2}{*}{$\begin{array}{c}\text { XRD - X-ray diffraction analyses } \\
\text { (crystalilno compounds or mincralogy) }\end{array}$} & \multicolumn{2}{|c|}{ XRS - X-ray spectrographlc analyses } \\
\hline & & & (heavy elements) & (IIght elements) \\
\hline $\mathbf{x}$ & $\begin{array}{l}\text { Major } \\
\text { Moderate } \\
\text { MInor }\end{array}$ & $\begin{array}{l}\text { Megnetite and quarts } \\
\text { None } \\
\text { Calcite, hallte, hemette, and mecollaneous and } \\
\text { unidentifled }\end{array}$ & $\mathrm{Ba}, \mathrm{Sr}, \mathrm{Fe}, \mathrm{Cu}, \mathrm{NL}$, and $\mathrm{Km}$ & $x, c 1$, and si \\
\hline $\boldsymbol{H}$ & $\begin{array}{l}\text { Major } \\
\text { Moderate } \\
\text { Minor }\end{array}$ & $\begin{array}{l}\text { Calcite } \\
\text { Quartz } \\
\text { Feldspar, magnetite, hematito, hallte and } \\
\text { miscellaneous and unidentified }\end{array}$ & $\begin{array}{c}\text { Fe and } S r \\
\text { None } \\
\text { Bs, } 2 \mathrm{n}, \mathrm{Cu}, \mathrm{NL}, \mathrm{N}, \text { end } \mathrm{IL}\end{array}$ & $\begin{array}{l}\mathrm{Ce} \\
\mathrm{K} \\
\mathrm{Cl} \text { and } \mathrm{S1}\end{array}$ \\
\hline 0 & $\begin{array}{l}\text { Magor } \\
\text { Modarate } \\
\text { Mlnor }\end{array}$ & $\begin{array}{l}\text { Magnetite } \\
\text { Nona } \\
\text { Hematite, maghemite, and mlscellaneous and } \\
\text { unidentifled }\end{array}$ & $\mathrm{Br}, \mathrm{gr}, \mathrm{Fu}$ & $\mathrm{R}, \mathrm{Cl}, \underset{\text { Nane }}{\cos } \mathrm{sL}$ \\
\hline $\mathbf{P}$ & $\begin{array}{l}\text { Major } \\
\text { Moderate } \\
\text { Minor }\end{array}$ & $\begin{array}{l}\text { Magnetite } \\
\text { None } \\
\text { Hematite, maghemite, and miacellaneous and } \\
\text { unidentifled }\end{array}$ & $\mathrm{Ba}, \mathrm{Fe}$ & $\begin{array}{c}\text { Ce } \\
\text { None } \\
\mathrm{N}, \mathrm{Cl} \text {, and } S L\end{array}$ \\
\hline$Q$ & $\begin{array}{l}\text { Major } \\
\text { Moderate } \\
\text { Minor }\end{array}$ & $\begin{array}{l}\text { Magnetite, hematite, and maghemite } \\
\text { Calcite and aragonite } \\
\text { quartz, halite, and miselianeous and } \\
\text { unldentffled }\end{array}$ & $\begin{array}{c}\text { Pe } \\
\text { None } \\
\mathrm{Se}, \mathrm{Cu}, \mathrm{Zn}, \mathrm{N} 1, \mathrm{Mn}, \text { and } \mathrm{IL}\end{array}$ & $C I, S_{1}^{C a}$ and $s i$ \\
\hline $\mathbf{R}$ & $\begin{array}{l}\text { Major } \\
\text { Moderate } \\
\text { Minor }\end{array}$ & $\begin{array}{l}\text { Calclte } \\
\text { None } \\
\text { Hematite, and miscellaneous and unidentifled }\end{array}$ & $\begin{array}{c}\text { Fe } \\
S r \text { and } M n \\
B n, C n, \text { and } T 1\end{array}$ & $x, c 1, s$, None $s t$ \\
\hline $\mathbf{s}$ & $\begin{array}{l}\text { Major } \\
\text { Moderate } \\
\text { MInor }\end{array}$ & $\begin{array}{l}\text { Calcite } \\
\text { None } \\
\text { Hematite, and miecalianeous and unidentified }\end{array}$ & $\begin{array}{c}\mathrm{Ye} \\
\mathrm{Sr} \\
\mathrm{Be}, \mathrm{Zn}, \mathrm{Cu}, \mathrm{NL}, \mathrm{Mn}, \text { and } \mathrm{TL}\end{array}$ & 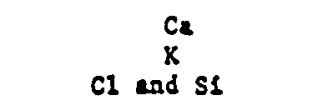 \\
\hline $\mathbf{T}$ & $\begin{array}{l}\text { Major } \\
\text { Moderate } \\
\text { MInor }\end{array}$ & $\begin{array}{l}\text { Calcite } \\
\text { None } \\
\text { Helite, hemacite, and miscellaneous and } \\
\text { unidentifled }\end{array}$ & Be, $\mathrm{Zn}, \mathrm{Nr}$, and $\mathrm{TI}$ & $\begin{array}{l}C_{2} \\
k \\
S 1\end{array}$ \\
\hline 0 & $\begin{array}{l}\text { Major } \\
\text { Moderato } \\
\text { Minor }\end{array}$ & $\begin{array}{l}\text { Calcite } \\
\text { None } \\
\text { Hematite, and mescllaneous and unidentiflod }\end{array}$ & 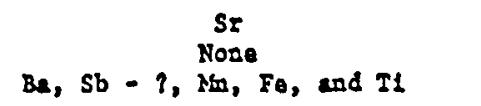 & $\mathrm{X}, \mathrm{Cl}, \underset{\text { None }}{\mathrm{Cend}} \mathrm{si}$ \\
\hline
\end{tabular}

